\title{
International Energy Agency Building Energy Simulation Test and Diagnostic Method (IEA BESTEST) \\ Multi-Zone Non-Airflow In-Depth Diagnostic Cases: \\ MZ320 - MZ360 \\ (Revised Cover)
}

By

J. Neymark

J. Neymark \& Associates, Wheat Ridge, Colorado, U.S.

R. Judkoff

National Renewable Energy Laboratory, Golden, Colorado, U.S.

\author{
With \\ D. Alexander \\ Cardiff University, Cardiff, Wales, U.K. \\ C. Felsmann \\ Dresden University of Technology, Dresden, Germany \\ P. Strachan \\ University of Strathclyde, Glasgow, Scotland, U.K. \\ A. Wijsman \\ VABI Software BV, Delft, The Netherlands
}

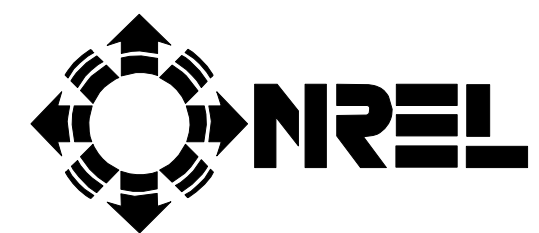

National Renewable Energy Laboratory 1617 Cole Boulevard Golden, Colorado 80401-3393 


\section{International Energy Agency Building Energy Simulation Test and Diagnostic Method (IEA BESTEST)}

\section{Multi-Zone Non-Airflow In-Depth Diagnostic Cases: MZ320 - MZ360}

J. Neymark

J. Neymark \& Associates

R. Judkoff

National Renewable Energy Laboratory

Contributors:
D. Alexander
Cardiff University
C. Felsmann
Dresden University of Technology
P. Strachan
University of Strathclyde
A. Wijsman
VABI Software

Technical Report NREL/TP-550-43827

September 2008

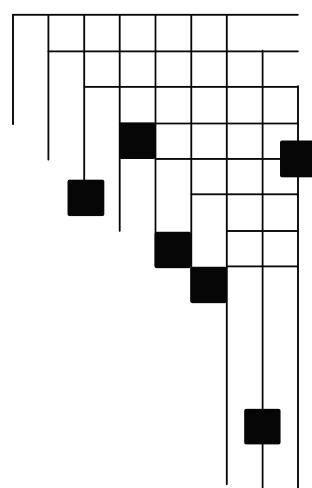

Prepared under Task No. BEC76051

National Renewable Energy Laboratory

1617 Cole Boulevard, Golden, Colorado 80401-3393

303-275-3000 • www.nrel.gov

Operated for the U.S. Department of Energy

Office of Energy Efficiency and Renewable Energy

by Midwest Research Institute $\bullet$ Battelle

Contract No. DE-AC36-99-G010337 


\section{NOTICE}

This report was prepared as an account of work sponsored by an agency of the United States government. Neither the United States government nor any agency thereof, nor any of their employees, makes any warranty, express or implied, or assumes any legal liability or responsibility for the accuracy, completeness, or usefulness of any information, apparatus, product, or process disclosed, or represents that its use would not infringe privately owned rights. Reference herein to any specific commercial product, process, or service by trade name, trademark, manufacturer, or otherwise does not necessarily constitute or imply its endorsement, recommendation, or favoring by the United States government or any agency thereof. The views and opinions of authors expressed herein do not necessarily state or reflect those of the United States government or any agency thereof.

Available electronically at http://www.osti.gov/bridge

Available for a processing fee to U.S. Department of Energy and its contractors, in paper, from:

U.S. Department of Energy

Office of Scientific and Technical Information

P.O. Box 62

Oak Ridge, TN 37831-0062

phone: 865.576 .8401

fax: 865.576 .5728

email: mailto:reports@adonis.osti.gov

Available for sale to the public, in paper, from:

U.S. Department of Commerce

National Technical Information Service

5285 Port Royal Road

Springfield, VA 22161

phone: 800.553 .6847

fax: 703.605.6900

email: orders@ntis.fedworld.gov

online ordering: http://www.ntis.gov/ordering.htm 


\section{Acknowledgments}

The work described in this report was a cooperative effort involving the members of the International Energy Agency (IEA) Testing and Validation of Building Energy Simulation Tools Experts Group. The group was composed of experts from the IEA Solar Heating and Cooling (SHC) Programme, Task 34, and Energy Conservation in Buildings and Community Systems (ECBCS) Programme Annex 43.

The project participants that provided the majority of early field-trial work, preliminary sensitivity tests, and feedback on the test specification are listed as co-authors. We also gratefully acknowledge the contributions from modelers and authors of sections on additional computer programs used in this effort, including:

- Robert Henninger and Michael Witte; GARD Analytics, United States: EnergyPlus

- Julien L'Hoest, Christophe Adam, Philippe André and Corinne Rogiest; University of Liege, Belgium: TRNSYS-16

- Harry Boyer, Frederic Miranville, and Alain Bastide; University of Reunion Island, France: CODYRUN

- Bruno Peuportier; Paris School of Mines, France: COMFIE

- Jean Noel; JNLOG, France: KoZiBu.

The following participants at the beginning of the project provided preliminary simulations and early valuable feedback on test cases: Juan Travesi, ACHSL, Spain; Pavel Charvat, Brno University of Technology, Czech Republic; Peter Riederer and Zaki El Khoury, Centre Scientifique et Technique du Batiment, France.

We appreciate the support and guidance of Drury Crawley, U.S. Department of Energy (DOE) program manager for this IEA research task and DOE representative to the IEA SHC Programme Executive Committee; and Richard Karney, DOE representative to the IEA ECBCS Programme Executive Committee. 


\section{Preface}

This report is a product of a joint effort between the International Energy Agency (IEA) Solar Heating and Cooling (SHC) and Energy Conservation in Buildings and Community Systems (ECBCS) Programmes. SHC monitors this work as Task 34 and ECBCS monitors this work as Annex 43. Ron Judkoff of the National Renewable Energy Laboratory (NREL) was the Operating Agent for IEA SHC 34/ECBCS 43 on behalf of the United States Department of Energy.

\section{International Energy Agency}

The International Energy Agency (IEA) was established in 1974 within the framework of the Organisation for Economic Co-operation and Development (OECD) to implement an international energy programme. A basic aim of the IEA is to foster co-operation among the twenty-four IEA participating countries and to increase energy security through energy conservation, development of alternative energy sources and energy research, development and demonstration (RD\&D).

\section{Solar Heating and Cooling Programme}

The Solar Heating and Cooling Programme was one of the first IEA Implementing Agreements to be established. Since 1977, its members have been collaborating to advance active solar and passive solar technologies and their application in buildings and other areas, such as agriculture and industry. Current members are:

$\begin{array}{lll}\text { Australia } & \text { Finland } & \text { Portugal } \\ \text { Austria } & \text { France } & \text { Spain } \\ \text { Belgium } & \text { Italy } & \text { Sweden } \\ \text { Canada } & \text { Mexico } & \text { Switzerland } \\ \text { Denmark } & \text { Netherlands } & \text { United States } \\ \text { European Commission } & \text { New Zealand } & \\ \text { Germany } & \text { Norway } & \end{array}$

A total of 39 Tasks have been initiated, 30 of which have been completed. Each Task is managed by an Operating Agent from one of the participating countries. Overall control of the program rests with an Executive Committee comprised of one representative from each contracting party to the Implementing Agreement. In addition to the Task work, a number of special activities-Memorandum of Understanding with solar thermal trade organizations, statistics collection and analysis, conferences and workshops - have been undertaken.

The Tasks of the IEA Solar Heating and Cooling Programme, both underway and completed are as follows:

\section{Current Tasks:}

Task 36

Task 37

Task 38

Task 39
Solar Resource Knowledge Management

Advanced Housing Renovation with Solar \& Conservation

Solar Assisted Cooling Systems

Polymeric Materials for Solar Thermal Applications

\section{Completed Tasks:}

Task 1

Task 2
Investigation of the Performance of Solar Heating and Cooling Systems Coordination of Solar Heating and Cooling R\&D 
Task 3 Performance Testing of Solar Collectors

Task 4

Task 5

Task 6

Task 7

Task 8

Task 9

Task 10

Task 11

Task 12

Task 13

Task 14

Task 16

Development of an Insolation Handbook and Instrument Package

Task 17

Task 18

Task 19

Use of Existing Meteorological Information for Solar Energy Application

Performance of Solar Systems Using Evacuated Collectors

Central Solar Heating Plants with Seasonal Storage

Passive and Hybrid Solar Low Energy Buildings

Solar Radiation and Pyranometry Studies

Solar Materials R\&D

Passive and Hybrid Solar Commercial Buildings

Building Energy Analysis and Design Tools for Solar Applications

Advance Solar Low Energy Buildings

Advance Active Solar Energy Systems

Photovoltaics in Buildings

Measuring and Modeling Spectral Radiation

Advanced Glazing and Associated Materials for Solar and Building Applications

Solar Air Systems

Task 20

Solar Energy in Building Renovation

Task $21 \quad$ Daylight in Buildings

Task 23

Task 22

Task 24

Task 25

Task 26

Task 28

Task 27

Task 29

Task 31

Task 32

Task 33

Task 34

Optimization of Solar Energy Use in Large Buildings

Building Energy Analysis Tools

Solar Procurement

Solar Assisted Air Conditioning of Buildings

Solar Combisystems

Solar Sustainable Housing

Performance of Solar Facade Components

Solar Crop Drying

Daylighting Buildings in the 21st Century

Advanced Storage Concepts for Solar and Low Energy Buildings

Solar Heat for Industrial Processes

Testing and Validation of Building Energy Simulation Tools

Task 35

PV/Thermal Solar Systems

Completed Working Groups:

CSHPSS, ISOLDE, Materials in Solar Thermal Collectors, and the Evaluation of Task 13 Houses

To find more IEA Solar Heating and Cooling Programme publications or learn about the Programme visit our Internet site at www.iea-shc.org or contact the SHC Executive Secretary, Pamela Murphy, e-mail: pmurphy@MorseAssociatesInc.com.

\section{Energy Conservation in Buildings and Community Systems}

The IEA sponsors research and development in a number of areas related to energy. The mission of one of those areas, the ECBCS - Energy Conservation for Building and Community Systems Programme, is to facilitate and accelerate the introduction of energy conservation, and environmentally sustainable technologies into healthy buildings and community systems, through innovation and research in decisionmaking, building assemblies and systems, and commercialisation. The objectives of collaborative work within the ECBCS R\&D program are directly derived from the on-going energy and environmental challenges facing IEA countries in the area of construction, energy market and research. ECBCS addresses major challenges and takes advantage of opportunities in the following areas: 
- exploitation of innovation and information technology;

- impact of energy measures on indoor health and usability;

- integration of building energy measures and tools to changes in lifestyles, work environment alternatives, and business environment.

\section{The Executive Committee}

Overall control of the program is maintained by an Executive Committee, which not only monitors existing projects but also identifies new areas where collaborative effort may be beneficial. To date the following projects have been initiated by the executive committee on Energy Conservation in Buildings and Community Systems (completed projects are identified by $(*)$ ):

Annex 1: $\quad$ Load Energy Determination of Buildings (*)

Annex 2: $\quad$ Ekistics and Advanced Community Energy Systems (*)

Annex 3: $\quad$ Energy Conservation in Residential Buildings (*)

Annex 4: $\quad$ Glasgow Commercial Building Monitoring (*)

Annex 5: $\quad$ Air Infiltration and Ventilation Centre

Annex 6: $\quad$ Energy Systems and Design of Communities (*)

Annex 7: $\quad$ Local Government Energy Planning (*)

Annex 8: $\quad$ Inhabitants Behaviour with Regard to Ventilation (*)

Annex 9: $\quad$ Minimum Ventilation Rates (*)

Annex 10: $\quad$ Building HVAC System Simulation (*)

Annex 11: $\quad$ Energy Auditing (*)

Annex 12: $\quad$ Windows and Fenestration (*)

Annex 13: $\quad$ Energy Management in Hospitals $(*)$

Annex 14: $\quad$ Condensation and Energy $(*)$

Annex 15: $\quad$ Energy Efficiency in Schools (*)

Annex 16: $\quad$ BEMS 1- User Interfaces and System Integration $\left(^{*}\right)$

Annex 17: $\quad$ BEMS 2- Evaluation and Emulation Techniques (*)

Annex 18: $\quad$ Demand Controlled Ventilation Systems (*)

Annex 19: $\quad$ Low Slope Roof Systems (*)

Annex 20: $\quad$ Air Flow Patterns within Buildings (*)

Annex 21: $\quad$ Thermal Modelling (*)

Annex 22: $\quad$ Energy Efficient Communities (*)

Annex 23: $\quad$ Multi Zone Air Flow Modelling (COMIS) (*)

Annex 24: $\quad$ Heat, Air and Moisture Transfer in Envelopes (*)

Annex 25: $\quad$ Real time HEVAC Simulation (*)

Annex 26: $\quad$ Energy Efficient Ventilation of Large Enclosures (*)

Annex 27: $\quad$ Evaluation and Demonstration of Domestic Ventilation Systems (*)

Annex 28: $\quad$ Low Energy Cooling Systems (*)

Annex 29: Daylight in Buildings (*)

Annex 30: $\quad$ Bringing Simulation to Application (*)

Annex 31: $\quad$ Energy-Related Environmental Impact of Buildings (*)

Annex 32: $\quad$ Integral Building Envelope Performance Assessment (*)

Annex 33: $\quad$ Advanced Local Energy Planning (*)

Annex 34: $\quad$ Computer-Aided Evaluation of HVAC System Performance (*)

Annex 35: Design of Energy Efficient Hybrid Ventilation (HYBVENT) $(*)$

Annex 36: Retrofitting of Educational Buildings (*)

Annex 37: Low Exergy Systems for Heating and Cooling of Buildings (LowEx) $(*)$

Annex 38: $\quad$ Solar Sustainable Housing (*)

Annex 39: $\quad$ High Performance Insulation Systems (*) 
Annex 40: $\quad$ Building Commissioning to Improve Energy Performance (*)

Annex 41: Whole Building Heat, Air and Moisture Response (MOIST-ENG)

Annex 42: The Simulation of Building-Integrated Fuel Cell and Other Cogeneration Systems (FC+COGEN-SIM)

Annex 43: $\quad$ Testing and Validation of Building Energy Simulation Tools

Annex 44: Integrating Environmentally Responsive Elements in Buildings

Annex 45: $\quad$ Energy Efficient Electric Lighting for Buildings

Annex 46: Holistic Assessment Tool-kit on Energy Efficient Retrofit Measures for Government Buildings (EnERGo)

Annex 47: $\quad$ Cost-Effective Commissioning for Existing and Low Energy Buildings

Annex 48: $\quad$ Heat Pumping and Reversible Air Conditioning

Annex 49: $\quad$ Low Exergy Systems for High Performance Built Environments and Communities

Annex 50: $\quad$ Prefabricated Systems for Low Energy / High Comfort Building Renewal

Working Group - Energy Efficiency in Educational Buildings (*)

Working Group - Indicators of Energy Efficiency in Cold Climate Buildings (*)

Working Group - Annex 36 Extension: The Energy Concept Adviser (*)

$(*)$ - Completed

\section{Participating countries in ECBCS:}

Australia, Belgium, CEC, Canada, Czech Republic, Denmark, Finland, France, Germany, Greece, Israel, Italy, Japan, the Netherlands, New Zealand, Norway, Poland, Portugal, Sweden, Switzerland, Turkey, United Kingdom and the United States of America.

\section{SHC Task 34/ECBCS Annex 43: Testing and Validation of Building Energy Simulation Tools}

\section{Goal and Objectives}

The goal of this Task/Annex is to undertake pre-normative research to develop a comprehensive and integrated suite of building energy analysis tool tests involving analytical, comparative, and empirical methods. These methods will provide for quality assurance of software, and some of the methods will be enacted by codes and standards bodies to certify software used for showing compliance to building energy standards. This goal will be pursued by accomplishing the following objectives:

- Create and make widely available a comprehensive and integrated suite of IEA Building Energy Simulation Test (BESTEST) cases for evaluating, diagnosing, and correcting building energy simulation software. Tests will address modeling of the building thermal fabric and building mechanical equipment systems in the context of innovative low energy buildings.

- Maintain and expand as appropriate analytical solutions for building energy analysis tool evaluation.

- Create and make widely available high-quality empirical validation data sets, including detailed and unambiguous documentation of the input data required for validating software, for a selected number of representative design conditions.

\section{Scope}

This Task/Annex investigates the availability and accuracy of building energy analysis tools and engineering models to evaluate the performance of innovative low-energy buildings. Innovative lowenergy buildings attempt to be highly energy efficient by using advanced energy-efficiency technologies or a combination of energy efficiency and solar energy technologies. To be useful in a practical sense, such tools must also be capable of modeling conventional buildings. The scope of the Task is limited to 
building energy simulation tools, including emerging modular type tools, and to widely used innovative low-energy design concepts. Activities will include development of analytical, comparative and empirical methods for evaluating, diagnosing, and correcting errors in building energy simulation software.

The audience for the results of the Task/Annex is building energy simulation tool developers, and codes and standards (normes) organizations that need methods for certifying software. However, tool users such as architects, engineers, energy consultants, product manufacturers, and building owners and managers are the ultimate beneficiaries of the research, and will be informed through targeted reports and articles.

\section{Means}

The objectives are to be achieved by the participants in the following projects.

\section{Comparative and Analytical Verification Tests:}

Project A: Ground-Coupled Heat Transfer with Respect to Floor Slab and Basement Constructions Project B: Multi-Zone Buildings and Air Flow

\section{Empirical Validation and Comparative Tests:}

Project C: Shading/Daylighting/Load Interaction

Project D: Mechanical Equipment and Controls

Project E: Buildings with Double-Skin Facades

Other:

Project G: Web Site for Consolidation of Tool Evaluation Tests

\section{Participants}

The participants in the Task are Australia, Belgium, Canada, Czech Republic, Denmark, France, Germany, Japan, The Netherlands, Spain, Sweden, Switzerland, the United Kingdom, and the United States. The United States served as the Operating Agent for this Task; Ron Judkoff of the National Renewable Energy Laboratory provided Operating Agent services on behalf of the U.S. Department of Energy.

This report documents work carried out under Project B: Multi-Zone Buildings and Air Flow. 


\section{Table of Contents}

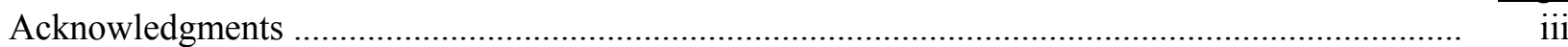

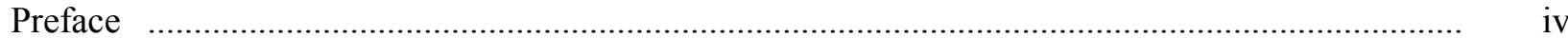

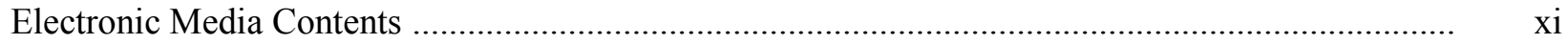

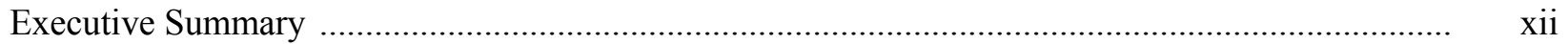

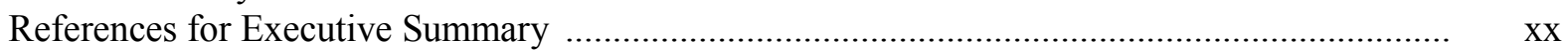

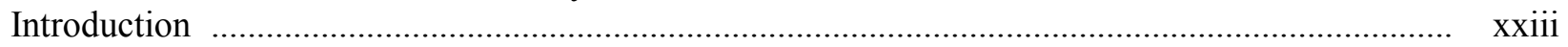

References for Introduction

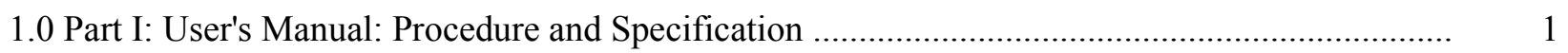

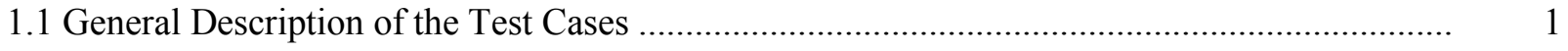

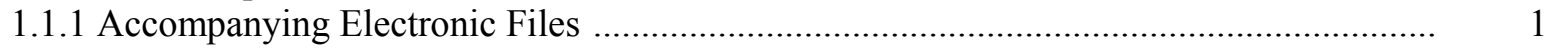

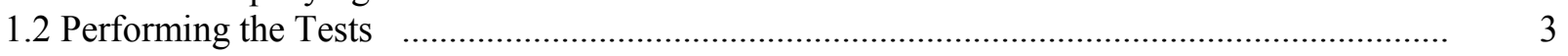

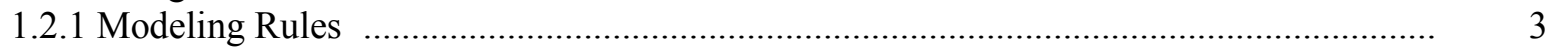

1.2.2 Comparing Your Output to the Analytical Solution and Example Simulation Results .... 5

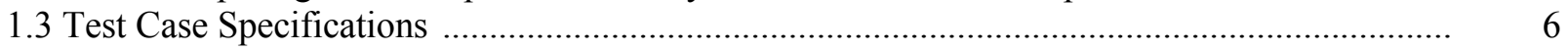

1.3.1 Case MZ320: 3-Zone Steady-State Conduction Analytical Verification Test ................ 6

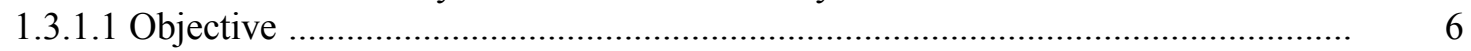

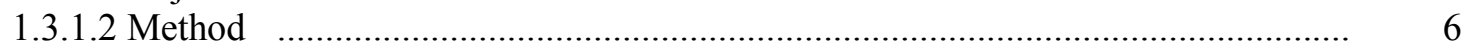

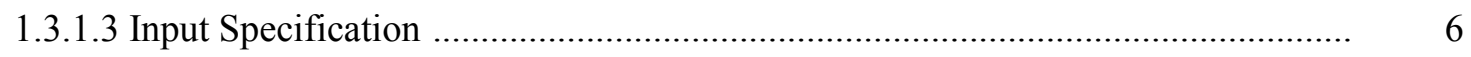

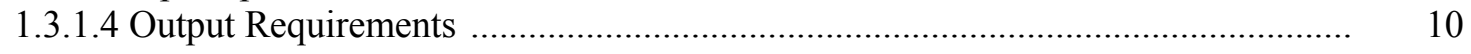

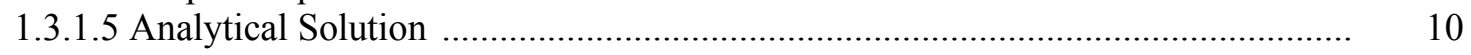

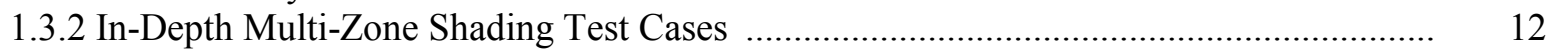

1.3.2.1 Case MZ340: Unshaded Calorimeter - In-Depth Shading Test Base Case .......... 12

1.3.2.1.1 Objective ........................................................................................... 12

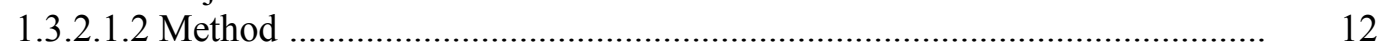

1.3.2.1.3 Input Specification ...................................................................... 12

1.3.2.1.4 Output Requirements ......................................................................... 16

1.3.2.2 Case MZ350: In-Depth Multi-Zone Fin Shading …............................................ 17

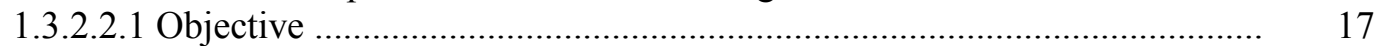

1.3.2.2.2 Method …............................................................................. 17

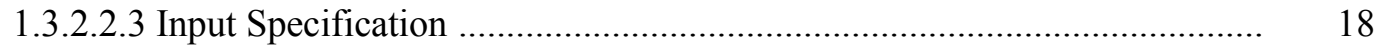

1.3.2.2.4 Output Requirements ........................................................................ 19

1.3.2.3 Case MZ355 In-Depth Multi-Zone Automated Building Self-Shading ............... 20

1.3.2.3.1 Objective ............................................................................................ 20

1.3.2.3.2 Method .................................................................................. 20

1.3.2.3.3 Input Specification ......................................................................... 20

1.3.2.3.4 Output Requirements ........................................................................ 22

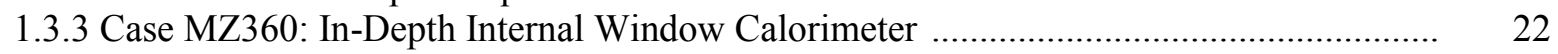

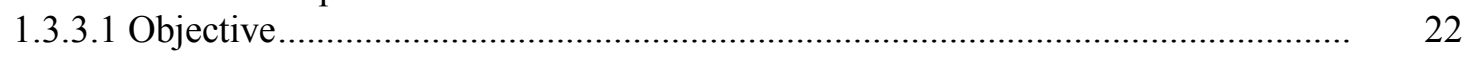

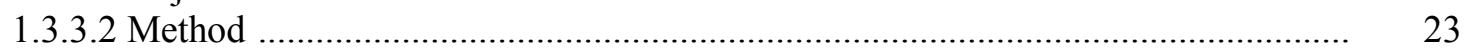

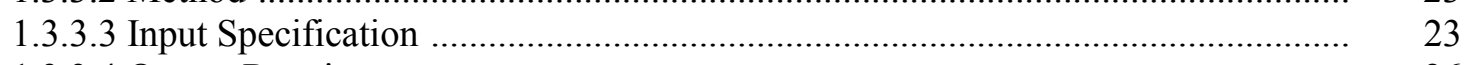

1.3.3.4 Output Requirements .............................................................................. 26

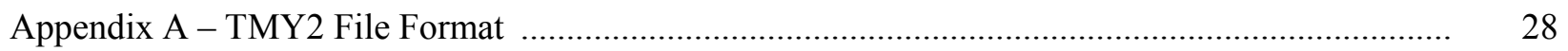

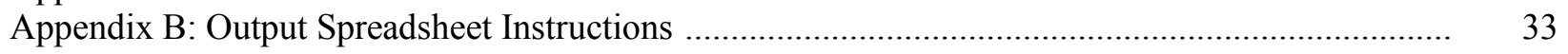

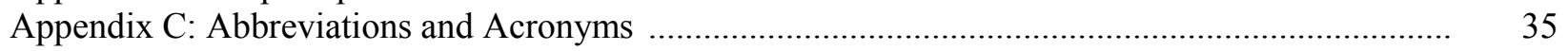

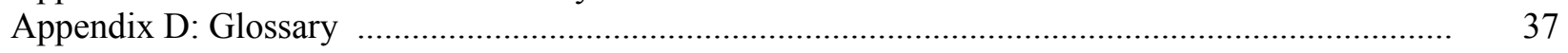




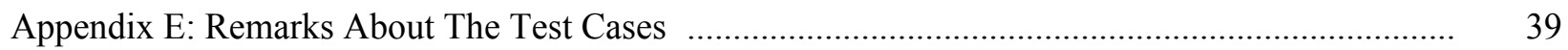

Appendix F: Using the Flow Diagrams to Diagnose the Results................................................. 41

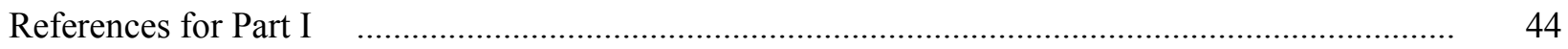

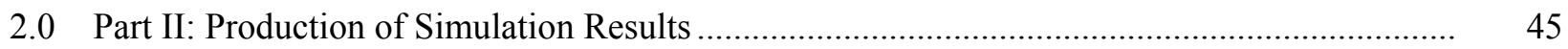

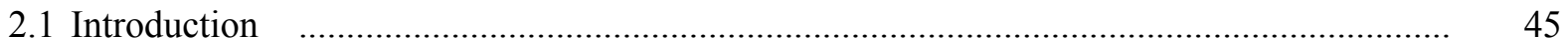

2.2 Selection of Simulation Programs and Modeling Rules for Simulations ............................ 45

2.3 Improvements to the Test Specification as a Result of the Field Trials................................. 47

2.4 Examples of Error Trapping with BESTEST Diagnostics.................................................... 53

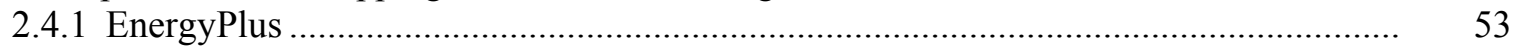

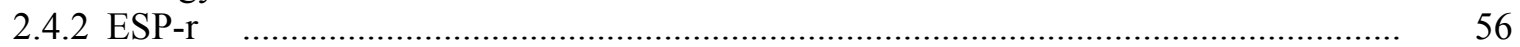

2.4 .3 HTB2

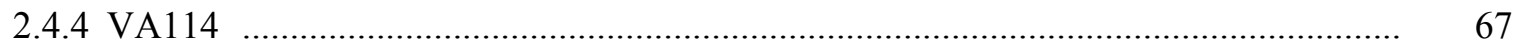

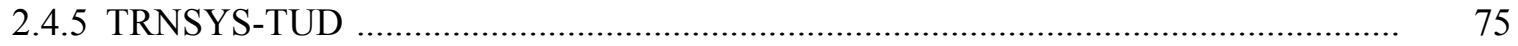

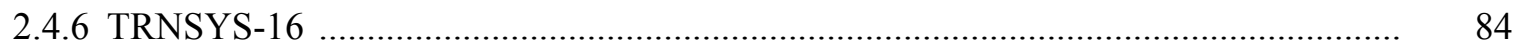

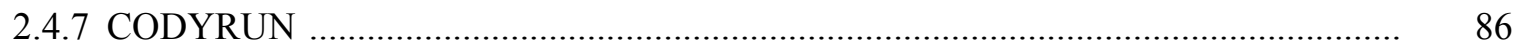

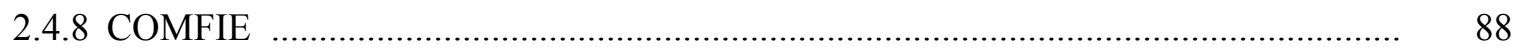

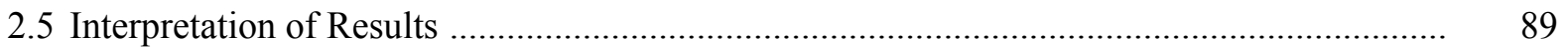

2.5.1 Use of Calorimetry and An Analytical Solution to Isolate Effects of Specific Models 89

2.5.2 Improvements to Simulations during the Field Trials.............................................. 90

2.5.3 Test Cases for Future Work ........................................................................... 98

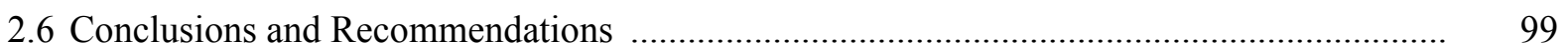

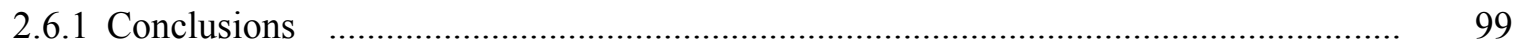

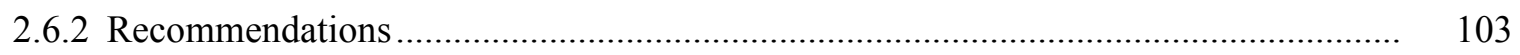

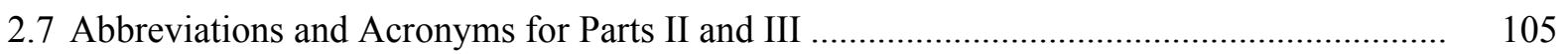

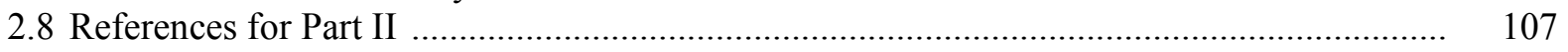

2.9 Appendix II: Simulation Modeler Reports...................................................................... 110

Appendix II-A: EnergyPlus Version 2.1.0.012, GARD Analytics, United States............. 111

Appendix II-B: ESP-r Version 11.5, University of Strathclyde, United Kingdom .......... 119

Appendix II-C: HTB2 Version 2.20AD, Cardiff University, United Kingdom .............. 122

Appendix II-D: TRNSYS-TUD, Dresden University of Technology, Germany …......... 127

Appendix II-E: TRNSYS-16, University of Liège, Belgium ......................................... 132

Appendix II-F: VA114 Version 2.25, VABI Software, The Netherlands ...................... 140

Appendix II-G: CODYRUN, University of Reunion Island, France .............................. 169

Appendix II-H: COMFIE, Paris School of Mines, France …...................................... 172

Appendix II-I: KoZiBu, JNLOG, France ................................................................ 181

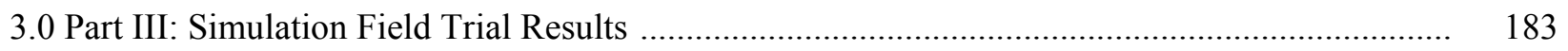

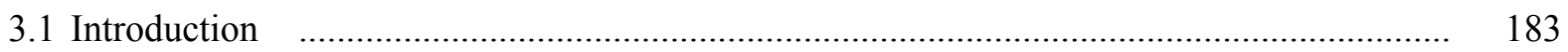

3.2 Zone Cooling Load Versus Transmitted Solar Radiation Results for Cases MZ340 - MZ360 183

3.3 Further Comments on Results for Multi-Zone Shading Cases MZ340, MZ350, and MZ355 184

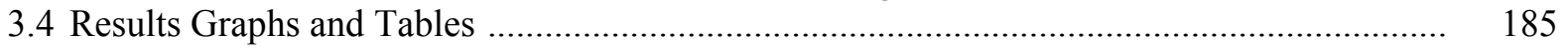

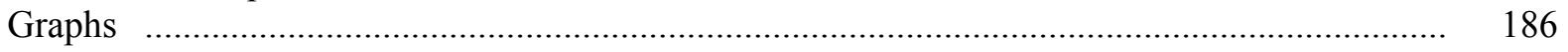

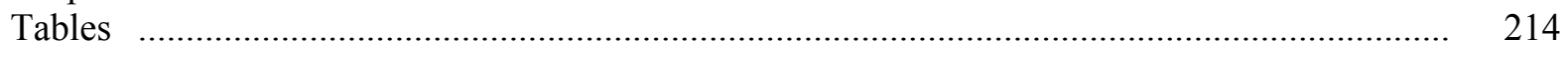




\section{Electronic Media Contents}

Files apply as they are called out in the test procedure.

README-MZ.DOC: Electronic media contents

MZ320.TM2: TMY2 weather data for $20^{\circ} \mathrm{C}$ constant ODB, $4.3 \mathrm{~m} / \mathrm{s}$ wind speed, solar off

MZ340.TM2: TMY2 weather data for $20^{\circ} \mathrm{C}$ constant ODB, $4.3 \mathrm{~m} / \mathrm{s}$ wind speed, solar on (Miami.TM2)

MZ-Output.XLS: Raw output data spreadsheet

MZ-RESULTS-Annuals.XLS: Results spreadsheet to assist users with plotting their results versus the example simulation annual summary results

MZ-RESULTS-Hourlies.XLS: Results spreadsheet to assist users with plotting their results versus the example simulation hourly results

MZ-Results.DOC: Documentation for navigating MZ-RESULTS-Annuals.XLS and MZ-RESULTSHourlies.XLS

InpFiles-MZ subfolder: (IEA SHC Task 34/ECBCS Annex 43 participant simulation input files)

EnergyPlus

ESP-r

$\backslash$ HTB2

ITRNSYS-TUD

IVA114

ICOMFIE 


\section{Executive Summary}

This report documents a set of in-depth diagnostic test cases for multi-zone heat transfer models that do not include the heat and mass transfer effects of airflow between zones. Another set of test cases dealing with airflow modeling is under development by the Japanese team participating in this IEA Task and will be published in a separate report. The multi-zone non-airflow test cases represent an extension to IEA BESTEST. ${ }^{1}$ This new work was conducted by the National Renewable Energy Laboratory (NREL), United States in collaboration with a working group of international experts under International Energy Agency (IEA) Solar Heating and Cooling (SHC) Programme Task 34 and IEA Energy Conservation in Buildings and Community Systems (ECBCS) Programme Annex 43 (IEA 34/43).

\section{Background}

The development of practical procedures and data for tool evaluation and improvement is part of an overall IEA validation methodology that $\mathrm{NREL}^{2,3,4}$ and the IEA $^{5,6}$ have been developing for many years. The methodology combines empirical validation, analytical verification, and comparative analysis techniques; details are discussed in the Background Section of HVAC BESTEST Volume $1{ }^{7}$ with updates published in the 2005 ASHRAE Handbook of Fundamentals ${ }^{8}$ and elsewhere. ${ }^{4}$ NREL originally developed the BESTEST method in IEA SHC Task 12 to test building thermal fabric (envelope) models, and to diagnose sources of predictive disagreements. ${ }^{1}$ This method of test was adopted with some refinements by the American Society of Heating, Refrigerating and Air-Conditioning Engineers (ASHRAE) in accordance with procedures of the American National Standards Institute (ANSI), and now forms the basis for ANSI/ASHRAE Standard 140, Method of Test for the Evaluation of Building Energy Analysis Computer Programs. ${ }^{9,10,11}$ Since Standard 140 was first published, three HVAC BESTEST test suites developed within IEA SHC Task 22 have been added: two that address unitary space cooling equipment, ${ }^{7,12}$ and one that addresses fuel-fired furnaces. ${ }^{13}$ The new in-depth multi-zone non-airflow test cases described in this report are also planned for inclusion in Standard 140.

\section{Importance of the Multi-Zone Modeling Problem}

Many buildings have multiple mechanical equipment control zones, and are therefore better modeled with multiple zones. Additionally, architectural features related to shading or that use internal windows are often applied in a multi-zone context. For example, a shading device associated with one zone of a model may cast a shadow on a window associated with another zone of that model.

Current IEA BESTEST building thermal fabric test cases originally published by NREL in $1995^{1,11}$ test the ability to model the thermal physics related to many typical building features such as thermal mass, windows, shading devices, orientation, internal gains, mechanical ventilation, and thermostat set point variation. These test cases are applied in a single-zone modeling context, except for one test case for modeling a sunspace that interacts with a conditioned zone via a common wall. HERS BESTEST, ${ }^{14}$ also published by NREL in 1995, is designed to similarly test simplified tools commonly used with residential modeling. These test cases provide a more realistic, but less diagnostic context than IEA BESTEST. ${ }^{15}$ HERS BESTEST includes the possibility for (but does not require) multi-zone modeling in all of its cases for an unconditioned attic, and in two of its cases that include a basement. However, the HERS BESTEST output requirements do not disaggregate results for separate zones, which inhibits multi-zone modeling diagnostics.

If a model has good agreement for the current set of building thermal fabric test cases that emphasize single-zone modeling, phenomena specific to multi-zone configurations are not necessarily being correctly modeled. Additional work published during IEA SHC Task 12 by Tampere University of 
Technology ${ }^{16}$ developed six test cases in a realistic commercial building/multi-zone context using two conditioned zones separated by a conditioned or unconditioned corridor zone, where only walls with windows are exposed to ambient conditions. NREL reviewed this work and observed the following: ${ }^{17}$

- Although the cases use a multi-zone configuration, multi-zone modeling effects are not well isolated.

○ The only discernible multi-zone modeling observation was that an unconditioned corridor caused disagreement among simulation results to expand versus a conditioned corridor.

- Other than that, because of many simultaneously acting phenomena, it was difficult to make specific conclusions regarding multi-zone interactions.

- No found bugs were documented for the simulation programs that ran the field trials of the multizone test cases, whereas several found bugs were documented and fixed during field trials of the IEA BESTEST single-zone test cases that were also developed during IEA SHC Task 12.

As none of the test suites described above adequately isolates phenomena specific to multi-zone modeling, test cases must be developed to address such phenomena.

\section{The Current IEA 34/43 Multi-Zone Non-Airflow Diagnostic Test Cases}

This report documents a set of five diagnostic test cases for multi-zone non-airflow heat transfer models. The test cases cover modeling of:

- Interzonal conduction heat transfer, assuming one-dimensional conduction

- Multi-zone shading, including building self shading

- Internal windows between zones.

We began the test cases by developing a relatively simple steady-state analytical solution (analytical verification test) for multi-zone conduction. Good agreement for the multi-zone conduction analytical verification tests was obtained early in the project. This provided a good starting point for developing diagnostic comparative test cases that test multi-zone shading models and internal window models.

We specified the multi-zone shading and internal window test cases by using building zones designed to be modeled as precise calorimeters, where the only thermal mass is for the zone air. The basic principle is that all solar radiation incident on an exterior window is captured within a zone, such that the zone cooling load is equivalent to the solar radiation incident on that window. Causes of disagreements are therefore limited to either an issue with the specific model being tested (the shading or internal window model), modeling of incident solar radiation, inability to precisely model the idealizations defining the zone as a calorimeter, or an input error. Additionally, sensitivity "delta" cases allow intermodel comparison of the difference between zone cooling loads with a shading device and without shading. This allows better isolation of shading model effects, as differences among models not related specifically to shading models should cancel out.

The effects of thermal mass were not tested in these new cases because the original IEA BESTEST ${ }^{1}$ comparative cases explored building envelope thermal mass effects in detail in a single-zone context (and in a two-zone case with a sunspace). By excluding thermal inertia and minimizing other simultaneous effects, the current specialized multi-zone cases maximize diagnostic power, and also minimize the number of cases required to address the tested phenomena. In the absence of multi-zone mass interaction test cases for the current configurations, if a simulation model demonstrates agreement for the original IEA BESTEST cases with thermal mass and demonstrates agreement for the new multi-zone test cases, that would suggest that such tested simulations may provide agreement where aspects of both types of test cases are combined. As thermal mass interactions (and other interactions) are important to test explicitly, 
our recommendations for future activities (see Section 2.5.3) include developing multi-zone cases with thermal mass.

\section{Results and Conclusions}

Field trials of the new IEA BESTEST cases were conducted with a number of detailed state-of-the-art whole-building energy simulation programs from around the world (see Table ES-1). The field-trial process was iterative in that executing the simulations led to refinement of the BESTEST cases, and the results of the tests led to improving and debugging the models. Improvements to simulation programs or simulation inputs made by participants must have a mathematical and a physical basis, and must be applied consistently across tests. Arbitrary modification of a simulation program's input or internal code just for the purpose of more closely matching a given set of results is not allowed. All improvements were required to be documented and justified in the modeler reports.

Initial results for the multi-zone conduction cases with adiabatic exterior walls and conducting internal walls are shown in Figure ES-1. Disagreement for the initial two- and three-zone cases with a simple analytical solution ranged from $6 \%$ to $8 \%$, where only two programs are shown as disagreeing. Here, disagreement is the difference between the maximum and minimum results for each case, divided by the mean of the results for each case ((max-min)/mean). Two other software developers reported fixing issues before submitting their results; based on anecdotal discussion from modeler reports these "pre-initial" results would have had disagreements with order of magnitude similar to those shown for the other programs. Additionally, three of the four reported initial disagreements arose because the boundary conditions specified by the test cases could not be modeled exactly; the other was an input error. Subsequent fixes to the programs yielded very good agreement with the analytical solutions.

This initial good agreement led us to design a more challenging three-zone test case with more conduction interactions, which was still analytically solvable. This case is a system of three zones in series with a conditioned zone on one end adjacent to two adjacent unconditioned (floating temperature) zones, where both the interior and exterior walls are conductive (see Part I, Section 1.3.1 for details). All models tested agreed with the analytical solution within $\leq 0.3 \%$ except for one program (see Figure ES-2). (For results shown in Figures ES-1 and ES-2, some participants for the earliest cases were not able to submit results for later cases, and vice versa.)

For the multi-zone shading and internal window test cases, improvements to the simulation programs are evident when initial results are compared to final results, as shown in Figures ES-3 and ES-4, respectively, for the multi-zone shading cases, and Figures ES-5 and ES-6, respectively, for the internal window cases. These results indicate that there was initially $20 \%-90 \%$ and $40 \%-155 \%$ disagreement among annual cooling loads for various zones for the multi-zone shading and internal window cases, respectively, with substantial scatter among the programs. After correcting software and modeling errors using BESTEST diagnostics - there have been 31 fixes so far - the remaining disagreements among results for various zones for multi-zone shading are $5 \%-13 \%$, and for a single internal-window configuration are $7 \%-34 \%$. For the most challenging configuration with a second internal window in series, disagreement for annual cooling load for the zone interior to the second internal window is $112 \%$ (see bars for Zone C in Figure ES-6), thus indicating further refinement of models for this configuration may be warranted. Scatter among results was reduced for all the cases. 
Table ES-1. Participating Organizations and Models

\begin{tabular}{|c|c|c|c|}
\hline $\begin{array}{l}\text { Simulation } \\
\text { Program }\end{array}$ & Authoring Organization & Implemented by & Abbreviation \\
\hline $\begin{array}{l}\text { EnergyPlus } \\
2.1 .0 .012\end{array}$ & $\begin{array}{l}\text { LBNL/UIUC/DOE-BT, }{ }^{\text {a,b,c }} \text { United } \\
\text { States }\end{array}$ & $\begin{array}{l}\text { GARD Analytics, Inc., United } \\
\text { States }\end{array}$ & EnergyPlus/GARD \\
\hline ESP-r & ESRU, ${ }^{d}$ United Kingdom & ESRU, ${ }^{d}$ United Kingdom & ESP-r/ESRU \\
\hline HTB2 & WSA, ${ }^{\mathrm{e}}$ United Kingdom & WSA, ${ }^{\mathrm{e}}$ United Kingdom & HTB2/WSA \\
\hline TRNSYS-TUD & $\begin{array}{l}\text { University of Wisconsin/Dresden } \\
\text { University of Technology, United } \\
\text { States/Germany }\end{array}$ & $\begin{array}{l}\text { Dresden University of } \\
\text { Technology, Germany }\end{array}$ & TRNSYS-TUD/TUD \\
\hline TRNSYS-16 & $\begin{array}{l}\text { University of Wisconsin, United } \\
\text { States }\end{array}$ & University of Liège, Belgium & TRNSYS-16/ULg \\
\hline VA114 2.25 & $\begin{array}{l}\text { VABI Software BV, The } \\
\text { Netherlands }\end{array}$ & $\begin{array}{l}\text { VABI Software BV, The } \\
\text { Netherlands }\end{array}$ & $\begin{array}{l}\text { VA114-CirBm/VABI } \\
\text { VA114-CirDf/VABI }\end{array}$ \\
\hline $\begin{array}{l}\text { Simulation } \\
\text { Program } \\
\text { (MZ320 Only) }\end{array}$ & Authoring Organization & Implemented by & Abbreviation \\
\hline CODYRUN & $\begin{array}{l}\text { University of Reunion Island, } \\
\text { France }\end{array}$ & $\begin{array}{l}\text { University of Reunion Island, } \\
\text { France }\end{array}$ & UR \\
\hline COMFIE & EdMP/IZUBA, ${ }^{\text {f,g }}$ France & EdMP, ${ }^{f}$ France & EdMP \\
\hline KoZiBu & INSA-Lyon/JNLOG, ${ }^{\mathrm{h}, \mathrm{i}}$ & JNLOG, ${ }^{i}$ France & JNLOG \\
\hline
\end{tabular}

aLBNL: Lawrence Berkeley National Laboratory, United States

bUIUC: University of Illinois Urbana/Champaign, United States

'DOE-BT: U.S. Department of Energy, Office of Building Technologies, Energy Efficiency and Renewable Energy, United States

${ }^{d}$ ESRU: Energy Systems Research Unit, University of Strathclyde, United Kingdom

'Welsh School of Architecture, Cardiff University, United Kingdom

fEcole des Mines de Paris, France

${ }^{9}$ IZUBA Energies, France

hINSA-Lyon Thermal Center, France

'Jean Noel, France 


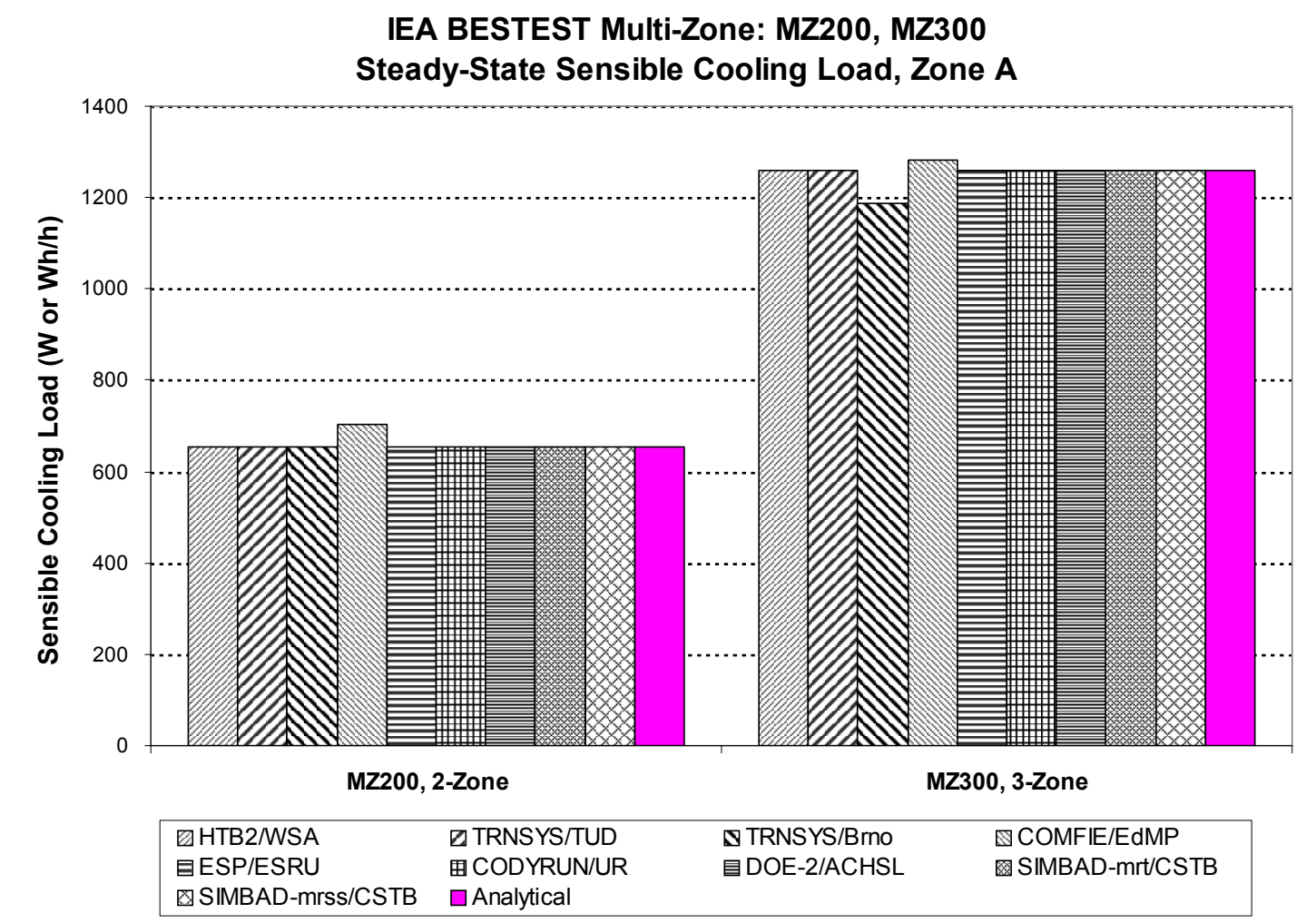

Figure ES-1. BESTEST multi-zone conduction - preliminary case results before BESTESTing

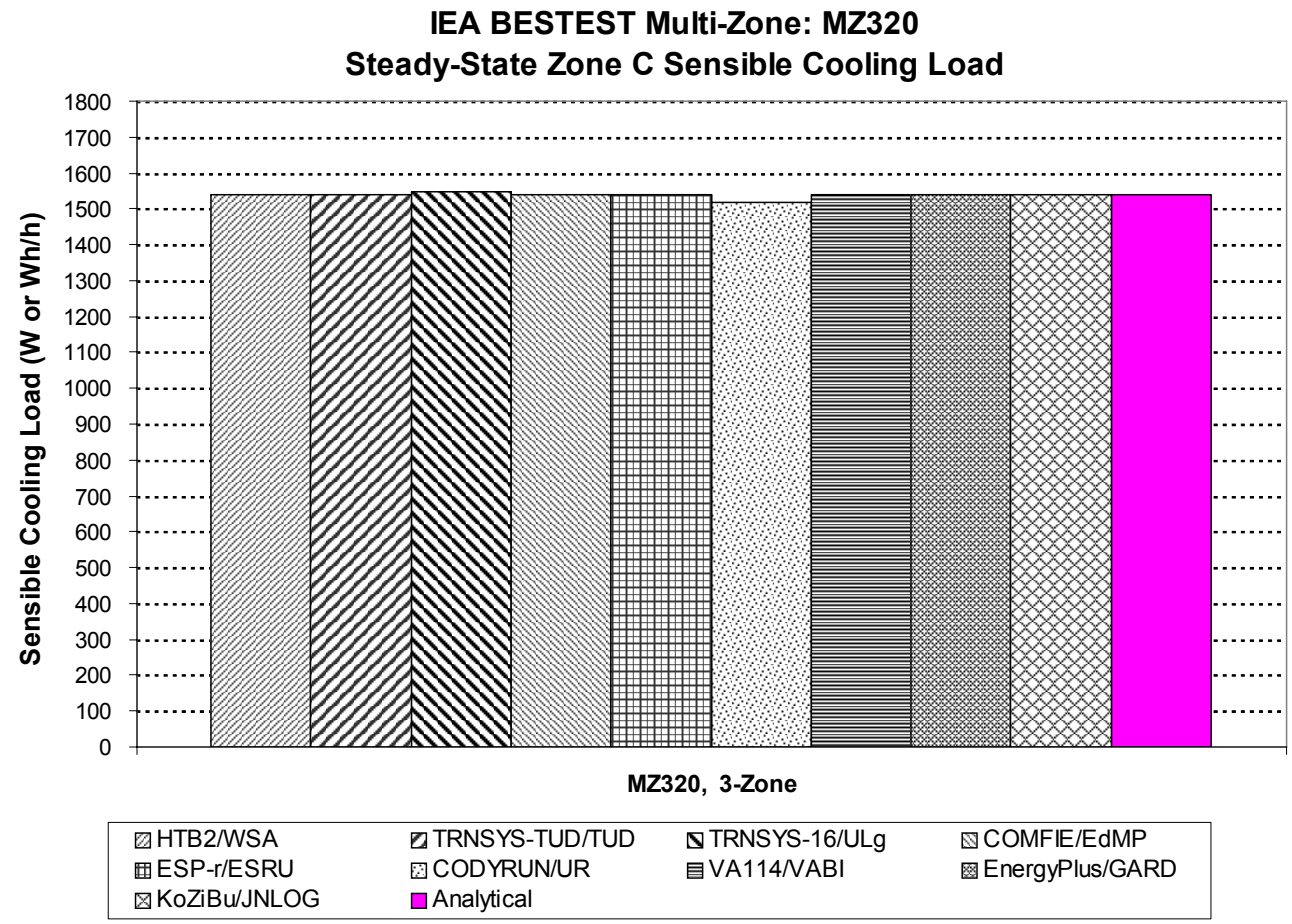

Figure ES-2. BESTEST multi-zone conduction - final case results after BESTESTing 


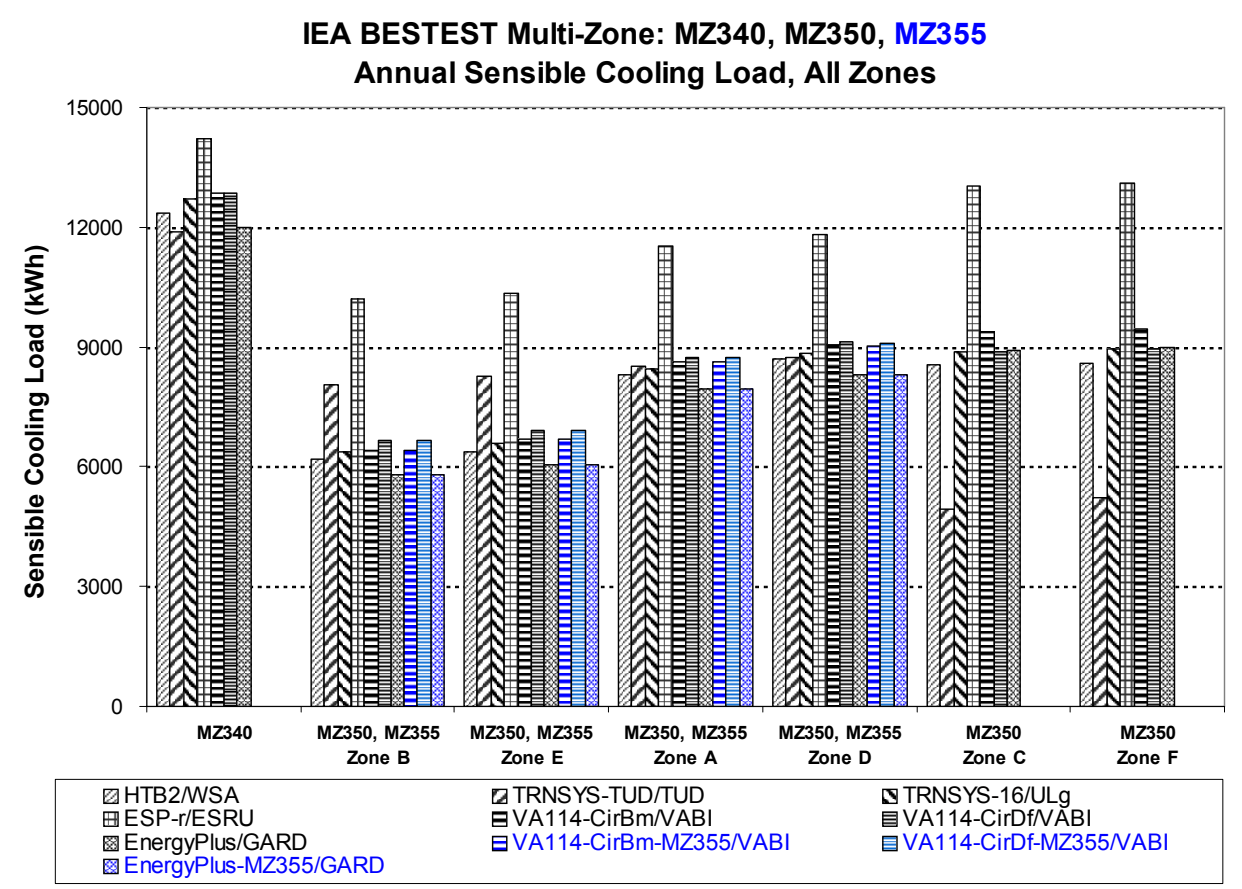

Figure ES-3. BESTEST multi-zone shading cases - sensible cooling load, before BESTESTing (Abbreviations along the $\mathrm{x}$-axis are shorthand for the case descriptions; see Part I for full case descriptions; building self-shading results are three rightmost bars for zones B, E, A, and D.)

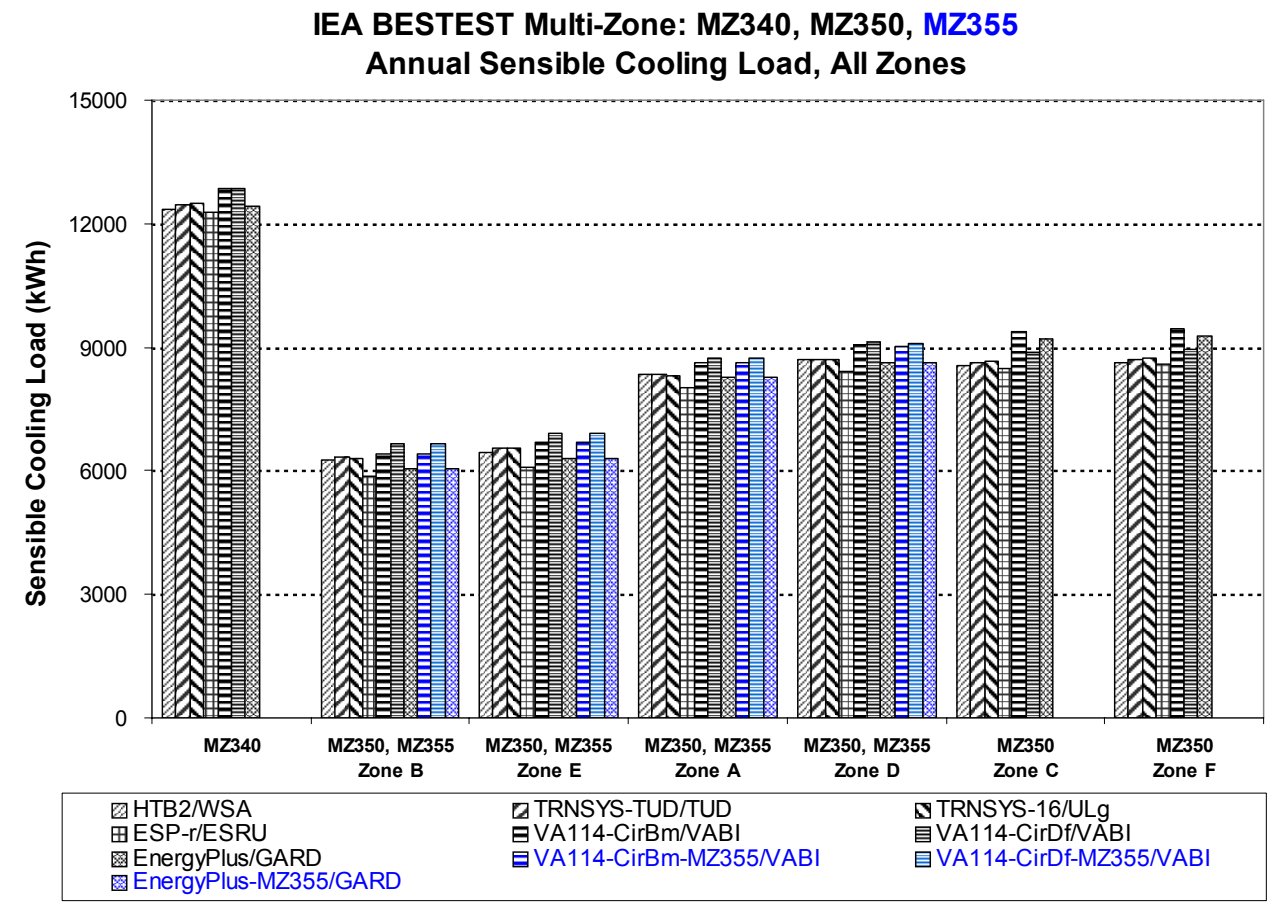

Figure ES-4. BESTEST multi-zone shading cases - sensible cooling load, after BESTESTing (Abbreviations along the $\mathrm{x}$-axis are shorthand for the case descriptions; see Part I for full case descriptions; building self-shading results are three rightmost bars for zones B, E, A, and D.) 


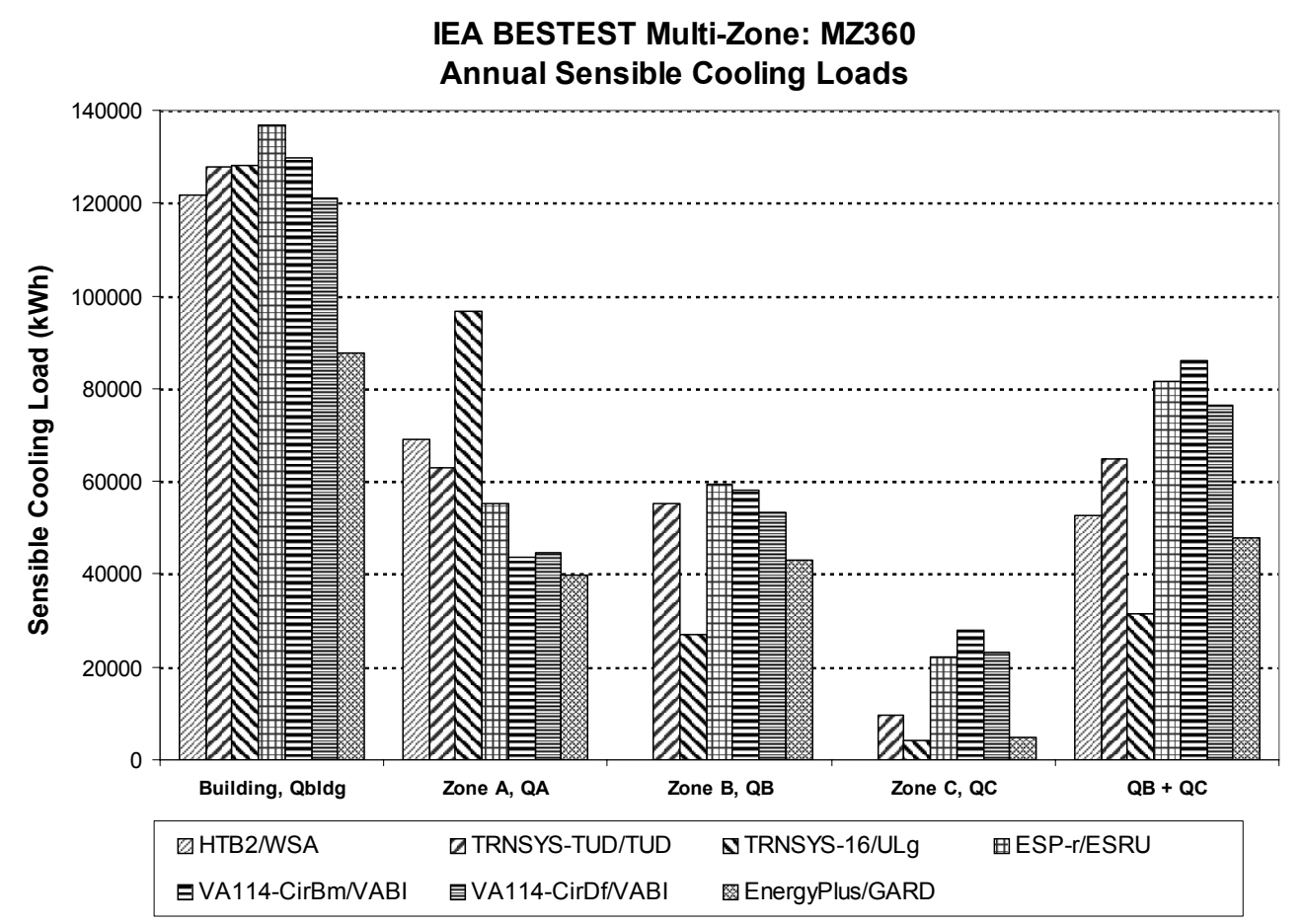

Figure ES-5. BESTEST internal windows - sensible cooling load, before BESTESTing (Abbreviations along the $\mathrm{x}$-axis are shorthand for the output descriptions; see Part I for full case descriptions.)

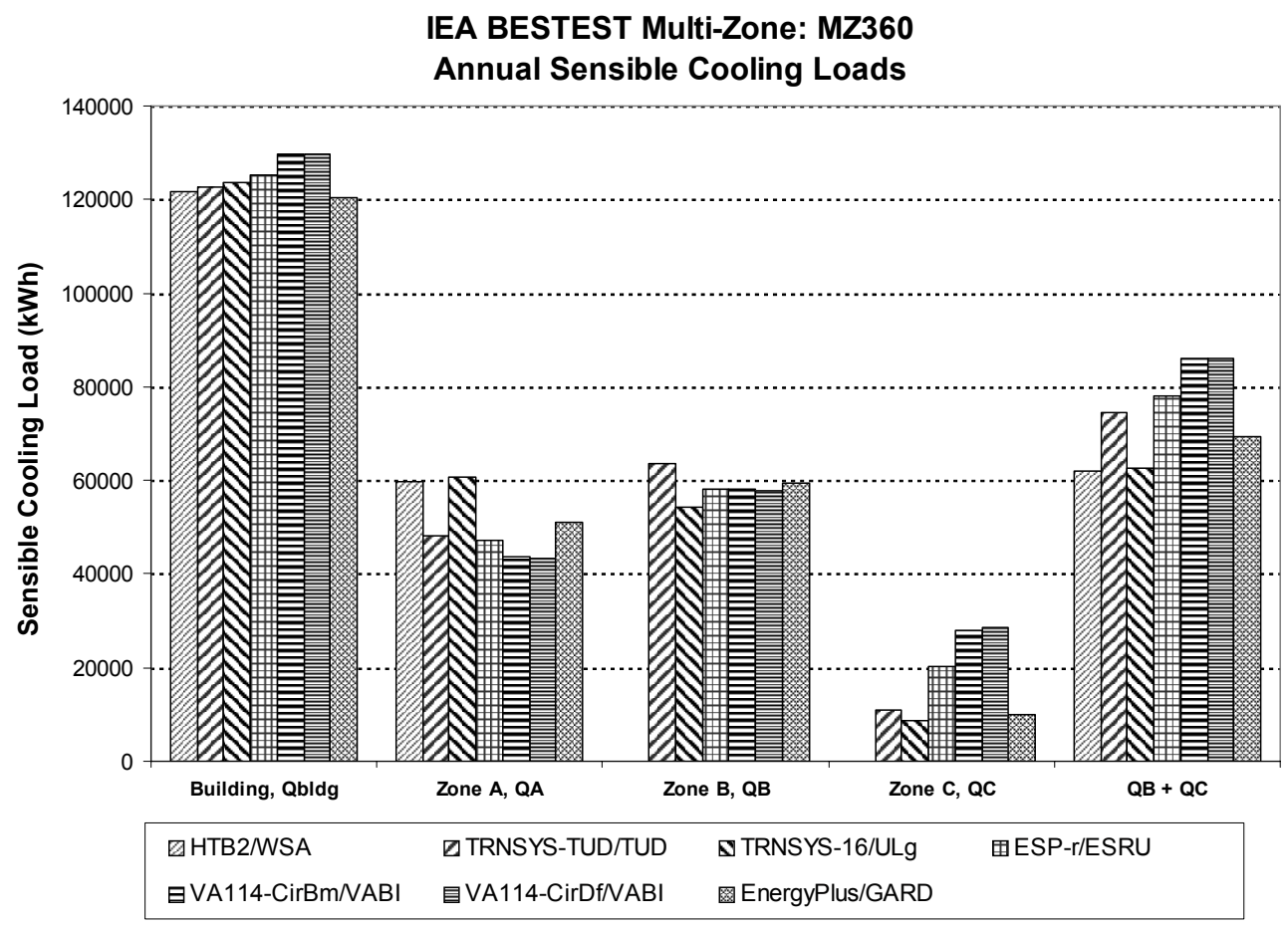

Figure ES-6. BESTEST internal windows - sensible cooling load, after BESTESTing (Abbreviations along the $\mathrm{x}$-axis are shorthand for the output descriptions; see Part I for full case descriptions.) 


\section{Findings}

A number of important technology advances occurred as a result of running the test cases:

- The improved final agreement for shading cases using idealized/modeled calorimetry enabled us to identify disagreements and diagnose errors that may have been missed using the original IEA BESTEST shading cases, ${ }^{1}$ where for the original IEA BESTEST cases disagreements related to modeling realistic optical properties of glazing and interior opaque surfaces along with realistic wall conduction employing thermal mass may have obscured disagreements caused by shading models.

- Of 49 found disagreements, 31 were diagnosed and fixed, 11 are planned for investigation by the software authors, 3 were judged as acceptable by the software authors, and 4 are awaiting notification of the software developer by the modeler. Several of the found errors affected some individual results by $>20 \%$. A list of the problems found among the tested models appears in Table 2-12 (see Part II, Section 2.6.1); supporting details are included in Part II, Section 2.4.

- Based on this work, there are a number of recommended areas for further investigation with respect to developing additional validation test cases for multi-zone modeling. These are described in detail in Part II, Section 2.5.3.

Based on results after several iterations of BESTESTing, and resulting model improvements, all the tested programs now appear to have reliable models for phenomena isolated by the test cases including interzonal conduction, multi-zone shading, and internal windows where there are no multiple internal windows in series. These test cases did not address thermal inertia interactions for the modeled phenomena because thermal mass effects were tested in IEA BESTEST. ${ }^{1}$ Some remaining disagreements (discussed in Part II, Section 2.4) should be addressed, especially with respect to deficiencies identified for three of the models related to modeling a second internal window in series. The simulation results (with the noted exceptions) may therefore be used as a reference or benchmark against which other software can be tested.

With respect to the value of the test cases to software developers, a software-developer/vendor participants made the following comment about this IEA project:

"Bestest and IEA-34/43 tests brought a number of new errors to the surface. This shows the importance of these test [cycles]!! And still there will be errors in the software!! Development of new, specific test cases is of big importance!!"18

\section{Closing Remarks}

The work presented in this report, other work of IEA 34/43, and the work that preceded it in IEA SHC Tasks 8, 12, and 22 are important for two reasons:

- The methods have been extremely successful at correcting software errors in advanced building energy simulation programs throughout the world.

- The methods are finding their way into industry by being adopted as the theoretical basis for formalized standard methods of test and software certification procedures; in this sense the work may be thought of as pre-normative research.

ANSI/ASHRAE Standard $140^{11}$ and the BESTEST reports that comprise the test suites contained therein are being referenced and used by a growing number of code promulgation authorities throughout the world. ASHRAE Standard 90.1, ${ }^{19}$ which is ASHRAE's consensus energy code for commercial buildings and for non-low-rise residential buildings, requires that software used for demonstrating performance 
compliance with Standard 90.1 be tested using ASHRAE Standard 140-2004. ${ }^{10}$ Software used for calculating energy savings for purposes of the energy-efficient commercial building tax deductions in the United States must be tested with Standard 140-2007. ${ }^{20}$ As part of building energy performance assessments under the European Community's Energy Performance Directive, ${ }^{21}$ several countries are using software tools that have been checked with BESTEST. Further details of international use of BESTEST, along with growing evidence that the BESTEST procedures are becoming part of software developers' normal in-house quality control efforts, are included elsewhere. ${ }^{4,22}$

Computer scientists universally accept the merits of software testing. A well-known rule of thumb is that in a typical programming project more than $50 \%$ of the total cost is expended in testing the program or system being developed. ${ }^{23}$ Of this about $20 \%$ of development time goes toward system testing. ${ }^{24}$ Because new energy-related technologies are continually being introduced into the buildings market, there will always be a need for further development of simulation models, combined with a substantial program of testing and validation. Such an effort should contain all the elements of an overall validation methodology, ${ }^{4,8}$ including:

- Analytical verification

- Comparative testing and diagnostics

- Empirical validation.

Future work should therefore:

- Continue to produce a standard set of analytical tests.

- Develop a set of diagnostic comparative tests that emphasize the important modeling issues in large commercial buildings, including more tests for heating, ventilating, and air-conditioning systems, and other mechanical equipment including on-site power generation equipment.

- Develop a sequentially ordered series of high-quality data sets for empirical validation.

Finally, the authors wish to acknowledge that the expertise available through the IEA and the dedication of the participants were essential to the success of this project. Over the four-year field trial effort, there were several revisions to the BESTEST specifications and subsequent re-executions of the computer simulations. This iterative process led to the refining of the new BESTEST cases, and the results of the tests helped us improve and debug the simulation models. The process underscores the leveraging of resources for the IEA countries participating in this project. Such extensive field trials, and resulting enhancements to the tests, were much more cost effective with the participation of the IEA-34/43 experts.

\section{References for Executive Summary}

${ }^{1}$ Judkoff, R.; Neymark, J. (1995). International Energy Agency Building Energy Simulation Test (IEA BESTEST) and Diagnostic Method. NREL/TP-472-6231. Golden, Colorado, US: National Renewable Energy Laboratory. Available from http://www.nrel.gov/docs/legosti/old/6231.pdf (PDF 13.8 MB).

${ }^{2}$ Judkoff, R.; Wortman, D.; O’Doherty, B.; Burch, J. (2008). A Methodology for Validating Building Energy Analysis Simulations. NREL/TP-550-42059. Golden, Colorado, US: National Renewable Energy Laboratory. This is a formal publication of work that was brought to final draft in 1983 and referenced in a number of documents as SERI/TR-254-1508. The two reports are identical except for a few minor edits to complete the previous draft. 
${ }^{3}$ Judkoff, R. (1988). "Validation of Building Energy Analysis Simulation Programs at the Solar Energy Research Institute." Energy and Buildings, Vol. 10, No. 3, p. 235. Lausanne, Switzerland: Elsevier Sequoia.

${ }^{4}$ Judkoff, R.; Neymark, J. (2006). "Model Validation and Testing: The Methodological Foundation of ASHRAE Standard 140." ASHRAE Transactions, 112 (2) 367-376. Atlanta, Georgia, US: American Society of Heating, Refrigerating and Air-Conditioning Engineers.

${ }^{5}$ Bloomfield, D., ed. (November 1989). Design Tool Evaluation: Benchmark Cases. IEA T8B4. Solar Heating and Cooling Programme, Task VIII: Passive and Hybrid Solar Low-Energy Buildings. Building Research Establishment. Garston, Watford, UK: Building Research Establishment.

${ }^{6}$ Lomas, K. (1991). "Dynamic Thermal Simulation Models of Buildings: New Method of Empirical Validation.” BSER\&T 12(1):25-37.

${ }^{7}$ Neymark J.; Judkoff, R. (2002). International Energy Agency Building Energy Simulation Test and Diagnostic Method for Heating Ventilating and Air-Conditioning Equipment Models (HVAC BESTEST), Volume 1: Cases E100-E200. NREL/TP-550-30152. Golden, Colorado, US: National Renewable Energy Laboratory. Available from http://www.nrel.gov/docs/fy02osti/30152.pdf.

${ }^{8}$ ASHRAE. (2005). 2005 Handbook of Fundamentals, Atlanta, Georgia, US: American Society of Heating, Refrigerating and Air-Conditioning Engineers.

${ }^{9}$ ANSI/ASHRAE Standard 140-2001. (2001). Standard Method of Test for the Evaluation of Building Energy Analysis Computer Programs. Atlanta, Georgia, US: American Society of Heating, Refrigerating and Air-Conditioning Engineers.

${ }^{10}$ ANSI/ASHRAE Standard 140-2004. (2004). Standard Method of Test for the Evaluation of Building Energy Analysis Computer Programs. Atlanta, Georgia, US: American Society of Heating, Refrigerating and Air-Conditioning Engineers.

${ }^{11}$ ANSI/ASHRAE Standard 140-2007. (2007). Standard Method of Test for the Evaluation of Building Energy Analysis Computer Programs. Atlanta, Georgia, US: American Society of Heating, Refrigerating and Air-Conditioning Engineers.

${ }^{12}$ Neymark, J.; Judkoff, R. (2004). International Energy Agency Building Energy Simulation Test and Diagnostic Method for Heating, Ventilating, and Air-Conditioning Equipment Models (HVAC BESTEST), Volume 2: Cases E300-E545. NREL/TP-550-36754. Golden, Colorado, US: National Renewable Energy Laboratory. www.nrel.gov/docs/fy05osti/36754.pdf.

${ }^{13}$ Purdy, J.; Beausoleil-Morrison, I. (2003). Building Energy Simulation Test and Diagnostic Method for Heating, Ventilation, and Air-Conditioning Equipment Models (HVAC BESTEST): Fuel-Fired Furnace Test Cases. Ottawa, Ontario, Canada: CANMET Energy Technology Centre, Natural Resources Canada. Available from www.iea-shc.org/task22/deliverables.htm.

${ }^{14}$ Judkoff, R.; Neymark, J. (1995). Home Energy Rating System Building Energy Simulation Test (HERS BESTEST). NREL/TP-472-7332. Golden, Colorado, US: National Renewable Energy Laboratory.

Volume 1: Tier 1 and Tier 2 Tests User's Manual, NREL/TP-472-7332a, available from http://www.nrel.gov/docs/legosti/fy96/7332a.pdf (PDF 5.6 MB);

Volume 2: Tier 1 and Tier 2 Tests Reference Results, NREL/TP-472-7332b, available from http://www.nrel.gov/docs/legosti/fy96/7332b.pdf (PDF 1.9 MB). 
${ }^{15}$ Neymark, J.; Judkoff, R. (1997). “A Comparative Validation Based Certification Test for Home Energy Rating System Software.” Proc. Building Simulation '97. September 8-10, Prague, Czech Republic. International Building Performance Simulation Association.

${ }^{16}$ Haapala, T.; Kalema, T.; Kataja, S. (1995). Energy Analysis Tests for Commercial Buildings (Commercial Benchmarks). Report 101. Tampere, Finland: Tampere University of Technology.

${ }^{17}$ Neymark, J; Judkoff, R. (2003). IEA BESTEST Multi-Zone Review. Golden, Colorado, US: J. Neymark \& Associates and National Renewable Energy Laboratory. Presented at $1^{\text {st }}$ Experts Meeting of IEA SHC Task 34/ECBCS Annex 43, Duebendorf, Switzerland, 30 Sep 2003. See files "MZ-Breakout092703.ppt" and "MZ-Prelim092203.doc", available upon request.

${ }^{18}$ Wijsman, A. (2008). Modeler Report for BESTEST Cases MZ320-MZ360, VA114 Version 2.25. Delft, Netherlands: VABI Software BV. March 2008. Included with Section 2.9, Appendix II-F, of this final report.

${ }^{19}$ ANSI/ASHRAE/IESNA. (2007). ANSI/ASHRAE/IESNA Standard 90.1-2007, Energy Standard for Buildings Except Low-Rise Residential Buildings. Atlanta, Georgia, US: American Society of Heating, Refrigerating and Air-Conditioning Engineers.

${ }^{20}$ Internal Revenue Service (IRS). (2008). Amplification of Notice 2006-52, Deduction for Energy Efficient Commercial Buildings. IRS Notice 2008-40. Appears in Internal Revenue Bulletin (IRB) No. 2008-14, April 7, 2008. Washington, DC, US: United States Department of Treasury, Internal Revenue Service.

${ }^{21}$ European Union. (2002). On the Energy Performance of Buildings. Directive 2002/91/EC of the European Parliament and of the Council, Official Journal of the European Communites, December.

${ }^{22}$ Neymark, J.; Judkoff, R.; with Beausoleil-Morrison, I; Ben-Nakhi, A.; Crowley, M.; Deru, M.; Henninger, R.; Ribberink, H.; Thornton, J.; Wijsman, A.; Witte, M. (2008). International Energy Agency Building Energy Simulation Test and Diagnostic Method (IEA BESTEST) In-Depth Diagnostic Cases for Ground Coupled Heat Transfer Related to Slab-On-Grade Construction. NREL/TP-550-43388. Golden, Colorado, US: National Renewable Energy Laboratory.

${ }^{23}$ Myers, G. (2004). The Art of Software Testing. Hoboken NJ: John Wiley \& Sons. See p. xiii.

${ }^{24}$ McConnell, S. (2004). Code Complete: A Practical Handbook of Software Construction. Microsoft Press, p. 502. 


\section{Introduction}

A method of test for evaluating building energy simulation computer programs - International Energy Agency Building Energy Simulation Test and Diagnostic Method (IEA BESTEST) - was developed by the National Renewable Energy Laboratory (NREL), United States, in collaboration with IEA SHC Task 12 and ECBCS Annex 21 (Judkoff and Neymark 1995a). New work presented herein, which follows up Task 12, was conducted by NREL in collaboration with the participants of IEA SHC Task 34/ECBCS Annex 43, Project B ("Multi-Zone Buildings and Air Flow"). The objective of this sub-project is to extend the original IEA BESTEST to include additional test cases for multi-zone conduction, multi-zone shading, and modeling of internal windows.

\section{Background}

A discussion of the importance of the multi-zone modeling problem is included in the Executive Summary of this report.

\section{Advantages of BESTEST Methodology}

An advantage of the BESTEST methodology is that a program is examined over a broad range of parametric interactions based on a variety of output types, minimizing the possibility that compensating errors will conceal problems. Performance of the tests resulted in quality improvements to all but one of the building energy simulation models used in the field trials, and all of the models used in the multi-zone shading and internal window test cases. Some of the bugs that were found may well have been present for several years. The fact that they have just now been uncovered shows the power of BESTEST and suggests the importance of continuing to develop formalized validation and diagnostic methods. Only after coding bugs have been eliminated can the assumptions and approximations in the algorithms be evaluated.

Checking a building energy simulation program for the first time with the BESTEST in-depth multi-zone non-airflow test cases requires a few days for an experienced user, not including any necessary improvements to the software. Subsequent program checks are faster because input files may be reused. Because the simulation programs have taken many years to produce, the new BESTEST cases provide a cost-effective way of testing them. As we continue to develop new test cases, we will adhere to the principle of parsimony so that the entire suite of BESTEST cases may be implemented by users with a reasonable time commitment.

Software developers, architects, engineers, and researchers can use these new BESTEST cases in a number of ways, to:

- Compare output from building energy simulation programs to a set of analytical solutions that constitute a reliable set of theoretical results given the underlying physical assumptions in the case definitions.

- Compare several building energy simulation programs to determine their degree of disagreement.

- Diagnose the algorithmic sources of prediction differences among several building energy simulation programs.

- Compare predictions from other building energy simulation programs to the analytical solution and simulation results in this report.

- Check a program against a previous version of itself after internal code modifications to ensure that only the intended changes actually resulted. 
- Check a program against itself after a single algorithmic change to understand the sensitivity among algorithms.

\section{Other BESTEST Procedures}

As a BESTEST user, if you have not already tested your software with previously developed BESTEST procedures, we strongly recommend that you run all the building thermal fabric and mechanical equipment cases currently included in ANSI/ASHRAE Standard 140-2007. (ANSI/ASHRAE 2007. Also see: Judkoff and Neymark 1995a; Neymark and Judkoff 2002, 2004; Purdy and Beausoleil-Morrison 2003.) Another set of building thermal fabric test cases, which were designed to test simplified tools such as those currently used for home energy rating systems (HERS), is included in HERS BESTEST (Judkoff and Neymark 1995b; Judkoff and Neymark 1997). HERS BESTEST, which is being adapted for Standard 140 , has a more realistic base building than the IEA BESTEST building thermal fabric test cases currently included with Standard 140; however, its ability to diagnose sources of differences among results is not as robust (Neymark and Judkoff 1997).

\section{Final Report Structure}

This report is divided into three parts. Part I is a user's manual that furnishes instructions on how to apply this BESTEST procedure. Part II describes the development, field-testing, and production of results data for the procedure. Part III presents the simulation program example results in tables and graphs along with disagreement statistics that compare the simulation programs to each other; these data can be used to compare results from other programs to Part III results.

\section{References for Introduction}

ANSI/ASHRAE Standard 140-2007. Standard Method of Test for the Evaluation of Building Energy Analysis Computer Programs. (2007). Atlanta, GA: American Society of Heating, Refrigerating and AirConditioning Engineers.

Judkoff, R.; Neymark, J. (1995a). International Energy Agency Building Energy Simulation Test (BESTEST) and Diagnostic Method. Golden, Colorado, US: National Renewable Energy Laboratory, NREL/TP-472-6231, www.nrel.gov/docs/legosti/old/6231.pdf.

Judkoff, R.; Neymark, J. (1995b). Home Energy Rating System Building Energy Simulation Test (HERS BESTEST). Golden, Colorado, US: National Renewable Energy Laboratory, NREL/TP-472-7332.

Volume 1: Tier 1 and Tier 2 Tests User's Manual, NREL/TP-472-7332a, www.nrel.gov/docs/legosti/fy96/7332a.pdf;

Volume 2: Tier 1 and Tier 2 Tests Reference Results, NREL/TP-472-7332b, www.nrel.gov/docs/legosti/fy96/7332b.pdf.

Judkoff, R.; Neymark, J. (1997). Home Energy Rating System Building Energy Simulation Test for Florida (Florida-HERS BESTEST). Golden, Colorado, US: National Renewable Energy Laboratory, NREL/TP-550-23124, www.nrel.gov/docs/legosti/fy97/23124a.pdf.

Neymark, J.; Judkoff, R. (1997). "A Comparative Validation Based Certification Test for Home Energy Rating System Software.” Proc. Building Simulation '97. September 8-10, Prague, Czech Republic. International Building Performance Simulation Association. 
Neymark J.; Judkoff, R. (2002). International Energy Agency Building Energy Simulation Test and Diagnostic Method for Heating Ventilating and Air-Conditioning Equipment Models (HVAC BESTEST), Volume 1: Cases E100-E200. NREL/TP-550-30152. Golden, Colorado, US: National Renewable Energy Laboratory. Available from www.nrel.gov/docs/fy02osti/30152.pdf.

Neymark, J.; Judkoff, R. (2004). International Energy Agency Building Energy Simulation Test and Diagnostic Method for Heating, Ventilating, and Air-Conditioning Equipment Models (HVAC BESTEST), Vol. 2: Cases E300-E545. Golden, Colorado, US: National Renewable Energy Laboratory, NREL/TP550-36754, www.nrel.gov/docs/fy05osti/36754.pdf.

Purdy, J.; Beausoleil-Morrison, I. (2003). Building Energy Simulation Test and Diagnostic Method for Heating, Ventilating, and Air-Conditioning Equipment Models (HVAC BESTEST): Fuel-Fired Furnace Test Cases. Ottawa, Canada: Natural Resources Canada, CANMET Energy Technology Centre. www.ieashc.org/task22/deliverables.htm. 


\subsection{Part I: BESTEST User's Manual: Procedure and Specification Cases MZ320 - MZ360}

\subsection{General Description of the Test Cases}

Five test cases are summarized in Table 1-1. The test cases are designed to test the ability of building energy analysis tools to model multi-zone conduction (one case), multi-zone shading including automated building self-shading (three cases), and modeling of internal windows (one case). The multi-zone conduction case is an analytical verification test, where simulation results are compared to an analytical solution (mathematical truth standard). The remaining cases are comparative tests, where simulation results are compared to each other.

\subsubsection{Accompanying Electronic Files}

\subsubsection{Weather Data Files}

The following TMY2-format weather data files are included with the accompanying electronic media:

\section{MZ320.TM2}

MZ340.TM2.

A summary of site and weather parameters is given in Table 1-2. The weather data files are applied to the test cases as follows:

\begin{tabular}{ll} 
Case & Weather Data \\
\hline MZ320 & MZ320.TM2 \\
MZ340 & MZ340.TM2 \\
MZ350 & MZ340.TM2 \\
MZ355 & MZ340.TM2 \\
MZ360 & MZ340.TM2
\end{tabular}

\subsubsection{Other Accompanying Electronic Files}

For reporting output use the following file provided with the accompanying electronic media:

\section{MZ-Output.XLS.}


Table 1-1. Multi-Zone Steady-State Conduction Test Case Summary

\begin{tabular}{|c|c|c|c|c|c|c|c|c|c|}
\hline \multirow[t]{2}{*}{ Case } & \multirow[t]{2}{*}{ Description } & \multicolumn{3}{|c|}{ Set Point $\left({ }^{\circ} \mathrm{C}\right)$} & \multicolumn{3}{|c|}{ Internal Gains (W) } & \multirow[b]{2}{*}{ Weather } & \multirow[t]{2}{*}{ Comments } \\
\hline & & $\mathbf{A}$ & B & $\mathbf{C}$ & $\mathbf{A}$ & B & $\mathbf{C}$ & & \\
\hline \multicolumn{10}{|c|}{ In-Depth Conduction } \\
\hline MZ320 & $\begin{array}{l}\text { Base Case (Steady State) } \\
\text { External Conduction } \\
\text { Constant interior and exterior combined } \\
\text { surface coefficients }\end{array}$ & OFF & OFF & 15 & 2500 & 1000 & 0 & $\begin{array}{l}\text { To }=20^{\circ} \mathrm{C} \\
\text { Solar OFF }\end{array}$ & $\mathrm{T}_{\mathrm{A}}, \mathrm{T}_{\mathrm{B}}, \mathrm{q}_{\mathrm{C}}$ have 1st Law analytical solutions \\
\hline \multicolumn{2}{|c|}{ In-Depth MZ Window/Shading } & \multicolumn{3}{|c|}{ All } & \multicolumn{3}{|c|}{ All } & & \\
\hline MZ340 & $\begin{array}{l}\text { Unshaded "Calorimeter" } \\
\text { Shading test base case, } 2 \text { story } \\
\text { Adiabatic walls, ideal windows }\end{array}$ & \multicolumn{3}{|c|}{20} & \multicolumn{3}{|c|}{0} & $\begin{array}{l}\text { To }=20^{\circ} \mathrm{C} \\
\text { Real solar }\end{array}$ & \begin{tabular}{|l} 
Zone cooling loads = absorbed solar loads \\
Establishes solar disagreement "noise"
\end{tabular} \\
\hline MZ350 & $\begin{array}{l}\text { Fin Shading } \\
\text { Fin height }>\text { Building height }\end{array}$ & \multicolumn{3}{|c|}{20} & \multicolumn{3}{|c|}{0} & $\begin{array}{l}\text { To }=20^{\circ} \mathrm{C} \\
\text { Real solar }\end{array}$ & MZ350-MZ340 tests shade effect each zone \\
\hline MZ355 & $\begin{array}{l}\text { Building Shading } \\
\text { Add zone to match fin shading }\end{array}$ & \multicolumn{3}{|c|}{20} & \multicolumn{3}{|c|}{0} & $\begin{array}{l}\text { To }=20^{\circ} \mathrm{C} \\
\text { Real solar }\end{array}$ & MZ355 = MZ350 intended (for Zones A, B, D, E) \\
\hline \multicolumn{2}{|c|}{ In-Depth Internal Window } & \multicolumn{3}{|c|}{ All } & \multicolumn{3}{|c|}{ All } & & \\
\hline MZ360 & $\begin{array}{l}2 \text { Internal Windows in Series } \\
\text { Internal window base case } \\
\text { Calorimetry using adiabatic walls and } \\
\text { ideal windows }\end{array}$ & \multicolumn{3}{|c|}{20} & \multicolumn{3}{|c|}{0} & $\begin{array}{l}\text { To }=20^{\circ} \mathrm{C} \\
\text { Real solar }\end{array}$ & $\begin{array}{l}\text { Zone cooling loads }=\text { absorbed solar loads } \\
\text { Tracks ideally transmitted beam \& diffuse } \\
\text { solar radiation with } 2 \text { internal windows in series }\end{array}$ \\
\hline
\end{tabular}


Table 1-2. Site and Weather Summary for Multi-Zone Non-Airflow Tests-TMY2 Data

\begin{tabular}{|c|c|c|c|}
\hline \multicolumn{2}{|l|}{ Weather Type } & \multicolumn{2}{|c|}{ Artificial Conditions } \\
\hline \multicolumn{2}{|l|}{ Weather Format } & \multicolumn{2}{|c|}{ TMY2 } \\
\hline Latitude & & \multicolumn{2}{|c|}{$25.8^{\circ}$ North } \\
\hline \multicolumn{2}{|l|}{ Longitude (local site) } & \multicolumn{2}{|c|}{$80.3^{\circ}$ West } \\
\hline \multicolumn{2}{|l|}{ Altitude } & \multicolumn{2}{|c|}{$2 \mathrm{~m}(6.56 \mathrm{ft})$} \\
\hline \multicolumn{2}{|l|}{ Time Zone (Standard Meridian Longitude) } & \multicolumn{2}{|c|}{$5\left(75^{\circ}\right.$ West $)$} \\
\hline \multicolumn{2}{|l|}{ Site } & \multicolumn{2}{|c|}{$\begin{array}{l}\text { Flat, unobstructed, located exactly at } \\
\text { weather station }\end{array}$} \\
\hline \multicolumn{2}{|l|}{ Mean Ambient Dry-Bulb Temperature (constant) } & \multicolumn{2}{|c|}{$20^{\circ} \mathrm{C}\left(68^{\circ} \mathrm{F}\right)$} \\
\hline \multicolumn{2}{|l|}{ Dew Point Temperature (constant) } & \multicolumn{2}{|c|}{$-56.6^{\circ} \mathrm{C}\left(-69.9^{\circ} \mathrm{F}\right)$} \\
\hline \multicolumn{2}{|l|}{ Humidity Ratio (constant) } & \multicolumn{2}{|c|}{$\begin{array}{l}0.000007 \mathrm{~kg} \text { moisture } / \mathrm{kg} \text { dry air } \\
(0.000007 \mathrm{lb} \text { moisture } / \mathrm{lb} \text { dry air })\end{array}$} \\
\hline \multicolumn{2}{|l|}{ Relative Humidity (constant) } & \multicolumn{2}{|c|}{$0.05 \%$} \\
\hline \multicolumn{2}{|l|}{ Mean Annual Wind Speed } & \multicolumn{2}{|c|}{$4.3 \mathrm{~m} / \mathrm{s}(9.62 \mathrm{miles} / \mathrm{h})$} \\
\hline \multicolumn{2}{|l|}{ Maximum Annual Wind Speed } & \multicolumn{2}{|c|}{$4.3 \mathrm{~m} / \mathrm{s}(9.62 \mathrm{miles} / \mathrm{h})$} \\
\hline Q Quantities That Vary between Data Sets & MZ320.TM2 & & MZ340.TM2 \\
\hline Global Horizontal Solar Radiation Annual Total & $0 \mathrm{kWh} / \mathrm{m}^{2}(0$ & $\left.3 \mathrm{tu} / \mathrm{ft}^{2}\right)$ & $1793 \mathrm{kWh} / \mathrm{m}^{2}\left(568 \mathrm{kBtu} / \mathrm{ft}^{2}\right)$ \\
\hline Direct Normal Solar Radiation Annual Total & $0 \mathrm{kWh} / \mathrm{m}^{2}(0$ & $\left.3 \mathrm{tu} / \mathrm{ft}^{2}\right)$ & $1505 \mathrm{kWh} / \mathrm{m}^{2}\left(477 \mathrm{kBtu} / \mathrm{ft}^{2}\right)$ \\
\hline Diffuse Horizontal Solar Radiation Annual Total & $0 \mathrm{kWh} / \mathrm{m}^{2}(0$ & $\left.3 \mathrm{tu} / \mathrm{ft}^{2}\right)$ & $810 \mathrm{kWh} / \mathrm{m}^{2}\left(257 \mathrm{kBtu} / \mathrm{ft}^{2}\right)$ \\
\hline
\end{tabular}

\subsection{Performing the Tests}

\subsubsection{Modeling Rules}

\subsubsection{Consistent Modeling Methods}

If a simulation program has options for modeling a specific thermal behavior, consistent modeling methods shall be used for all cases. For example, if the program being tested gives a choice of methods for modeling interior walls, the same interior-wall modeling method shall be used for all cases. Similarly, if the program being tested allows different shading algorithms (e.g., shading for a window determined by one central point of the window versus disaggregated shading for multiple sub-areas of the window), the same shading algorithm shall be used for all cases and for all zones/windows for a given case.

To generate the example results, the IEA SHC Task 34/ECBCS Annex 43 (IEA 34/43) participants used the most detailed level of modeling that was allowed by their simulation programs and that was consistent with the level of detail provided in this test specification; more discussion about this is included in Part II, Section 2.2. When a program has options for modeling this specification, these were discussed in the IEA-34/43 participant modeler reports included in Part II (Section 2.9).

\subsubsection{Equivalent Modeling Methods}

If a program or specific model within a program does not allow direct input of specified values, or if input of specified values causes instabilities in a program's calculations, modelers should develop equivalent inputs that match the intent of the test specification as nearly as the software being tested allows. Such equivalent inputs are to be developed based on the data provided in the test specification, and such equivalent inputs shall have a mathematical, physical, or logical basis, and shall be applied consistently throughout the test cases. Document the equivalent modeling method in the modeler report for the tested program. 


\subsubsection{Non-applicable Inputs}

In some instances the specification will include input values that do not apply to the input structure of the program being tested. When this occurs, disregard the non-applicable inputs and continue. Such inputs are in the specification for programs that may need them.

\subsubsection{Time Convention}

References to time in this specification are to local standard time. Assume that hour 1=0:00-1:00 (the interval from midnight to 1:00 a.m.). Do not use daylight savings time or holidays for scheduling. The required TMY2 data are in hourly bins corresponding to standard time, consistent with all other schedules.

\subsubsection{Geometry Convention}

For these multi-zone cases, geometry convention varies depending on the objective of the test case. Instructions regarding the geometry convention for each test case are included with specific test cases descriptions where appropriate.

\subsubsection{Simulation Initialization and Preconditioning}

If the program being tested allows, begin the simulation initialization process with zone air conditions that equal the outdoor air conditions. If the program being tested allows for preconditioning (iterative simulation of an initial time period until temperatures or fluxes, or both, stabilize at initial values), use that capability.

\subsubsection{Simulation Duration}

Use the weather data provided to run the full annual simulation. Give outputs as required per the test case descriptions below.

\subsubsection{Simulation Input Files}

All supporting data required for generating results with the tested software shall be saved, including:

- Input files

- Processed weather data

- Intermediate files containing calculations used for developing inputs

- A "Readme-softwarename-yymmdd.pdf" file that briefly describes the contents of the above files according to their file type (i.e., their ".xyz" file extension).

\subsubsection{Omitted Test Cases}

If a program being tested omits a test case, provide an explanation in the modeler report.

\subsubsection{Modeler Reports}

The IEA-34/43 participants submitted modeler reports along with their simulation results (see Part II, Section 2.9). Users developing modeler reports may consider using the structure of any of those modeler reports as a template. 


\subsubsection{Comparing Your Output to the Analytical Solution and Example Simulation Results}

For Case MZ320, compare output with the Case MZ320 analytical solution; output may also be compared with other example simulation results provided in Part III, or with other results that were generated using this test procedure. For the other test cases (MZ340 through MZ 360), output may be compared with example simulation results provided in Part III, or with other results that were generated using this test procedure. For the convenience to users who wish to plot or tabulate their results along with the example results of Part III, electronic versions of the example results have been included with the accompanying files MZ-RESULTS-Annuals.XLS and MZ-RESULTS-Hourlies.XLS.

\subsubsection{Criteria for Determining Agreement between Results}

There are no formal criteria for when results agree or disagree. Determination of when results agree or disagree is left to the user. In making this determination the user should consider:

- Magnitude of results for individual cases

- Magnitude of difference in results between certain cases (e.g., Case MZ350-MZ340)

- Same direction of sensitivity (positive or negative) for difference in results between certain cases (e.g., MZ350-MZ340)

- If results are logically counterintuitive with respect to known or expected physical behavior

- Availability of a mathematical truth standard (analytical solution)

- Where a mathematical truth standard is provided, the degree of disagreement that occurred for other simulation results versus the mathematical truth standard

- Example simulation results do not represent a truth standard.

For any given case, a tested program may fall outside the range of example results without necessarily being incorrect. However, it is worthwhile to investigate the source of significant differences, as the collective experience of the authors is that such differences often indicate problems with the software or its use, including, but not limited to:

- User input error, where the user misinterpreted or incorrectly entered one or more program inputs

- A problem with a particular algorithm in the program

- One or more program algorithms used outside their intended range.

Also, for any given case, a program that yields values in the middle of the range established by the example results should not be perceived as better or worse than a program that yields values at the borders of the range.

\subsubsection{Diagnostic Logic for Determining Causes of Differences among Results}

To help you identify which algorithm in the tested program is causing specific differences between programs, we have included diagnostic flow charts in Appendix F.

\subsubsection{Rules for Modifying Simulation Programs or Simulation Inputs}

Modifications to simulation programs or simulation inputs shall have a mathematical, physical, or logical basis, and shall be applied consistently across tests. Such improvements must be documented in modeler reports. Arbitrary modification of a simulation program's input or internal code just for the purpose of more closely matching a given set of results shall not be allowed. 


\subsection{Test Case Specifications}

\subsubsection{Case MZ320: 3-Zone Steady-State Conduction Analytical Verification Test}

\subsubsection{Objective}

Test the ability of whole-building energy simulation software to model steady-state interzonal conduction for three zones.

\subsubsection{Method}

This case tests steady-state multi-zone conduction in a three-zone building with temperature controlled in one zone, temperature floating in two other zones, and conduction to the exterior environment. Cooling loads are generated with internal gains. Interzonal heat transfer is driven by different temperatures in each zone. Constant combined surface coefficients are used to eliminate disagreements among the tested programs that may be caused by different convective or radiative surface heat transfer models. This helps to better isolate disagreements related specifically to multi-zone modeling, and allows for calculation of an analytical solution assuming one-dimensional conduction. Surface heat transfer models are tested in the single-zone context in IEA BESTEST (Judkoff and Neymark 1995). Constant temperature weather data (TMY2-format) are provided. Compare whole-building simulation results to the analytical solution.

\subsubsection{Input Specification}

Case MZ320 is summarized in Figure 1-1. Input parameters are described below.

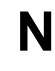

N

$$
\mathrm{T}_{\mathrm{o}}=20^{\circ} \mathrm{C} \text {, Solar OFF }\left(\alpha_{\mathrm{ext}}=0\right)
$$

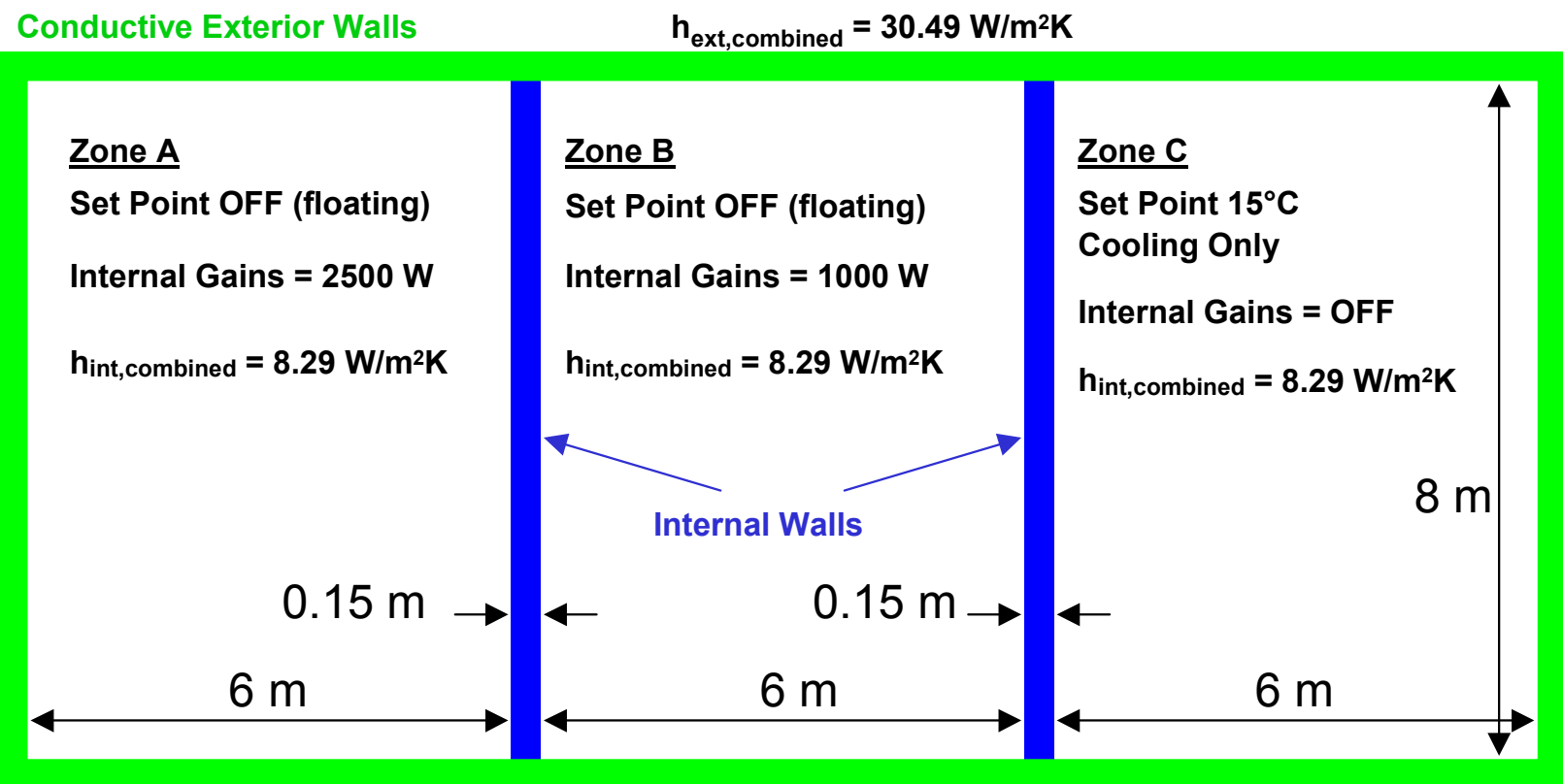

Figure 1-1. Case MZ320 - plan view 
1.3.1.3.1 Geometry Convention. If the program being tested automatically includes the thickness of walls in a three-dimensional definition of the building geometry, define the wall, roof, and floor dimensions such that the interior air volume of each zone remains as specified (e.g., $6 \mathrm{~m} \times 8 \mathrm{~m} \times 2.7 \mathrm{~m}=129.6 \mathrm{~m}^{3}$ ).

\subsection{Building Construction}

- Zone plan dimensions: each zone $=6 \mathrm{~m}(19.685 \mathrm{ft})$ by $8 \mathrm{~m}(26.247 \mathrm{ft})$, see Figure $1-1$.

- Zone height $=2.7 \mathrm{~m}(8.858 \mathrm{ft})$.

- Air volume of each zone $=129.6 \mathrm{~m}^{3}\left(4577 \mathrm{ft}^{3}\right)$

$\circ \quad$ Site altitude $=2 \mathrm{~m}(6.56 \mathrm{ft})$

- If the program being tested does not automatically calculate zone air properties or provide default values, for density $(\rho)$ and specific heat $\left(c_{p}\right)$ of air use:

- $\rho=1.204 \mathrm{~kg} / \mathrm{m}^{3}\left(0.075 \mathrm{lb} / \mathrm{ft}^{3}\right)$

- $\mathrm{c}_{\mathrm{p}}=1.004 \mathrm{~kJ} /(\mathrm{kg} \cdot \mathrm{K})\left(0.24 \mathrm{Btu} /\left(\mathrm{lb} \cdot{ }^{\circ} \mathrm{F}\right)\right)$, for dry air.

- The internal walls common to and separating Zone A from Zone B, and Zone B from Zone C have material properties as described in Tables 1-3a and 1-3b using SI and IP units, respectively; IP units were developed using conversions of ASHRAE (2005).

- Internal wall dimensions: length $=8 \mathrm{~m}(26.247 \mathrm{ft})$, height $=2.7 \mathrm{~m}(8.858 \mathrm{ft})$, thickness $=0.15 \mathrm{~m}$ $(0.4921 \mathrm{ft})$.

- All external surfaces of the zones including exterior walls, floor, and roof have material properties as described in Tables 1-4a and 1-4b using SI and IP units, respectively; IP units were developed using conversions of ASHRAE (2005).

- Exterior solar absorptance $=0$; if the software being tested does not allow a value of 0 , use the lowest value the software allows (e.g., 0.000001).

- Interior solar absorptance $=0$; if the software being tested does not allow a value of 0 , use the lowest value the software allows (e.g., 0.000001).

- Ground reflectance $=0$; if the software being tested does not allow a value of 0 , use the lowest value the software allows (e.g., 0.000001).

- The floor is suspended above the ground such that its exterior surface interacts with outside air at ambient conditions (similar to other exterior surfaces).

- No windows.

- No infiltration or ventilation.

\subsection{Internal Gains}

- Zone A: $2500 \mathrm{~W}(8530 \mathrm{Btu} / \mathrm{h})$

- Zone B: $1000 \mathrm{~W}(3412 \mathrm{Btu} / \mathrm{h})$

- Zone C: $0 \mathrm{~W}(0 \mathrm{Btu} / \mathrm{h})$

- Internal gains are $100 \%$ convective, $0 \%$ radiative

- Internal gains are $100 \%$ sensible, $0 \%$ latent.

These are internally generated sources of heat (from equipment, lighting, occupants, etc.) that are not related to operation of mechanical space cooling equipment. 
Table 1-3a. Common Wall Material Properties - SI Units

\begin{tabular}{||lcccccc||}
\hline Element & $\begin{array}{c}\text { Conductivity } \\
(\mathbf{W} /(\mathbf{m} \cdot \mathbf{K}))\end{array}$ & $\begin{array}{c}\text { Thickness } \\
(\mathbf{m})\end{array}$ & $\begin{array}{c}\text { Conductance } \\
\left(\mathbf{W} /\left(\mathbf{m}^{2} \cdot \mathbf{K}\right)\right)\end{array}$ & $\begin{array}{c}\text { Resistance } \\
\left(\mathbf{m}^{2} \cdot \mathbf{K} / \mathbf{W}\right)\end{array}$ & $\begin{array}{c}\text { Density } \\
\left(\mathbf{k g} / \mathbf{m}^{3}\right)\end{array}$ & $\begin{array}{c}\text { Specific Heat } \\
(\mathbf{J} /(\mathbf{k g} \cdot \mathbf{K}))\end{array}$ \\
\hline Int Combined Surf Coef & & & 8.2900 & 0.1206 & & \\
Common Wall Material & 1.20 & 0.15 & 8.0000 & 0.1250 & 1400 & 1000 \\
Int Combined Surf Coef & & & 8.2900 & 0.1206 & & \\
\hline Total air-air & & 2.7303 & 0.3663 & & \\
\hline
\end{tabular}

Table 1-3b. Common Wall Material Properties - IP Units

\begin{tabular}{|c|c|c|c|c|c|c|}
\hline Element & $\begin{array}{l}\text { Conductivity } \\
\left(\mathrm{Btu} /\left(\mathrm{h} \cdot \mathrm{ft}^{\circ} \cdot \mathrm{F}\right)\right)\end{array}$ & $\begin{array}{c}\text { Thickness } \\
\text { (ft) }\end{array}$ & 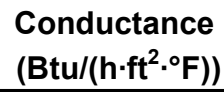 & $\begin{array}{l}\text { Resistance } \\
\left(\mathrm{h} \cdot \mathrm{ft}^{2} \cdot{ }^{\circ} \mathrm{F} / \mathrm{Btu}\right)\end{array}$ & $\begin{array}{l}\text { Density } \\
\left(\mathrm{lb} / \mathrm{ft}^{3}\right)\end{array}$ & $\begin{array}{l}\text { Specific Heat } \\
\left(\mathrm{Btu} /\left(\mathrm{lb} \cdot{ }^{\circ} \mathrm{F}\right)\right)\end{array}$ \\
\hline Int Combined Surf Coef & & & 1.4600 & 0.6849 & & \\
\hline Common Wall Material & 0.6932 & 0.4921 & 1.4089 & 0.7098 & 87.5 & 0.2390 \\
\hline Int Combined Surf Coef & & & 1.4600 & 0.6849 & & \\
\hline Total air-air & & & 0.4809 & 2.0796 & & \\
\hline
\end{tabular}

Table 1-4a. Exterior Wall Material Properties - SI Units

\begin{tabular}{||lcccccc||}
\hline Element & $\begin{array}{c}\text { Conductivity } \\
(\mathbf{W} /(\mathbf{m} \cdot \mathbf{K}))\end{array}$ & $\begin{array}{c}\text { Thickness } \\
(\mathbf{m})\end{array}$ & $\begin{array}{c}\text { Conductance } \\
\left(\mathbf{W} /\left(\mathbf{m}^{2} \cdot \mathbf{K}\right)\right)\end{array}$ & $\begin{array}{c}\text { Resistance } \\
\left(\mathbf{m}^{2} \cdot \mathbf{K} / \mathbf{W}\right)\end{array}$ & $\begin{array}{c}\text { Density } \\
\left(\mathbf{k g} / \mathbf{m}^{\mathbf{3}}\right)\end{array}$ & $\begin{array}{c}\text { Specific Heat } \\
(\mathbf{J} /(\mathbf{k g} \cdot \mathbf{K}))\end{array}$ \\
\hline Int Combined Surf Coef & & & 8.2900 & 0.1206 & & \\
Exterior Wall Material & 0.24 & 0.15 & 1.6000 & 0.6250 & 1400 & 1000 \\
Ext Combined Surf Coef & & & 30.4872 & 0.0328 & & \\
\hline Total air-air & & 1.2846 & 0.7784 & & \\
\hline
\end{tabular}

Table 1-4b. Exterior Wall Material Properties - IP Units

\begin{tabular}{|c|c|c|c|c|c|c|}
\hline Element & $\begin{array}{l}\text { Conductivity } \\
(\text { Btu/(h-ft } \cdot F))\end{array}$ & $\begin{array}{c}\text { Thickness } \\
\text { (ft) }\end{array}$ & 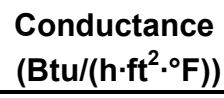 & $\begin{array}{l}\text { Resistance } \\
\left(\mathrm{h} \cdot \mathrm{ft}^{2} \cdot{ }^{\circ} \mathrm{F} / \mathrm{Btu}\right)\end{array}$ & $\begin{array}{c}\text { Density } \\
\left(\mathrm{lb} / \mathrm{ft}^{3}\right)\end{array}$ & $\begin{array}{l}\text { Specific Heat } \\
\left.\left(\text { Btu/(lb- }{ }^{\circ} \mathrm{F}\right)\right)\end{array}$ \\
\hline Int Combined Surf Coef & & & 1.4600 & 0.6849 & & \\
\hline Exterior Wall Material & 0.1386 & 0.4921 & 0.2818 & 3.5488 & 87.5 & 0.2390 \\
\hline Ext Combined Surf Coef & & & 5.3694 & 0.1862 & & \\
\hline Total air-air & & & 0.2262 & 4.4199 & & \\
\hline
\end{tabular}

1.3.1.3.4 Interior Combined Surface Coefficients. Interior combined surface coefficients $=8.29$ $\mathrm{W} /\left(\mathrm{m}^{2} \cdot \mathrm{K}\right)\left(1.46 \mathrm{Btu} /\left(\mathrm{h} \cdot \mathrm{ft}^{2} \cdot{ }^{\circ} \mathrm{F}\right)\right)$, per ASHRAE $(2005)$. This value is applied to:

- Both sides of the common internal walls, see Tables 1-3a and 1-3b.

- The interior side of the exterior surfaces (walls, floor, and ceiling), see Tables 1-4a and 1-4b.

If the program being tested allows direct user input of combined interior surface coefficients, ignore the remainder of this paragraph. If it allows direct user input of convective surface coefficients, but allows only automatically calculated surface infrared radiative exchange, set the convective surface coefficient to $8.29 \mathrm{~W} /\left(\mathrm{m}^{2} \cdot \mathrm{K}\right)\left(1.46 \mathrm{Btu} /\left(\mathrm{h} \cdot \mathrm{ft}^{2} \cdot{ }^{\circ} \mathrm{F}\right)\right)$ and set the surface infrared emittance to 0 (or as low as the program allows). If the program does not allow direct user input of convective surface coefficients, input infrared 
emittance $=0.9$ and use the convective surface coefficient that the program being tested automatically calculates. Discuss in your modeler report any resulting deviation from the combined surface coefficients specified above.

1.3.1.3.5 Exterior Combined Surface Coefficients. Exterior combined surface coefficients $=30.4872$ $\mathrm{W} /\left(\mathrm{m}^{2} \cdot \mathrm{K}\right)\left(5.3694 \mathrm{Btu} /\left(\mathrm{h} \cdot \mathrm{ft}^{2} \cdot{ }^{\circ} \mathrm{F}\right)\right)$, see Tables $1-4 \mathrm{a}$ and $1-4 \mathrm{~b}$. This value applies to all exterior surfaces, including the floor. This value corresponds with $4.3 \mathrm{~m} / \mathrm{s}$ wind speed in the weather data for a rough (brick or rough plaster) surface (Judkoff and Neymark 1995, p. C-1; Walton 1983, p. 71).

If the program being tested allows direct user input of combined exterior surface coefficients, ignore the remainder of this paragraph. If the program allows direct user input of convective surface coefficients, but allows only automatically calculated surface infrared radiative exchange, set the convective surface coefficient to $30.4872 \mathrm{~W} /\left(\mathrm{m}^{2} \cdot \mathrm{K}\right)\left(5.3694 \mathrm{Btu} /\left(\mathrm{h} \cdot \mathrm{ft}^{2} \cdot{ }^{\circ} \mathrm{F}\right)\right.$ ) and set the surface infrared emittance to 0 (or as low as the program allows). If the program does not allow direct user input of convective surface coefficients, input infrared emittance $=0.9$ and use the convective surface coefficient that the program automatically calculates. Discuss in your modeler report any resulting deviation from the combined surface coefficients specified above.

1.3.1.3.6 Mechanical System. Zone A and Zone B have no heating or cooling; those zone temperatures are allowed to float to equilibrium.

The Zone $\mathrm{C}$ mechanical system provides sensible cooling only (no heating), and is ideal. The purpose of the cooling system is to give results for energy consumption that are equal to the sensible cooling load. Model the cooling system as closely as the program being tested allows, as follows:

- Set points

Z Zone A: $\mathrm{Cool}=$ always $\mathrm{OFF} ;$ Heat $=$ always $\mathrm{OFF}$

- Zone B: $\mathrm{Cool}=$ always $\mathrm{OFF}$; Heat $=$ always $\mathrm{OFF}$

$\circ$ Zone $\mathrm{C}$ : $\mathrm{Cool}=\mathrm{ON}$ if temperature $>15^{\circ} \mathrm{C}\left(59^{\circ} \mathrm{F}\right)$; otherwise $\mathrm{Cool}=\mathrm{OFF}$. Heat $=$ always $\mathrm{OFF}$

- Sufficient (or greater) capacity to maintain the zone air temperature set point; for example, 1000 $\mathrm{kW}(3412 \mathrm{kBtu} / \mathrm{h})$

- Uniform zone air temperature (well-mixed air)

- $100 \%$ efficiency (coefficient of performance $[\mathrm{COP}]=1$ )

- $100 \%$ convective air system

- Ideal controls (zone always at set point); for example, assume the heat extraction rate equals the equipment capacity (non-proportional control) and there is continuous ON/OFF cycling within the hour as needed

- Thermostat sensing the zone air temperature only

- There is no moisture (latent heat) removal.

1.3.1.3.7 Weather Data. Use the TMY2-format weather data provided with the file

"MZ320.TM2."

TMY2 weather data format is described in Appendix A. A summary of site and weather data parameters was provided in Table 1-2. This weather data file is based on Miami.TM2, but has ambient dry-bulb temperature set to a constant value of $20^{\circ} \mathrm{C}\left(68^{\circ} \mathrm{F}\right)$, constant wind speed of $4.3 \mathrm{~m} / \mathrm{s}$, and solar radiation off. The weather data also include many data elements set to 0 or approximate lower limits, and other data elements set to neutral (non-extreme) constant values, as follows: 
- Global horizontal, direct normal, and diffuse horizontal radiation and illuminance are all set to 0 (extraterrestrial horizontal and direct normal radiation were left unchanged from the original weather data file).

- Total and opaque sky cover $=10$ tenths, implying the entire sky dome is covered by clouds; this setting intended to reduce exterior infrared radiation exchange.

- Dew-point temperature $=-56.6^{\circ} \mathrm{C}\left(-69.9^{\circ} \mathrm{F}\right)$ (corresponds with humidity ratio of $0.000007 \mathrm{~kg} / \mathrm{kg}$ and standard atmospheric pressure); calculation of dew point temperature applies common psychrometric formulae (ASHRAE 2005; Brandemuehl 1993). TMY2 documentation indicates that $-60^{\circ} \mathrm{C}\left(-76^{\circ} \mathrm{F}\right)$ is the lower limit for TMY2 data.

- Relative humidity $=0.05 \%$ (corresponds with humidity ratio of $0.000007 \mathrm{~kg} / \mathrm{kg}$, standard atmospheric pressure, and given dry-bulb temperature); calculations apply common psychrometric formulae (ASHRAE, 2005; Brandemuehl 1993). This value rounds to $0 \%$ in the weather data.

- If the program being tested does not allow a very low value for relative humidity, adjust the input weather data (or other software input) to use the lowest allowable relative humidity.

- Atmospheric pressure $=1013$ millibars $(=$ standard atmosphere of 14.696 psia $)$.

- Wind speed $=4.3 \mathrm{~m} / \mathrm{s}(9.73 \mathrm{miles} / \mathrm{h})($ Miami.TM2 annual average wind speed $=4.34 \mathrm{~m} / \mathrm{s}$, but TM2 weather data allow input only to the nearest $0.1 \mathrm{~m} / \mathrm{s}$ ).

- Visibility $=20 \mathrm{~km}$ (rough annual average for Miami and Denver).

- Ceiling height $=2000 \mathrm{~m}$ (rough annual average for Miami and Denver).

- Present weather: no rain, hail, etc.

- Precipitable water $=0 \mathrm{~mm}$.

- Aerosol optical depth $=0.1$ broadband turbidity (rough annual average of Miami and Denver).

- Snow depth $=0 \mathrm{~cm}$, with $\geq 88$ days since last snowfall.

\subsubsection{Output requirements}

To obtain equivalent steady-state results, run the simulation for one year and submit the following values for the last hour of the year:

- $\quad$ Sensible cooling load in Zone $\mathrm{C}\left(\mathrm{q}_{\mathrm{C}}\right)$ in $\mathrm{W}$ or $\mathrm{Wh} / \mathrm{h}$

- Air temperature in Zone $\mathrm{A}\left(\mathrm{T}_{\mathrm{A}}\right)\left({ }^{\circ} \mathrm{C}\right)$

- Air temperature in Zone $\mathrm{B}\left(\mathrm{T}_{\mathrm{B}}\right)\left({ }^{\circ} \mathrm{C}\right)$

- Air temperature in Zone $\mathrm{C}\left(\mathrm{T}_{\mathrm{C}}\right)\left({ }^{\circ} \mathrm{C}\right)$.

\subsubsection{Analytical solution}

Steady-State First Law Energy Balances:

Zone A: $\mathrm{q}_{\mathrm{A}}=0=\mathrm{q}_{\text {intA }}-\mathrm{UA}_{\text {com }}\left(\mathbf{T}_{\mathrm{A}}-\mathrm{T}_{\mathbf{B}}\right)-\mathrm{UA}_{\mathrm{extAC}}\left(\mathbf{T}_{\mathrm{A}}-\mathrm{T}_{\mathrm{O}}\right)$

Zone B: $\mathrm{q}_{\mathrm{B}}=0=\mathrm{q}_{\mathrm{intB}}+\mathrm{UA}_{\text {com }}\left(\mathrm{T}_{\mathrm{A}}-\mathrm{T}_{\mathbf{B}}\right)-\mathrm{UA}_{\text {com }}\left(\mathbf{T}_{\mathbf{B}}-\mathrm{T}_{\mathrm{C}}\right)-\mathrm{UA}_{\mathrm{extB}}\left(\mathrm{T}_{\mathbf{B}}-\mathrm{T}_{\mathrm{O}}\right)$

Zone $\mathrm{C}: \mathrm{q}_{\mathrm{C}}=\mathrm{q}_{\mathrm{intC}}+\mathrm{UA}_{\mathrm{com}}\left(\mathrm{T}_{\mathrm{B}}-\mathrm{T}_{\mathrm{C}}\right)+\mathrm{UA}_{\mathrm{extAC}}\left(\mathrm{T}_{\mathrm{O}}-\mathrm{T}_{\mathrm{C}}\right)$

Unknowns: $\mathbf{T}_{\mathrm{A}}, \mathbf{T}_{\mathrm{B}}, \mathbf{q}_{\mathrm{C}}$ 
The three equations solve the three unknowns. Heat flow conventions used in the equations are for flow arrows indicated in Figure 1-2. Nomenclature is defined below:

$\mathrm{q}_{\mathrm{A}} \quad$ Sensible cooling load, Zone A ( $=0 \mathrm{~W}$, zone temperature allowed to float)

$\mathrm{q}_{\mathrm{B}} \quad$ Sensible cooling load, Zone B ( $=0 \mathrm{~W}$, zone temperature allowed to float)

$\mathrm{q}_{\mathrm{C}} \quad$ Sensible cooling load, Zone C (W, to be solved, cooling load indicated by solution value $>0$ )

$\mathrm{q}_{\text {intA }} \quad$ Internal gains, Zone A $(=2500 \mathrm{~W})$

$\mathrm{q}_{\text {intB }} \quad$ Internal gains, Zone B $(=1000 \mathrm{~W})$

$\mathrm{q}_{\text {intC }} \quad$ Internal gains, Zone $\mathrm{C}(=0 \mathrm{~W})$

$\mathrm{T}_{\mathrm{A}} \quad$ Air temperature, Zone $\mathrm{A}\left({ }^{\circ} \mathrm{C}\right.$, to be solved $)$

$\mathrm{T}_{\mathrm{B}} \quad$ Air temperature, Zone $\mathrm{B}\left({ }^{\circ} \mathrm{C}\right.$, to be solved $)$

$\mathrm{T}_{\mathrm{C}} \quad$ Air temperature, Zone $\mathrm{C}\left(=15^{\circ} \mathrm{C}\right)$

$\mathrm{T}_{\mathrm{O}} \quad$ Ambient air temperature $\left(=20^{\circ} \mathrm{C}\right)$

$\mathrm{UA}_{\text {com }}$ Wall conductance, common wall $\left(\mathrm{W} /{ }^{\circ} \mathrm{C}\right.$, calculated from the test specification)

$\mathrm{UA}_{\text {extAC }}$ Combined exterior surface conductance, Zones $\mathrm{A}, \mathrm{C}\left(\mathrm{W} /{ }^{\circ} \mathrm{C}\right.$, calculated from the test specification)

$\mathrm{UA}_{\text {extB }}$ Combined exterior surface conductance, Zone $\mathrm{B}\left(\mathrm{W} /{ }^{\circ} \mathrm{C}\right.$, calculated from the test specification).

This is a simple system of equations to solve, as Eqn. 1 and Eqn 2 are a system of two equations with two unknowns that can be used to solve for $\mathrm{T}_{\mathrm{A}}$ and $\mathrm{T}_{\mathrm{B}}$. Solved $\mathrm{T}_{\mathrm{B}}$ can then be entered into Eqn. 3 to obtain $\mathrm{q}_{\mathrm{C}}$. Solution follows.

Using Eqn. 1 to isolate $\mathrm{T}_{\mathrm{B}}$ as $\mathrm{f}\left(\mathrm{T}_{\mathrm{A}}\right)$ gives:

$\mathrm{T}_{\mathrm{B}}=\left(-\mathrm{q}_{\text {intA }}+\left(\mathrm{UA}_{\mathrm{com}}+\mathrm{UA}_{\mathrm{extAC}}\right) \mathrm{T}_{\mathrm{A}}-\mathrm{UA}_{\mathrm{extAC}} \mathrm{T}_{\mathrm{O}}\right) / \mathrm{UA}_{\mathrm{com}}$

[Eqn. 1a]

Replacing $\mathrm{T}_{\mathrm{B}}$ where it appears in Eqn. 2 with the right side of Eqn. 1a, and solving Eqn. 2 for $\mathrm{T}_{\mathrm{A}}$ gives:

[Eqn. 4]

$\mathrm{T}_{\mathrm{A}}=\frac{\left(\mathrm{q}_{\mathrm{intB}}+\left(2+\mathrm{UA}_{\mathrm{extB}} / \mathrm{UA}_{\mathrm{com}}\right) \mathrm{q}_{\mathrm{intA}}+\mathrm{UA}_{\mathrm{com}} \mathrm{T}_{\mathrm{C}}+\left(2 \mathrm{UA}_{\mathrm{extAC}}+\mathrm{UA}_{\mathrm{extB}} \mathrm{UA}_{\mathrm{extAC}} / \mathrm{UA}_{\mathrm{com}}+\mathrm{UA}_{\mathrm{extB}}\right) \mathrm{T}_{\mathrm{O}}\right)}{\left(\mathrm{UA}_{\mathrm{com}}+2 \mathrm{UA}_{\mathrm{extAC}}+\mathrm{UA}_{\mathrm{extB}}+\mathrm{UA}_{\mathrm{extB}} \mathrm{UA}_{\text {extAC }} / \mathrm{UA}_{\mathrm{com}}\right)}$

Entering appropriate known values from the test specification into the above system of equations results in the solution values shown in Figure 1-2.

Additional symbols used in Figure 1-2 are:

$\mathrm{q}_{\mathrm{AO}} \quad$ Heat flow between ambient and Zone $\mathrm{A}(\mathrm{W}$, negative value is outward flow from zone)

$\mathrm{q}_{\mathrm{BO}} \quad$ Heat flow between ambient and Zone B (W, negative value is outward flow from zone)

$\mathrm{q}_{\mathrm{CO}} \quad$ Heat flow between ambient and Zone $\mathrm{C}(\mathrm{W}$, positive value is inward flow to zone)

$\mathrm{q}_{\mathrm{AB}} \quad$ Heat flow between Zone $\mathrm{A}$ and Zone $\mathrm{B}$ (W, negative value is outward flow from Zone $\mathrm{A}$ )

$\mathrm{q}_{\mathrm{BC}} \quad$ Heat flow between Zone $\mathrm{B}$ and Zone $\mathrm{C}$ (W, negative value is outward flow from Zone $\mathrm{B}$ ). 


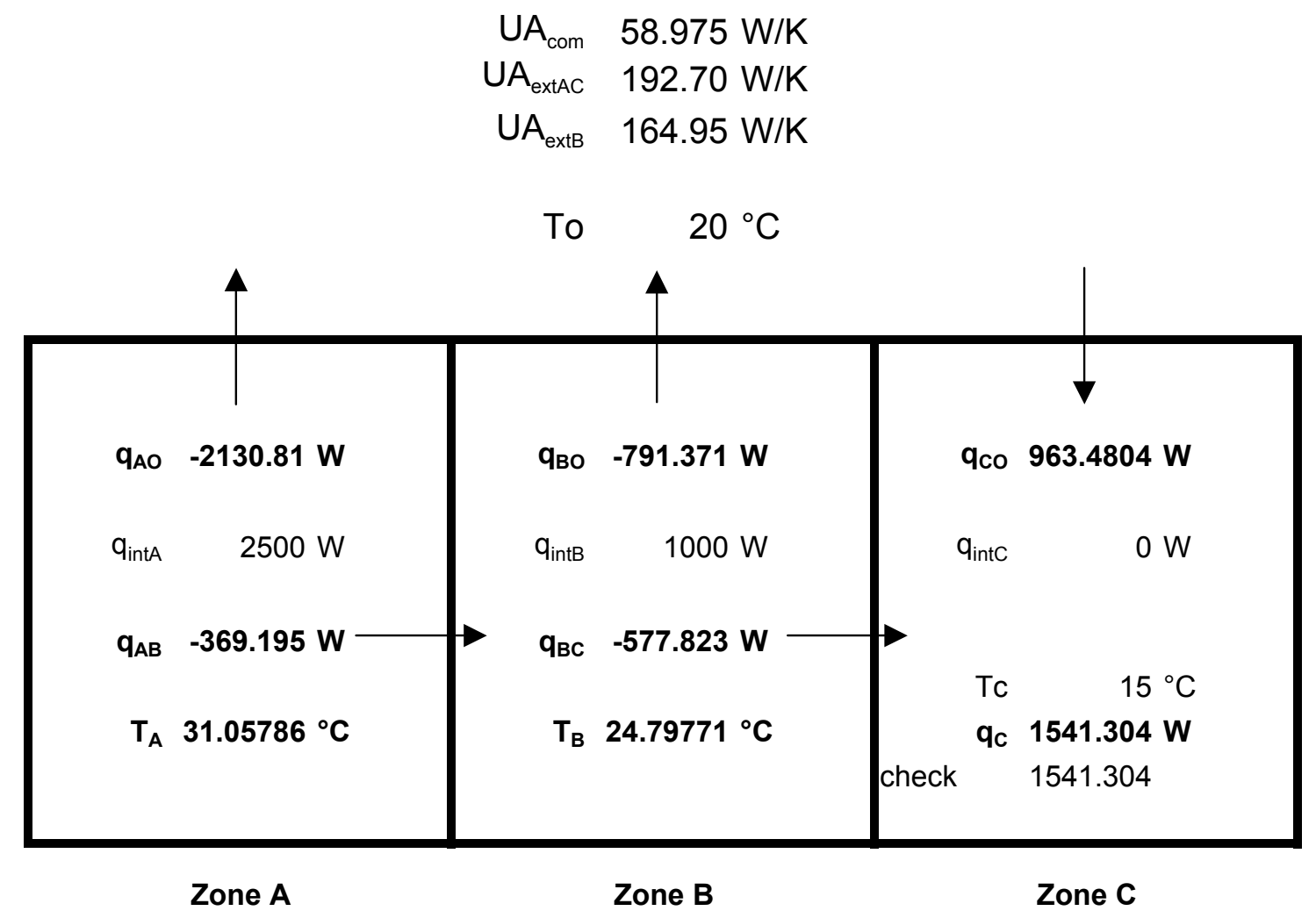

Figure 1-2. Analytical solution for Case MZ320

\subsubsection{In-Depth Multi-Zone Shading Test Cases}

\subsubsection{Case MZ340: Unshaded Calorimeter - In-Depth Shading Test Base Case}

1.3.2.1.1 Objective. Define a multi-zone building calorimeter for measuring sensible cooling loads caused by transmitted solar radiation. These results will be compared to cases MZ350 and MZ355 that test shading of windows by a large fin and by other zones of the building, respectively.

1.3.2.1.2 Method. Apply a six-zone building as a calorimeter with idealized windows such that results disagreements are attributable either to modeling of incident solar radiation, or to inability to model the idealizations. Six zones allow comparison of shading effects among different zones (and window locations) in later cases. The calorimeter is achieved by specifying ideal windows with solar transmittance $=1$ and thermal conductance $=0$, and non-conductive exterior and interior walls. Interior walls have solar absorptance $=1$ (to eliminate reflections). Constant combined interior surface coefficients are applied. Weather data are provided with typical hourly varying solar radiation. Compare whole-building simulation results to each other.

1.3.2.1.3 Input Specification. The bulk of the work for implementing cases MZ340 through MZ355 is assembling an accurate base building model. Thoroughly check base building inputs and results before going on to the other cases. 
1.3.2.1.3.1 Geometry Convention. If the program being tested automatically includes the thickness of walls in a three-dimensional definition of the building geometry, define the wall, roof, and floor dimensions such that the exterior dimensions of each zone are as specified (e.g., $6 \mathrm{~m} \times 8 \mathrm{~m} \times 5 \mathrm{~m}$ ).

1.3.2.1.3.2 Building Construction. The overall six-zone building configuration for Case MZ340 is summarized in Figure 1-3. The building comprises six geometrically identical zones with windows on only the side facing due west. Geometry of a typical zone is described in Figure 1-4. Input parameters are described below.

- Zone plan dimensions each zone $=6 \mathrm{~m} \times 8 \mathrm{~m}(19.685 \mathrm{ft} \times 26.247 \mathrm{ft})$, with zone height $=5 \mathrm{~m}$ (16.404 ft); see Figure 1-4.

- $\quad$ Air volume of each zone $=240 \mathrm{~m}^{3}\left(8476 \mathrm{ft}^{3}\right)$

- Site altitude and air properties are the same as for MZ320.

- All opaque external boundaries and common walls of the zones (including all walls, floors, and roofs) are adiabatic (thermal conductance $=0 \mathrm{~W} /\left(\mathrm{m}^{2} \cdot \mathrm{K}\right)$ ); if the program being tested does not allow adiabatic surfaces, use the lowest allowable thermal conductance or thermal conductivity (e.g. $0.000001 \mathrm{~W} /\left(\mathrm{m}^{2} \cdot \mathrm{K}\right)$ or $\left.1 \cdot 10^{-8} \mathrm{~W} /(\mathrm{m} \cdot \mathrm{K})\right)$.

- Wall thickness $=0.01 \mathrm{~m}(0.0328 \mathrm{ft})$, for all walls (including floors and roofs)

$\circ$ This thickness minimizes disagreements that could arise if there is difficulty with adherence to the geometry convention.

- All external boundaries and common walls are massless; if the program does not allow massless surfaces, use the lowest allowable density and/or thermal capacitance (e.g. $0.000001 \mathrm{~kg} / \mathrm{m}^{3}$ and/or $\mathrm{J} /(\mathrm{kg} \cdot \mathrm{K}))$.

- Exterior solar absorptance $=0$; if the software does not allow a value of 0 , use the lowest allowable value (e.g., 0.000001).

- Interior solar absorptance = 1 (no internal reflections); if the program does not allow a value of 1 , use the highest allowable value (e.g., 0.99999...).

- Ground reflectance $=0$; if the program does not allow a value of 0 , use the lowest allowable value (e.g., 0.000001).

- No internal gains (set to $0 \mathrm{~W}$ for all zones).

- No infiltration or ventilation.

1.3.2.1.3.3 Interior Combined Surface Coefficients for Opaque Surfaces. Interior combined surface coefficients $=30.4872 \mathrm{~W} /\left(\mathrm{m}^{2} \cdot \mathrm{K}\right)\left(5.3694 \mathrm{Btu} /\left(\mathrm{h} \cdot \mathrm{ft}^{2} \cdot{ }^{\circ} \mathrm{F}\right)\right)$; this is the same as the exterior surface coefficients, and is applied to keep the calorimeter inside surface temperatures to reasonable values. This value is applied to:

- Both sides of the common internal walls

- The interior side of the exterior surfaces (walls, floor, and ceiling).

If the program being tested allows direct user input of combined interior surface coefficients, ignore the remainder of this paragraph. If the program allows direct user input of convective surface coefficients, but allows only automatically calculated surface infrared radiative exchange, set the convective surface coefficient to $30.4872 \mathrm{~W} /\left(\mathrm{m}^{2} \cdot \mathrm{K}\right)\left(5.3694 \mathrm{Btu} /\left(\mathrm{h} \cdot \mathrm{ft}^{2} \cdot{ }^{\circ} \mathrm{F}\right)\right.$ ) and set the surface infrared emittance to 0 (or as low as the program allows). If the program does not allow direct user input of convective surface coefficients, input infrared emittance $=0.9$ and use the convective surface coefficient that the program automatically calculates. Discuss in your modeler report any resulting deviation from the combined surface coefficients specified above.

See Section 1.3.2.1.3.6 regarding surface coefficients for windows. 


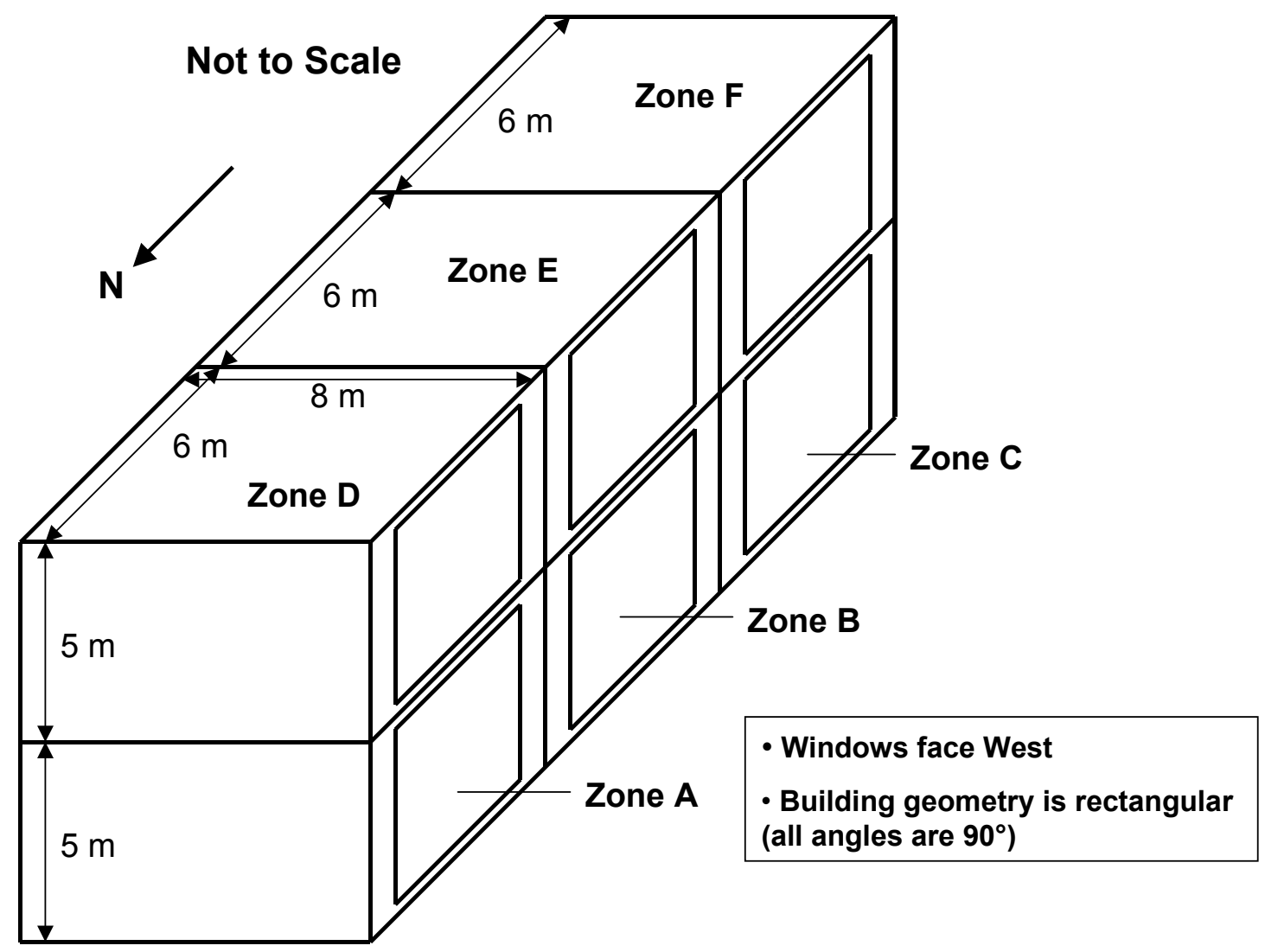

Figure 1-3. Case MZ340 - unshaded calorimeter isometric

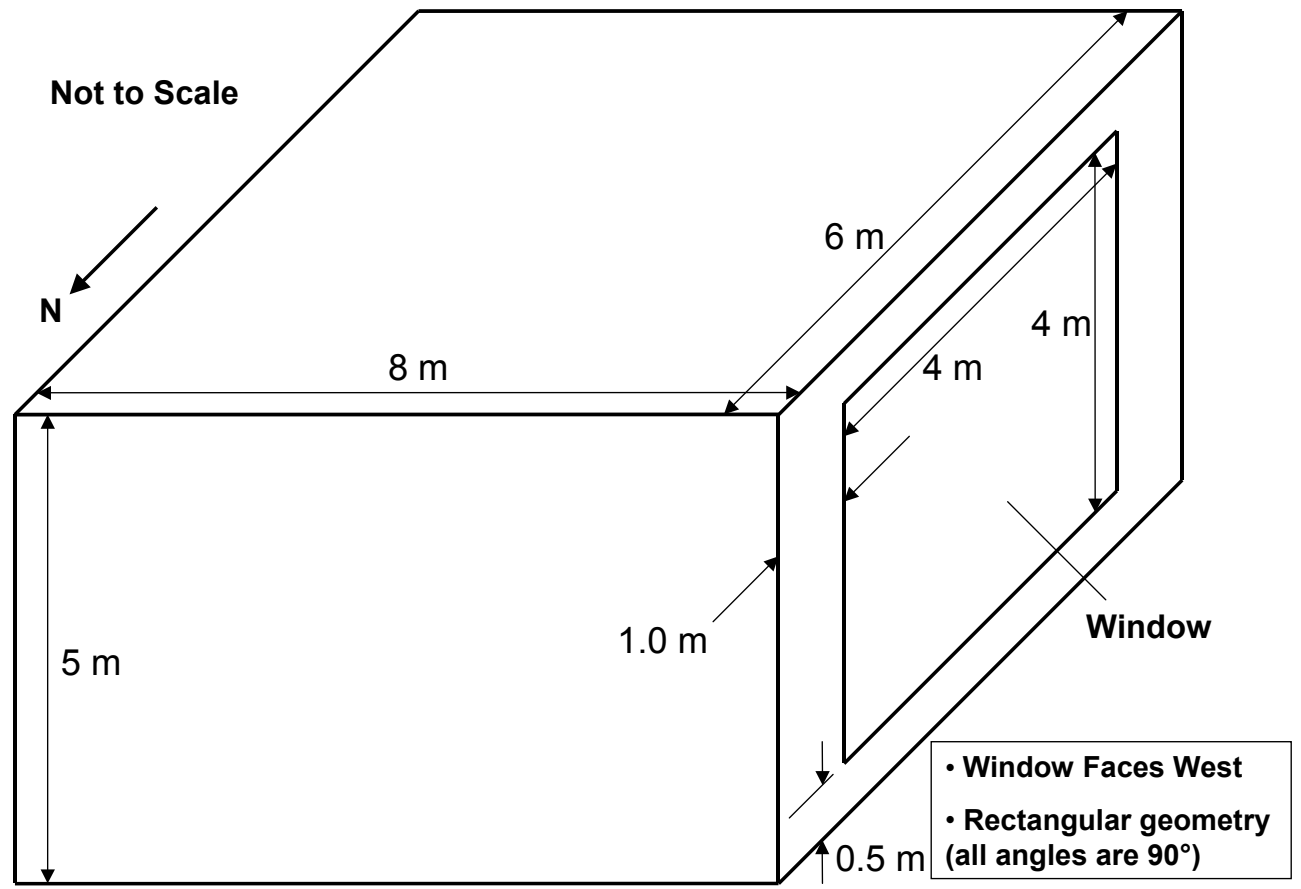

Figure 1-4. Case MZ340 - single zone detail 


\subsection{Exterior Combined Surface Coefficients for Opaque Surfaces}

- Exterior combined surface coefficients for opaque surfaces are the same as for Case MZ320.

- See Section 1.3.2.1.3.6 regarding surface coefficients for windows.

1.3.2.1.3.5 Windows. Each zone has one west-facing window located as shown in Figures 1-3 and 1-4.

Window physical properties are ideal. To achieve the ideal window properties listed below as nearly as possible, use whatever means the program being tested allows. Describe in your modeler report how windows were modeled. The window properties are:

- Window area $=16 \mathrm{~m}^{2}\left(172.22 \mathrm{ft}^{2}\right)$

$\circ \quad$ Window height $=4 \mathrm{~m}(13.123 \mathrm{ft})$

○ Window length $=4 \mathrm{~m}(13.123 \mathrm{ft})$.

- Solar transmittance $=1$ (independent of incidence angle)

$\circ$ Window index of refraction $=1$ (same as air)

$\circ \quad$ Window extinction coefficient $=0 / \mathrm{mm}$

$\circ$ Equations relating index of refraction and extinction coefficient to window transmittance are included in Judkoff and Neymark (1995), p. E-1.

- $\quad$ Thermal conductance $=0 \mathrm{~W} /\left(\mathrm{m}^{2} \cdot \mathrm{K}\right)\left(0 \mathrm{Btu} /\left(\mathrm{h} \cdot \mathrm{ft}^{2} \cdot{ }^{\circ} \mathrm{F}\right)\right)$

$\circ \quad$ Window conductivity $=0 \mathrm{~W} /(\mathrm{m} \cdot \mathrm{K})\left(0 \mathrm{Btu} /\left(\mathrm{h} \cdot \mathrm{ft} \cdot{ }^{\circ} \mathrm{F}\right)\right)$.

- $\quad$ Thermal mass $=0$

$\circ \quad$ Window density $=0$

$\circ \quad$ Window specific heat $=0$.

- Exterior face of the window is flush with the exterior face of the wall (no setback).

If the program being tested can achieve an ideal window with single-pane construction, use the following window thickness:

- $\quad$ Total window thickness $=3.175 \mathrm{~mm}(0.125 \mathrm{in}$. $)$

○ Number of panes $=1$

$\circ$ Pane thickness $=3.175 \mathrm{~mm}(0.125 \mathrm{in}$. $)$.

If the program requires multiple pane construction to achieve or approximate a zero-conductance window, use the lowest allowable conductance air gap (between panes). For example:

- $\quad$ Total window thickness $=19.35 \mathrm{~mm}(0.762 \mathrm{in}$.)

- Number of panes $=2$

$\circ \quad$ Pane thickness $=3.175 \mathrm{~mm}(0.125$ in. $)$

$\circ$ Air gap combined radiative and convective coefficient $=0 \mathrm{~W} /\left(\mathrm{m}^{2} \cdot \mathrm{K}\right)\left(0 \mathrm{Btu} /\left(\mathrm{h} \cdot \mathrm{ft}^{2} \cdot{ }^{\circ} \mathrm{F}\right)\right)$

$\circ \quad$ Air gap thickness $=13 \mathrm{~mm}(0.512$ in.)

- If necessary, use a thicker air gap, and adjust overall thickness accordingly.

- The exterior face of the window must remain flush with the exterior face of the wall (no setback).

\subsection{Window Combined Surface Coefficients}

Interior and exterior combined surface coefficients for the windows are the same as those for opaque surfaces. 
If the zero-conductance windows can be modeled without using very low combined surface coefficients, ignore the remainder of this paragraph. For the ideal windows, the window surface coefficients are not of primary importance; IF the program being tested requires very low values of combined surface coefficients to achieve very low window thermal conductance, use very low combined surface coefficient values instead. (IF reduced surface coefficients are applied to windows AND only the convective portion of surface coefficients can be reduced, also set window interior and exterior surface emittances $=0$ [or as low as the program allows].) Discuss in your modeler report any resulting deviation from the combined surface coefficients specified above.

1.3.2.1.3.7 Mechanical System. All zones apply the same mechanical system and set points. The mechanical system is the same as in Case MZ320, except for the following changes to cooling set points.

- All zones: $\mathrm{Cool}=\mathrm{ON}$ if temperature $>20^{\circ} \mathrm{C}\left(68^{\circ} \mathrm{F}\right)$; otherwise $\mathrm{Cool}=\mathrm{OFF}$. Heat $=$ always $\mathrm{OFF}$.

1.3.2.1.3.8 Weather Data. Use the TMY2-format weather data provided with the file

\section{“MZ340.TM2."}

TMY2 weather data format is described in Appendix A. A summary of site and weather data parameters was provided in Table 1-2. This weather data file is based on Miami.TM2, but has ambient dry-bulb temperature set to a constant value of $20^{\circ} \mathrm{C}\left(68^{\circ} \mathrm{F}\right)$ and constant wind speed of $4.3 \mathrm{~m} / \mathrm{s}$. The weather data also include some data elements set to 0 or approximate lower limits, and other data elements set to neutral (non-extreme) constant values, as follows:

- Dew-point temperature $=-56.6^{\circ} \mathrm{C}\left(-69.9^{\circ} \mathrm{F}\right)$ (corresponds with humidity ratio of $0.000007 \mathrm{~kg} / \mathrm{kg}$ and standard atmospheric pressure); calculation of dew point temperature applies common psychrometric formulae (ASHRAE 2005; Brandemuehl 1993). TMY2 documentation indicates that $-60^{\circ} \mathrm{C}\left(-76^{\circ} \mathrm{F}\right)$ is the lower limit for TMY2 data.

- Relative humidity $=0.05 \%$ (corresponds with humidity ratio of $0.000007 \mathrm{~kg} / \mathrm{kg}$, standard atmospheric pressure, and given dry-bulb temperature); calculations apply common psychrometric formulae (ASHRAE 2005; Brandemuehl 1993). This value rounds to 0\% in the weather data.

- If the program being tested does not allow a very low value for relative humidity, adjust the input weather data (or other software input) to use the lowest allowable relative humidity.

- Atmospheric pressure $=1013$ millibars $(=$ standard atmosphere of 14.696 psia $)$.

- Wind speed $=4.3 \mathrm{~m} / \mathrm{s}$ (Miami.TM2 annual average wind speed $=4.34 \mathrm{~m} / \mathrm{s}$, but TM2 weather data allows input only to the nearest $0.1 \mathrm{~m} / \mathrm{s}$.).

1.3.2.1.4 Output requirements. Nomenclature and units described here are for use with the output spreadsheet, "MZ-Output.xls." Instructions for inputting time of occurrence (for maximum values) are included in the upper left portion of the output spreadsheet. If a maximum value occurs for more than one hour, give the time of first occurrence.

Include the following outputs for Case MZ340:

- Annual sensible cooling load for entire building $\left(\mathrm{Q}_{\text {Bldg }}[\mathrm{kWh}]\right)$

- Annual hourly integrated maximum sensible cooling load for entire building, with the time of first occurrence $\left(\mathrm{q}_{\max , \mathrm{Bldg}}[\mathrm{Wh} / \mathrm{h}]\right)$

- Annual sensible cooling load for each zone $\left(\mathrm{Q}_{\mathrm{A}}, \mathrm{Q}_{\mathrm{B}}, \mathrm{Q}_{\mathrm{C}}, \mathrm{Q}_{\mathrm{D}}, \mathrm{Q}_{\mathrm{E}}, \mathrm{Q}_{\mathrm{F}}[\mathrm{kWh}]\right)$ 
- Annual hourly integrated maximum sensible cooling loads for each zone, with the time of first occurrence $\left(\mathrm{q}_{\max , \mathrm{A}}, \mathrm{q}_{\max , \mathrm{B}}, \mathrm{q}_{\max , \mathrm{C}}, \mathrm{q}_{\max , \mathrm{D}}, \mathrm{q}_{\max , \mathrm{E}}, \mathrm{q}_{\max , \mathrm{F}}[\mathrm{Wh} / \mathrm{h}]\right)$

- Annual average air temperature for each zone $\left(\mathrm{T}_{\mathrm{A}}, \mathrm{T}_{\mathrm{B}}, \mathrm{T}_{\mathrm{C}}, \mathrm{T}_{\mathrm{D}}, \mathrm{T}_{\mathrm{E}}, \mathrm{T}_{\mathrm{F}}\left[{ }^{\circ} \mathrm{C}\right]\right)$

- Annual hourly integrated maximum air temperature for each zone, with the time of first occurrence $\left(\mathrm{T}_{\max , \mathrm{A}}, \mathrm{T}_{\max , \mathrm{B}}, \mathrm{T}_{\max , \mathrm{C}}, \mathrm{T}_{\max , \mathrm{D}}, \mathrm{T}_{\max , \mathrm{E}}, \mathrm{T}_{\max , \mathrm{F}}\left[{ }^{\circ} \mathrm{C}\right]\right)$

- Annual incident unshaded total solar radiation (sum of diffuse and direct) on west facing surface of Zone A $\left(\mathrm{I}_{\mathrm{A}}\left[\mathrm{kWh} / \mathrm{m}^{2}\right]\right)$

- Disaggregated annual incident direct beam $\left(\mathrm{I}_{\mathrm{bA}}\right)$ and diffuse $\left(\mathrm{I}_{\mathrm{dA}}\right)$ solar radiation on the westfacing surface of Zone A $\left(\mathrm{kWh} / \mathrm{m}^{2}\right)$

- These results directly categorize solar processor disagreements, and may be useful if a program does not disaggregate transmitted beam and diffuse solar in its output.

- Annual transmitted total solar radiation (sum of diffuse and direct) through each window $\left(\mathrm{I}_{\mathrm{tr}, \mathrm{A}}\right.$, $\left.\mathrm{I}_{\mathrm{tr}, \mathrm{B}}, \mathrm{I}_{\mathrm{tr}, \mathrm{C}}, \mathrm{I}_{\mathrm{tr}, \mathrm{D}}, \mathrm{I}_{\mathrm{tr}, \mathrm{E}}, \mathrm{I}_{\mathrm{tr}, \mathrm{F}}[\mathrm{kWh}]\right)$

- This quantity may be taken as the optically transmitted solar radiation through a window that is backed by a perfectly absorbing black cavity.

- Disaggregated annual transmitted direct beam ( $\left.\mathrm{I}_{\mathrm{trb}, \mathrm{A}}, \mathrm{I}_{\mathrm{trb}, \mathrm{B}}, \mathrm{I}_{\mathrm{trb}, \mathrm{C}}, \mathrm{I}_{\mathrm{trb}, \mathrm{D}}, \mathrm{I}_{\mathrm{trb}, \mathrm{E}}, \mathrm{I}_{\mathrm{trb}, \mathrm{F}}\right)$ and diffuse $\left(\mathrm{I}_{\mathrm{trd}, \mathrm{A}}\right.$, $\left.\mathrm{I}_{\text {trd,B }}, \mathrm{I}_{\mathrm{trd}, \mathrm{C}}, \mathrm{I}_{\mathrm{trd}, \mathrm{D}}, \mathrm{I}_{\mathrm{trd}, \mathrm{E}}, \mathrm{I}_{\mathrm{trd}, \mathrm{F}}\right)$ solar radiation through each window $(\mathrm{kWh})$

- These results are for scaling the importance of direct beam versus diffuse shading in a multi-zone context.

- Daily hourly transmitted total solar radiation for Zone A only for March 15 (high direct normal radiation during the afternoon), August 4 (high direct normal radiation after 18:00), and October 14 (low direct normal radiation during the afternoon) $\left(\mathrm{I}_{\text {trh, } \mathrm{A}}[\mathrm{Wh} / \mathrm{h}]\right)$

- Daily hourly disaggregated transmitted direct beam $\left(\mathrm{I}_{\text {trbh,A }}\right)$ and diffuse $\left(\mathrm{I}_{\text {trdh,A }}\right)$ solar radiation for Zone A only, for August $4(\mathrm{Wh} / \mathrm{h})$

- This allows identification of results disagreements caused by differences in solar data processing; within MZ340.TM2, August 4 provides a robust mix of direct-normal and diffuse-horizontal solar radiation.

- Daily hourly sensible cooling load for Zone A only, for March 15 (high direct normal radiation during the afternoon) $\left(\mathrm{q}_{\mathrm{A}}[\mathrm{Wh} / \mathrm{h}]\right)$

$\circ$ This is to check sensible cooling load versus transmitted solar radiation for an unshaded zone.

- To produce daily hourly output, run the program for a normal annual run. Do not just run the required days because the results could contain temperature history errors.

\subsubsection{Case MZ350: In-Depth Multi-Zone Fin Shading}

1.3.2.2.1 Objective. Test shading effect on neighboring zones, by a shading fin not directly attached to those zones. Compare results to Case MZ340 (unshaded calorimeter).

1.3.2.2.2 Method. Use multiple methods for implementing shading, applying all shading-object models that the program being tested is capable of. For example, a shading device may be modeled as associated with:

- Zone C window (MZ350a)

- Zone C exterior wall (MZ350b)

- Separate shading object; e.g., as the software would account for a tree or neighboring building (MZ350c)

- Other (MZ350d). 
Submit separate results for each shading method tested, and document the methods in your modeler report. Note that Case MZ355 addresses automated building self-shading, i.e., equivalent shading of Zones $A, B, D$, and $E$ by another zone of the building.

Compare sensible cooling loads and transmitted solar radiation for the entire building and for each zone to results of Case MZ340. Compare whole-building simulation results to each other.

1.3.2.2.3 Input Specification. These cases are exactly as Case MZ340 except for changes described below.

1.3.2.2.3.1 Building Construction. A $24 \mathrm{~m} \times 24 \mathrm{~m}(78.74 \mathrm{ft} \times 78.74 \mathrm{ft})$ external shading fin is applied as shown in Figure 1-5 (such that it primarily shades Zones A, B, D, and E during the afternoon).

\section{- Windows face West \\ - Building geometry is rectangular (all angles are $90^{\circ}$ )}

\section{Shading Fin}

\section{$24 \mathrm{~m}$}

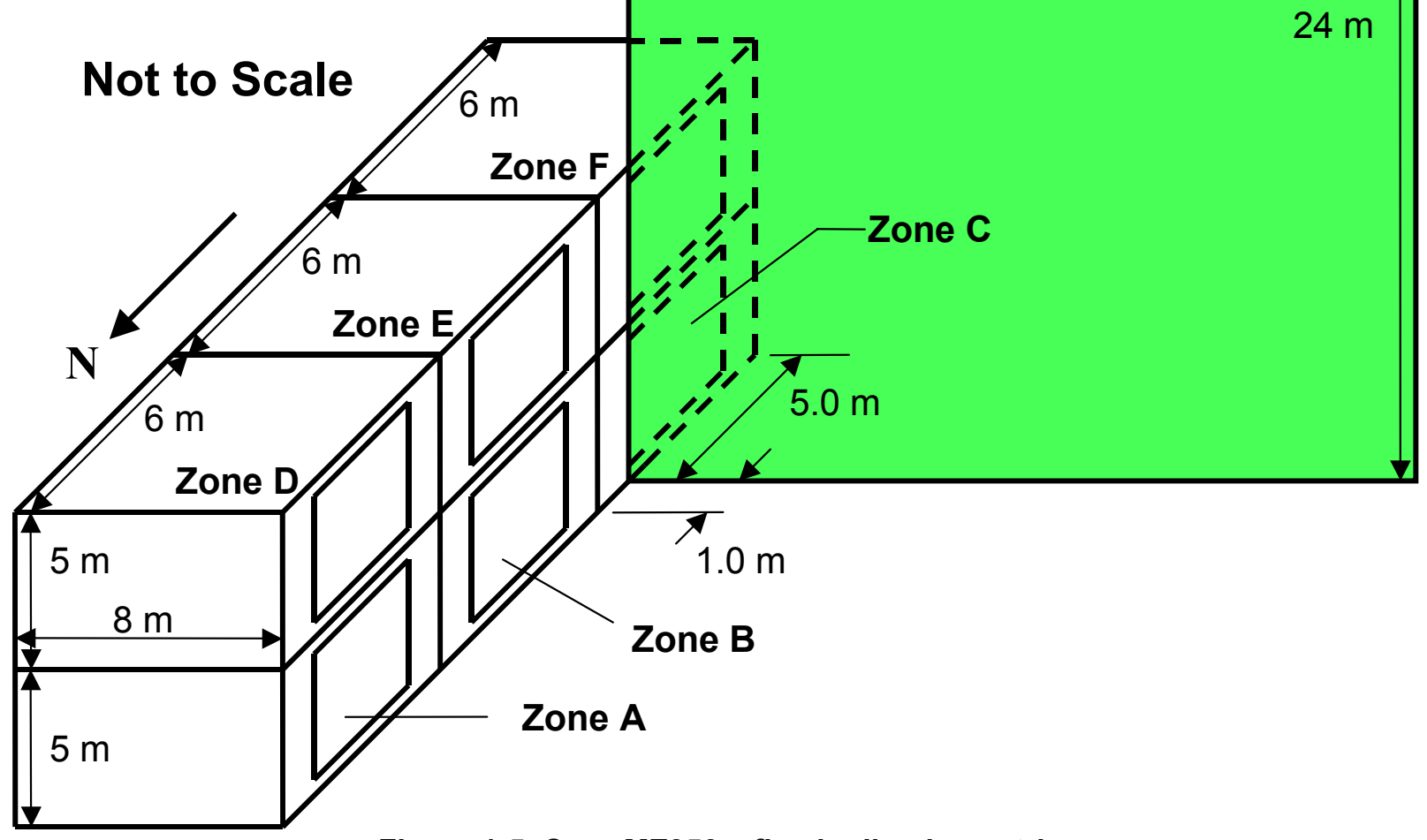

Figure 1-5. Case MZ350 - fin shading isometric 
To model this case, apply all shading-object models that the program being tested is capable of; associate the following possible modeling techniques with the following results designations:

MZ350a: shading device associated with Zone $\mathrm{C}$ window

MZ350b: shading device associated with Zone $\mathrm{C}$ exterior wall

MZ350c: shading device defined as separate shading object (e.g., a tree)

MZ350d: other (describe in your modeler report).

Do not provide results for these modeling techniques that the program does not use.

If the program includes more than four ways to describe a shading object, use an additional results spreadsheet and discuss additional modeling methods in your modeler report.

\subsection{Fin Construction}

Fin optical properties:

- Solar absorptance $=1($ reflectance $=0$, transmittance $=0)$ independent of incidence angle

- Infrared emittance $=0$

- Apply these values as nearly as the program being tested allows

- All heat from solar radiation absorbed by the fin is dissipated to the ambient environment via convection

- Both sides of the fin actively shade the building

- The properties listed above apply to both sides of the fin.

Thickness: If the program requires an input for thickness of shading devices, use the smallest allowable value (e.g., $0.001 \mathrm{~m})$.

1.3.2.2.4 Output requirements. To model this case, apply all shading-object models that the program being tested is capable of; associate the following possible modeling techniques with the following results designations:

MZ350a: shading device associated with Zone $\mathrm{C}$ window

MZ350b: shading device associated with Zone $\mathrm{C}$ exterior wall

MZ350c: shading device defined as separate shading object (e.g., a tree)

MZ350d: other

Do not provide results for these modeling techniques that the program does not use.

If the program includes more than four ways to describe a shading object, use an additional results spreadsheet and discuss additional modeling methods in your modeler report.

In addition to the outputs for MZ340, include:

- Daily hourly transmitted total solar radiation for Zones A, B, D, and E for March 15 (high direct normal radiation during the afternoon) and October 14 (low direct normal radiation during the afternoon) ( $\left(\mathrm{I}_{\text {trh,A }} \mathrm{I}_{\text {trh,B }} \mathrm{I}_{\text {trh,D }} \mathrm{I}_{\text {trh, }}[\mathrm{Wh} / \mathrm{h}]\right)$

- Daily hourly transmitted total solar radiation for Zones C and F for August 4 (high direct normal radiation after 18:00) and October 14 (low direct normal radiation during the afternoon) ( $\mathrm{I}_{\text {trh }, \mathrm{C}} \mathrm{I}_{\text {trh, } \mathrm{F}}$ $[\mathrm{Wh} / \mathrm{h}])$

$\circ$ This is to check the back side of fin shading of direct normal and diffuse solar radiation. 
- Daily hourly sensible cooling load for Zone B only, for March 15 (high direct normal radiation during the afternoon) and October 14 (low direct normal radiation during the afternoon) ( $\mathrm{q}_{\mathrm{B}}$, $[\mathrm{Wh} / \mathrm{h}])$

○ This is to check cooling load versus transmitted solar radiation for a shaded zone

- To produce this output, run the program for a normal annual run. Do not just run the required days because the results could contain temperature history errors.

Do not include:

- Annual incident unshaded total solar radiation (diffuse and direct) on the west-facing surface of Zone A $\left(\mathrm{I}_{\mathrm{A}}\left[\mathrm{kWh} / \mathrm{m}^{2}\right]\right)$

- For the ideal glass, transmitted solar radiation results are sufficient for determining shading effects after checking transmitted versus incident solar radiation in unshaded Case MZ340.

- Daily hourly cooling loads for Zone A

- Hourly cooling loads for Zone A of Case MZ340 and Zone B of MZ350 are sufficient for checking hourly cooling loads versus transmitted solar gains in unshaded and shaded cases.

\subsubsection{Case MZ355: In-Depth Multi-Zone Automated Building Self-Shading}

1.3.2.3.1 Objective. Test automated building self-shading. This is the automated shading effect for a zone of a building by a neighboring zone of the same building. Compare results to Case MZ340 (unshaded calorimeter), and MZ350 (shading by an external fin).

1.3.2.3.2 Method. Attach an additional adiabatic zone (Zone $G$ ) to the west side of the southern most zones of the six-zone calorimeter of MZ340. This zone is applied such that it shades Zones A, B, D, and E exactly as the fin of Case MZ350. Sensible cooling loads and transmitted solar radiation for Zones A, B, $\mathrm{D}$, and E should be the same as for Case MZ350. Also, compare results with Case MZ340. Compare whole-building simulation results to each other.

If the program being tested can automatically model shading of zones by neighboring zones of the building, ignore the remainder of this paragraph. If the program being tested cannot automatically shade zones by neighboring zones of the building, do not run this test case. If the program can do Case MZ350 but not Case MZ355, its ability to model multi-zone shading can be judged based on its Case MZ350 output.

1.3.2.3.3 Input Specification. This case is exactly as Case MZ340 except for changes described below.

An additional zone is affixed to the west side exterior surfaces of Zones $\mathrm{C}$ and $\mathrm{F}$ (such that it primarily shades Zones A, B, D, and E during the afternoon), as shown by Zone G in Figure 1-6. 


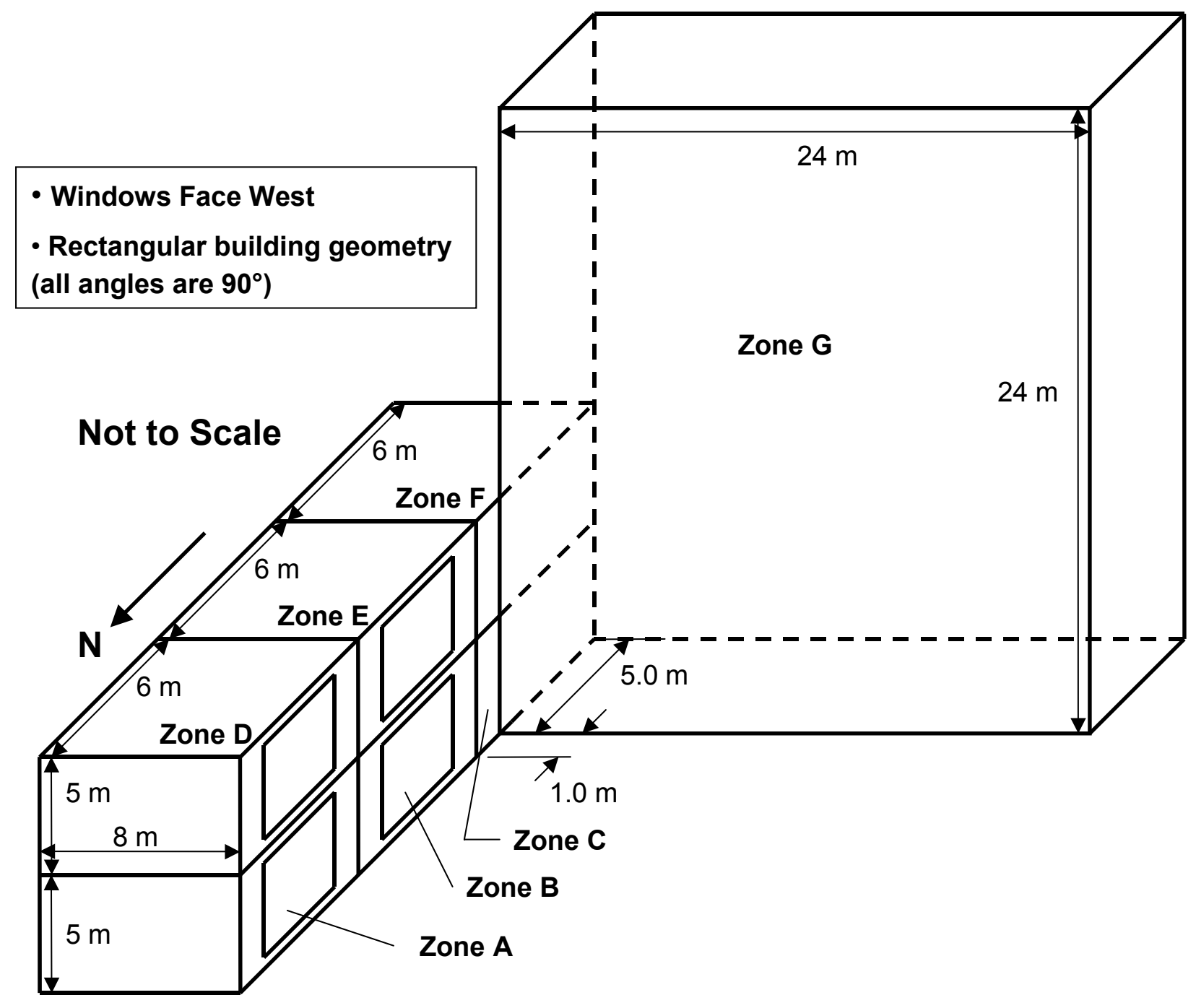

Figure 1-6. Case MZ355 - building self-shading isometric

\subsection{Zone G Material Properties}

- Zone $\mathrm{G}$ is $24 \mathrm{~m}(78.74 \mathrm{ft})$ long $\times 5 \mathrm{~m}(16.404 \mathrm{ft})$ deep $\times 24 \mathrm{~m}(78.74 \mathrm{ft})$ high; see Figure 1-6.

- $\quad$ Air volume of Zone $\mathrm{G}=2880 \mathrm{~m}^{3}\left(101706 \mathrm{ft}^{3}\right)$

- Site altitude and air properties are the same as for MZ320.

- All opaque external boundaries and common walls of the zones (including all walls, floors, and roofs) have thermal conductance $=0 \mathrm{~W} /\left(\mathrm{m}^{2} \cdot \mathrm{K}\right)$; if the program being tested does not allow zeroconductance surfaces, use the lowest allowable thermal conductance or thermal conductivity (e.g., $0.000001 \mathrm{~W} /\left(\mathrm{m}^{2} \cdot \mathrm{K}\right)$ or $1 \cdot 10^{-8} \mathrm{~W} /(\mathrm{m} \cdot \mathrm{K})$ ).

- Wall thickness $=0.01 \mathrm{~m}$, for all walls (including floor and roof)

○ This thickness minimizes disagreements that could arise related to adherence to the geometry convention. If the program being tested automatically includes the thickness of walls in a three-dimensional definition of the building geometry, adjust the dimensions of Zone $\mathrm{G}$ such that it shades the building equivalently as the fin of Case MZ350. 
- All Zone $\mathrm{G}$ external boundaries and common walls (with Zones $\mathrm{C}$ and $\mathrm{F}$ ) are massless; if the program being tested does not allow massless surfaces, use the lowest allowable density or thermal capacitance or both (e.g., $0.000001 \mathrm{~kg} / \mathrm{m}^{3}$ or $\mathrm{J} /(\mathrm{kg} \cdot \mathrm{K})$ or both).

- Exterior solar absorptance $=1$ (no external reflections); if the program being tested does not allow a value of 1 , use the highest allowable value (e.g., 0.99999...).

- Exterior surface infrared emittance $=0$ (or as low as the program being tested allows).

- $\quad$ Exterior combined surface coefficients $=25.4 \mathrm{~W} /\left(\mathrm{m}^{2} \cdot \mathrm{K}\right)\left(4.47 \mathrm{Btu} /\left(\mathrm{h} \cdot \mathrm{ft}^{2} \cdot{ }^{\circ} \mathrm{F}\right)\right)$. This value applies to all exterior surfaces, including the floor.

○ This value corresponds with the $4.3 \mathrm{~m} / \mathrm{s}$ wind speed in the weather data for a rough (brick or rough plaster) surface (Walton 1983, p. 71; Judkoff and Neymark 1995, p. C-1), with the infrared radiation exchange portion of $5.13 \mathrm{~W} /\left(\mathrm{m}^{2} \cdot \mathrm{K}\right)$ subtracted because exterior surface infrared emittance $=0$ (Judkoff and Neymark 1995, p. D-1).

- If the program being tested does not allow direct user input of combined or convective surface coefficients, use the convective surface coefficient the program automatically calculates.

- Interior solar absorptance $=0$; if the program being tested does not allow a value of 0 , use the lowest allowable value (e.g., 0.000001).

- Interior surface coefficients are the same as for the other zones (see Case MZ340).

- No internal gains (set to $0 \mathrm{~W}$ for all zones).

- No infiltration or ventilation.

- No windows.

1.3.2.3.3.2 Zone G Mechanical System. Zone G applies the same mechanical system and set point as the other zones, as described for Case MZ340 in Section 1.3.2.1.3.7.

1.3.2.3.3.3 Adjustments to Zones $\mathrm{C}$ and F. Replace the previous west wall and window of both Zones $\mathrm{C}$ and $\mathrm{F}$ with:

- Common walls adjoining Zone $\mathrm{G}$ with dimensions of $5 \mathrm{~m}(16.404 \mathrm{ft})$ length $\times 5 \mathrm{~m}(16.404 \mathrm{ft})$ height, as shown in Figure 1-6

- These common walls do not include a window.

- Exterior walls with dimensions of $1 \mathrm{~m}(3.281 \mathrm{ft})$ length $\times 5 \mathrm{~m}(16.404 \mathrm{ft})$ height as shown in Figure 1-6.

These walls have the same properties as noted above under "Zone G Material Properties."

1.3.2.3.4 Output requirements. Give same outputs as for MZ350, with changes noted below:

- Do not give any outputs for Zones C, F, or G.

\subsubsection{Case MZ360: In-Depth Internal Window Calorimeter}

\subsubsection{Objective}

This case defines a multi-zone building calorimeter for measuring sensible cooling loads caused by solar radiation transmitted through internal windows. This case tests the ability to track transmitted beam and diffuse solar radiation through multiple zones. 


\subsubsection{Method}

Apply a three-zone building as a calorimeter with idealized exterior and internal windows such that results disagreements are attributable either to modeling of internal windows, or to inability to model the idealizations. Two internal windows are modeled in series; an alternative two-zone modeling specification is provided for simulation tools that allow only one internal window (not two internal windows in series). The calorimeter is achieved similarly as in Case MZ340. Compare whole-building simulations to each other.

\subsubsection{Input Specification}

1.3.3.3.1 Geometry Convention. If the program being tested automatically includes the thickness of walls in a three-dimensional definition of the building geometry, define the wall, roof, and floor dimensions such that the given dimensions for the spacing of southwest-facing surfaces correspond to the southwest-facing side of those surfaces (e.g., in Figure 1-7, the distance between the southwest-facing sides of Walls AB and $\mathrm{BC}$ is exactly $3 \mathrm{~m}$.)

1.3.3.3.2 Building Construction. The overall three-zone building configuration with two internal windows is summarized in Figure 1-7. The building is oriented such that windows face to the southwest ( $45^{\circ}$ west of south). In Figure 1-7, gray dashed lines indicate window outer edge boundaries. The detailed locations of windows within each wall are included in Figures 1-8, 1-9, and 1-10, respectively for Walls $\mathrm{AO}, \mathrm{AB}$, and $\mathrm{BC}$ identified in Figure 1-7. Input parameters are described below.

- Zone plan dimensions:

○ Zone $\mathrm{A}=12 \mathrm{~m}(39.370 \mathrm{ft})$ by $1 \mathrm{~m}(3.281 \mathrm{ft})$.

○ Zone $\mathrm{B}=12 \mathrm{~m}(39.370 \mathrm{ft})$ by $3 \mathrm{~m}(9.843 \mathrm{ft})$.

○ Zone $\mathrm{C}=12 \mathrm{~m}(39.370 \mathrm{ft})$ by $6 \mathrm{~m}(19.685 \mathrm{ft})$

$\circ$ Height, all zones $=12 \mathrm{~m}(39.370 \mathrm{ft})$.

- Air volumes:

○ Zone $\mathrm{A}=144 \mathrm{~m}^{3}\left(5085 \mathrm{ft}^{3}\right)$

- Zone $\mathrm{B}=432 \mathrm{~m}^{3}\left(15256 \mathrm{ft}^{3}\right)$

○ Zone $\mathrm{C}=864 \mathrm{~m}^{3}\left(30512 \mathrm{ft}^{3}\right)$

- Site altitude and air properties are the same as for MZ340.

- All opaque external boundary and common wall thermal properties, except for zone dimensions and air volume noted above, are as in Case MZ340 (see Section 1.3.2.1.3.2).

- Ground reflectance $=0$; if the program being tested does not allow a value of 0 , use the lowest allowable value (e.g., 0.000001).

- Wall thickness $=0.01 \mathrm{~m}(0.0328 \mathrm{ft})$, for all walls (including floors and roofs).

$\circ$ This thickness minimizes disagreements that could arise if there is difficulty with adherence to the geometry convention.

- No internal gains (set to $0 \mathrm{~W}$ for all zones).

- No infiltration or ventilation.

1.3.3.3.3 Interior Combined Surface Coefficients for Opaque Surfaces. Interior combined surface coefficients for opaque surfaces are the same as for Case MZ340 (see Section 1.3.2.1.3.3).

1.3.3.3.4 Exterior Combined Surface Coefficients for Opaque Surfaces. Exterior combined surface coefficients for opaque surfaces are the same as for Case MZ340 (see Section 1.3.2.1.3.4). 


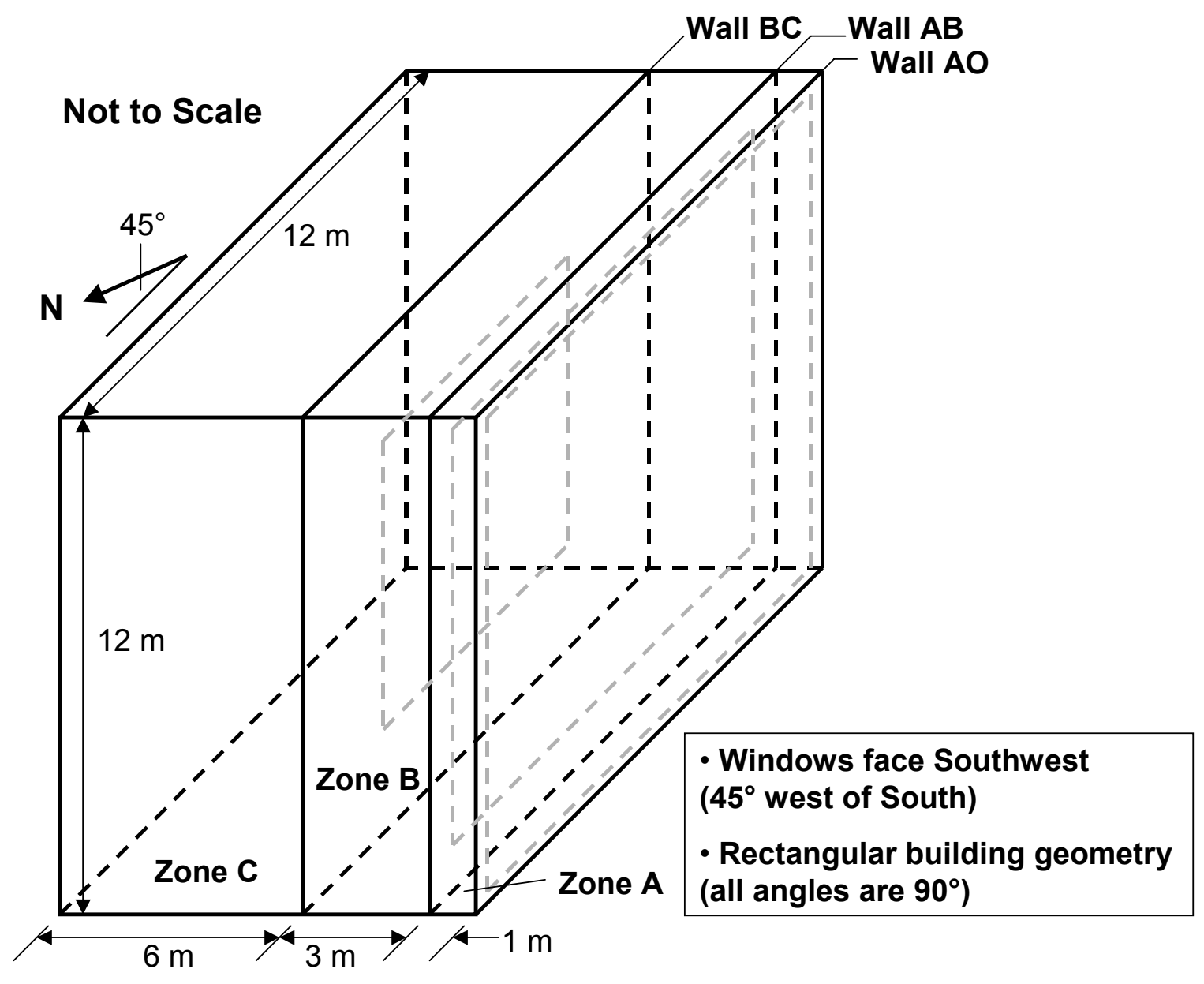

Figure 1-7. Case MZ360 - internal window isometric

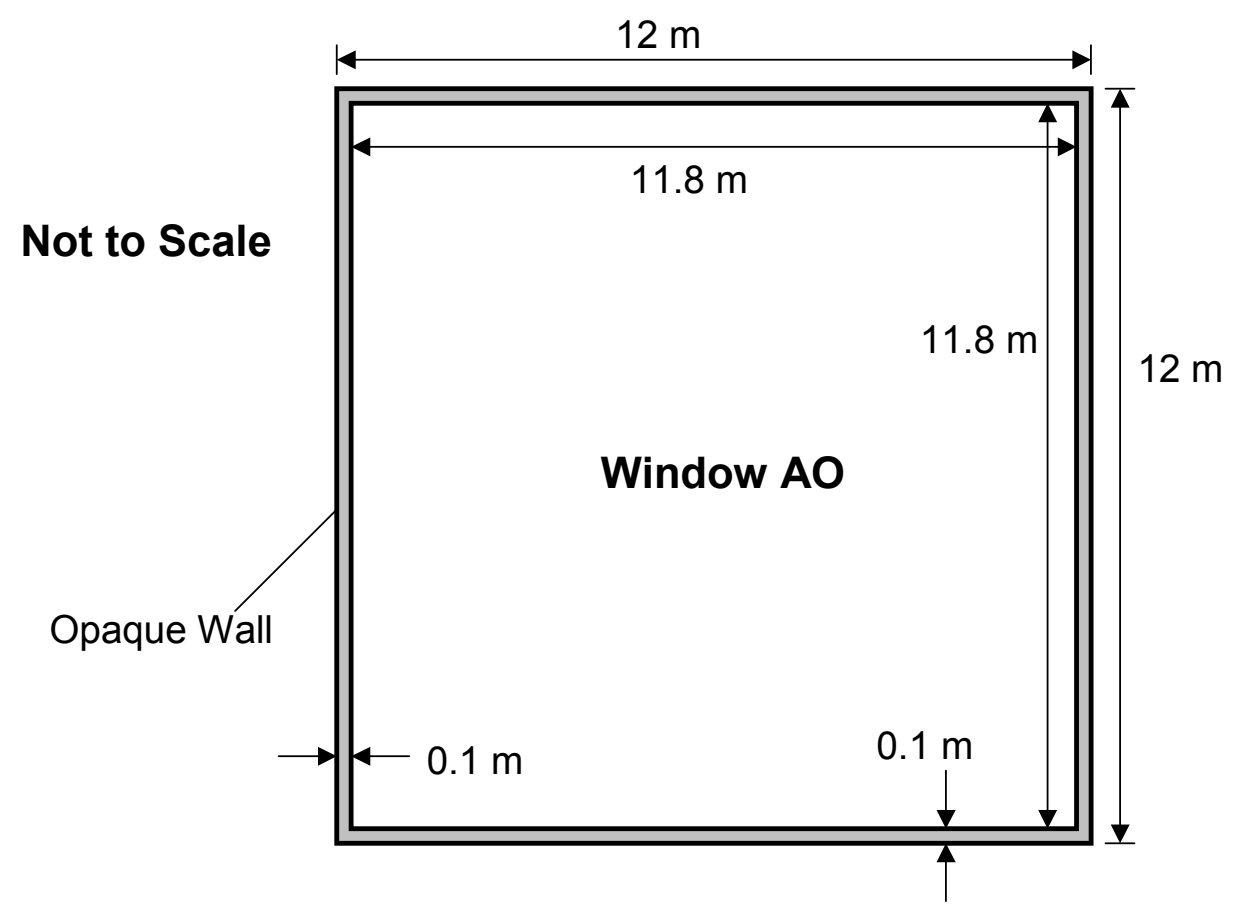

Figure 1-8. Wall AO with Window AO, elevation facing southwest 


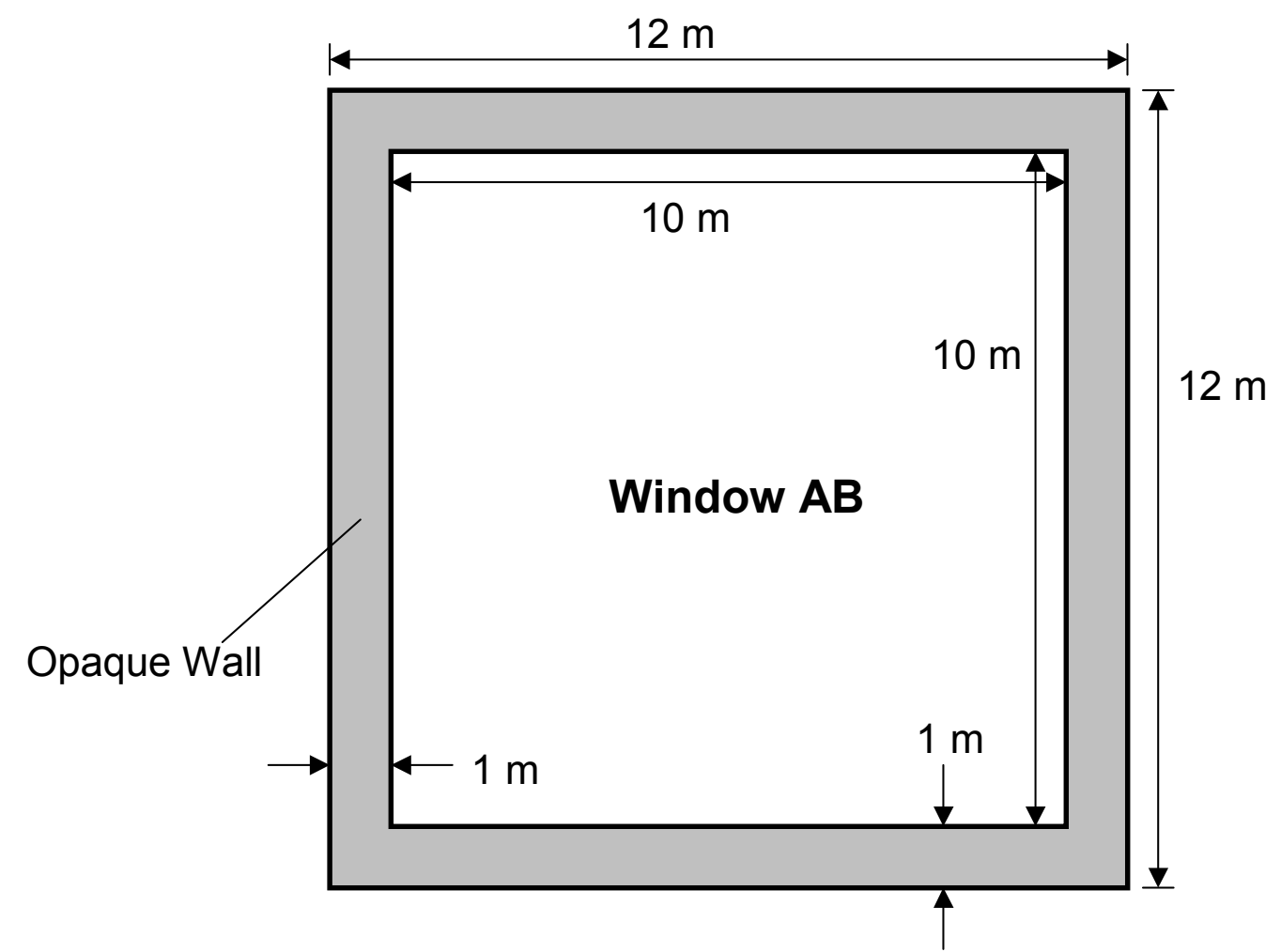

Figure 1-9. Wall $A B$ with Window $A B$, elevation facing southwest

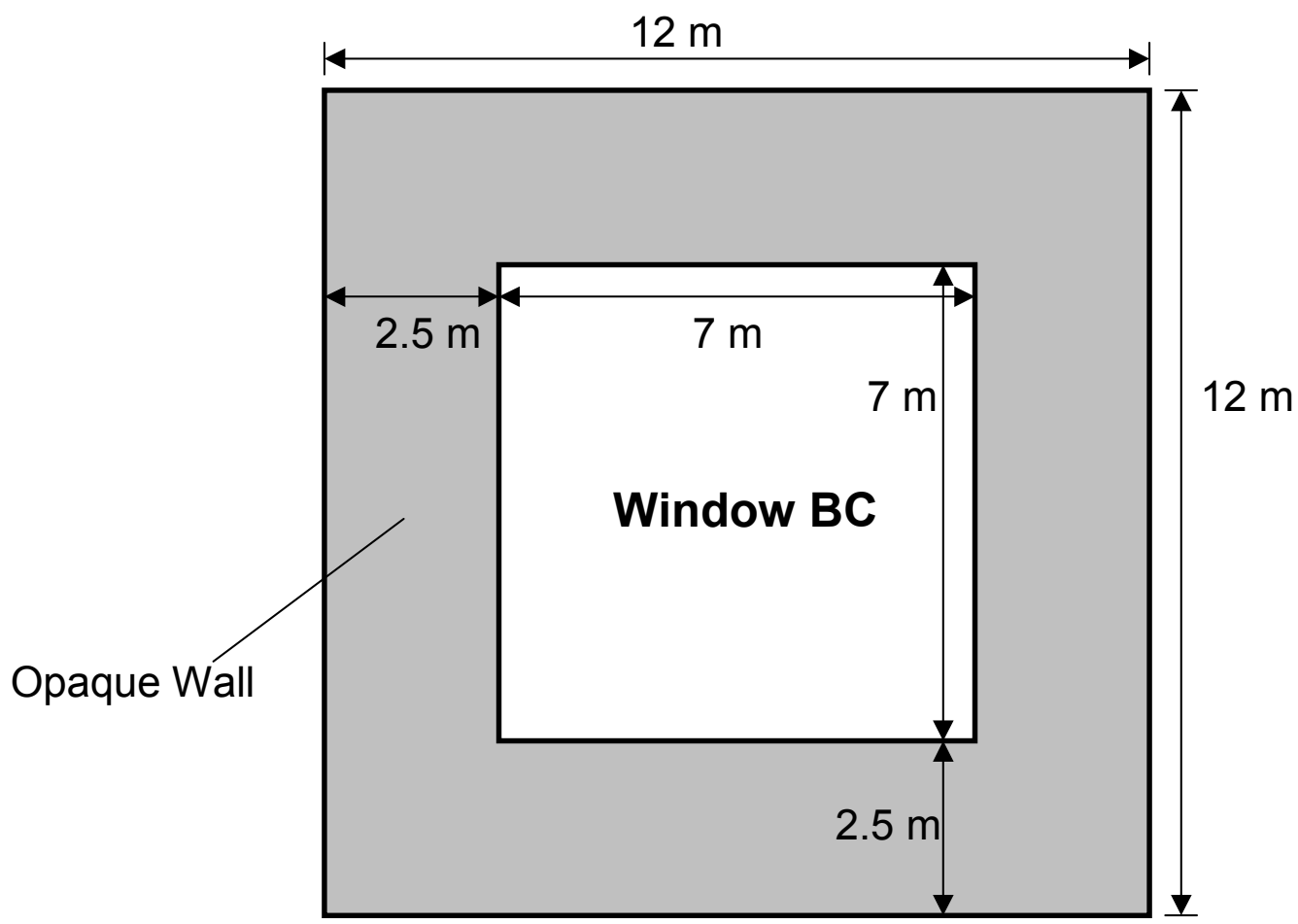

Figure 1-10. Wall BC with Window BC, elevation facing southwest 


\subsection{Windows}

- Each zone has one southwest-facing window located as shown in Figures 1-8, 1-9, and 1-10.

- Window thermal and optical properties are as in Case MZ340 (see Section 1.3.2.1.3.5).

- Interior and exterior combined surface coefficients for the windows are the same as for Case MZ340 (see Section 1.3.2.1.3.6).

- The southwest-facing side of each window is flush with the southwest-facing side of its corresponding wall (no setback).

1.3.3.3.6 Mechanical System. All zones apply the same mechanical system and set points. The mechanical system is the same as in Case MZ340 (see Section 1.3.2.1.3.7).

1.3.3.3.7 Weather Data. Weather data are the same as for Case MZ340 (MZ340.TM2).

1.3.3.3.8 Alternative Two-Zone Modeling Specification. If the program being tested allows modeling of two internal windows in series, ignore the remainder of this paragraph. If it does not allow modeling of two internal windows in series, model Case MZ360 exactly as described above except for the following instructions.

- Change Window BC to a black opaque surface with the same properties as Wall BC.

- Provide the same outputs as listed in Section 1.3.3.4; enter "n/a" as outputs for Zone C.

- Include a note in the modeler report for the tested software that the two-zone alternative modeling specification was applied for Case MZ360.

- Analysis notes

$\circ$ For the annual results, compare $\mathrm{Q}_{\mathrm{B}}$ for two-zone models to $\left(\mathrm{Q}_{\mathrm{B}}+\mathrm{Q}_{\mathrm{C}}\right)$ for three-zone models.

- Transmitted solar radiation through windows $\mathrm{AO}$ and $\mathrm{AB}$ remains directly comparable for two-zone and three-zone models.

\subsubsection{Output requirements.}

Nomenclature and units described here are for use with the output spreadsheet, "MZ-Output.xls." Instructions for inputting time of occurrence (for maximum values) are included in the upper left portion of the output spreadsheet. If a maximum value occurs for more than one hour, give the time of first occurrence.

Include the following outputs for Case MZ360:

- Annual sensible cooling load for entire building ( $\left.\mathrm{Q}_{\mathrm{Bldg}}[\mathrm{kWh}]\right)$

- Annual hourly integrated maximum sensible cooling load for entire building, with the time of first occurrence ( $\left.\mathrm{q}_{\max , \mathrm{Bldg}}[\mathrm{Wh} / \mathrm{h}]\right)$

- Annual sensible cooling load for each zone $\left(\mathrm{Q}_{\mathrm{A}}, \mathrm{Q}_{\mathrm{B}}, \mathrm{Q}_{\mathrm{C}}[\mathrm{kWh}]\right)$

- Annual hourly integrated maximum sensible cooling loads for each zone, with the time of first occurrence $\left(\mathrm{q}_{\max , \mathrm{A}}, \mathrm{q}_{\max , \mathrm{B}}, \mathrm{q}_{\max , \mathrm{C}}[\mathrm{Wh} / \mathrm{h}]\right)$

- Annual average air temperature for each zone $\left(\mathrm{T}_{\mathrm{A}}, \mathrm{T}_{\mathrm{B}}, \mathrm{T}_{\mathrm{C}}\left[{ }^{\circ} \mathrm{C}\right]\right)$

- Annual hourly integrated maximum air temperature for each zone, with the time of first occurrence $\left(\mathrm{T}_{\max , \mathrm{A}}, \mathrm{T}_{\max , \mathrm{B}}, \mathrm{T}_{\max , \mathrm{C}}\left[{ }^{\circ} \mathrm{C}\right]\right)$

- Annual incident unshaded total solar radiation (sum of diffuse and direct) on the southwest-facing surface of Zone A $\left(\mathrm{I}_{\mathrm{A}}\left[\mathrm{kWh} / \mathrm{m}^{2}\right]\right)$ 
- Disaggregated annual incident direct beam $\left(\mathrm{I}_{\mathrm{bA}}\right)$ and diffuse $\left(\mathrm{I}_{\mathrm{dA}}\right)$ solar radiation on the southwestfacing surface of Zone A $\left(\mathrm{kWh} / \mathrm{m}^{2}\right)$

- These results directly categorize solar processor disagreements, and may be useful if a program does not disaggregate transmitted beam and diffuse solar.

- Annual transmitted total solar radiation (sum of diffuse and direct) through each window $\left(\mathrm{I}_{\mathrm{tr}, \mathrm{A}}\right.$ [through Window AO], $\mathrm{I}_{\mathrm{tr}, \mathrm{B}}$ [through Window AB], $\mathrm{I}_{\mathrm{tr}, \mathrm{C}}$ [through Window $\left.\mathrm{BC}\right][\mathrm{kWh}]$ ).

$\circ$ This quantity may be taken as the optically transmitted solar radiation through a window that is backed by a perfectly absorbing black cavity.

- This quantity is NOT the net solar transmission for the zone (e.g., is not initially transmitted radiation less the radiation transmitted to a neighboring zone).

- Disaggregated annual transmitted direct beam $\left(\mathrm{I}_{\mathrm{trb}, \mathrm{A}}, \mathrm{I}_{\mathrm{trb}, \mathrm{B}}, \mathrm{I}_{\mathrm{trb}, \mathrm{C}}\right)$ and diffuse $\left(\mathrm{I}_{\mathrm{trd}, \mathrm{A}}, \mathrm{I}_{\mathrm{trd}, \mathrm{B}}, \mathrm{I}_{\mathrm{trd}, \mathrm{C}}\right)$ solar radiation through each window $(\mathrm{kWh})$

$\circ$ These results are for scaling the importance of direct beam versus diffuse transmission in an internal-window context.

- Daily hourly sensible cooling load for Zone B only, and daily hourly transmitted total solar radiation for Zones A, B, and $\mathrm{C}$ for March 15 (high direct normal radiation during the afternoon) and October 14 (low direct normal radiation during the afternoon) $\left(\mathrm{q}_{\mathrm{B}}, \mathrm{I}_{\text {trh, } \mathrm{A}}, \mathrm{I}_{\text {trh, } \mathrm{B}}, \mathrm{I}_{\text {trh, }}[\mathrm{Wh} / \mathrm{h}]\right)$.

- To produce this output, run the program for a normal annual run. Do not just run the required days because the results could contain temperature history errors. 


\section{Appendix A. TMY2 File Format}

This format information was taken from the TMY2 User's Manual (Marion and Urban 1995), and can be found at www.nrel.gov.

\section{Data and Format}

For each station, a TMY2 file contains 1 year of hourly solar radiation, illuminance, and meteorological data. The files consist of data for the typical calendar months during 1961-1990 that are concatenated to form the typical meteorological year for each station.

Each hourly record in the file contains values for solar radiation, illuminance, and meteorological elements. A two-character source and uncertainty flag is attached to each data value to indicate whether the data value was measured, modeled, or missing, and to provide an estimate of the uncertainty of the data value.

\section{File Header}

The first record of each file is the file header that describes the station. The file header contains the WBAN number, city, state, time zone, latitude, longitude, and elevation. The field positions and definitions of these header elements are given in Table A-1, along with sample FORTRAN and C formats for reading the header.

Table A-1. TMY2 Weather File Header Format (for First Record of Each File)

\begin{tabular}{|c|c|c|}
\hline Field Position & Element & Definition \\
\hline $002-006$ & WBAN Number & $\begin{array}{l}\text { Station's Weather Bureau Army Navy } \\
\text { number (see Table 2-1 of Marion and Urban } \\
\text { [1995]) }\end{array}$ \\
\hline $008-029$ & City & $\begin{array}{l}\text { City where the station is located (maximum of } 22 \\
\text { characters) }\end{array}$ \\
\hline $031-032$ & State & $\begin{array}{l}\text { State where the station is located (abbreviated to } \\
\text { two letters) }\end{array}$ \\
\hline $034-036$ & Time Zone & $\begin{array}{l}\text { Time zone is the number of hours by which the } \\
\text { local standard time is ahead of or behind } \\
\text { Universal Time. For example, Mountain Standard } \\
\text { Time is designated }-7 \text { because it is } 7 \text { hours } \\
\text { behind Universal Time. }\end{array}$ \\
\hline $\begin{array}{l}038-044 \\
038 \\
040-041 \\
043-044\end{array}$ & Latitude & $\begin{array}{l}\text { Latitude of the station } \\
\mathrm{N}=\text { North of equator } \\
\text { Degrees } \\
\text { Minutes }\end{array}$ \\
\hline $\begin{array}{l}046-053 \\
046 \\
048-050 \\
052-053\end{array}$ & Longitude & $\begin{array}{l}\text { Longitude of the station } \\
W=\text { West, } E=\text { East } \\
\text { Degrees } \\
\text { Minutes }\end{array}$ \\
\hline $056-059$ & Elevation & Elevation of station in meters above sea level \\
\hline \multicolumn{3}{|c|}{ 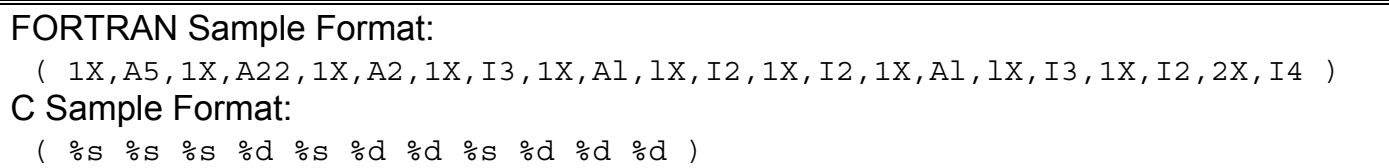 } \\
\hline
\end{tabular}




\section{Hourly Records}

Following the file header, 8760 hourly data records provide 1 year of solar radiation, illuminance, and meteorological data, along with their source and uncertainty flags. Table A-2 provides field positions, element definitions, and sample FORTRAN and C formats for reading the hourly records.

Each hourly record begins with the year (field positions 2-3) from which the typical month was chosen, followed by the month, day, and hour information in field positions 4-9. The times are in local standard time (previous TMYs based on SOLMET/ERSATZ data are in solar time).

For solar radiation and illuminance elements, the data values represent the energy received during the 60 minutes preceding the hour indicated. For meteorological elements (with a few exceptions), observations or measurements were made at the hour indicated. A few of the meteorological elements had observations, measurements, or estimates made at daily, instead of hourly, intervals. Consequently, the data values for broadband aerosol optical depth, snow depth, and days since last snowfall represent the values available for the day indicated.

\section{Source and Uncertainty Flags}

With the exception of extraterrestrial horizontal and extraterrestrial direct radiation, the two field positions immediately following the data value provide source and uncertainty flags both to indicate whether the data were measured, modeled, or missing, and to provide an estimate of the uncertainty of the data. Source and uncertainty flags for extraterrestrial horizontal and extraterrestrial direct radiation are not provided because these elements were calculated using equations considered to give exact values.

For the most part, the source and uncertainty flags in the TMY2 data files are the same as the ones in NSRDB, from which the TMY2 files were derived. However, differences do exist for data that were missing in the NSRDB, but then filled while developing the TMY2 data sets. Uncertainty values apply to the data with respect to when the data were measured, and not as to how "typical" a particular hour is for a future month and day. More information on data filling and the assignment of source and uncertainty flags is found in the TMY2 User's Manual (Marion and Urban 1995). 
Table A-2. TMY2 Data Records

\begin{tabular}{|c|c|c|c|}
\hline $\begin{array}{l}\text { Field } \\
\text { Position }\end{array}$ & Element & Values & Definition \\
\hline $\begin{array}{l}\mathbf{0 0 2}-\mathbf{0 0 9} \\
002-003 \\
004-005 \\
006-007 \\
008-009\end{array}$ & $\begin{array}{l}\text { Local Standard Time } \\
\text { Year } \\
\text { Month } \\
\text { Day } \\
\text { Hour }\end{array}$ & $\begin{array}{l}61-90 \\
1-12 \\
1-31 \\
1-24\end{array}$ & $\begin{array}{l}\text { Year, 1961-1990 } \\
\text { Month } \\
\text { Day of month } \\
\text { Hour of day in local standard time }\end{array}$ \\
\hline $010-013$ & $\begin{array}{l}\text { Extraterrestrial Horizontal } \\
\text { Radiation }\end{array}$ & $0-1415$ & $\begin{array}{l}\text { Amount of solar radiation in } \mathrm{Wh} / \mathrm{m}^{2} \\
\text { received on a horizontal surface at the } \\
\text { top of the atmosphere during the } 60 \\
\text { minutes preceding the hour indicated }\end{array}$ \\
\hline $014-017$ & $\begin{array}{l}\text { Extraterrestrial Direct } \\
\text { Normal Radiation }\end{array}$ & $0-1415$ & $\begin{array}{l}\text { Amount of solar radiation in } \mathrm{Wh} / \mathrm{m}^{2} \\
\text { received on a surface normal to the } \\
\text { sun at the top of the atmosphere } \\
\text { during the } 60 \text { minutes preceding the } \\
\text { hour indicated }\end{array}$ \\
\hline $\begin{array}{l}018-023 \\
018-021 \\
022 \\
023\end{array}$ & $\begin{array}{l}\text { Global Horizontal } \\
\text { Radiation } \\
\text { Data Value } \\
\text { Flag for Data Source } \\
\text { Flag for Data Uncertainty }\end{array}$ & $\begin{array}{l}0-1200 \\
A-H, ? \\
0-9\end{array}$ & $\begin{array}{l}\text { Total amount of direct and diffuse } \\
\text { solar radiation in } \mathrm{Wh} / \mathrm{m}^{2} \text { received on } \\
\text { a horizontal surface during the } 60 \\
\text { minutes preceding the hour indicated }\end{array}$ \\
\hline $\begin{array}{l}024-029 \\
024-027 \\
028 \\
029\end{array}$ & $\begin{array}{l}\text { Direct Normal Radiation } \\
\text { Data Value } \\
\text { Flag for Data Source } \\
\text { Flag for Data Uncertainty } \\
\end{array}$ & $\begin{array}{l}0-1100 \\
A-H, ? \\
0-9\end{array}$ & $\begin{array}{l}\text { Amount of solar radiation in } \mathrm{Wh} / \mathrm{m}^{2} \\
\text { received within a } 5.7^{\circ} \text { field of view } \\
\text { centered on the sun during the } 60 \\
\text { minutes preceding the hour indicated }\end{array}$ \\
\hline $\begin{array}{l}030-035 \\
030-033 \\
034 \\
035\end{array}$ & $\begin{array}{l}\text { Diffuse Horizontal } \\
\text { Radiation } \\
\text { Data Value } \\
\text { Flag for Data Source } \\
\text { Flag for Data Uncertainty } \\
\end{array}$ & $\begin{array}{l}0-700 \\
\text { A - H, ? } \\
0-9\end{array}$ & $\begin{array}{l}\text { Amount of solar radiation in } \mathrm{Wh} / \mathrm{m}^{2} \\
\text { received from the sky (excluding the } \\
\text { solar disk) on a horizontal surface } \\
\text { during the } 60 \text { minutes preceding the } \\
\text { hour indicated }\end{array}$ \\
\hline $\begin{array}{l}036-041 \\
036-039 \\
040 \\
041\end{array}$ & $\begin{array}{l}\text { Global Horiz. Illuminance } \\
\text { Data Value } \\
\text { Flag for Data Source } \\
\text { Flag for Data Uncertainty }\end{array}$ & $\begin{array}{l}0-1300 \\
\text { I, ? } \\
0-9\end{array}$ & $\begin{array}{l}\text { Average total amount of direct and } \\
\text { diffuse illuminance in hundreds of lux } \\
\text { received on a horizontal surface } \\
\text { during the } 60 \text { minutes preceding the } \\
\text { hour indicated } \\
0 \text { to } 1300=0 \text { to } 130,000 \text { lux }\end{array}$ \\
\hline $\begin{array}{l}042-047 \\
042-045 \\
046 \\
047\end{array}$ & $\begin{array}{l}\text { Direct Normal Illuminance } \\
\text { Data Value } \\
\text { Flag for Data Source } \\
\text { Flag for Data Uncertainty }\end{array}$ & $\begin{array}{l}0-1100 \\
\text { I, ? } \\
0-9\end{array}$ & $\begin{array}{l}\text { Average amount of direct normal } \\
\text { illuminance in hundreds of lux } \\
\text { received within a } 5.7^{\circ} \text { field of view } \\
\text { centered on the sun during the } 60 \\
\text { minutes preceding the hour indicated. } \\
0 \text { to } 1100=0 \text { to } 110,000 \text { lux }\end{array}$ \\
\hline $\begin{array}{l}048-053 \\
048-051 \\
052 \\
053\end{array}$ & $\begin{array}{l}\text { Diffuse Horiz. Illuminance } \\
\text { Data Value } \\
\text { Flag for Data Source } \\
\text { Flag for Data Uncertainty }\end{array}$ & $\begin{array}{l}0-800 \\
\text { I, ? } \\
0-9\end{array}$ & $\begin{array}{l}\text { Average amount of illuminance in } \\
\text { hundreds of lux received from the sky } \\
\text { (excluding the solar disk) on a } \\
\text { horizontal surface during the } 60 \\
\text { minutes preceding the hour indicated. } \\
0 \text { to } 800=0 \text { to } 80,000 \text { lux }\end{array}$ \\
\hline
\end{tabular}




\begin{tabular}{|c|c|c|c|}
\hline $\begin{array}{l}\text { Field } \\
\text { Position }\end{array}$ & Element & Values & Definition \\
\hline $\begin{array}{l}054-059 \\
054-057 \\
058 \\
059\end{array}$ & $\begin{array}{l}\text { Zenith Luminance } \\
\text { Data Value } \\
\text { Flag for Data Source } \\
\text { Flag for Data Uncertainty }\end{array}$ & $\begin{array}{l}0-7000 \\
\text { I, ? } \\
0-9\end{array}$ & $\begin{array}{l}\text { Average amount of luminance at the } \\
\text { sky's zenith in tens of } \mathrm{Cd} / \mathrm{m}^{2} \text { during } \\
\text { the } 60 \text { minutes preceding the hour } \\
\text { indicated. } \\
0 \text { to } 7000=0 \text { to } 70,000 \mathrm{Cd} / \mathrm{m}^{2}\end{array}$ \\
\hline $\begin{array}{l}060-063 \\
060-061 \\
062 \\
063\end{array}$ & $\begin{array}{l}\text { Total Sky Cover } \\
\text { Data Value } \\
\text { Flag for Data Source } \\
\text { Flag for Data Uncertainty }\end{array}$ & $\begin{array}{l}0-10 \\
A-F \\
0-9\end{array}$ & $\begin{array}{l}\text { Amount of sky dome in tenths } \\
\text { covered by clouds or obscuring } \\
\text { phenomena at the hour indicated }\end{array}$ \\
\hline $\begin{array}{l}064-067 \\
064-065 \\
066 \\
067\end{array}$ & $\begin{array}{l}\text { Opaque Sky Cover } \\
\text { Data Value } \\
\text { Flag for Data Source } \\
\text { Flag for Data Uncertainty }\end{array}$ & $\begin{array}{l}0-10 \\
\text { A - F } \\
0-9\end{array}$ & $\begin{array}{l}\text { Amount of sky dome in tenths } \\
\text { covered by clouds or obscuring } \\
\text { phenomena that prevent observing the } \\
\text { sky or higher cloud layers at the hour } \\
\text { indicated }\end{array}$ \\
\hline $\begin{array}{l}068-073 \\
068-071 \\
072 \\
073\end{array}$ & $\begin{array}{l}\text { Dry Bulb Temperature } \\
\text { Data Value } \\
\text { Flag for Data Source } \\
\text { Flag for Data Uncertainty }\end{array}$ & $\begin{array}{l}-500 \text { to } 500 \\
A-F \\
0-9\end{array}$ & $\begin{array}{l}\text { Dry bulb temperature in tenths of }{ }^{\circ} \mathrm{C} \\
\text { at the hour indicated } \\
-500 \text { to } 500=-50.0 \text { to } 50.0^{\circ} \mathrm{C}\end{array}$ \\
\hline $\begin{array}{l}074-079 \\
074-077 \\
078 \\
079\end{array}$ & $\begin{array}{l}\text { Dew Point Temperature } \\
\text { Data Value } \\
\text { Flag for Data Source } \\
\text { Flag for Data Uncertainty }\end{array}$ & $\begin{array}{l}-600 \text { to } 300 \\
A-F \\
0-9\end{array}$ & $\begin{array}{l}\text { Dew point temperature in tenths of } \\
{ }^{\circ} \mathrm{C} \text { at the hour indicated } \\
-600 \text { to } 300=-60.0 \text { to } 30.0^{\circ} \mathrm{C}\end{array}$ \\
\hline $\begin{array}{l}080-084 \\
080-082 \\
083 \\
084\end{array}$ & $\begin{array}{l}\text { Relative Humidity } \\
\text { Data Value } \\
\text { Flag for Data Source } \\
\text { Flag for Data Uncertainty }\end{array}$ & $\begin{array}{l}0-100 \\
\text { A - F } \\
0-9\end{array}$ & $\begin{array}{l}\text { Relative humidity in percent at the } \\
\text { hour indicated }\end{array}$ \\
\hline $\begin{array}{l}085-090 \\
085-088 \\
089 \\
090\end{array}$ & $\begin{array}{l}\text { Atmospheric Pressure } \\
\text { Data Value } \\
\text { Flag for Data Source } \\
\text { Flag for Data Uncertainty }\end{array}$ & $\begin{array}{l}700-1100 \\
A-F \\
0-9\end{array}$ & $\begin{array}{l}\text { Atmospheric pressure at station in } \\
\text { millibars at the hour indicated }\end{array}$ \\
\hline $\begin{array}{l}091-095 \\
091-093 \\
094 \\
095\end{array}$ & $\begin{array}{l}\text { Wind Direction } \\
\text { Data Value } \\
\text { Flag for Data Source } \\
\text { Flag for Data Uncertainty }\end{array}$ & $\begin{array}{l}0-360 \\
\text { A - F } \\
0-9\end{array}$ & $\begin{array}{l}\text { Wind direction in degrees at the hour } \\
\text { indicated. }(N=0 \text { or } 360, E=90 \text {, } \\
S=180, W=270) \text {. For calm winds, } \\
\text { wind direction equals zero. }\end{array}$ \\
\hline $\begin{array}{l}096-100 \\
096-098 \\
099 \\
100 \\
\end{array}$ & $\begin{array}{l}\text { Wind Speed } \\
\text { Data Value } \\
\text { Flag for Data Source } \\
\text { Flag for Data Uncertainty }\end{array}$ & $\begin{array}{l}0-400 \\
\text { A - F } \\
0-9\end{array}$ & $\begin{array}{l}\text { Wind speed in tenths of meters per } \\
\text { second at the hour indicated. } \\
0 \text { to } 400=0 \text { to } 40.0 \mathrm{~m} / \mathrm{s}\end{array}$ \\
\hline $\begin{array}{l}101-106 \\
101-104 \\
105 \\
106\end{array}$ & $\begin{array}{l}\text { Visibility } \\
\text { Data Value } \\
\text { Flag for Data Source } \\
\text { Flag for Data Uncertainty }\end{array}$ & $\begin{array}{l}0-1609 \\
A-F, ? \\
0-9\end{array}$ & $\begin{array}{l}\text { Horizontal visibility in tenths of } \\
\text { kilometers at the hour indicated. } \\
7777=\text { unlimited visibility } \\
0 \text { to } 1609=0.0 \text { to } 160.9 \mathrm{~km} \\
9999=\text { missing data }\end{array}$ \\
\hline $\begin{array}{l}107-113 \\
107-111 \\
112 \\
113\end{array}$ & $\begin{array}{l}\text { Ceiling Height } \\
\text { Data Value } \\
\text { Flag for Data Source } \\
\text { Flag for Data Uncertainty }\end{array}$ & $\begin{array}{l}0-30450 \\
A-F, ? \\
0-9\end{array}$ & $\begin{array}{l}\text { Ceiling height in meters at the hour } \\
\text { indicated. } \\
\begin{aligned} 77777=\text { unlimited ceiling height } \\
88888=\text { cirroform } \\
99999=\text { missing data }\end{aligned}\end{array}$ \\
\hline
\end{tabular}




\begin{tabular}{|c|c|c|c|}
\hline $\begin{array}{l}\text { Field } \\
\text { Position }\end{array}$ & Element & Values & Definition \\
\hline $114-123$ & Present Weather & $\begin{array}{l}\text { See } \\
\text { Appendix B of } \\
\text { Marion and } \\
\text { Urban (1995) }\end{array}$ & $\begin{array}{l}\text { Present weather conditions denoted by } \\
\text { a } 10 \text {-digit number. See Appendix B in } \\
\text { the Marion and Urban (1995) for key to } \\
\text { present weather elements. }\end{array}$ \\
\hline $\begin{array}{l}124-128 \\
124-126 \\
127 \\
128\end{array}$ & $\begin{array}{l}\text { Precipitable Water } \\
\text { Data Value } \\
\text { Flag for Data Source } \\
\text { Flag for Data Uncertainty }\end{array}$ & $\begin{array}{l}0-100 \\
\text { A - F } \\
0-9\end{array}$ & $\begin{array}{l}\text { Precipitable water in millimeters at } \\
\text { the hour indicated }\end{array}$ \\
\hline $\begin{array}{l}129-133 \\
129-131 \\
132 \\
133\end{array}$ & $\begin{array}{l}\text { Aerosol Optical Depth } \\
\text { Data Value } \\
\text { Flag for Data Source } \\
\text { Flag for Data Uncertainty }\end{array}$ & $\begin{array}{l}0-240 \\
\text { A - F } \\
0-9\end{array}$ & $\begin{array}{l}\text { Broadband aerosol optical depth } \\
\text { (broad-band turbidity) in thousandths } \\
\text { on the day indicated. } \\
0 \text { to } 240=0.0 \text { to } 0.240\end{array}$ \\
\hline $\begin{array}{l}134-138 \\
134-136 \\
137 \\
138\end{array}$ & $\begin{array}{l}\text { Snow Depth } \\
\text { Data Value } \\
\text { Flag for Data Source } \\
\text { Flag for Data Uncertainty }\end{array}$ & $\begin{array}{l}0-150 \\
\text { A-F,? } \\
0-9\end{array}$ & $\begin{array}{l}\text { Snow depth in centimeters on the day } \\
\text { indicated. } \\
999=\text { missing data }\end{array}$ \\
\hline $\begin{array}{l}139-142 \\
139-140 \\
141 \\
142\end{array}$ & $\begin{array}{l}\text { Days Since Last Snowfall } \\
\text { Data Value } \\
\text { Flag for Data Source } \\
\text { Flag for Data Uncertainty }\end{array}$ & $\begin{array}{l}0-88 \\
\text { A - F, ? } \\
0-9\end{array}$ & $\begin{array}{l}\text { Number of days since last snowfall. } \\
88=88 \text { or greater days } \\
99=\text { missing data }\end{array}$ \\
\hline \multicolumn{4}{|c|}{ 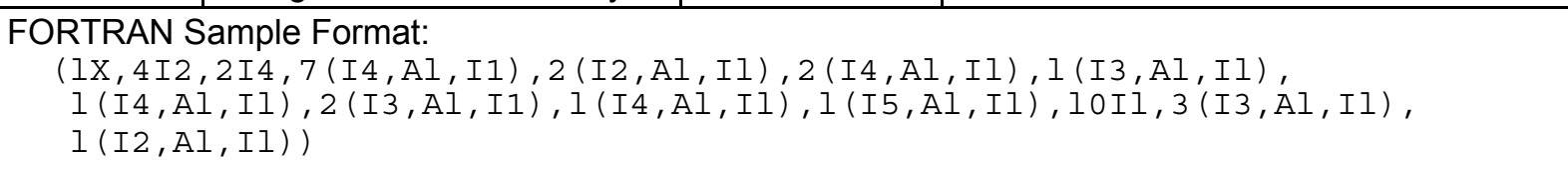 } \\
\hline \multicolumn{4}{|c|}{ 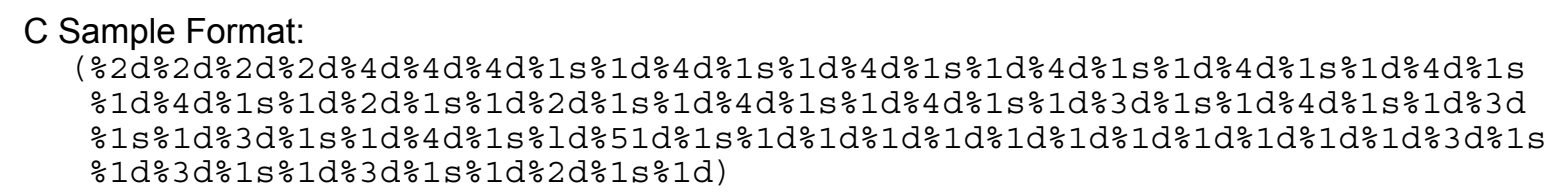 } \\
\hline
\end{tabular}




\section{Appendix B. Output Spreadsheet Instructions}

MZ-Output.XLS

Output spreadsheet for Multi-Zone Non-Airflow InDepth Cases: MZ320-MZ360

INSTRUCTIONS

1. Use specified units

2. Data entry is restricted to the following ranges:

E60..E62: $\quad$ Software Name, Version, and Date of Results

E70..H70: $\quad$ MZ320 Steady-State Outputs

E79..AL85: $\quad$ MZ340-MZ360 Calorimetry Annual Summary Outputs

E93..Y99; H102..Y108: $\quad$ MZ340-MZ360 Calorimetry Hourly Integrated Maxima Ouputs

E116..J139: $\quad$ MZ340 Hourly Outputs

E146..BN169: $\quad$ MZ350a through MZ350d Hourly Outputs

E176..L199: $\quad$ MZ355 Hourly Outputs

E206..L229: $\quad$ MZ360 Hourly Outputs

3. MZ320 Steady-state results are for the final hour of the one-year simulation

4. Annual totals are for the entire annual simulation. Similarly, annual means, maxima, and minima are those values that occur for the entire annual simulation.

5. Output terminology is defined in the output section of the specification for each case, where applicable

6. Format dates using the appropriate two-digit date followed by a three-letter month code and two-digit hour code (24-hour clock) as shown below.

\section{MONTH CODES:}

MONTH

JANUARY

FEBRUARY

MARCH

APRIL

MAY

JUNE

JULY

AUGUST

SEPTEMBER

OCTOBER

NOVEMBER

DECEMBER

\section{CODE}

Jan

Feb

Mar

Apr

May

Jun

Jul

Aug

Sep

Oct

Nov

Dec 
For example a maximum value occuring on August 16 during the 15th hour interval (2:00-3:00 p.m.), should be input as:

Date Hour

16-Aug 15 


\section{Appendix C. Abbreviations and Acronyms}

\begin{tabular}{|c|c|}
\hline $\begin{array}{l}\text { Abs: } \\
\text { ASHRAE: }\end{array}$ & $\begin{array}{l}\text { absorptance } \\
\text { American Society of Heating, Refrigerating and Air-Conditioning Engineers }\end{array}$ \\
\hline BESTEST: & Building Energy Simulation Test and Diagnostic Method \\
\hline $\begin{array}{l}\text { Coef: } \\
\text { Const: } \\
\text { COP: }\end{array}$ & $\begin{array}{l}\text { coefficient } \\
\text { constant } \\
\text { coefficient of performance }\end{array}$ \\
\hline $\begin{array}{l}\text { ECBCS: } \\
\text { Ext: }\end{array}$ & $\begin{array}{l}\text { Energy Conservation in Buildings and Community Systems Programme of IEA } \\
\text { exterior }\end{array}$ \\
\hline $\begin{array}{l}\mathrm{h}_{\text {int,combined }} \text { : } \\
\mathrm{h}_{\text {ent,combined }} \text { : }\end{array}$ & $\begin{array}{l}\text { combined convective and radiative interior surface coefficient } \\
\text { combined convective and radiative exterior surface coefficient }\end{array}$ \\
\hline $\mathrm{I}_{\mathrm{A}}:$ & $\begin{array}{l}\text { annual incident total solar radiation (sum of diffuse and direct) on west-facing surface of } \\
\text { Zone A for cases MZ340, MZ350, and MZ355, and on southwest-facing surface of Zone } \\
\text { A for Case MZ360 }\end{array}$ \\
\hline $\mathrm{I}_{\mathrm{bA}}:$ & $\begin{array}{l}\text { annual incident direct beam solar radiation on west-facing surface of Zone A for cases } \\
\text { MZ340, MZ350, and MZ355, and on southwest-facing surface of Zone A for Case } \\
\text { MZ360 }\end{array}$ \\
\hline $\mathrm{I}_{\mathrm{dA}}:$ & $\begin{array}{l}\text { annual incident diffuse solar radiation on west-facing surface of Zone A for cases } \\
\text { MZ340, MZ350, and MZ355, and on southwest-facing surface of Zone A for Case } \\
\text { MZ360 }\end{array}$ \\
\hline $\mathrm{I}_{\mathrm{tr}, \mathrm{x}}$ : & $\begin{array}{l}\text { annual transmitted total solar radiation (sum of diffuse and direct) through window } \\
\text { corresponding with subscripted zone }\end{array}$ \\
\hline $\mathrm{I}_{\mathrm{trb}, \mathrm{x}}:$ & $\begin{array}{l}\text { annual transmitted direct beam solar radiation through window corresponding with } \\
\text { subscripted zone }\end{array}$ \\
\hline $\mathrm{I}_{\text {trd, }, \mathrm{x}}:$ & $\begin{array}{l}\text { annual transmitted diffuse solar radiation through window corresponding with } \\
\text { subscripted zone }\end{array}$ \\
\hline $\mathrm{I}_{\text {trh, }, \mathrm{x}}:$ & $\begin{array}{l}\text { hourly transmitted total solar radiation (sum of diffuse and direct) through window } \\
\text { corresponding with subscripted zone }\end{array}$ \\
\hline $\mathrm{I}_{\mathrm{trbh}, \mathrm{x}}$ : & $\begin{array}{l}\text { hourly transmitted direct beam solar radiation through window corresponding with } \\
\text { subscripted zone }\end{array}$ \\
\hline $\mathrm{I}_{\text {trdh, } \mathrm{x}}$ : & $\begin{array}{l}\text { hourly transmitted diffuse solar radiation through window corresponding with } \\
\text { subscripted zone }\end{array}$ \\
\hline IEA: & International Energy Agency \\
\hline IEA 34/43: & IEA SHC Task 34/ECBCS Annex 43 \\
\hline Int: & interior \\
\hline I-P: & inch-pound \\
\hline MZ: & multi-zone \\
\hline NSRDB: & National Solar Radiation Data Base \\
\hline $\mathrm{q}_{\mathrm{x}}$ : & hourly or steady-state sensible cooling load of subscripted zone (W or $\mathrm{Wh} / \mathrm{h}$ ) \\
\hline $\mathrm{q}_{\max , \mathrm{bldg}}$ : & $\begin{array}{l}\text { annual hourly integrated maximum sensible cooling load for subscripted zone (W or } \\
\mathrm{Wh} / \mathrm{h} \text { ) }\end{array}$ \\
\hline $\mathrm{q}_{\mathrm{max}, \mathrm{x}}$ : & $\begin{array}{l}\text { annual hourly integrated maximum sensible cooling load for subscripted zone (W or } \\
\mathrm{Wh} / \mathrm{h} \text { ) }\end{array}$ \\
\hline & annual sensible cooling load for entire building $(\mathrm{kWh} / \mathrm{y})$ \\
\hline & annual sensible cooling load for subscripted zone $(\mathrm{kWh} / \mathrm{y})$ \\
\hline
\end{tabular}


SHC: $\quad$ Solar Heating and Cooling Programme of IEA

SI: Système Internationale

Surf: $\quad$ surface

$\mathrm{T}_{\mathrm{x}}$ :

$\mathrm{T}_{\max , \mathrm{x}}$ :

$\mathrm{T}_{\mathrm{O}}$ : air temperature of subscripted zone $\left({ }^{\circ} \mathrm{C}\right)$

TMY:

TMY2:

annual hourly integrated maximum air temperature of subscripted zone $\left({ }^{\circ} \mathrm{C}\right)$ ambient air temperature $\left({ }^{\circ} \mathrm{C}\right)$

Total air-air: total air-to-air conductance, including materials and interior and exterior combined surface coefficients

trans: $\quad$ transmittance

$\mathrm{U}: \quad$ unit thermal conductance $\left(\mathrm{W} /\left(\mathrm{m}^{2} \cdot \mathrm{K}\right)\right)$

WBAN: $\quad$ Weather Bureau Army Navy

$\alpha_{\text {ext }}: \quad$ exterior solar absorptance 


\section{Appendix D. Glossary}

[Note: This glossary highlights terms that are either already defined in ANSI/ASHRAE Standard 1402007 (ANSI/ASHRAE 2007), or may be included or revised in a later version of Standard 140. Italicized terms used within the glossary are also defined elsewhere within the glossary.]

Adiabatic is without loss or gain of heat; an adiabatic boundary does not allow heat to flow through it.

Analytical solution is the mathematical solution of a model that has an exact result for a given set of parameters and simplifying assumptions.

Annual hourly integrated maximum sensible cooling load is the hourly load that represents the maximum for the one-year simulation period.

Annual hourly integrated maximum air temperature is the hourly temperature that represents the maximum for the one-year simulation period.

Annual incident unshaded total solar radiation is the sum of direct solar radiation and diffuse solar radiation that strikes a given surface for the entire one-year simulation period when no shading is present; e.g., for hourly simulation programs this is the sum of the hourly total incident solar radiation for the oneyear simulation period.

Annual sensible cooling load is the sensible cooling load for the entire one-year simulation period; e.g., for hourly simulation programs this is the sum of the hourly sensible cooling loads for the one-year simulation period.

Annual transmitted total solar radiation is the sum of direct solar radiation and diffuse solar radiation that passes through a given window for the entire one-year simulation period. This quantity does not include radiation that is absorbed in the glass and conducted inward as heat. This quantity may be taken as the optically transmitted solar radiation through a window that is backed by a perfectly absorbing black cavity.

Combined surface coefficient is a constant of proportionality relating the rate of convective and radiative heat transfer at a surface to the temperature difference across the air film on that surface.

Diffuse solar radiation is the solar radiation received from the sun after its direction has been changed by scattering by the atmosphere or other objects on the ground.

Direct solar radiation is the solar radiation received from the sun without having been scattered by the atmosphere or other objects on the ground; this is also called beam or direct-beam radiation.

Dry-bulb temperature is the temperature a thermometer would measure.

Extinction coefficient is the proportionality constant $\mathrm{K}$ in Bouguer's Law $((d I)=(I \mathrm{~K} d x)$, where $I$ is the local intensity of solar radiation within a medium and $x$ is the distance the radiation travels through the medium.

Hourly sensible cooling load is the sensible cooling load for a given hour.

Hourly transmitted total solar radiation is the sum of direct solar radiation and diffuse solar radiation that passes through a given window for a given hour. 
Incidence angle is the angle defined by the intersection of a line normal to a surface and a ray that strikes that surface.

Index of refraction relates the angle of refraction $\left(x_{2}\right)$ to the angle of incidence $\left(x_{1}\right)$ at the surface interface of two media according to Snell's law $\left(n_{1} \sin \left(x_{1}\right)=n_{2} \sin \left(x_{2}\right)\right)$, where $n_{1}$ and $n_{2}$ are indices of refraction for each medium.

Infrared emittance is the ratio of the infrared spectrum radiant flux emitted by a body to that emitted by a blackbody at the same temperature under the same conditions.

Internal gains are heat gains generated inside the space or zone.

Mathematical truth standard is the standard of accuracy for predicting system behavior based on an analytical solution.

Sensible heat is the change in enthalpy associated with a change in dry-bulb temperature caused by the addition or removal of heat.

Solar absorptance is the ratio of the solar spectrum radiant flux absorbed by a body to that incident on it.

Zone air temperature is the temperature of just the zone air, not including infrared radiation from the interior surfaces; such a temperature would be measured by a sensor housed in a well-aspirated containment shielded by a material with a solar and infrared reflectance of one; well-mixed air is assumed. 


\section{Appendix E. Remarks About the Test Cases}

The following remarks relate to development of the test cases.

\section{MZ340}

To analyze the effects of shading on direct and diffuse solar, analysis of given hourly data in the delta context (MZ340-MZ350) for each zone should be sufficient. Especially per MZ340.TM2 for March 15, diffuse horizontal radiation is $5 \%-9 \%$ of direct beam radiation (beam is heavily dominant), and for October 14 direct normal radiation is $<1 \%$ of diffuse horizontal radiation (diffuse is heavily dominant). Therefore, adding more hourly outputs (e.g., hourly disaggregated shaded direct beam and diffuse for each zone of MZ350x) would not produce a much clearer diagnostic regarding analysis of direct versus diffuse shading.

\section{MZ350}

The current test specification allows testing multiple shading methods, if they are provided by the tested software, as follows:

"For modeling this case apply all shading-object models that the program being tested is capable of; associate the following possible modeling techniques with the following results designations:

MZ350a: shading device associated with Zone $\mathrm{C}$ window

MZ350b: shading device associated with Zone $\mathrm{C}$ exterior wall

MZ350c: shading device defined as separate shading object (e.g. a tree)

MZ350d: other (describe in your modeler report).

Do not provide results for above listed modeling techniques that the software being tested does not use.

If the software being tested includes more than four ways to describe a shading object, use an additional results spreadsheet and discuss additional modeling methods in your modeler report."

The analysis spreadsheet that resulted for this may be difficult to adapt for Standard 140, or may be difficult to adapt for automating tabulation and plotting new results. When this work is adapted for Standard 140, it may be worthwhile to revise the test specification and accompanying spreadsheets so a complete individual spreadsheet is submitted for each tested shading method.

\section{Output Requirements}

For Case MZ360 hourly results, we are looking at $\mathrm{qB}$ only because it is the center zone. If $\mathrm{qB}=(\mathrm{Itrh}, \mathrm{B}$ Itrh,C) and if Itr,A, Itr,B, and Itr,C are checked, it is not necessary to check qA and qC.

For cases MZ340 through MZ360, disaggregated annual incident and transmitted beam and diffuse solar radiation for each zone allows scaling of importance of beam versus diffuse shading in multi-zone context. Disaggregated incident beam and diffuse solar are useful if a program doesn't disaggregate transmitted beam and diffuse. 
It is necessary to compare only incident versus transmitted solar radiation (ideal window check) for Case MZ340. For MZ350 and MZ355, comparing transmitted solar through ideal windows is enough: a transmittance problem implies a shading/significance problem.

For cases MZ340 through MZ360, maximum zone temperatures are a basic controller check; for an ideal controller the programs should have $20^{\circ} \mathrm{C}\left(68^{\circ} \mathrm{F}\right)$ for hour 1 . 


\section{Appendix F. Using the Flow Diagrams to Diagnose the Results}

\section{F.1 General Description}

Figure F-1 is a flow diagram that serves as a guide for diagnosing the cause of disagreeing results that may arise from using this test. The flow diagram lists the features being tested, thus indicating potential sources of algorithmic differences, and may be used in two ways. The most powerful but time-consuming way is to perform all the cases, and then use the diagnostic logic in the flow diagrams to analyze the results. The least time-consuming way is to perform the tests in sequence according to the flow diagrams.

\section{F.2 Comparing Tested Software Results to Verified Numerical-Model Results and Example Simulation Results}

Analytical solution (Case MZ320 only) and example simulation results are presented in Part III. At a minimum, compare output with the analytical solution results. For cases without analytical solution results, compare output with the example simulation results, or with other results that were generated using this test procedure. Information about how the analytical solution was produced is included in Section 1.3.1.5. Information about how example simulation results were produced is included in the modeler reports of Section 2.9. For convenience to users who wish to plot or tabulate their results along with the analytical solution or example simulation results, or both, an electronic version of the example results has been included with the accompanying electronic files MZ-RESULTS-Annuals.XLS and MZRESULTS-Hourlies.XLS.

There are no formal criteria for when results agree or disagree; determination of the agreement or disagreement of results is left to the user. In making this determination, the user should consider that an analytical solution represents a mathematical truth standard based on acceptance of the underlying physical assumptions represented by the case specifications. The authors recognize that the underlying physical assumptions of the case definitions are a simplification of reality and may not fully represent real empirical behavior. As discussed in Section 1.2.2.1, in making a determination about the agreement of results, the user should also consider:

- Magnitude of results for individual cases

- Magnitude of difference in results between certain cases (e.g., "MZ350-MZ340")

- Same direction of sensitivity (positive or negative) for difference in results between certain cases (e.g., "MZ350-MZ340")

- If results are logically counterintuitive with respect to known or expected physical behavior

- Availability of a mathematical truth standard (analytical solution)

- Where a mathematical truth standard is provided, the degree of disagreement that occurred for other simulation results versus the mathematical truth standard

- Example simulation results do not represent a mathematical truth standard.

Check the program being tested for agreement with the absolute outputs and the sensitivity (or "delta") outputs. For example, when comparing to the example simulation results for Case "MZ350-MZ340" in Figure F-1, the program results are compared with both the Case MZ350 results and the Case MZ350MZ340 sensitivity results.

Compare all available output types specified for each case that can be produced by the program being tested. This includes appropriate zone cooling loads, transmitted solar radiation, peak-hour results, and supporting results presented in Part III, for all of that listed output the software being tested can produce. A disagreement with any one of the output types may be cause for concern. 
It is recommend to perform/analyze results of the tests in logical blocks as shown in the flow diagrams, or all at once for each series of cases. For cases MZ320 and MZ340, it is very important to have confidence in results of both before proceeding to the other cases. If output from the tested program agrees satisfactorily with the results for those cases, continue to check output for the remaining cases according to the flow diagram (Figure F-1). If output from the tested program disagrees with results for cases MZ320 and MZ340, check for input errors. If no input error is found, run all other test cases and follow the diagnostic logic accordingly, as this may help to isolate the source of the difference (especially with respect to Case MZ340) to one of the specifically tested parameters.

For other BESTEST suites, there are some cases where it is reasonable to proceed, even if disagreements were uncovered in the previous case. However, for these cases we recommend to obtain a satisfactory result for each case the software being tested can perform, as listed sequentially in Figure F-1, before proceeding to the next case.

\section{F.2.1 If Tested Software Results Disagree with Example Results}

For all test cases, if the tested program shows disagreement (as defined above) with an analytical solution or other example simulation results, recheck the inputs against the specified values. Use the diagnostic logic flow diagram to help isolate the source of the difference. If no input error can be found, look for an error in the software. If an error is found, fix it and rerun the tests. If in the engineering judgment of the user the disagreement is caused by a reasonable difference in algorithms between the tested software and the example results, continue with the next test case.

\section{F.2.2 Example}

A program shows disagreement with MZ360. Figure F-1 suggests the potential source of algorithmic differences includes modeling of internal windows, incident solar radiation, idealizations, or internal shading. If no input error can be found, recheck diagnostics A, B1, and B2. If the disagreement persists for A, it may be related to shading of an internal window. If there is no disagreement for B1 or B2, the difference may be related specifically to internal window modeling.

Section 2.4 gives examples of how the tests were used to trace and correct specific algorithmic and input errors in the programs used in the field trials.

\section{F.2.3 Note for Future Integration of Diagnostic Logic with Other Test Suites}

Because of idealizations in the test cases (see Section 2.5.1), these new multi-zone test cases have more diagnostic power for testing the modeling of some specific phenomena than the tests for some of these phenomena currently included in the building thermal fabric test cases of ANSI/ASHRAE Standard 1402007, Section 5.2 (ANSI/ASHRAE 2007). For future integration of these test cases with Standard 140, the Standard 140 diagnostic logic flow diagrams should be revised to indicate the new multi-zone tests as in-depth diagnostics, especially with respect to modeling thermal conduction (Case MZ320) and shading (cases MZ350 and MZ355). 
START

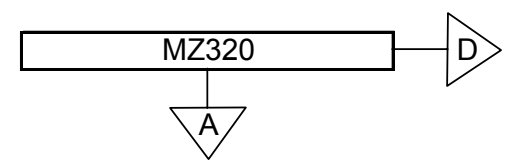

(Multi-Zone Shading Cases)

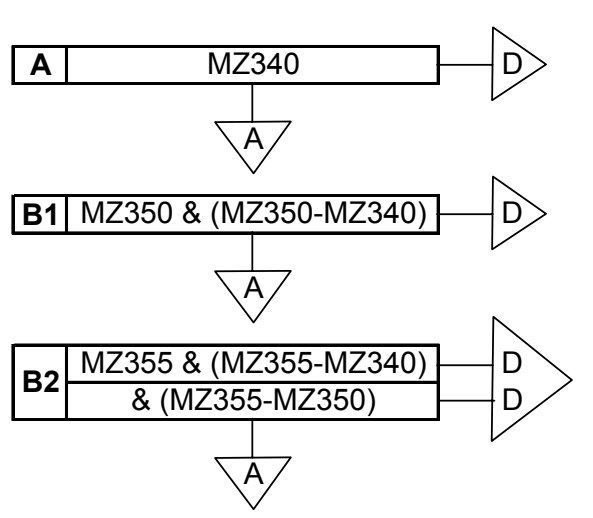

(Internal Windows Case)

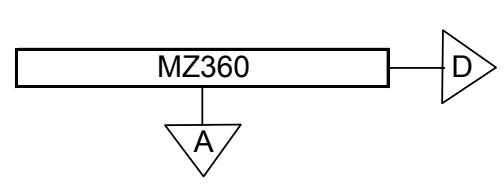

\section{Steady State Multi-Zone Conduction}

Analytical Verification

Iterative closure, solid conduction and/or internal gains

\section{Shading Test Base Case, Unshaded \\ Incident solar, idealizations (windows: \\ trans. $=1, U=0$; walls: abs, int. $=1, U=0$ )}

Shading device, incident solar, idealizations

Automated building self shading

END

\begin{tabular}{|c|}
\hline Internal windows \\
\hline Incident solar, idealizations \\
\hline Internal shading \\
\hline
\end{tabular}

\section{ABBREVIATIONS}

$A=$ Agree; $D=$ Disagree. For Case MZ320 agreement/disagreement is determined relative to analytical solution results. For the remaining cases agreement/disagreement is determined relative to example simulation results or other userprovided results for the case itself and for the listed sensitivity case(s).

Figure F-1. Multi-zone non-airflow in-depth diagnostic logic flow diagram 


\section{References for Part I}

ANSI/ASHRAE Standard 140-2007. Standard Method of Test for the Evaluation of Building Energy Analysis Computer Programs. (2007). Atlanta, Georgia, US: American Society of Heating, Refrigerating and Air-Conditioning Engineers.

ASHRAE, 2005 Handbook of Fundamentals, American Society of Heating, Refrigerating and AirConditioning Engineers, Atlanta, GA. Regarding conversion factors, see Chapter 38; regarding psychrometrics, see Chapter 6; regarding surface heat transfer coefficients, see Chapter 25.

Brandemuehl, M. (1993). HVAC 2 Toolkit. Atlanta, Georgia, US: American Society of Heating, Refrigerating, and Air-Conditioning Engineers. See pp. 7-15.

Judkoff, R.; Neymark, J. (1995). International Energy Agency Building Energy Simulation Test (BESTEST) and Diagnostic Method, NREL/TP-472-6231. Golden, Colorado, US: National Renewable Energy Laboratory. www.nrel.gov/docs/legosti/old/6231.pdf (PDF 13.8 MB)

Marion, W.; Urban, K. (1995). User's Manual for TMY2s. Golden, Colorado, US: National Renewable Energy Laboratory.

Walton, G. (1983). Thermal Analysis Research Program Reference Manual (TARP). NBSIR 83-2655. Washington, D.C., US: National Bureau of Standards. 


\section{Part II: Production of Simulation Results}

\subsection{Introduction}

In this section we describe how the working group members produced example results for several stateof-the-art whole-building energy simulation programs from Europe and North America. The objectives of developing the simulation results were to:

- Demonstrate the applicability and usefulness of the Building Energy Simulation Test Multi-Zone Non-Airflow In-Depth Diagnostic Cases: MZ320-MZ360.

- Improve the test procedure through field trials.

- Identify the range of disagreement that may be expected for simulation programs relative to each other (see Part III).

The field trial effort took about three years and involved revisions to the test specifications and subsequent re-execution of the computer simulations. The process was iterative in that executing the simulations led to the refinement of the test suite, and the results of the tests led to improving and debugging various models in the programs related to modeling multi-zone shading and internal windows. This process underscores the importance of IEA participation in this project; such extensive field trials, and resulting enhancements to the tests, were much more cost effective with the participation of the IEA$34 / 43$ experts.

Table 2-1 describes the models used to generate the simulation results. Appendix II (Section 2.9) presents reports written by the modelers for each simulation program. For three of the programs, final results were generated for Case MZ320 only, as noted in Table 2-1. For cases MZ340 through MZ360, the VA114 modelers provided results for two modeling approaches for shading and solar radiation transmission through windows: modeling circumsolar diffuse radiation as diffuse radiation, and modeling circumsolar diffuse radiation as beam radiation.

The tables and graphs in Part III present the final results from all the models used in this study.

Abbreviations and acronyms used in Sections 2.2 through 2.6 and in Part III are given in Section 2.7. References cited in Section 2.2 through 2.7 are given in Section 2.8.

\subsection{Selection of Simulation Programs and Modeling Rules for Simulations}

The countries participating in this IEA task made the initial selections of the simulation programs used in this study. The selection criteria required that:

- The program be a true simulation based on hourly weather data and calculative time increments of one hour or less.

- The program be representative of the state of the art in whole-building energy simulation as defined by the country making the selection.

The modeling rules were somewhat more stringent for the simulation programs used for Part III example results than for a given program to be normally tested with this BESTEST suite (see Section 1.2.1, Modeling Rules). For the Part III simulation results, we allowed a variety of modeling approaches. However, we required that these cases be modeled in the most detailed way possible for each simulation program. 
Table 2-1. Participating Organizations and Models

\begin{tabular}{|l|l|l||l||}
\hline $\begin{array}{l}\text { Simulation } \\
\text { Program }\end{array}$ & Authoring Organization & Implemented by & Abbreviation \\
\hline $\begin{array}{l}\text { EnergyPlus } \\
2.1 .0 .012\end{array}$ & $\begin{array}{l}\text { LBNL/UIUC/DOE-BT, }{ }^{\mathrm{a}, \mathrm{b}, \mathrm{c}} \text { United } \\
\text { States }\end{array}$ & $\begin{array}{l}\text { GARD Analytics, Inc., United } \\
\text { States }\end{array}$ & EnergyPlus/GARD \\
\hline ESP-r & ESRU, ${ }^{\mathrm{d}}$ United Kingdom & ESRU, ${ }^{\mathrm{d}}$ United Kingdom & ESP-r/ESRU \\
\hline HTB2 & WSA, ${ }^{\mathrm{e}}$ United Kingdom & WSA, ${ }^{\mathrm{e}}$ United Kingdom & HTB2/WSA \\
\hline TRNSYS-TUD & $\begin{array}{l}\text { University of Wisconsin/Dresden } \\
\text { University of Technology, United } \\
\text { States/Germany }\end{array}$ & $\begin{array}{l}\text { Dresden University of } \\
\text { Technology, Germany }\end{array}$ & TRNSYS-TUD/TUD \\
\hline TRNSYS-16 & $\begin{array}{l}\text { University of Wisconsin, United } \\
\text { States }\end{array}$ & University of Liège, Belgium & TRNSYS-16/ULg \\
\hline VA114 2.25 & $\begin{array}{l}\text { VABI Software BV, The } \\
\text { Netherlands }\end{array}$ & $\begin{array}{l}\text { VABI Software BV, The } \\
\text { Netherlands }\end{array}$ & VA114-CirBm/VABI \\
VA114-CirDf/VABI
\end{tabular}

aLBNL: Lawrence Berkeley National Laboratory, United States

bUIUC: University of Illinois Urbana/Champaign, United States

'DOE-BT: U.S. Department of Energy, Office of Building Technologies, Energy Efficiency and Renewable Energy, United States

${ }^{d}$ ESRU: Energy Systems Research Unit, University of Strathclyde, United Kingdom

'Welsh School of Architecture, Cardiff University, United Kingdom

fEcole des Mines de Paris, France

${ }^{g}$ IZUBA Energies, France

hINSA-Lyon Thermal Center, France

'Jean Noel, France

To minimize the potential for user error, we encouraged more than one modeler to develop input files for each program. Where only a single modeler was involved, we strongly recommended that another modeler familiar with the program check the inputs carefully.

Where improvements to simulation programs or simulation inputs were made as a result of running the tests, such improvements must have a mathematical and physical basis, and must be applied consistently across tests. In addition, all improvements were required to be documented in modeler reports. Arbitrary modification of a simulation program's input or internal code just for the purpose of more closely matching a given set of results is not allowed. The diagnostic process of trapping bugs discussed in Section 2.4 also isolated input errors that were corrected, as noted there and in the modeler reports (Section 2.9). 


\subsection{Improvements to the Test Specification as a Result of the Field Trials}

Based on comments by the IEA-34/43 participants during the field trials, we made a number of improvements and revisions to the test specification. Although researching the comments and communicating specification revisions to the field trial participants was very time-consuming, the importance of the accuracy and clarity of the test specification for this type of work cannot be overstated.

The contribution of the IEA-34/43 participating countries was particularly valuable because the project experts supplied continuous feedback throughout the four-year field trial effort. Their feedback resulted in several revisions to the test specifications and subsequent re-execution of the computer simulations. This iterative process led to refinement of the test cases, and the results of the tests led to the improvement and debugging of the programs. The process underscores the leveraging of resources for the IEA countries participating in this project. Such extensive field trials, and resulting enhancements to the tests, would not have occurred without the participation of the IEA-34/43 experts.

\subsubsection{Revisions to Initial Draft Test Specification (March 2004 - May 2004)}

The initial draft of these in-depth diagnostic test cases was issued in March 2004 for comments; simulation by the participants was optional at this stage. The test specification included an initial set of four multi-zone conduction test cases, which included two 2-zone and two 3-zone cases where infrared radiation exchange was disabled (ideal version) or enabled. The ideal versions of these test cases also provided a configuration basis for the airflow test cases being developed by Utsumi and Mitamura (2008). One participant ran the conduction test cases and several participants provided comments. A revised version of the test specification was then distributed in May 2004 that included the following changes based on participants' comments:

- Added surface temperature outputs for cases with interior infrared radiation exchange enabled (all interior surfaces)

- Revised artificial/dummy weather data with many data elements set to 0 or approximate lower limits, and other data elements set to neutral (non-extreme) constant values as noted in the test specification

- Dual units employed (I-P units calculated from original SI units)

- Editorial revisions.

\subsubsection{Second Round of Revisions (May 2004-February 2005)}

Observations about the initial results based on simulations of the May 2004 version of the test specification indicated the following issues:

- For all cases, require use of constant combined surface heat transfer coefficients as if infrared radiation exchange were on, using typical values of ASHRAE, CIBSE, CEN, etc.

- Do not continue to pursue cases that test infrared radiation because they distract from the objective to address modeling issues that are specific to multi-zone cases (accounting, convergence, etc.); participants may be interested in returning to cases that enable radiative exchange calculations.

- Continue to develop additional test cases beginning with a three-zone configuration with separate analytically solvable cases for the center zone floating, and for two neighboring zones (center and an outer zone) floating. 
- Incrementally include (from initial steady state with conditions around the building clearly defined) varying internal gains and weather, transmitted solar radiation, internal window, and shading of neighboring zone by external fin and by the building.

- Final test case (for later work cycle) may be to develop a 27-zone building that includes dynamic loading, shading, etc.

We may also develop additional test cases to address the question: If single-zone results are satisfactory, can we extrapolate that multi-zone results will be satisfactory? To answer this question, consider developing cases that compare disagreement among simulation results for single-zone cases versus comparable multi-zone cases.

Based on these issues, other participant comments, further consideration by the lead authors, and planned test cases, the following revisions were made for the February 2005 version of the test specification:

- Case MZ320 was added, replacing previous cases MZ200 and MZ300; this was done because Case MZ320 represents an analytically solvable multi-zone conduction case that is potentially more difficult for simulations to solve iteratively than MZ300 and MZ200.

- Other notable changes for Case MZ320 are:

- Exterior walls are non-adiabatic.

- The floor is suspended above the ground such that its exterior surface interacts with outside air at ambient conditions (similar to other exterior surfaces).

- Constant combined convective and radiative surface coefficients replace constant convective-only coefficients (radiation exchange was previously disabled); this enables calculation of an analytical solution assuming one-dimensional conduction, which facilitates isolation of disagreements related specifically to multi-zone modeling while using a more realistic constant surface coefficient assumption. (Surface heat transfer models are tested in the single-zone context in IEA BESTEST [Judkoff and Neymark 1995].)

- Values for density and specific heat of zone air were included in the test specification.

- MZ320.TM2 artificial weather data were updated to have constant wind speed consistent with the constant exterior surface coefficient.

- $\quad$ The MZ320 analytical solution was left out, to keep first round blind.

- Cases MZ210 and MZ310 (radiation exchange enabled) were deleted.

- Cases MZ340, MZ350 and MZ355 were added for testing multi-zone shading models.

- $\quad$ Case MZ360 was added for testing internal window models.

- $\quad$ MZ340.TM2 artificial weather data were added for cases MZ340 through MZ360.

- The output results spreadsheet was revised to include outputs for cases MZ340 through MZ360; this spreadsheet file was named "MZ-Output022205.xls."

- Sections on "Modeling Rules" and "Comparing Your Output to the Analytical Solution and Example Results" were added, for consistency with Standard 140-2004.

\subsubsection{Third Round of Revisions (February 2005-August 2005)}

Observations about the second iteration of results, based on simulations of the February 2005 version of the test specification were:

- Shading models for both direct beam and diffuse radiation are working in multi-zone context.

- The shading models cause increased range of results disagreements versus unshaded solar results, and disagreement for "back side" of fin shading was unexpectedly large; diagnostics may be improved by specifying a larger fin, requiring outputs of disaggregated beam and diffuse solar radiation, and additional hourly results comparisons. 
- Include stronger language to require participants to test all shading methods their programs are capable of.

- Consider directly providing disaggregated incident beam and diffuse as an input (four of the programs that participated in the field trials can use such data for direct inputs - but this won't work for a general test if other programs must use solar data directly from weather data files).

- For the internal window cases, trend agreement between results for ESP-r and TRNSYS-TUD is encouraging, but additional diagnostic outputs are needed (similar for shading cases); also, some output specification clarifications are needed.

- Zone $\mathrm{C}$ would have more signal (transmitted solar radiation) if Zone $\mathrm{B}$ were less deep.

- Some minor non-substantive clarifications for Case MZ320 were recommended.

- Add note that if software does not allow very low relative humidity, adjust weather data or other input to use lowest value allowed.

- Incorporate various errata from February and March 2005 into the test specification.

Additional test cases were suggested, including:

- Develop a two-zone (one internal-window) version of the internal window case.

○ Incrementally include realistic windows and realistic walls in the 2-zone context.

- Keep the three-zone context as ideal only.

- Considering enabling and testing infrared radiation exchange in the pure-conduction test (Case MZ320) context by comparing relative disagreement for a set of multi-zone case results versus a similarly excited single zone case.

Based on the observations and recommendations from field trials of the February 2005 version of the test specification, the following revisions were made for the test specification version dated August 2005:

- Increased zone height in Case MZ340 to $4 \mathrm{~m}$ for greater variation of shading effects among the windows in cases MZ350 and MZ355

- Increased shading object height to $18 \mathrm{~m}$ for cases MZ350 and MZ355, for more robust shading

- Included clarification that both sides of the fin of Case MZ350 are actively shading the building

- Included reminder for participants to use the most detailed shading method their model allows - for developing example results; a note was also added to delete this statement for the final version of the test specification (as others may want to test simplified models as well as detailed models)

- Clarified for Case MZ355 that modelers are to run the case only if their programs can apply automated building self-shading

- Clarified Case MZ355 Zone G mechanical system and set points (same as for other zones), and that Zone $\mathrm{G}$ common walls do not include a window

- For Case MZ360, clarified that for required outputs transmitted solar radiation through each window is NOT the net solar transmission for the zone (does not include solar radiation transmitted to a neighboring zone)

- Included the following additional diagnostic outputs for MZ340, MZ350, MZ355, and MZ360:

$\circ$ Disaggregated annual incident direct beam and diffuse solar radiation on the west-facing surface of Zone A for Case MZ340, and on the southwest-facing surface for Case MZ360

- Disaggregated annual transmitted direct beam and diffuse solar radiation through each window for cases MZ340 through MZ360

- Added daily hourly transmitted total, direct beam, and diffuse solar radiation for August 4 (high dn after 18:00) for Case MZ340 
- Added daily hourly transmitted total solar radiation for Case MZ350 zones C and F for August 4 and October 14, to check back side of fin shading of direct and diffuse solar radiation

- Revised daily hourly cooling load for Zone A for only March 15 for Case MZ340; need to check versus transmitted total solar for one day only

- Updates included to output spreadsheet in "MZ-Output082205.xls."

- For all cases:

- Geometry convention revised to vary, based on the varying objectives of the test cases

$\circ \quad$ Clarified ground reflectance $=0$ for all test cases; this was the original (but unstated) intent

- Added statement that "if the program being tested does not allow a very low value for relative humidity, adjust the input weather data (or other software input) to use the lowest relative humidity allowed by the software."

- Incorporated other changes from February and March 2005 errata communications, and from comments received at the Spring 2005 experts meeting, in the modeler reports, and elsewhere

- Editorial revisions.

We decided to set aside the idea of directly providing incident radiation data as an input (with disaggregation of beam and diffuse). Shading effects are already demonstrated by differences between shaded (MZ35x) versus unshaded (MZ340) configurations for both annual summary results and selected hourly results for high beam (March 15) and high diffuse (October 14) days. Also, some computer programs may not be able to easily use these data as input.

\subsubsection{Fourth Round of Revisions (August 2005-August 2006)}

Field trials of the August 2005 test specification engendered further comments as noted:

- Shading disagreements are difficult to diagnose with BESTEST 1995, because those single-zone cases have large ranges of disagreement:

- 610-600 [south overhang] (Max-Min)/Mean = 1/1.8; see Figure 2-1

○ 630-620 [east/west fin and overhang] (Max-Min)/Mean = 0.9/1.5; see Figure 2-2.

- To refine hourly shading diagnostics, the MZ350 shading fin dimensions may be increased to $24 \mathrm{~m}$ height and $15 \mathrm{~m}$ width, based on analysis by one of the participants, using an ESP-r shading visualization tool; this change to be checked with further analysis by the project leader.

- Participants suggested developing a case to test the proper modeling of multiple shading projections on a shaded area; however, they agreed that completing the current set of internal window cases should be a higher priority.

- Include an option in the three-zone (two internal windows) internal-window case so simulation tools that cannot model two internal windows in series can run the test case. This can be accomplished by specifying an option to change window BC into an optically black, zeroconductance ideal surface and then comparing the cooling load in Zone B (of the two-zone model) to the combined cooling load of Zone $\mathrm{B}+$ Zone $\mathrm{C}$ in the three-zone model.

- Reduce the Zone B depth so that more solar radiation can be transmitted to Zone C.

- For internal window cases include the effect of realistic walls (reflectance about 0.5 [realistic] or 0.9 [ideal]) in a separate case; ideal reflectance may provide a more robust test.

- A case for realistic windows would be a lower priority because the amount of effort to specify realistic windows is large relative to what may be learned with respect to diagnosing internal reflections versus easier-to-specify realistic internal walls; however, because some windows have substantial reflectance, such a case should be included if possible. 


\section{SOUTH WINDOW SHADING (DELTA) ANNUAL HEATING AND SENSIBLE COOLING}

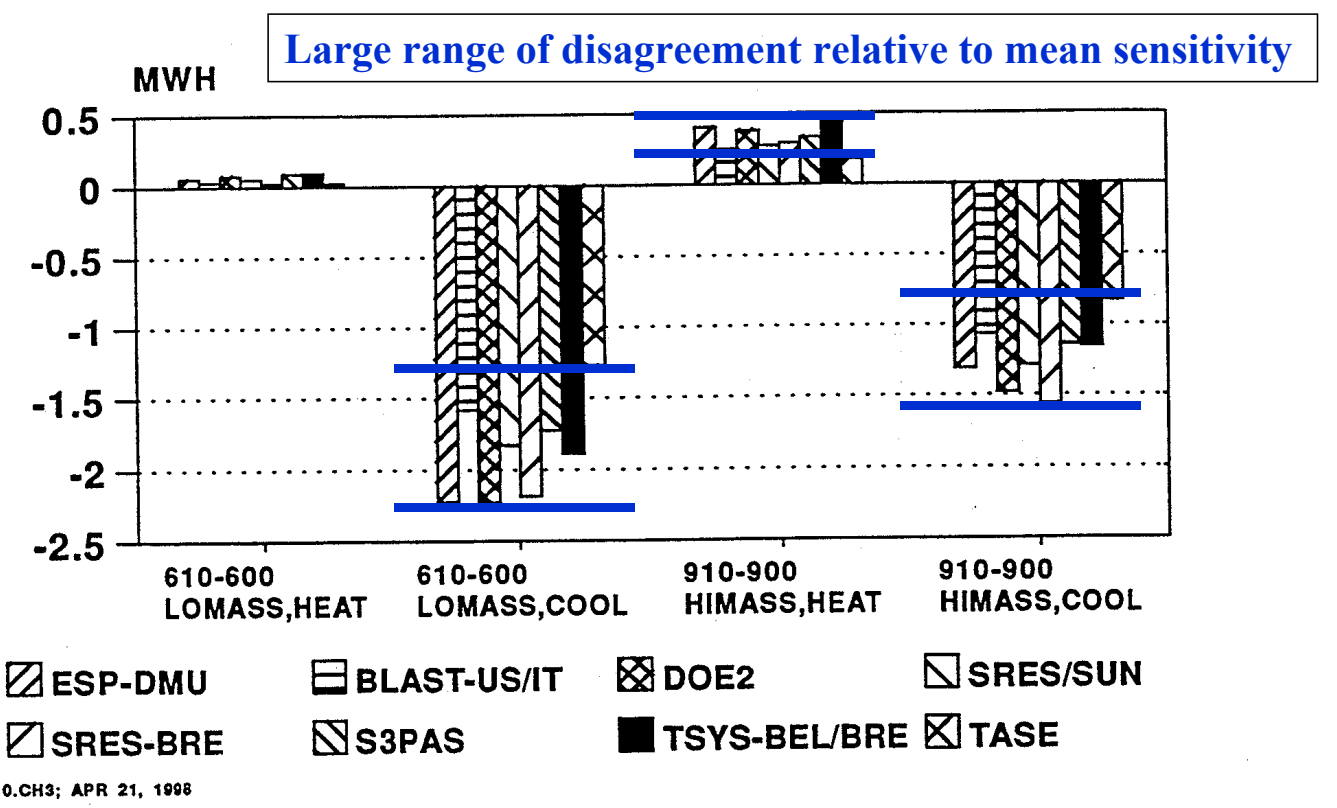

Figure 2-1. South overhang shading disagreements from IEA BESTEST (Judkoff and Neymark 1995)

\section{EAST \& WEST SHADED WINDOW (DELTA) ANNUAL HEATING AND SENSIBLE COOLING}

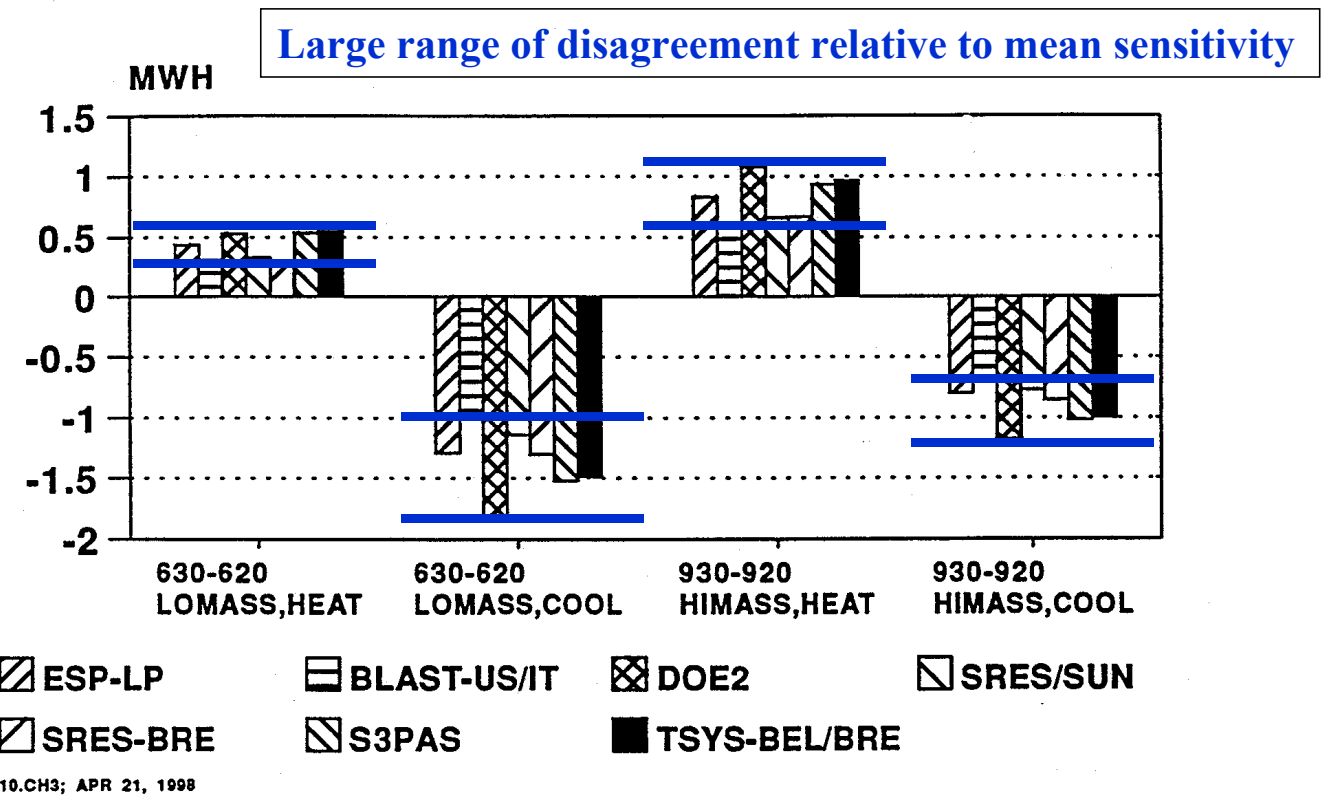

Figure 2-2. East/west overhang and fin shading disagreements from IEA BESTEST (Judkoff and Neymark 1995) 
Revisions incorporated in the August 2006 (substantively final) version, resulting from these comments, are listed below:

- Geometry revisions for cases MZ340, MZ350, and MZ355 for improved shading diagnostics; the following revisions, based on sensitivity tests using EnergyPlus run by NREL, resulted in more beam shaded hours for Zone A on March 15:

$\circ$ Increased zone height to $5 \mathrm{~m}$ and increased window size to $4 \mathrm{~m} \times 4 \mathrm{~m}$ for Case MZ340

$\circ$ Increased shading object size to $24 \mathrm{~m} \times 24 \mathrm{~m}$ for cases MZ350 and MZ355

- For Case MZ360

- Depth of Zone B reduced

- Alternative two-zone modeling specification provided

- Included analytical solution for Case MZ320

- Added clauses from ANSI/ASHRAE Standard 140-2004, Addendum $b$ (ANSI/ASHRAE 2004a) regarding

- Equivalent modeling methods (ANSI/ASHRAE 2007, Section 5.1.5)

- To include input files with final results (ANSI/ASHRAE 2007, Section 4.3.2)

- Explaining test case results omissions (ANSI/ASHRAE 2007, Section 4.3.1)

- Changes to software must have a logical basis (revisions to previous language)

(ANSI/ASHRAE 2007, Section 4.4.3)

- Editorial revisions.

It was not possible to develop additional test cases because of temporary funding cuts during this project cycle.

\subsubsection{Fifth Round of Revisions (non-substantive changes after August 2006)}

Additional minor clarifications were made for the final published version of the user's manual, including:

- Typical users are to apply consistent modeling methods; the IEA-34/43 field trial participants applied the most detailed modeling methods their program allowed.

- Deleted references to the modeler report template that was used by the IEA-34/43 participants only (which is consistent with the HVAC BESTEST final reports) and replaced that with instructions of Section 1.2.1.10. To adapt this test suite for Standard 140, the Standard-140 modeler reports will apply.

- For convenience to future users we added the following appendices:

- Appendix B, "Output Spreadsheet Instructions"

- Appendix C, "Abbreviations and Acronyms" (includes editing of symbols for consistency)

○ Appendix D, "Glossary"

- Appendix E, "Remarks about the Test Cases"; this consolidates informational remarks previously included with each case into one section

- Appendix F, Using the Flow Diagrams to Diagnose the Results.

- Editorial revisions

$\bigcirc$ Section, table, and figure numbering

○ Remove extraneous notes from MZ-Output082205.xls and renamed it as MZ-Output0308.xls

- Further minor revisions to MZ-Output-0308.xls and renamed it as MZ-Output.xls for the final revision

○ Etc. 


\subsection{Examples of Error Trapping with BESTEST Diagnostics}

This section summarizes examples that demonstrate how the IEA BESTEST in-depth diagnostic cases for multi-zone non-airflow modeling were used to isolate and correct bugs in the simulation programs used for the field trials of the test specification. Further description may be found in the individual modeler reports presented in Appendix II (see Section 2.9).

Simulations were performed for each test case with the participating computer programs. At each stage of the exercise, output data from the simulations were compared to each other, and to the Case MZ320 analytical solution, according to the diagnostic logic of the test cases. The test diagnostics revealed (and led to the correction of) bugs, faulty algorithms, input errors, or some combination of those in all models, except for one of the models that was applied for Case MZ320 only. In the following examples improvements to the models that were used for field trials of all the test cases (i.e. EnergyPlus, ESP-r, HTB2, TRNSYS-TUD, TRNSYS-16, and VA114) are presented first in sections 2.4.1 to 2.4.6. Improvements identified for models for Case MZ320 that did not run the other cases in their final form (i.e., CODYRUN and COMFIE) follow in sections 2.4.7 and 2.4.8. KoZiBu ran only Case MZ320 and did not report any changes to their model as a result of running the test case.

\subsubsection{EnergyPlus}

EnergyPlus (2008) is developed and maintained by the U. S. Department of Energy (DOE), and is the department's next-generation building energy simulation program. Table 2-2 describes field trial iterations by GARD Analytics (GARD) for this project. Input file and software modifications for each iteration are also shown. A single results set was submitted corresponding to changes described in each row of the table.

Table 2-2 Summary of EnergyPlus Changes that Were Implemented

\begin{tabular}{|l|l|l|}
\hline Version & Code Changes & Input File Changes \\
\hline $\begin{array}{l}1.2 .2 .023 \\
(\text { March 2005) }\end{array}$ & Initially tested version for IEA-34/43 in-depth cases & Initial IEA-34/43 input files \\
\hline $\begin{array}{l}1.2 .2 .039 \\
(\text { September 2005) }\end{array}$ & $\begin{array}{l}\text { Updated version, no changes related to this } \\
\text { testing }\end{array}$ & $\begin{array}{l}\text { Incorporate August 2005 } \\
\text { test specification updates }\end{array}$ \\
\hline $\begin{array}{l}1.4 .0 .016 \\
(\text { September 2006) }\end{array}$ & Updated version, no changes related to this testing & $\begin{array}{l}\text { Incorporate August 2006 } \\
\text { test specification updates }\end{array}$ \\
\hline $\begin{array}{l}2.1 .0 .012 \\
\text { (October 2007) }\end{array}$ & $\begin{array}{l}\text { Modeling of diffuse solar transmitted through } \\
\text { exterior and interior windows improved to better } \\
\text { account for initial absorption, transmittance and } \\
\text { reflection of short-wave radiation }\end{array}$ & \\
\hline
\end{tabular}

\subsubsection{Unintended lost diffuse solar radiation; 33\% increase in cooling load for Case MZ360 and 4\% increase in cooling load for cases MZ340 through MZ355}

Before EnergyPlus 2.1.0.012, the diffuse radiation transmitted through an exterior window (e.g. Window AO in Case MZ360) was evenly distributed to all surfaces within the zone, including the inside of the exterior window. For version 2.1.0.012 the method for modeling transmitted diffuse solar radiation was reworked to first be incident all interior surfaces except the inside surface of the exterior window. Figure 2-3 shows the effect on results before and after the fix, indicating a 33\% increase in Case MZ360 total building annual cooling load after the fix. This fix also increased cooling loads for cases MZ340, MZ350, and MZ355 by $4 \%$. 


\subsubsection{No beam radiation to Zone $C$ of Case MZ360; likely increase for Zone $C$ cooling load of $240 \%$ and overall building cooling load of $6 \%$}

Results for Zone C in Figure 2-3 also indicate that after the described fix, Zone C cooling load may be low. The EnergyPlus modeler report (see Section 2.9, Appendix II-A) indicates that EnergyPlus allows transmission of diffuse radiation only (no direct beam radiation) through a second-in-series internal window (Window BC). Comparison with results for programs that allow transmission of direct beam radiation through Window BC (ESP-r and VA114) indicate that including transmission of direct beam radiation would increase the Zone $\mathrm{C}$ cooling load by a factor of 2 to almost 3 (factor of 2.4 average estimate). This could cause about $6 \%$ underestimation of total building cooling load, assuming half the beam radiation modeled as diffuse is lost back through Window AO. The TRNSYS-TUD and TRNSYS16 models also exclude transmission of beam radiation, and have Zone $\mathrm{C}$ results similar to the EnergyPlus results. Disaggregated transmitted direct and diffuse solar radiation results for Case MZ360 are included in Part III. As double-skin facades become more popular in buildings (e.g., see Poirazis 2007), more accurate modeling of solar radiation through a series of internal windows gains importance. The EnergyPlus developers have been notified of this issue, and they are looking at their diffuse solar modeling algorithms.

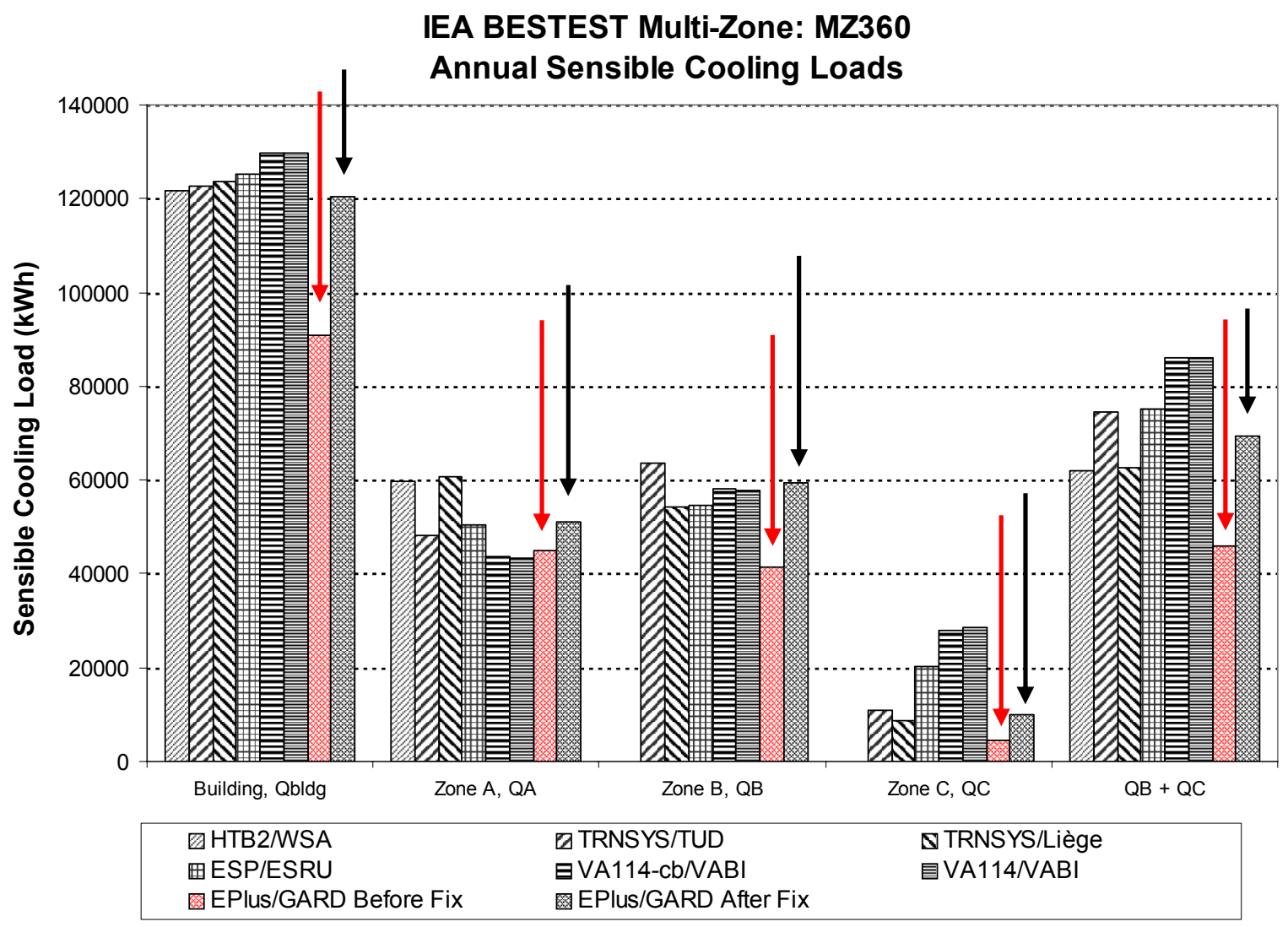

Figure 2-3. EnergyPlus annual cooling loads before and after fix of unintended solar lost error 
2.4.1.3 Documentation unclear to modeler regarding if MZ360 Zone B transmitted solar is gross or net (after some diffuse transmitted through to Zone $C$ ); no effect on cooling load, limits diagnosis of results

The EnergyPlus team is developing outputs for interior window transmitted diffuse solar radiation, which tracks such transmitted solar radiation as specified by the test cases.

\subsubsection{Check October 17 hourly shaded solar; minor difference worth noting}

Hourly results for shaded solar radiation (MZ340-MZ350 difference) shown in Figures 2-4 and 2-5 indicate possible disagreement for Zone B (front side of fin shading) for hours 17 and 18, and for Zone C (back side of fin shading) for hours 15 and 17. The EnergyPlus developers have been notified of this issue, and they are looking at their diffuse solar modeling and shading algorithms.

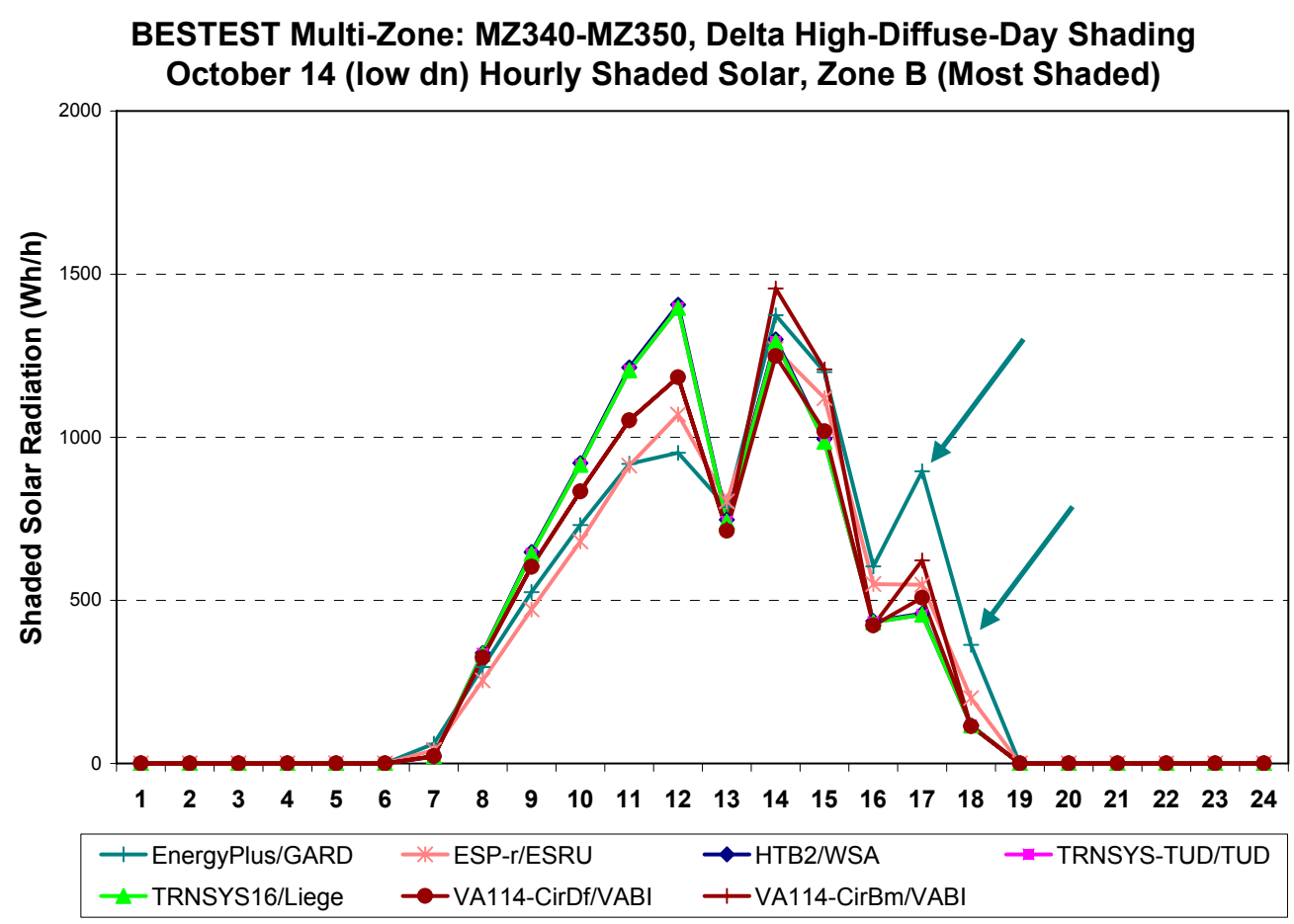

Figure 2-4. Hourly shaded total solar radiation for high diffuse day, Zone B 


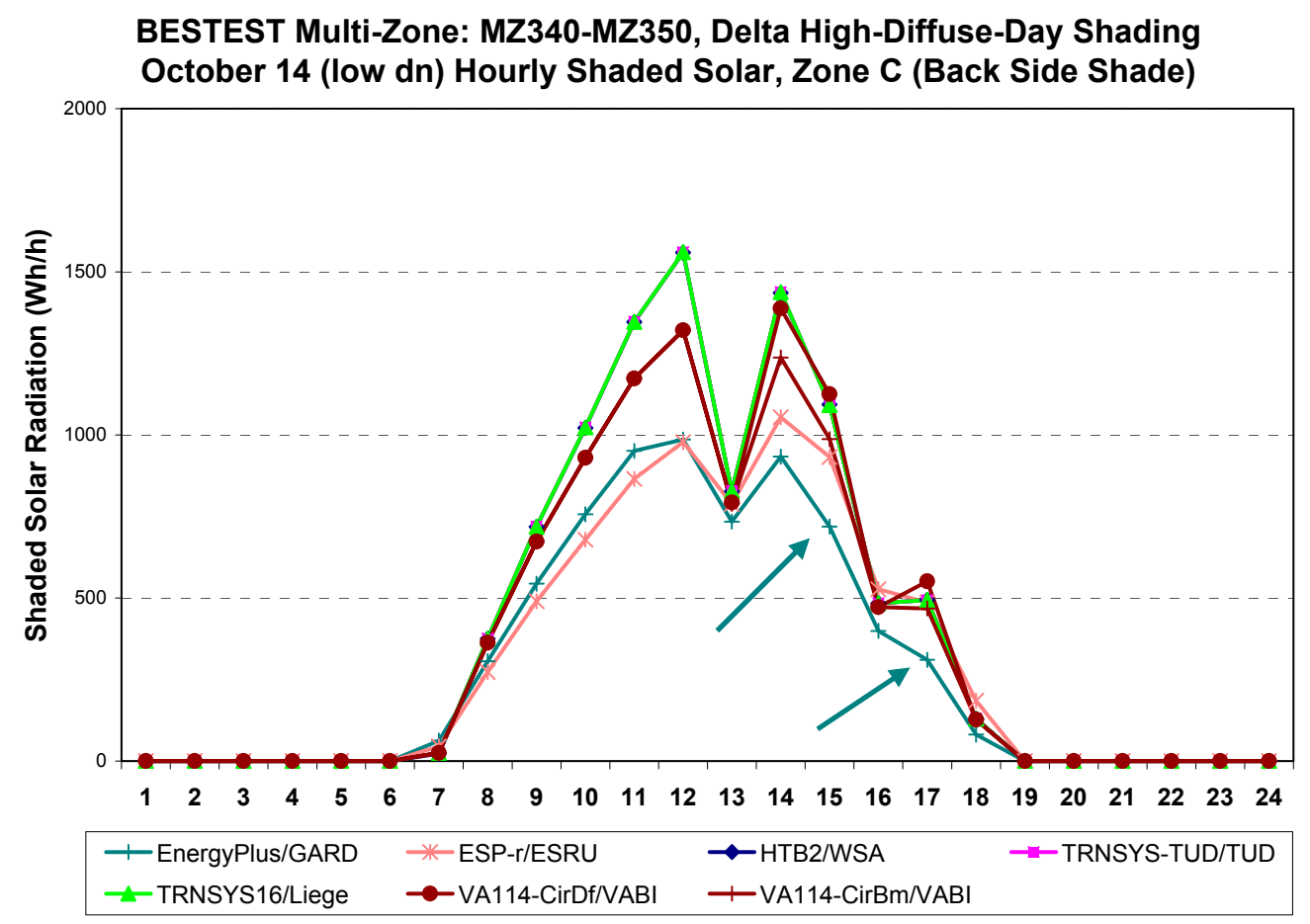

Figure 2-5. Hourly shaded total solar radiation for high diffuse Day, Zone C

\subsubsection{ESP-r}

ESP-r (ESRU 2008) is developed by the Energy Systems Research Unit, University of Strathclyde, Scotland, UK. Modeling details are described in ESRU's modeler report; see Section 2.9, Appendix II-B.

\subsubsection{Interprets half-hour hour centered solar data as hour-centered; $12 \%$ cooling load effect for MZ340}

Figure 2-6 indicates a timing offset for solar radiation for ESP-r results submitted in December 2005, for initial simulations of the final fin and window design for cases MZ340 and MZ350. The source of the disagreement was diagnosed to be that ESP-r assumes solar data are hour-centered, whereas TMY2 data are preceding-hour (e.g. 00:00-01:00) half-hour centered data. A software modification was made to allow halfhour centered solar data. Comparison in Figure 2-7 for ESP-r results submitted December 2005

("ESP/ESRU-Dec2005") and September 2006 ("ESP/ESRU-Sep2006")—see red arrow—indicates a 12\% decrease in Case MZ340 (unshaded) cooling load results from the improvement. 


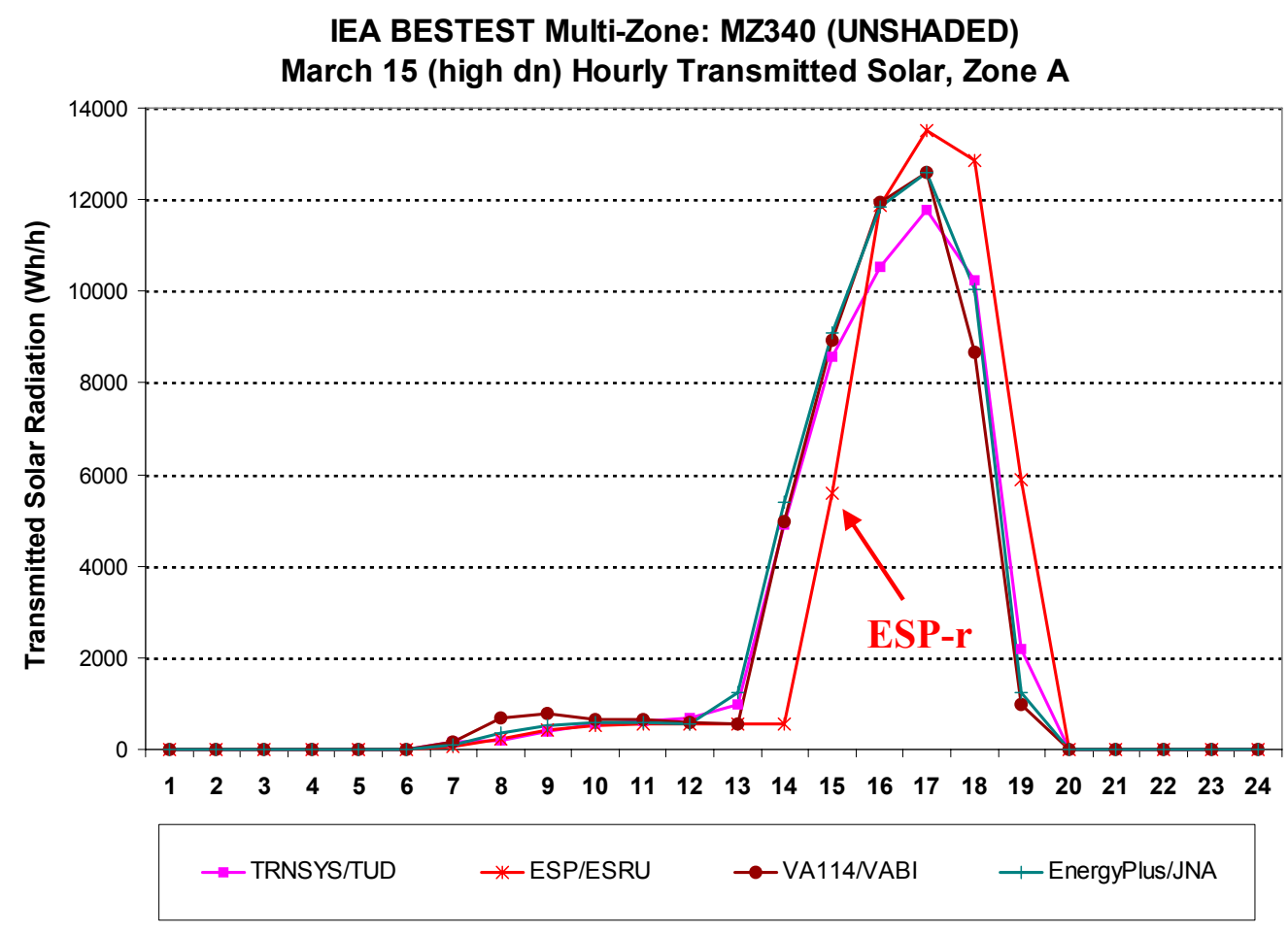

Figure 2-6. ESP-r hourly solar offset disagreement from December 2005

\subsubsection{No diffuse shading; $19 \%-35 \%$ effect on cooling load}

Figure 2-7 also indicates that after the above fix, which results in good agreement for Case MZ340, ESP-r has mostly increased disagreements (error described in Section 2.4.2.1 was somewhat compensating) for shaded solar radiation for all zones in sensitivity Case MZ340-MZ350 (see "ESP/ESRU-Sep2006" results marked with black arrows). Furthermore, hourly results shown in Figure 2-8 indicate no shading occurs on a day dominated by diffuse solar radiation. Based on these results, a major enhancement was made to ESP-r to add diffuse shading based on the daylight coefficient method documented in Section 4 of the ESP-r modeler report (see Appendix II-B).

Results for after implementation of the new shading method are shown in Figure 2-7 (see results labeled "ESP/ESRU-Mar2007," patterned bar just to right of arrows). These results indicate a small decrease (around 2\%) in annual solar load for Case MZ340 (unshaded), for sensitivity Case MZ340-MZ350 an 82\% to $87 \%$ increase in the amount of shaded solar radiation for zones where the front (south) side of the fin dominates shading and about a $230 \%$ increase to shaded solar radiation for zones where the back (north) side of the fin (diffuse shading) dominates shading. This translates to a $19 \%-35 \%$ reduction in Case MZ350 cooling load, depending on the position of the shading fin with respect to a given zone. 


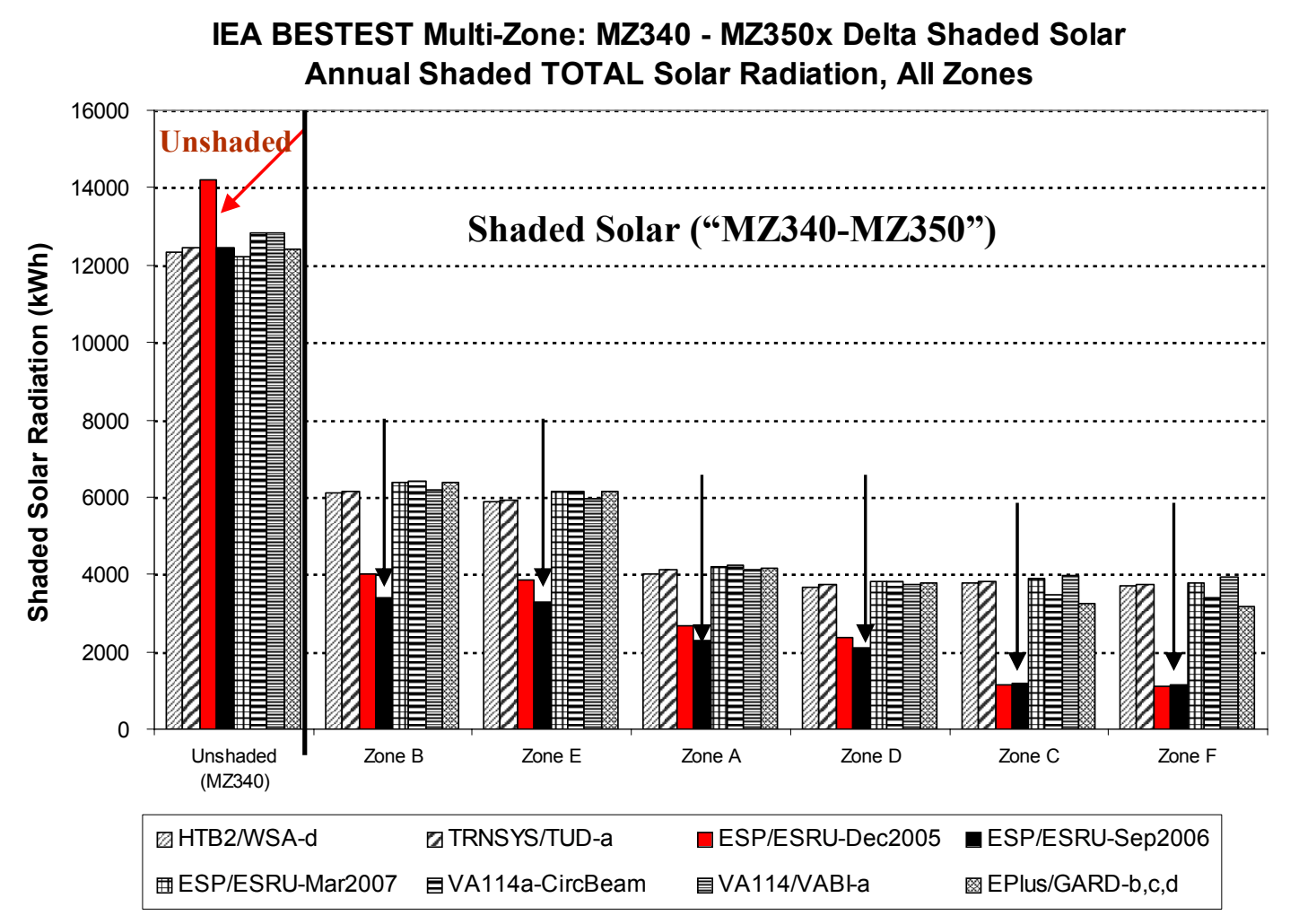

Figure 2-7. ESP-r total solar radiation, from Dec. 2005, Sep. 2006, and March 2007

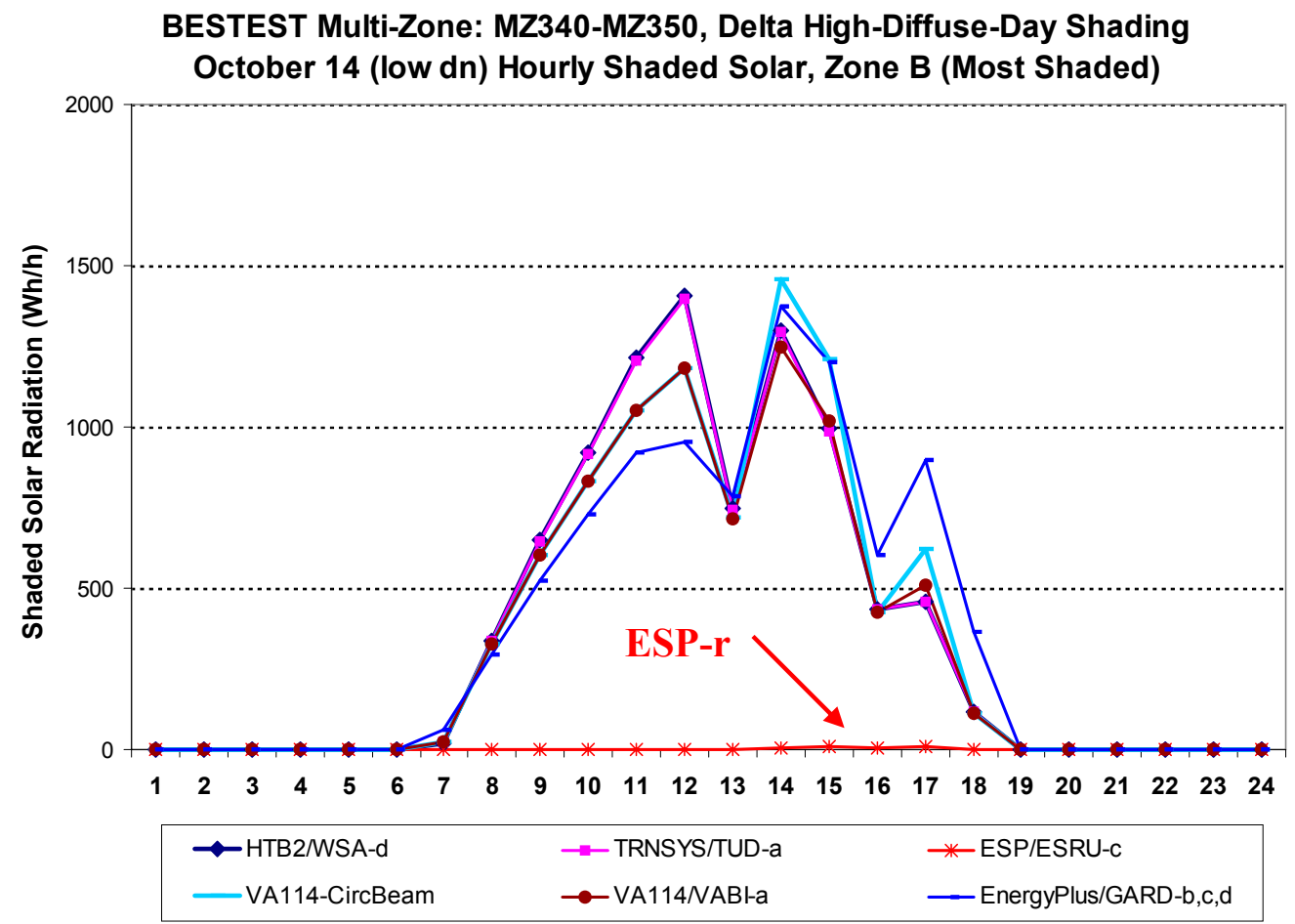

Figure 2-8. Hourly results indicating no shaded solar radiation by ESP-r for a diffuse solardominated day, from September 2006 


\subsubsection{Custom weather processor}

Also for results submitted in September 2006, a disagreement was found (see Figure 2-9). This led to discovery in the climate file for March 15, hours 13:00 and 14:00, the values in the weather file for direct normal radiation were 1006 and $1000 \mathrm{~W} / \mathrm{m}^{2}$ respectively, but were incorrectly set as 6 and $0 \mathrm{~W} / \mathrm{m}^{2}$. These were the only two hours in the year where the direct normal reached $1000 \mathrm{~W} / \mathrm{m}^{2}$. At some stage in the conversion from the original TMY2 climate format, an error was made in the formatting. The ESP-r modeler considers this to be more of a modeler error than an error in ESP-r, as a TMY2 processor was custom written for this project. (For typical TMY2 files ESP-r normally uses EPW [EnergyPlus processed] data files.) The modeler did not provide separate results for this fix. The overall impact of the fix is masked by changes in solar modeling for diffuse shading (see Section 2.4.2.2), but this error would not be present for weather data typically used by ESP-r. However, identification of this relatively minor problem further underscores the power of the diagnostics.

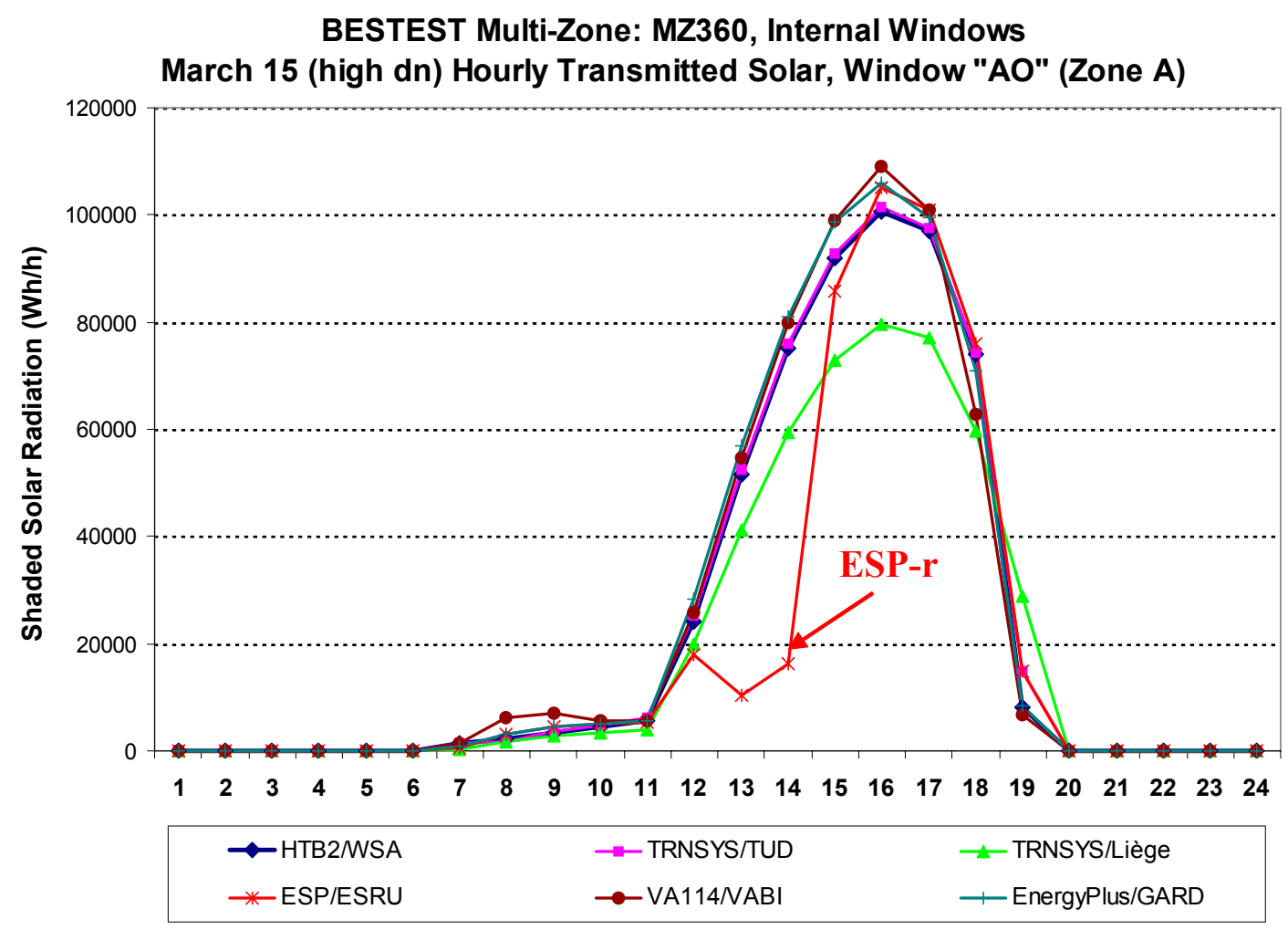

Figure 2-9. Results from March 2007 including ESP-r with new solar shading algorithm

\subsubsection{No disaggregation of direct and diffuse solar in output}

For results submitted in March 2007, ESP-r did not disaggregate direct and diffuse solar radiation from total solar radiation in its output. The ESP-r developers agreed that disaggregating solar radiation in the output is a useful diagnostic feature, and included that capability in their software for generating results submitted in July 2007. 

MZ350, zones B and E; $<2 \%$ annual cooling load effect cases MZ340, MZ350, all zones

For results submitted in March 2007, ESP-r also exhibited some disagreement for MZ350 peak cooling load, as shown in Figure 2-10 (solid red bars). The results submitted in July 2007 improve the resolution of modeling the direct sky component with increased numbers of daylight coefficients for direct radiation (going from 145 preset positions to 2035 preset positions). This caused an increase in Case MZ350 peak cooling load (see Figure 2-10, solid black bars) for zones B and E (most shaded zones) of $11 \%$ and 10\%, respectively; peak load variation for the other shaded zones and for unshaded zones (Case MZ340) was < $1 \%$. Annual load variation (not shown here) was $<2 \%$ for all zones in both the shaded and unshaded cases.

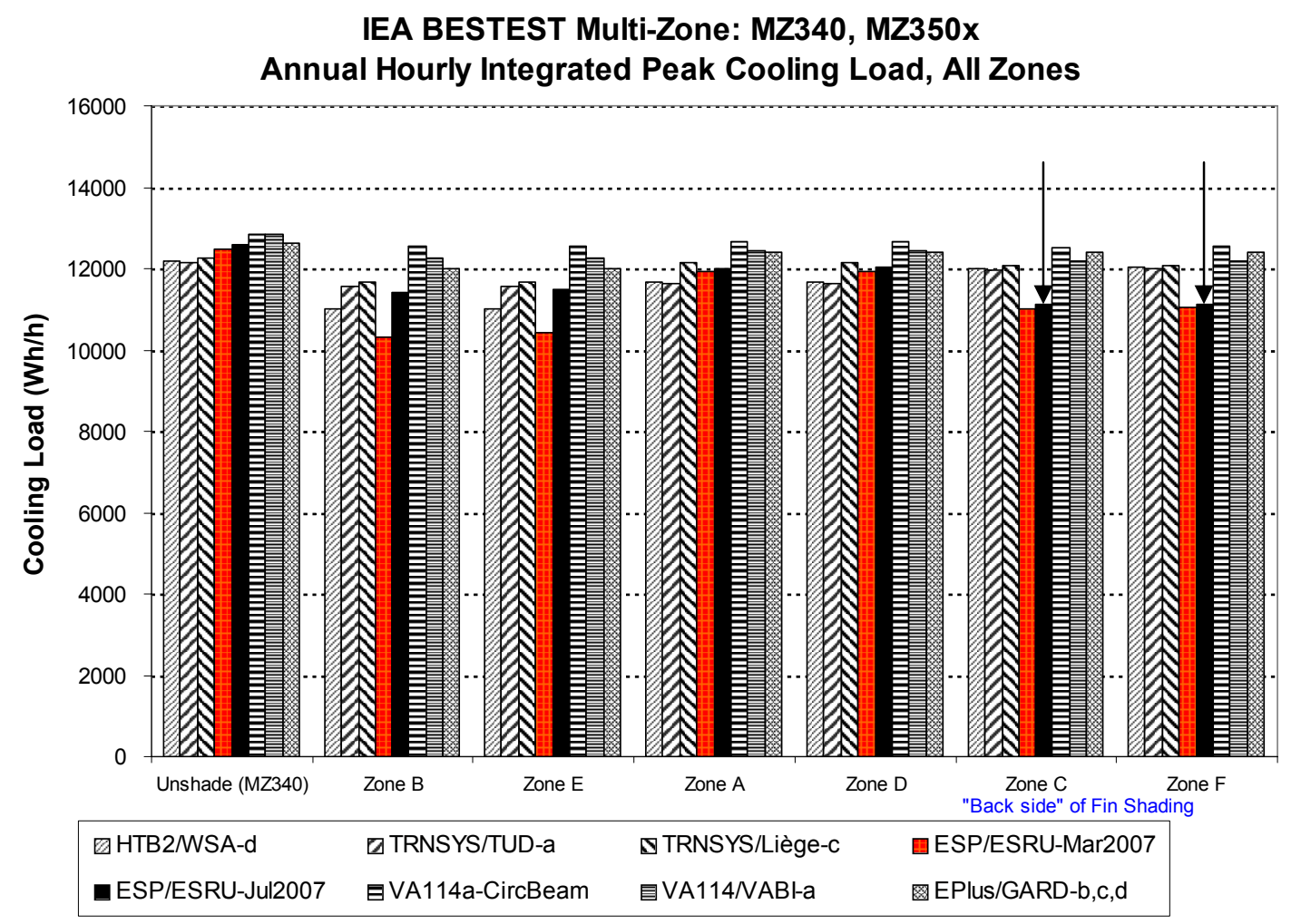

Figure 2-10. MZ340-MZ350 peak cooling load sensitivity, from March 2007 and Sep. 2007 Results

\subsubsection{Back side of fin shading disagreement, Case MZ350, zones $C$ and $F$}

Figure 2-10 indicates some remaining peak cooling disagreement for results submitted July 2007, for zones $\mathrm{C}$ and $\mathrm{F}$ (back side of fin shading), see black arrows in the figure. The ESP-r developers have been informed of this issue and indicate they are further revising their shading algorithm (Strachan 2008). Updated results were not ready in time for inclusion in this report. 


\subsubsection{HTB2}

HTB2 is a research-based thermal modeling program developed and maintained by the Welsh School of Architecture at Cardiff University. Other modeling details are described in the HTB2 modeler report; see Section 2.9, Appendix II-C.

\subsubsection{User-input constant exterior combined surface coefficients ignored; $1.3 \%$ effect}

Initial specification of fixed external combined coefficients for Case MZ320 led to disagreement with the analytical solution. The difference was traced to the default exterior surface coefficient calculation algorithm still being used; the user-input values specified were being ignored. HTB2's initialization code was altered to allow the proper detection and use of exterior surface coefficient override values. This fault applied only to exterior surface coefficients; user-specified interior surface coefficients were detected and used properly in the original code. This fault has been fixed in the latest version. Table 2-3 indicates a $1.3 \%$ effect for the change, going from version $2.20 \mathrm{R}$ to $2.20 \mathrm{~T}$.

Table 2-3. HTB2 Results before and after Fix to Detect User-Input Exterior Surface Coefficients

\begin{tabular}{|l|c|c|}
\hline & HTB2 2.20R & HTB2 2.20T \\
\hline $\mathbf{Q}_{\mathbf{C}}(\mathbf{W})$ & 1521.06 & 1541.3 \\
\hline $\mathbf{T}_{\mathbf{A}}\left({ }^{\circ} \mathbf{C}\right)$ & 31.283 & 31.058 \\
\hline $\mathbf{T}_{\mathbf{B}}\left({ }^{\circ} \mathbf{C}\right)$ & 24.910 & 24.798 \\
\hline
\end{tabular}

\subsubsection{Infrared emittance $=0$ not allowed; program crashed}

Case MZ340 required the use of zero emissivity for all surfaces in a zone; the original code failed when the total emissivity of a zone was zero. The failure was traced to a previously undetected divide-by-zero fault. The code was revised to allow the use of zero emissivity surfaces. (This issue was not detected in Case MZ320, as radiant calculations for that case were disabled to use the required combined surface heat transfer coefficients, and as solar calculations were not needed for that case.)

\subsubsection{Shadow/window overlap; $1 \%-2 \%$ effect on MZ340-MZ350 load sensitivity}

During the modeler's inspection of the shading preprocessor output before revisions were run, anomalous behavior was noticed in the shading factor data for high altitude angles (there were discontinuous "jumps" in the data). This was traced to faulty logic in determining the shadow overlap cases in HTB2's Hshade preprocessor, which wrongly excluded a valid case triggered at acute vertical angles. This was corrected to produce more smoothly varying factors. Although this error was present for results using the February 2005 version of the test specification, the larger fin size for the August 2005 test specification revision made the problem more noticeable. Differences in results documented in the HTB2 modeler report (see Section 2.9, Appendix II-C) were generally small (2\% or less for solar shading [MZ340-MZ350 sensitivity]) but notable in some of the hourly solar data. Table 2-4 includes the results comparison. 
Table 2-4. HTB2 Results before and after Shadow/Window Overlap Fix

\begin{tabular}{|c|c|c|c|c|c|c|c|}
\hline \multirow[b]{2}{*}{ Case } & \multicolumn{4}{|c|}{ Annual Cooling Loads } & \multirow[b]{2}{*}{$\begin{array}{c}\mathbf{Q}_{\mathbf{D}} \\
(\mathrm{kWh})\end{array}$} & \multirow[b]{2}{*}{$\begin{array}{c}\mathbf{Q}_{\mathbf{E}} \\
(\mathrm{kWh})\end{array}$} & \multirow[b]{2}{*}{$\begin{array}{c}\mathbf{Q}_{\mathbf{F}} \\
(\mathrm{kWh})\end{array}$} \\
\hline & $\begin{array}{c}\mathbf{Q}_{\text {Bldg }} \\
(\mathrm{kWh})\end{array}$ & $\begin{array}{c}\mathbf{Q}_{\mathbf{A}} \\
(\mathrm{kWh})\end{array}$ & $\begin{array}{c}\mathbf{Q}_{\mathbf{B}} \\
(\mathrm{kWh})\end{array}$ & $\begin{array}{c}\mathbf{Q}_{\mathbf{C}} \\
(\mathrm{kWh})\end{array}$ & & & \\
\hline MZ340 & 27780.97 & 4630.163 & 4630.162 & 4630.163 & 4630.162 & 4630.162 & 4630.162 \\
\hline MZ350 after & 19780.07 & 3662.931 & 2598.483 & 3522.517 & 3778.519 & 2689.97 & 3529.65 \\
\hline MZ350 before & 19671.46 & 3654.766 & 2574.947 & 3511.967 & 3770.976 & 2650.103 & 3508.705 \\
\hline MZ350 del\% & $-0.5 \%$ & $-0.2 \%$ & $-0.9 \%$ & $-0.3 \%$ & $-0.2 \%$ & $-1.5 \%$ & $-0.6 \%$ \\
\hline MZ340-350 after & 8000.9 & 967.232 & 2031.679 & 1107.646 & 851.643 & 1940.192 & 1100.512 \\
\hline MZ340-350 before & 8109.51 & 975.397 & 2055.215 & 1118.196 & 859.186 & 1980.059 & 1121.457 \\
\hline MZ340-MZ350 del\% & $1.4 \%$ & $0.8 \%$ & $1.2 \%$ & $1.0 \%$ & $0.9 \%$ & $2.1 \%$ & $1.9 \%$ \\
\hline
\end{tabular}

\subsubsection{Shading interpolation}

Investigation into the afternoon "hump" (see Figure 2-11) observed in the HTB2 shaded results for Zone A of Case MZ350 (August 2005 version of test specification) suggested that the time and spatial interpolation used for shading factors in HTB2 were too coarse; as a result a transient shadow could be considered to be in place for a full recalculation interval. This effect was magnified by the large fin dimensions set by the test. For runs using the August 2006 version of the test specification, HTB2 was modified to increase the shading recalculation interval and a new interpolation algorithm was used to estimate shading factors at arbitrary angles. A small reduction in disagreement was noted as a result. It was not possible to establish what the effect of this change was on overall cooling loads, because of changes to the test specification for the shading cases, modifications to other program models based on diagnosis of previous results (no consistent point of comparison), and insufficient time for the HTB2 participant to go back and run the unrepaired version of HTB2 using the new test specification.

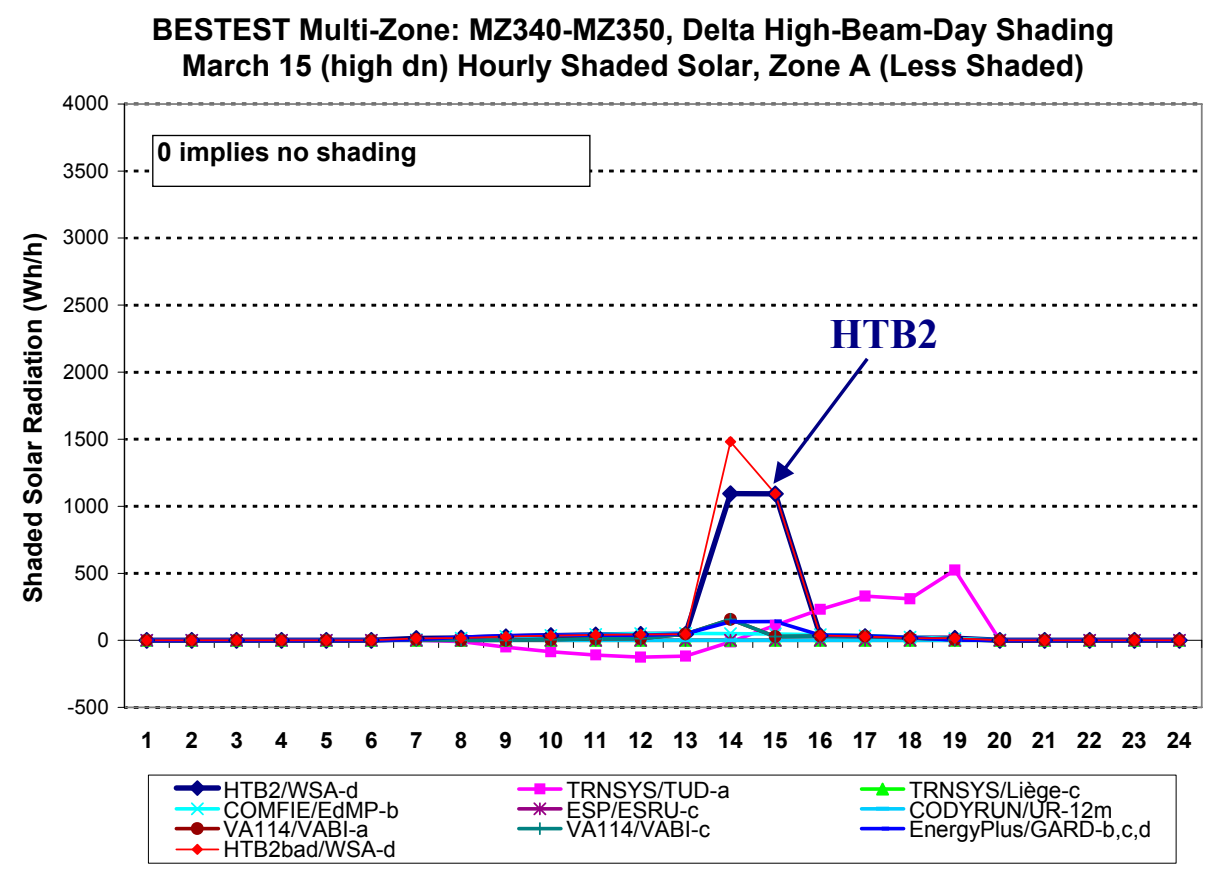

Figure 2-11. HTB2 shaded solar radiation disagreement from September 2005 


\subsubsection{Synchronization of solar data with surface insolation model; up to $0.4 \%$ increase in zone peak cooling load, up to $23 \%$ effect on specific-hour cooling load, negligible effect on annual cooling load}

Initial results for the August 2006 test specification shown in Table 2-5 indicate a difference of up to 23\% in hourly output of solar gain versus cooling load for cases MZ340 and MZ360. Inspection of the dataflow in the model led to the conclusion that the solar data, as generated by HTB2's meteorological and solar transmission modules, and the surface insolation data, as used by HTB2's fabric module, were one time step (on the order of 100 seconds) out of phase when the fabric calculations were made. This would be significant at reporting and solar calculation boundaries for hourly outputs, and could lead to differences in highly transient conditions (e.g., at sunset). As of version $2.20 \mathrm{AB}$, the ordering of the calculation modules has been revised, but otherwise no changes were made to algorithms, parameters, or data. This appears to have solved the problem: hourly cooling loads now match hourly total transmitted solar (hourly transmitted solar did not change), and the solar gains and cooling loads in a zone are now essentially identical. As shown in Table 2-6, the change has negligible effect on annual cooling load (minor variation in seventh significant digit), and caused up to a $0.4 \%$ increase to zone peak cooling load.

Table 2-5. HTB2 Cooling Load versus Transmitted Solar Gains Discrepancies from September 2006, before (Version 2.20AA) and after (Version 2.20AB) Fix

\begin{tabular}{|c|c|c|c|c|c|c|}
\hline $\begin{array}{l}\text { HTB2 } \\
2.20 A A\end{array}$ & \begin{tabular}{|l} 
MZ340 Ho \\
March 15 \\
\end{tabular} & $\begin{array}{l}\text { rly Result } \\
\text { igh dn) }\end{array}$ & & $\begin{array}{l}\text { MZ360 Ho } \\
\text { Mar. } 15 \text { (h }\end{array}$ & $\begin{array}{l}\text { ly Result } \\
\text { h dn) }\end{array}$ & \\
\hline Hour & $\begin{array}{c}q_{A} \\
(W h / h)\end{array}$ & $\begin{array}{c}I_{\text {trh,A }} \\
(W h / h)\end{array}$ & Delta \% & $\begin{array}{c}q_{B} \\
(W h / h)\end{array}$ & $\begin{array}{c}I_{\text {trh,B }} \\
(W h / h)\end{array}$ & Delta \% \\
\hline 6 & 0 & 0 & \#DIV/0! & 0 & 0 & \#DIV/0! \\
\hline 7 & 153 & 155 & $-1.5 \%$ & 569 & 577 & $-1.5 \%$ \\
\hline 8 & 251 & 255 & $-1.6 \%$ & 933 & 948 & $-1.6 \%$ \\
\hline 9 & 395 & 398 & $-0.9 \%$ & 1467 & 1481 & $-0.9 \%$ \\
\hline 10 & 507 & 510 & $-0.5 \%$ & 1885 & 1895 & $-0.5 \%$ \\
\hline 11 & 596 & 598 & $-0.4 \%$ & 2202 & 2208 & $-0.3 \%$ \\
\hline 12 & 644 & 646 & $-0.2 \%$ & 6684 & 6911 & $-3.3 \%$ \\
\hline 13 & 1131 & 1177 & $-3.9 \%$ & 18226 & 18560 & $-1.8 \%$ \\
\hline 14 & 4652 & 4753 & $-2.1 \%$ & 32508 & 32879 & $-1.1 \%$ \\
\hline 15 & 8278 & 8362 & $-1.0 \%$ & 45983 & 46296 & $-0.7 \%$ \\
\hline 16 & 11032 & 11092 & $-0.5 \%$ & 55273 & 55450 & $-0.3 \%$ \\
\hline 17 & 12180 & 12197 & $-0.1 \%$ & 55804 & 55743 & $0.1 \%$ \\
\hline 18 & 10488 & 10433 & $0.5 \%$ & 43047 & 42665 & $0.9 \%$ \\
\hline 19 & 1461 & 1200 & $21.8 \%$ & 5389 & 4379 & $23.1 \%$ \\
\hline 20 & 6 & 0 & \#DIV/0! & 22 & 0 & \#DIV/0! \\
\hline 21 & 0 & 0 & \#DIV/0! & 0 & 0 & \#DIV/0! \\
\hline
\end{tabular}




\begin{tabular}{|c|c|c|c|c|c|c|}
\hline $\begin{array}{l}\text { HTB2 } \\
2.20 A B\end{array}$ & $\begin{array}{l}\text { MZ340 Ho } \\
\text { March 15 }\end{array}$ & $\begin{array}{l}\text { ly Result } \\
\text { igh dn) }\end{array}$ & & $\begin{array}{l}\text { MZ360 Ho } \\
\text { Mar. } 15 \text { (hi }\end{array}$ & $\begin{array}{l}\text { rly Result } \\
\text { h dn) }\end{array}$ & \\
\hline Hour & $\begin{array}{c}q_{A} \\
(W h / h)\end{array}$ & $\begin{array}{c}I_{\text {trh,A }} \\
(W h / h)\end{array}$ & Delta \% & $\begin{array}{c}q_{B} \\
(W h / h)\end{array}$ & $\begin{array}{c}I_{\text {trh,B }} \\
(W h / h)\end{array}$ & Delta \% \\
\hline$\overline{6}$ & $\overline{0}$ & $\overline{0}$ & \#DIV/0! & $\overline{0}$ & 0 & \#DIV/0! \\
\hline 7 & 155 & 155 & $0.0 \%$ & 577 & 577 & $0.0 \%$ \\
\hline 8 & 255 & 255 & $0.0 \%$ & 948 & 948 & $0.0 \%$ \\
\hline 9 & 398 & 398 & $0.0 \%$ & 1481 & 1481 & $0.0 \%$ \\
\hline 10 & 510 & 510 & $0.0 \%$ & 1895 & 1895 & $0.0 \%$ \\
\hline 11 & 598 & 598 & $0.0 \%$ & 2208 & 2208 & $0.0 \%$ \\
\hline 12 & 646 & 646 & $0.0 \%$ & 6911 & 6911 & $0.0 \%$ \\
\hline 13 & 1177 & 1177 & $0.0 \%$ & 18560 & 18560 & $0.0 \%$ \\
\hline 14 & 4753 & 4753 & $0.0 \%$ & 32879 & 32879 & $0.0 \%$ \\
\hline 15 & 8362 & 8362 & $0.0 \%$ & 46296 & 46296 & $0.0 \%$ \\
\hline 16 & 11092 & 11092 & $0.0 \%$ & 55450 & 55450 & $0.0 \%$ \\
\hline 17 & 12197 & 12197 & $0.0 \%$ & 55743 & 55743 & $0.0 \%$ \\
\hline 18 & 10433 & 10433 & $0.0 \%$ & 42665 & 42665 & $0.0 \%$ \\
\hline 19 & 1200 & 1200 & $0.0 \%$ & 4379 & 4379 & $0.0 \%$ \\
\hline 20 & 0 & 0 & \#DIV/0! & 0 & 0 & \#DIV/0! \\
\hline 21 & 0 & 0 & \#DIVIO! & 0 & 0 & \#DIV/0! \\
\hline
\end{tabular}

Table 2-6. HTB2 Results before (version 2.20AA) and After (version 2.20AB) Fix

\begin{tabular}{|c|c|c|c|c|}
\hline \multirow[b]{2}{*}{ Case } & \multicolumn{2}{|c|}{$\begin{array}{l}\text { Annual Cooling } \\
\text { Loads }\end{array}$} & \multirow{2}{*}{$\begin{array}{c}\text { Peak Cooling } \\
\mathbf{q}_{\text {bldg }} \\
(\mathrm{Wh} / \mathrm{h})\end{array}$} & \multirow{2}{*}{$\begin{array}{l}\text { Loads } \\
\text { q }_{\text {zones }} \\
(\mathrm{Wh} / \mathrm{h})\end{array}$} \\
\hline & $\begin{array}{c}Q_{\text {bldg }} \\
(\mathrm{kWh})\end{array}$ & $\begin{array}{l}\mathbf{Q}_{\text {zones }} \\
\text { (kWh) }\end{array}$ & & \\
\hline MZ340 “9/13/06”(before) & 74116.84 & 12352.80 & 73081.4 & 12180.2 \\
\hline MZ340 “9/24/06” (after) & 74116.93 & 12352.82 & 73182.2 & 12197.0 \\
\hline MZ340 del\% & negligible & negligible & $0.14 \%$ & $0.14 \%$ \\
\hline MZ360 “9/13/06”(before) & 121815.50 & $52654.00^{*}$ & 110796 & $70722^{*}$ \\
\hline MZ360 “9/24/06”" (after) & 121815.48 & $52654.05^{*}$ & 111067 & 70999* \\
\hline MZ360 del\% & negligible & negligible & $0.24 \%$ & $0.36 \%$ \\
\hline
\end{tabular}

* for Zone B of two-zone implementation of Case MZ360

\subsubsection{Internal window reflection Case $M Z 360 ; Q_{A}$ decreased by $16 \%, Q_{B}$ increased by $18 \%$, negligible change to $Q_{b l d g}$}

Figures 2-12 and 2-13 indicate disagreements for HTB2 (bars with red background and red arrows) versus results with no known fundamental anomalies as of field trials completed October 2006 (bars with blue background). Investigation of these differences led to discovery that cosine of incidence angle was effectively accounted for twice in the calculation of transmission through the internal glazing (Window $\mathrm{AB}$ ); the end effect was that energy so "lost" in transmission to Zone B appeared as a diffuse reflection back into Zone A. This problem was corrected in version $2.20 \mathrm{AD}$, and the case rerun with no changes to input parameters. This caused a $16 \%$ decrease in $\mathrm{Q}_{\mathrm{A}}$ and an $18 \%$ increase in $\mathrm{Q}_{\mathrm{B}}$, with negligible change to Qbldg; the results now appear more consistent with other models, as shown in Part III. 


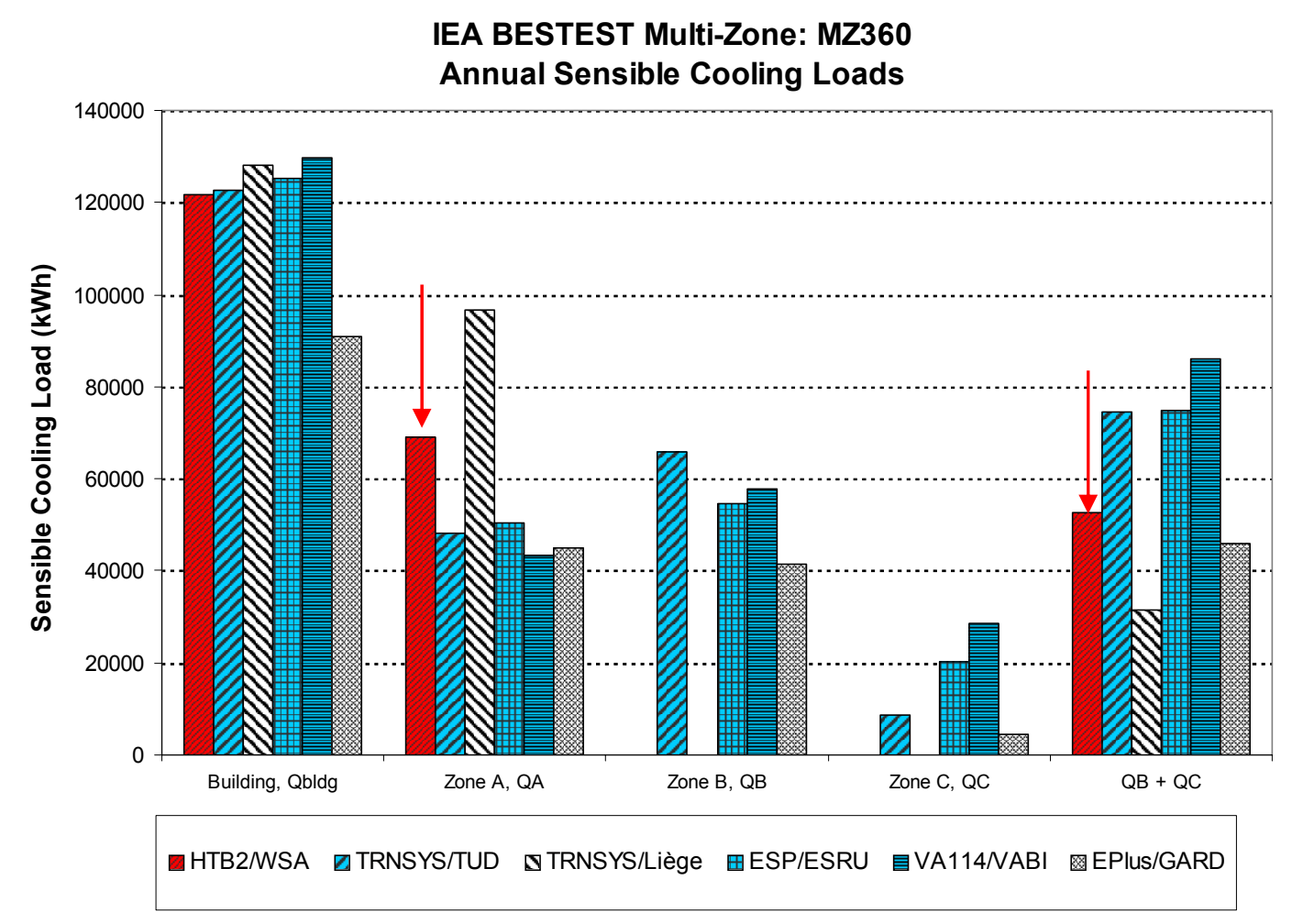

Figure 2-12. HTB2 cooling load disagreements from September 2006

IEA BESTEST Multi-Zone: MZ360

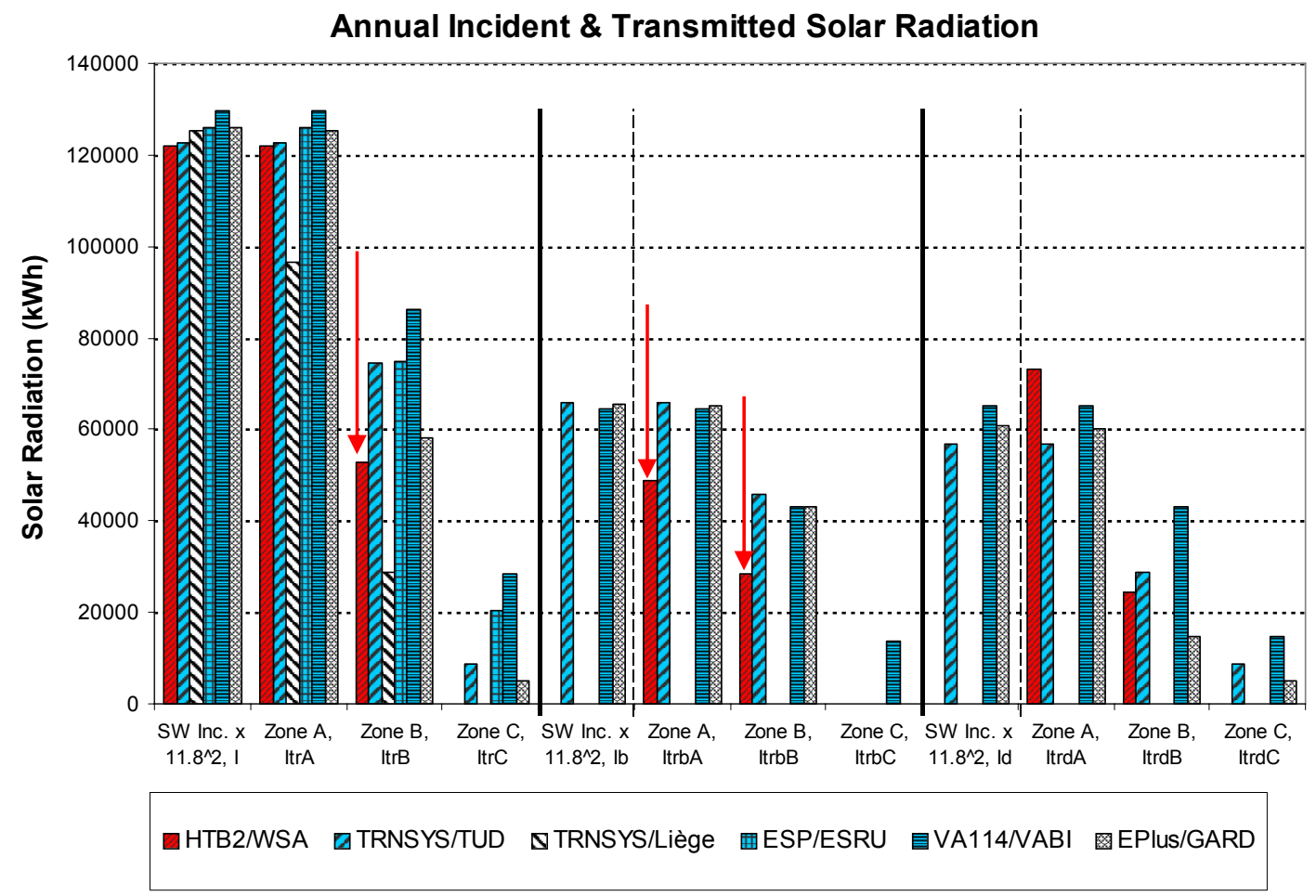

Figure 2-13. HTB2 transmitted solar radiation disagreements from September 2006 


\subsubsection{March 15, hour 17 disagreement for sensitivity Case MZ340-MZ350}

For the final results for the MZ340-MZ350 hourly shading sensitivity for March 15 (dominated by direct normal solar), a disagreement occurs for hour 17 (see Figure 2-14). According to the HTB2 modeler report, this is similar to an issue reported in Section 2.4.3.4: "The suspected source of the difference may be a limitation of the sky mask model. The problem is likely that the sectoring is too coarse for this sensitive problem. Currently the descriptions are given in steps of 10 degrees; the solar position is updated every 15 minutes. Some interpolation is done using neighboring sectors, and that if the shadow is sharp edged then the result would be fuzzy. At hour 17, the sun may be just passing the shade, so the coarseness of the mask may introduce an error. It is possible to increase the mask resolution (to 5 and 2 degrees), to see if that improves the result, and this issue has been flagged to check for a future update." The modifications to the software required to check this were not completed for inclusion in this report.

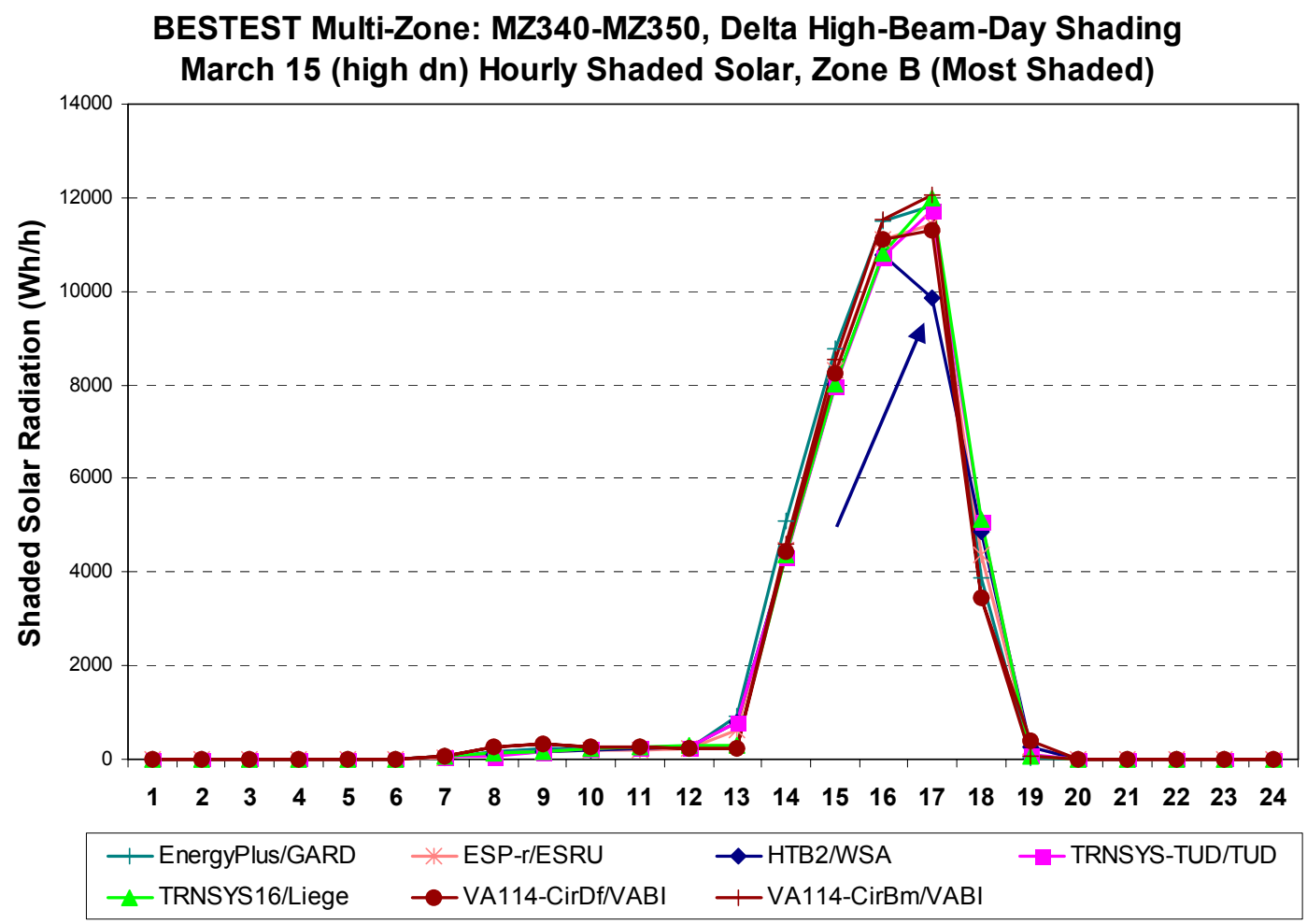

Figure 2-14. HTB2 shaded solar radiation disagreements for Hour 17 of a day with high direct normal solar radiation

\subsubsection{October 14, hourly disagreement for Case MZ360}

For the final results for MZ360, the hourly results of Figure 2-15 for October 14 (dominated by diffuse solar) indicate that the cooling load for Zone B using the alternative two-zone specification for HTB2 (comparable to zones $\mathrm{B}+\mathrm{C}$ for the other programs) is less than the Zone-B-only results for the other programs. According to the HTB2 modeler report, this difference is attributable to the relatively simplified method of modeling internal windows using assigned user input transfer ratios based on the geometry of the case; e.g., relative areas of window and wall surfaces. Additionally, this disagreement is seen only for diffuse solar; the direct-solar dominated day has better agreement. The code author considers that there is no coding error involved, but that this result indicates the limitation of the 
underlying method used to estimate interzone diffuse solar radiation transfer. To improve the result it would have been possible to "tune" the input parameters. However, the code author prefers to provide unbiased results, so no further changes will be made.

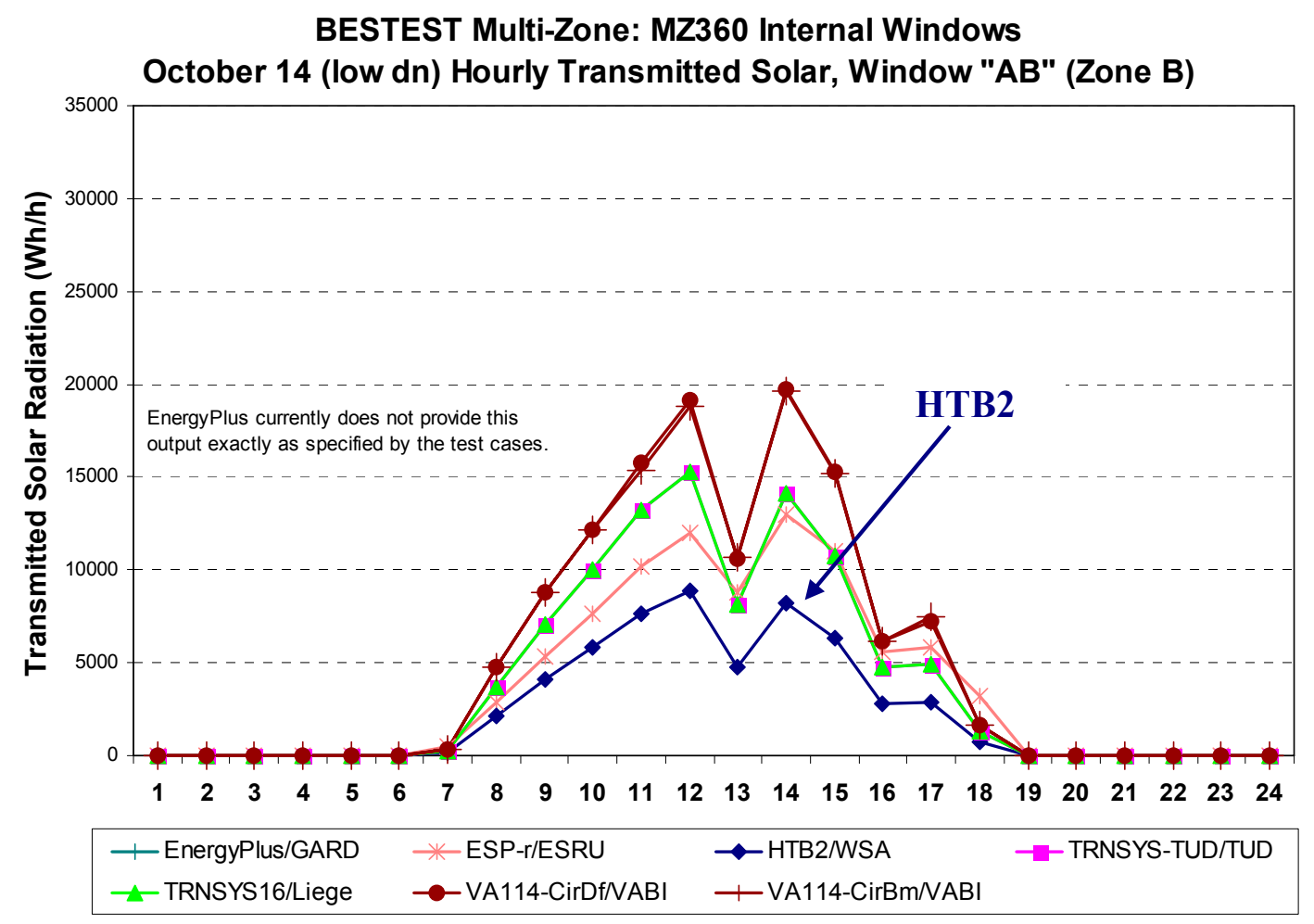

Figure 2-15. HTB2 shaded solar radiation disagreements for Hour 17 of a day with high direct normal solar radiation

\subsubsection{VA114}

VA114, initial development by TNO, current development and distribution, maintenance, and support by VABI Software BV, The Netherlands, is widely used in The Netherlands (VABI Software 2008).

Before participating in this project beginning in April 2005, VABI made some major changes to VA114 (beginning in 2004):

- Calculated solar distribution using ray tracing

- Implemented internal window modeling

- Improved of solar shading and solar distribution modeling

- Added features to reduce solar calculation computation time.

This IEA research task gave VABI an opportunity to test these new features, which replaced old, less general, models. Both the old and the new models were part of the tests; the old models were checked only for comparison with the new models, and are no longer available to users of VA114. After these changes some of the old features were not called correctly anymore. 
A number of errors were reported by VABI in the June 30, 2005 draft of its modeler report, which accompanied initial results of the same date. For these errors VABI did not submit prior results showing the effect of those errors (old features that did not work correctly anymore). More detailed discussion of these errors is included with the VA114 modeler report in Section 2.9, Appendix II-F.

\subsubsection{For emittances or absorptances < 0.2, sum of exchange factors $>1$; submitted with June 30, 2005 modeler report, effect not given (Case MZ320)}

For Case MZ320, for internal infrared emittances $<0.2$, the sum of exchange factors was $>1.0$. A software correction was made so that VA114 properly calculates exchange factors for emittances $>0.01$. A similar error occurred for developing distribution factors for diffuse solar radiation using inside-surface solar absorptance; VA114 was also repaired to properly calculate such exchange factors for absorptances $>0.01$. VABI did not submit prior results showing the effect of these revisions.

\subsubsection{VA114 "comfort cube" in wrong coordinate system; submitted with June 30, 2005 modeler report, effect not given (Case MZ320)}

VA114's comfort module calculates the radiative temperature on the six surfaces of a comfort cube. It was found that after running Case MZ320 that the position of the comfort cube was in a wrong coordinate system. VABI fixed this error, but did not submit prior results showing the effect of this revision.

\subsubsection{Thermal conductance of a construction layer cannot $=0$; submitted with June 30, 2005 modeler report, effect not given (Case MZ340)}

For Case MZ340, thermal conductance of a construction layer cannot $=0$ in VA114; however, very low values are allowed. VA114 was modified to provide a warning if thermal conductance $<0.00001$. VABI did not submit prior results showing the effect of this revision.

\subsubsection{Shading of direct solar radiation excluded for model using shading device affixed to building (Case MZ350a)}

For a shading device modeled as affixed to a building, VABI tested numerous related modeling options available for VA114. The initial run of Case MZ350a indicated a large difference among results when the modeling option for rectangular zones was applied ("Ishape" $=0$ ) and for where only surface areas are known ("Ishape" =-1), versus for any shape zone ("Ishape" =1). It was found that when either Ishape $=0$ or Ishape $=-1$ (which are no longer available to VA114 users) were designated that the modeling of shading of direct solar radiation was bypassed (old feature not called correctly). VABI did not submit prior results showing the effect of this error.

\subsubsection{Shading of direct solar radiation excluded for model using shading by objects not affixed to building, diffuse shading intentionally excluded (Case MZ350c)}

For a shading device modeled as not affixed to a building (e.g., other building or trees) VA114 intentionally excludes shading of diffuse solar radiation. VABI tested numerous related modeling options available for VA114 using this shading method. Initial run of Case MZ350c indicated a large difference among results when modeling option for rectangular zones was applied ("Ishape" $=0$ ) and for where only surface areas are known ("Ishape" $=-1$ ) versus for any shape zone ("Ishape" =1). It was found that when either Ishape $=0$ or Ishape $=-1$ (which are no longer available to VA114 users) were designated that the modeling of shading of direct solar radiation was bypassed (old feature not called correctly). VABI did not submit prior results showing the effect of this error. 


\subsubsection{Shading of all solar radiation excluded for model using automated building self- shading, two errors (Case MZ355)}

For automated building self-shading, the initial VA114 run of Case MZ355 indicated no shading. VABI's June 30, 2005 modeler report indicates two related errors: a direct shading routine was not called (old feature not called correctly), and a problem with the ray-tracing algorithms. VABI did not submit prior results showing the effect of these errors.

\subsubsection{Minor differences for beam shading of solar radiation by fin affixed to building versus automated building self-shading; $<0.3 \%$ transmitted beam radiation, $<0.1 \%$ zone cooling load (Case MZ355)}

For VABI's final results for cases MZ355 and MZ350, for comparable zones (zones A, B, D, and E) there are minor differences between results for automated building self-shading versus results for shading with a fin affixed to a building. These differences amount to $<0.3 \%$ for transmitted beam radiation to $<0.1 \%$ for zone cooling load. Table 2-7 (circled data) and Figure 2-16 indicate where a related difference in hourly results for March 15, hour 16 occurs for circumsolar radiation modeled as diffuse radiation ("VA114-CirDf/VABI") and circumsolar radiation modeled as beam radiation ("VA114-CirBm/VABI"). VABI's modeler report indicates that this difference occurs for March 12 through March 17, and that VABI is searching for the cause of the difference, but has not yet been able to find it. [Primary author's note: This difference could be caused by minor differences in a program's geometry convention for locating a shading device as affixed to a building versus for building self-shading by a zone (the fin of Case MZ350 and Zone G of Case MZ355 are specified in the BESTEST user's manual to have matching shading characteristics with respect to zones $A, B, D$, and E).]

Table 2-7 VA114 MZ355 v. MZ350 Disagreements for Hour 16 of a Day with High Direct Normal Solar Radiation

\begin{tabular}{rrrr} 
March 15 (high dn) Zone A Hourly Transmitted Solar (MZ355 & MZ350x) / MZ355 [fraction] \\
Hour & \multicolumn{1}{c}{ EnergyPlus/GARD } & VA114-CirDf/VABI & VA114-CirBm/VABI \\
1 & \#DIV/0! & \#DIV/0! & \#DIV/0! \\
2 & \#DIV/0! & \#DIV/0! & \#DIV/0! \\
3 & \#DIV/0! & \#DIV/0! & \#DIV/0! \\
4 & \#DIV/0! & \#DIV/0! & \#DIV/0! \\
5 & \#DIV/0! & \#DIV/0! & \#DIV/0! \\
6 & \#DIV/0! & \#DIV/0! & \#DIV/0! \\
7 & 0.00000 & 0.00000 & 0.00000 \\
8 & 0.00000 & 0.00000 & 0.00000 \\
9 & 0.00000 & 0.00000 & 0.00000 \\
10 & 0.00000 & 0.00000 & 0.00000 \\
11 & 0.00000 & 0.00000 & 0.00000 \\
12 & 0.00000 & 0.00000 & 0.00000 \\
13 & 0.00000 & 0.00000 & 0.00000 \\
14 & 0.00000 & 0.00000 & 0.00000 \\
15 & 0.00000 & 0.00000 & 000000 \\
16 & 0.00000 & -1.30595 & -2.74037 \\
17 & 0.00000 & 0.00000 & 0.00000 \\
18 & 0.00000 & 0.00000 & 0.00000 \\
19 & 0.00000 & 0.00000 & 0.00000 \\
20 & \#DIV/0! & \#DIV/0! & \#DIV/0! \\
21 & \#DIV/0! & \#DIV/0! & \#DIV/0! \\
22 & \#DIV/0! & \#DIV/0! & \#DIV/0! \\
23 & \#DIV/0! & \#DIV/0! & \#DIV/0! \\
24 & \#DIV/0! & \#DIV/0! & \#DIV/0!
\end{tabular}




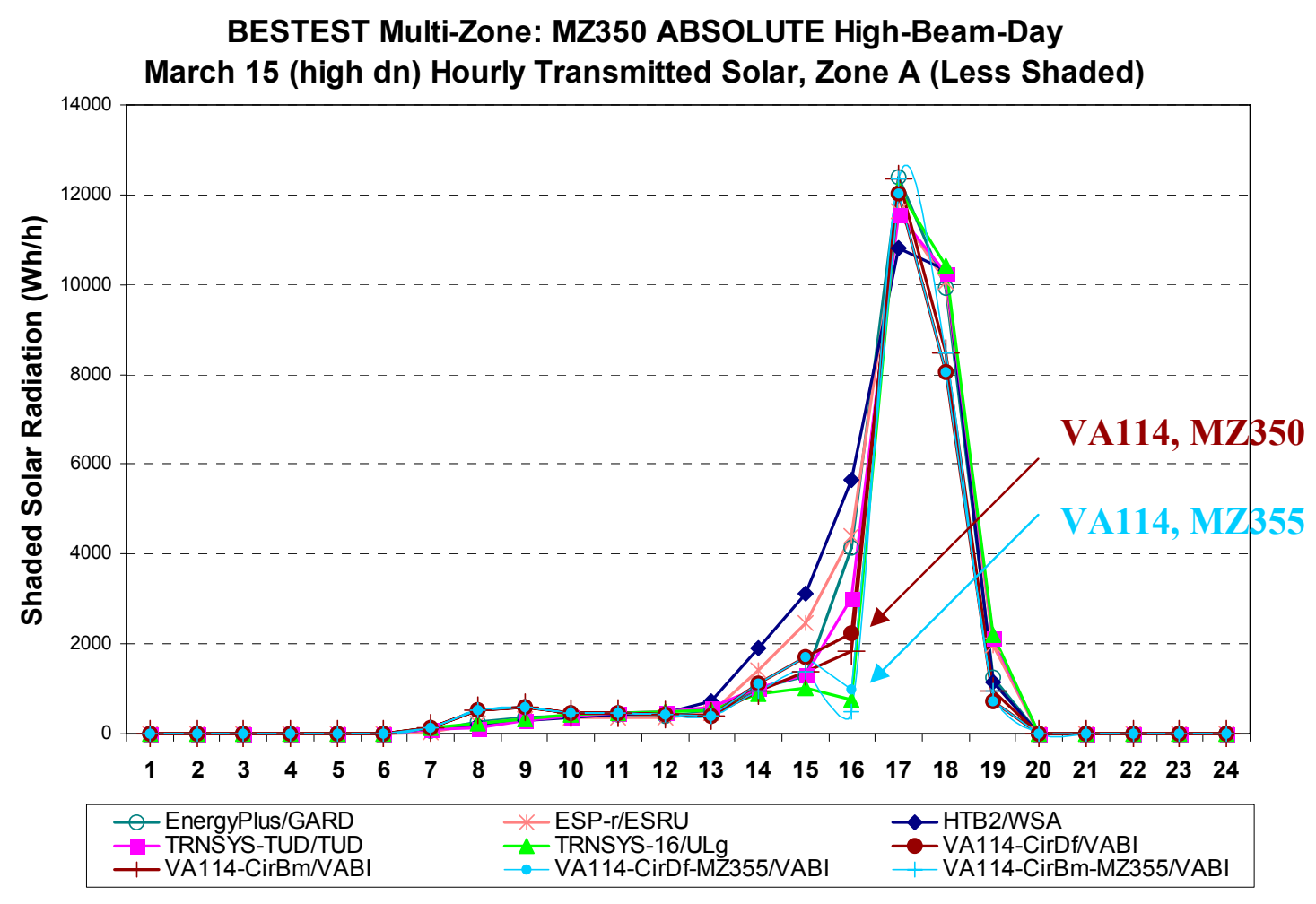

Figure 2-16. VA114 March 15 hourly transmitted total solar: MZ355 v. MZ350

2.4.4.8 Hard-coded internal window reflectance $=0.1 ; 7 \%$ effect for Case MZ360 total building annual cooling load, 22\% effect for Zone C cooling load, similar effects for peak cooling loads

VABI's modeler report indicates that for Case MZ360 the total cooling load was "a few \%" lower than the total incident solar radiation on Window AO (area * total solar in $\mathrm{kWh} / \mathrm{m}^{2}$ ). It was found, for the routine that calculates the distribution of the diffuse solar radiation, the reflectance of the window was fixed (hard-coded) at 0.10 . So, $10 \%$ of the solar (direct and diffuse) incident on an internal window is reflected, and therefore partly reflected through the external window in zone A to ambient. To properly model the test, the solar reflection was reprogrammed as 1.0 - transmittance (for user-input transmittance). Simulation results provided by VABI for Case MZ360 with interior window reflectance $=0.1$, compared with final results for idealized reflectance $=0$, are shown in Table 2-8. (Wijsman 2008a)

Table 2-8 Case MZ360 Results for VA114 with Internal Window Reflectance $=0.1$ versus Final Results with Internal Window Reflectance $=0$ (Transmittance $=1)$

\begin{tabular}{|l|c|c|c|c|}
\hline Case MZ360 & Building & Zone A & Zone B & Zone C \\
\hline Annual Cooling (kWh/y): Refl = 0.1 & 121101 & 44579 & 53285 & 23237 \\
\hline Annual Cooling (kWh/y): Refl = 0.0 & 129653 & 43480 & 57751 & 28421 \\
\hline Delta \% & $\mathbf{7 . 1 \%}$ & $\mathbf{- 2 . 5 \%}$ & $\mathbf{8 . 4 \%}$ & $\mathbf{2 2 . 3 \%}$ \\
\hline & & & & \\
\hline Peak Cooling (W): Refl = 0.1 & 109753 & 40009 & 50969 & 33498 \\
\hline Peak Cooling (W): Refl = 0.0 & 118713 & 39057 & 55176 & 41037 \\
\hline Delta \% & $\mathbf{8 . 2} \%$ & $\mathbf{- 2 . 4 \%}$ & $\mathbf{8 . 3} \%$ & $\mathbf{2 2 . 5 \%}$ \\
\hline
\end{tabular}




\subsubsection{Input error: incorrect time zone}

Figure 2-17 indicates a phase shift for hourly unshaded transmitted solar radiation for March 15 (day dominated by direct normal solar radiation). The problem was traced to proper time zone not input, which caused misinterpretation of longitude. New results were completed after changes to cases MZ340 through MZ360 in the test specification. So, direct comparison with later-submitted results is not available except for annual incident solar radiation, which for Case MZ340 (west-facing surface) changed from $886 \mathrm{kWh} / \mathrm{m}^{2}$ to $804 \mathrm{kWh} / \mathrm{m}^{2}$ (9\% reduction), and for Case MZ360 (southwest-facing surface) changed from $995 \mathrm{kWh} / \mathrm{m}^{2}$ to $931 \mathrm{kWh} / \mathrm{m}^{2}$ (6\% reduction). For the idealized zones used in these cases, the change in incident solar radiation translates directly to $9 \%$ and $6 \%$ reductions in cooling load for cases MZ340 and MZ360, respectively.

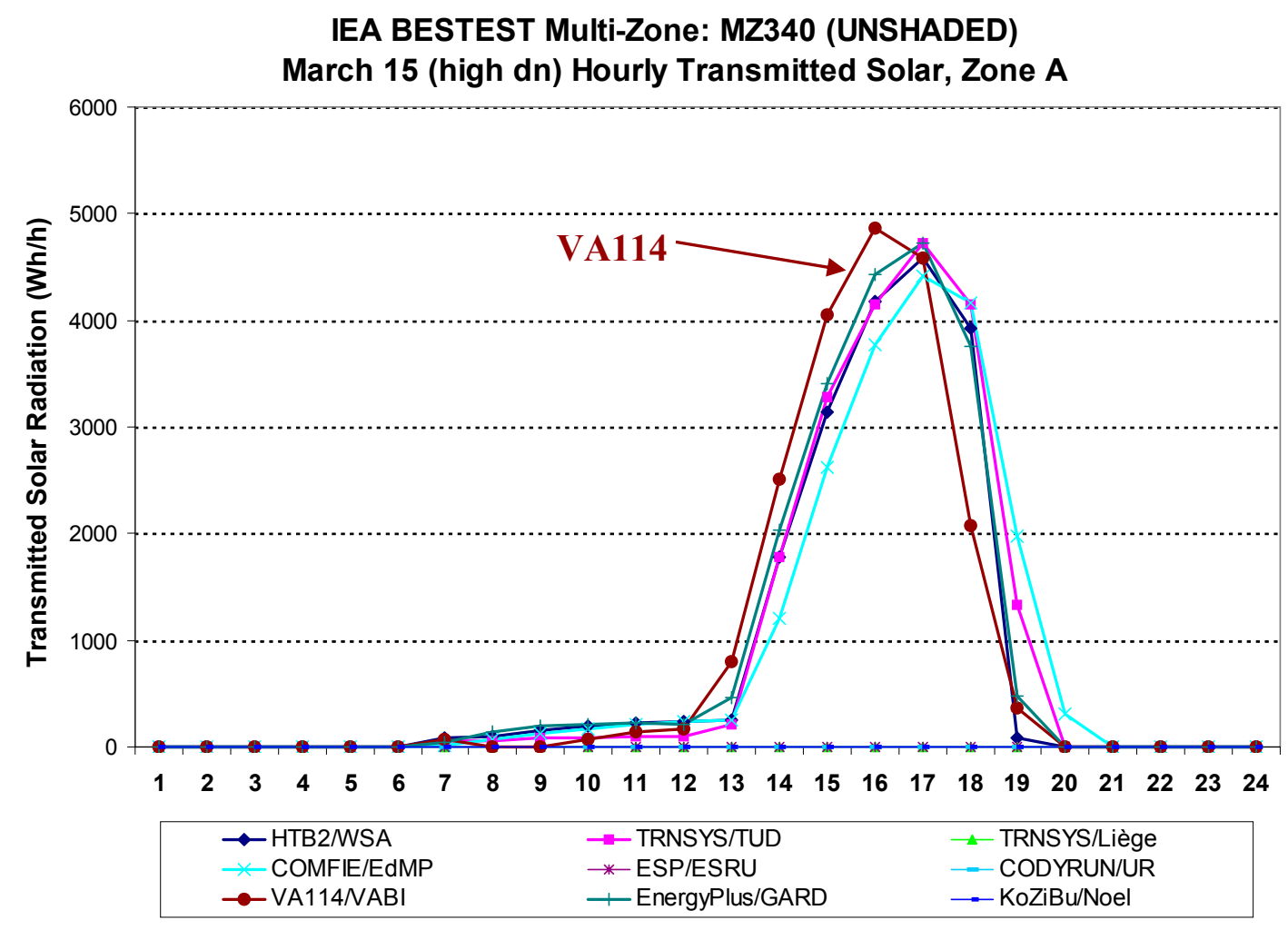

Figure 2-17. VA114 hourly high DN day unshaded transmitted solar from August 2005

\subsubsection{Input error: fin input twice for modeling fin as neighboring building}

VA114 results from August 2005 indicated greater back side of fin shading (for zones C and F) of incident beam radiation for sensitivity Case MZ340-MZ350 by VA114 with fin modeled as not affixed to the building (MZ350c) than the other programs (including VA114 with fin modeled as affixed to the building [MZ350a]). VABI notes in its modeler report (see Section 2.9, Appendix II-F) that this was caused by an input error. 


\subsubsection{Case MZ360 Total cooling load slightly greater than solar transmitted through Window $A O ; 0.04 \%$ difference}

For Case MZ360, the annual total building cooling (Zone A + Zone B + Zone C $=129653 \mathrm{kWh}$ ) is not exactly the same as the transmitted solar radiation through Window $\mathrm{AO}=129595 \mathrm{kWh}$. According to VABI's modeler report, the hourly results show a constant cooling load of $-4 \mathrm{~W}$ (Zone A), $-2 \mathrm{~W}$ (Zone $\mathrm{B}$ ), and $-1 \mathrm{~W}$ (Zone $\mathrm{C}$ ) during the hours when there is no solar input. A run without solar radiation incident on the window gives the same flows for all hours. This annual cooling load is $58 \mathrm{kWh}$; this is equal to the found imbalance between solar radiation and cooling load $(0.04 \%)$. So the imbalance is not caused by the solar calculation method, but by some other reason (probably the infrared radiative exchange model, which may become slightly inaccurate at emissivities of 0.01 ).

\subsubsection{Note regarding testing of VA114 option for modeling a shading device as not affixed to a building (e.g., a surrounding building or tree); omitting diffuse intentionally may be reasonable in this context, but it is important to test all options}

VA114 includes two methods for modeling shading: shading device affixed to the building, and shading device not affixed to the building. The primary difference in the models is that for a shading device not affixed to the building, shading of diffuse solar radiation is intentionally not calculated. Such shading devices are assumed to be remote enough from building windows that only the obstruction of beam radiation would be considered important. The final shaded solar radiation (sensitivity Case MZ340 MZ350) results for this modeling method are shown in Figure 2-18, and indicate a substantial difference in results versus other programs, as expected. However, as noted in Section 2.4.4.5 it was important to test this model. Additionally, including diagnostic output requiring disaggregating transmitted direct beam radiation allowed analysis of this specific model. VABI remarked in its modeler report that to model diffuse shading by surrounding buildings, the surrounding buildings should be modeled as "affixed to the building" (as shading devices don't have to be "affixed" to the building in VA114). We might recommend including an option in VA114 to allow the user to switch diffuse shading on or off (allow user discretion, with default as diffuse shading $=$ off) to model shading by surrounding buildings. 


\section{IEA BESTEST Multi-Zone: MZ340 - MZ350x Delta Shaded Solar Annual Shaded TOTAL Solar Radiation, All Zones}

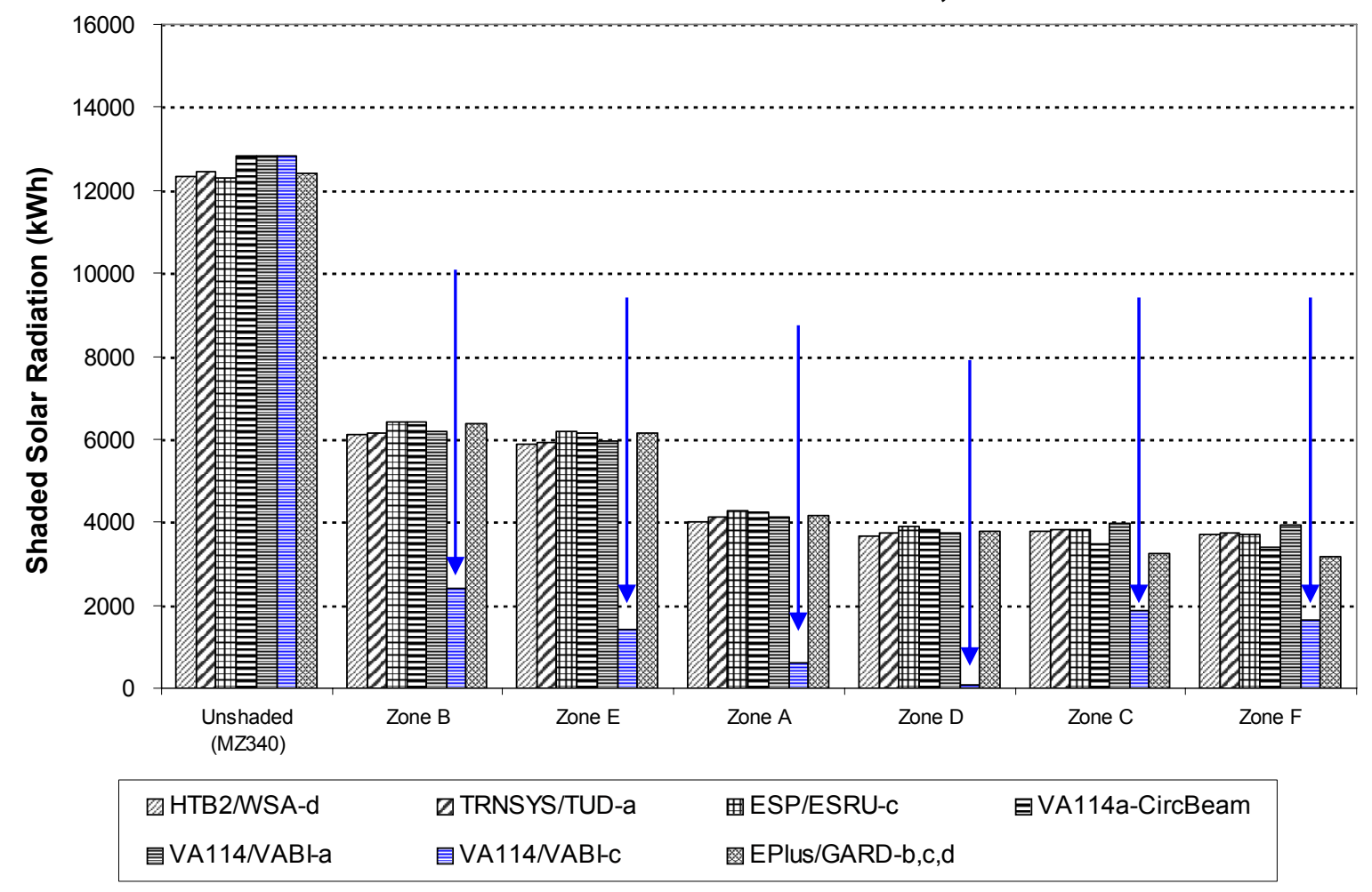

Figure 2-18. VA114 total shaded solar for shade not affixed to building from September 2007

\subsubsection{Annual unshaded transmitted diffuse solar disagreement; $8 \%$ difference for transmitted diffuse solar, $4 \%$ difference for cooling load}

In reviewing the final results, VABI noticed that VA114's diffuse radiation is about $8 \%$ higher than the other programs (see arrow in Figure 2-19). Figure 2-19 also indicates beam radiation is the same; propagation of the diffuse radiation difference to total solar radiation (beam + diffuse) results in about $4 \%$ higher total incident solar radiation. This may be the cause of similar differences versus other results shown in Part III. VABI indicates this difference was not apparent in the Subtask E (Double-Skin Façade tests) results. VABI plans to check modeling of diffuse radiation in the VA114 solar processor (Wijsman 2008a, 2008b).

\subsubsection{Note regarding testing isolation of VA114 window discretization}

VABI also found evidence of the strength of the tests in that Case MZ360 isolated the discretization method used in VA114 to model solar radiation (beam) through an internal window, as shown in Figure 2-20; also see VABI's modeler report (Section 2.9, Appendix II-F). This difference does not seem to appear for Case MZ360 annual hourly integrated peak zone loads shown in Part III, which occur on different dates (not March 15). 
IEA BESTEST Multi-Zone: MZ340

Annual Incident Total Solar Radiation, Facing West

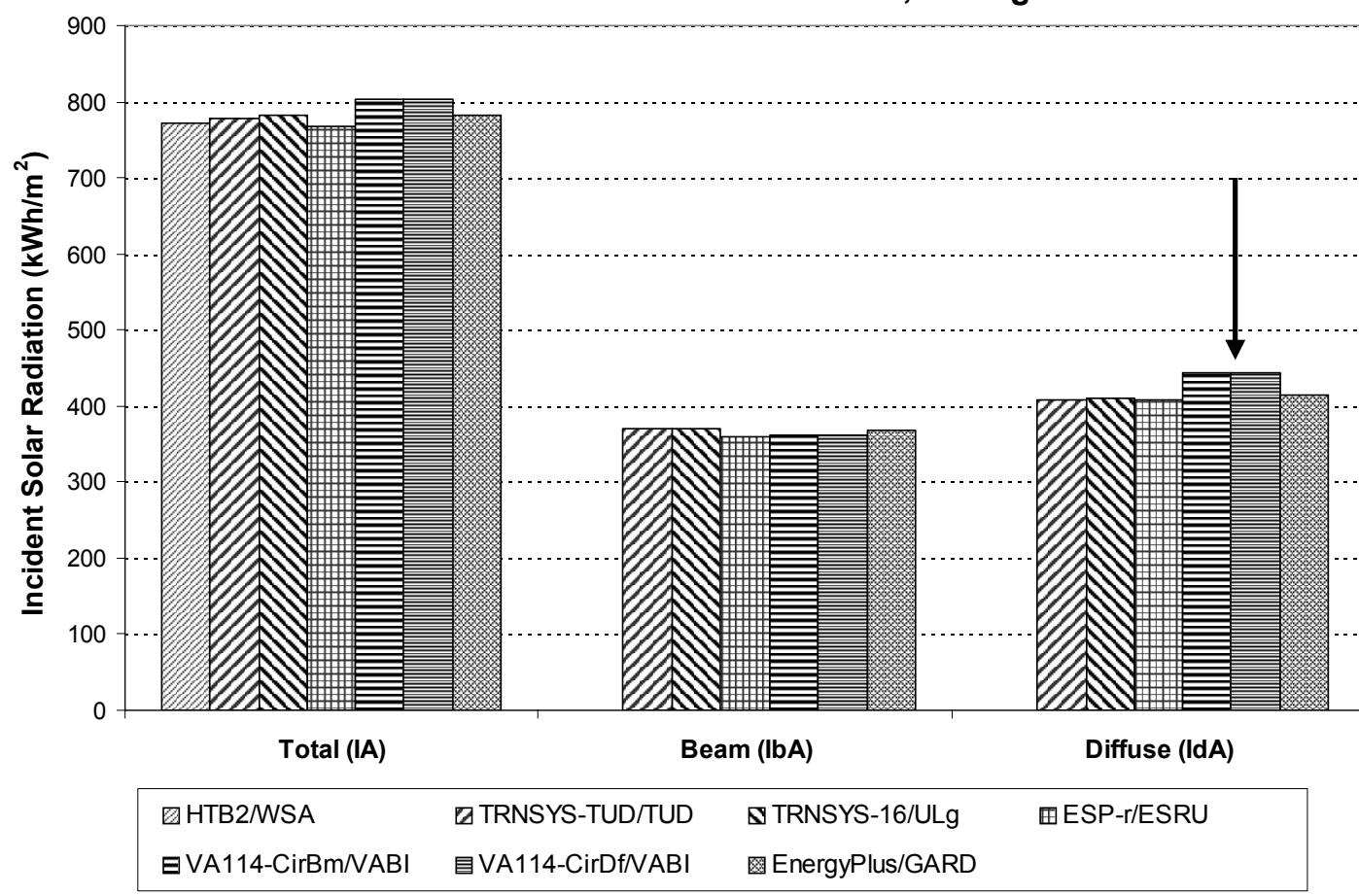

Figure 2-19. VA114 annual incident diffuse solar radiation disagreement

BESTEST Multi-Zone: MZ360 Internal Windows

March 15 (high dn) Hourly Transmitted Solar, Window "AB" (Zone B)

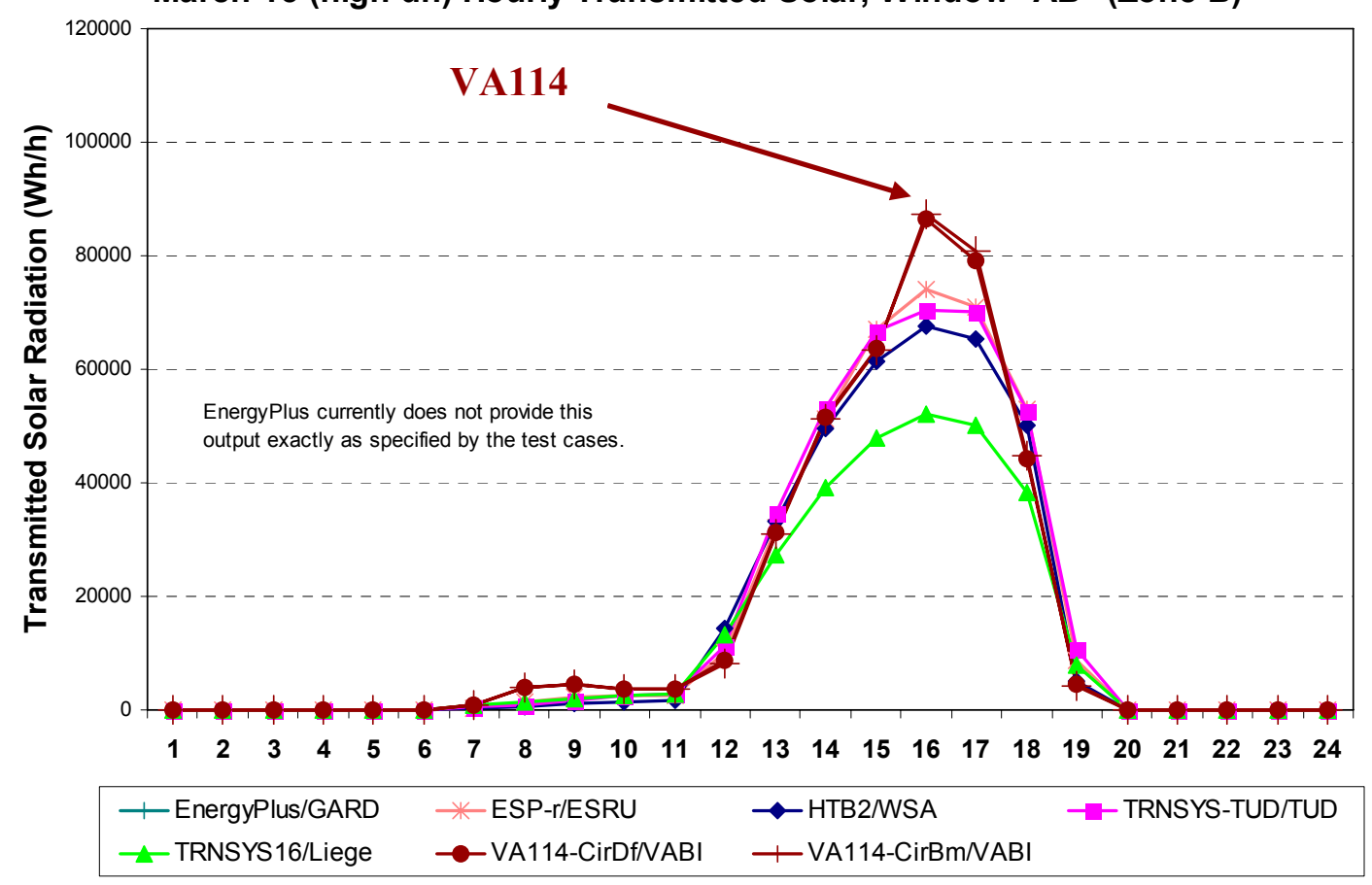

Figure 2-20. Hourly Transmitted Solar Radiation for Case MZ 360, Window AB, Submitted October 2007 


\subsubsection{TRNSYS-TUD}

TRNSYS is considered to be the most advanced program that DOE has sponsored for simulating active solar systems. The program was originally written at the University of Wisconsin. Technische Universitat Dresden (TUD) acquired a license for the source code and has since developed new source code for TUD's own calculation routines. This new version is designated TRNSYS-TUD, and was originally based on TRNSYS 14.2 distributed by TRANSSOLAR, Germany. New algorithms developed at TUD related to multi-zone modeling were tested for this project.

Two errors were reported by TUD in the September 9, 2005 draft of its modeler report. For these errors TUD did not submit prior results showing their effects. However, for one error it was possible to estimate its effect based on the occurrence of a similar error in another program. More detailed discussion is included with the TRNSYS-TUD modeler report in Section 2.9, Appendix II-D; also see Felsmann (2008).

\subsubsection{Zone cooling load not equal to transmitted solar radiation; discussed in September 9, 2005 modeler report, 3\%-4\% increase in cooling load for Case MZ340}

The TUD participant discussed in the modeler report that, although it was assumed that interior walls do not reflect any solar radiation (solar absorptance $=1$ ) and ideal windows neither reflect nor absorb any solar radiation (solar transmittance $=1$ ), the zone cooling load was not equal to the net transmitted solar radiation. The reason for this error was that within a zone, i.e., just after passing through the window, solar radiation was treated to be diffuse before contact with interior walls. This caused some transmitted solar radiation to be lost back out the window before contacting (potential reflection by) any interior surfaces (no such reflection occurs in these idealized test cases). To avoid this problem, the calculation procedure for solar distribution was revised. In the current program version only solar radiation that was reflected at interior surfaces (walls and windows) is diffusely reflected. For cases MZ340, MZ350, and MZ360 with idealized windows and interior walls, the cooling load now equals the transmitted solar radiation, as shown in the final results of Part III. The TUD participant did not provide results before fixing this error, but recollects that for the initial run of Case MZ340, cooling load was 3\%-4\% lower than total solar radiation transmitted into the zone. This matches the effect of a similarly described error documented for EnergyPlus (see Section 2.4.1.1), where the effect of fixing this error was a $4 \%$ increase in cooling load for cases MZ340 and MZ350, and a 33\% increase in cooling load for Case MZ360.

\subsubsection{Ray tracing algorithm error; discussed in September 9, 2005 modeler report; effect of error not given}

TRNSYS-TUD offers the option to use ray tracing for direct solar radiation that enters the room through an external window. Only multi-zone test Case MZ360 was calculated with this program feature. Use of ray tracing has no effect in cases MZ340 and MZ350, because the solar absorptance of interior surfaces is 1 and there is no heat conduction between zones; so it does not matter on which surface solar radiation has been absorbed. Ray tracing has a substantial effect for Case MZ360 because transmittance of solar radiation through an internal window depends on how beam radiation is modeled (Felsmann 2008). The test results revealed a loop error in the calculation routine that only occurred if there are at least two zones in a building. TUD did not submit prior results showing the effect of this revision. 

AB transmitted radiation as $100 \%$ diffuse for Case MZ360; 15\%-23\% effect on specific zone load

To check the importance of detailed modeling of interior solar distribution for zones with internal windows, TUD used the test cases to compare results of models included in TRNSYS-TUD. For Case MZ360, the comparison between a simplified solar distribution model that assumes any solar radiation entering a room to be diffuse versus a more detailed ray tracing model (developed between 2001 and 2004) for the direct part of solar radiation shows substantial differences in solar transmission through internal windows and annual cooling load. In Figure 2-21 the annual transmitted solar radiation of each zone as calculated from the models with and without ray tracing are compared. Transmittance into Zone A must be the same in both approaches, but transmittance through Window $\mathrm{AB}$ into Zone $\mathrm{B}$ is much higher if the ray tracing model is used. This consequently has an impact on annual cooling load, where Figure 2-22 shows that for the ray tracing method annual cooling load is lower in zone A and higher in Zone B than for the simplified method. The total annual cooling load of the building is the same for both models, as expected for the non-reflective interior surfaces. The TRNSYS-TUD modeler report (see Section 2.9, Appendix II-D) includes further discussion of this comparison, including figures showing effects of the different modeling techniques on dynamic (hourly) load profiles.

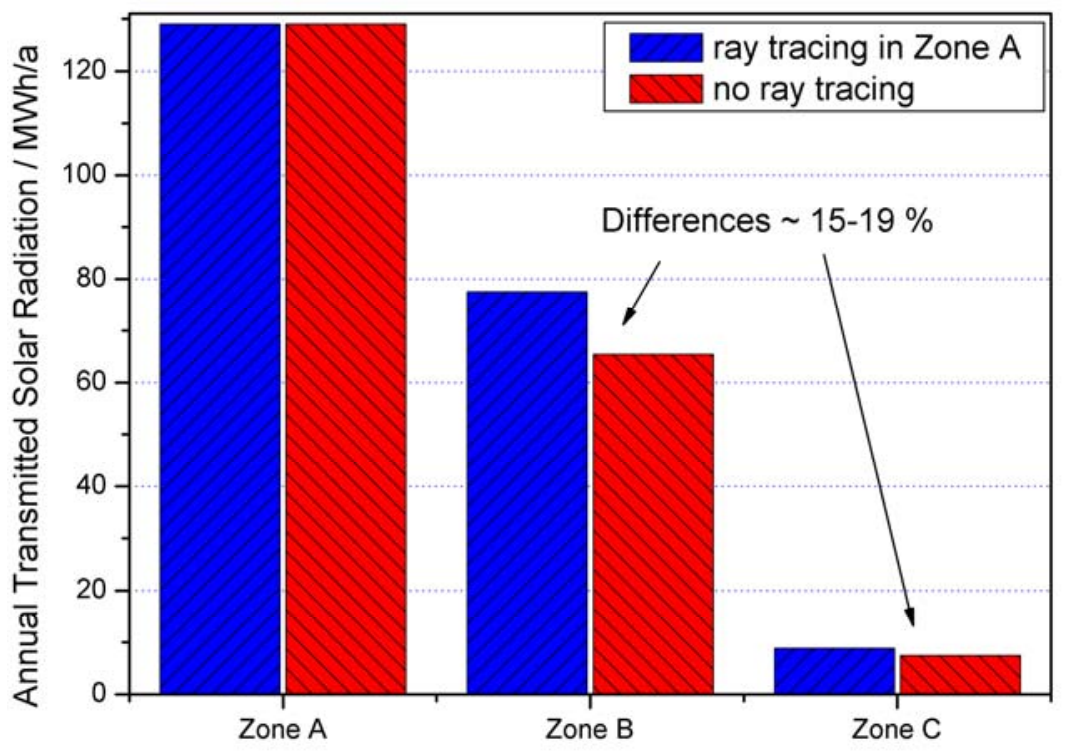

Figure 2-21. MZ360, comparison of annual transmitted solar radiation 


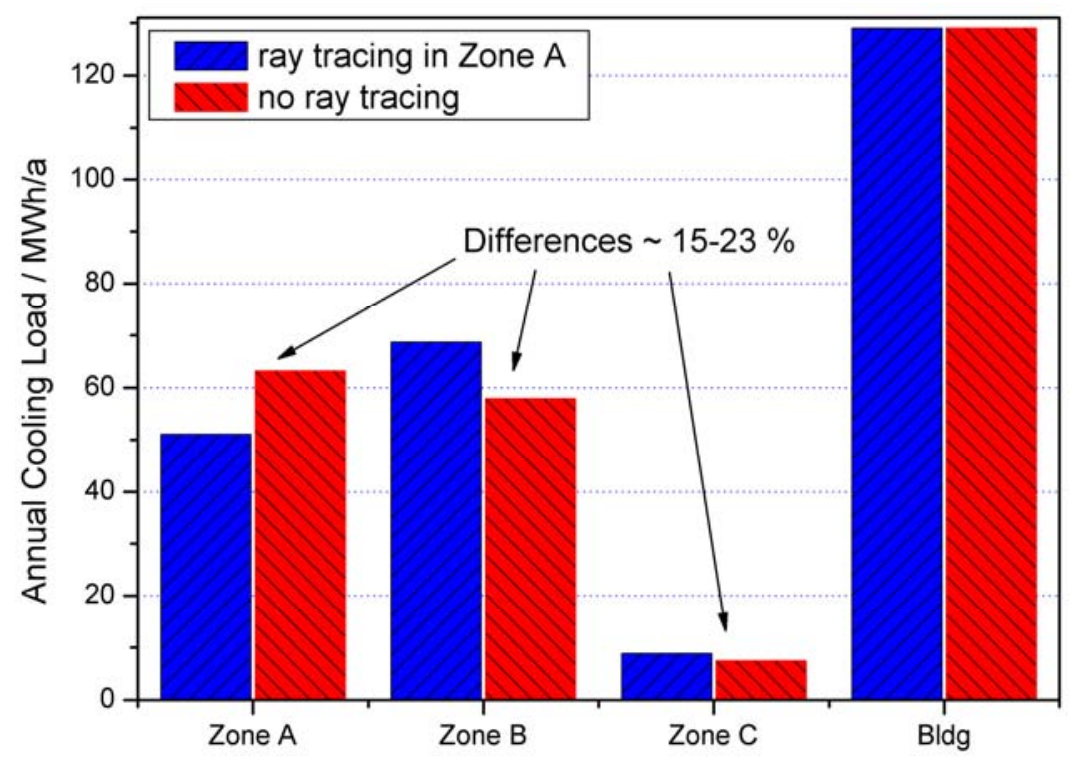

Figure 2-22. MZ360, comparison of annual cooling loads

\subsubsection{No disaggregation of direct and diffuse solar in output}

For results submitted in September 2005, TRNSYS-TUD did not disaggregate transmitted direct and diffuse solar radiation from total solar radiation in its output. The TRNSYS-TUD developers agreed that disaggregating solar radiation in the output is a useful diagnostic feature, and included that capability in their software for generating results submitted in September 2006.

\subsubsection{Shading model input error; $30 \%-40 \%$ effect on cooling load for zones $B, E, C$, and $F$, and $5 \%-8 \%$ on cooling loads for zones $A$ and $D$}

For results submitted in September 2005, TRNSYS-TUD indicated a disagreement for Case MZ350 (shaded) hourly transmitted solar radiation, as shown in Figure 2-23. Additionally, results for sensitivity Case MZ340-MZ350 annual shaded solar radiation indicated low shaded solar radiation for zones B and E, and high shaded solar radiation for zones $\mathrm{C}$ and F, as shown in Figure 2-24.

The reason diagnosed for that disagreement was incorrect input of the shading device. In TRNSYS, shading devices are modeled by assigning a separate wing-wall to each window. During this process the left- and right-hand sides of the window were juxtaposed such that they were seen as viewed from the room to the outside rather than from outside into the room. So the initial calculations were for a shading device moved to the south for zones $\mathrm{C}$ and $\mathrm{F}$ (higher shading effect) and assumed to be moved to the north for zones $\mathrm{A}, \mathrm{B}$, D, and E (lower shading effect), which is why Figure 2-23 shows additional unshaded solar (Felsmann 2008).

Based on the disagreement shown in Figure 2-25 versus the mean of the other results shown, and current agreement for results shown in Part III, the effect of this input error is $30 \%-40 \%$ on cooling loads for zones $\mathrm{B}, \mathrm{E}, \mathrm{C}$, and $\mathrm{F}$, and $5 \%-8 \%$ on cooling loads for zones A and D. 


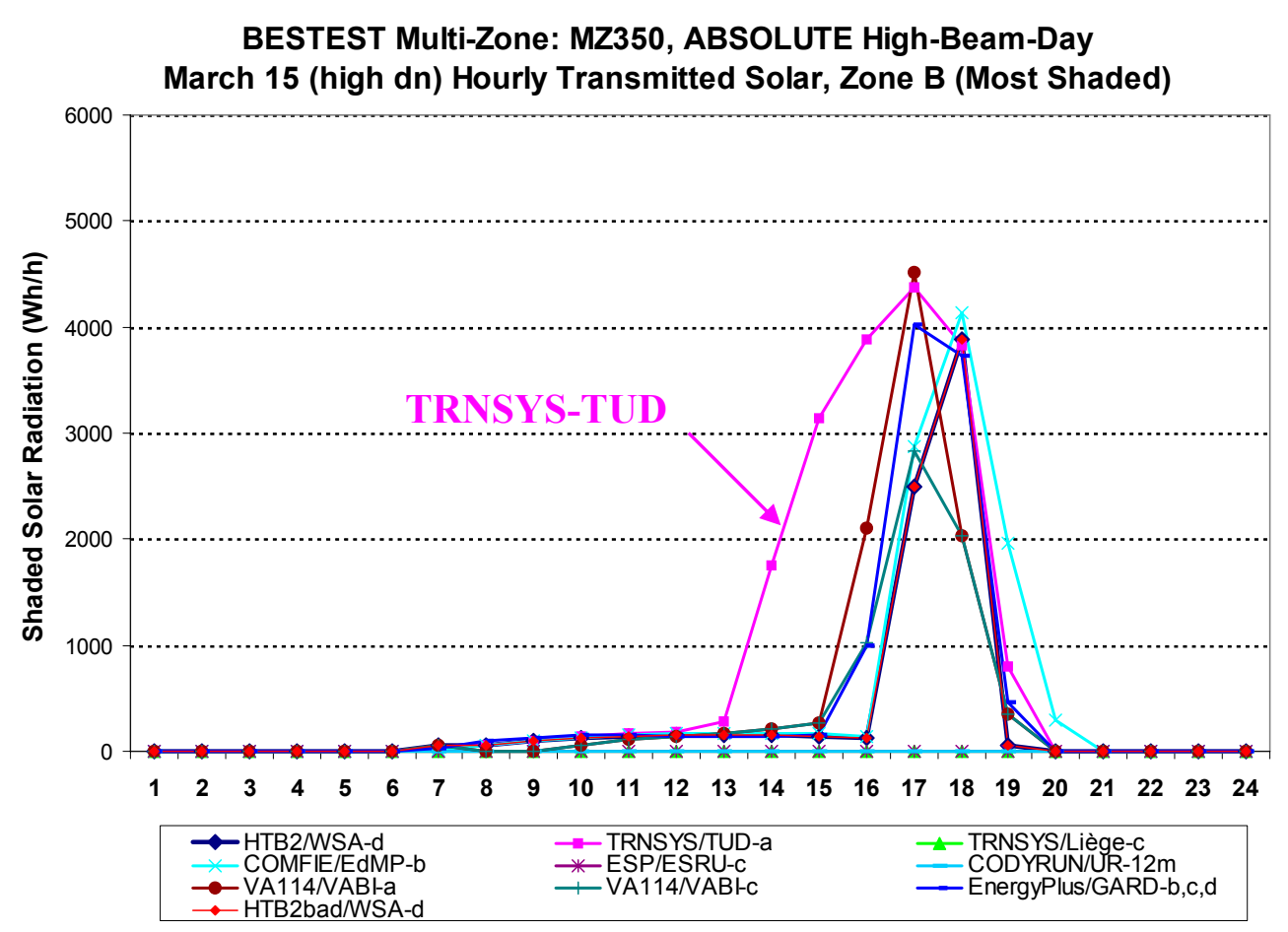

Figure 2-23. TRNSYS-TUD disagreement for Case MZ350 hourly transmitted solar for diffusedominated day, from results submitted September 2005

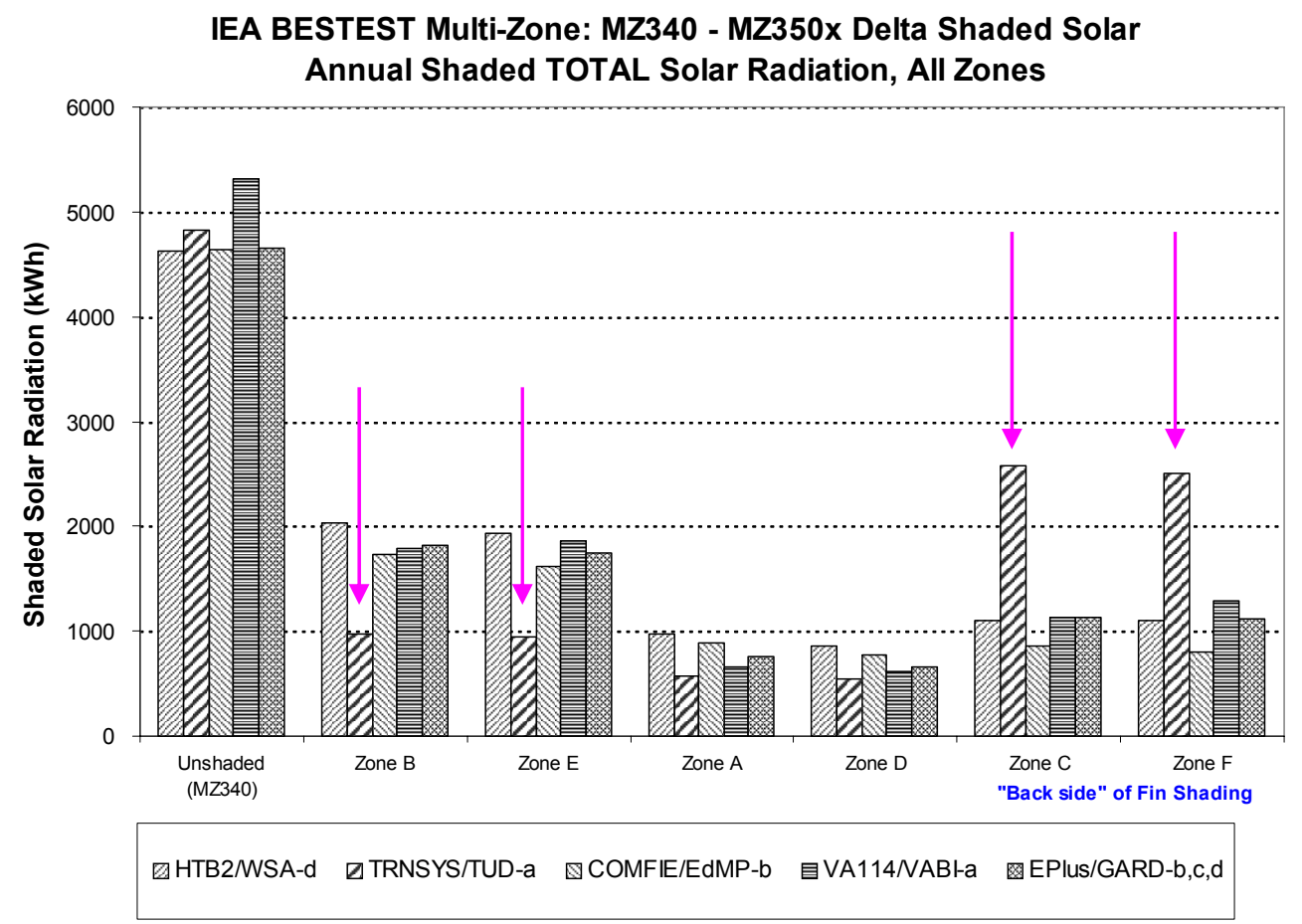

Figure 2-24. TRNSYS-TUD disagreement for Case MZ350 annual total shaded solar radiation, from results submitted September 2005 


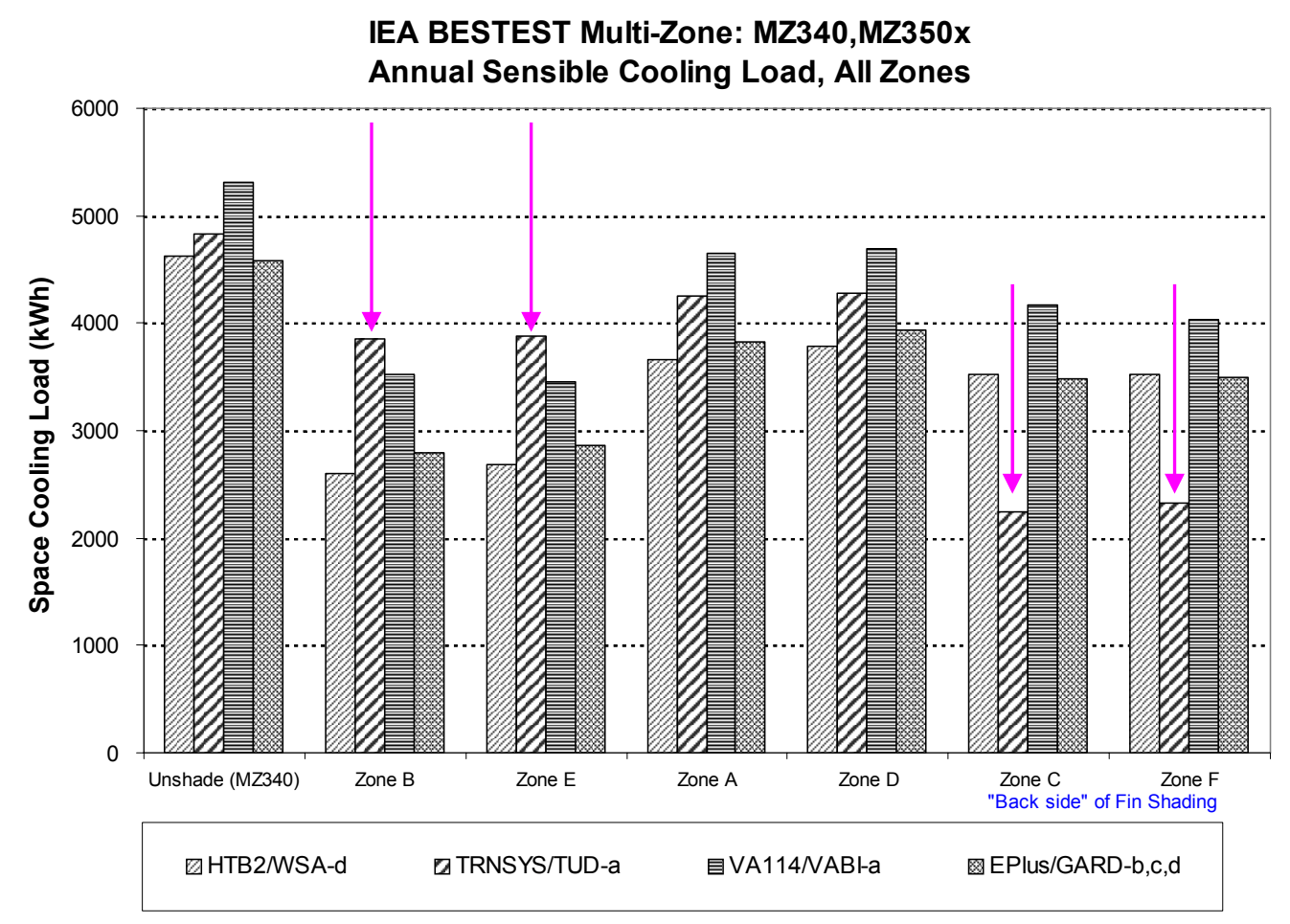

Figure 2-25. TRNSYS-TUD disagreement for Case MZ350 annual sensible cooling load, from results submitted September 2005

\subsubsection{Calculation of solar transmittance as function of incidence angle; $1 \%$ effect on cooling load for Case MZ340}

Normally TRNSYS-TUD internally calculates window optical properties as a function of incidence angle using a quartic approximation based on optical properties given at discrete incidence angles $(0,10$, $20 \ldots 90$ degrees). Figure 2-26 shows both transmittance as defined in the specification and as used in the TRNSYS-TUD model based on the approximation formula. Because of this difference TRNSYS-TUD was revised to check for the root mean square of the difference between optical properties given for certain incident angles and those normally calculated internally. If the RMS is greater than a critical value TRNSYS-TUD now linearly interpolates between values (Felsmann 2008).

Based on results submitted in December 2005 and September 2006 applying the software revision, Case MZ340 (unshaded) total transmitted solar radiation using TRNSYS' isotropic diffuse model increased $1 \%$, from $12327 \mathrm{kWh} / \mathrm{y}$ to $12454 \mathrm{kWh} / \mathrm{y}$ as a result of this modeling improvement. A similar increase was observed for April 2008 sensitivity tests by TUD using the Reindl solar radiation model. 


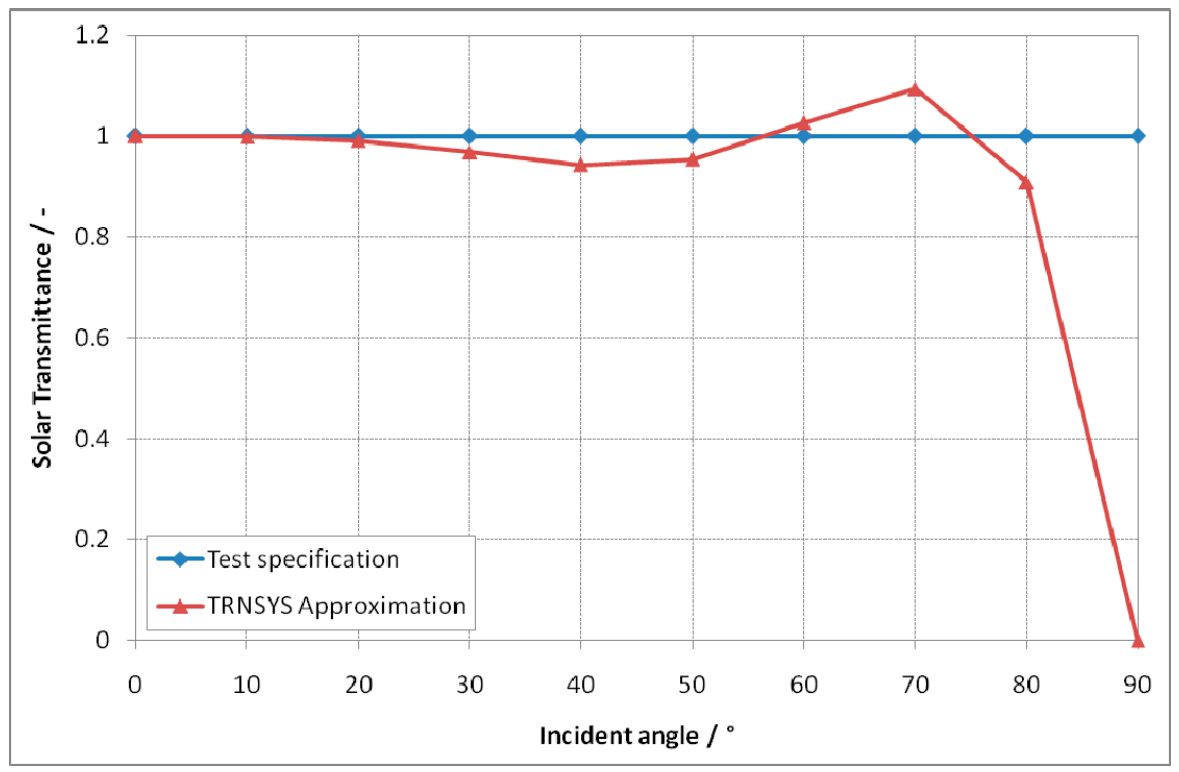

Figure 2-26. TRNSYS-TUD approximation of solar transmittance depending on incident angle for a window with $100 \%$ transmittance (Felsmann 2008)

\subsubsection{No beam radiation to Zone C of Case MZ360; likely increase for Zone C cooling load of $220 \%$ and overall building cooling load of $5 \%$}

Current results for Zone $\mathrm{C}$ in Figure 2-27 (see arrow) indicate that Zone $\mathrm{C}$ cooling load may be low. The TRNSYS-TUD modeler report (see Section 2.9, Appendix II-D) indicates that TRNSYS-TUD allows transmission of diffuse radiation only (no direct beam radiation) through a second-in-series internal window (Window BC). Comparison with results for programs that allow transmission of direct-beam radiation through Window BC (ESP-r and VA114) indicate that including transmission of direct-beam radiation would increase the Zone $\mathrm{C}$ cooling load by a factor of 1.8 to 2.6 (factor of 2.2 average estimate). This could cause about $5 \%$ underestimation of total building cooling load, assuming half the beam radiation modeled as diffuse is lost back through Window AO. The EnergyPlus and TRNSYS-16 models also exclude transmission of beam radiation, and have Zone $C$ results similar to the TRNSYS-TUD results. Disaggregated transmitted direct and diffuse solar radiation results for Case MZ360 are included in Part III. As double-skin facades become more popular in buildings (see Poirazis 2007), more accurate modeling of solar radiation through a series of internal windows gains importance. The TRNSYS-TUD developers have been notified of this issue. 


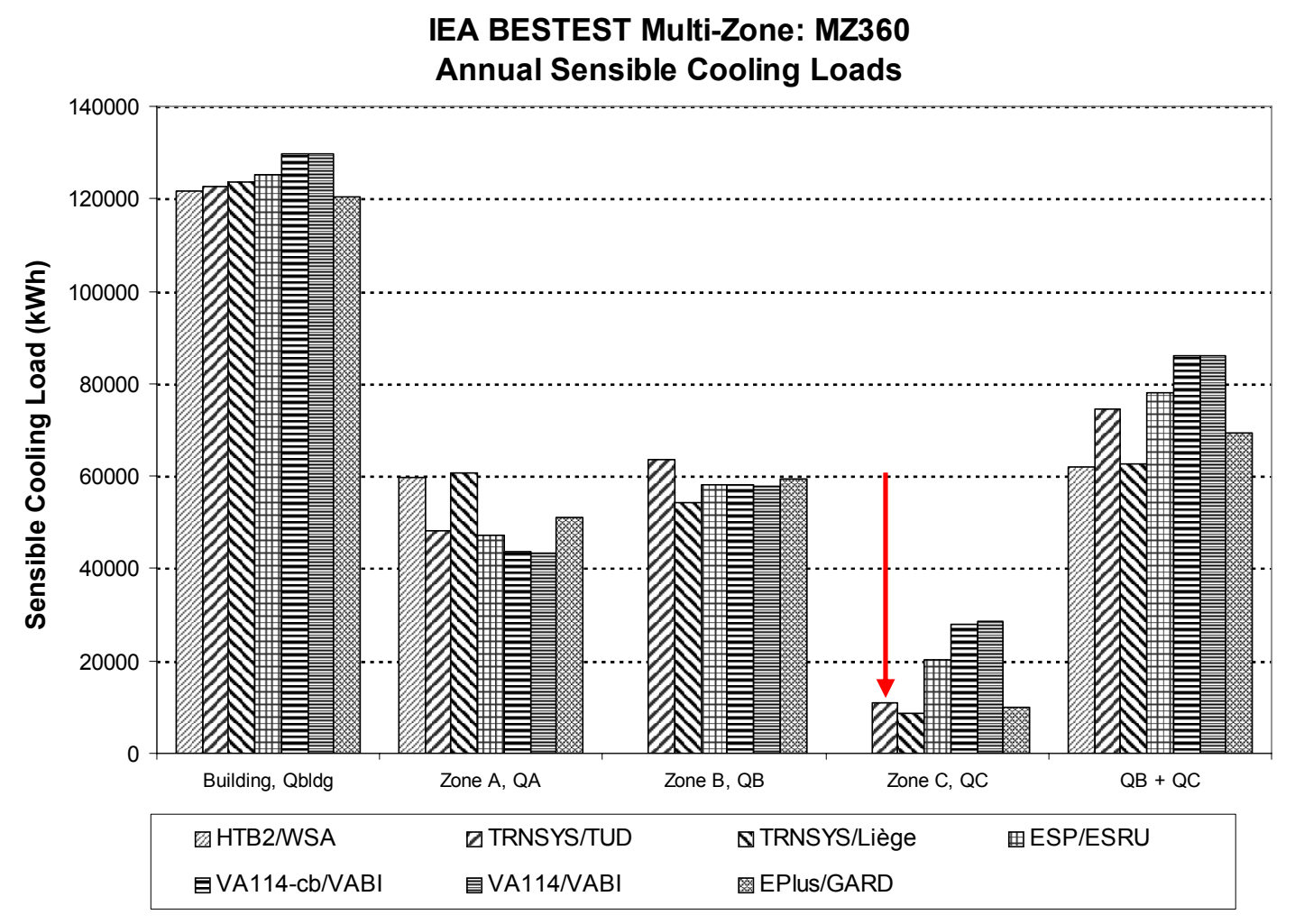

Figure 2-27. Annual cooling loads for Case MZ360 indicating low Zone C cooling load attributable to no beam radiation transmitted to Zone $C$ (through Window $B C$ )

\subsubsection{Inconsistency with implementation of Reindl diffuse solar radiation model for unshaded and shaded cases; for Case MZ340-MZ350 sensitivity: potential 18\%-32\% effect on annual diffuse shaded solar radiation (MZ340-MZ350), potential 9\%-14\% effect on annual cooling load sensitivity for shading (total shaded solar radiation)}

The TRNSYS-TUD modeler report indicates a modeling difficulty that occurred is an inconsistency related to TRNSYS' implementation of the Reindl anisotropic sky model for shading calculations. Although windows without a shading device apply the Reindl model, for a shaded window both skydiffuse and ground reflected radiation apply diffuse solar radiation based on an isotropic sky model. Thus, when the Reindl model is applied the comparison of results for shading sensitivity Case MZ340-MZ350 apply different diffuse radiation models. Estimation of the disagreement for shaded diffuse solar radiation that results from use of inconsistent models among the cases MZ340 and MZ350 is shown in Figure 2-28. This indicates that the potential effect of the modeling inconsistency is an $18 \%-32 \%$ effect on annual diffuse shaded solar radiation for sensitivity Case MZ340-MZ350 (compare results for "TRNSYS/TUD'Reindl"” to "TRNSYS/TUD-a" in Figure 2-28). This represents a potential 9\%-14\% effect on annual cooling load sensitivity (total shaded solar radiation) for sensitivity Case MZ340-MZ350.

This problem has been reported to the TRNSYS-TUD author. Currently, to obtain consistent results for their implementation of the test specification, they have applied the isotropic sky model option. 


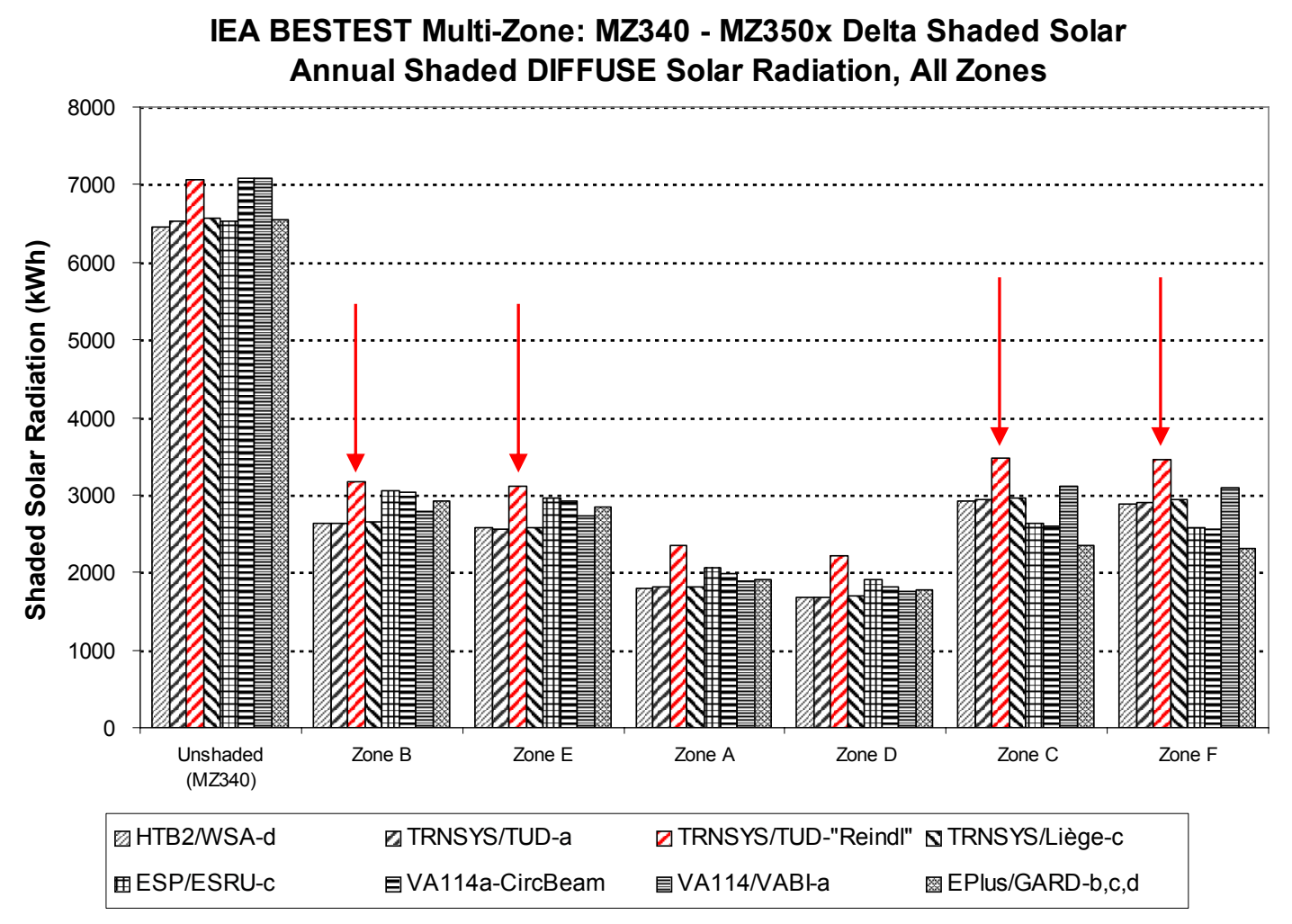

Figure 2-28. Reindl model implementation inconsistency in TRNSYS-TUD

2.4.5.9 Further observations about Reindl versus isotropic diffuse solar model; $4 \%$ effect on annual load, $8 \%$ effect on annual peak load

Figure 2-29 indicates the difference between the Reindl and isotropic models for hourly results. For these test cases, this difference for hourly behavior of the sky models seems consistent with the relatively lower annual hourly integrated peak cooling loads for the final results as indicated by the arrow for Case MZ340 in Figure 2-30. (Compare TRNSYS-TUD, TRNSYS-16 and HTB2 results that use isotropic diffuse sky models versus other results.) Annual and peak load effects of Reindl versus isotropic sky models are summarized in Table 2-9.

Table 2-9. Peak Load Differences for Reindl versus Isotropic Sky Models in TRNSYS-TUD

\begin{tabular}{|l|c|c|c|}
\hline $\begin{array}{l}\text { TRNSYS-TUD Case MZ340 } \\
\text { Results }\end{array}$ & Isotropic Model & Reindl Model & $\%$ Difference \\
\hline $\mathbf{Q}_{\mathrm{A}}$ (annual load) & $12454 \mathrm{kWh}$ & $12995 \mathrm{kWh}$ & $+4.3 \%$ \\
\hline $\mathbf{q}_{\mathrm{A}}$ (peak load) & $12164 \mathrm{~W}$ & $13091 \mathrm{~W}$ & $+7.6 \%$ \\
\hline
\end{tabular}


BESTEST Multi-Zone: MZ340 Unshaded

August 4 TOTAL Hourly Transmitted Solar, Zone A

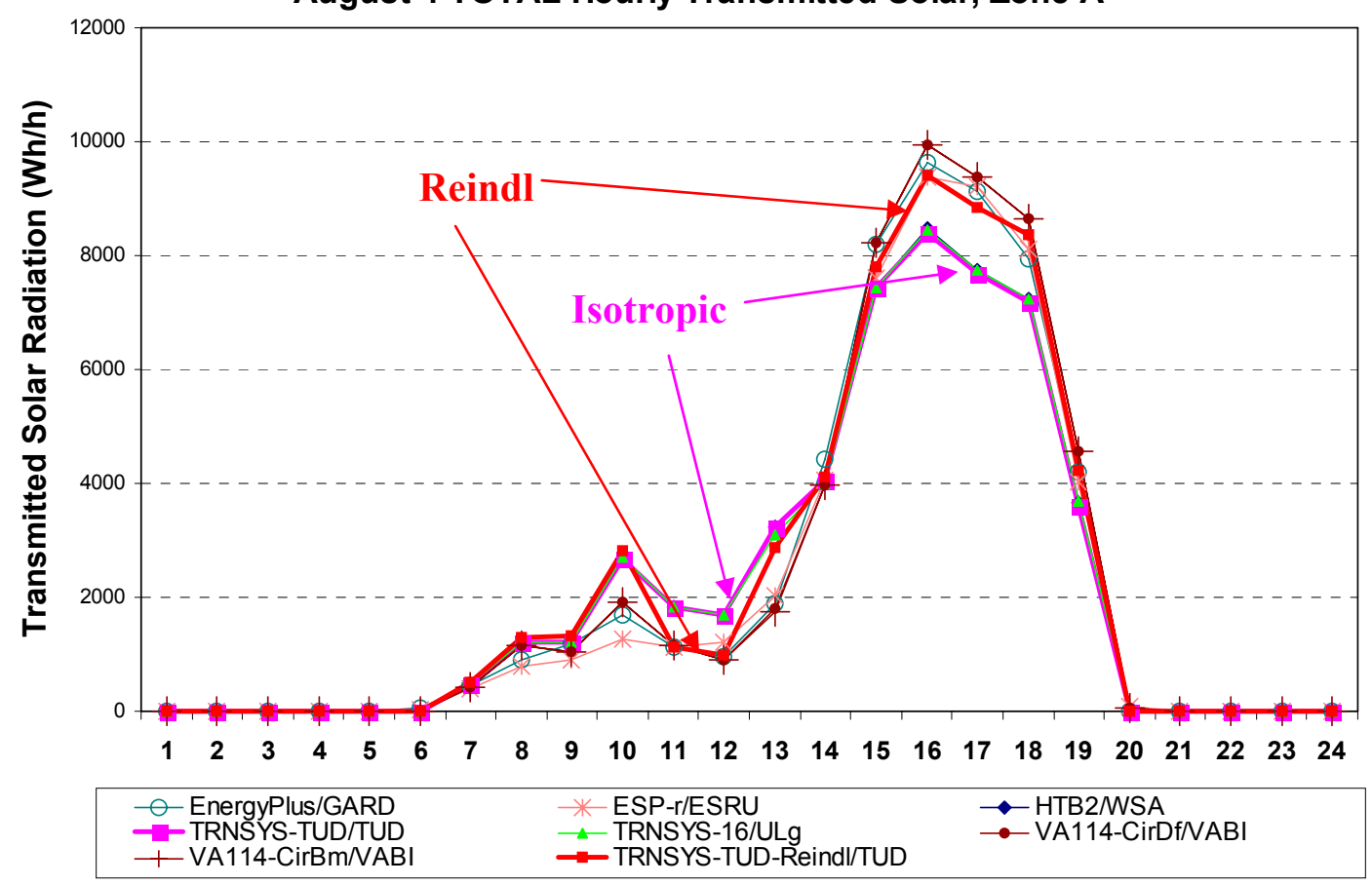

Figure 2-29. Reindl model versus isotropic sky model in TRNSYS-TUD

IEA BESTEST Multi-Zone: MZ340, MZ350, MZ355

Annual Hourly Integrated Peak Cooling Load, All Zones

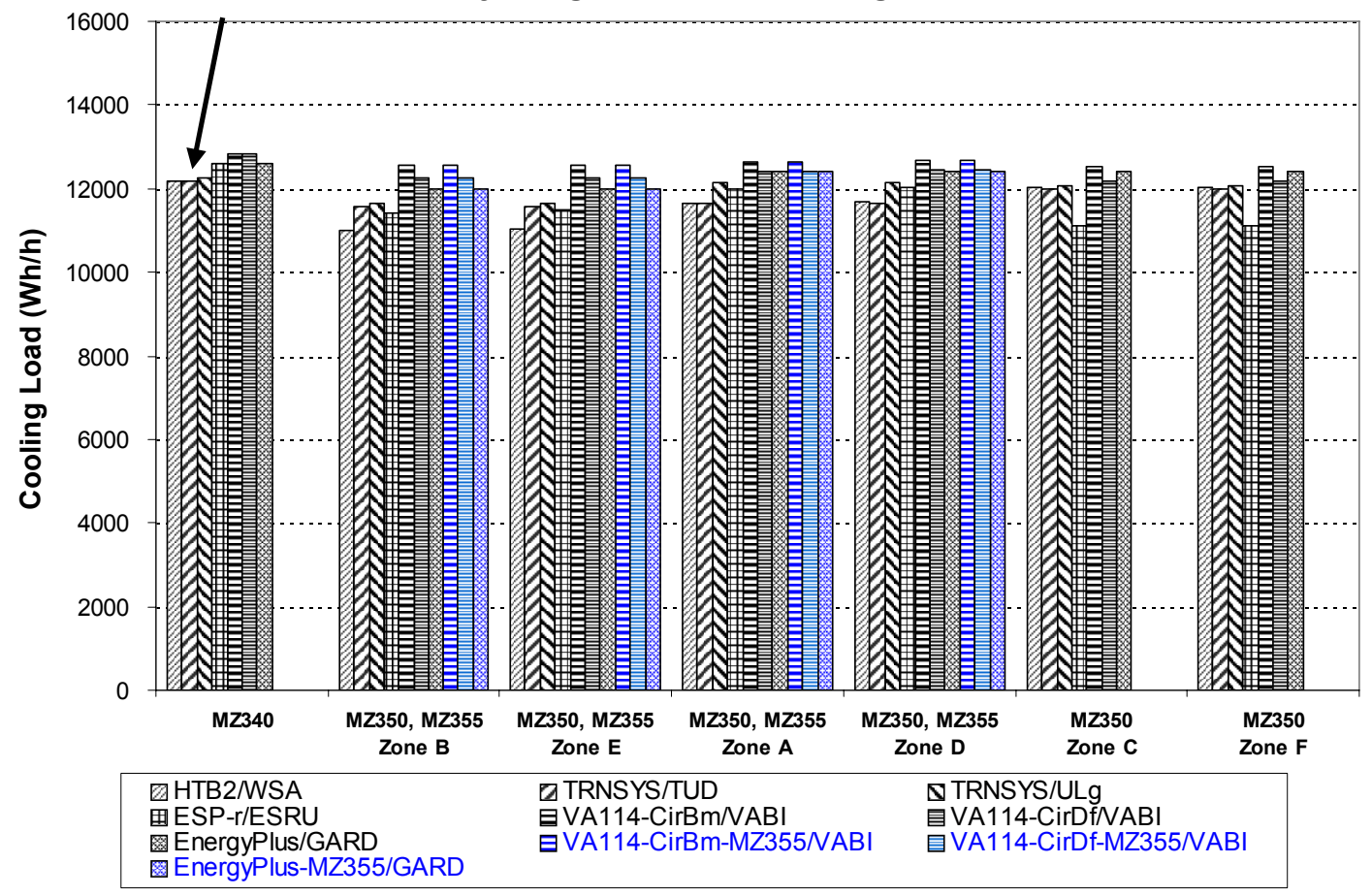

Figure 2-30. Integrated hourly peak cooling loads, Cases MZ340 through MZ355 


\subsubsection{TRNSYS-16}

TRNSYS is considered to be the most advanced program that DOE has sponsored for simulating active solar systems. The TRNSYS version is TRNSYS 16.01.0002, developed by Solar Energy Laboratory, University of Wisconsin-Madison, United States (University of Wisconsin 2005). The building model used in this work is TYPE 56, developed by TRANSSOLAR Energietechnik GmbH, Stuttgart, Germany. The ideal window was modeled using WINDOW 5.2. More detailed discussion of the modeling is included with the TRNSYS-16 modeler report by University of Liège in Section 2.9, Appendix II-E.

\subsubsection{Zone cooling load not equal to transmitted solar radiation; initially discussed in February 13, 2007 modeler report, effect of fixing similar error in another program was $33 \%$ increase in cooling load for Case MZ360 and 4\% increase in cooling load for cases MZ340 and MZ350}

The University of Liège (ULg) participants discussed in their modeler report that to have better control over diffuse radiation, it was added to direct radiation; otherwise, part of the initially transmitted diffuse radiation would be lost back out Window AO. This is a work-around for a problem that was fixed in TRNSYS-TUD (see Section 2.4.5.1), but not in TRNSYS-16. The ULg participants did not provide results before applying the work-around, so its effect is not known. However, for a similarly described error documented for EnergyPlus (see Section 2.4.1.1), the effect of fixing this error was 33\% increase in cooling load for Case MZ360 and 4\% increase in cooling load for cases MZ340 and MZ350. The ULg modelers have been asked to inform the TRNSYS-16 developers of this issue.

\subsubsection{Solar processor; $1.6 \%$ and $2.3 \%$ annual cooling load effect for MZ340 and MZ360 respectively, $8.6 \%$ peak cooling load effect (MZ340)}

Figure 2-31 indicates a disagreement for Case MZ340 unshaded hourly transmitted solar radiation for hour 19. This occurred for the Type 109 solar processor provided with TRNSYS. For subsequent simulation runs, ULg changed to the Type $16 \mathrm{~g}$ solar processor, which provided better agreement with the other results. The ULg modelers have been asked to inform the TRNSYS-16 developers of this issue. The change of solar processor had the following effects:

- $\quad$ Case MZ340 annual unshaded solar/load decrease $=1.6 \%$

- $\quad$ Case MZ340 peak load decrease $=8.6 \%$

- Case MZ350 (shaded) annual transmitted solar decrease $=1.6 \%$

- Case MZ350 (shaded) annual transmitted peak load decrease $=0.2 \%$

- $\quad$ Case MZ360 (internal windows) annual load decrease $=2.3 \%$.

2.4.6.3 Less detailed modeling method for TRNSYS-16 versus TRNSYS-TUD; for Case MZ360 annual cooling load effect of $27 \%$ and $15 \%$ for zones $A$ and B, respectively, peak cooling load effect of $81 \%$ and $23 \%$ for zones $A$ and $B$, respectively

For Case MZ360, Figure 2-32 (see red arrows) indicates that annual cooling loads for zones A and B are $27 \%$ higher and $15 \%$ lower, respectively, for TRNSYS-16 versus TRNSYS-TUD. Similarly, additional results included in Part III indicate that peak cooling loads for zones A and B are $81 \%$ higher and 23\% lower, respectively, for TRNSYS-16 versus TRNSYS-TUD. The difference is likely attributable to more detailed modeling of direct-beam radiation through Window AB using ray tracing for TRNSYS-TUD, versus less detailed modeling of transmitted solar radiation through Window AB for TRNSYS-16. This produces results differences similar to those observed for model sensitivity testing by the TUD participant documented in Section 2.4.5.3. The ULg modelers have been asked to inform the TRNSYS-16 developers of this issue. 
BESTEST Multi-Zone: MZ340 Unshaded March 15 (high dn) Hourly Transmitted Solar, Zone A

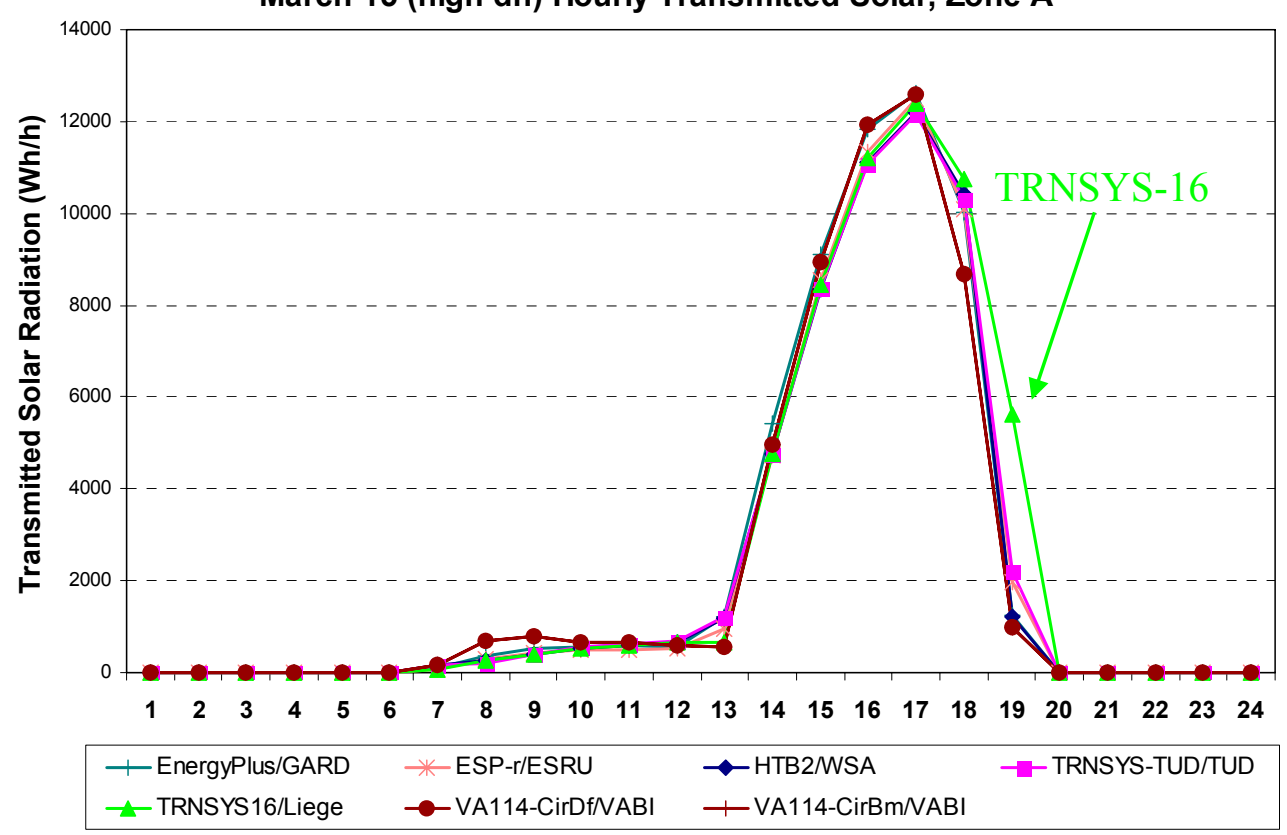

Figure 2-31. Case MZ340 March 15 unshaded hourly transmitted solar radiation, including TRNSYS-16 results submitted March 2007

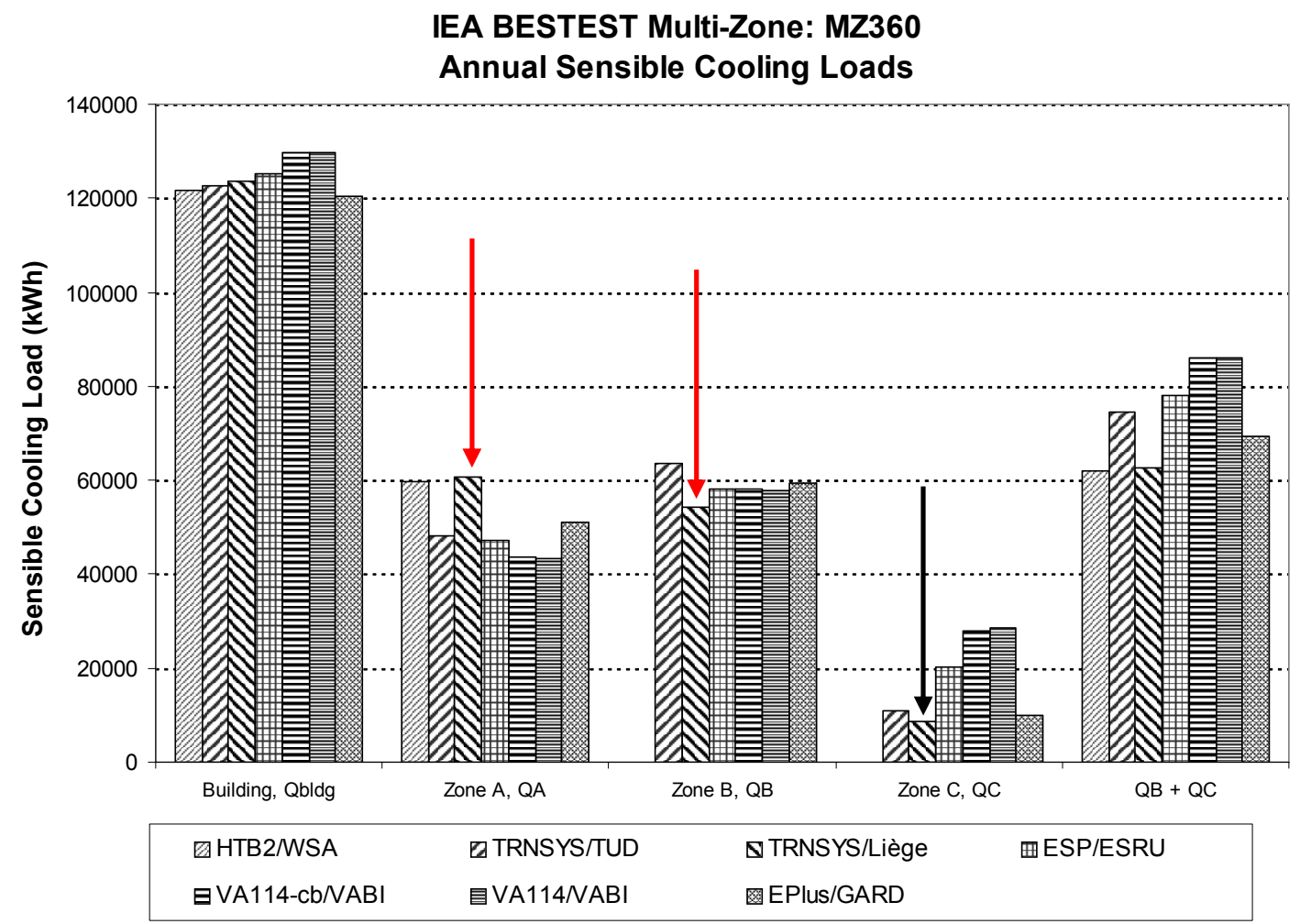

Figure 2-32. Annual cooling loads for Case MZ360 indicating differences between TRNSYS-16 and TRNSYS-TUD for Zones A and B, and low Zone C cooling load for both TRNSYS models 


\subsubsection{No beam radiation to Zone C of Case MZ360; likely increase for Zone C cooling load of $290 \%$ and overall building cooling load of $6 \%$}

Current results for Zone C, also shown in Figure 2-32 (see black arrow), indicate that Zone C cooling load may be low. The TRNSYS-TUD modeler report (see Section 2.9, Appendix II-D) indicates that TRNSYS-TUD allows transmission of diffuse radiation only (no direct beam radiation) through a secondin-series internal window (Window BC). It appears that similar behavior is exhibited by TRNSYS-16, although ULg indicates that for Zone $\mathrm{C}$ the allocation of direct and diffuse is recalculated as a function of user-defined average annual ratio (Andre 2008). Comparison with results for programs that allow transmission of direct beam radiation through Window BC (ESP-r and VA114) indicates that including transmission of direct beam radiation would increase the Zone $\mathrm{C}$ cooling load by a factor of 2.4 to 3.3 (factor of 2.9 average estimate). This could cause about $6 \%$ underestimation of total building cooling load, assuming half the beam radiation modeled as diffuse is lost back through Window AO. The EnergyPlus and TRNSYS-TUD models also exclude transmission of beam radiation, and have Zone C results similar to the TRNSYS-16 results. Disaggregated transmitted direct and diffuse solar radiation results for Case MZ360 are included in Part III. As double-skin facades become more popular in buildings (see Poirazis 2007), more accurate modeling of solar radiation through a series of internal windows gains importance. The ULg modelers have been asked to inform the TRNSYS-16 developers of this issue.

\subsubsection{CODYRUN}

CODYRUN is a whole-building energy simulation program under development at Laboratoire de Génie Industriel (Industrial Engineering Laboratory) of University of Reunion Island (UR), France. Information about the software is provided in the modeler report in Section 2.9, Appendix II-G.

\subsubsection{Constant surface coefficients not allowed; submitted with March 2005 modeler report, $2 \%-8 \%$ effect on zone cooling load for preliminary cases MZ200 and MZ300 based on results for a similar correction for another program}

The UR modeler report indicates that CODYRUN was modified to allow specification of individual wall convective surface coefficients. No results were submitted before changes were made; however, based on results for a similar modification described for COMFIE (see Section 2.4.8.1), there is potentially a $2 \%$ $8 \%$ effect on cooling load.

\subsubsection{Minor modifications to allow modeling of the test cases; submitted with March 2005 modeler report, effect of changes not given}

The UR modeler report discusses the following modifications that were made to CODYRUN to be able to run Case MZ320 as specified:

- Allow more significant digits for long wave emissivities; previous limit was 0.01

- Allow input of specific values for density and specific heat of air composing each thermal zone.

No results were submitted before changes were made, so the effects of the changes are not known. However, effects of these revisions should be minor. 


\subsubsection{Case MZ320 Zone C cooling load is $2 \%$ below analytical solution; authors}

notified

As shown in Figure 2-33, Case MZ320 Zone C load for CODYRUN is 2\% lower than the analytical solution; Zone A air temperature is $0.9^{\circ} \mathrm{C}$ above the analytical solution. Results for all other programs show much closer agreement with the analytical solution. The code authors have been notified of this disagreement.

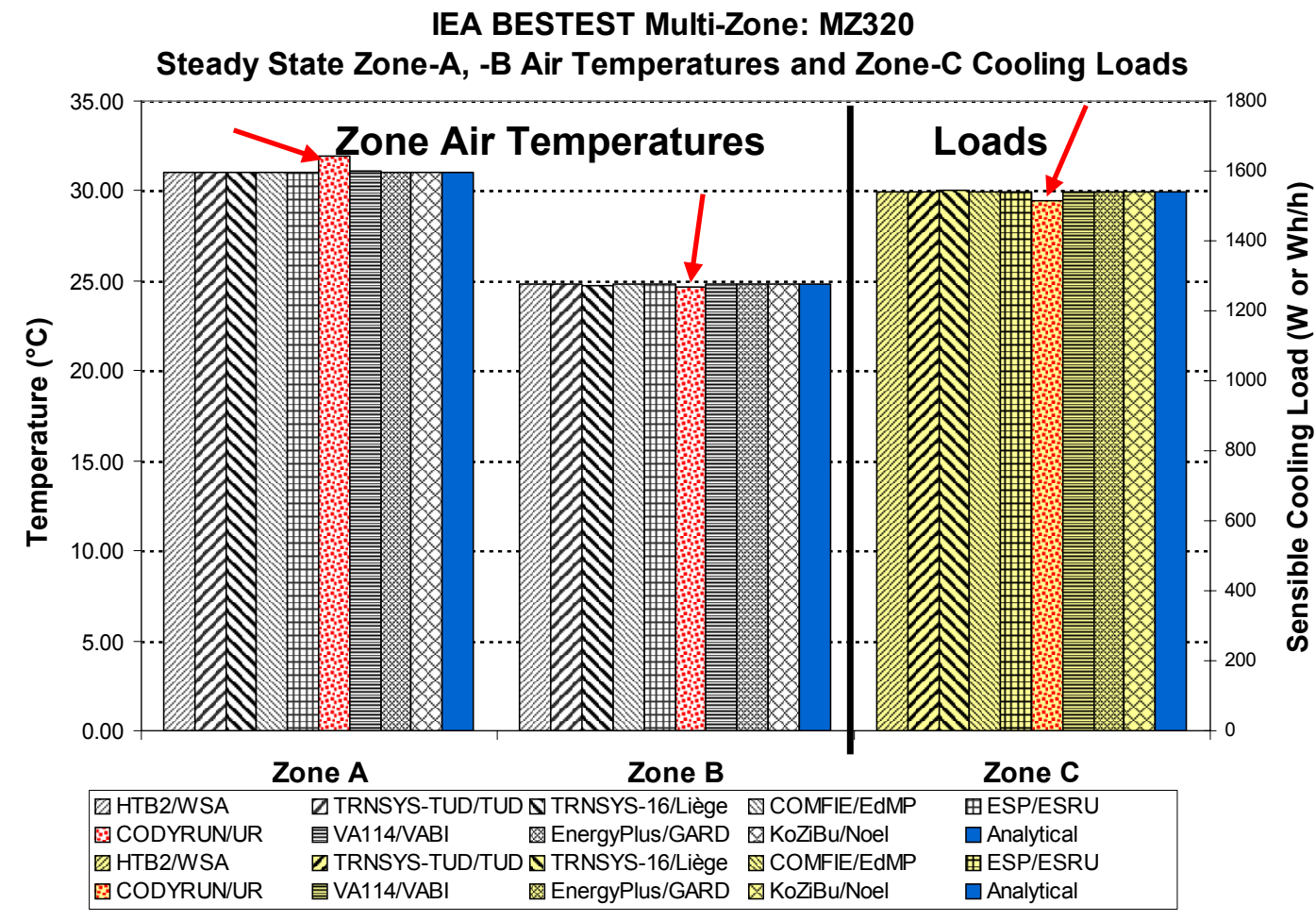

Figure 2-33. Results for Case MZ320 indicating CODYRUN disagreements 


\subsubsection{COMFIE}

COMFIE is a whole-building energy simulation program developed by Ecole des Mines de Paris and Izuba Energies (for the PLEIADES interface), France. Information about the software is provided in the modeler report in Section 2.9, Appendix II-H.

\subsubsection{Constant surface coefficients not allowed; $2 \%-8 \%$ effect on zone cooling load for preliminary cases MZ200 and MZ300}

As described in the COMFIE modeler report, COMFIE applies automatically calculated surface coefficients. For this work the COMFIE developers modified the source code so the constant combined surface heat transfer coefficients indicated in the test specification are used. This was hardwired for a custom version of COMFIE specifically for these test cases. The developers note in their modeler report that they do not plan to modify COMFIE to allow the user to choose surface heat transfer coefficients, because that would add unnecessary complexity to the user interface. Table 2-10 shows the effects of changing from automated to constant surface coefficients on zone cooling loads for preliminary cases MZ200 and MZ300 (for the May 2004 preliminary version of the test specification — see Section 2.3.1).

Table 2-10. Effect of Constant versus Automated Surface Coefficients for COMFIE

\begin{tabular}{|l|c|c|}
\hline Case & $\mathbf{q}_{\mathbf{A}}(\mathbf{W})$ & $\mathbf{q}_{\mathbf{B}}(\mathbf{W})$ \\
\hline MZ200 - automated surface coefs & 704 & 1294 \\
\hline MZ200 - constant surface coefs & 653 & 1345 \\
\hline Del \% MZ200, (auto - const)/const & $\mathbf{+ 7 . 8 \%}$ & $-\mathbf{3 . 8 \%}$ \\
\hline MZ300 - automated surface coefs & 1282 & 1578 \\
\hline MZ300 - constant surface coefs & 1257 & 1603 \\
\hline Del \% MZ300, (auto - const)/const & $\mathbf{+ 2 . 0 \%}$ & $\mathbf{- 1 . 6 \%}$ \\
\hline
\end{tabular}




\subsection{Interpretation of Results}

\subsubsection{Use of Calorimetry and an Analytical Solution to Isolate Effects of Specific Models}

The diagnostic power of test cases is enhanced when modeling errors are easy to identify. Identification of errors is facilitated when the potential range of disagreement for a given set of test results is minimized, which can occur when a specific modeling effect is isolated as well as possible by a given test case. This requires minimizing noise from other models used to perform a whole-building simulation that are not intended to be tested by a given test case. Specification of precise boundary conditions required for analytical verification tests inherently isolates the effects of specific models and inhibits extraneous noise, thereby minimizing potential legitimate disagreement among simulation program results (Neymark and Judkoff et al. 2008; Neymark and Judkoff 2002) Where meaningful analytical verification cases cannot be achieved, diagnostic comparative tests can be designed with a strong signal-to-noise ratio for the phenomena of interest.

A major accomplishment of this work was to enhance the diagnostic power of the multi-zone shading and internal window test cases by using building zones designed to be precise calorimeters, where the only thermal mass is for the zone air. The basic principle is that all solar radiation incident on an exterior window is captured within a zone, such that the zone cooling load is equivalent to the solar radiation incident on that window. This is achieved by specifying ideal windows with solar transmittance $=1$ and thermal conductance $=0$, and non-conductive exterior and interior walls, where interior walls have solar absorptance $=1$ (to eliminate reflections). Constant combined interior surface coefficients are also applied, and are sufficiently high to avoid a simulation crash that may be caused by high interior surface temperatures. Causes of disagreements are therefore limited to an issue with the specific model being tested (the shading or internal window model), modeling of incident solar radiation, inability to precisely model the idealizations defining the zone as a calorimeter, or an input error. Additionally, sensitivity "delta" cases (MZ350-MZ340, MZ355-MZ340) allow intermodel comparison of the difference between zone cooling loads with a shading device and without shading. This allows better isolation of shading model effects, as differences among models not related specifically to shading models should cancel out.

The effects of thermal mass were not tested in these new cases because the original IEA BESTEST ${ }^{1}$ comparative cases explored building envelope thermal mass effects in detail in a single-zone context (and in a two-zone case with a sunspace). By excluding thermal inertia and minimizing other simultaneous effects, the current specialized multi-zone cases maximize diagnostic power, and also minimize the number of cases required to address the tested phenomena. In the absence of multi-zone mass interaction test cases for the current configurations, if a simulation model demonstrates agreement for the original IEA BESTEST cases with thermal mass and demonstrates agreement for the new multi-zone test cases, that would suggest that such tested simulations may provide agreement where aspects of both types of test cases are combined. As thermal mass interactions (and other interactions) are important to test explicitly, our recommendations for future activities (see Section 2.5.3) include developing multi-zone cases with thermal mass.

It was possible in these test cases to specify limits of parametric extremes required to define zones as precise calorimeters, because all but one project participant were also authors of the programs being tested. Having program authors do the modeling for this project was important because they understand which parametric extremes can be exactly modeled for a given program versus which extremes must be approximated for their program to run in a stable manner. Absolute limits of parametric extremes could not be used for the IEA BESTEST single-zone cases (Judkoff and Neymark 1995), because an objective for those cases was to allow non-code authors to run them, so that selected parametric extremes were 
chosen to excite modeling sensitivities as robustly as possible while avoiding stability issues (e.g., divide by zero).

Improvement in the ability to diagnose shading models using this calorimetry method for in-depth diagnostics is evident from comparing final disagreement ranges for the original single-zone IEA BESTEST shading cases versus the final range of disagreement for the new in-depth diagnostic multizone shading cases, as discussed in Section 2.5.2. The improved diagnostics also allowed identification of 44 disagreements related to modeling multi-zone shading and internal windows, resulting in 28 fixes to the models so far, as documented in Section 2.6.1.2.

Another accomplishment of this work is the development of a relatively simple steady-state analytical solution for testing the modeling of multi-zone conduction, which provides a mathematical truth standard. Here the term analytical solution is the mathematical solution of a model that has an exact result for a given set of parameters and simplifying assumptions. In general, it is difficult to develop worthwhile test cases that can be solved analytically, but such solutions are extremely useful.

Where simulation programs have results that disagree substantially with analytical solution results, investigating the sources of the differences is recommended. In this case a difference does not necessarily mean that such a program or model is faulty, because differences among modeling techniques, boundary condition approximations, and other input assumptions may cause unavoidable differences among results. However, our collective experience in this task and previous BESTEST work has indicated that when such programs show substantial disagreement with analytical solution results, we often find a coding error, a questionable algorithm, a documentation problem, or an input error. Similarly, for the comparative test cases, where a simulation program has results that fall substantially outside of the range of disagreement of the example results, investing the source of the difference is recommended. Criteria for determining agreement among results is provided in Section 1.2.2.1.

It is important to understand the difference between a mathematical truth standard and an absolute truth standard. In the former, we test only the solution process for a model, not the appropriateness of the solution; that is, we accept the given underlying physical assumptions while recognizing that these assumptions represent a simplification of physical reality. An approximate truth standard from an experiment tests both the solution process and appropriateness of the model within experimental uncertainty. The ultimate or absolute validation truth standard would be a comparison of simulation results with a perfectly performed empirical experiment, with all simulation inputs perfectly defined. In reality, an experiment is performed and the experimental object is specified within some acceptable range of uncertainty. Such experiments are possible, but expensive. We recommend developing a set of empirical validation experiments in the future.

\subsubsection{Improvements to Simulations during the Field Trials}

Because of iterative correction of input errors, software bugs, and clarification of the test specifications, the agreement among simulation results improved with each iteration of the field trials. Improvements to simulation programs or simulation inputs made by participants must have a mathematical and a physical basis, and must be applied consistently across tests. Arbitrary modification of a simulation program's input or internal code just for the purpose of more closely matching a given set of results is not allowed. Also, all improvements were required to be documented in modeler reports.

Initial results for the preliminary version of the multi-zone conduction cases, with adiabatic exterior walls and conducting internal walls (cases MZ200 and MZ300) are shown in Figure 2-34. Disagreement for the initial two- and three-zone cases with a simple analytical solution ranged from $6 \%$ to $8 \%$, where only two programs are shown as disagreeing. Here, disagreement is the difference between the maximum and 
minimum results for each case, divided by the mean of the results for each case ((max-min)/mean). Two other software developers reported fixing issues before submitting their results; based on anecdotal discussion from modeler reports these "pre-initial" results would have had disagreements with order of magnitude similar to the disagreements shown for the other programs. Additionally, three of the four reported initial disagreements were caused by inability to exactly model the boundary conditions specified by the test cases; the other was an input error. Subsequent fixes to the programs allowed direct user input of (or hardwired in a special version) previously automatically determined parameters to enable precise matching of the surface heat transfer coefficient boundary conditions, and yielded very good agreement with the analytical solutions.

This initial good agreement led us to design a more challenging three-zone test case with more conduction interactions (Case MZ320), which was still analytically solvable. This case is a system of three zones in series with a conditioned zone on one end adjacent to two adjacent unconditioned (floating temperature) zones, where the interior and exterior walls are conductive (see Section 1.3.1 for details). All models tested agreed with the analytical solution within $\leq 0.3 \%$ except for one program, as shown in Figure 2-35. (Note for results shown in Figures 2-34 and 2-35, some participants for the earliest cases were not able to submit results for later cases, and vice versa.)

For the multi-zone shading and internal window test cases, improvements to the simulation programs are evident when initial results are compared to final results, as shown in Figures 2-36 and 2-37, respectively, for the multi-zone shading cases, and Figures 2-38 and 2-39, respectively, for the internal window cases. (In these figures abbreviations along the $\mathrm{x}$-axis are shorthand for the case descriptions given in Part I.)

Because a number of parameters for the final set of multi-zone shading and internal window test cases varied substantially from the first round of test cases distributed in February 2005 - see Section 2.3 - it was difficult to develop a direct comparison between cases for initial results that were submitted before the current test cases were developed in August 2006. Therefore, Figures 2-36 and 2-38 include some results that were determined based on estimates of what they would have been, had corrections not been made during earlier test cases. Estimates are based on examples of error trapping documented in Section 2.4. For Figures 2-36 and 2-38, initial results are included for each model:

- EnergyPlus: Results were initially submitted for the February 2005 version of the test specification in March 2005. For cases MZ340, MZ350, and MZ355, results submitted September 13, 2006 are shown as submitted, as there were no changes to EnergyPlus related to field trials of the test cases before this submittal. For Case MZ360 results submitted March 2005 are used. For those results, original values of $\mathrm{Q}_{\text {bldg, }}, \mathrm{Q}_{\mathrm{A}}$, and $\mathrm{Q}_{\mathrm{B}+\mathrm{C}}$ are used; however, to normalize for increased depth of Zone B in the final version of Case MZ360, $Q_{B}$ and $Q_{C}$ are modified to sum to $Q_{B+C}$ and to have the same ratio $Q_{B} / Q_{C}$ as for results submitted for the August 2006 test specification. For EnergyPlus Case MZ360, values of Qbldg for the March 2005 results (before fixes documented in Section 2.4.1) were 3\% lower than for the September 2006 results, which were also submitted before fixes documented in Section 2.4.1.

- ESP-r: Results were initially submitted for the February 2005 version of the test specification in March 2005. For cases MZ340 and MZ350, results submitted December 17, 2005 are used, as there were no changes to ESP-r related to field trials of the test cases before this submittal; these are for preliminary simulations of the substantively final (August 2006) test specification. For Case MZ360, results submitted March 2005 are used. For those results, original values of $Q_{b l d g}$, $\mathrm{Q}_{\mathrm{A}}$, and $\mathrm{Q}_{\mathrm{B}+\mathrm{C}}$ are used; however, to normalize for increased depth of Zone $\mathrm{B}$ in the final version of Case MZ360, $Q_{B}$ and $Q_{C}$ are modified to sum to $Q_{B+C}$ and to have the same ratio $Q_{B} / Q_{C}$ as for results submitted for the August 2006 test specification. This allows results to be estimated for $Q_{B}$ and $\mathrm{Q}_{\mathrm{C}}$ prior to the change documented in Section 2.4.2.1 (which was made between December 2005 and September 2006). 
IEA BESTEST Multi-Zone: MZ200, MZ300

Steady-State Sensible Cooling Load, Zone A

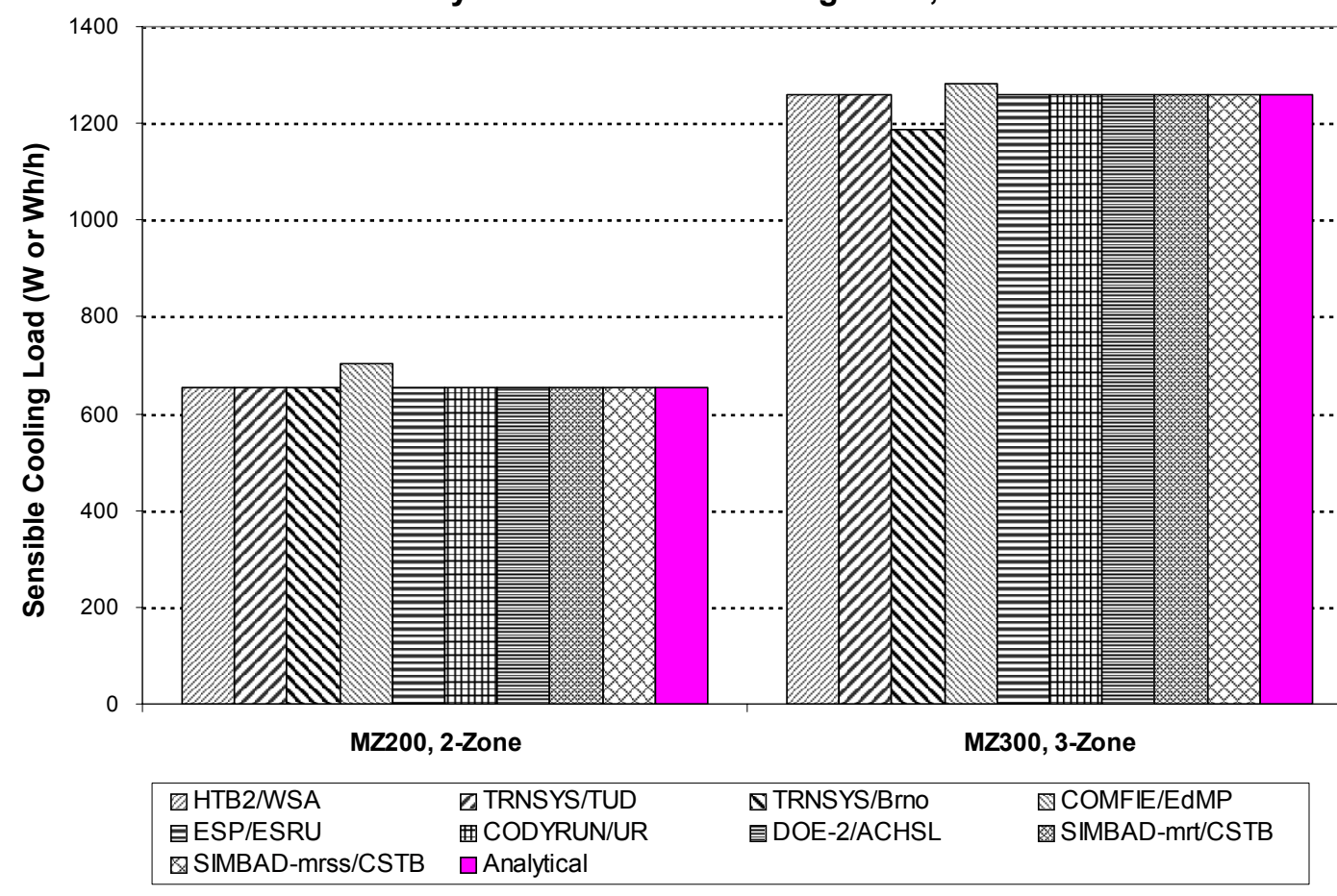

Figure 2-34. BESTEST multi-zone conduction-preliminary case results before BESTESTing

IEA BESTEST Multi-Zone: MZ320

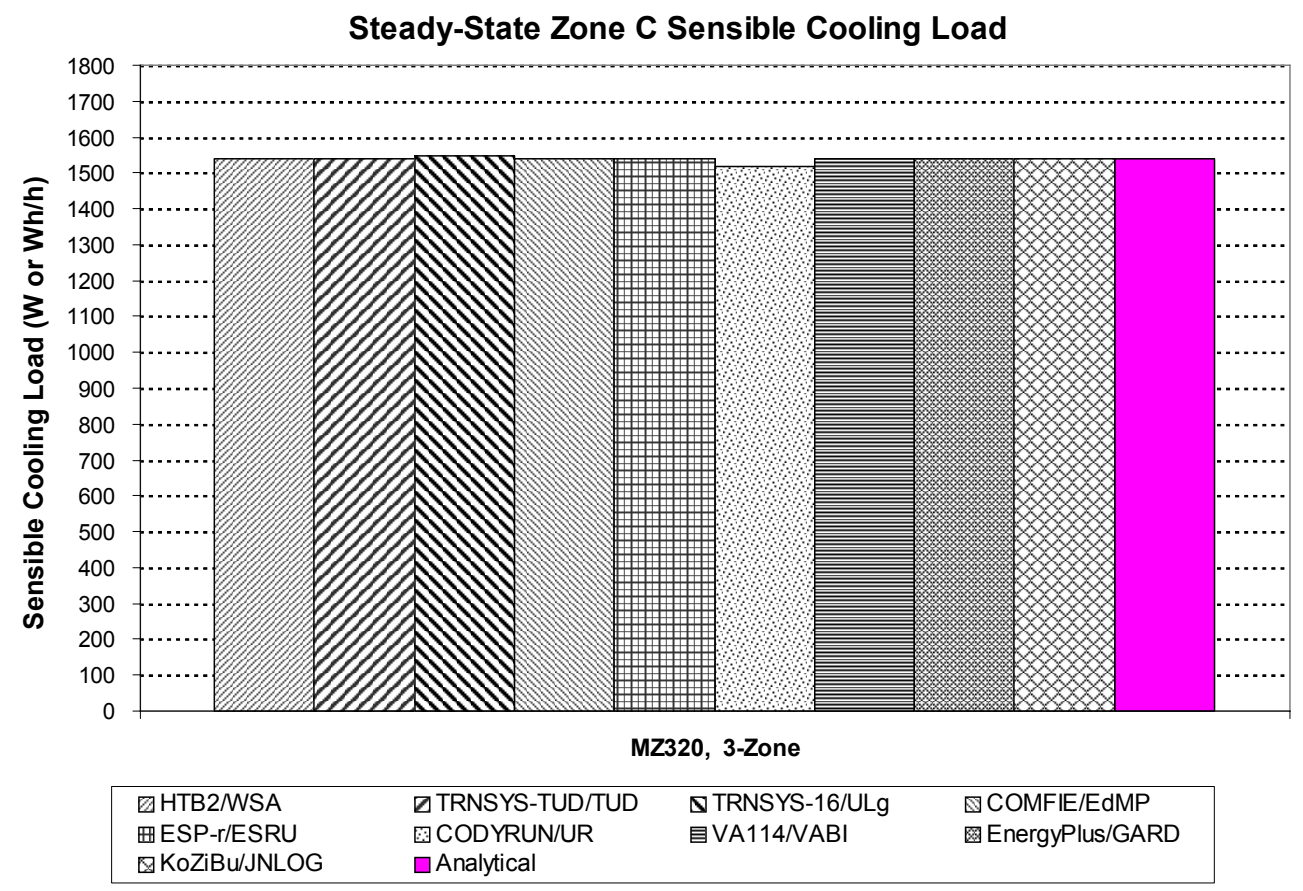

Figure 2-35. BESTEST multi-zone conduction-final case results after BESTESTing 
IEA BESTEST Multi-Zone: MZ340, MZ350, MZ355

Annual Sensible Cooling Load, All Zones

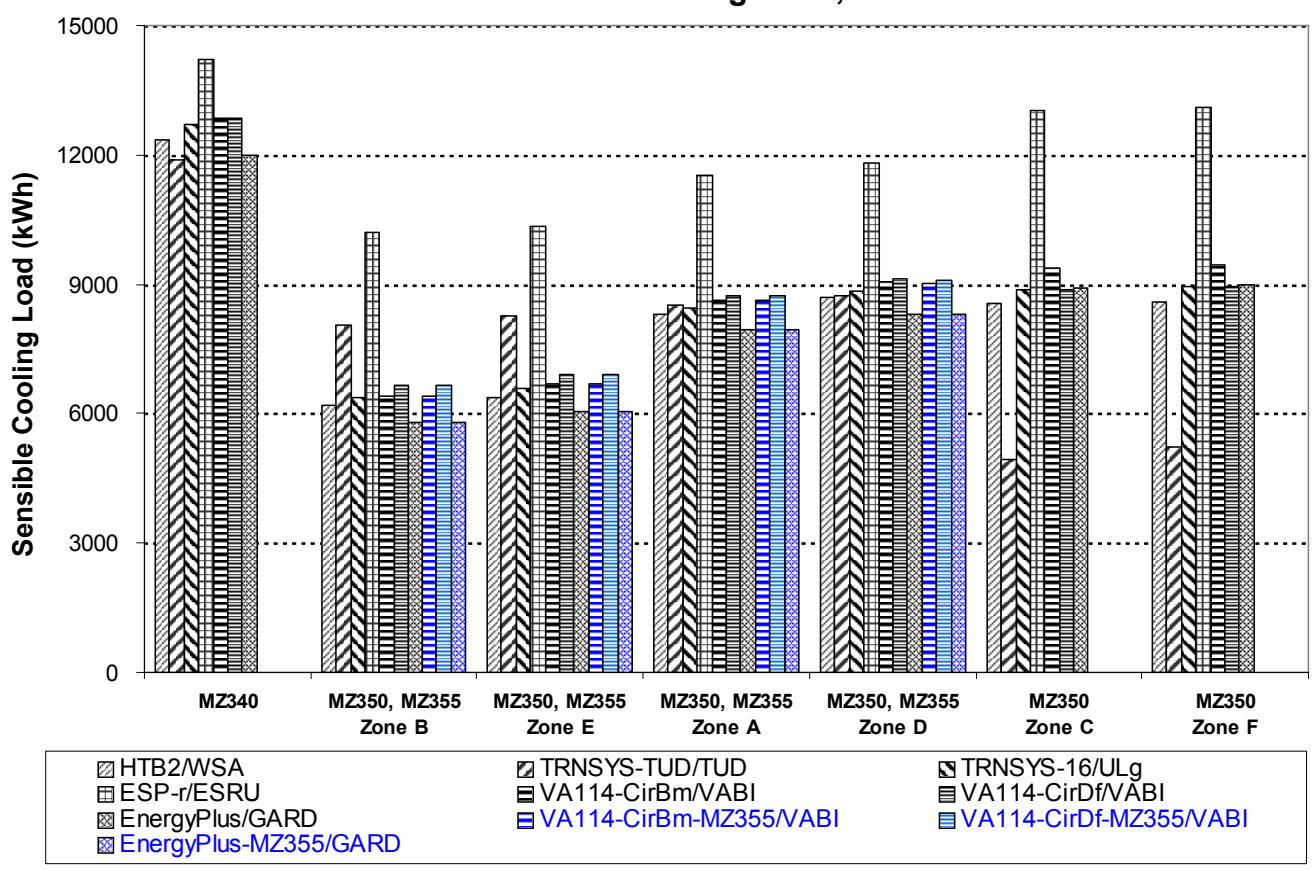

Figure 2-36. BESTEST multi-zone shading cases-sensible cooling load, before BESTESTing (Case MZ355 results are three rightmost bars for zones $B, E, A$, and D.)

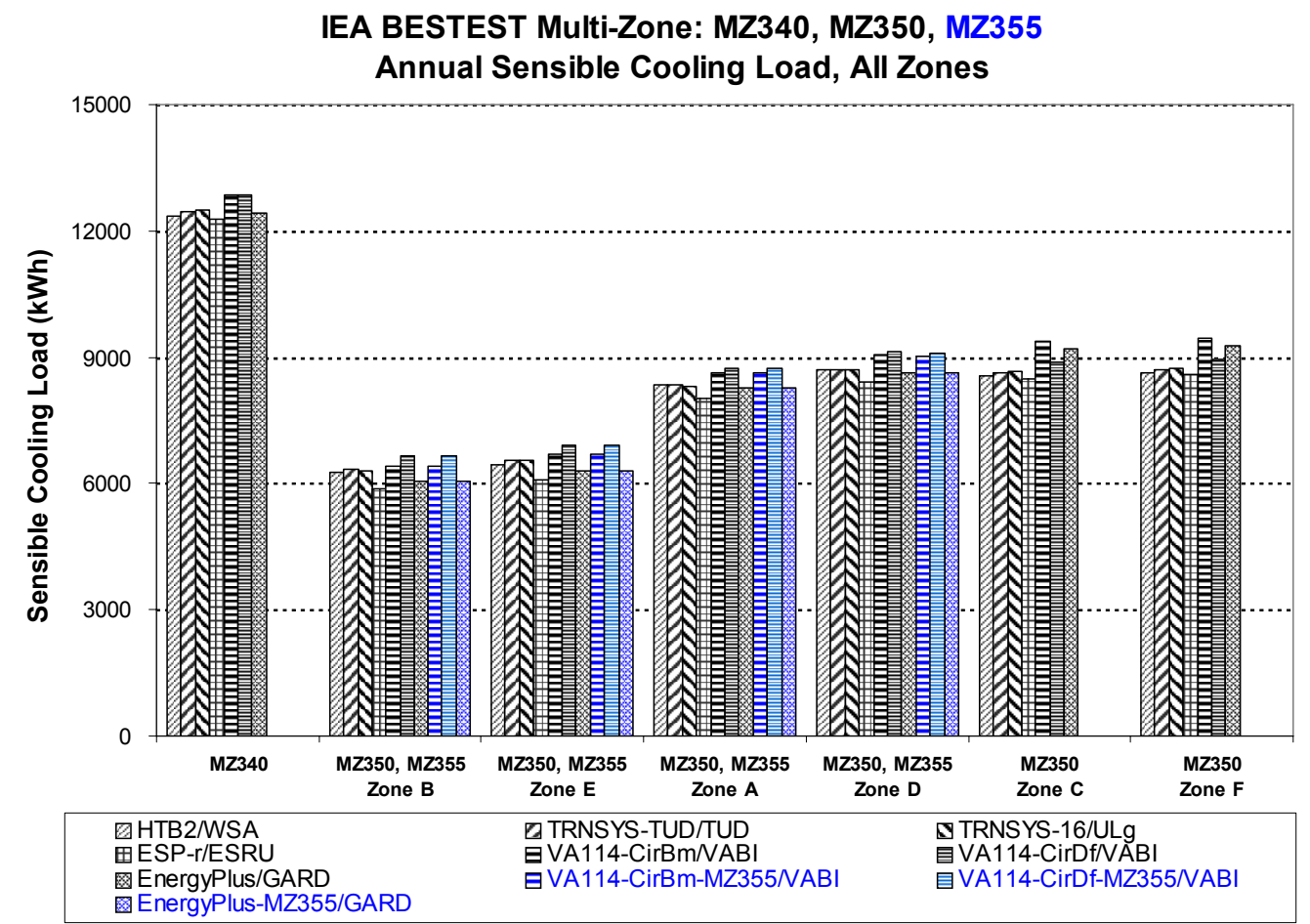

Figure 2-37. BESTEST multi-zone shading cases - sensible cooling load, after BESTESTing (Case MZ355 results are three rightmost bars for zones B, E, A, and D.) 
IEA BESTEST Multi-Zone: MZ360

Annual Sensible Cooling Loads

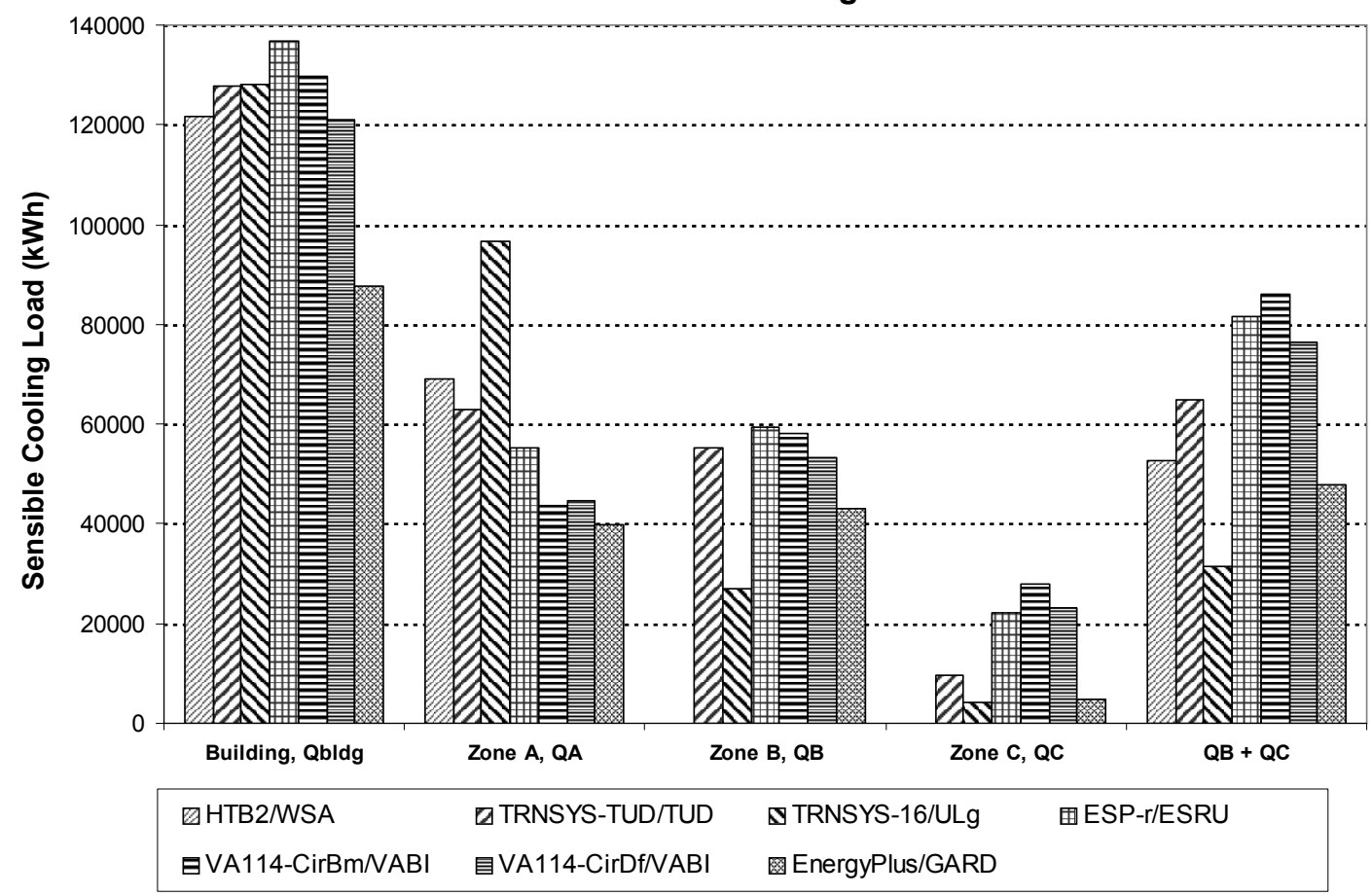

Figure 2-38. BESTEST internal windows, MZ360—sensible cooling load, before BESTESTing

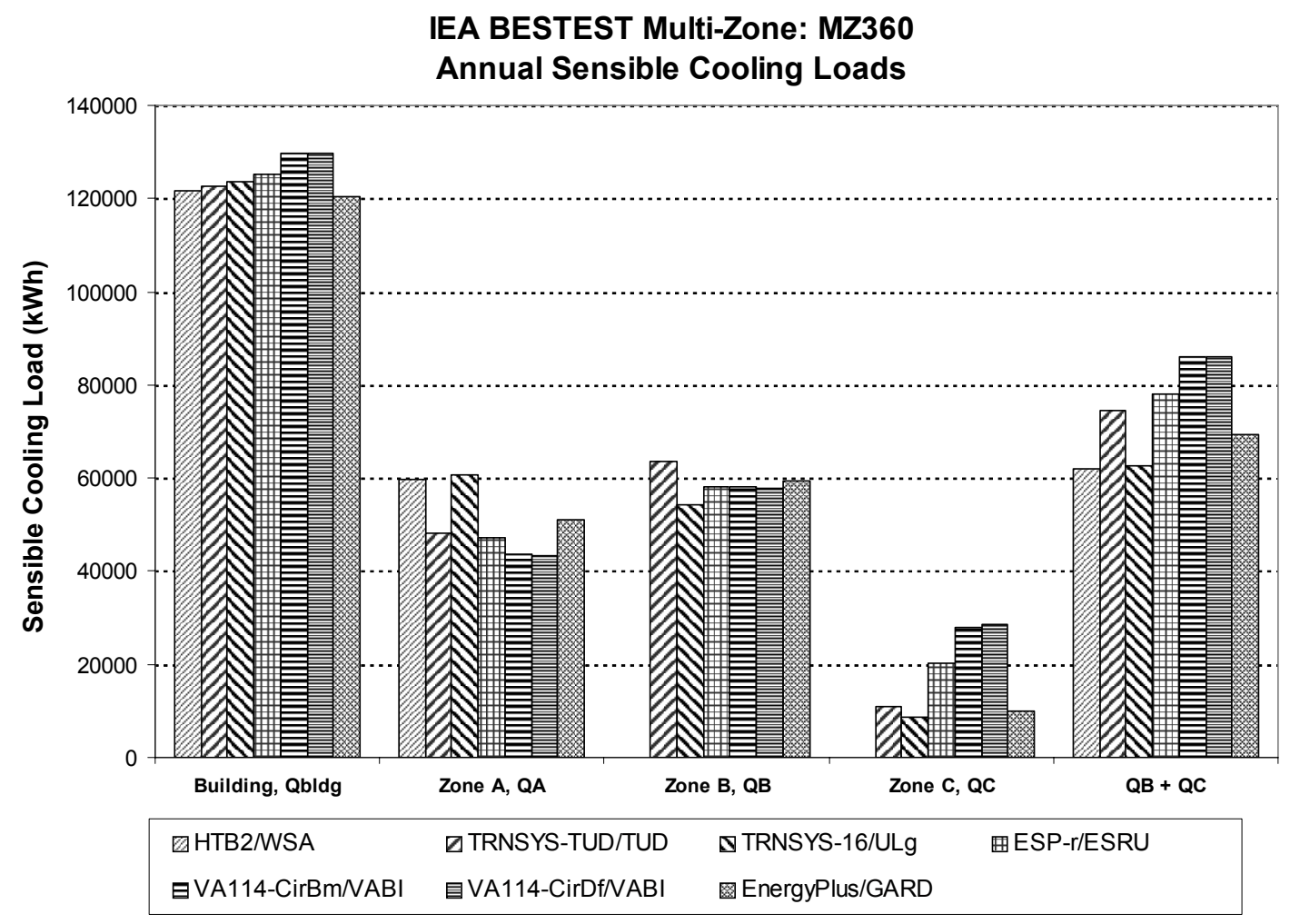

Figure 2-39. BESTEST internal windows, MZ360—sensible cooling load, after BESTESTing 
- HTB2: Results for cases MZ340 and MZ350 were initially submitted for the February 2005 version of the test specification in March 2005. For cases MZ340 and MZ350, results submitted September 24, 2006 provide the basis for estimates of initial results. These results were reduced based on Section 2.4.3.3. The effect of another change to HTB2 before September 2006 (see Section 2.4.3.4) was not documented and could not be included in the initial results chart. For Case MZ360, results shown are those initially submitted September 24, 2006.

- TRNSYS-TUD: Results for all cases were initially submitted for the February 2005 version of the test specification in March 2005. For cases MZ340 and MZ350, results shown are those submitted December 17, 2005 for preliminary simulations of the substantively final (August 2006) test specification, and revised based on model corrections before this submittal (see Sections 2.4.5.1 and 2.4.5.5). For Case MZ360, results submitted March 2005 are used. For those results, original values of $\mathrm{Q}_{\text {bldg }}, \mathrm{Q}_{\mathrm{A}}$, and $\mathrm{Q}_{\mathrm{B}+\mathrm{C}}$ are used; however, to normalize for increased depth of Zone B in the final version of Case MZ360, $Q_{B}$ and $Q_{C}$ are modified to sum to $Q_{B+C}$ and to have the same ratio $\mathrm{Q}_{\mathrm{B}} / \mathrm{Q}_{\mathrm{C}}$ as for results submitted for the August 2006 test specification.

- TRNSYS-16: Results for all cases were initially submitted for the February 2005 version of the test specification in March 2005. For cases MZ340 and MZ350, results submitted February 20, 2007 are shown. The modeler report does not indicate any changes to the TRNSYS-16 model related to field trials of cases MZ340 and MZ350 before this submittal. For Case MZ360, results submitted March 2005 are used. For those results, original values of $\mathrm{Q}_{b l d g}, \mathrm{Q}_{\mathrm{A}}$, and $\mathrm{Q}_{\mathrm{B}+\mathrm{C}}$ are used; however, to normalize for increased depth of Zone B in the final version of Case MZ360, $Q_{B}$ and $\mathrm{Q}_{C}$ are modified to sum to $\mathrm{Q}_{\mathrm{B}+\mathrm{C}}$ and to have the same ratio $\mathrm{Q}_{\mathrm{B}} / \mathrm{Q}_{\mathrm{C}}$ as for results submitted for the August 2006 test specification.

- VA114 (Circumsolar as Beam): Although a number of fixes were discussed in Section 2.4.4 and in VABI's modeler report, VABI did not submit results that show direct effects of the changes. Showing the effects of these changes and input errors is found not applicable according to VABI Software BV (Wijsman 2008a). Therefore, for the VA114 results for cases MZ340, MZ350, MZ355, and MZ360, the initial results for VA114 (see Figure 2-36) are equal to the VA114 final results.

- VA114 (Circumsolar as Diffuse): VABI ran VA114 with circumsolar radiation modeled as diffuse radiation to make a better comparison with the other simulation programs, which model circumsolar diffuse radiation as diffuse radiation rather than as direct-beam radiation. For cases MZ340, MZ350, and MZ355, results shown are those initially submitted for this model on December 15, 2005; these are for preliminary simulations of the substantively final (August 2006) test specification. Results for these cases were generated after corrections to VA114 shading and internal window models were made using VA114's usual method of modeling circumsolar diffuse radiation as beam radiation (see Sections 2.4.4.3, 2.4.4.9 and 2.4.4.10). For Case MZ360, results shown are those documented in Section 2.4.4.8 for internal window reflectance $=0.1$ (what these results would have been before VA114 was changed to allow other internal window transmittances).

The results shown in Figures 2-36 and 2-38 indicate that there was initially a $20 \%-90 \%$ and $40 \%-155 \%$ disagreement among annual cooling loads for various zones for the multi-zone shading and internal window cases, respectively, with substantial scatter among the programs. Figures 2-37 and 2-39 show that after correcting software errors with BESTEST diagnostics, the remaining disagreements among results for various zones for multi-zone shading are $5 \%-13 \%$, and for a single internal window configuration are $7 \%-34 \%$. For the most challenging configuration with a second internal window in series, disagreement for annual cooling load for the zone interior to the second internal window is $112 \%$ (see bars for Zone $\mathrm{C}$ in Figure 2-39), thus indicating further refinement of the models for this configuration may be warranted. Scatter among results was reduced for all the cases. This shows how the BESTEST method is used to diagnose and correct faulty algorithms in complex simulation programs. 
Table 2-11 summarizes final ranges of disagreement for predictions of cooling loads, disaggregated by test case and zone. The results indicate excellent agreement compared with the Case MZ320 interzonal conduction analytical solution within $2 \%$ for Zone $\mathrm{C}$ steady-state space cooling load, where all but one model are within $0.3 \%$ of the analytical solution for this result.

Table 2-11. Final ranges of disagreement among simulation results

\begin{tabular}{|c|c|c|c|c|c|c|c|c|}
\hline Output & Building & Zone A & Zone B & Zone C & Zone D & Zone E & Zone $\mathrm{F}$ & $\begin{array}{l}\text { Unshaded } \\
\text { (MZ340) }\end{array}$ \\
\hline MZ320, steady-state cooling & -- & -- & -- & $0.3 \%-1.9 \%$ & -- & -- & -- & -- \\
\hline \multicolumn{9}{|l|}{ MZ340, MZ350, MZ355 Shading } \\
\hline Annual cooling (MZ35x) & $8.8 \%$ & $8.6 \%$ & $12.8 \%$ & $10.2 \%$ & $8.1 \%$ & $12.3 \%$ & $9.8 \%$ & $4.5 \%$ \\
\hline Delta ann. cooling (MZ35x-MZ340) & $5.1 \%$ & $6.3 \%$ & $5.1 \%$ & $19.9 \%$ & $6.3 \%$ & $5.0 \%$ & $20.6 \%$ & -- \\
\hline Peak annual cooling (MZ35x) & $11.9 \%$ & $8.4 \%$ & $13.0 \%$ & $11.8 \%$ & $8.4 \%$ & $13.0 \%$ & $11.8 \%$ & $5.4 \%$ \\
\hline Delta peak cooling (MZ35x-MZ340)* & $142.9 \%$ & $124.8 \%$ & $123.6 \%$ & $281.9 \%$ & $127.3 \%$ & $126.8 \%$ & $283.1 \%$ & -- \\
\hline MZ360 Internal Windows & & \multicolumn{7}{|c|}{ Zones B+C } \\
\hline Annual cooling & $7.3 \%$ & $34.3 \%$ & $16.0 \%$ & $112.4 \%$ & $32.5 \%$ & -- & -- & -- \\
\hline Peak cooling & $11.6 \%$ & $66.4 \%$ & $27.3 \%$ & $155.6 \%$ & -- & -- & -- & -- \\
\hline
\end{tabular}

${ }^{*}$ Reasonable variation relative to small sensitivity

The results for the shading cases (MZ340, MZ350, and MZ355) indicate good agreement, within 13\% for zone annual cooling loads in all cases. The delta annual cooling-load sensitivity comparisons for the shading cases (MZ350-MZ340, MZ355-MZ340) reduce disagreement noise from algorithms that calculate incident solar radiation, and indicate 5\%-21\% ranges of disagreement when shading model effects are isolated. The greatest differences for shading results occurred for zones $\mathrm{C}$ and $\mathrm{F}$, where beam shading by the north-facing side of the fin and diffuse shading are more predominant. Peak cooling load differences are consistent with annual cooling load differences. Delta peak cooling loads for the shading cases indicate large percentage differences. However, as peak cooling loads occur at times when solar radiation is not obscured by the shading device, peak cooling load sensitivity to shading is slight, and the large percentages there indicate reasonable differences relative to a slight sensitivity.

Improvement in the ability to diagnose shading models is evident from comparing final disagreement ranges for the original single-zone IEA BESTEST shading cases for more realistic constructions, versus the final range of disagreement for the new in-depth diagnostic multi-zone shading cases. For the more realistic original single-zone cases with shading devices, the range of annual cooling load disagreement is $38 \%-73 \%$ for the absolute results (cases considered alone), and $46 \%-63 \%$ for the delta results (sensitivity results to isolate shading model effects, e.g., Case 630-620) (ANSI/ASHRAE 2007; Judkoff and Neymark 1995). A graphic example of original single-zone shading case disagreement in the delta context, excerpted from IEA BESTEST, is provided in Figure 2-40. Disagreement ranges for final delta results of the current multi-zone cases are smaller relative to mean sensitivities, (see Figure 2-41).

Table 2-11 also indicates that for the internal window case (MZ360), results for whole-building annual cooling load have good agreement (within 7\%), consistent with differences among algorithms for calculating incident solar gains. However, disagreement increases for cooling load (allocation of transmitted solar gains) disaggregated for each zone to: $34 \%$ for Zone A, 16\% for Zone B, and 112\% for Zone $\mathrm{C}$. The large disagreement for Zone $\mathrm{C}$ is caused by three of the models not allowing direct-beam radiation transmission through a second internal window. As double-skin facades become more popular in buildings (see Poirazis 2007), more accurate modeling of solar radiation through a series of internal windows gains importance. 


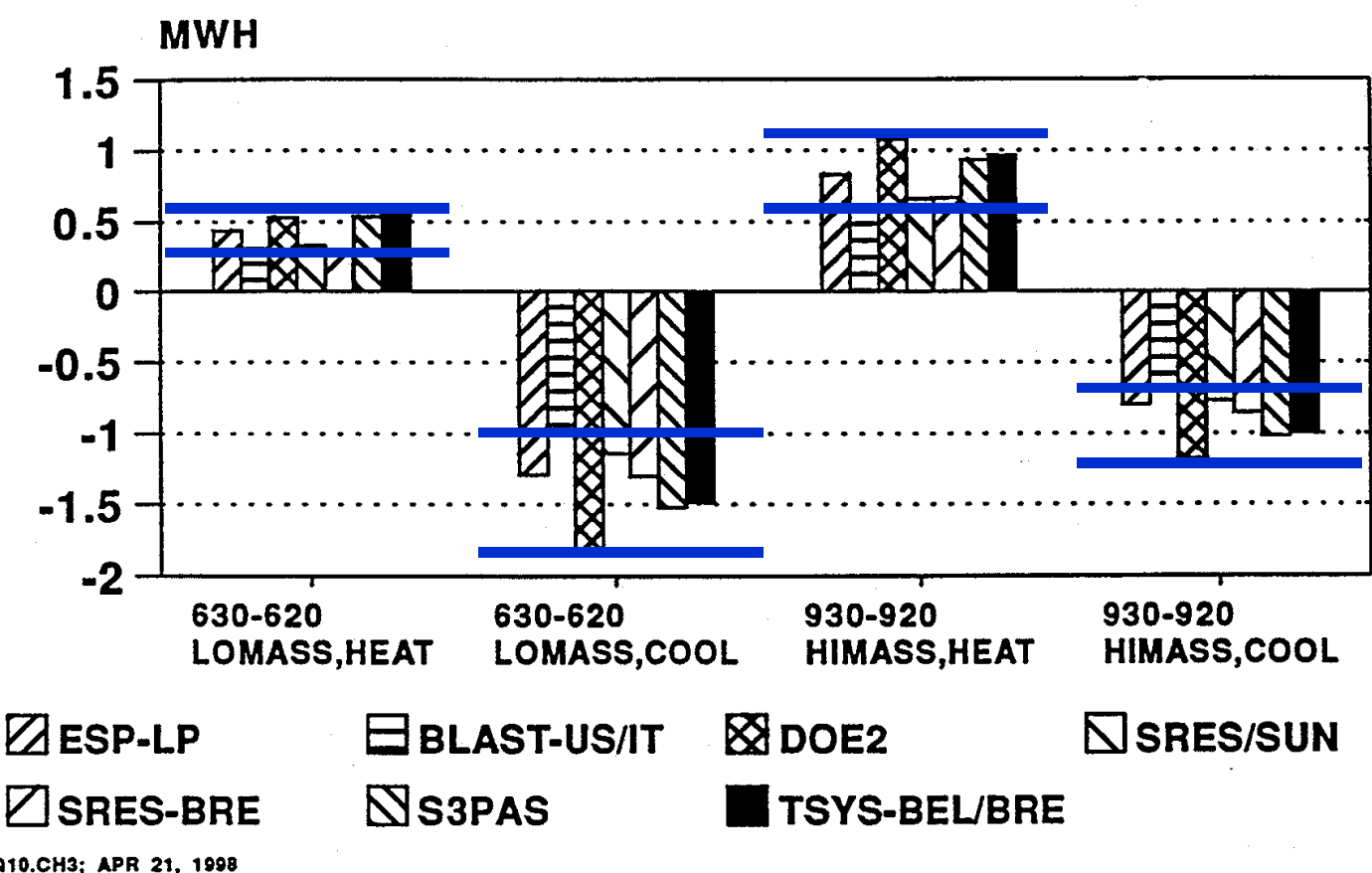

DAEWSQ10.CH3; APR 21, 1998

Figure 2-40. IEA BESTEST single-zone east- and west-shaded window delta sensitivity, annual heating and sensible cooling loads (Judkoff and Neymark 1995)

IEA BESTEST Multi-Zone: MZ350-MZ340, MZ355-MZ340 Delta Annual Cooling Load, All Zones

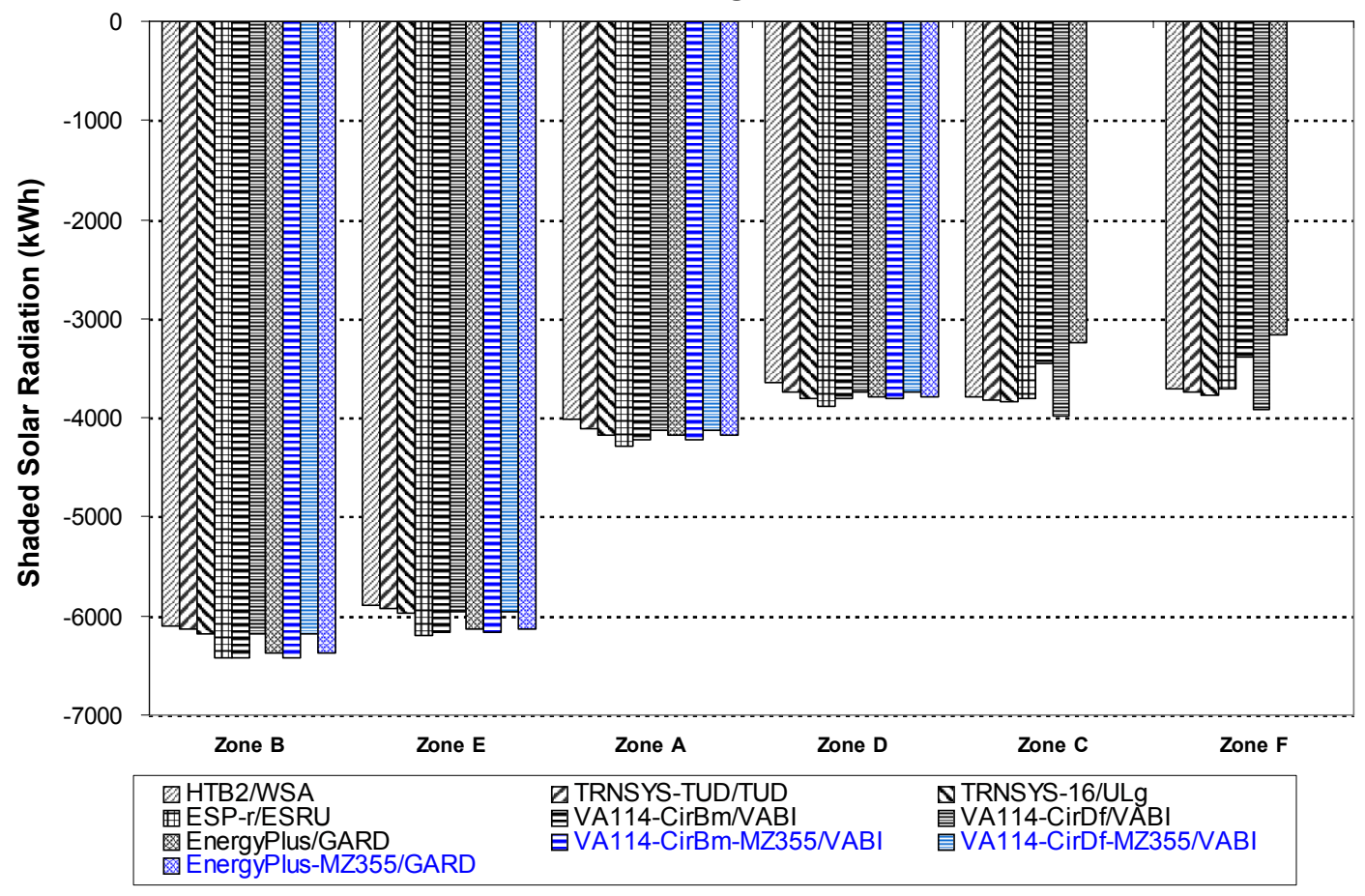

Figure 2-41. In-depth diagnostic multi-zone delta sensible cooling loads 
Based on results after several iterations of BESTESTing, and resulting model improvements, all the tested programs now appear to have reliable models for phenomena isolated by the test cases including interzonal conduction, multi-zone shading, and internal windows where there are no multiple internal windows in series. These test cases did not address thermal inertia interactions for modeled phenomena because thermal mass effects were tested in IEA BESTEST (Judkoff and Neymark 1995). Some remaining disagreements (discussed in Section 2.4) should be addressed, and especially with respect to Case MZ360 for deficiencies identified for three of the models related to modeling a second internal window in series. The simulation results (with the noted specific exceptions for Case MZ360) may therefore be used as a reference or benchmark against which other software can be tested.

\subsubsection{Test Cases for Future Work}

We suggest that additional work related to model testing and validation, outlined in the sections that follow, be considered.

\subsubsection{Additional Shading and Internal Window Cases}

This project developed a set of idealized in-depth diagnostic test cases for multi-zone conduction, multizone shading, and internal window models. During this project, participants discussed a number of important test case configurations that could not be included with the current test cases because of funding flow constraints. These test cases would include:

- Shading case parametric variations, including:

$\circ$ Shading fin surface reflectance $>0$

- Modeling of multiple shading projections on a shaded area

- Internal window parametric variations in a two-zone context, including:

$\circ \quad$ Two-zone version of MZ360 (idealized calorimeter)

- Zero-conductance walls with realistic interior solar reflectance, with ideal windows

- Realistic windows, with ideal walls (zero-conductance; interior solar absorptance $=1$ )

$\circ$ Realistic windows, and zero-conductance walls with realistic interior solar absorptance

o Realistic windows with realistic thermally conducting walls

- Shading/Internal window interaction.

Other cases to consider include:

- Enable/test infrared radiation exchange in the conduction context of Case MZ320 by comparing relative disagreement for a set of multi-zone case results versus a similarly excited single-zone case.

- Whether an analytically solvable dynamic version of Case MZ320 can be developed using either stepped internal gains or thermostat set points

- Addressing the question, "If single-zone results are satisfactory, can we extrapolate that multizone results will be satisfactory?" Answering this question may require developing cases that compare disagreement among a set of results from multiple programs for a multi-zone case versus a similar set of results for a comparable single-zone case.

- Multi-zone shading and internal windows with thermal mass interactions

- Develop a 27-zone building that includes full dynamic interactions of loading, shading, interzonal air exchange, thermal mass, etc.

- This case could provide a starting point for future certification tests for software intended for modeling large buildings, and for future BESTEST diagnostic logic.

- This case would not provide diagnostic capability by itself because of many simultaneously active physical phenomena. 


\subsubsection{Additional Building Thermal Fabric and Mechanical Equipment Test Cases}

Additional building thermal fabric and mechanical equipment model test cases, for consideration to be developed in the future, are summarized in HVAC BESTEST Volume 2 (Neymark and Judkoff 2004, Section 2.5.2), and in IEA BESTEST In-Depth Diagnostic Cases for Ground Coupled Heat Transfer Related to SlabOn-Grade Construction (Neymark and Judkoff et al. 2008, Section 2.5.4.1).

\subsection{Conclusions and Recommendations}

\subsubsection{Conclusions}

\subsubsection{Major Accomplishments}

The major accomplishments of this project were:

- Extension of the IEA BESTEST building thermal fabric envelope tests to include an in-depth diagnostic analytical verification test case for interzonal conduction, and in-depth diagnostic comparative test cases for multi-zone shading and internal windows

- Use of idealized calorimetry to enhance the diagnostic power of the multi-zone shading and internal window test cases, which avoids noise from potentially larger results disagreements related to modeling realistic windows and opaque internal surfaces

- Range of annual cooling load disagreement for cases with shading devices decreased from 38\%-73\% for the original single-zone IEA BESTEST cases (ANSI/ASHRAE 2007; Judkoff and Neymark 1995) to $8 \%-13 \%$ for these new test cases, allowing the numerous disagreements listed in Section 2.6.1.2 to be identified and diagnosed.

- Development of a steady-state analytical solution for the interzonal conduction test case, assuming one-dimensional conduction

- Accuracy improvements to all but one of the models that participated in the field trials of the test cases, and to all the models that participated in the multi-zone shading and internal-window test cases

○ 31 errors were diagnosed and fixed

- By applying the diagnostic logic of the test cases to expose problems with the models, disagreement ranges for steady-state or annual cooling loads were improved during the field trials of the test cases, as follows:

- For interzonal conduction, initial disagreement of $4 \%-8 \%$ improved to $\leq 0.3 \%$, except for one model that has $2 \%$ disagreement

- For multi-zone shading, initial disagreement of $20 \%-90 \%$ improved to $5 \%-13 \%$

- For the internal windows case:

- Overall building load initial disagreement of $40 \%$ improved to $7 \%$

- Individual zone loads initial disagreement of $65 \%-155 \%$ improved to $16 \%-$ $112 \%$ (or from $65 \%-95 \%$ to $16 \%-34 \%$, excluding disagreements for the zone with a second internal window in series).

With respect to the value of the test cases to software developers, one software-developer/vendor participant made the following comment about this IEA project: 
"Bestest and IEA-34/43 tests brought a number of new errors to the surface. This shows the importance of these test [cycles]!! And still there will be errors in the software!! Development of new, specific test cases is of big importance!!” (Wijsman 2008b)

\subsubsection{Summary of Findings}

Test cases for in-depth diagnosis of models for interzonal heat transfer, multi-zone shading, and internal windows have been added to the IEA's method for systematically comparing whole-building energy simulation software and determining the algorithms responsible for prediction differences. This work applied an analytical solution result (Case MZ320) as a mathematical truth standard for modeling interzonal conduction, and applied idealized calorimetry as described in Section 2.5.1 to enhance identification of and diagnostics for multi-zone shading and internal window model disagreements.

The procedure has been field tested using a number of building energy simulation programs from around the world. The method has proven effective at isolating the sources of predictive differences. The diagnostic procedures revealed bugs, faulty algorithms, limitations, and input errors in all but one of the simulation models tested in this study, and in all of the simulation models that ran the shading and internal window cases. This includes the following models that ran all the cases-EnergyPlus, ESP-r, HTB2, TRNSYSTUD, TRNSYS-16, and VA114 - along with two of the three programs that did not run all of the cases in their final form - CODYRUN and COMFIE; the developer of KoZiBu did not report finding any issues for the Case MZ320 results. Some important technology advances occurred by running the test cases:

- The improved final agreement for shading cases using idealized/modeled calorimetry (cooling loads equal to solar radiation incident on external glazing) allowed disagreements to be identified and errors to be diagnosed that may have been missed using the original IEA BESTEST singlezone shading cases (Judkoff and Neymark 1995), where for the original IEA BESTEST cases disagreements related to modeling realistic optical properties of glazing and interior opaque surfaces along with realistic wall conduction employing thermal mass may have obscured disagreements caused by shading models.

- Of 49 found disagreements, 31 were diagnosed and fixed, 11 are planned for investigation by the software authors, 3 were judged as acceptable by the software authors, and 4 are awaiting notification of the software developer by the modeler; Table 2-12 summarizes notable examples of error trapping; supporting details are given in Section 2.4.

Many of the errors listed in Table 2-12 were significant with greater than 20\% effect on sensible cooling load. For individual programs applying the current in-depth cases, some errors had relatively minor $(<2 \%)$ effect on cooling load. Where a program had multiple errors of smaller magnitude, such errors did not necessarily compensate each other, and may have been cumulative. Therefore, correcting the minor as well as the major errors was important.

After correcting software errors using BESTEST diagnostics, the remaining disagreements for cooling load results are:

- $\leq 0.3 \%$ for the interzonal conduction analytical verification test case, except for one program with $2 \%$ disagreement

- $5 \%-13 \%$ for the multi-zone shading cases

- $7 \%-112 \%$ for the internal window case $(7 \%-34 \%$ if the zone with second internal window in series is excluded). 
Table 2-12. Summary of Software Problems Found Using IEA BESTEST Multi-Zone Cases

\begin{tabular}{|c|c|c|c|}
\hline Model $^{\mathrm{a}, \mathrm{b}}$ & Error Description $^{a}$ & $\begin{array}{l}\text { \% Cooling Load Effect or } \\
\text { Disagreement }^{\text {a,c }}\end{array}$ & Outcome $e^{a, b}$ \\
\hline CODYRUN & User input surface coefficients not allowed & $\leq 8 \% ?(\mathrm{MZ2} / 300$ see COMFIE $)$ & Fixed \\
\hline CODYRUN (2) & IR emit $<0.01$, custom zone air properties & Minor (MZ320) & Fixed (2) \\
\hline CODYRUN & Case MZ320 Zone C cooling load & $2 \%(\mathrm{MZ320})$ & A.N. ${ }^{d}$ \\
\hline COMFIE & User input surface coefficients not allowed & $2 \%-8 \%$ (prelim MZ200, MZ300) & A.N..$^{\mathrm{d}, \mathrm{e}}$ \\
\hline EnergyPlus & Unintended lost diffuse solar radiation & $33 \%(\mathrm{MZ360}) ; 4 \%(\mathrm{MZ340})$ & Fixed \\
\hline EnergyPlus & No beam radiation to Zone $\mathrm{C}(\mathrm{MZ360)}$ & MZ360: $6 \%$ ? bldg, $240 \%$ Zone C & A.N. ${ }^{d}$ \\
\hline EnergyPlus & Internal windows output documentation & $0 \%(\mathrm{MZ360})$, limits diagnosis & A.N. ${ }^{d}$ \\
\hline EnergyPlus & October 14 hour- 17,18 disagreements & Minor issue? (MZ340-MZ350) & A.N. $^{d}$ \\
\hline ESP-r & Only allows hour-centered solar time & $12 \%(\mathrm{MZ340})$ & Fixed \\
\hline ESP-r & No diffuse shading & $19 \%-35 \%(M Z 350)$ & Fixed \\
\hline ESP-r & Custom solar data processing by modeler & Minor issue $(M Z 340-M Z 360)$ & Fixed \\
\hline ESP-r & Beam and diffuse output not disaggregated & $0 \%$; limited diagnosis & Fixed \\
\hline ESP-r & Solar/shading algorithm improvement & Up to $11 \%$ peak clg. (MZ350) & Fixed \\
\hline ESP-r & High back side of fin shading & ?\% (MZ350, MZ340-MZ350) & A.N. ${ }^{d}$ \\
\hline HTB2 & User input ext surface coefficients ignored & $1 \%(\mathrm{MZ320})$ & Fixed \\
\hline HTB2 & Infrared emittance $=0$ not allowed & Crashed (MZ340) & Fixed \\
\hline HTB2 & Shadow/window overlap & $1 \%-2 \%(\mathrm{MZ340}-\mathrm{MZ350})$ & Fixed \\
\hline HTB2 & Shading interpolation algorithm & $? \%(\mathrm{MZ340,} M Z 350)$ & Fixed \\
\hline HTB2 & Synch solar data with surf. insolation model & $\leq 23 \% \mathrm{hr}, 0.4 \% \mathrm{pk}(\mathrm{MZ340,360)}$ & Fixed \\
\hline HTB2 & Internal window reflection (MZ360) & $-16 \% Q_{A},+18 \% Q_{B}, 0 \% Q_{b l d g}$ & Fixed \\
\hline HTB2 & March 15, hour 17 disagreement & $? \%(\mathrm{MZ340-MZ350)}$ & A.N. ${ }^{d}$ \\
\hline HTB2 & October 14, hourly disagreement & $? \%(\mathrm{MZ360})$ & A.N. ${ }^{\mathrm{d}, \mathrm{e}}$ \\
\hline TRNSYS-TUD & Unintended lost diffuse solar radiation & $3 \%-4 \%(M Z 340)$ & Fixed \\
\hline TRNSYS-TUD & Ray tracing algorithm error & $? \%(\mathrm{MZ360})$ & Fixed \\
\hline TRNSYS-TUD & Ray tracing versus $100 \%$-diffuse transmitted & $15 \%, 23 \%$ zones A,B (MZ360) & Fixed \\
\hline TRNSYS-TUD & Beam and diffuse output not disaggregated & $0 \%$; limited diagnosis & Fixed \\
\hline TRNSYS-TUD & Shading device input error & $30 \%-40 \% \mathrm{MZ350}$ zones B,E,C,F & Fixed \\
\hline TRNSYS-TUD & Optical properties as f(incidence angle) & $1 \%(\mathrm{MZ340})$ & Fixed \\
\hline TRNSYS-TUD & No beam radiation to Zone $\mathrm{C}(\mathrm{MZ360)}$ & MZ360: 5\%? bldg, 220\%? Zone C & A.N. ${ }^{d}$ \\
\hline TRNSYS-TUD & Reindl model shading inconsistency & $7 \%-14 \%(\mathrm{MZ340-350)}$ & A.N. ${ }^{d}$ \\
\hline TRNSYS-TUD & Isotropic sky model versus Reindl model & $4 \%$ annual, $8 \%$ peak (MZ340) & A.N. $^{d}$ \\
\hline TRNSYS-16 & Unintended lost diffuse solar radiation & 33\%? (MZ360); 4\%? (MZ340) & M.N. ${ }^{f, g}$ \\
\hline TRNSYS-16 & Modeler used less detailed solar processor & $2 \%$ annual, $9 \%$ peak (MZ340) & M.N. ${ }^{f, g}$ \\
\hline TRNSYS-16 & Less detailed beam model v.TRNSYS-TUD & $15 \%, 27 \%$ zones A,B (MZ360) & M.N. ${ }^{f, h}$ \\
\hline TRNSYS-16 & No beam radiation to Zone C (MZ360) & MZ360: 6\%? bldg, 290\% ?Zone C & M.N. ${ }^{f, h}$ \\
\hline VA114 & If emit or abs $<0.2, \Sigma$ (exchange factors) $>1$ & $? \%(\mathrm{MZ320})$ & Fixed \\
\hline VA114 & Comfort modeling uses wrong coordinates & $? \%(\mathrm{MZ320})$ & Fixed \\
\hline VA114 & $\mathrm{U}=0$ not allowed & $? \%(\mathrm{MZ340})$ & Fixed \\
\hline VA114 & Beam shading excluded, fin affixed to bldg. & $(\mathrm{MZ350a)}$ & Fixed \\
\hline VA114 & Beam shading excluded, not affixed to bldg. & $(\mathrm{MZ350c})$ & Fixed \\
\hline VA114 (2) & All shading excluded, auto-self shading & (MZ355) & Fixed (2) \\
\hline VA114 & MZ355 not $=$ MZ350 for hr 16, Mar 12-17 & $<0.1 \%(\mathrm{MZ355}$ v. MZ350) & A.N. ${ }^{d}$ \\
\hline VA114 & Internal window hard-coded refl. $=0.1$ & MZ360: 7\% bldg, 22\% Zone C & Fixed \\
\hline VA114 & Input error: incorrect time zone & $(\mathrm{MZ340,}$ MZ360) & Fixed \\
\hline VA114 & Input error: fin input twice & $(\mathrm{MZ350c})$ & Fixed \\
\hline VA114 & Total cooling not $=$ Window AO transmitted & $0.04 \%(\mathrm{MZ360})$ & A.N. ${ }^{\mathrm{d}, \mathrm{e}}$ \\
\hline VA114 & Annual diffuse solar & $4 \% ?(\mathrm{MZ340})$ & A.N. $^{d}$ \\
\hline
\end{tabular}

a Acronyms and abbreviations used in this column are defined in Section 2.7. 
b Numbers in parenthesis are number of changes associated with the listing, if > 1

c Effects are for annual cooling load unless otherwise noted; specific cases relevant to the described effects are included in parentheses. For disagreements listed as fixed, listed percentage values are the effect of the change for new results versus previous results for a given model.

d A.N. = Authors notified.

e Software developer indicates this disagreement is acceptable for their model; no software revision planned.

M.N. = Modelers notified. Modelers have been asked to inform the software developers of the issue.

g Modelers developed an input work-around.

h No work-around available.

i Errors were related to calling older models no longer available to users; these errors were fixed to allow comparison of new models versus the previous models.

This shows how the BESTEST method is used to diagnose and correct faulty algorithms in complex simulation programs. Based on results after several iterations of BESTESTing, and resulting model improvements, all of the tested programs now appear to have reliable models for phenomena isolated by the test cases including interzonal conduction, multi-zone shading, and internal windows where there are no multiple internal windows in series. These test cases did not address thermal inertia interactions for the modeled phenomena because thermal mass effects were tested in IEA BESTEST (Judkoff and Neymark 1995). Some remaining disagreements (discussed in Section 2.4) should be addressed, especially with respect to Case MZ360 for deficiencies identified for three of the models related to modeling a second internal window in series. The simulation results (with the noted specific exceptions for Case MZ360) may therefore be used as a reference or benchmark against which other software can be tested.

Based on this work, there are a number of recommended areas for further investigation with respect to developing additional validation test cases for multi-zone modeling. These are described in detail in Section 2.5.3.1. For the longer term we hope to develop test cases that emphasize special modeling issues associated with more complex building types and HVAC systems (see Section 2.5.3.2).

\subsubsection{Advantages of BESTEST Methodology}

Similar to previous test suites that applied BESTEST, these new cases have a variety of uses, including:

- Comparing output from building energy simulation programs to a set of analytical solutions that constitute a reliable set of theoretical results given the underlying physical assumptions in the case definitions

- Comparing several building energy simulation programs to determine the degree of disagreement among them

- Diagnosing the algorithmic sources of prediction differences among several building energy simulation programs

- Comparing predictions from other building energy simulation programs to the analytical solution, and simulation results in this report

- Checking a program against a previous version of itself after the internal code has been modified, to ensure that only the intended changes actually resulted

- Checking a program against itself after a single algorithmic change to understand the sensitivity between algorithms.

An advantage of the BESTEST methodology is that a program is examined over a broad range of parametric interactions based on a variety of output types, minimizing the possibility of concealing problems by compensating errors. Performance of the tests resulted in quality improvements to all but one of the building energy simulation models used in the field trials, and all the models used in the multi-zone shading and internal window test cases. Some of the bugs that were found may well have been present for several years. The fact that they have just now been uncovered shows the power of BESTEST and suggests the importance of continuing to develop formalized validation and diagnostic methods. Only 
after coding bugs have been eliminated can the assumptions and approximations in the algorithms be evaluated where necessary.

Checking a building energy simulation program for the first time with the BESTEST in-depth multi-zone non-airflow test cases requires a few days for an experienced user, not including improvements to the software, if necessary. Subsequent program checks are faster because input files may be reused. Because the simulation programs have taken many years to produce, the new BESTEST cases provide a very costeffective way of testing them. As we continue to develop new test cases, we will adhere to the principle of parsimony so the entire suite of BESTEST cases may be implemented by users with a reasonable time commitment.

\subsubsection{Recommendations}

\subsubsection{Adaptation of Test Procedures for ANSI/ASHRAE Standard 140}

The work presented in this report, other work of IEA 34/43, and the work that has preceded it in IEA SHC Tasks 8,12 , and 22 is important for two reasons:

- The methods have been extremely successful at correcting software errors in advanced building energy simulation programs throughout the world.

- The methods are finding their way into industry by being adopted as the theoretical basis for formalized standard methods of test and software certification procedures; in this sense the work may be thought of as pre-normative research.

Along with the overall validation methodology (Judkoff 1988; Judkoff and Neymark 2006; Judkoff et al. 2008), which has recently been added to the ASHRAE Handbook of Fundamentals (ASHRAE 2005), the following test suites, developed in conjunction with IEA, have been code-language adapted and formally approved as a standard method of test, ANSI/ASHRAE Standard 140-2007, Standard Method of Test for the Evaluation of Building Energy Analysis Computer Programs (ANSI/ASHRAE 2007):

- IEA BESTEST, building thermal fabric comparative tests (Judkoff and Neymark 1995)

- HVAC BESTEST Volume 1, unitary cooling equipment analytical verification tests (Neymark and Judkoff 2002)

- HVAC BESTEST Volume 2, unitary cooling equipment comparative tests (Neymark and Judkoff 2004)

- $\quad$ HVAC BESTEST Fuel-Fired Furnace analytical verification and comparative tests (Purdy and Beausoleil-Morrison 2003).

Within the BESTEST/Standard 140 structure, there is room to add new test cases. BESTEST is better developed in areas related to energy flows and energy storage in the architectural fabric of the building. BESTEST work related to mechanical equipment is still in its early phases in that there are many kinds and configurations of mechanical systems to test.

The new in-depth multi-zone non-airflow test cases described in this report are planned for inclusion in Standard 140. Additional test cases either currently being adapted for inclusion in Standard 140, or planned for future inclusion in Standard 140, are listed elsewhere. (Neymark and Judkoff et al. 2008) 


\subsubsection{Closing Remarks}

Standard 140 and the BESTEST reports that comprise the test suites contained therein, are being referenced and used worldwide by a growing number of code promulagation authorities. ASHRAE Standard 90.1 (ANSI/ASHRAE/IESNA 2007), which is ASHRAE's consensus energy code for commercial buildings and for non-low-rise residential buildings, requires that software used for demonstrating performance compliance with Standard 90.1 be tested using ASHRAE Standard 140-2004 (ANSI/ASHRAE 2004b). Software used for calculating energy savings for purposes of the energy-efficient commercial building tax deductions in the United States must be tested with Standard 140-2007 (IRS 2008). As part of their building energy performance assessments under the European Community's Energy Performance Directive (European Union 2002), several countries are using software tools that have been checked with BESTEST. Further details of international use of BESTEST, along with growing evidence that the BESTEST procedures are becoming part of software developers' normal in-house quality control efforts, are included elsewhere (Judkoff and Neymark 2006; Neymark and Judkoff et al. 2008, Section 2.6.2).

Computer scientists universally accept the merits of software testing. A well-known rule of thumb is that in a typical programming project more than $50 \%$ of the total cost is expended in testing the program or system being developed (Myers 2004). Of this, about 20\% of development time goes toward system testing (McConnell 2004). Because new energy-related technologies are continually being introduced into the buildings market, there will always be a need for further development of simulation models, combined with a substantial program of testing and validation. Such an effort should contain all the elements of an overall validation methodology (ASHRAE 2005, Chp. 32; Judkoff and Neymark 2006), including:

- Analytical verification

- Comparative testing and diagnostics

- Empirical validation.

Future work should therefore:

- Continue to produce a standard set of analytical tests.

- Develop a set of diagnostic comparative tests that emphasize the modeling issues important in large commercial buildings, including more tests for heating, ventilating, and air-conditioning systems, and other mechanical equipment, including on-site power generation equipment.

- Develop a sequentially ordered series of high-quality data sets for empirical validation.

The work described here represents continuing progress in the effort to develop carefully validated building energy simulation tools. Continued development and validation of whole-building energy simulation programs are two of the most important activities meriting the support of national energy research programs. The U.S. Department of Energy and IEA Executive Committees for Solar Heating and Cooling and for Energy Conservation in Buildings and Community Systems should diligently consider what sort of future collaborations would best support this essential research area.

Finally, the authors wish to acknowledge that the expertise available through IEA and the dedication of the participants were essential to the success of this project. Over the four-year field trial effort, there were several revisions to the BESTEST specifications and subsequent re-executions of the computer simulations. This iterative process led to the refining of the new BESTEST cases, and the results of the tests led to improving and debugging of the simulation models. The process underscores the leveraging of resources for the IEA countries participating in this project. Such extensive field trials, and resulting enhancements to the tests, were much more cost effective with the participation of the IEA-34/43 experts. 


\subsection{Abbreviations and Acronyms for Parts II and III}

These abbreviations and acronyms are used in Sections 2.1 through 2.6 and in Part III.

abs absorptance

ACHSL ACHSL Consultoria

ANSI American National Standards Institute

Apr April

ASHRAE American Society of Heating, Refrigerating and Air-Conditioning Engineers

BESTEST Building Energy Simulation Test and Diagnostic Method

bldg building

BLAST-US/IT BLAST run by NREL and Politecnico Torino (Judkoff and Neymark 1995)

Brno Brno University of Technology

CEN European Committee for Standardization

CIBSE Chartered Institution of Building Services Engineers

CSTB Centre Scientifique et Technique du Batiment

Dec December

disag disaggregated

DMU DeMontfort University

dn direct normal solar radiation

DOE U.S. Department of Energy

DOE2 DOE-2.1D, see Judkoff and Neymark (1995)

ECBCS Energy Conservation in Buildings and Community Systems programme (of the IEA)

EdMP Ecole des Mines de Paris

emit emittance

ESP ESP-r

ESP-LP ESP run by Leicester Polytechnic (Judkoff and Neymark 1995)

ESRU Energy Systems Research Unit, University of Strathclyde

Feb February

GARD GARD Analytics

HIMASS high mass

hr hour

HVAC heating, ventilating, and air-conditioning

I solar radiation, see subscripts; incident solar radiation for no subscript

IEA International Energy Agency

IEA 34/43 International Energy Agency joint Solar Heating and Cooling Programme Task 34 and Energy Conservation in Buildings and Community Systems Programme Annex 43 


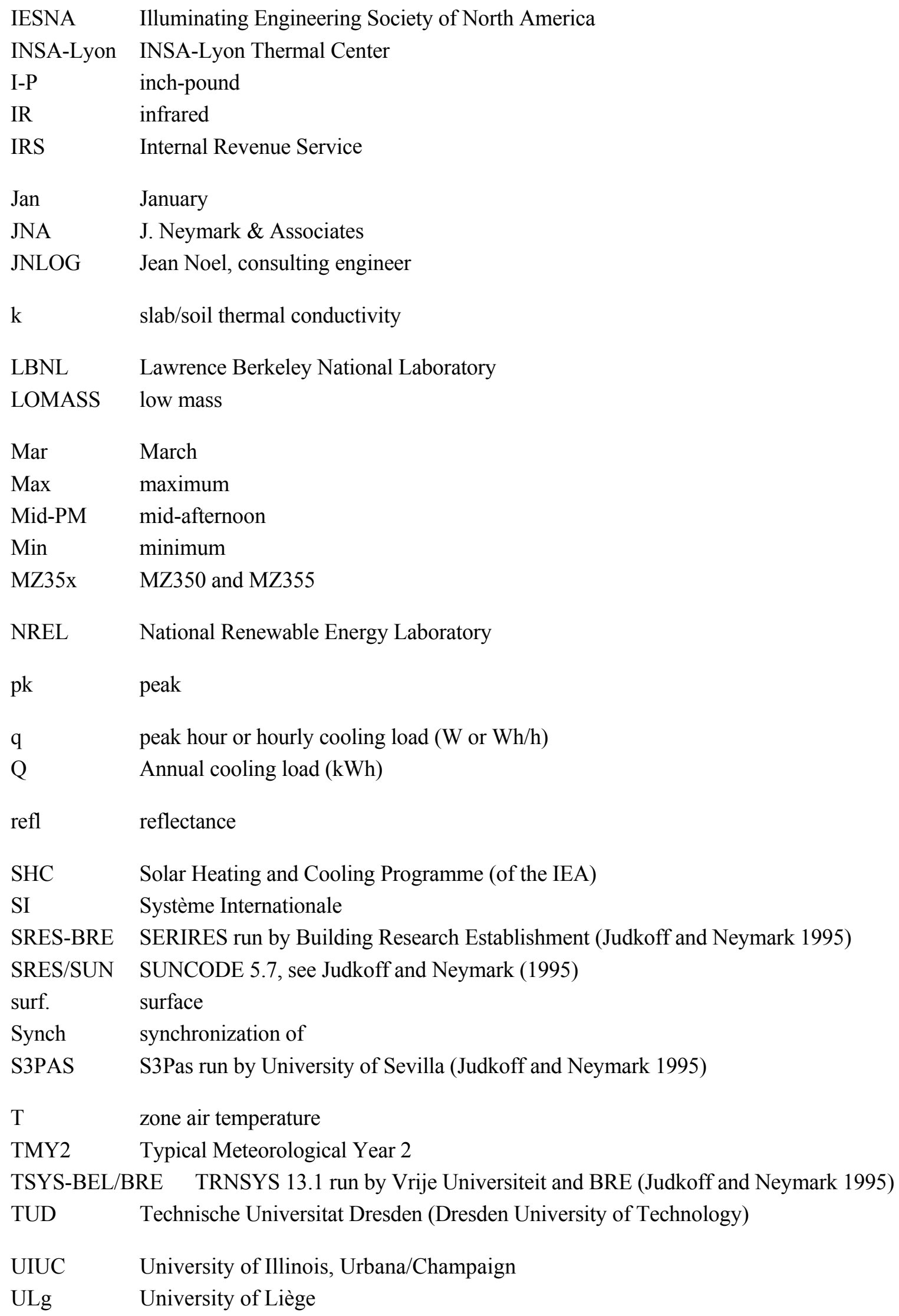




\begin{tabular}{|c|c|}
\hline UR & University of Reunion Island \\
\hline v. & versus \\
\hline VABI & VABI Software BV \\
\hline VA114-CirBm & n VA114 with circumsolar diffuse radiation modeled as beam radiation \\
\hline VA114-CirDf & VA114 with circumsolar diffuse radiation modeled as diffuse radiation \\
\hline WSA & Welsh School of Architecture, Cardiff University \\
\hline \multicolumn{2}{|l|}{ Subscripts } \\
\hline $\begin{array}{l}\text { A,B,C,D,E,F } \\
\text { b } \\
\text { bldg } \\
\text { B+C }\end{array}$ & $\begin{array}{l}\text { Zone designators } \\
\text { beam (direct normal) solar radiation } \\
\text { building } \\
\text { Sum of given value for Zone B and Zone C }\end{array}$ \\
\hline $\mathrm{d}$ & diffuse solar radiation \\
\hline $\max$ & maximum \\
\hline $\operatorname{tr}$ & transmitted solar radiation \\
\hline $\operatorname{trb}$ & transmitted beam (direct normal) solar radiation \\
\hline $\operatorname{trd}$ & transmitted diffuse solar radiation \\
\hline $\operatorname{trh}$ & hourly transmitted solar radiation \\
\hline
\end{tabular}

\subsection{References for Part II}

André, P. (2008). Email communications from André (University of Liège, Liège, Belgium) to Neymark (Wheat Ridge, Colorado, US: J. Neymark \& Associates) of April 1, 2008.

ANSI/ASHRAE Standard 140-2004. Addendum $b$. Standard Method of Test for the Evaluation of Building Energy Analysis Computer Programs. (2004a). Atlanta, Georgia, US: American Society of Heating, Refrigerating and Air-Conditioning Engineers.

ANSI/ASHRAE Standard 140-2004. Standard Method of Test for the Evaluation of Building Energy Analysis Computer Programs. (2004b). Atlanta, Georgia, US: American Society of Heating, Refrigerating and Air-Conditioning Engineers.

ANSI/ASHRAE Standard 140-2007. Standard Method of Test for the Evaluation of Building Energy Analysis Computer Programs. (2007). Atlanta, Georgia, US: American Society of Heating, Refrigerating and Air-Conditioning Engineers.

ANSI/ASHRAE/IESNA (2007). ANSI/ASHRAE/IESNA Standard 90.1-2007, Energy Standard for Buildings Except Low-Rise Residential Buildings. Atlanta, Georgia, US: American Society of Heating, Refrigerating and Air-Conditioning Engineers.

ASHRAE. (2005). 2005 Handbook of Fundamentals, Atlanta, Georgia, US: American Society of Heating, Refrigerating and Air-Conditioning Engineers. 
EnergyPlus. (2008). U.S. Department of Energy, Energy Efficiency and Renewable Energy, Office of Building Technologies. www.energyplus.gov

European Union. (2002). On the Energy Performance of Buildings. Directive 2002/91/EC of the European Parliament and of the Council, Official Journal of the European Communites, December.

ESRU. (2008). ESP-r web site. See www.esru.strath.ac.uk. Glasgow, Scotland, UK: University of Strathclyde, Energy Systems Research Unit.

Felsmann, C. (2008). Email communications from Felsmann (Dresden University of Technology, Dresden, Germany) to Neymark (Wheat Ridge, Colorado, US: J. Neymark \& Associates) of April 3 and April 11, 2008.

Internal Revenue Service (IRS). (2008). Amplification of Notice 2006-52, Deduction for Energy Efficient Commercial Buildings. IRS Notice 2008-40. Appears in Internal Revenue Bulletin (IRB) No. 2008-14, April 7, 2008. Washington, D.C., US: United States Department of Treasury, Internal Revenue Service.

Judkoff, R. (1988). "Validation of Building Energy Analysis Simulation Programs at the Solar Energy Research Institute." Energy and Buildings, 10 (3) 235. Lausanne, Switzerland: Elsevier Sequoia.

Judkoff, R.; Neymark, J. (1995). International Energy Agency Building Energy Simulation Test (BESTEST) and Diagnostic Method. NREL/TP-472-6231. Golden, Colorado, US: National Renewable Energy Laboratory, Golden, CO. www.nrel.gov/docs/legosti/old/6231.pdf

Judkoff, R.; Neymark, J. (2006). "Model Validation and Testing: The Methodological Foundation of ASHRAE Standard 140." ASHRAE Transactions, Volume 112 (2) 367-376. Atlanta, Georgia, US: American Society of Heating, Refrigerating and Air-Conditioning Engineers.

Judkoff, R.; Wortman, D.; O'Doherty, B.; Burch, J. (2008). A Methodology for Validating Building Energy Analysis Simulations. NREL/TP-550-42059. Golden, Colorado, US: National Renewable Energy Laboratory. Based on unpublished report of 1983 with same authors and title, previously referenced as SERI/TR-254-1508.

McConnell, S. (2004). Code Complete: A Practical Handbook of Software Construction. Microsoft Press, p. 502.

Myers, G. (2004). The Art of Software Testing. Hoboken, New Jersey, US: John Wiley \& Sons, p. xiii.

Neymark, J.; Judkoff, R. (2002). International Energy Agency Building Energy Simulation Test and Diagnostic Method for Heating, Ventilating, and Air-Conditioning Equipment Models (HVAC

BESTEST) Volume 1: Cases E100-E200. NREL/TP-550-30152. Golden, Colorado, US: National Renewable Energy Laboratory. www.nrel.gov/docs/fy02osti/30152.pdf

Neymark, J.; Judkoff, R. (2004). International Energy Agency Building Energy Simulation Test and Diagnostic Method for Heating, Ventilating, and Air-Conditioning Equipment Models (HVAC BESTEST), Vol. 2: Cases E300-E545. NREL/TP-550-36754. Golden, Colorado, US: National Renewable Energy Laboratory. www.nrel.gov/docs/fy05osti/36754.pdf. 
Neymark, J.; Judkoff, R.; with Beausoleil-Morrison, I; Ben-Nakhi, A.; Crowley, M.; Deru, M.;

Henninger, R.; Ribberink, H.; Thornton, J.; Wijsman, A.; Witte, M. (2008). International Energy Agency Building Energy Simulation Test and Diagnostic Method (IEA BESTEST) In-Depth Diagnostic Cases for Ground Coupled Heat Transfer Related to Slab-On-Grade Construction. NREL/TP-550-43388. Golden, Colorado, US: National Renewable Energy Laboratory.

Poirazis, H. (2007). Double Skin Facades, A Literature Review. Lund, Sweden: Lund Institute of Technology, Lund University.

Purdy, J.; Beausoleil-Morrison, I. (2003). Building Energy Simulation Test and Diagnostic Method for Heating, Ventilating, and Air-Conditioning Equipment Models (HVAC BESTEST): Fuel-Fired Furnace Test Cases. Ottawa, Canada: Natural Resources Canada, CANMET Energy Technology Centre. www.ieashc.org/task22/deliverables.htm

Strachan, P. (2008). Email communication with J. Neymark. 31 March 2008. University of Strathclyde, Scotland, U.K.

University of Wisconsin. (2005). TRNSYS 16 (version 16.00.0037), A Transient System Simulation Program. Madison, Wisconsin, US: Solar Energy Laboratory, University of Wisconsin, Wisconsin, United States.

Utsumi, Y.; Mitamura, T. (2008). Air Flow Test Cases including Multi-Zone. Natori, Japan: Institutes of National Colleges of Technology; Ashikaga, Japan: Ashikaga Institute of Technology. In conjunction with IEA: SHC Task 34/ECBCS Annex 43, Project B. Draft, June 2008.

VABI Software. (2008). VABI web site. www.vabi.nl. Delft, The Netherlands: VABI Software BV.

Wijsman, A. (2008a). Email communications with J. Neymark. 19 May - 03 June 2008. Delft, The Netherlands: VABI Software BV.

Wijsman, A. (2008b). Modeler Report for BESTEST Cases MZ320-MZ360, VA114 Version 2.25. Delft, The Netherlands: VABI Software BV. March 2008. Included with Section 2.9, Appendix II-F, of this final report. 


\subsection{APPENDIX II: Simulation Modeler Reports}

In Appendix II, we present reports written by the modelers for each simulation program. The modelers were asked to document:

- Modeling assumptions (required inputs not explicitly described in the test specification)

- Modeling options (alternative modeling techniques)

- Difficulties experienced in developing input files for the test cases with their programs

- Bugs, faulty algorithms, documentation problems, and input errors uncovered during the field trials

- Source code or input modifications made because of the diagnostic results

- Comments on agreement or disagreement of results compared to other simulation results

- Any odd results obtained with their programs

- Sensitivity studies conducted to further understand the sources of differences between their programs and the others

- Conclusions and recommendations about their simulation models, the test specification, or both. 


\title{
Appendix II-A
}

\section{Modeler Report for BESTEST Cases MZ320 - MZ360 EnergyPlus Version 2.1.0.012}

\author{
by \\ Robert Henninger and Michael Witte \\ GARD Analytics, Inc. \\ United States
}

March 2008

\section{Introduction}

$\begin{array}{ll}\text { Software: } & \text { EnergyPlus Version 2.1.0.012 } \\ \text { Authoring Organization: } & \text { U.S. Department of Energy } \\ & \begin{array}{l}\text { Energy Efficiency and Renewable Energy } \\ \text { Office of Building Technologies }\end{array} \\ \text { Authoring Country: } & \text { USA }\end{array}$

This report describes the modeling methodology and results for Round 3 of testing done for the IEA BESTEST Multi-Zone Conduction Cases: MZ320 - MZ360 which were simulated using the EnergyPlus software. The specifications for the test suite are described in Proposed IEA BESTEST Multi-Zone NonAirflow In-Depth Cases: MZ320 - MZ360, IEA: SHC Task 34 / ECBCS Annex 43, August 2006 (referred to as the BESTEST Multi-Zone specification in this report).

\section{EnergyPlus Shading Module}

When assessing heat gains in buildings due to solar radiation, it is necessary to know how much of each part of the building is shaded and how much is in direct sunlight. The sunlit area of each surface changes as the position of the sun changes during the day. The purpose of the EnergyPlus shadow algorithm is to compute such sunlit areas. Predecessors to the EnergyPlus shadowing concepts include the BLAST and TARP shadowing algorithms. The EnergyPlus shadow algorithm is based on coordinate transformation methods similar to Groth and Lokmanhekim and the shadow overlap method of Walton.

Shading surfaces are entities outside of the building that may cast shadows on the building's heat transfer surfaces. These entities do not typically have enough thermal mass to be described as part of the building's thermal makeup.

The most important effect of shading surfaces is to reduce solar gain in windows that are shadowed. (However, in some cases, shading surfaces can reflect solar onto a wall or window and increase solar gain.)

There are two kinds of shading surfaces in EnergyPlus: detached and attached. A detached shading surface, such as a tree or neighboring building, is not connected to the building. An attached shading surface is typically an overhang or fin that is attached to a particular base surface of the building, usually a wall; attached shading surfaces are usually designed to shade specific windows. 
EnergyPlus creates "bi-directional" shades from each shading surface entered. This means that the shade you input will cast a shadow no matter which side of the shade the sun is on. For example, a vertical fin will cast a shadow whether the sun is on the left side or right side of the fin.

It is important to note that EnergyPlus will automatically account for "self-shading" effects - such as in L-shaped buildings - in which some of the building's wall and roof surfaces shade other parts of the building, especially windows. This means that you need to describe only shading elements that aren't building heat-transfer surfaces.

Shading surfaces can also reflect solar radiation onto the building. This feature is simulated if you choose FullExteriorWithReflections or FullInteriorAndExteriorWithReflections in the Building input object (ref: Building - Field: Solar Distribution). In this case, you specify the reflectance properties of a shading surface with the Shading Surface Reflectance input object.

Shading surfaces also automatically shade diffuse solar radiation (and long-wave radiation) from the sky. And they will automatically shade diffuse solar radiation from the ground if Solar Distribution Field = FullExteriorWithReflections or FullInteriorAndExteriorWithReflections in the Building input object. Otherwise, shading surfaces will not shade diffuse radiation from the ground unless you enter a reduced value for View Factor to Ground for those building surfaces that are shaded (ref: Surface:HeatTransfer Field: View Factor to Ground and Surface:HeatTransfer:Sub - Field: View Factor to Ground).

\section{Initial Distribution of Diffuse Solar Transmitted through Exterior and Interior Windows}

EnergyPlus calculates the distribution of short-wave radiation in the interior of each thermal zone. This radiation consists of beam solar radiation, diffuse solar radiation, and short-wave radiation from electric lights. The program determines the amount of this radiation that is (1) absorbed on the inside face of opaque surfaces, (2) absorbed in the glass and shading device layers of the zone's exterior and interior windows, (3) transmitted through the zone's interior windows to adjacent zones, and (4) transmitted back out of the exterior windows.

The algorithm for the distribution of diffuse solar has been improved in EnergyPlus Version 2.1. Previously, all diffuse solar entering the zone was distributed over all surfaces in the zone using a weighted distribution based on area and solar absorptance for opaque surfaces or reflectance for windows. For shallow zones with large windows, such as Case MZ360, this method caused a significant portion of the diffuse solar to incorrectly leave the zone through the windows. The new algorithm, described below (excerpted from EnergyPlus Engineering Reference, version 2.1.0, p.103), has corrected this problem.

"As of Version 2.1 the treatment of diffuse solar transmitted first through exterior windows and subsequently through interior windows has been improved. Diffuse solar (from sky and ground sources) transmitted through exterior windows is first distributed to the interior heat transfer surfaces in the zone containing the exterior windows. This initial distribution apportions the transmitted diffuse solar to interior surfaces using the approximate view factors described above in 'LW Radiation Exchange Among Zone Surfaces.' The amount of this initially distributed diffuse solar absorbed by each interior surface, and each window material layer, is calculated and later added to the 'short-wave radiation absorbed' values described below. The amount of this initially distributed diffuse solar that is reflected is accumulated for each zone and redistributed uniformly as part of the QD calculation described below. The amount of this initially distributed diffuse solar that is transmitted by interior windows to adjacent zones is initially distributed to the interior heat transfer surfaces in the adjacent zone in the same manner as just described. This new treatment of diffuse solar is intended to more accurately account for the initial absorption, transmittance, and reflection of short-wave radiation prior to the uniform distribution." 


\section{Diffuse Sky Model}

In EnergyPlus the calculation of diffuse solar radiation from the sky incident on an exterior surface takes into account the anisotropic radiance distribution of the sky. For this distribution, the diffuse sky irradiance on a surface is given by

AnisoSkyMult(SurfNum) * DifSolarRad

where DifSolarRad is the diffuse solar irradiance from the sky on the ground and SurfNum is the number of the surface.

AnisoSkyMult is determined by surface orientation and sky radiance distribution, and accounts for the effects of shading of sky diffuse radiation by shadowing surfaces such as overhangs. It does not account for reflection of sky diffuse radiation from shadowing surfaces.

The sky radiance distribution is based on an empirical model based on radiance measurements of real skies, as described in Perez et al. 1990. In this model the radiance of the sky is determined by three distributions that are superimposed

- An isotropic distribution that covers the entire sky dome

- A circumsolar brightening centered at the position of the sun

- A horizon brightening.

The proportions of these distributions depend on the sky condition, which is characterized by two quantities, clearness factor and brightness factor, defined below, which are determined from sun position and solar quantities from the weather file.

The circumsolar brightening is assumed to be concentrated at a point source at the center of the sun although this region actually begins at the periphery of the solar disk and falls off in intensity with increasing angular distance from the periphery.

The horizon brightening is assumed to be a linear source at the horizon and to be independent of azimuth. In actuality, for clear skies, the horizon brightening is highest at the horizon and decreases in intensity away from the horizon. For overcast skies the horizon brightening has a negative value since for such skies the sky radiance increases rather than decreases away from the horizon.

For further details regarding the EnergyPlus diffuse sky model refer to the EnergyPlus Engineering Reference Manual and the section titled Sky and Solar/Shading Calculations.

\section{Modeling Assumptions}

The following comments are provided in regards to user inputs that were used with EnergyPlus to model each of the cases described in the BESTEST multi-zone specification. Except where discussed below, all other requirements of the specification were met. 


\section{Case MZ320}

a) The exterior and interior surface solar absorptance could not be set to 0.0. EnergyPlus requires that this input have a value $>0.0$. Accordingly, the solar absorptance was set to 0.000001 for both the exterior and interior surfaces.

b) The exterior surface roughness was not specified and was set to VerySmooth.

c) Number of timesteps per hour was set to 4 .

d) Building outdoor terrain was set to FlatOpenCountry.

\section{Case MZ340}

a) To simulate external walls which were adiabatic and massless and because the exterior and interior absorptance of the exterior wall surfaces were different, the exterior wall had to be described as two layers of fiberglass insulation each with a thermal resistance of $500000 \mathrm{~m}^{2} \mathrm{~K} / \mathrm{W}$ as follows:

MATERIAL:Regular-R,

Wall-ExteriorLayer, !- Name

VerySmooth, !- Roughness

500000.00, !- Thermal Resistance $\{\mathrm{m} 2-\mathrm{K} / \mathrm{W}$ \}

0.000001, !- Absorptance:Thermal

0.000001, !- Absorptance:Solar

0.000001; !- Absorptance:VisibleMATERIAL:Regular-R,

MATERIAL:Regular-R,

Wall-InteriorLayer, !- Name

VerySmooth, !- Roughness

500000.00, !- Thermal Resistance $\{\mathrm{m} 2-\mathrm{K} / \mathrm{W}\}$

0.000001, !- Absorptance:Thermal

1.000000, !- Absorptance:Solar

1.000000; !- Absorptance:Visible

CONSTRUCTION,

ExtWall, !- Name

Wall-ExteriorLayer, !- Outside Layer

Wall-InteriorLayer; !- Layer \#2

b) The common wall separating zones was defined as follows:

CONSTRUCTION,

ComWall,

!- Name

Wall-InteriorLayer, !- Outside Layer

Wall-InteriorLayer; 
c) All opaque exterior surfaces except for the west walls, which contained windows and all common walls, were made to see themselves so that they would be truly adiabatic and did not see external weather conditions.

d) The west walls, which contained windows had to see external weather conditions including the sun and so had to be treated differently. For this case the ExtWall CONSTRUCTION of double layer insulation described above was used to simulate adiabatic conditions.

e) The ideal windows were simulated as described by input objects below. Transmittance values had to $<1.0$ and reflectance, IR emittance and conductivity values had to be $>0.0$.

\begin{tabular}{|c|c|}
\hline IDEAL GLASS, & ame \\
\hline SpectralAverage, & !- Optical Data Type \\
\hline & !- Name of Window Glass Spectral Data Set \\
\hline 0.003175 & !- Thickness $\{m\}$ \\
\hline 99999999, & !- Solar Transmittance at Normal Incidence \\
\hline 0.000000001 & !- Solar Reflectance at Normal Incidence: Front Side \\
\hline 0.000000001 & !- Solar Reflectance at Normal Incidence: Back Side \\
\hline 0.99999999 & !- Visible Transmittance at Normal Incidence \\
\hline 000000001 & !- Visible Reflectance at Normal Incidence: Front Side \\
\hline 0.000000001 & !- Visible Reflectance at Normal Incidence: Back Side \\
\hline 0.0 & !- IR Transmittance at Normal Incidence \\
\hline 0.000000001 & !- IR Hemispherical Emissivity: Front Side \\
\hline 0.000000001 & !- IR Hemispherical Emissivity: Back Side \\
\hline 0.000000001 & !- Conductivity $\{\mathrm{W} / \mathrm{m}-\mathrm{K}\}$ \\
\hline $\begin{array}{l}\text { ONSTRUCTION, } \\
\text { IDEAL WINDOW, } \\
\text { IDEAL GLASS; }\end{array}$ & $\begin{array}{l}\text { !- Name } \\
\text { !- Outside LayerCONSTRUCTION, }\end{array}$ \\
\hline
\end{tabular}

\section{Case 350}

a) Case 350a with the shading device associated with the Zone $\mathrm{C}$ window could not be simulated with EnergyPlus. Windows in EnergyPlus are considered sub-surfaces of exterior heat transfer surfaces and therefore any shading devices must be defined as being associated with the exterior heat transfer surface.

b) Case 350b was simulated using the Surface:Shading:Attached object where the shading surface was associated with the Zone $\mathrm{C}$ exterior wall. Although attached to the Zone $\mathrm{C}$ window it can cast shadows on other surfaces of the building.

c) Case 350c was simulated using the Surface:Shading:Detached:Fixed object where the shading surface is exterior to and separated from the building. If the building is rotated this shading surface will remain stationary.

d) Case 350d was simulated using the Surface:Shading:Detached:Building object where the shading surface is exterior to and separated from the building but if the building is rotated the shading surface rotates with it. 


\section{Case 355}

a) No exceptions taken with the specification

\section{Case 360}

a) No exceptions taken with the specification

\section{Modeling Options}

Variations modeling options as far as simulating adiabatic surfaces, simulating exterior surfaces that have different radiation properties for the external and internal surfaces, and simulating shading surfaces were discussed in the Section 2.

\section{Modeling Difficulties}

EnergyPlus was not able to fully simulate windows with ideal properties as discussed above in Section 2. Evidence of this was seen in Cases MZ340, MZ350, MZ355, and MZ 360 where the hourly transmittance of the glass ranged from 0.989 to 1.007 .

\section{8. $\quad$ Results}

Results for each test tested are presented in an Excel spreadsheet provided with the BESTEST multi-zone test suite. The EnergyPlus results have been provided in a spreadsheet named EnergyPlus-Round3-MZOutput092607-2.1.0.012Unlinked.xls.

For cases MZ340, MZ350, MZ355, and MZ360 where all exterior walls and common walls are massless, although each of the simulations were successful and produced results, EnergyPlus gave the following "severe warning":

** Severe ** This building has no thermal mass which can cause an unstable solution.

** $\sim \sim * *$ Use MATERIAL:REGULAR for all opaque material types except very light insulation layers.

This severe error message is normal when the building is entirely made up of R-layers. In some cases that can result in an unstable solution, but it is not a problem for these test cases.

For Case MZ360 with internal windows between zones, EnergyPlus is calculating diffuse solar in both directions through internal windows. For example, on March 15 at 12:00, EnergyPlus shows results as follows:

Zone A: Zone Transmitted Solar (W)

28190.74

Zone A: Zone Beam Solar from Exterior Windows (W)

22198.48

Zone A: Zone Beam Solar from Interior Windows (W)

Zone A: Zone Diff Solar from Exterior Windows (W)

5992.25

Zone A: Zone Diff Solar from Interior Windows (W)

2553.10

Zone B: Zone Transmitted Solar (W)

Zone B: Zone Beam Solar from Exterior Windows (W)

Zone B: Zone Beam Solar from Interior Windows (W)

7935.66 
Zone B: Zone Diff Solar from Exterior Windows (W)

Zone B: Zone Diff Solar from Interior Windows (W)

Zone C: Zone Transmitted Solar (W)

Zone C: Zone Beam Solar from Exterior Windows (W)

Zone C: Zone Beam Solar from Interior Windows (W)

Zone C: Zone Diff Solar from Exterior Windows (W)

Zone C: Zone Diff Solar from Interior Windows (W)

Some of the solar gain which enters Zone B returns to Zone A through the interior window between Zones A and B. This is reported as "Zone A: Zone Diff Solar from Interior Windows." For Zone A, it is clear what has entered through the exterior window and what has come back through the interior window. For Zone B, solar will enter through the $\mathrm{AB}$ interior window, some will leave through the $\mathrm{BC}$ interior window, and some will return through the $\mathrm{BC}$ interior window. It is not clear what components are summed for the "Zone B: Zone Diff Solar from Interior Windows." The Zone Transmitted Solar numbers are the ones that were recorded in the results spreadsheet and appear to be the NET amount not the GROSS as required by the specification. THERE CURRENTLY ARE NO ENERGYPLUS OUTPUT REPORT VARIABLES THAT ALLOW US TO REPORT WHAT IS REQUIRED. A LATER VERSION OF ENERGYPLUS WILL HAVE THIS CAPABILITY.

Prior to EnergyPlus 2.1.0.012 the diffuse radiation entering an exterior window (Window AO) was evenly distributed to all surfaces within the zone, even the inside of the exterior window.

The methodology for handling solar diffuse through a window was completely reworked in EnergyPlus 2.1.0.012 and was changed uniform interior distribution of transmitted diffuse solar to distribution based on approximate view factors between transmitting windows and zone heat transfer surfaces. This improved EnergyPlus results compared to the results of other programs participating in this IEA BESTEST Multi-Zone Non-Airflow test suite. 


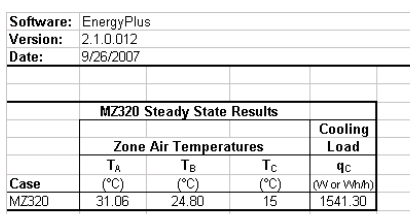

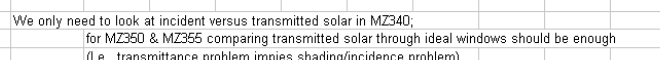

Disaggregated annual beam and diffuse for each zone allows scaling of importance of beam $v$. diffuse shading

MZ340.MZ360 Calorimety Annual Summary Results

Tor Radiaten

\begin{tabular}{|c|c|c|c|c|c|c|c|c|c|c|c|c|c|c|c|c|c|c|c|c|c|c|c|c|c|c|c|c|c|c|c|c|c|c|}
\hline & & A & eny $\mathrm{Am}$ & summa & Kesults & & & & & & & & & & & & & $\begin{array}{l}\text { ansmitt } \\
\text { Znone }\end{array}$ & ted So & 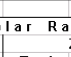 & 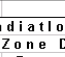 & & & & & & & & & & & & & \\
\hline & $\begin{array}{l}a_{\text {Eldeg }} \\
(k-W h)\end{array}$ & 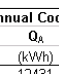 & 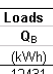 & $\begin{array}{c}a_{c} \\
(k-W W n)\end{array}$ & $\begin{array}{c}a_{0} \\
\left(\frac{k W h}{k}\right)\end{array}$ & $\begin{array}{r}O_{E} \\
(k \mathrm{kWh})\end{array}$ & 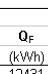 & $\begin{array}{c}\text { Total } \\
\text { Ia } \\
\left(\mathrm{kWWh}^{\mathrm{W} / \mathrm{m}^{2}}\right)\end{array}$ & 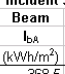 & 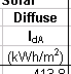 & 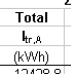 & 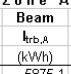 & 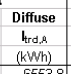 & 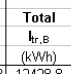 & 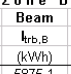 & 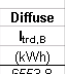 & 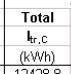 & $\begin{array}{l}\text { Beam } \\
\text { htoc. } \\
\text { (kWh) } \\
\end{array}$ & $\begin{array}{c}\text { Diffuse } \\
\text { htrd.c. } \\
(k \mathrm{kWh}) \\
\end{array}$ & 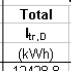 & 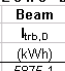 & 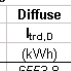 & $\begin{array}{c}\text { Total } \\
\mathrm{h}_{\mathrm{r}, \mathrm{E}} \\
(\mathrm{k} W \mathrm{Wh}) \\
\end{array}$ & 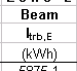 & 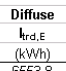 & 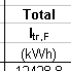 & 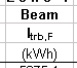 & 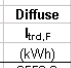 & 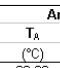 & 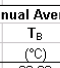 & 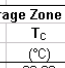 & 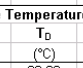 & $\begin{array}{l}T_{E} \\
\left.{ }^{\circ}{ }^{\circ} C\right) \\
\end{array}$ & $\begin{array}{l}T_{\mathrm{F}} \\
\left.\left({ }^{\circ} \mathrm{C}\right){ }^{2}\right)\end{array}$ \\
\hline & 74565 & & & & & & & & & & & & & & & & & & & & & & & & & & & & & & 20.00 & & 20.00 & 20.00 \\
\hline & $\begin{array}{l}477701 \\
47701\end{array}$ & $\begin{array}{l}8258 \\
8258\end{array}$ & $\begin{array}{l}6052 \\
6052\end{array}$ & $\begin{array}{l}9193 \\
9193\end{array}$ & $\begin{array}{l}8642 \\
8642\end{array}$ & $\begin{array}{l}6291 \\
62911\end{array}$ & $\begin{array}{l}9264 \\
9264\end{array}$ & $\begin{array}{l}\text { nla } \\
\text { nta } \\
\text { n/a }\end{array}$ & $\begin{array}{l}\text { na } \\
\text { na } \\
n / a\end{array}$ & $\begin{array}{l}\text { nata } \\
\text { n/a } \\
\text { n/a }\end{array}$ & $\begin{array}{l}8257.3 \\
8257.3\end{array}$ & $\begin{array}{l}3612.8 \\
3612.8\end{array}$ & $\begin{array}{l}4644.5 \\
4644.5\end{array}$ & $\begin{array}{l}60551.8 \\
6051.8\end{array}$ & $\begin{array}{l}2428.3 \\
2428.3\end{array}$ & $\begin{array}{l}3623.5 \\
3623.5 \\
6\end{array}$ & $\begin{array}{l}9191.9 \\
9191.9\end{array}$ & $\begin{array}{l}4987.6 \\
4987.6\end{array}$ & $\begin{array}{l}4204.3 \\
4204.3\end{array}$ & \begin{tabular}{|l|l}
8641.1 .1 \\
8641.1
\end{tabular} & $\begin{array}{l}33657.1 \\
3657.1\end{array}$ & $\begin{array}{l}4784.1 \\
4784.1\end{array}$ & $\begin{array}{l}6290.1 \\
6290.1\end{array}$ & \begin{tabular}{|l}
2557.4 \\
2574.4
\end{tabular} & $\begin{array}{l}3715.7 \\
3715.7\end{array}$ & $\begin{array}{l}9263.5 \\
9263.5\end{array}$ & $\begin{array}{l}5025.8 \\
5025.8\end{array}$ & $\begin{array}{l}42337.7 \\
4237.7\end{array}$ & $\begin{array}{l}20.00 \\
20.00\end{array}$ & $\begin{array}{l}20.00 \\
20.00\end{array}$ & $\begin{array}{l}20.00 \\
20.00\end{array}$ & $\begin{array}{l}.00 \\
.00\end{array}$ & $\begin{array}{l}20.00 \\
20.00\end{array}$ & .00 \\
\hline & $\begin{array}{l}477701 \\
47021\end{array}$ & 82558 & $\begin{array}{l}60022 \\
6052\end{array}$ & 9193 & 8642 & $\begin{array}{l}6291 \\
62291\end{array}$ & $\begin{array}{l}9264 \\
9264\end{array}$ & n/a & n/a & nia & 8257.3 & $\begin{array}{r}3612.8 \\
362.8\end{array}$ & 4644.5 & 6051.8 & $\begin{array}{l}2420.3 \\
24283\end{array}$ & $\begin{array}{l}302035 \\
3623.5 \\
3625\end{array}$ & 9191.9 & 4987.6 & 4204.3 & \begin{tabular}{|l|l|}
8641.1 \\
\end{tabular} & $\begin{array}{l}30557.1 \\
30571\end{array}$ & 4784.1 & 6290.1 & 2574.4 & $\begin{array}{l}3715.7 \\
37157\end{array}$ & 9263.5 & 5025.8 & 4237.7 & 2000 & 20.00 & 20.00 & 20.00 & 2000 & 20.00 \\
\hline & $\begin{array}{l}292254 \\
120538\end{array}$ & $\begin{array}{l}8259 \\
51113\end{array}$ & $\begin{array}{l}6053 \\
599411 \\
5\end{array}$ & $\begin{array}{c}n / a \\
10015\end{array}$ & $\begin{array}{l}8642 \\
n \text { na }\end{array}$ & $\begin{array}{c}6291 \\
\text { nala }\end{array}$ & $\begin{array}{l}n / a \\
n / a \\
n / a\end{array}$ & 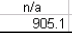 & $\begin{array}{l}n=1 / 2 \\
469.2\end{array}$ & 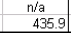 & $\begin{array}{r}8255.3 \\
125148.0\end{array}$ & $\begin{array}{r}36121.8 \\
65004.7\end{array}$ & $\begin{array}{r}4644.5 \\
60033.4\end{array}$ & \begin{tabular}{|l|}
6051.8 \\
44095.4
\end{tabular} & $\begin{array}{l}2428.3 \\
43257.1\end{array}$ & $\begin{array}{r}6623.5 \\
838.3 \\
3\end{array}$ & $\begin{array}{c}n / a \\
3682.6 \\
3\end{array}$ & $\begin{array}{l}\text { nala } \\
0.0\end{array}$ & $\begin{array}{c}n / 2 \\
3682.6 \\
\end{array}$ & $\begin{array}{r}8661.1 \\
n \text { h/a } \\
\end{array}$ & $\begin{array}{r}3856.1 \\
\text { n/a }\end{array}$ & $\begin{array}{c}4784.1 \\
\text { nnta }\end{array}$ & $\begin{array}{c}6200.1 \\
n / a \\
\end{array}$ & $\begin{array}{c}25644.4 \\
n / a \\
n\end{array}$ & & nta & $\begin{array}{l}\text { nla } \\
\text { nhla }\end{array}$ & $\begin{array}{l}n / a \\
n / a \\
n / a\end{array}$ & $\begin{array}{l}20.000 \\
20.00\end{array}$ & $\begin{array}{l}20.00 \\
20.00\end{array}$ & $\begin{array}{c}\text { nda } \\
20.00\end{array}$ & $\begin{array}{l}20.00 \\
\text { nata }\end{array}$ & $\begin{array}{l}20.00 \\
n / a \\
n / a\end{array}$ & va \\
\hline
\end{tabular}

\begin{tabular}{|c|c|c|c|c|c|c|c|c|c|c|c|c|c|c|c|c|c|c|c|c|c|}
\hline & & 17340-MIZ & Calorim & ual Ho & Surly Int & ateded Ma & & & & & & & & & & & & & & & \\
\hline \multirow{7}{*}{ 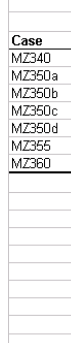 } & $\begin{array}{l}\text { qEldg } \\
\text { (Mhh/h) } \\
75652\end{array}$ & $\begin{array}{l}\text { Date } \\
03 / 15\end{array}$ & $\begin{array}{l}\text { Hour } \\
17: 00\end{array}$ & 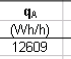 & $\begin{array}{l}\text { Date } \\
0315\end{array}$ & $\begin{array}{l}\text { Hour } \\
17: 00\end{array}$ & $\begin{array}{l}\begin{array}{c}q_{8} \\
(W h / h) \\
12609\end{array} \\
\end{array}$ & $\begin{array}{c}\text { Date } \\
03 / 15\end{array}$ & $\begin{array}{l}\text { Hour } \\
17: 00\end{array}$ & 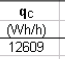 & & & 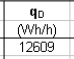 & $\begin{array}{l}\text { Date } \\
\text { D3/15 }\end{array}$ & $\begin{array}{l}\text { Hour } \\
17: 00\end{array}$ & \begin{tabular}{|c|} 
qE \\
Whhh \\
12609 \\
\end{tabular} & $\begin{array}{l}\text { Date } \\
03 / 15\end{array}$ & $\begin{array}{l}\text { Hour } \\
\text { 17:00 }\end{array}$ & 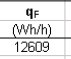 & $\begin{array}{l}\text { Date } \\
03 / 15 \\
\end{array}$ & $\begin{array}{l}\text { Hour } \\
17: 00\end{array}$ \\
\hline & $\begin{array}{r}71278 \\
71278 \\
72278 \\
41286 \\
105575\end{array}$ & $\begin{array}{l}04 / 19 \\
04419 \\
04 / 19 \\
00419 \\
12211 \\
\end{array}$ & $\begin{array}{l}17: 00 \\
17: 00 \\
17: 00 \\
17: 00 \\
15: 00 \\
\end{array}$ & $\begin{array}{l}12395 \\
12395 \\
12395 \\
12395 \\
.40913 \\
.4\end{array}$ & $\begin{array}{l}03 / 115 \\
03 / 15 \\
03 / 1 / 5 \\
03 / 15 \\
02 / 21\end{array}$ & $\begin{array}{l}17: 00 \\
17: 00 \\
17000 \\
17: 00 \\
15: 00\end{array}$ & $\begin{array}{l}12001 \\
12001 \\
12001 \\
12001 \\
5720006\end{array}$ & $\begin{array}{l}04 / 19 \\
04 / 19 \\
04 / 19 \\
04 / 9 \\
02 / 108\end{array}$ & $\begin{array}{l}17: 00 \\
17: 00 \\
17: 00 \\
17: 00 \\
16: 00\end{array}$ & $\begin{array}{l}12400 \\
12400 \\
12400 \\
n \text { nal } \\
7100\end{array}$ & $\begin{array}{l}03 / 15 \\
03 / 15 \\
03 / 15 \\
\text { n/a } \\
11 / 28\end{array}$ & $\begin{array}{c}17: 00 \\
17: 00 \\
17: 00 \\
n / a \\
15: 00 \\
150\end{array}$ & $\begin{array}{l}12399 \\
12399 \\
123999 \\
123999 \\
129\end{array}$ & $\begin{array}{l}03 / 15 \\
03 / 15 \\
03315 \\
03 / 15 \\
n / a\end{array}$ & $\begin{array}{r}17: 00 \\
17: 00 \\
17000 \\
17: 00 \\
\text { nia }\end{array}$ & \begin{tabular}{|c|}
12004 \\
12004 \\
12004 \\
12004 \\
$n / a$
\end{tabular} & $\begin{array}{l}04 / 19 \\
04419 \\
04 / 19 \\
04 / 19 \\
04 / 9\end{array}$ & $\begin{array}{c}17: 00 \\
17.00 \\
17.00 \\
17.00 \\
n / a\end{array}$ & $\begin{array}{l}12401 \\
12401 \\
12401 \\
\mathrm{n} / \mathrm{a} \\
\mathrm{n} / \mathrm{a}\end{array}$ & $\begin{array}{l}03 / 15 \\
03115 \\
03 / 15 \\
n / a \\
n / a\end{array}$ & $\begin{array}{l}17: 00 \\
17: 00 \\
17: 00 \\
\mathrm{na} / \mathrm{a} \\
\mathrm{n} / \mathrm{a}\end{array}$ \\
\hline & & & Case & $\begin{array}{l}T_{T_{R}} \\
\left({ }^{\circ} \mathrm{C}\right)\end{array}$ & Dare & Hour & 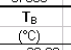 & Date & Hour & 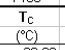 & Wale & & $\begin{array}{l}T_{0} \\
\rho_{0}\end{array}$ & Dare & nour & 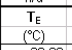 & Dac & nour & $\begin{array}{l}T_{T_{F}} \\
\left(\rho^{\circ} \mathrm{C}\right)\end{array}$ & Sate & Hour \\
\hline & & & MZ340 & & & 20:00 & & $06 / 12$ & 20:00 & & $06 / 12$ & $20: 00$ & & & 20:00 & & $06 / 12$ & $20: 00$ & & $06 / 12$ & 20:00 \\
\hline & & & $\begin{array}{l}\text { M25350 } \\
\text { M }\end{array}$ & $\begin{array}{l}20.00 \\
20.00\end{array}$ & $\begin{array}{l}05 / 22 \\
05 / 22\end{array}$ & $\begin{array}{l}20: 000 \\
20: 00\end{array}$ & $\begin{array}{l}20.00 \\
20.00\end{array}$ & $\begin{array}{l}06 / 28 \\
06 / 28\end{array}$ & $\begin{array}{l}20: 000 \\
20: 00\end{array}$ & $\begin{array}{l}20.00 \\
20.00\end{array}$ & $\begin{array}{l}08 / 16 \\
08 / 16\end{array}$ & $\begin{array}{l}20.00 \\
20: 00\end{array}$ & $\begin{array}{l}20.00 \\
20.00\end{array}$ & $\begin{array}{l}06 / 28 \\
066 / 28\end{array}$ & $\begin{array}{l}20: 00 \\
20: 00\end{array}$ & $\begin{array}{l}20.00 \\
20.00\end{array}$ & $\begin{array}{l}06 / 28 \\
06628\end{array}$ & $\begin{array}{l}20: 00 \\
20: 00\end{array}$ & $\begin{array}{l}20.00 \\
20.00\end{array}$ & $\begin{array}{l}0121 \\
0121\end{array}$ & $\begin{array}{l}19: 00 \\
19: 00\end{array}$ \\
\hline & & & $\begin{array}{l}\text { M2750d } \\
\text { M7255 }\end{array}$ & $\begin{array}{l}20000 \\
20.00\end{array}$ & $\begin{array}{l}05 / 22 \\
05 / 22\end{array}$ & $\begin{array}{l}{ }_{20: 00} \\
20: 000\end{array}$ & $\begin{array}{l}200.00 \\
20.00\end{array}$ & $\begin{array}{l}06 / 28 \\
06 / 28\end{array}$ & $\begin{array}{l}{ }_{20: 00}^{20: 00} \\
20\end{array}$ & $\begin{array}{l}20.00 \\
\text { na }\end{array}$ & $\begin{array}{l}0,1 / 6 \\
\text { n/a }\end{array}$ & $\begin{array}{l}20.00 \\
\text { nota } \\
\text { nata }\end{array}$ & $\begin{array}{l}200.00 \\
20.00\end{array}$ & 0628 & $\begin{array}{l}200.00 \\
20: 00\end{array}$ & $\begin{array}{l}20.00 \\
20.00\end{array}$ & $\begin{array}{l}06 / 288 \\
06128\end{array}$ & $\begin{array}{l}20000 \\
20: 00\end{array}$ & $\begin{array}{l}20.00 \\
\text { nala }\end{array}$ & D1121 & $\begin{array}{l}19: 00 \\
\text { nna }\end{array}$ \\
\hline & & & & & & & & & & & & & & & & & & & & & \\
\hline
\end{tabular}

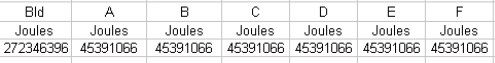

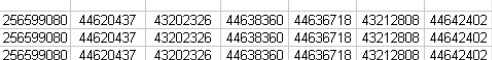

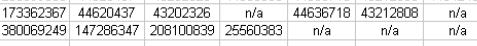


Appendix II-B

Modeler Report for BESTEST Cases MZ320 - MZ360

ESP-r Version 11.5

\author{
by \\ Paul Strachan \\ Energy Systems Research Unit, University of Strathclyde \\ United Kindom
}

March 2008

\title{
1. Introduction
}

ESP-r, Version 11.5 of March/April 2008 with some modifications for shading as described below Open Source software. Authors are Energy Systems Research Unit, University of Strathclyde, Scotland, UK

Finite volume, with user-selectable timesteps.

\section{Modelling Algorithms and Assumptions}

ESP-r uses the Perez 1990 anisotropic diffuse sky model for calculating diffuse radiation. Direct and diffuse transmission, glazing absorption and internal zone distribution are calculated separately. In the models $\mathrm{mz} 340$ and $\mathrm{mz} 350 \mathrm{c}$ this is not important as the windows have $100 \%$ transmittance and all radiation is absorbed in the zone, with none re-transmitted out of the window. For model mz360, ray tracing is used to allocate the direct solar transmittance to the appropriate internal surface for both zones. Diffuse radiation passing through the window is allocated to surfaces not in the same plane as the window based on surface area and absorptivity. After the first bounce, direct radiation is treated as diffuse and added to the reflected diffuse radiation. This is iteratively spread to all internal zone surfaces based on the area and absorptivity (in the case of opaque surfaces) or the absorptances and transmittances (in the case of transparent constructions) until all radiation is accounted for.

As mentioned in section 4, shading for the mz350c test is calculated using the daylight coefficient method and the link to Radiance. Daylight coefficients are pre-calculated for each sensor point - each window was set up with 80 sensor points.

During simulation, the irradiance is calculated for each sensor point and averaged for the window, with direct and diffuse radiation held separately. Simulations were carried out at 15 minute timesteps.

\section{Modelling Options}

\section{Modelling Difficulties and Enhancements}

Solar data provided were half-hour centred, whereas ESP-r has traditionally used hour-centred data. Code modifications were made to allow a flag to be set to indicate that the solar data are either hour or half-hour centred. This code change was incorporated in the versions of ESP-r starting at 11.2, allowing users the option (although it should be noted climate data sets vary in their time intervals). 
The windows cannot be modelled as adiabatic because this would not allow radiation through in ESP-r's definition of adiabatic. Therefore windows are given low conductivity $(0.0001)$ and low surface heat transfer coefficients (0.001). All optical properties are included as specified.

The relative humidity cannot be set to $0 \%$ because this causes errors in ESP-r's external longwave algorithm for sky radiation. It was set to $50 \%$. This should not matter in the tests MZ320 - MZ360 because external surface emissivity is set to (close to) zero and humidity does not influence the other processes considered.

For the mz350c tests, use was made of an enhancement to ESP-r based on the daylight coefficient method, with work by Christoph Reinhart and Denis Bourgeois of NRC in Canada. In this [method], the ESP-r export to Radiance is used, Radiance is used to generate the coefficients for a discrete sky patches (145 in the current implementation for diffuse radiation and 2035 for direct radiation) for direct and diffuse radiation as a pre-computation, and then at each simulation timestep the appropriate radiation is calculated in ESP-r for direct and diffuse radiation. The facility was originally developed for lighting control purposes but has been extended from calculating illuminance data to also calculate irradiance data. It can be extended for complex shading systems and for complex internal radiation distributions. The current version is a beta version and it is likely that further tests and refinements will take place in the next few months. Nevertheless, the results to date are considered reasonable. Because most of the results of interest are a comparison of the unshaded case (mz340) with the unshaded case (mz350), the daylight coefficient method was used for both models. This results in a small decrease (less than $2 \%$ ) in the annual solar loads in the rooms for the unshaded case compared to ESP-r's usual calculation. The reason for this will be investigated, but the effect on differences between the mz340 and mz350 cases should be negligible.

\section{Software Errors Discovered and Comparison between Different Versions of the Same Software}

As noted in the last section, a software modification was made to allow half-hour centred solar data. In these tests, where there are large west-facing windows, the difference is significant (in the order of $12 \%$ increase in cooling load if it is assumed that the data are hour-centred instead of half-hour centred). The differences are much smaller in the case of south-facing windows.

Results differ for test MZ360 compared to the previous submission in the internal distribution of direct solar radiation. The total solar entering the building is unchanged, but there are some, mostly small, changes to the insolation distribution, which has the effect of changing the amount of direct radiation passing from Zone $\mathrm{A}$ to Zone B and from there to Zone $\mathrm{C}$.

\section{Results}

Attached as MZ-Output310308_esp-r.xls

7. Other (optional)

\section{Conclusions and Recommendations}

Adding shading blocks with different reflectances could be used to extend the series of tests. 


\section{References}

The daylight coefficient method is documented in Bourgeois D, Reinhart C F and Ward G, "Standard Daylight Coefficient Model for Dynamic Daylighting Simulations", Building Research and Information, 36(1), January 2008, pp68-82. 


\title{
Appendix II-C
}

\section{Modeler Report for BESTEST Cases MZ320 - MZ360 \\ HTB2 Version 2.20AD}

\author{
by \\ Don Alexander \\ Welsh School of Architecture, Cardiff University \\ United Kindom
}

March 2008

\section{Introduction}

HTB2 is a research based thermal modelling code.

Current version: 2.20AD.

Authors: Welsh School of Architecture, Cardiff University, Cardiff UK.

- Explicit finite-difference fabric model is used for all fabric transfer, including internal partitions and glazing.

- Inter-zone air transfer can be specified or calculated, or treated as an interzone conductance.

- Surface shading calculated using a preprocessor (hshade 2.0). Shading effect specified to HTB2 as a "Sky Mask" (further described below) in 10 degree sectors, rather than as geometric structures. Hshade 2.0 considers finite fins and overhangs.

- Diffuse solar gain is determined through isotropic sky model.

- Calculation timestep variable; typically in range 10-180 seconds. For these cases, a 90 second timestep was used, with integrated hourly data output.

\section{Modeling Assumptions}

The specification of massless fabric is not feasible in this code. External fabric material required specification of thermal capacity as $1 \mathrm{~J} / \mathrm{m}^{3} \mathrm{~K}$ for stability at timestep used. There were no changes in result values if capacity specified as 0.1 or 10.0 .

As external surfaces were to be modeled, adiabatic walls were specified using a very low conductance material.

Radiant calculation modules disabled for MZ320 test, with surface transfer specified using combined coefficients. Radiant calculation modules were required for other tests, in order to calculate solar gains. Combined surface transfer coefficients again used, but surface emissivity set to 0 to disable longwave calculations.

MZ320 test disabled meteorological input, setting fixed external conditions. Other tests utilized TM2 data reformatted to HTB2 format.

MZ360 modelling of internal glazing requires precalculated transfer ratio (amount of direct solar passing through external window that falls on internal window). This was calculated from relative area ratios of internal glass and its surround. Other surface areas were assumed not to receive direct solar. 
Transmission, reflection and absorption of internal window are calculated for an incidence angle based on the solar ray and the orientation of the internal window. Diffuse radiation through external window is sent to all surfaces in zone (area weighted); including the internal window, which allows it to be transmitted, reflected and absorbed. Solar reflected off the internal window becomes diffuse solar in the source zone. A second pass is used to estimate the diffuse transmission back through the internal window to the source zone (n.b. all beam radiation not absorbed (or transmitted by surfaces becomes diffuse). Solar lost from the first window is a separate, fixed ratio. It is not calculated from the geometry. In this case, Solar lost for the external window was left at the default value, 0 .

For modeling shading, the sky mask model describes the view factor from a sector of the sky to a surface area; if a shading device obstructs the surface from the sector then no radiation from that sector reaches the surface. For direct solar, the sector the sun is in is determined at the recalculation time, and this factor is applied to the beam radiation. Diffuse shading is determined by integrating the mask with the sky brightness. Shading is determined for the whole surface (e.g. not subdivided) during the precalculation phase (hshade 2.0); shading effect for a surface is fraction 0-1 of unshaded incident direct and diffuse; ground reflection is not shaded.

Solar geometry and shading effect are calculated on a meteorological interval (e.g. 60 minute default), when shading is changed (schedule), and on an inner 10 minute (default) loop.

\section{Modeling Options}

No options specific to multi-zone modeling apply.

\section{Modeling Difficulties}

MZ320 - no problems

MZ340 - no problems, though specification of fixed external heat transfer coefficient revealed bug, described below.

Beam transmission not available in output. Values quoted are determined from TotalDiffuse.

MZ350 - method to determine shading effect seems to best match option d - "other"; in HTB2 cumulative shading effect of external objects (whether fins, overhangs, trees or self shading) are specified for each element (e.g. window) as a sky mask. Results submitted under MZ350d only.

MZ355 - As shading of neighboring zones is not an automatic calculation, no results are submitted for MZ355.

MZ360 - Current version allows for two windows in series. Not capable of three windows in series. Therefore the two zone alternative modeling spec used for this case.

Cannot break transmission down to beam and diffuse. Gross diffuse transmission is not held in output data, only net diffuse transmission is available (from zone data, not per window). Per window data saved is total transmission (beam and diffuse combined). Therefore diffuse transmission to Zone $\mathrm{B}$ was available, but beam transmission to Zone B was calculated from Total transmission to zone B less Diffuse component. Zone A net transmission calculated similarly. Zone A Gross transmission calculated from Zone A net + Zone B net. 


\section{Software Errors Discovered and Comparison between Different Versions of the Same Software}

Three faults in code identified:

- Initial specification of fixed external combined coefficients, for case MZ320 initially, led to disagreement with hand-calculated results. The difference was traced to the default external coefficient algorithm still being used; the override values specified were being ignored. Initialization code was altered to allow the proper detection and use of external coefficient override values. This fault applied only to external coefficients; override values for internal coefficients were detected and used properly in original code. This fault has been fixed in the latest version.

- The case MZ340 required the use of zero emissivity for all surfaces in a zone, the original code failed when the total emissivity of a zone was zero. This was traced to an undetected divide- byzero. The code was altered to allow zero emissivity zones. (This was not detected in earlier cases as radiant calculations were turned off in order to treat the required combined coefficients; however, this would also disable solar calculations needed in the later cases.)

- Case MZ355 was originally defined incrementally from Case MZ350, using a feature to "Skip" unwanted elements (e.g. the windows for Zones C and F). This "Skip" feature was originally intended as a convenience feature, in order to allow incremental testing or changes to fabric to be undertaken without affecting index codes. When "Skipped", an element is removed from fabric calculations. Used in this case, solar gains were still found in zones C and F. It was determined that the skip logic had not been applied to solar calculations for transparent elements. In order to complete the case, the Case MZ355 files were re-edited to explicitly remove the unwanted window elements. This has fault has been flagged for correction in a future version.

Also, in the hourly output of solar gain and cooling for Case MZ340 it is noted that there is a slight difference between the two for each hour. This is not a fault in the internal energy balance (the balance is adequate over a longer period (e.g. 1 day), but rather a "feature" of the reporting accounting. At the end of an accounting period, there remains, at the time of the report, uncertainty of one timestep (e.g. at the time of the report energy from some sources is left over for the next timestep loop, but from others it has already been applied). Therefore in this instance the cooling load is one timestep (e.g. 90 seconds) delayed compared to the solar gains. Within the overall structure of the model, this effect would be difficult to remove; it is not considered to be a "bug", but the cause of the effect will be considered more carefully in future revisions.

While this effect has been investigated further, a solution is not yet forthcoming. This effect is also evident in the MZ360 results; in both it may be mistaken as representing thermal mass; however, it is an accounting problem in the reporting procedure. Internally, verified by debugging inspection, there is a much closer energy balance between incoming solar and cooling. The effect reduces significantly if shorter timesteps for calculation or reporting are used. There is a slight residual thermal mass effect, on the order of $10 \mathrm{~W}$ during peak changes of solar incoming.

Recent detailed inspection of the dataflow in the model has lead to the conclusion that the solar data, as generated by the Meteorological and Solar transmission modules, and the surface insolation data, as used by the Fabric module, were one timestep out of phase when the fabric calculations were made. As of version $2.20 \mathrm{AB}$, the ordering of the calculation modules has been altered; no changes were made to algorithms, parameters or data. This appears to have solved the problem described above; the solar gains and cooling 
loads of a zone are now essentially identical in the MZ340 and MZ360 tests. The change has made little difference to other $\mathrm{MZ}$ results apart from those for peak cooling.

During inspection of the shading preprocessor output prior to running latest revisions, anomalous behaviour (e.g. discontinuous "jumps" in the angular data) in the shading factors for high altitude angles was noticed visually in the data text. This was traced to faulty logic in determining the shadow overlap cases in the Hshade preprocessor which wrongly excluded a valid case triggered at acute vertical angles. This was corrected and better (more smoothly varying factors) were produced; this version has been used in these results. Although this error was present in the previous round of results, the larger fin size exacerbated the problem and made it more noticeable. Differences in results were generally small $(<2 \%$ of cooling energy) but notable in some of the hourly solar data. Results obtained for case MZ350 with the buggy shading code is in file "HTB2_badshading_MZ-Output082205.xls" for interest.

Investigation into the "late afternoon" lump observed in the HTB2 shaded results for the original case 350 indicated that the time and spatial interpolation used for shading were too coarse for the test. Current version changed to increase shading recalculation interval and new interpolation algorithm used to estimate arbitrary shading values from user fixed data (set at 10 degree steps).

Investigation of the initial MZ360 case comparisons lead to discovery of issue in code dealing with internal windows; cosine of incidence angle was effectively accounted for twice in the calculation of transmission through the internal glazing case, the result appeared as a reflection back into zone A. This problem removed and case rerun (Code version 2.20AD) with no changes to input parameters; results appear more consistent with other models. (NB Greater agreement could be achieved through manipulation of the input factors (transfer rations discussed in section 2), but as this could not have been done blind, the original estimates were kept for this submission.)

For the final results for MZ360, the hourly results for Oct 14 (dominated by diffuse solar) indicate that the cooling load for Zone B using the alternative spec for HTB2 (comparable to Zones B $+\mathrm{C}$ for the other programs) is less than the Zone-B-only results for the other programs. This difference is attributable to the relatively simplified method of modeling internal windows using assigned user-input transfer ratios based on the geometry of the case; e.g. relative areas of window and wall surfaces. Additionally, this disagreement is only seen for diffuse solar; the direct-solar dominated day has better agreement. To improve the result it is possible to "tune" the input parameters. The results were not changed as they may represent what a user may be more likely to obtain without the benefit of comparison with other models.

For the final results for the MZ340-MZ350 hourly shading sensitivity for March 15 (dominated by direct normal solar), a disagreement occurs for hour 17. The suspected source of the difference may be a limitation of the sky mask model. The problem is likely that the sectoring is too coarse for this sensitive problem. Currently the descriptions are given in steps of 10 degrees (a fairly arbitrary decision made at least 20 years ago); the solar position is updated every 15 minutes. Some interpolation is done using neighbouring sectors, but if the shadow is sharp edged, the result would be fuzzy. At hour 17, the sun may be just passing the shade, so the coarseness of the mask may introduce an error. It is possible to increase the mask resolution (to 5 and 2 degrees), to see if that improves the result, and this issue has been flagged to check for a future update.

\section{6. $\quad$ Results}

$\mathrm{n} / \mathrm{a}$ 


\section{Other (optional)}

Noted a potential for conflict in specification data in case MZ340 onwards: external dimensions for walls are specified, with allowance for walls of $0.1 \mathrm{~m}$ thick, but specified zone volumes appear to be calculated using those external dimensions. If e.g. $0.1 \mathrm{~m}$ walls are specified, then zone volume would be $189.93 \mathrm{~m} 3$. This would make no difference in these cases, but in potential future cases with free-floating temperatures or ventilation flows, this would introduce an area for disagreement.

\section{Conclusions and Recommendations}

A resolution for the accounting problem in the output will be sought, and has been provisionally solved in this latest revision, as described in section 5 above.

\section{References}




\title{
Appendix II-D
}

\section{Modeler Report for BESTEST Cases MZ320 - MZ360 TRNSYS-TUD}

\author{
by \\ Clemens Felsmann \\ Dresden University of Technology \\ Germany
}

\section{April 2008}

\section{Introduction}

All calculations have been performed with the program TRNSYS-TUD. This program is originally based on TRNSYS 14.2 (distributed by TRANSSOLAR, Germany) but a lot of major revisions and additions were made at TUD, especially in the multi-zone model.

The multi-zone heat transfer through walls is always calculated with the transfer factor method (TFM). The simulation time step in the multi zone test cases was $0.05 \mathrm{~h}$.

\section{Modeling Assumptions}

The solar modeling was originally done with the Reindl model [1], [2] because it is more accurate than the rather simple isotropic sky model. The Reindl model accounts for isotropic diffuse, circumsolar radiation and for horizontal brightening to estimate sky diffuse radiation. But in addition to that the isotropic sky model had to be used to guarantee consistency between building models with (MZ350) and without (MZ340) a shading device. So the Reindl model is available but isotropic model was used for the final results reported for MZ340, MZ350, and MZ360. See Chapters 4 and 5 for more detailed information about this issue. In both cases - isotropic and Reindl model - the input data for the solar processor are total horizontal and direct normal radiation taken from the TMY weather file.

The fin shading in case MZ350 was modelled with six identical side fins associating each fin with one of the windows. This approach is necessary because the geometrical relation between a window and the given side fin is different for each window. It is not possible to associate a single fin to several windows. The fin shading definitions of case MZ350 can be used also to model the shading by another building zone as defined in MZ 355 when at the same time incident radiation for completely blinded surfaces (walls and windows) is fixed to zero.

\section{Modeling Options}

The heat transfer through walls between zones is calculated with an identical mathematical approach than for all other walls in the model (TFM).

Furthermore the simulation model asks the user for two basic options:

a.) The transfer factor method also accounts for the thermal history of the wall. The program asks for a so called time base that indicates a discrete time interval for updating thermal 
history of the wall. Normally TRNSYS works with a time base of $1 \mathrm{hr}$. But for these multizone tests the time base is $0.1 \mathrm{hr}$ for the exterior walls and $0.05 \mathrm{hr}$ for the internal walls.

b.) The user has to make a decision between two different approaches to calculate longwave radiation exchange: a normally used but simplified calculation method (star network by SEEM) or a more accurate one (view factors). For these multi-zone tests the more accurate approach has been used.

\section{Modeling Difficulties}

No problems were encountered with representing any of the specifications in the TRNSYS-TUD model, nor problems with interpreting the User's Manual. All inputs required for the model were described in the input specification.

The only problem has occurred when the Reindl model for calculating the solar radiation and a fin shading device should be used together in the same model. The conflict is caused by the assumption that both diffuse and ground reflected radiation on a shaded window area are isotropic whereas walls and windows without a shading device are correlated to the diffuse radiation calculated with the Reindl model. Thus the comparison of building energy loads of shaded (MZ350) and not shaded (MZ340) buildings will lead to some additional differences caused by different diffuses radiation models. The only solution to solve this modeling problem was to always use the isotropic sky model when predicting the solar radiation.

\section{Software Errors Discovered and/or Comparison between Different Versions of the Same Software}

There are three kinds of errors and curiosities that were discovered:

1. Although it was assumed that interior walls do not reflect any solar radiation (solar absorptance $=1$ ) and ideal windows do neither reflect nor absorb any solar radiation (solar transmittance $=1$ ) the zone cooling load was not equal to the net transmitted solar radiation. The reason for this error was that in the program transmitted solar radiation was originally distributed to the interior surfaces (walls and windows) accordingly to solar distribution factors that were calculated as follows:

$$
f_{\text {sol,s }}=\frac{\alpha_{s} A_{s}}{\sum_{\text {surfaces }}\left(1-\rho_{d, s}\right) A_{s}}
$$

The solar energy absorbed at interior surfaces was then calculated as

$$
\dot{q}_{a b s, s}=I_{t o t} f_{s o l, s}
$$

Within a zone, i.e. after passing the window, solar radiation was treated to be diffuse. As seen from equation (1) a certain amount of transmitted solar radiation is not taken into account for energy balances and goes lost this way. To avoid this problem the calculation procedure for solar distribution was revised. In the current program version only solar radiation that was reflected at interior surfaces (walls and windows) will be distributed based on above mentioned factors.

2. TRNSYS-TUD offers the opportunity to use ray tracing for direct solar radiation that enters the room through an external window. Only multi-zone test case MZ360 was calculated with this program feature. The computation revealed a loop-error in the calculation routine that only occurred if there are at least two zones in a building. This error was already fixed. 
The comparison between a solar distribution model that assumes any solar radiation entered the room to be diffuse and a ray tracing model for the direct part of solar radation on the basis of MZ360 shows big differences in solar transmission through internal windows, annual cooling loads and in dynamic load profiles. In Figure 2D-1 the annual transmitted solar radiation of each zone as calculated from the models with and without ray tracing are compared. While transmittance into zone A must be the same in both approaches transmittance through internal window into zone B is much higher if the ray tracing model is used. This consequently also has an impact on annual cooling load. By looking at Figure 2D-2 it can be seen that annual cooling load is lower in zone A and higher in Zone B if when using the ray tracing method the annual transmitted solar radiation into zone B is higher, too. The total annual cooling load of the building is not affected at all. Figures 2D-3 and 2D-4 are useful to check load profiles. Figure 2D-4 also depicts that there is an impact of solar distribution models only if a direct part of solar radiation occurs.

3. The calculation of solar shading effects of a fin is done with TRNSYS-Type 34 "Overhang and Wingwall Shading." The solar radiation incident on the shaded windows consists of beam, diffuse and ground reflected components, which depend on view factors. The sky and ground radiation view factors are calculated assuming radiation to be isotropic. For that reason only simulation results based on an isotropic sky model have been reported for all test cases to be consistent for shaded and un-shaded test cases.

\section{Results}

In general results of TRNSYS-TUD simulations agree very well to results of other participants. But for MZ360 there are some differences to others, which could be caused by two facts:

a.) The ray tracing method used to calculate solar paths from outside to the most inner zone $\mathrm{C}$ only works fine for external windows. See Figures 2D-1 through 2D-4 for more details of impact of ray tracing on cooling loads.

b.) Solar radiation is assumed to be $100 \%$ diffuse when transmitted trough an internal window.

\section{Other (optional)}

\section{Conclusions and Recommendations}

The multi-zone test cases are very useful to detect program and modeling errors that mainly occur within a multi zone building:

- Addressing of solar heat gains

- Multi-zone partly shading effects

- Heat transfer through inner walls

- Internal windows.

It is recommended to have a further look at

- Distribution of solar radiation within the building (internal shadings, several windows vis-àvis, ...etc)

- Interzonal air change.

\section{References}

[1] Reindl, D.T., Beckmann, W.A., Duffie, J.A., 1990. Diffuse fraction correlations. Solar Energy 45:1-7

[2] Reindl, D.T., Beckmann, W.A., Duffie, J.A., 1990. Evaluation of hourly tilted surface radiation models. 31 Solar Energy 45:9-17 
10. Figures

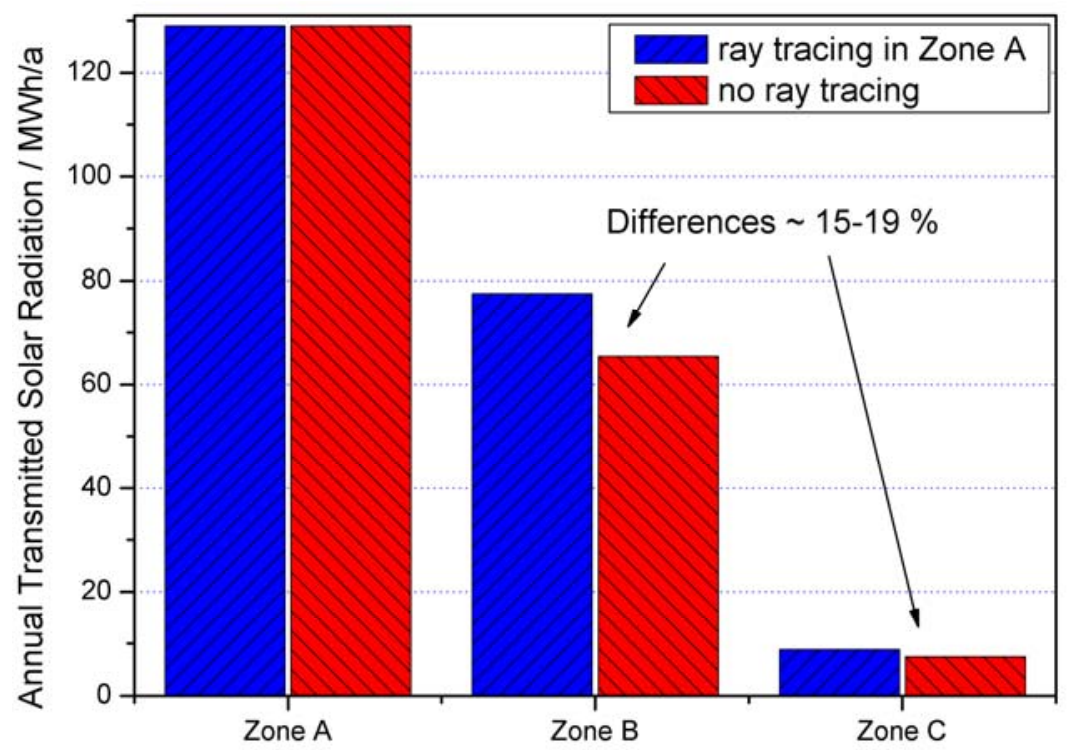

Figure 2D-1. MZ360, Comparison of annual transmitted solar radiation

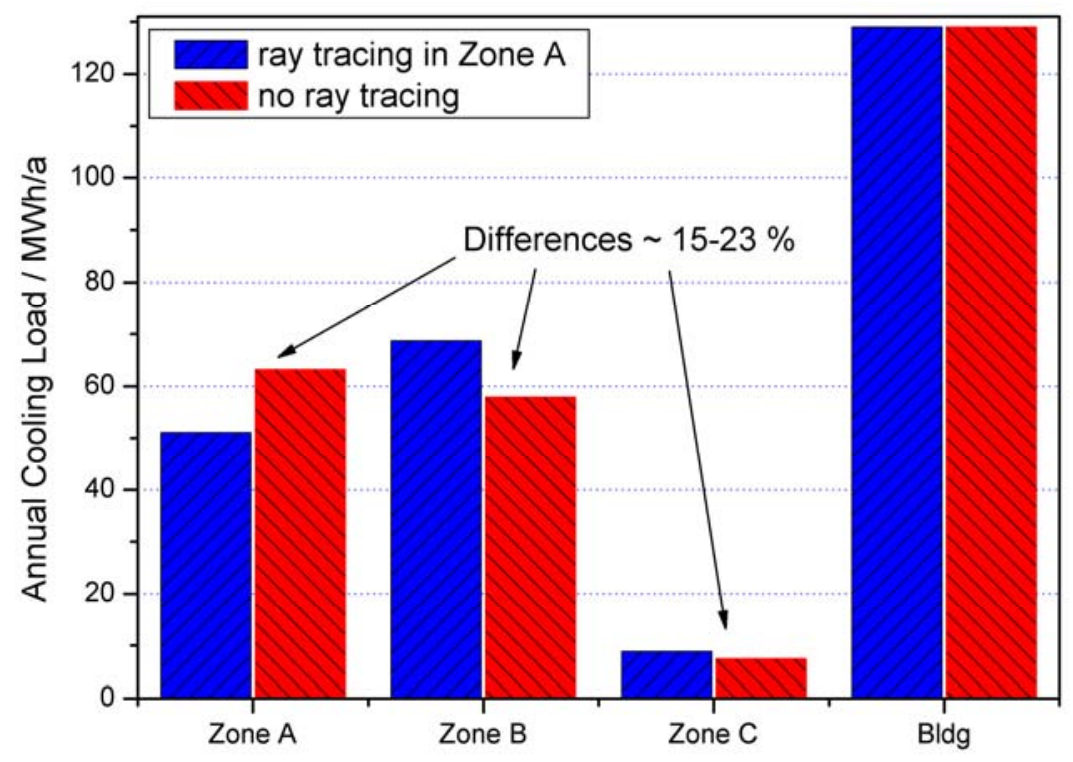

Figure 2D-2. MZ360, Comparison of annual cooling loads 


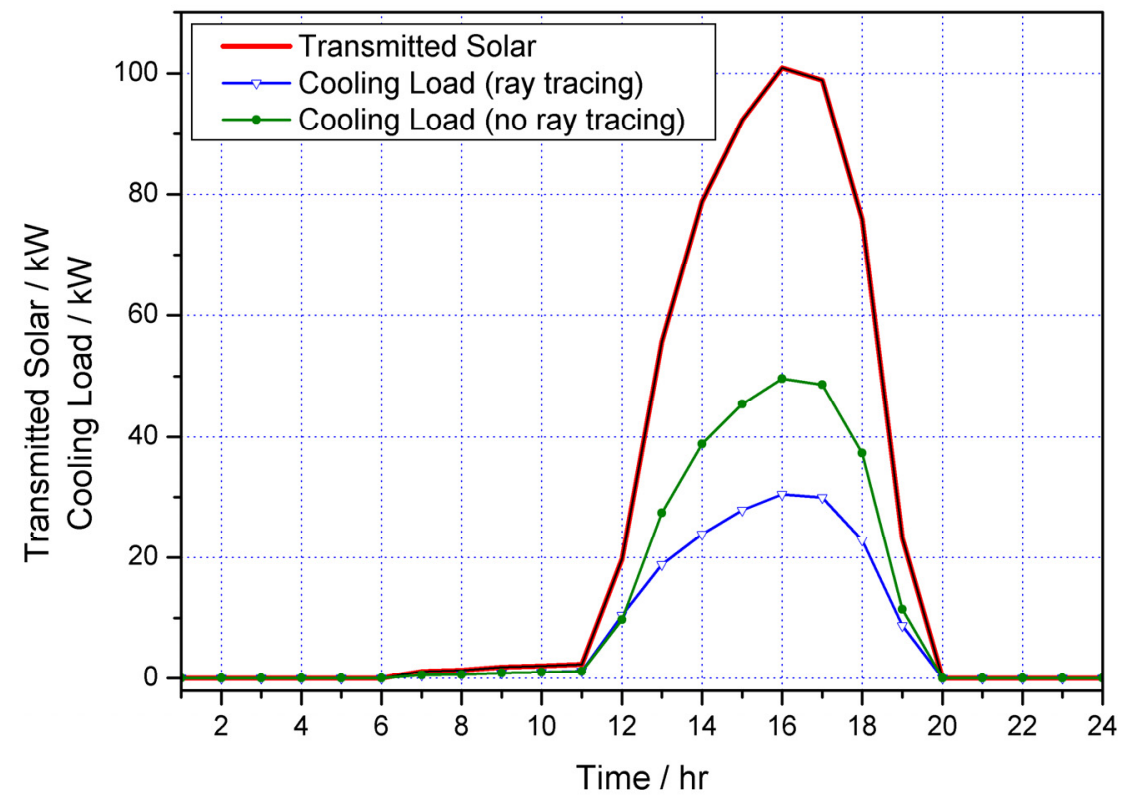

Figure 2D-3. MZ360, comparison of transmitted solar and cooling loads in Zone A on March 15

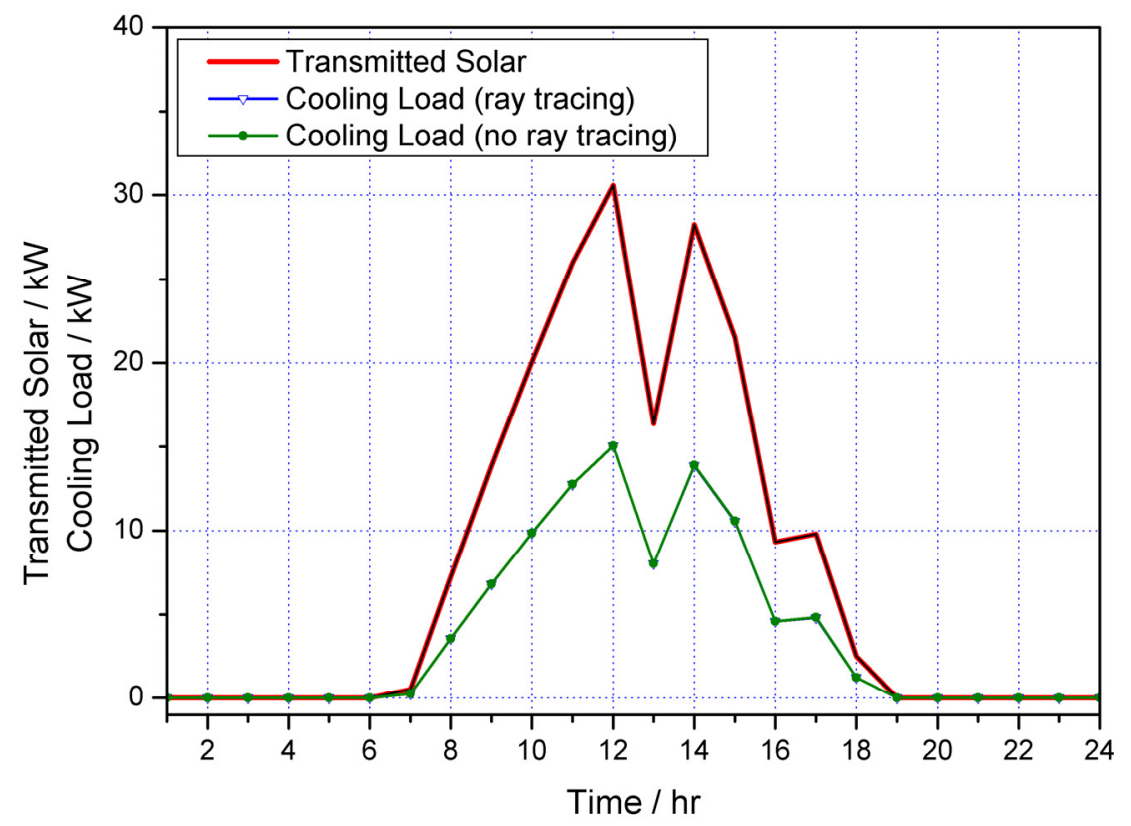

Figure 2D-4. MZ360, comparison of transmitted solar and cooling loads in Zone A on October 14 


\title{
Appendix II-E
}

\section{Modeler Report for BESTEST Cases MZ320 - MZ360 TRNSYS-16}

\author{
by \\ Julien L'Hoest, Christophe Adam, Corinne Rogiest and Philippe André \\ University of Liège \\ Belgium
}

April 2008

\section{Introduction}

This report presents the major results of the application of the IEA-BESTEST Multi-zone Non-Airflow cases MZ320 - MZ360 to the TRNSYS software. TRNSYS [1] ("Transient System Simulation") is a transient system simulation program with a modular structure, with each component of the simulated system being defined as a "Type". The modular nature of TRNSYS gives the program tremendous flexibility, and facilitates the addition to the program of mathematical models not included in the standard TRNSYS library. TRNSYS is well suited to detailed analyses of systems whose behavior is dependent on the passage of time.

The TRNSYS version is TRNSYS 16.01.0002 developed by Solar Energy Laboratory (University of Wisconsin-Madison) in Madison, USA (February 2005).

This validation exercise made use of the following TRNSYS types:

Type 56: Multizone Building model

Type 34: Overhang and wingwall shading

Type 109: Data reader and weather processing.

Additional types like equations and on-line plotters were used in the simulation.

The building model used in this work is TYPE 56 developed by TRANSSOLAR Energietechnik GmbH in Stuttgart, GERMANY. The TYPE 56 version is the version which is included in the TRNSYS 16.01.0002 version. TRNFLOW isn't used. This version of TYPE 56 is opened.

To model the window, the window library has been implemented with WINDOW 5.2 [2]. The exported file was corrected with the "Notepad" editor (in order to impose the specifications).

The simulation time step is 1 hour.

\section{Modeling Assumptions}

The required inputs which are not described in the specifications are: the sky temperature (for TYPE 56) and the ground reflectance (for TYPE 109: Data Reader and Radiation Processor).

It was specified there is no heat transfer by radiation. So the sky temperature is arbitrarily fixed to $0^{\circ} \mathrm{C}$ and the view factor to sky is fixed to 0 , which eliminates any radiation. The ground reflectance is also fixed to 0 . 


\section{Modeling Options}

- TYPE 56 (version 16) can evaluate the convection heat transfer coefficients for vertical and horizontal surfaces. As it was specified to use constant combined surface coefficients to eliminate the disagreements that might be caused by different convective and/or radiative surface heat transfer models, these internal calculations have not been used. Instead, constant combined coefficients were used with the following values: 29.844 for inside conditions and/or 109.754 $\mathrm{kJ} / \mathrm{h} \cdot \mathrm{m}^{2} . \mathrm{K}$ for outside conditions.

- TYPE 56 uses a Transfer Function approach[4] to calculate the dynamic behaviour of walls and doesn't accept zero-conductance walls. The greatest accepted resistance value is $1999 \mathrm{~h} . \mathrm{m}^{2} . \mathrm{K} / \mathrm{kJ}$ (for the massless layer) which corresponds to $0.001801 \mathrm{~W} / \mathrm{m}^{2} . \mathrm{K}$. TRNBuild which is the new building editor (TRNSYS 16) does not accept decimal values.

- In the MZ355-case the zone G was not simulated, because there is no window. In this case the walls are zero-conductance walls. So, we decided to simulate only the zones A to F. The same configuration like MZ350-case was used for zones A, B, D, E. The external walls of the zones C and $\mathrm{F}$ are limited to the real external boundaries with the ambient. That means the windows of the zones $\mathrm{C}$ and $\mathrm{F}$ were not simulated. The surface area of the western walls was limited to $4.05 \mathrm{~m}^{2}$ $(1.5 \mathrm{~m} \times 2.7 \mathrm{~m})$.

\section{Modeling Difficulties}

\section{- Simulation of ideal windows}

We started from the "without glass" window which is supplied in the Trnsys window library. The optical properties of that window are the same as the ideal window. Then the thermal properties was directly changed into the text file generally generated by WINDOW 5.1.

No use of WINDOW 5.1 was made, the text file containing the window properties can be found in the appendix ["annex" at the end of this modeler report].

\section{- $\underline{\text { Sky model }}$}

Type 16 provides four models for estimating the total radiation on a tilted surface. Each model requires knowledge of total and diffuse (or beam) radiation on a horizontal surface as well as the sun's position. In general the total tilted surface radiation is calculated by estimating and adding beam, diffuse and reflected radiation components on the tilted surface. All tilted surface radiation models use the same techniques for projecting the beam and ground reflected radiation onto a tilted surface; they differ only in the calculation of diffuse radiation on a tilted surface.

The contribution of diffuse radiation on a tilted surface is determined by using one of the four models provided in Type109 Tilted Surface Radiation Mode (equivalent to the models contained in the Type 16).

- Tilted Surface Radiation Mode 1 uses the isotropic sky model. This model was used.

- Tilted Surface Radiation Mode 2 uses a model developed by Hay and Davies.

$\circ$ Tilted Surface Radiation Mode 4 uses a version of the tilted surface model developed by Perez, et al.

- The Tilted Surface Radiation Mode 3 is a model developed by Reindl based on the work of several previous authors. This model adds a horizon brightening diffuse term to the Hay and Davies model. The horizon brightening is lumped with the isotropic diffuse term and its magnitude is controlled by a modulating factor. 
- Shading model

This part of the specification was treated by Type 34 "Overhang and wingwall shading". Solar radiation incident on a shaded receiver consists of beam, diffuse and ground reflected components. (Solar radiation reflected from the overhang or wingwalls onto the receiver is not considered in this model, and is suppressed in the multi-zone test specification.)

$$
\begin{aligned}
& \left(I_{T}\right)_{S}=I_{b T} f_{i}+I_{b T} F_{A-S}+I_{d \rho g n d} F_{A-G} \\
& \text { Total }=\text { Beam + Diffuse + Reflected }
\end{aligned}
$$

The fraction of the receiver area irradiated by direct beam, $f_{i}$, is a function of shading geometry and the position of the sun relative to the receiver. The irradiated fraction is given by

$$
f_{i}=A_{i}
$$

An ASHRAE algorithm [5] that determines $A_{i}$ is used in TYPE 34 to compute $f_{i}$.

Sky and ground radiation view factors are calculated assuming diffuse and reflected radiation to be isotropic. For unshaded vertical surfaces, the receiver radiation view factors of the sky and ground are both equal to one half. These view factors are reduced when wingwalls or an overhang are present. The view factor between the receiver and the wingwall, FA-W is computed by integrating the differential receiver area radiation view factor of the wingwall over the receiver area.

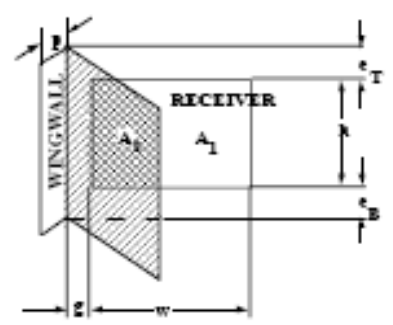

Figure 2E-1. shading geometry

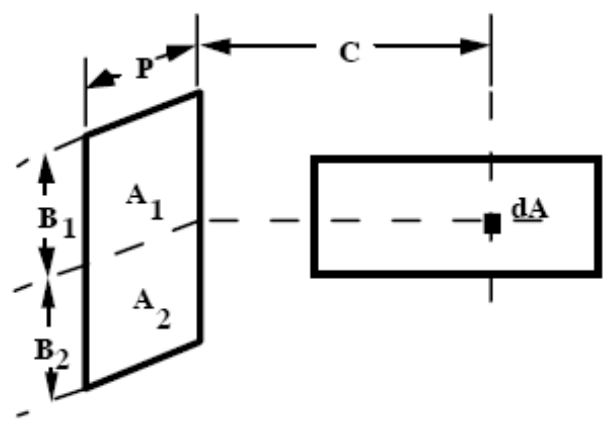

Figure 2E-2. Radiation geometry 
The receiver radiation view factor of the wingwall is given by

$$
\mathrm{F}_{\mathrm{A}-\mathrm{W}}=\int_{\mathrm{A}} \mathrm{F}_{\mathrm{dA}-\mathrm{A}_{1}} \mathrm{dA}+\int_{\mathrm{A}} \mathrm{F}_{\mathrm{dA}-\mathrm{A}_{2}} \mathrm{dA}
$$

Where FdA-A1 and FdA-A2 are given by Siegel and Howell [3] as

$$
\mathrm{F}_{\mathrm{dA}-\mathrm{Ai}}=\frac{1}{2 \pi}\left[\tan ^{-1}\left(\frac{\mathrm{B}_{\mathrm{i}}}{\mathrm{C}}\right)-\left[\frac{\frac{\mathrm{C}}{\mathrm{B}_{\mathrm{i}}}}{\sqrt{\left(\frac{\mathrm{P}}{\mathrm{B}_{\mathrm{i}}}\right)^{2}+\left(\frac{\mathrm{C}}{\mathrm{B}_{\mathrm{i}}}\right)^{2}}}\right] \tan ^{-1}\left[\frac{1}{\sqrt{\left(\frac{\mathrm{P}}{\mathrm{B}_{\mathrm{i}}}\right)^{2}+\left(\frac{\mathrm{C}}{\mathrm{B}_{\mathrm{i}}}\right)^{2}}}\right]\right]
$$

Type 34 uses numerical integration to compute the view factor at the first time step of the simulation.

The table below shows the amount of time (in hours) during which the glazing is partially or totally shaded over the year. The second column shows the ratio of the time during which the window is totally shaded on the time during which it's irradiated by the sun ( 2258 hours).

Table 2E-1. Percentage of shaded radiation on the different windows

\begin{tabular}{|l|c|c|c|c|}
\hline & \multicolumn{2}{|c|}{ Partially or totally shaded } & \multicolumn{2}{c|}{ Totally shaded } \\
\hline & Hours & $\%$ & Hours & 30.56 \\
\hline Window A & 1008 & 44.64 & 690 & 48.94 \\
\hline Window B & 1494 & 66.16 & 1105 & 11.25 \\
\hline Window C & 524 & 23.21 & 254 & 25.29 \\
\hline Window D & 939 & 41.59 & 571 & 44.60 \\
\hline Window E & 1453 & 64.35 & 1007 & 10.58 \\
\hline Window F & 524 & 23.21 & 239 & \\
\hline
\end{tabular}

- $\quad$ Treatment of diffuse radiation

In TRNSYS, direct and diffuse radiation are not treated the same. Direct radiation distribution can be specified by the user whereas sky diffuse radiation cannot.

The incoming (primary) direct solar radiation is distributed according to the distribution coefficients (Geosurf) defined in the building description. These values are distribution factors related to the total direct solar radiation entering the zone and not related to a surface area. The sum of Geosurf values given for all inside surfaces of a zone should sum up to 1 at all times. The fraction of incoming direct solar that is absorbed by any surface $\mathrm{i}$ is given by the product of solar absorptance $\alpha_{\mathrm{s}}$ value times the Geosurf value given for this surface $\mathrm{s}$. If the Geosurf values for all surfaces of a zone are set to zero, all direct solar radiation entering this zone is treated as diffuse radiation and distributed with the absorptance-weighted area ratios described below.

With the Geosurf values, solar beam radiation might be distributed even when passing internal 
windows between zones up to two passages. After passing the second internal window all solar radiation is treated as diffuse radiation.

The incoming diffuse solar radiation and reflected primary direct solar radiation is distributed according to absorptance-weighted area ratios. The fraction of diffuse solar that is absorbed by any surfaces is

where

$$
f_{\text {dif }, s, s}=\frac{\alpha_{s} \cdot A_{s}}{\sum^{\text {surfaces }}\left(1-\rho_{d, s}\right) \cdot A_{s}}
$$

$\alpha_{s}$ is the solar absorptance of the surface (defined in the building description)

$\rho_{d, s}$ is the reflectance for diffuse solar of the surface

For wall surfaces, where

$$
\tau_{s}=0, \rho_{d, s}=\left(1-\alpha_{s}\right)
$$

In this case, the absorptance of all surfaces was set to 1 for walls and 0 for windows. Then, the distribution of the direct radiation was only governed by the Geosurf value. If the Geosurf value is let to zero, then the solar radiation is distributed among all surfaces of the zone, including the windows. That's a realistic hypothesis when wall absorptance is around 0.6 but in our case, it's equal to 1 and then no solar radiation is reflected by the walls.

Therefore, Geosurf value was set so that solar radiation was distributed among all surfaces except the window by which it entered the zone. Therefore, geosurf values were calculated according to the ratio between each surface and the total of the surfaces of each zone, excluding the window by which the solar radiation entered the zone.

The values which were used in test MZ360 are given by Table 2E-2.

Table 2E-2. Calculation of "geosurf" coefficients for the 3 zone of Case MZ-360

\begin{tabular}{|l|ccc|}
\hline Geosurf & Zone A & Zone B & Zone C \\
Front & 0.02419191 & 0.13253012 & 0.18026565 \\
Left & 0.06098801 & 0.10843373 & 0.13662239 \\
Right & 0.06098801 & 0.10843373 & 0.13662239 \\
Back & 0.22362269 & 0.28614458 & 0.27324478 \\
Floor & 0.06098801 & 0.10843373 & 0.13662239 \\
Ceiling & 0.06098801 & 0.10843373 & 0.13662239 \\
Inside & & & \\
window & 0.50823338 & 0.14759036 & 0 \\
\hline Sum & 1 & 1 & 1 \\
\hline
\end{tabular}

In order to have a better control on the diffuse radiation, it was added to the direct radiation so the 
total incoming radiation was considered as direct for all experiments (MZ 340, 350 and 360). Otherwise a part of the initially transmitted solar diffuse radiation would be lost back out of the "external" window.

As shown in Figure 2E-3, when diffuse radiation is taken into account as direct radiation, the outgoing solar radiation is null contrary to when it's taken into account as diffuse, although transmitted radiation is equal. The absorbed radiation by the walls is directly affected.

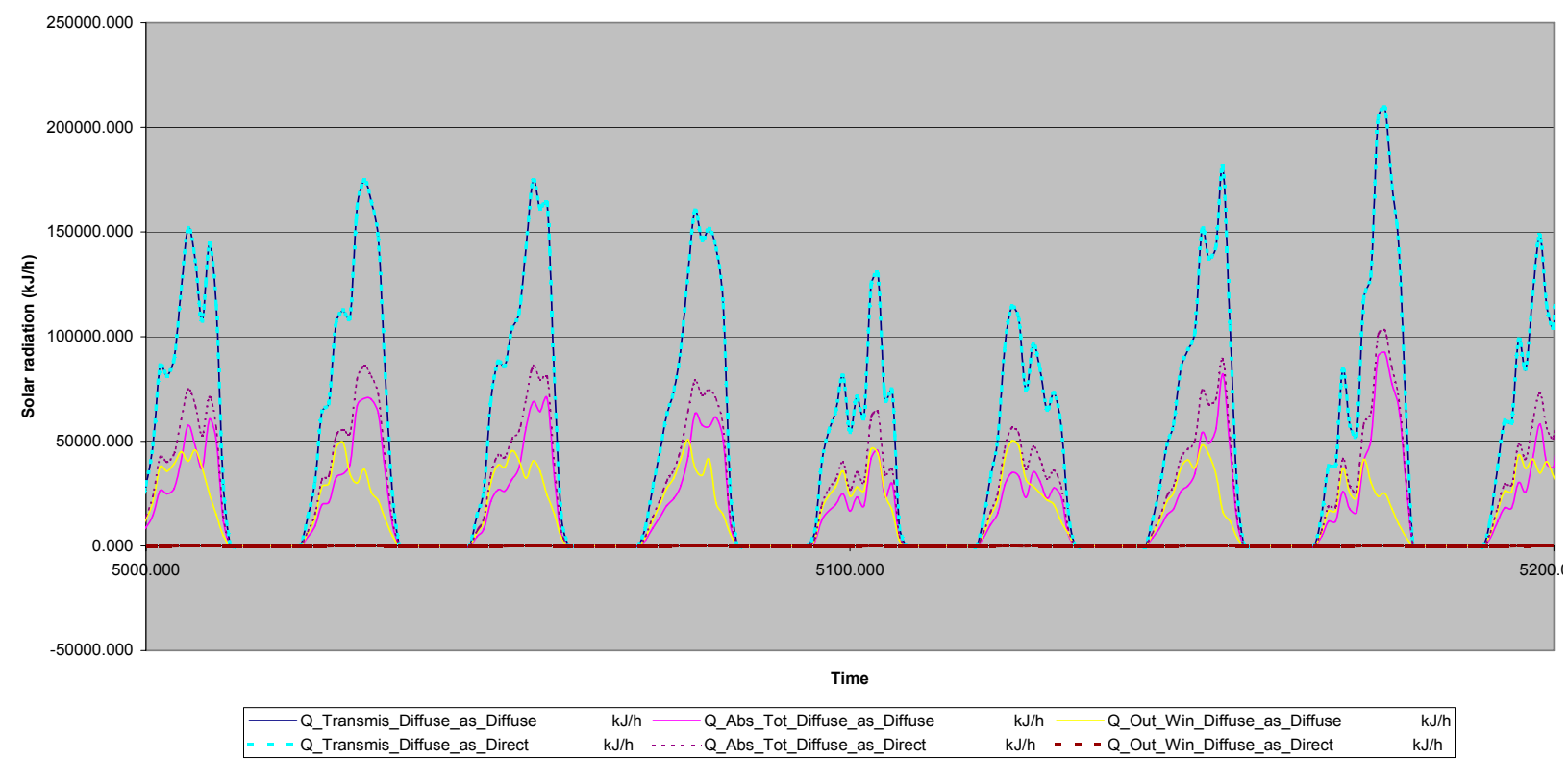

Figure 2E-3. Comparison between diffuse solar radiation taken into account as diffuse or as direct

\section{Changes since first set of results (august 2006)}

- The perfect window was modeled correctly.

- The diffuse radiation was entered as direct radiation and the Geosurf parameter was used to control the distribution of solar radiation among the interior walls.

\section{Software Errors Discovered and Comparison between Different Versions of the Same Software}

The incident solar radiation on March 15 hour 19 calculated by Type 109 is different from the one from type $16 \mathrm{~g}$ and from other software tested in the subtask B. It differs usually at the end of the day and not for everyday, it could be due to a programming error.

\section{Results}

See the associated output file.

\section{Other Results}

[None] 


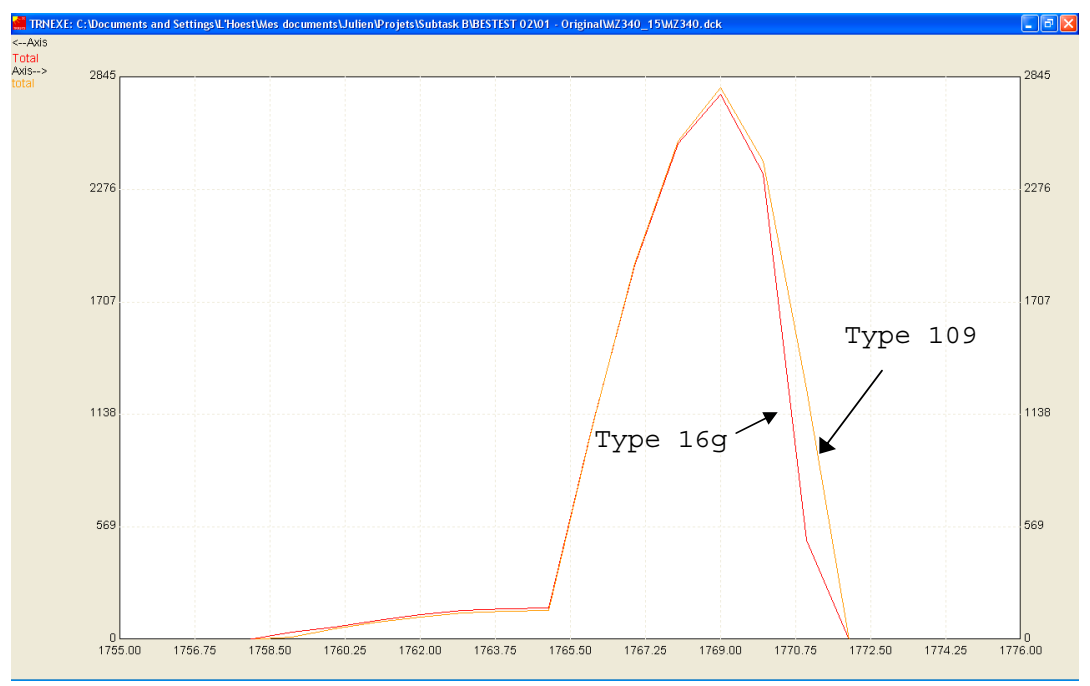

Figure 2E-4. March 15 west incident radiation by Type 109-TMY2 and Type 16g

\section{Conclusions and Recommendations}

TRNSYS (TYPE 56) is a very powerful software to solve real building problems. It calculates the heat transfer by conduction into the walls, by convection between walls and air and by radiation between wall surfaces. The number of walls is not a problem. The developers have limited the software to the resolution of generic problems with wall emittance equal to one and without geometrical description. The principal objective of this BESTEST was to define a multi-zone-building calorimeter for measuring cooling loads caused by transmitted solar radiation. We were able to simulate the ideal window but we had to use a trick to have a better control on diffuse radiation so as to complete the exercise.

Additional TRNSYS types like TYPE 34 allow the introduction of overhang and wingwall shading. That kind of type requires a geometrical description that is enough to simulate only perpendicular external shading, not parallel. With this TYPE 34, we have generated good results, which could be compared to the MZ340 reference. The MZ355 case cannot be simulated with TRNBuild because TRNBuild doesn't integrate the geometrical description of the building.

\section{References}

[1] Solar energy laboratory - February 2005 - TRNSYS 16 (version 16.00.0037), A Transient System Simulation Program - Solar energy laboratory, University of Wisconsin (Madison), Madison WI 53706 USA.

[2] Window \& Daylighting Group - December 2004 - WINDOW 5.2 (5.2.17), for analyzing window thermal and optical performance - Window \& Daylighting Group, Building Technologies Program, Environmental Energy Technologies Department, Lawrence Berkeley National Laboratory, Berkeley, CA 94720 USA.

[3] Siegel, R. and Howell, J. Thermal Radiation Heat Transfer - McGraw Hill, 1972

[4] John Ervin Seem - 1987 - Modeling of heat transfer in building - A thesis submitted in partial fulfillment of the requirements for the degree of Doctor of Philosophy (Mechanical Engineering) at the University of Wisconsin-Madison. 
[5] Sun, Tseng-Yao, 'SHADOW 1', Procedure for Determining Heating and Cooling Loads for Computerizing Energy Calculations, ASHRAE Task Group on Energy Requirements, 1975, pp. 48-56.

Annex

\section{Listing: $\quad$ BESTEST win.lib}

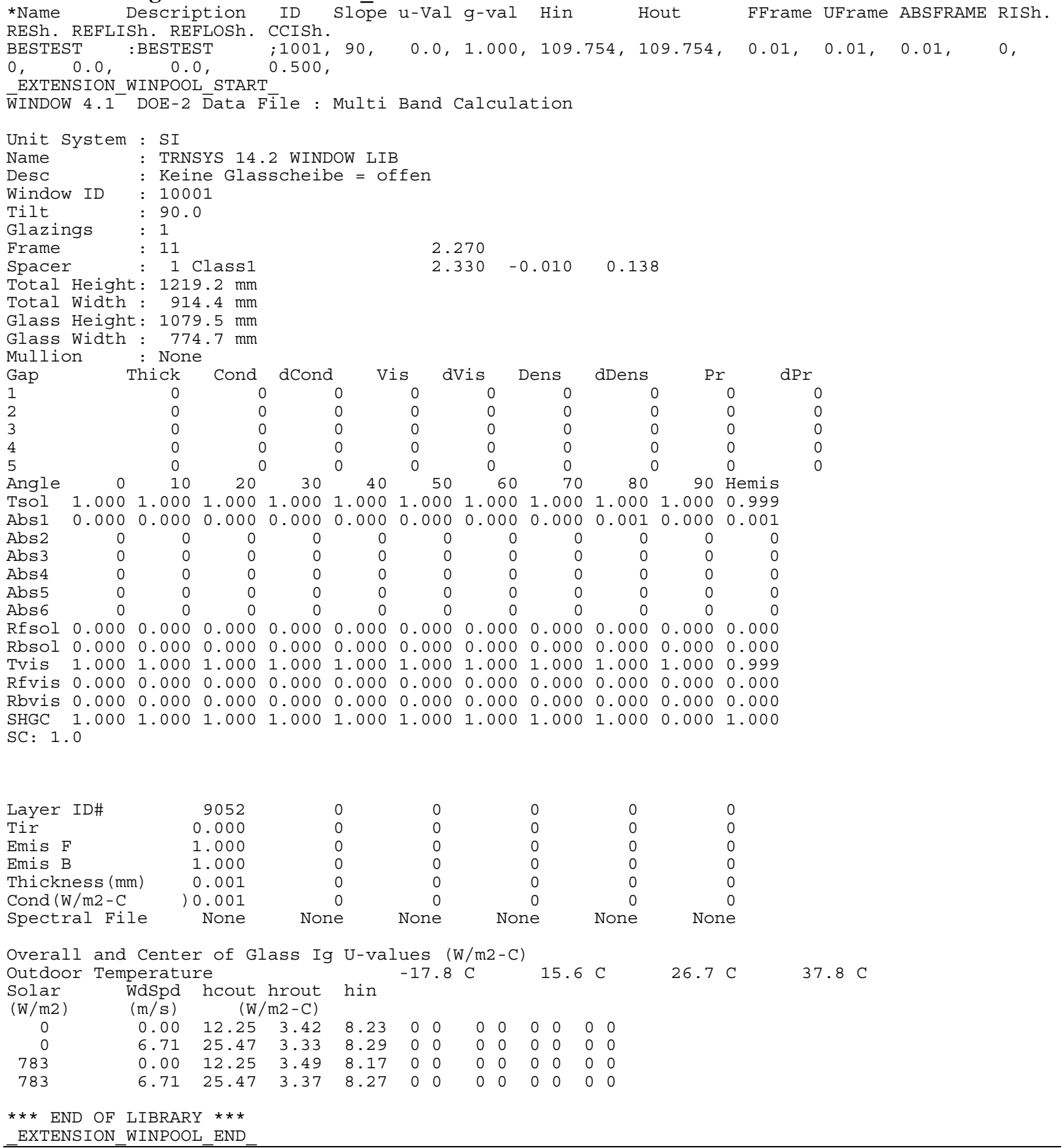




\section{Appendix II-F}

Modeler Report for BESTEST Cases MZ320 - MZ360

VA114 Version 2.25

by

Aad Wijsman

\section{VABI Software BV}

The Netherlands

March 2008

July 03, 2007 (final, seventh draft)

September 12, 2006 (sixth draft)

February 01, 2006 (fifth draft)

August 29, 2005 (fourth draft)

August 25, 2005 (third draft)

June 30, 2005 (second draft)

May 02, 2005 (first draft)

\section{VA114}

\section{VABI Software BV}

P.O. Box 29

2600 AA Delft

The Netherlands 
Remark:

This report is the seventh, final draft. Observations done at the last meeting (Golden, March 2007) were studied. Extra information has been added to the Modeler Report. No re-runs were done, so results are the same as for September 2006 ( $6^{\text {th }}$ draft)

\section{Heat Exchange within a Zone and between Zones}

\section{Introduction}

The building simulation program VA114 is developed and distributed by VABI Software bv. The current version is 2.25 .

The program calculates the demand, the supply, the distribution and the generation of heat and cold for a building with its energy supply system. Moreover the internal comfort temperature and overheating are calculated.

VA114 is a multi-zone program (up to 30 ).

The time step applied in VA114 is 1 hour.

The boundary conditions, that are possible in VA114 are:

- bounded to ambient

- bounded to a neighbour zone

- bounded to a mirror zone

- bounded to the underground.

The current program VA114 models:

- heat exchange within a zone

- heat exchange between zones by conduction

- heat exchange between zones by airflow (ventilation)

- solar gain and solar exchange between zones

- solar shading

- $\quad$ and other processes.

The simulation program VA114 passed the BESTEST [1],[2],[3]. In the summer of 2005 the simulation program was subjected to the new IEA-34/43 tests [4] (MZ320, MZ340, MZ350, MZ355 and MZ360). In August 2005 revised test specs were received. The runs were done again and reported. A first comparison with the other programs was made (Aalborg-meeting). This led to some observations:

- $\quad$ there is a time shift for VA114

- unshaded hourly diffuse shows an afternoon "hump" on October 14

- the MZ350c seems to have "double" shading

- VA114 treats circumsolar diffuse radiation as beam radiation, whereas other programs count this solar component to diffuse radiation.

The "problems" were countered (time shift and double shading were caused by input errors made by tester A. Wijsman) and re-runs were done. For results see draft 5 (February 2006). Results both for circumsolar diffuse radiation counted to diffuse radiation (as other programs do) and counted to direct radiation (as VA114 usually does). 
In August 2006 some dimensions in the test specifications (zone height, window area, fin size, ...) were adjusted and the test runs were done again. The results for the adjusted dimensions were reported in September 2006 (see draft 6).

This report is the seventh, final draft. Observations done at the last meeting (Golden, March 2007) were studied. Extra information has been added to the Modeler Report. No re-runs were done, so results are the same as for September 2006 (6 ${ }^{\text {th }}$ draft $)$

This Modeler Report starts with a brief description of the software.

Remark:

VABI Software bv is developing the simulation program VA114. In 2004 VA114 has undergone a lot of changes: the solar distribution is calculated by a new method (Ray-tracing), internal window is implemented, integration of solar shading and solar distribution was done, acceleration of these 'solar' methods to reduce the computing time took place. Old 'solar' methods should stay available. A new version of VA114 was distributed to its users (about 200) by the end of June 2005. Before the distribution of this new version it was tested extensively. First by running the Bestest cases (1995) again and after that by running the new IEA$34 / 43$ test cases. Both tests cycles led us to errors in the software. The errors were repaired and tests were done again and again until we had enough confidence in the results.

In the autumn of 2005 again many modifications were made to the program VA114. The new version VA114-vs 2.20 was subjected to the Bestest, to the EDR and to the IEA34/43-MZ-tests.

In February 2006 this new version was distributed.

\section{Model description}

The current program VA114 models:

$\begin{array}{ll}\text { - } & \text { heat exchange within a zone } \\ \text { - } & \text { heat exchange between zones by conduction } \\ \text { - } & \text { heat exchange between zones by airflow (ventilation) } \\ \text { - } & \text { solar ghain and solar exchange between zones } \\ \text { - } & \text { and other processes. }\end{array}$

In more detail:

heat exchange within a zone

The zone air is described by one node. Between this zone air node and the internal surfaces heat exchange takes place by convection. The convection coefficient is user given and can be specific for each surface.

Heat exchange between the surfaces happens by long wave radiation. This heat exchange is dependent on the view factors and emittance factor of the internal surfaces.

Remark: there is an option in the model the value of the convection coefficient can switch between two values.

Remark: the view factors are calculated. Simple by VIEWA (area-weighted) or detailed by VIEW0 (an analytical method - for cases with rectangular zones) or by VIEW (Ray-tracing method - for cases with other shapes of zones). 
- $\quad$ heat exchange between zones by conduction Internal and external walls are simulated by a number of nodes. Each with a heat capacity and with heat resistances in between.

- $\quad$ heat exchange between zones by airflow (ventilation)

Air exchange takes place between ambient and the zone and between neighbouring zones. This air exchange can be user given or calculated according to a network node model.

- $\quad$ solar gain and solar exchange between zones

Solar radiation enters a zone by windows. This solar radiation is absorbed in the zone or can leave the zone through windows, to ambient or to a neighbouring zone. In Appendix A detailed information is given about the modelling aspects of this process.

- $\quad$ solar shading

Solar shading happens by surrounding buildings, by external façade parts, by own buildings parts and by setback of the window. In Appendix B detailed information is given about the modelling aspects of this process.

- $\quad$ and other processes

Like: internal heat production (by persons, equipment and lighting), mechanical ventilation, ....

\section{Modeling Assumptions}

Per test case the modeling assumptions are discussed.

\section{Case MZ320}

\section{Geometry}

All dimensions were assumed to be centre - centre dimensions, so whole building is $8,0 \times 18,0 \times 2,7 \mathrm{~m}$. Volumes are determined without taking wall thickness into account, so $3 \times 129,6 \mathrm{~m}^{3}$.

Interior infrared emittance

This value was put on 0,01 (see 6 . Modeling Errors). So the radiative surface coefficient is $0,06 \mathrm{~W} /\left(\mathrm{m}^{2} \cdot \mathrm{K}\right)$.

Interior Combined Surface Coefficients

The convective surface coefficients were put on the required values minus $0,06 \mathrm{~W} /\left(\mathrm{m}^{2} . \mathrm{K}\right)(=$ radiative surface coefficient)

Interior solar absorptance

This value was put on 0,01 (see 6. Modeling Errors)

Sensible cooling

Was simulated by cooling element with convective fraction $=1.0$

\section{Case MZ340}

\section{Geometry}

All dimensions were assumed to be centre - centre dimensions. Zone height $=5,0 \mathrm{~m}$ instead of $2,70 \mathrm{~m}$ (volume per zone $=240 \mathrm{~m}^{3}$ ). Remark: Window area $=16,0 \mathrm{~m}^{2}$ instead of $6,0 \mathrm{~m}^{2}$ in earlier tests. 
Walls are mass less

Specific mass was put on $0,01 \mathrm{~kg} / \mathrm{m}^{3}$. Zero is not possible.

Walls are adiabatic

Thermal conductance was put on 0,00001 . Zero is not possible.

Windows

Window physical properties are ideal (according to specifications): thermal conductance $=0,0$, transmittance $=1,0$ and is independent of incidence angle.

Windows are modelled by two panes with convective and radiative heat transfer coefficients in between: to achieve thermal conductance $=0,0 \mathrm{~W} /\left(\mathrm{m}^{2} . \mathrm{K}\right)$ the radiative heat transfer coefficient was put on $0,00 \mathrm{~W} /\left(\mathrm{m}^{2} . \mathrm{K}\right)$ and the two convective heat transfer coefficients were put on $0,001 \mathrm{~W} /\left(\mathrm{m}^{2} . \mathrm{K}\right)($ so $0,001 / / 0,001)$. Zero convective heat transfer coefficient is not possible

Interior infrared emittance was put on 0,01 (see Modeling Difficulties). So the radiative surface coefficient is $0,06 \mathrm{~W} /\left(\mathrm{m}^{2} \cdot \mathrm{K}\right)$.

Solar transmittance was put on 1,000 and the angular modifier was put on 1,000 (for all angles of incidence)

Mechanical system

In all zones there should be a sufficient cooling capacity. In case there is no or insufficient cooling capacity the zone temperatures become 'infinite' (because the heat losses of the zones are close to 0,0 ) and the program stops by error.

Ground reflectivity Rho

VA114 works with a hard-coded Rho $=0.20$. Because of these IEA- tests it was put to 0.0.

\section{Case MZ350}

Geometry of the zones is not different from case MZ340. The dimensions of the shading fin changed from 12 $\mathrm{x} 18 \mathrm{~m}$ in earlier tests to $24 \times 24 \mathrm{~m}$.

\section{Case MZ355}

Geometry of the zones is not different from cases MZ340 and MZ350. The dimensions of the shading building (zone G) changed from $12 \times 18 \times 5$ m in earlier tests to $24 \times 24 \times 5 \mathrm{~m}$.

\section{Case MZ360}

The geometry of the zone B changed: depth was $5 \mathrm{~m}$ in earlier tests and is now $3 \mathrm{~m}$.

No further assumptions had to be made. 


\section{Modeling Options}

First the modelling options are discussed in general and then what options are applied per test.

\section{Modeling options in general}

Infrared heat exchange (see chapter 2)

Infrared heat exchange within a zone works with view factors between the internal surfaces and with emittances of that internal surfaces.

For the calculation of the view factors 3 methods are available:

- $\quad$ VIEWA - simple area-weighted method - if only areas of surfaces are available

- $\quad$ VIEW0 - detailed analytical method - only applicable for rectangular zones

- $\quad$ VIEW - detailed Ray-tracing method - applicable for all shapes of zones.

Remark: sum of view factors from surface I to all the other surfaces should be 1,000 exactly; for the raytracing method this is not valid, it is almost 1,000 (i.e. 0,996-1,004).

Solar distribution over the internal surfaces (see chapter 2)

Direct radiation and diffuse radiation are treated separately.

For the direct radiation it is calculated which internal surfaces are hit; such a surface absorbs a part of that direct radiation and reflects the rest diffusely. For the calculation of the direct distribution 3 methods are available:

- $\quad$ PZONI0 - simple method - all direct radiation hits the floor

- $\quad$ PZONI1 - detailed projection method - only applicable for rectangular zones

- $\quad$ PZONI2 - detailed Ray-tracing method - applicable for all shapes of zones (See appendix C).

The distribution of the diffuse radiation (through windows and the reflected direct radiation by internal surfaces) is calculated by the view factors (see the 3 models above) and by the reflections $(=1,0-$ absorptance) of the internal surfaces.

Solar shading (see chapter 2)

Surrounding buildings cause shading of the direct solar radiation, not of the diffuse solar radiation. Two models (SCHADUW1) are available:

- $\quad$ level 1: only in 1 point of a window (the centre) shading $(=0 / 1)$ is determined

- $\quad$ level 2: in 5 points of a window (the centre and 4 corners) shading $(=0 / 1)$ is determined; shading of the window is the average shading $(0,0-0,2-0,4-0,6-0,8-1,0)$.

External façade parts, own building parts and set back of window cause both shading of the direct solar radiation and shading of the diffuse solar radiation. For the direct shading two models are available:

- SCHADUW2: detailed projection method - only applicable for rectangular shapes

- $\quad$ SCHADUW3: detailed Ray-tracing method - applicable for all shapes of zones (remark: SCHADUW3 is integrated in PZONI2).

For the diffuse shading 1 model is available:

- $\quad$ SCHADW2D: detailed Ray-tracing method - applicable for all shapes of zones.

Remark: Method is used to determine the view factors to the shading objects, the ground and the sky.

In Table $2 \mathrm{~F}-1$ is given what models can be used for a certain shape of a zone (Ishape $=-1,0,1$ ):

Ishape $=-1 \quad$ in case only the areas of surfaces are known

$=0$ rectangular zones

$=1$ all shapes of zones .

$\underline{\text { Remark: }}$ the distributed new version of VA114 works with Ishape $=1$. 
Table 2F-1. Models that can be used for a given shape of a zone (Ishape $=-1,0,1)$

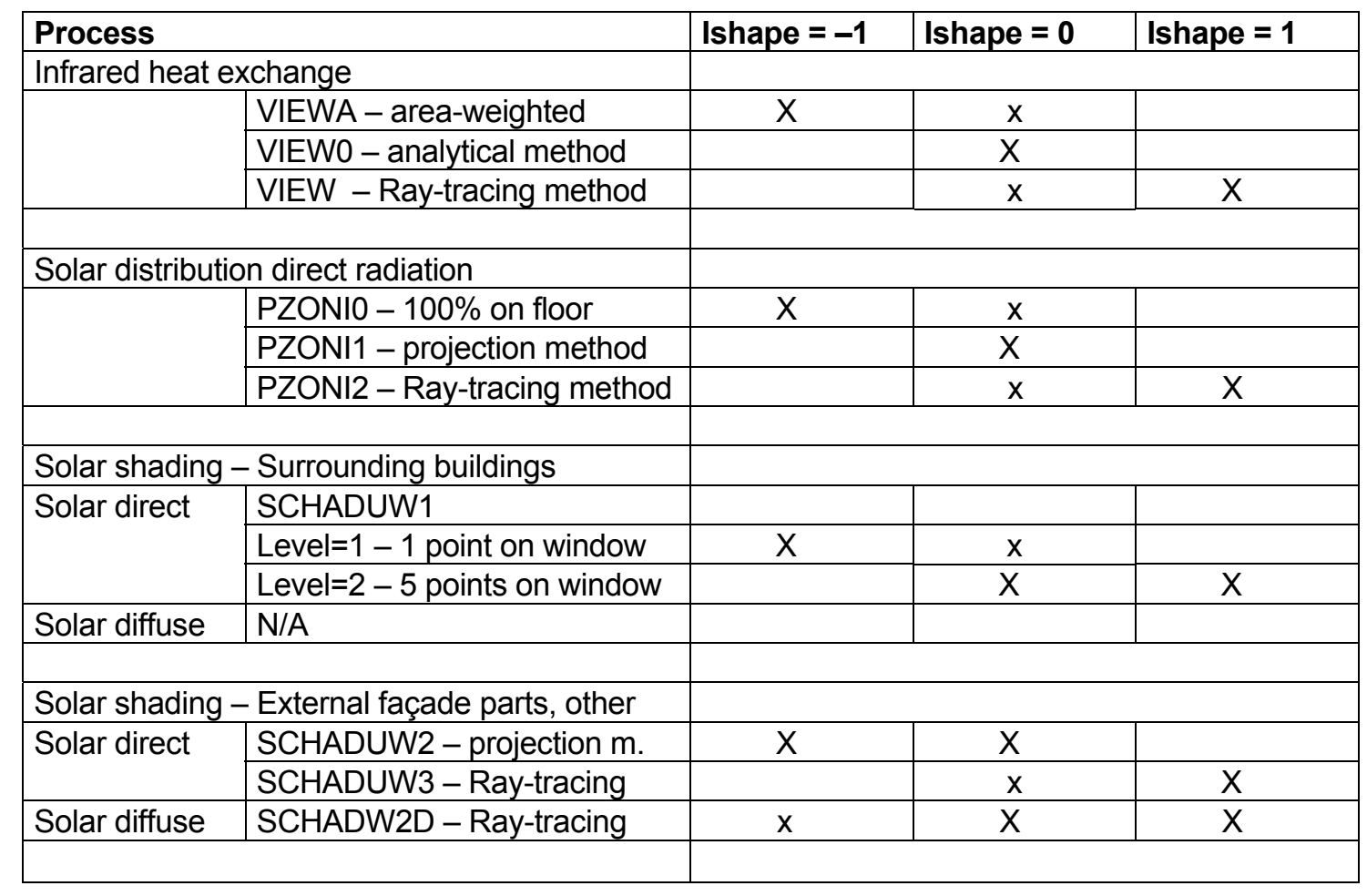

Note: ' $\mathrm{X}$ ' $=$ the model that is applied in VA114

' $\mathrm{x}$ ' = an alternative model that can be selected in VA114

So in principle for Ishape $=0$ (rectangular zones) all models can be applied.

\section{Modeling options per test}

Case MZ320

For the infrared heat exchange the models VIEWA, VIEW0 and VIEW were tested.

The comfort module calculates the radiative temperature on the 6 surfaces of a comfort cube. It works, depending on Ishape with VIEWCA, VIEWC0 and VIEWC.

Case MZ340

No options. 
Case MZ350

Several options:

$\rightarrow$ Shading by external façade parts, own buildings part, setback of window, and other

MZ350a0 - Ishape $=-1$

Solar distribution according to PZONIO

Shading by external shading parts: direct shading SCHADUW2

MZ350a1 - Ishape $=0$ diffuse shading SCHADW2D

Solar distribution according to PZONI1

Shading by external shading parts: direct shading SCHADUW2

diffuse shading SCHADW2D

MZ350a2 - Ishape $=1$

Solar distribution according to PZONI2

Shading by external shading parts:

direct shading SCHADUW3

diffuse shading SCHADW2D

$\rightarrow$ Shading by surrounding buildings

MZ350c0 - Ishape $=-1$

Solar distribution according to PZONI0

Shading by external shading parts:

MZ350c1 - Ishape $=0$

Solar distribution according to PZONI1

Shading by external shading parts:

MZ350c2 - Ishape $=1$

Solar distribution according to PZONI2

Shading by external shading parts: direct shading SCHADUW1, level 2

diffuse shading $-\mathrm{N} / \mathrm{A}$

direct shading SCHADUW1, level 1

diffuse shading $-\mathrm{N} / \mathrm{A}$

direct shading SCHADUW1, level 2

diffuse shading $-\mathrm{N} / \mathrm{A}$

So shading by surrounding buildings is without diffuse shading.

Remark: the circumsolar diffuse radiation component is treated as direct solar radiation.

Case MZ355

SCHADUW3 (direct solar shading) and SCHADW2D (diffuse solar shading) have shading by own building parts. In principle the results should be the same as case MZ350a.

Case MZ360

Internal window: no options. 


\section{Modeling Difficulties}

Per test case the modeling difficulties are discussed.

No specific modelling difficulties occurred. See chapter 3, 4 and 6.

\section{Software errors discovered and comparison between different versions of the same software.}

Deviating test results can be caused by:

- $\quad$ input errors made by the tester

- $\quad$ errors in the software

- $\quad$ the modelling approach.

\section{$\rightarrow$ Input errors by the tester:}

During the Aalborg meeting (October 2005) a first comparison was made between the results of VA114 and the results of the other programs. This led to some observations:

- $\quad$ there is a time shift for VA114

- $\quad$ unshaded hourly diffuse shows an afternoon "hump" on October 14

- the MZ350c seems to have "double" shading

- VA114 treats circumsolar diffuse radiation as beam radiation, whereas other programs count this solar component to diffuse radiation.

The first three "problems" were countered as input errors made by the tester:

- $\quad$ the time shift because of the longitude $(-80,267 / 15=-5,35)$ and the time zone $(=-5)$ was not taken into account. It is only a difference of $-0,35$ hour ( 21 minutes), but it has a rather big influence. By taking this time shift into account the newly calculated diffuse radiation on the horizontal (Total - Direct on horizontal) is very close to the diffuse radiation on the tape (hourly). So the incident solar on orientation West became $804 \mathrm{kWh} / \mathrm{m}^{2}$ (instead of 886), which is much closer to the other programs.

- $\quad$ Case MZ350c treats a fin as surrounding building. The tester switched this option 'ON', but did not switch 'OFF' the option 'fin treated as external building part'. So shading was calculated in two ways (Fshading1 and Fshading2). "Double" shading occurred because both options calculate shading individually and integrate them simple by the relation: Fshading $=1-(1-$ Fshading 1$) *(1-$ Fschading 2$)$.

Remark: VA114-users use VA114 in the VABI-Uniforme Omgeving (Uniform Environment) and can not make this mistake. This environment treats each obstruction (also a surrounding building) as an external building part and does a real integrated shading calculation. In this way shading of diffuse radiation is also taken into account for a surrounding building.

Remark: VA114 treats circumsolar diffuse radiation as beam radiation, whereas other programs count this solar component to diffuse radiation. This is not an error but a difference in the way of modelling. To make a comparison with the other programs easier calculations are done for both ways of modelling:

- circumsolar diffuse radiation treated as 'beam' (as VA114 does)

- circumsolar diffuse radiation treated as 'diffuse' (as other programs do). 
To conclude:

by taking away

- $\quad$ the input error in the time shift DTIME

- the input error that caused "double shading"

and by treating circumsolar diffuse radiation as diffuse radiation instead of beam radiation many of the remarks in the "Aalborg" spreadsheet are countered now.

\section{$\rightarrow$ Errors in the software:}

The following software errors were discovered and corrected.

Case MZ320

For the infrared heat exchange the models VIEWA, VIEW0 and VIEW were tested. It was observed, that for low emittances $(<0,20$ - all internal surfaces have the same emittance) the test with model VIEW (Raytracing) gives deviations: sum of exchange factors becomes $>1,0(1,02$ for emittance $=0,20$ and 1,45 for emittance $=0,01$; overflow at 0,001 ).

Remark: if not all emittances are so low than this problem does not occur.

Remark: a correction to the heat exchange model UITWIS (works with VIEW and emittances) was made; for emittances $>0,01$ it is $\mathrm{OK}$ now.

The same happened to model UITWISA (works with VIEW and absorptances), that is applied for the distribution of the diffuse solar radiation.

Remark: a correction to the model UITWISA (works with VIEW and absorptances) was made; for absorptances $>0,01$ it is OK now.

The comfort module works, depending on Ishape with VIEWCA, VIEWC0 and VIEWC. It was found that after the modifications of last year the position of the comfort cube was in a wrong coordinate system for VIEWCA and VIEWC0.

Case MZ340

Thermal conductance of a construction layer can not be 0,000 . Now a warning will be given if thermal conductance $<0,00001$.

Case MZ350

Cases MZ350a0 and a1 differed strongly from a2. It was found the old model SCHADUW2 was by-passed (no shading of direct solar) after the new extensions for SCHADUW3.

Cases MZ350c0 and $\mathrm{c} 1$ differed strongly from c2. It was found the old model SCHADUW1 was by-passed (no shading of direct solar) after the new extensions for SCHADUW3.

Remark: after correction of the errors a1 and a2 give the same results (within the last digit); the same is valid for $\mathrm{c} 1$ and $\mathrm{c} 2$. Results are presented in one: $\mathrm{a} 12$ and $\mathrm{c} 12$. 


\section{Case MZ355}

SCHADUW3 (direct solar shading) and SCHADW2D (diffuse solar shading) have shading by own building parts. In principle the results should be the same as case MZ350a.

First results showed a big difference: shading was not observed!! Results were the same as MZ340.

Two errors were found:

- $\quad$ SCHADUW2 was not called because the switch was at 0 in case there were no external façade parts or there was no setback of window.

- $\quad$ An error, that occurred both in SCHADUW3 and SCHADUW2D.

After correction of this error the results of MZ355 are the same as for MZ350a.

Remark: This is valid for the earlier tests with smaller dimensions of the fin (12 $\mathrm{m}$ width and $18 \mathrm{~m}$ height). However for the later tests with larger fin dimensions ( $24 \mathrm{~m}$ width and $24 \mathrm{~m}$ height) a small difference occurs: between March $12^{\text {th }}$ and March $17^{\text {th }}$ at hour 16 there is a difference between MZ350a and MZ355. Hour 16 is the moment the sun is coming from behind the fin, so at the very edge of the fin. It was found it has to do with the shading of beam radiation: MZ350 says at that hour it is partly shaded (as the 2-3 hours before) and MZ355 says it is completely shaded (whereas the 2-3 hours before it is partly shaded; numbers are exactly the same as MZ350). To our opinion in both cases the same shading subroutines are used ....

Because it happened around March $15^{\text {th }}$ (Spring) it was expected to find the same problem around October $1^{\text {st }}$ (Autumn) .... It was not found (even on no other days in the entire year it was found). At the moment the cause of the difference is not yet found.

\section{Case MZ360}

Internal window worked well, but the total cooling was a few $\%$ lower than the total incident solar radiation on that orientation (area * total solar in $\mathrm{kWh} / \mathrm{m}^{2}$ ). It was found, that in UITWISA (calculates the distribution of the diffuse solar radiation) the reflection of the window was fixed at 0,10 (a hard-coded value until now). So $10 \%$ of the solar (direct and diffuse) incident on an internal window is reflected. So also partly reflected through the external window in zone A to ambient. The solar reflection should be 0,0 for this case. It was put to the (1,0-transmittance) of the window (user given transmittance $=1,000$ for this case).

\section{$\rightarrow$ The modelling approach}

The following observations were done during this subtask:

- It looks like VA114's solar processor predicts a somewhat higher solar radiation incident on the façade than other programs do.

- $\quad$ In daily profiles on some hours VA114 shows deviating results with respect to the other programs.

\section{It looks like VA114's solar processor predicts a somewhat higher solar radiation incident on the façade than other programs do.}

In this subtask MZ (Multi-Zone-Non air), but also in subtask DSF (Double-Skin-Façade) this was observed. A description of VA114's solar processor was made and distributed among the other participants. Comments and suggestions were obtained. Until now no direct cause could be found. Some checks still have to be done. In appendix D this information is available. 
Remark: from the latest DSF-results it was found VA114 is not so very different as seemed to be earlier (after 3 iterations programs came closer and closer ..... and the incident solar radiation predicted by VA114 did not change during those iterations).

\section{In daily profiles VA114 shows on some hours deviating results with respect to the other programs}

In the Figure 2F-1 this can be seen for the hours 16 and 17. To our opinion this is caused by the modelling approach:

The external window is divided in 100 points (10 rows by 10 columns). A sun ray (beam radiation) through each point is followed. Counted is the number of points through which a sun ray reaches a certain surface in zone B respectively zone $\mathrm{C}$. It is found that in spite of the 100 points the method is somewhat discontinuous (see also appendix $\mathrm{C}$ ). Figure $2 \mathrm{~F}-2$ shows the fraction of incident solar that reaches zone $\mathrm{B}$ respectively zone $\mathrm{C}$ for March 15 ; Figure $2 \mathrm{~F}-3$ shows the same, but then for the period March $15-31$.

Figure 2F-2 shows that the fraction that reaches zone B is 0,64 for hour 14 and 15 and 0,81 for hour 16 and 17; the fraction that reaches zone $\mathrm{C}$ is respectively $0,12-0,24-0,30-[0]$,36 for the hours 14 to 17 .

Figure 2F-3 shows that these fractions are on the same level for a number of days and jumps then to another level.

These figures show the discontinuity in the solar radiation.

Remark: by this effect the solar radiation that stays in zone B (what enters from zone A minus what leaves to zone $\mathrm{C}$ ) is influenced too. That can be seen from the cooling load $\mathrm{q}_{\mathrm{B}}$ in that zone $\mathrm{B}$ : at hour 14 the fraction is $0,52(=0,64-0,12)$ of incident solar, at hour 15 fraction $0,40(=0,64-0,24)$, at hour 16 fraction 0,51 and hour 17 fraction 0,45. This was observed from the comparison (see Figure 2F-4). 


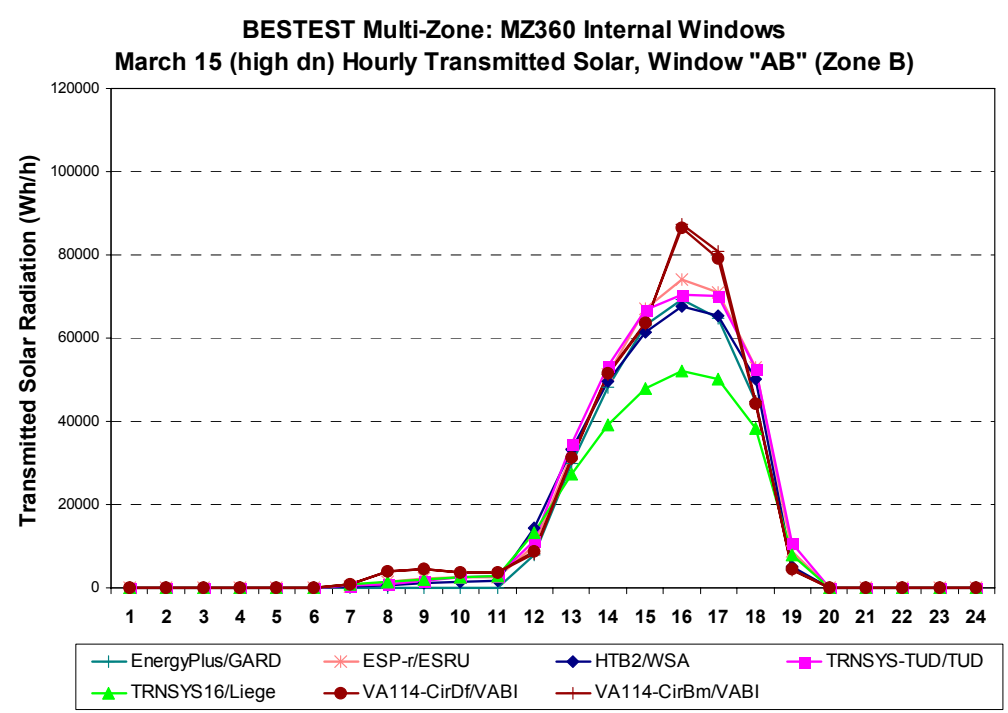

Figure 2F-1: Daily profile of transmitted solar with deviating results for VA114

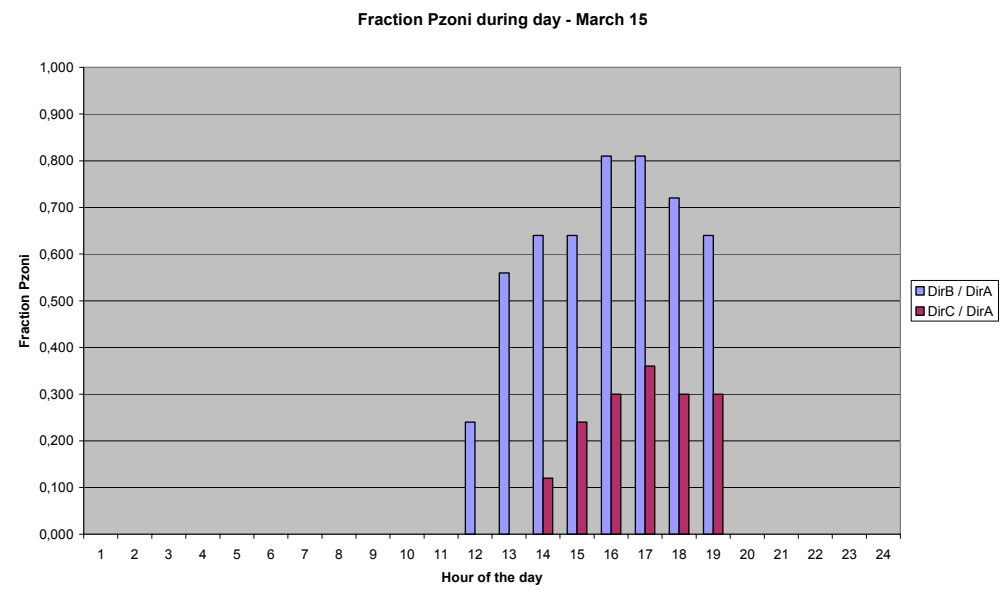

Figure 2F-2: Daily profile of fraction Pzoni - March 15 
Fraction Pzoni during day - Period March 15 - March 31

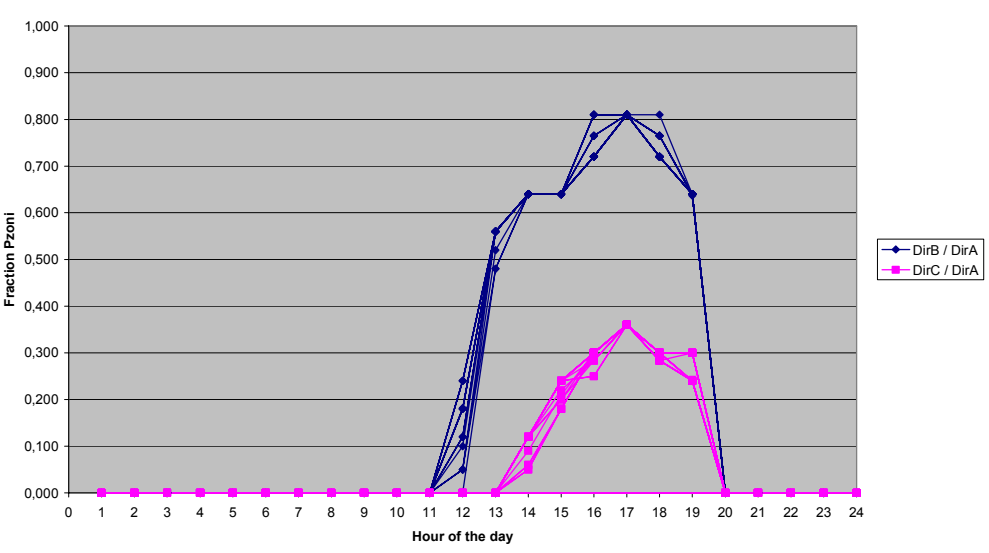

Figure 2F-3. Daily profile of fraction Pzoni - period March 15 - March 31

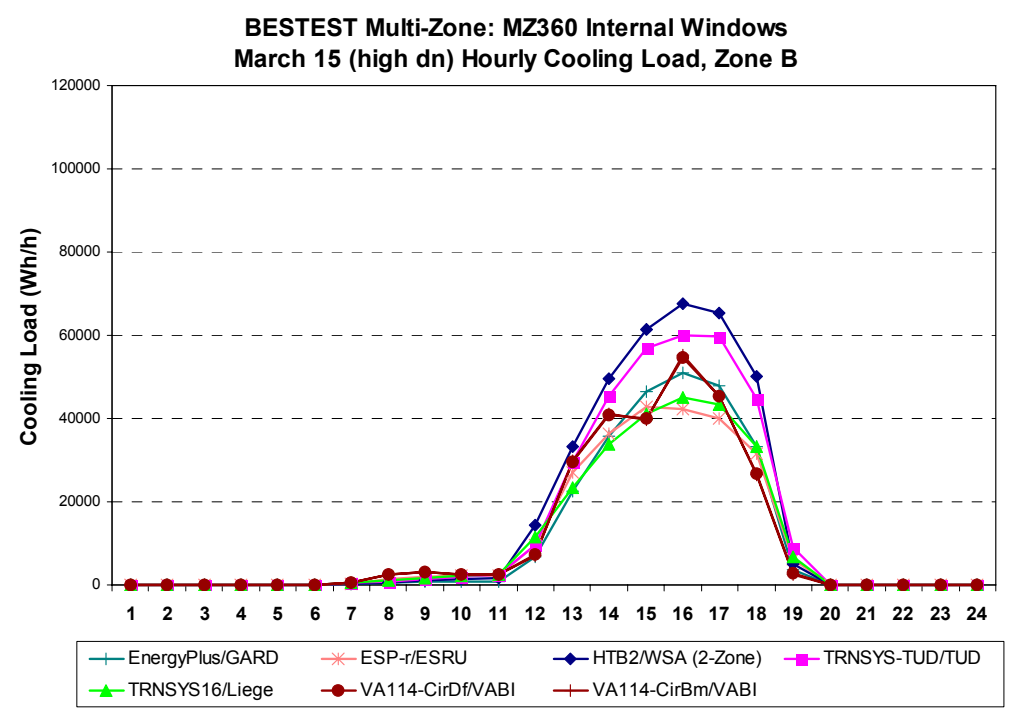

Figure 2F-4. Daily profile of cooling load in zone B on March 15 


\section{Results}

Results are given for two models:

- Circumsolar diffuse radiation is treated as direct radiation (VA114's model). Results in spreadsheet "MZ-output082205-VABI-difcir is beam-20060921A-output real beam and dif.xls".

- Circumsolar diffuse radiation is treated as diffuse radiation (other programs' model). Results in spreadsheet "MZ-output082205-VABI-difcir is dif-20060921A.xls".

Some additional comments:

\section{Case MZ320}

Zone temperatures are 31,1 C (Zone A), 24,8 C (Zone B) and 15,0 C (Zone C). Cooling power is $1541 \mathrm{~W}$.

If ground reflection \# 0,0 then there will be diffuse solar radiation on the back of the floor (floor is above air). It is necessary the solar absorptance at the outside is as prescribed 0,0 .

\section{Case MZ340}

All zones have the same solar input and the same cooling.

\section{Case MZ350}

Remark: a0 has some lower cooling with respect to a1 and a2 because of solar loss through the window: simple VIEWA (area-weighted) leads with absorptances to distribution of diffuse radiation entering through the window on the internal surface of that window. The same is valid for $\mathrm{c} 0$ with respect to $\mathrm{c} 1$ and $\mathrm{c} 2$.

Remark: after correction of the errors a1 and a2 give the same results (within the last digit); the same is valid for $\mathrm{c} 1$ and $\mathrm{c} 2$. Results are presented in one: a12 and c12.

Remark: cases MZ350a are lower than MZ350c because MZ350a does have diffuse solar shading, MZ350c does not.

\section{Case MZ355}

SCHADUW3 (direct solar shading) and SCHADW2D (diffuse solar shading) have shading by own building parts. In principle the results should be the same as case MZ350a.

After correction of the error the results of MZ355 are the same as for MZ350a (except for the earlier mentioned hour 16 for the days March 12 till March 17 - see chapter 6).

\section{Case MZ360}

The total cooling (Zone A + Zone B + Zone $\mathrm{C}=129653$ ) is not exactly the same as the net total incident solar (total incident solar minus loss through external window to ambient $=129595$ ).

The hourly results show a constant cooling load of $-4 \mathrm{~W}$ (zone $\mathrm{A}$ ), $-2 \mathrm{~W}$ (zone $\mathrm{B}$ ) and $-1 \mathrm{~W}$ (Zone C) during the hours there is no solar input. A run without solar radiation incident on to the window gives the same flows for all hours. On annual basis this cooling load is $58 \mathrm{kWh}$; this is equal to the found imbalance between solar radiation and cooling load $(0,04 \%)$.

So above found imbalance is not caused by the solar calculation method, but by some other reason (probably the Infra-Red model, that becomes a little bit inaccurate at emissivities of 0,01 ). 


\section{Other}

\section{Concerning circumsolar diffuse radiation}

Originally VA114 treats circumsolar diffuse radiation in the same way as beam radiation is treated. Other programs treat this component in the same way as diffuse radiation is treated.

The beam and diffuse treatment differs on:

- $\quad$ transmission by a window

- $\quad$ shading by obstacles

- $\quad$ distribution over the internal surfaces in a zone

- $\quad$ transfer from one zone to a neighbour zone through an internal window

On both options the tests were done and results were presented.

\section{Concerning shading by surrounding buildings}

Case MZ350c works with shading by surrounding buildings. It takes into account shading of beam radiation only. Diffuse radiation is not shaded.

This modelling option was tested and observations were done. Finally the module was found without errors.

Remark: To model diffuse shading by surrounding buildings, the surrounding buildings should be modelled as external facades parts. And then it works as MZ350a.

\section{No further optional work.}

\section{Conclusions and Recommendations}

VABI Software BV does developments on the building simulation program VA114.

In 2005 VA114 has undergone a lot of changes: the solar distribution is calculated by a new method (Raytracing), internal window is implemented, integration of solar shading and solar distribution was done, acceleration of these 'solar' methods to reduce the computing time took place. However old 'solar' methods should stay available.

A new version of VA114 was distributed to its users/clients (about 200 in the Netherlands) by the end of June 2005.

Before the distribution of this new version took place it was tested extensively. First by running the (old!!) Bestest cases (1995) [1] again and then by running the new IEA-34/43 test cases [4]. Both tests cycles led us to errors in the software.

The errors were repaired and tests were done again and again until we had enough confidence in the results.

For the old Bestest cases the exact results for VA114 were available (tests were done on earlier versions of VA114). After the modifications in 2005 we found a number of newly introduced errors. First the results of all cases were different. After the first errors were found and corrected only the shading cases still showed 
differences. And again we found errors. Correction left only one case (case960 with solar space) with a deviation from the original results. This error was found too!! Now all BESTEST-cases were the same (within a few explainable digits) as earlier results.

With that version of VA114 we started with the new IEA-34/43 tests(MZ320, MZ340, MZ350, MZ355 and MZ360). Again errors were found and corrected. The results were discussed at the Aalborg-meeting (October 2005). This led to some observations. These "problems" were countered and re-runs were done (see draft 5 of Modeller Report).

Modeller Report - draft 6 contained the results for adjusted dimensions.

In this final draft of the Modeller Report some observations done at the last meeting (Golden, March 2007) were studied. Extra information about these items has been added. No re-runs were done, so results are the same as for September 2006 ( $6^{\text {th }}$ draft $)$.

\section{$\underline{\text { Final remark: }}$}

The test cases are very useful during developments on the Building simulation program VA114. Modifications in / extensions on the software are first tested on "good physical understanding" and "good practice" of the developer. Also other internal users tested the new version by "working" with it. This led to errors and corrections.

But that is not enough. Bestest and IEA-34/43 tests brought a number of new errors to the surface. This shows the importance of these test circles!!

And still there will be errors in the software!! Development of new, specific test cases is of big importance!!

A MUST: after modifications (even if they are minor) in the software all tests (Bestest, IEA-34/43, others tests) have to be done again to be sure no derivative errors are introduced.

\section{References}

[1] Judkoff, R and Neymark, J

"International Energy Agency Building Energy Simulation Test (BESTEST) and Diagnostic Method”, IEA: SHC Task 12 / ECBCS Annex 21, February 1995.

[2] Soethout, L. L.

"BESTEST Kwalificatietesten uitgevoerd aan het gebouwsimulatieprogramma VA114, versienummer 1.35”. TNO-rapport 98-BBI-R0830, mei 1998.

[3] Wijsman, A.J.Th.M.; Plokker, W.

"Eerste thermische gebouwsimulatieprogramma's ondergingen de keurmerktest".

TVVL Magazine, augustus 1999.

[4] Neymark, J and Judkoff, R "Proposed IEA BESTEST Multi-Zone Non-Airflow In depth Cases: MZ320 - MZ360", IEA: SHC Task 34 / ECBCS Annex 43, August 2006. 


\section{Appendix A: Solar gain and solar exchange between zones}

\section{Model description}

In subroutine "ZONINT" the solar gain and solar exchange between zones is simulated. In Figure 2FA-1 this is given very schematically.

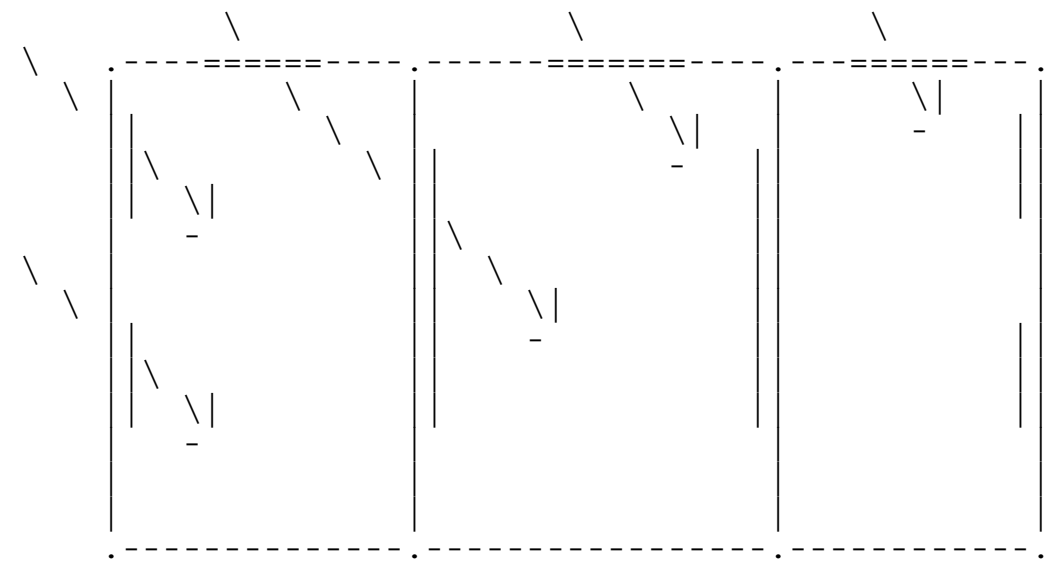

Figure 2FA-1. Solar enters a zone by external windows and by internal windows. Windows can be present in the facades and in the roof.

It is calculated what fraction of the solar gain of a zone: is used for the evaporation by plants

- $\quad$ comes sensible available to the air node

- $\quad$ comes sensible available to the walls; the distribution over all surfaces within the zone is calculated.

Direct and diffuse solar radiation are treated separately.

\section{Steps in the calculation process:}

calculation of the solar gain of a zone

External windows:

SOMZON $=\Sigma$ A(IV,IVLK)*TRANS(IV,IVLK)*

(Amdir*Gdir(IV,IVLK)+Amdif*Gdif(IV,IVLK))

with

SOMZON = solar gain

A $\quad=$ area of the window

TRANS $=$ transmission of the window (incident angle $45^{\circ}$ ) 
$\begin{array}{ll}\text { Amdir } & =\text { Angular Modifier-direct radiation }\left(=1.000 \text { at } 45^{\circ}\right) \\ \text { Gdir } & =\text { intensity direct solar radiation on the window } \\ \text { Amdif } & =\text { Angular Modifier-diffuse radiation }\left(\text { at } 58^{\circ}\right) \\ \text { Gdif } & =\text { intensity diffuse solar radiation on the window }\end{array}$

Internal Windows:

The solar radiation, that enters the zone by internal windows is added to the solar gain SOMZON.

calculation of the latent and the sensible part of the solar gain

Latent part (evaporation by plants)

SOMZONV $=$ VZON(IV) $*$ SOMZON

Sensible part

SOMZONS $\quad=(1.0-\mathrm{VZON}(\mathrm{IV})) * \mathrm{SOMZON}$

The fraction VZON is an input of the model.

calculation of the convective part and the radiative part

Convective part (to the air node)

$\mathrm{QZONL}(\mathrm{IV})=\mathrm{CZON}(\mathrm{IV}) * \mathrm{SOMZONS}$

Radiative part (to the wall surfaces)

$\mathrm{QZONW}(\mathrm{IV})=(1-\mathrm{CZON}(\mathrm{IV})) * \mathrm{SOMZONS}$

The fraction CZON is an input of the model.

Calculation of the internal distribution of the radiative part.

Many models are available here, from very simple ones (100\% goes to the floor) to very detailed ones.

For the calculation of the exchange between zones a detailed model, that calculates the actual solar distribution (so each time step) is applied.

Detailed model for the internal solar distribution

The distribution of the solar radiation is separately done for direct and for diffuse radiation and is dependent on the solar position, the geometry of the zone, the absorption / reflection of the internal surfaces bounding that zone.

Each window is treated separately.

The solar entering the zone by a window has two components:

- $\quad$ a direct component

- $\quad$ a diffuse component. 
Remark: a fraction FDIFRM of the direct radiation is converted into diffuse when it passes the window. The fraction FDIFRM is an input of the model (at this moment FDIFRM $=0.0$ ).

Remark: the circumsolar diffuse radiation component is treated as direct solar radiation.

The internal distribution is calculated in subroutine ZABSVLK: the fraction of the radiative part of the solar gain that is absorbed by each surface. The part absorbed by the surface of a window is assumed to pass that window (to outdoors or to a neighbouring zone) for $100 \%$.

\section{The direct component}

Subroutine PZONI2 calculates, based on the solar position, what internal surface(s) receive direct radiation, that enters the zone by a specific window (see Appendix C). A fraction (= absorption coefficient of the internal surface) of this direct radiation is absorbed, the rest ( 1 - absorption) is diffuse reflected.

Remark: in case the internal surface is an internal window PZONI2 calculates also what internal surface(s) of the neighbouring zone receive this direct radiation.

Remark: PZONI2 uses a Ray-tracing method; shading by external facade parts, by own building parts and by window setback is integrated in this method.

Remark: for simpler cases (rectangular zones; no internal window) subroutine PZONI0 $(100 \%$ of the direct radiation hits the floor) and subroutine PZONI1 (a projection method, that calculates where the direct solar radiation hits the internal surfaces) are available.

\section{The diffuse component}

The calculation of the distribution of the diffuse radiation (diffuse entered by the windows + the diffuse reflected direct radiation) happens by exchange factors. These exchange factors FUFACA(IV,I,J) are derived from the view factors and the reflection coefficients of all internal surfaces.

Remark: for the surface of an opaque wall the reflection coefficient is equal to $(1-$ absorption of that surface), for the surface of a window the reflection is equal to $(1-$ transmission - absorption in the panes).

Remark: in case of internal windows the solar radiation exchange between zones is calculated iteratively. Reason: the solar radiation goes in two directions - through a window the zone in and through a window the zone out.

The result of this calculation is the solar absorbed by each internal surface.

Final Remark: as can be seen from Figure 2FA-1 the following situations can occur:

- a beam of rays hits a part of an internal window

- $\quad$ a beam of rays hits more than one internal window

- $\quad$ several beams of rays hit the same internal window.

The model is able to handle these situations.

\section{Appendix B: Solar shading}

\section{Model description}

In subroutine "ZONEXT" the solar radiation on external surfaces is simulated. Based on the orientation of each surface and the known solar radiation on each orientation. Both the unshaded direct component 
(Gdir(IV,IVLK)) and the unshaded diffuse components (Gdif(IV,IVLK)) are known.

For solar shading a distinction is made between direct and diffuse solar shading.

\section{Direct solar shading}

Direct solar shading happens by surrounding buildings (subroutine 'schaduw1'), by external facade parts, by own building parts and by setback of the window (subroutine 'schaduw2').

Shading factors:

Pschv1 (IV,IVLK) surrounding buildings

Pschv2 (IV,IVLK) external facade parts, own building parts, setback window

Remark: Factor $=0.0$ is not shaded, factor $=1.0$ is fully shaded.

Remark: only windows have shading, shading of opaque walls is (until further notice) not taken into account.

These factors are combined to one factor

$$
\text { Psch0(IV,IVLK) }=1 .-(\text { 1.- Pschv1 }(I V, I V L K)) *(1 .- \text { Pschv2(IV,IVLK }))
$$

\section{Diffuse solar shading}

Diffuse solar shading by surrounding buildings is not taken into account; diffuse solar shading by external facade parts, by own building parts and by setback of the window is (subroutine 'schadw2d').

Shading factors:

Pschv1d (IV,IVLK) surrounding buildings (is not taken into account, i.e. $=0.0$ )

Pschv2d (IV,IVLK) external facade parts, own building parts, setback window.

Remark: Factor $=0.0$ is not shaded, factor $=1.0$ is fully shaded.

Remark: only windows have shading, shading of opaque walls is (until further notice) not taken into account.

These factors are combined to one factor

$$
\text { Psch1 }(I V, I V L K)=1 .-(1 .- \text { Pschv1d(IV,IVLK) }) *(1 .- \text { Pschv2d(IV,IVLK) })
$$

\section{Solar radiation, shading included}

The shaded solar radiation on external surfaces is given by:

$$
\begin{array}{ll}
\text { Direct solar radiation } & \text { Gdir(IV,IVLK })=(1.0-\text { Psch0(IV,IVLK) }) * \operatorname{Gdir}(I V, I V L K) \\
\text { Diffuse solar radiation } & \text { Gdif(IV,IVLK })=(1.0-\text { Psch } 1(I V, I V L K)) * \operatorname{Gdif}(I V, I V L K)
\end{array}
$$

Remark:

The circumsolar diffuse radiation component is treated as direct solar radiation.

More details about the mentioned models (subroutine Schaduw1, Schaduw2 and Schadw2d) is given below.

\section{Direct solar shading by surrounding buildings}

Direct solar shading by surrounding buildings is simulated in subroutine 'schaduw1'.

The method

For a number of points on an external surface (see Figure 2FB-1.) the skyline is determined:

$$
\text { SKYH(IGR,IV,IPUNT) }
$$

This is done once and for each external surface. 


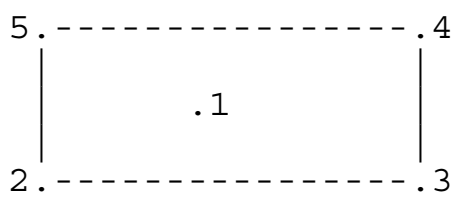

Figure 2FB-1. External surface with 5 points to determine shading

If the solar height at the given solar azimuth is below the skyline of a point then there is shading in that point $(\mathrm{Psch}=1.0)$, if it is above there is no shading $(\mathrm{Psch}=0.0)$.

The shading factor for that surface is the average shading factor of the 5 points.

Direct solar shading by external façade parts, own building parts and by setback of window Direct solar shading by external facade parts, by own building parts and by setback of the window is simulated in subroutine 'schaduw2'.

In Figures 2FB-2a and 2FB-2b the situation with obstructions is shown.

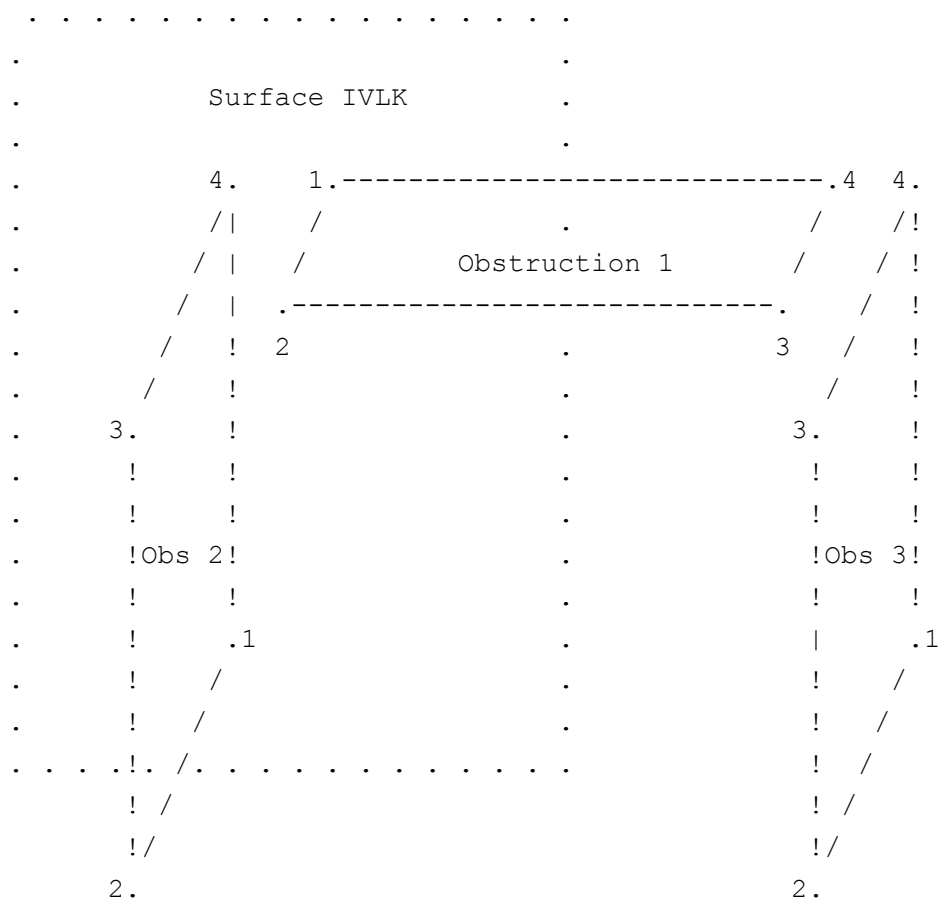

Figure 2FB-2a. External obstructions (facade parts) - side view 


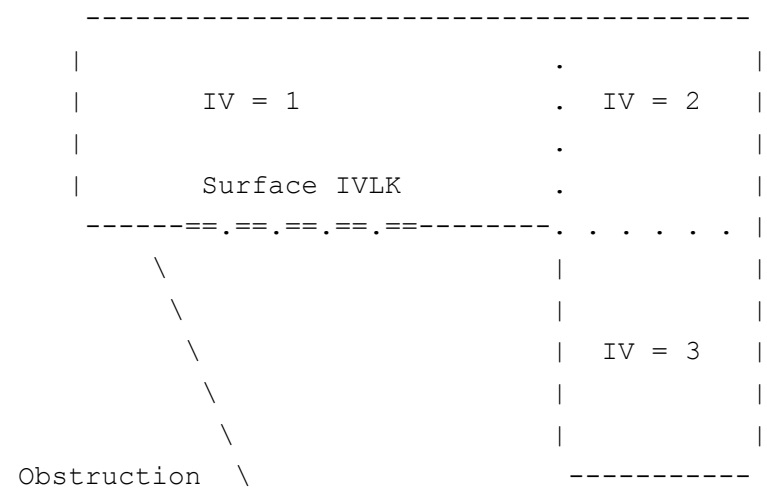

Figure 2FB-2b. External obstructions (facade parts) - top view

The method

The projections of all obstructions and all surfaces of the building on a plane perpendicular to the solar rays are determined. The overlap between the projection of an obstruction and the projection of a surface gives information about the shading:

- 'no overlap' means 'no shading'

- 'overlap' means 'shading'; the size of the overlap is a measure for the shading $(0.0-1.0)$.

Remark: another new method uses Ray-tracing to determine the shading factor; at the moment it is only in use for windows and is integrated with the calculation method for the internal solar distribution. For this method the window is divided into 10x10 points (see Appendix C).

\section{Diffuse solar shading}

Diffuse solar shading by external facade parts, by own building parts and by setback of the window is simulated in subroutine 'schadw2d'.

To the diffuse solar radiation belong the isotropic component, the component from the horizon and the ground reflection component. The circumsolar component is treated as direct solar radiation.

In Figures 2FB-2a and 2FB-2b the situation with obstructions is shown.

The method

The shading by an obstruction on a surface is determined by the view factor between that surface and that obstruction.

The shading by setback of the window follows from the sum of the view factors between that surface and the edges around that surface: Fschzyv(IV,IVLK).

The shading by own building parts follows from the sum of the view factors between that surface and the own building parts: Fschegd(IV,IVLK).

The shading by other facade parts (obstructions) follows from the sum of the view factors between that surface and the several obstructions: Fschbel(IV,IVLK). 
Total shading::

Fschdif $=$ Fschzyv(IV,IVLK) + Fschegd(IV,IVLK) + Fschbel(IV,IVLK).

\section{Appendix C: PZONI2 - Detailed ray-tracing method}

\section{Method}

For the direct (beam) radiation it is calculated which internal surfaces are hit; such a surface absorbs a part of that direct radiation and reflects the rest diffusely.

The external window is divided in 100 points (10 rows by 10 columns). A sun ray (beam radiation) through each point is followed. Determined is what internal surface is hit. In case the hit internal surface is an internal window the ray will pass that window and will hit an internal surface in that neighbour zone. Counted is the number of points through which a sun ray reaches a certain internal surface (see Figure 2FC-1).

The method is integrated with shading: in case the followed sun ray passed earlier an obstacle then there is shading and the sun ray will not reach any surface (dashed rays in Figure 2FC-1).

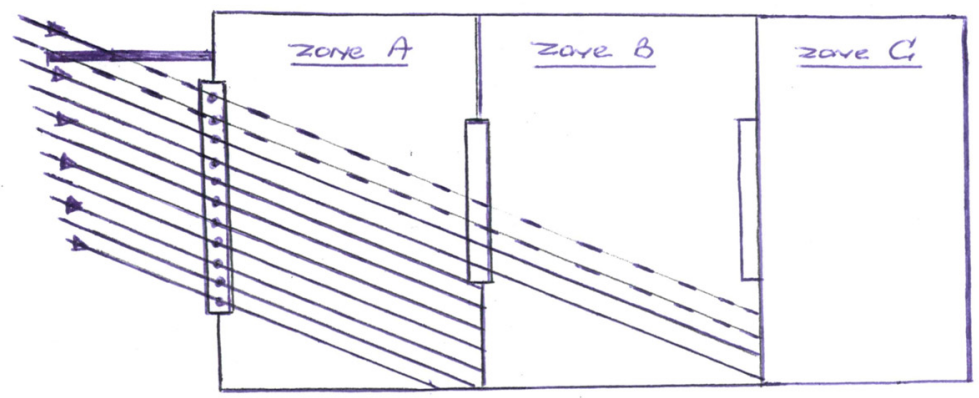

Figure 2FC-1. The method schematically (in 2-D)

\section{Comments to this method:}

In Figure 2FC-1 it can be seen that 2 rays are shaded by the overhang and the rest of the rays enter zone A; 2 rays pass zone $\mathrm{A}$ and enter zone $\mathrm{B}, 0$ rays pass zone $\mathrm{B}$ and enter zone $\mathrm{C}$.

In case the sun position at this hour of the day becomes somewhat higher (next days in Spring) the $3^{\text {rd }}$ ray (from the top) will be shaded and the $4^{\text {th }}$ ray from the top will not pass the window AB. So in that case 3 rays are shaded by the overhang and the rest of the rays enter zone A; 0 rays pass zone $\mathrm{A}$ and enter zone $\mathrm{B}, 0$ rays pass zone $\mathrm{B}$ and enter zone $\mathrm{C}$.

In case the sun position at this hour of the day becomes lower (next days in Autumn) only the first ray (from the top) will be shaded and the $5^{\text {th }}$ ray from the top will also pass the window AB. So in that case 1 ray is shaded by the overhang and the rest of the rays enter zone $\mathrm{A} ; 4$ rays pass zone $\mathrm{A}$ and enter zone $\mathrm{B}, 0$ rays pass zone $\mathrm{B}$ and enter zone $\mathrm{C}$. 
In case the sun position at this hour of the day becomes still lower (days towards winter) the first ray (from the top) will not be shaded, passes zone $\mathrm{A}$, passes window $\mathrm{AB}$, passes zone $\mathrm{B}$, passes window $\mathrm{BC}$ and enters zone $\mathrm{C}$. So in that case no rays are shaded by the overhang and all the rays enter zone A; 5-6 rays pass zone $\mathrm{A}$ and enter zone $\mathrm{B}, 1$ ray passes zone $\mathrm{B}$ and enters zone $\mathrm{C}$.

As can be seen from this 2-D explanation the fraction, that reaches a certain zone and stays in a certain zone changes not continuously.

The method uses 100 points $(10 \times 10)$, but still the change in fraction is very discontinuously (rays through a complete row of points stay in one zone or just pass through an internal window to another zone. In Figure $2 \mathrm{FC}-2$ that is shown as an example.

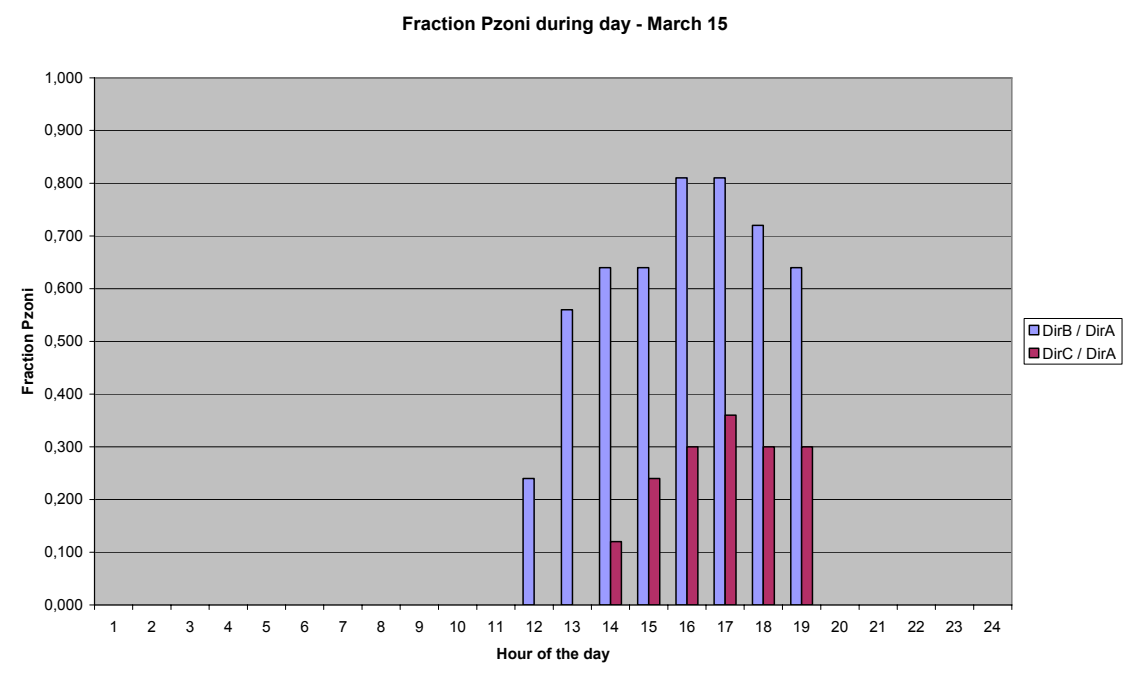

Figure 2FC-2. Daily profile of fraction Pzoni - March 15

\section{Conclusion:}

The method is very flexible, can handle all shapes of windows, shapes of zones, but on hourly bases the profile can be a little bit discontinuous.

\section{Appendix D: Solar processor of VA114}

\section{Introduction}

In IEA34/43 subtask B1 (MZ = Multi Zone-non air) and subtask E (DSF = Double Skin Façade) tests on Building Performance Simulations programs are conducted, where the solar radiation impinging on the façade is the most important driving force. From first comparisons it seemed VA114 predicts a somewhat higher incident solar radiation on the façade starting from the same solar source on the horizontal surface.

In this appendix the solar processor of VA114 is described in short to give the other task participants inside in that model. An earlier version of this appendix was distributed and reactions were gathered. A summary of these reactions is given. It did not lead directly to the cause, but the comments and suggestions given will be checked. That will be done in due time, but not as part of this IEA34/43 Task. 


\section{The description of VA114's solar processor}

\section{Solar position}

Solar position is given by solar height (h) and solar azimuth (az). Both are calculated half way the hour. Used formulas:

- hour angle OHM

$\mathrm{OHM}=2 * \pi / 24 *(12,5-\mathrm{ST})$

with solar time ST

$$
\mathrm{ST}=\mathrm{KL}-\mathrm{DTIME}
$$

In this formula

$$
\mathrm{KL}=\text { hour of the day }
$$

DTIME $=$ time shift in hours

The time shift DTIME is given by with

$$
\text { DTIME }=\text { EQT/60 }-(\text { DLONGD/15 }- \text { ITIMEZ })
$$

$\mathrm{EQT}=$ equation of time (in minutes); EQT depends on day of the year

DLONGD = longitude of site (in degrees; East = positive)

ITIMEZ $=$ time zone $($ East $=$ positive $)$

- Solar height $\mathrm{H}$ and solar azimuth AZ

Sinus of solar height (sinh) and cosinus of solar azimuth (cosaz) are both calculated based on solar declination, latitude of site and hour angle OHM.

\section{Splitting in direct and diffuse radiation}

For IEA-34/43 MZ (subtask Multi-Zone Non air) the GH (Global radiation on the horizontal) and GBN (Normal Beam radiation) is given on tape. With sinus of solar height (sinh) follows for the GBH (Horizontal Beam radiation):

$$
\mathrm{GBH}=\mathrm{GBN} * \sinh
$$

and for the GDH (Horizontal Diffuse radiation)

$$
\mathrm{GDH}=\mathrm{GH}-\mathrm{GBH} \text {. }
$$

For IEA-34/43 DSF (subtask Double Skin Façade) the GH (Global radiation on the horizontal) and GDH (Horizontal Diffuse radiation) is given on tape. For the GBH (Horizontal Beam radiation) follows:

$$
\mathrm{GBH}=\mathrm{GH}-\mathrm{GDH}
$$

and with sinus of solar height ( $\sinh$ ) the GBN (Normal Beam radiation):

$$
\mathrm{GBN}=\mathrm{GBH} / \sinh \text {. }
$$

\section{Remark:}

GBN should be lower than a maximum value GBN,max that is based on the outer atmospheric normal radiation $\mathrm{G} 0 \mathrm{~N}$ and the air mass AIRM. Correction:

$$
\text { IF }(\text { GBN }>(G B N, \max +55,6)) \text { THEN GBN }=\text { GBN, max }
$$

The corrected GBN results in a corrected GBH and with $\mathrm{GDH}=\mathrm{GH}-\mathrm{GBH}$ in a corrected GDH. 


\section{Splitting diffuse on the horizontal in 3 components}

The diffuse on the horizontal surface is split into 3 components based on Perez [1]:

- Isotropic component D1

$$
\mathrm{D} 1=\mathrm{GDH} *(1,0-\mathrm{F} 1 \mathrm{ACC})
$$

- Circumsolar component D2

$$
\mathrm{D} 2=\mathrm{GDH} *(\mathrm{~F} 1 \mathrm{ACC} / \mathrm{CZET})
$$

- Component from the horizon D3

$\mathrm{D} 3=\mathrm{GDH} * \mathrm{~F} 2 \mathrm{ACC}$

With

$\mathrm{F} 1 \mathrm{ACC}=$ new circumsolar brightness coefficient

$\mathrm{F} 2 \mathrm{ACC}=$ horizon brightness coefficient

Remark:

F1ACC and F2ACC should be both between 0,0 and 1,0; circumsolar (D1) has as maximum value of 500 $\mathrm{W} / \mathrm{m}^{2}$.

If not values F1ACC, F2ACC or D1 are given the limit value and components are recalculated.

\section{Calculation of total solar radiation on a tilted surface}

By geometric formulas the contribution of the direct component, the 3 diffuse components and the ground reflected component to the total radiation on the tilted surface are calculated.

The used formulas:

- Direct solar radiation:

$\mathrm{GBT}=\mathrm{GBN} * \operatorname{COS}($ Teta $)$

With

GBN $=$ Normal Beam radiation

Teta $=$ angle of incidence of solar radiation on the tilted surface

- Diffuse isotropic radiation:

$\mathrm{GD} 1=\mathrm{D} 1 * 0,5 *(1,0+\mathrm{COS}($ Beta $))$

With

D1 = diffuse isotropic component on horizontal

Beta $=$ tilt of surface

- Diffuse circumsolar radiation:

GD2 $=$ D2 $* \operatorname{COS}$ (Teta)

With

D2 = diffuse circumsolar component

Teta $=$ angle of incidence of solar radiation on the tilted surface

- Diffuse radiation component from horizon:

GD3 $=$ D3 $*$ SIN(Beta)

With

D3 = diffuse component from the horizon

Beta $=$ tilt of surface 
- Ground reflection:

$\mathrm{GRT}=\mathrm{GH} * \mathrm{RHO} * 0,5 *(1,0-\operatorname{COS}($ Beta $))$

With

$\mathrm{GH}=$ total radiation on the horizontal

$\mathrm{RHO}=$ ground reflectivity

Beta $=$ tilt of surface.

Total radiation on tilted surface:

$\mathrm{GT}=\mathrm{GBT}+\mathrm{GD} 1+\mathrm{GD} 2+\mathrm{GD} 3+\mathrm{GRT}$

$\underline{\text { Remark }}$

VA114's solar processor is described. The big lines are given. If necessary more details can be provided, such as details about calculation of:

- $\quad$ equation of time EQT

- solar height and solar azimuth

- outer atmospheric normal radiation G0N

- Perez factors F1ACC and F2ACC; zenith angle ZET

- Angle of incidence of solar radiation impinging on the tilted surface

$-\quad \ldots . . . .$.

\section{Reactions and suggestions from participants}

Valuable reactions were received from Joel Neymark (USA) and Paul Strachan (GB).

Joel Neymark

He read about the Perez 1987, 1988 anisotropic sky model in Duffie and Beckman (Solar Engineering of Thermal Processes, 1991) that there are a number of disagreements that could occur with respect to how the model details are implemented ...

e.g.

- for calculating circumsolar diffuse a maximum for $\cos (z e n i t h$ angle) of $\cos (85)$ is shown (remark VABI: VA114 takes that into account).

- the implementation of the brightness coefficients could easily be different among modelers (for those using a Perez model).

Duffie and Beckman note that this Perez model generally predicts slightly higher total radiation on a tilted surface, so in the MZ work the VA114 results are consistent with that. Duffie and Beckman recommend Perez for surfaces with azimuth angle far away from 0 [which is common for many building vertical surfaces].

\section{Paul Strachan}

Most of the calculations looked OK to him.

One difference is that VA114 is using Perez 1987. Paul's program ESPr was updated to the Perez 1990 model (probably also used by TRNSYS-TUD and Energy+). His experience: it does make some difference, but not a huge amount. 
Paul (ESPr) supplied detailed results on direct and diffuse radiation for the comparative tests concerning solar radiation on the façade. For the period April 17 - April 30 a comparison between ESPr and VA114 was made [2]:

- concerning the solar sum over the period:

- Direct - VA114 is 1,4\% higher than ESPr

- Diffuse - VA114 is 4,2\% higher than EPSr

- Total - VA114 is 2,8\% higher than EPSr

- daily plots show VA114 is somewhat higher in the peaks!!!

Paul suggested another possibility for comparisons: compare with the detailed solar processing analysis that used the EMPA data set. It was published as:

Loutzenhiser P G, Manz H, Felsmann C and Strachan P A, Frank T and Maxwell G M Empirical Validation of Models to Compute Solar Irradiance on Inclined Surfaces for Building Energy Simulation, Solar Energy, 81(2), Feb 2007, pp 254-267.

All the measured data and the predictions are included on the IEA34/43 FTP site. Measured were direct normal as well as global horizontal and diffuse horizontal.

\section{Other comparisons by Vabi Software BV}

The solar results of the comparative and empirical DSF-tests were studied intensively. There were a lot of observations, concerning all programs [3]. But our conclusion about the VA114 solar processor is:

On total radiation and direct radiation VA114 is close to the other programs. On diffuse radiation two groups of programs can be distinguished, a higher group and a lower group; VA114 belongs to the higher group and is the highest in that group.

So the differences are much smaller than was found from the earlier comparisons.

Remark: information about what model assumptions other solar processors are using is not available at the moment. The individual modeler's reports should provide that information. Not all modeler's reports are available at the moment.

\section{Resume}

In this appendix VA114's solar processor is described in big lines. Valuable reactions / suggestions were received from task participants. It did not lead directly to the cause of the differences, but the suggestions given will checked. That will be done in due time, but not as part of this IEA34/43 Task. Until now it was concluded the differences between VA114 and the other programs are much smaller than was found from the first, earlier comparisons.

\section{Literature}

[1] Perez et al.

"A new simplified version of the Perez diffuse irradiation model for tilted surfaces", Solar Energy Voume 30, No. 3, pp. 221-231, 1987.

[2] Wijsman, A

"Solar radiation VA114 versus ESPr", Excel sheet, June 12 2007

[3] Wijsman, A

"Solar radiation predicted by the several programs", May $31^{\text {st }}, 2007$ 


\title{
Appendix II-G
}

\section{Modeler Report for BESTEST Cases MZ320 - MZ360 CODYRUN}

\author{
by \\ Harry Boyer, Frederic Maranville, Alain Bastide \\ University of Reunion Island \\ France
}

March 2005

\section{Introduction}

CODYRUN is a tool for the thermal and airflow simulation of buildings, mostly dedicated to passive building design; It has been developed and is currently maintained by Harry Boyer, who is the head of the Civil Engineering and Building Physics Research Team of the Industrial Engineering Laboratory. In this team, others researchers are involved in CODYRUN's validation. A previous step was BESTEST IEA task 12 cases for monozone cases a few years ago. Being involved in other research themes (renewable energy), this laboratory is a research component of the University of Reunion Island.

Based on iteratively connected thermal, airflow and humidity models, this software is design for research and professional use. This goal is facilitated by a multi-model approach [3]. The thermal model is based on a finite difference scheme [1] and solved numerically by using a LU matrix inversion method. The airflow pressure model [2] is solved using a modified Picard/Newton-Raphson method.

The time step is specified by the meteorological file. At the end of a simulation the modeler obtain a set of results (usable with a spreadsheet) including among other outputs temperatures, airflow rate, pressures, radiation and heat flux.

\section{Modeling Assumptions}

The mathematical model elaborated with the software is based on a macroscopic description of the building and consider the air volume surrounded by the several walls constituting the building envelope as transparent (non participating media) and characterized by one temperature, the dry-air temperature. Moreover, a building is composed of several zones, each zone being essentially representative of a room. Once this description is made, the software is able to set up and solve the set of equations relatives to the thermal and airflow transfers taking place in the building. The inputs are the climatic data of the location chosen, the geometrical and physical characteristic values of the building. The specification of these data combined with the elaboration of a model of the building lead to the numerical simulation.

\section{Modeling Options}

As previously mentioned, the software allows a multiple model approach. Different level of modeling are available for heat conduction, convective coefficients, short and long wave radiative exchanges, airflow transfers, humidity storage in the envelope and numerical methods. This has been initially designed for a few following major reasons. During building construction process, data base available is growing up. It allows 
only rough models at the beginning and detailed one at the end. Objectives of simulation can also be very different from one user to another (analysis of solar exposition, annual energy need, condensation risk, ...) and a single model's monolithic tool is often disadvantaged in terms of precision or calculation time. At least, during software validation, this method was powerful in to highlight models limitations (for example surface temperatures are obviously unreachable with low quality conduction models).

So, for each case of this benchmark, models involved were chosen as the closest in terms of physical hypothesis.

\section{Modeling Difficulties}

The code was slightly modified in order to take into account more significant digits for long wave emissivities (it was previously limited to 0.01 ).

Model modification was made to be able to specify individual wall exchange convective coefficients. So, the library model of convective models was enriched.

Modifications were also made for permitting the input of specific values for the density and the specific heat of the air composing each thermal zone.

No indications were given for diffuse transmitance. Value used in 1.0. Problems arise in the code when indoor absorbtivity is taken to 1.0 . Used value is 0.99 .

Albedo was assumed to be 0.0 .

Shadow mask are supposed to minimize diffuse radiation, through view factors.

[Editor's note. University of Reunion Island's comments regarding cases MZ350 and MZ360 relate to their simulations for earlier versions of the test specification. As they did not submit results for the final version of the test specification (see Part I), their results were not included in Part III.]

For MZ350 case, two sets of results are provided. The first one corresponds to infinite vetical height of the shading fin and the second one to finite case (12 $\mathrm{m}$ height).

For MZ360, we do not track direct couplings (because the building is not geometrically descripted). Our indoor short wave coupling allows only diffuse couplings through indoor windows. In a zone, our model makes the hypothesis of direct incident on the floor and eventually reflected. With absorptivity taken to 0.99 , energy transmitted to zone $\mathrm{B}$ and $\mathrm{C}$ is certainly underestimated. To match energy loads, it would have to be much physical to modify indoor floor A absorptivity, but this would not have be the descripted case. LARGE DISCREPANCIES WILL APPEAR with other codes allowing direct couplings, especially if absorptivities $=1.0$.

Simulations could be done again, with much smaller absorptivity. 


\section{Software Errors Discovered and Comparison between Different Versions of the Same Software}

Once the preceding modification made in the software, no major error has been encountered. Nevertheless, comparing to the initial version of the software, the results obtained with the modified version have showed better agreement with the given results (analytical).

\section{Results}

The code results can't be compared with analytical results yet because data are not provided (first round is "blind").

\section{Other (optional)}

\section{Conclusions and Recommendations}

After passing BESTEST task 12 for monozone cases, the heat transfer multizone cases is much less difficult. This cases were not available elsewhere, and this was for us a slight but a valuable step. Additional cases should be designed in order to test airflow transfers handling and prediction, including moisture taking into account.

\section{References}

H. Boyer et al.

Thermal building simulation and computer generation of nodal models

Building and Environment, Vol. 31, n 3, 1996, pp. 207-214

H. Boyer, F. Garde, J.C. Gatina, J. Brau

A multi model approach of thermal building simulation for design and research purposes

Energy and Buildings, 28 (1998), 1, pp. 71-79

H. Boyer, A.P. Lauret, L. Adelard, T.A. Mara

Building ventilation : a pressure airflow model computer generation and elements of validation

Energy and Buildings, 29 (1999), 283-292 


\title{
Appendix II-H
}

\section{Modeler Report for BESTEST Cases MZ320 - MZ360 COMFIE}

\author{
by \\ Bruno Peuportier \\ Paris School of Mines \\ France
}

\section{Introduction}

\section{September 2005}

\section{PLEIADES + COMFIE}

Developers: Ecole des Mines de Paris (COMFIE simulation tool) and IZUBA Energies (PLEIADES

interface), France

Multizone heat transfer :

- through walls (or floors/ceilings) with surface heat transfer coefficients (radiation + convection), conduction and heat storage in walls,

- accounting for solar gains received by the wall in one zone and transmitted to the adjacent zone through the wall,

- through ventilation,

- accounting for possible multizone control, e.g. the thermostat controlling the heating/cooling system of one zone can be situated in another zone.

Time step: from 6 to 60 minutes, 6 minutes has been used in this exercise.

Solar radiation model

Incident direct and diffuse radiation on the sloped surface are calculated from Duffie and Beckmann ${ }^{1}$ assuming isotropic sky.

\section{Modeling Assumptions}

Each thermostat is assumed to be placed in the same room as the cooling system. Thermal bridges are assumed to be zero.

Ventilation air flow rates between zones and from outside are assumed to be zero.

\section{Modeling Options}

The simulation time step can be chosen from 6 to 60 minutes. In the steady state calculations concerned here, a one hour time step has been chosen because it is consistent with the climatic data. If a smaller time step is chosen, the climatic data is interpolated between 2 hours : the climatic data for hour $\mathrm{h}$ is assumed to correspond to an average from $\mathrm{h}-30$ minutes to $\mathrm{h}+30$ minutes. This does not correspond to the TMY file,

\footnotetext{
${ }^{1}$ Solar engineering of thermal processes, Wiley, 1991
} 
where the value for hour $\mathrm{h}$ corresponds to $\mathrm{h}-60$ to $\mathrm{h}$. Therefore a one hour time step has been chosen to avoid this interpolation. This induces small temperature / cooling load oscillations, which would not occur using a smaller time step (e.g. $1 / 4 \mathrm{~h}$ ).

\section{Modeling Difficulties}

The values for surface heat transfer coefficients cannot be chosen by the user in our software, which has been developed for building professionals (architects and engineers).

The surface heat transfer coefficient $\mathrm{h}$ considered is obtained from :

Energy and Architecture, the European Passive Solar Handbook, J. R. Goulding, J. O. Lewis and T.C. Steemers, Batsford for the Commission of the European Communities, London, 1992

Surface resistance (vertical wall, internal side)

$\mathrm{R}=0.123$ (high surface emissivity) and 0.304 (low emissivity)

From this we derive $\mathrm{h}=1 / \mathrm{R}$ for the two levels of the emissivity $\varepsilon$

And we consider $\mathrm{h}=3.29+4.84 * \varepsilon / 0.9$

The convective part is thus $3.29 \mathrm{~W} /(\mathrm{m} 2 . \mathrm{K})$ instead of 4 proposed in the exercise.

For the inter-comparison exercise, we have modified the source code so that the surface heat transfer coefficients indicated in the specifications are used.

The minimum U-value of a window is $0.01 \mathrm{~W} /(\mathrm{m} 2 . \mathrm{K})$.

A thin layer (e.g. $1 \mathrm{~cm}$ plywood) had to be added in walls. We have added this layer on the external part of the insulation. The insulation has also a little thermal mass, and $2 \mathrm{~m}$ thickness has been used (cf. the data description in annex).

\section{Case MZ350a}

[Editor's note. Ecole des Mines Paris' comments regarding Case MZ350 relates to their simulations for earlier versions of the test specification. As they did not submit results for the final version of the test specification (see Part I), their results were not included in Part III.]

If a vertical shading fin is applied to a window, the model considers a very high fin (cf. next picture) and some reflexion (such architectural components are usually not black). It would be time consuming to modify the source code, for a case that does not really occur in practice (black fin), therefore this case has not been performed. We assume that the reflected radiation equals the diffuse radiation that would be sent by the sky portion corresponding to the fin. i.e. the diffuse radiation considered is the same as without fin. The same assumption applies to all windows.

This case has not been simulated in the exercise because the height of the fin $(18 \mathrm{~m})$ is not infinite, therefore the calculation would be less precise than case $b$. 


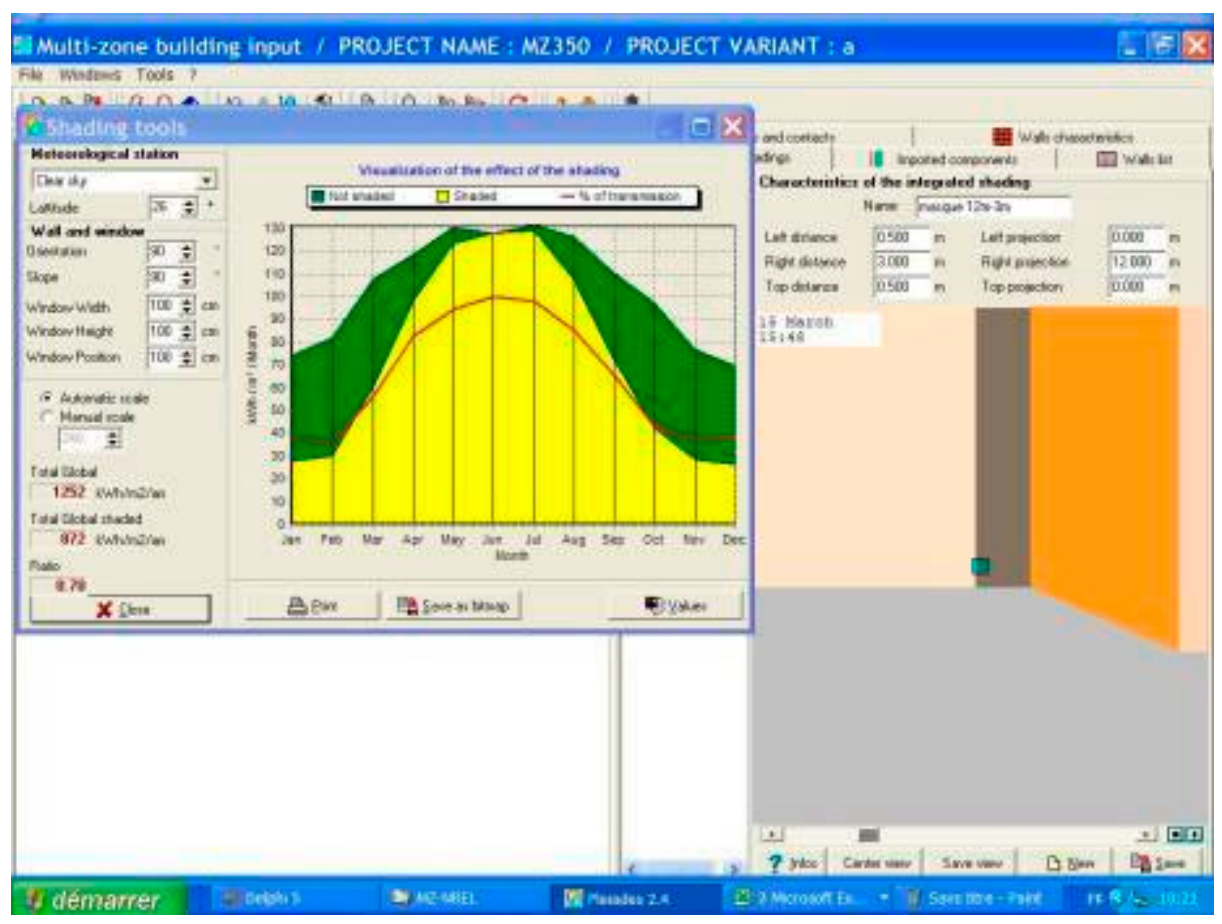

Case MZ $350 \mathrm{~b}$, azimuth and height angles of the shading fin seen from each window

The fin is described for each shaded wall using 5 parameters (cf. next figure) :

- the average height of the fin above the shaded wall (we used the average height above the middle of the window),

- the left and right azimuth of the fin related to the normal incidence (this azimuth is $+/-90^{\circ}$ on one side, where the fin is attached to the wall),

- the left and right distances between the fin and the wall (this distance is zero on one side, where the fin is attached to the wall).

Height angles are derived from the height and distance values, so that the shading effect can be represented in a solar path diagram providing, for the given latitude, the height angle of the sun in terms of the azimuth for a typical day of each month. This diagram shows when the direct solar radiation is blocked by the fin.

In the thermal simulation, the position of the sun is calculated hourly (no typical day is used).

The diffuse radiation is reduced according to the estimated proportion of the sky hidden by the fin. This proportion depends on the height of the fin, and the difference between right and left azimuth.

No reflexion is considered at the surface of the fin (black surface).

If a fin shades different walls, a shading object has to be defined for each wall because the height, distance and azimuth parameters may vary. These parameters are not automatically calculated and the shading object description is not automatically generated by a geometry description. If a zone of a building shades other zone walls, the shading object is also not automatically generated, therefore the case MZ355 has not been performed. 

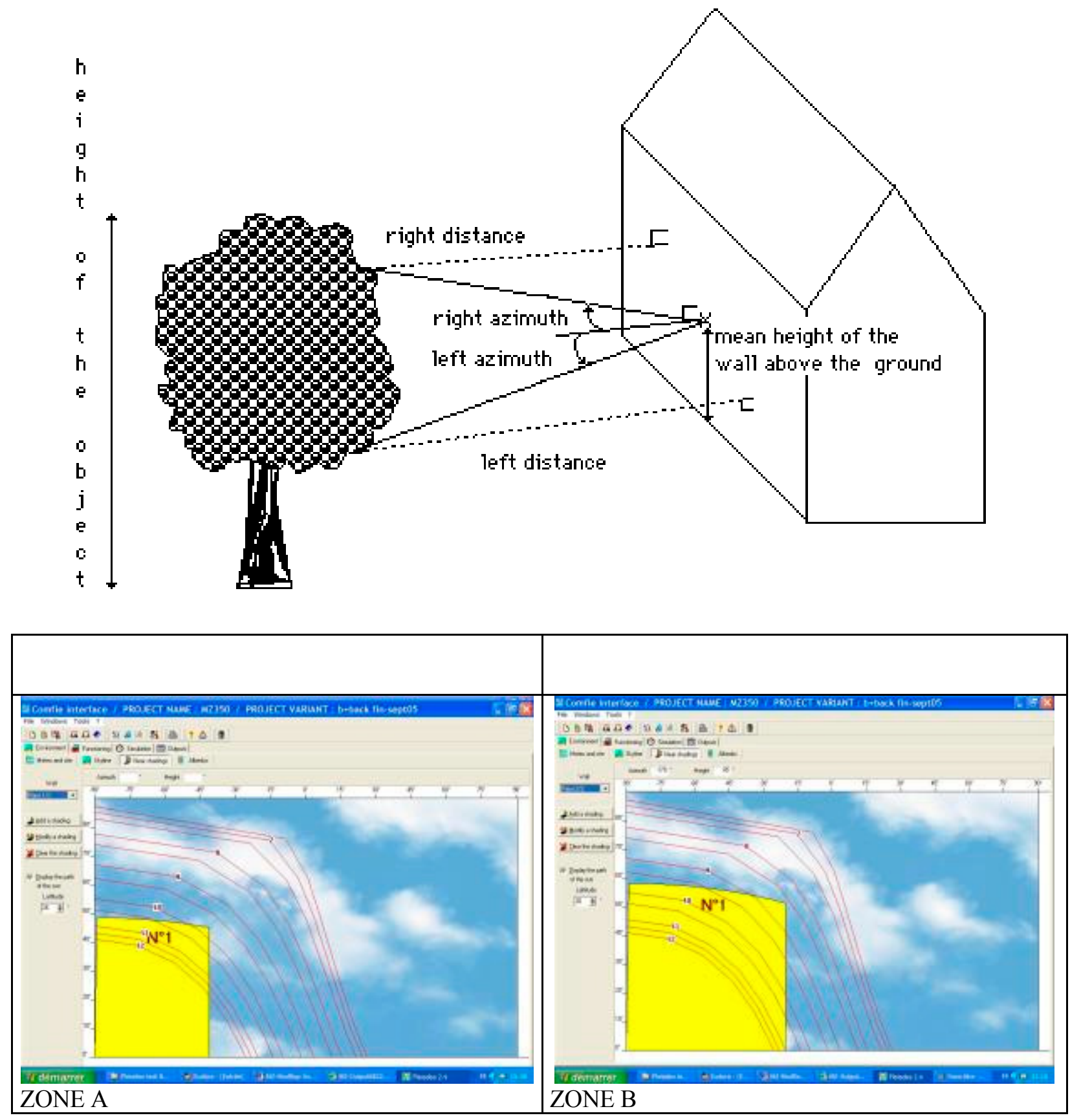


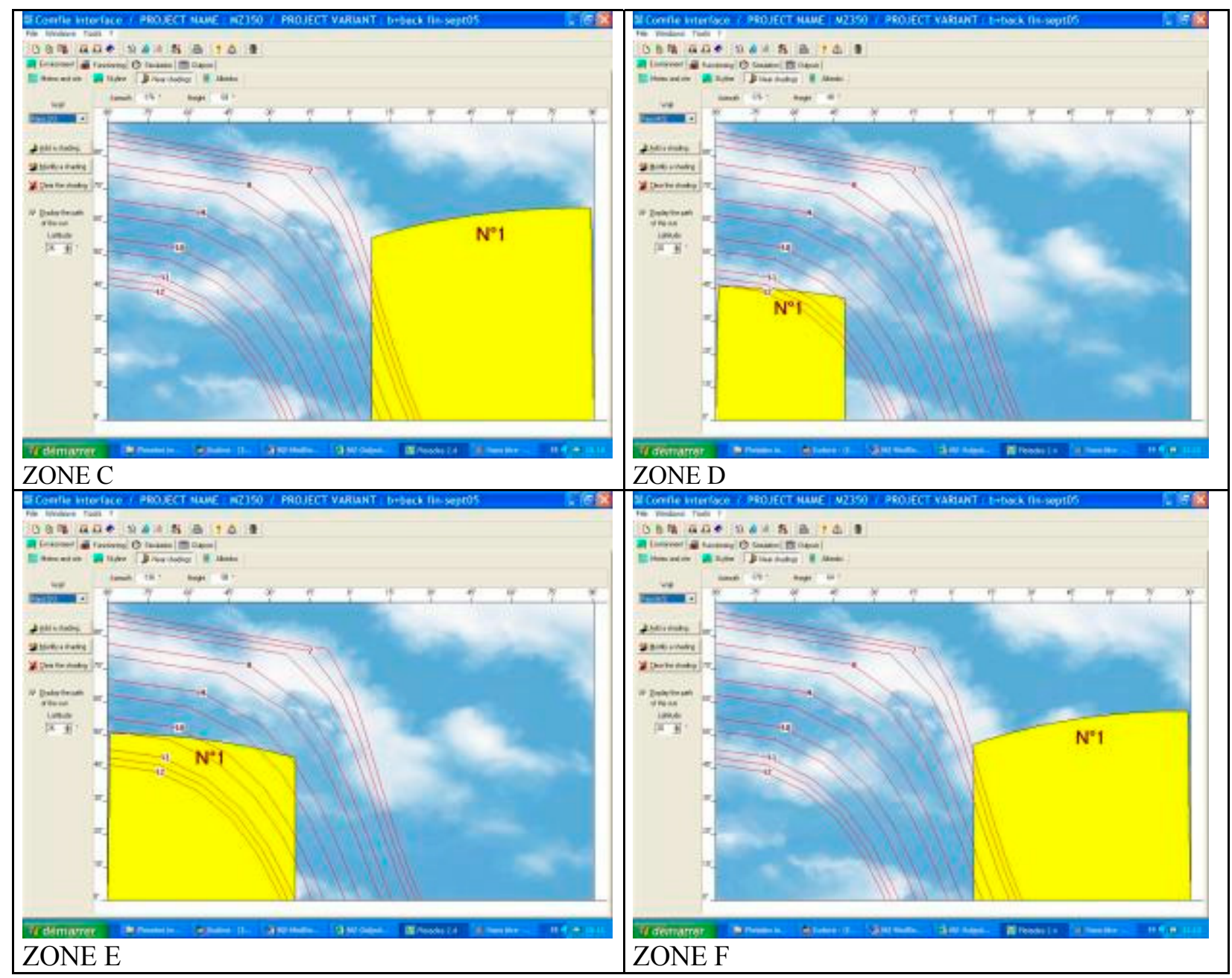

Case MZ350c

The possibility to model a distant shading like a neighbouring building does not apply in our software to a shading fin attached to a wall (cf. next picture): it would be necessary to change the description for each window because the azimuth angles would vary. 


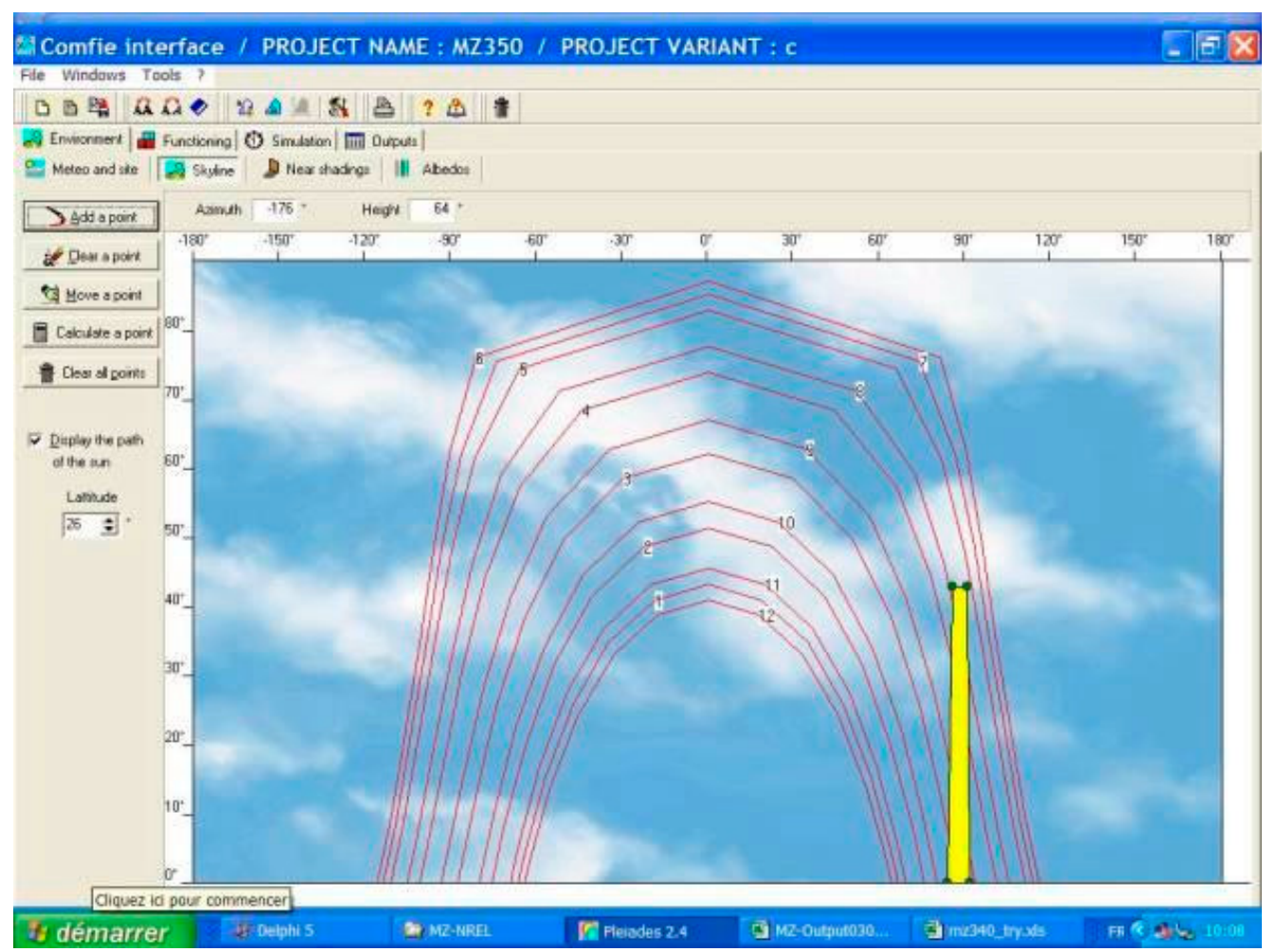

Therefore case MZ $350 \mathrm{c}$ has not been performed: we have only studied the most appropriate way to describe a vertical fin in our software : MZ $350 \mathrm{~b}$.

The case MZ 360 is also very specific : in practice solar radiation enters very rarely a room through three successive windows. Our model is limited to 2 successive glazing, e.g. the first glazing corresponds to the external glazing of a sunspace or a double skin façade, the second glazing corresponds to a window between this sunspace (or double skin space) and the adjacent zone. We would prefer to perform a validation exercise in such a case.

\section{Software Errors Discovered and Comparison between Different Versions of the Same Software}

We would not like to allow the user to choose surface heat transfer coefficients because is would make the interface more complex for professional users and we think that this is not necessary. 


\section{Results}

[Editor's note. These results are for the August 2005 version of the test specification; only COMFIE results for Case MZ320 are included in Part III.]

MZ 320

\begin{tabular}{|c|c|c|c|c|}
\hline & & \multicolumn{3}{|c|}{$\begin{array}{l}\text { MZ320 Steady State } \\
\text { Results }\end{array}$} \\
\hline & & & & Cooling \\
\hline & & \multicolumn{2}{|c|}{$\begin{array}{c}\text { Zone Air } \\
\text { Temperatures }\end{array}$} & Load \\
\hline & $\mathbf{T}_{\mathrm{A}}$ & $T_{B}$ & $\mathbf{T}_{\mathrm{C}}$ & $\mathbf{q}_{\mathrm{C}}$ \\
\hline Case & $\left({ }^{\circ} \mathrm{C}\right)$ & $\left({ }^{\circ} \mathrm{C}\right)$ & $\left({ }^{\circ} \mathrm{C}\right)$ & (W or $\mathrm{Wh} / \mathrm{h}$ ) \\
\hline MZ320 & 31,06 & 24,8 & 15 & 1541 \\
\hline
\end{tabular}

The surface temperatures are not calculated in COMFIE-PLEIADES : the comfort indication is provided by a zone temperature (combination of surface and air temperatures).

MZ $340-$ MZ 350 b - MZ 355

\begin{tabular}{|c|c|c|c|c|c|c|c|}
\hline \multicolumn{8}{|c|}{ Annual Cooling Loads } \\
\hline & QBldg & QA & QB & QC & QD & $\mathrm{QE}$ & $\mathrm{QF}$ \\
\hline Case & $(\mathrm{kWh})$ & $(\mathrm{kWh})$ & $(\mathrm{kWh})$ & $(\mathrm{kWh})$ & $(\mathrm{kWh})$ & $(\mathrm{kWh})$ & $(\mathrm{kWh})$ \\
\hline MZ340 & 27892 & 4649 & 4649 & 4649 & 4649 & 4649 & 4649 \\
\hline \multicolumn{8}{|l|}{ MZ350a } \\
\hline $\mathrm{MZ350b}$ & 21194 & 3756 & 2910 & 3780 & 3867 & 3032 & 3849 \\
\hline \multicolumn{8}{|l|}{ MZ350c } \\
\hline \multicolumn{8}{|l|}{ MZ350d } \\
\hline MZ355 & & & & $\mathrm{n} / \mathrm{a}$ & & & $\mathrm{n} / \mathrm{a}$ \\
\hline MZ360 & & & & & $\mathrm{n} / \mathrm{a}$ & $\mathrm{n} / \mathrm{a}$ & $\mathrm{n} / \mathrm{a}$ \\
\hline
\end{tabular}

Only the total radiation is an output, therefore we cannot provide separate values for beam and diffuse.

\begin{tabular}{|l|l|l|l|l|l|l|l|}
\hline & $\begin{array}{l}\text { West* } \\
\text { Incident } \\
\text { Solar }\end{array}$ & \multicolumn{9}{l|}{ Transmitted Solar Radiation } \\
\hline & IA & Itr,A & Itr,B & Itr,C & Itr,D & Itr,E & Itr,F \\
\hline Case & $(\mathrm{kWh} / \mathrm{m} 2)$ & $(\mathrm{kWh})$ & $(\mathrm{kWh})$ & $(\mathrm{kWh})$ & $(\mathrm{kWh})$ & $(\mathrm{kWh})$ & $(\mathrm{kWh})$ \\
\hline MZ340 & 773 & 4636 & 4636 & 4636 & 4636 & 4636 & 4636 \\
\hline MZ350a & n/a & & & & & & \\
\hline MZ350b & n/a & 3745 & 2902 & 3770 & 3857 & 3024 & 3839 \\
\hline MZ350c & n/a & & & & & & \\
\hline MZ350d & n/a & & & & & & \\
\hline MZ355 & n/a & & & n/a & & & n/a \\
\hline MZ360 & & & & & n/a & n/a & n/a \\
\hline
\end{tabular}


An ideal controller has been modelled.

\begin{tabular}{|l|l|l|l|l|l|l|}
\hline \multicolumn{2}{|l|}{ Annual Average Zone Temperatures } & TB & TC & TD & TE & TF \\
\hline & TA & TB & $\left({ }^{\circ} \mathrm{C}\right)$ & $\left({ }^{\circ} \mathrm{C}\right)$ & $\left({ }^{\circ} \mathrm{C}\right)$ & $\left({ }^{\circ} \mathrm{C}\right)$ \\
\hline Case & $\left({ }^{\circ} \mathrm{C}\right)$ & 20 & 20 & 20 & 20 \\
\hline MZ340 & 20 & 20 & 20 & & & \\
\hline MZ350a & & & & 20 & 20 & 20 \\
\hline MZ350b & 20 & 20 & 20 & & & \\
\hline MZ350c & & & & & & \\
\hline MZ350d & & & n/a & & n/a \\
\hline MZ355 & & & & n/a & n/a & n/a \\
\hline MZ360 & & & & & & \\
\hline
\end{tabular}

\begin{tabular}{|l|l|l|l|l|l|l|l|}
\hline & $\mathrm{qBldg}$ & $\mathrm{qA}$ & $\mathrm{qB}$ & $\mathrm{qC}$ & $\mathrm{qD}$ & $\mathrm{qE}$ & $\mathrm{qF}$ \\
\hline Case & $(\mathrm{Wh} / \mathrm{h})$ & $(\mathrm{Wh} / \mathrm{h})$ & $(\mathrm{Wh} / \mathrm{h})$ & $(\mathrm{Wh} / \mathrm{h})$ & $(\mathrm{Wh} / \mathrm{h})$ & $(\mathrm{Wh} / \mathrm{h})$ & $(\mathrm{Wh} / \mathrm{h})$ \\
\hline MZ340 & 26522 & 4422 & 4421 & 4421 & 4420 & 4419 & 4419 \\
\hline MZ350a & & & & & & & \\
\hline MZ350b & 25649 & 4388 & 4272 & 4362 & 4388 & 4275 & 4364 \\
\hline MZ350c & & & & & & & \\
\hline MZ350d & & & & & & & \\
\hline MZ355 & & & & n/a & & & n/a \\
\hline MZ360 & & & & & n/a & n/a & n/a \\
\hline
\end{tabular}

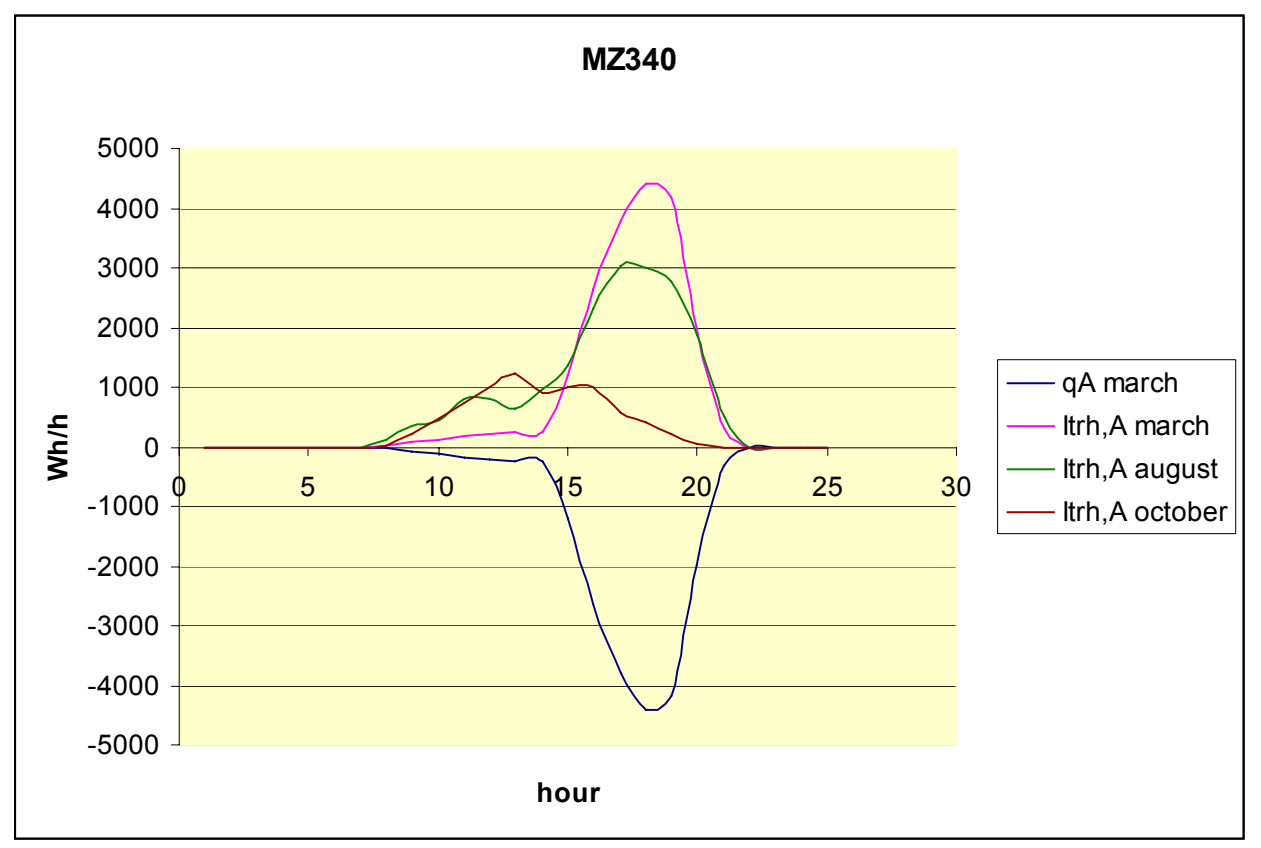




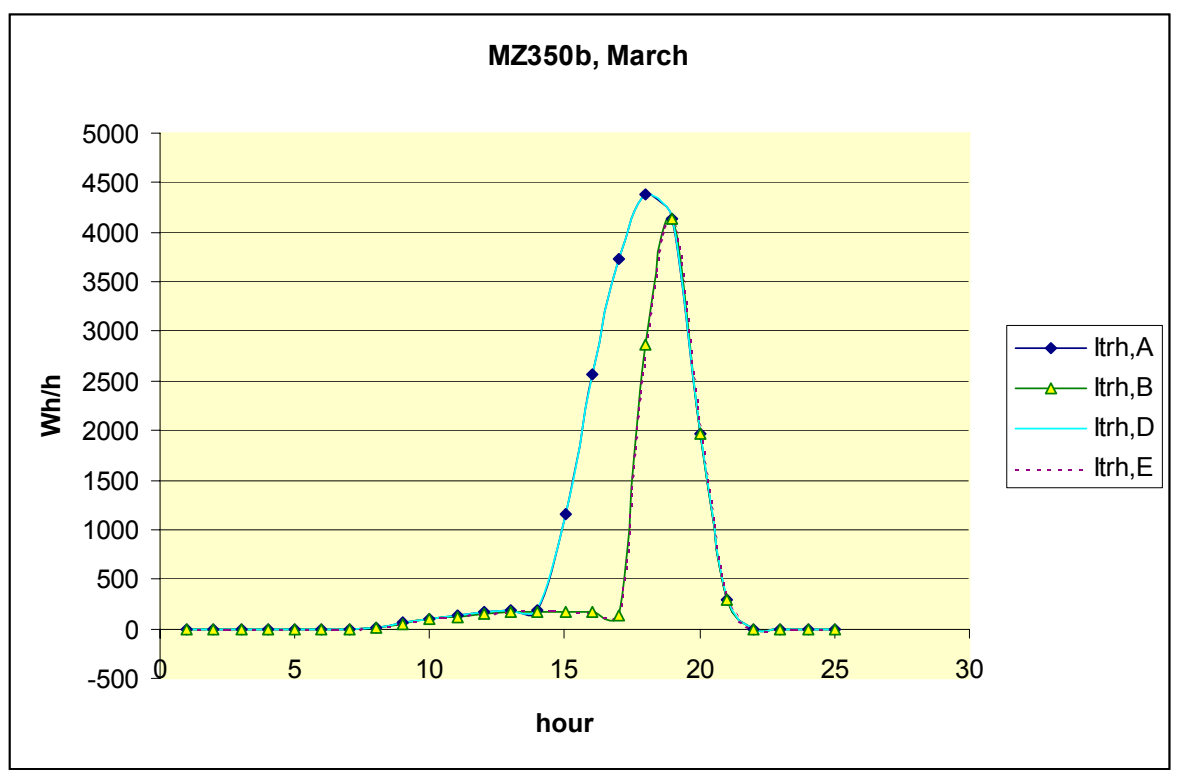

7. Other (optional)

\section{Conclusions and Recommendations}

COMFIE could be improved by asking the height and reflexion coefficient of a shading fin attached to a window.

\section{References}

Bruno Peuportier and Isabelle Blanc Sommereux, Simulation tool with its expert interface for the thermal design of multizone buildings , International Journal of Solar Energy, 1990.

Bruno Peuportier and Isabelle Blanc Sommereux, COMFIE users manual, Ecole des Mines de Paris, 1994. 


\title{
Appendix II-I
}

\section{Modeler Report for BESTEST Cases MZ320 - MZ360 \\ KoZiBu}

\author{
by \\ Jean Noel \\ JNLOG \\ France
}

\section{Introduction}

\section{March 2005}

KoZiBu (CoDyBa) is a software, jointly developed by the CETHIL (INSA-Lyon Thermal Center) and a freelance engineer, without any state help. It is aimed for design offices, teaching and research organizations.

The software is used to determinate the heat flows in a building. It permits to estimate the instant heating or cooling powers needed to maintain a given set-point, or to calculate the interior temperatures when the heating or cooling system is insufficient. Humidity is treated in the same way.

The tool is aimed to conduct studies of heating and cooling strategy, air conditioning or ventilation options, insulating materials to be installed. The room occupancy is included. The software does not permit the study of the dynamic behaviour of a set of technological components : the main objective is to forecast the energy consumption and temperature evolution range.

$\mathrm{KoZiBu}$ runs on classical PC. The building is described accurately and the building description is given by the use of a graphical interface. KoZiBu is based on simply bricks assembled to form a complex building with its equipment. The assembly is conducted in a form to minimise data size and calculation time. The physical models of KoZiBu are those commonly admitted, but numerical algorithms are specific.

The organization that wrote the old version of the software (until 1995) is :

\section{CETHIL - ETB}

INSA de Lyon - Bât. Freyssinet

40 avenue des Arts

69100 Villeurbanne

France

The software is now developed by a free-lance, and its future name is $\mathrm{KoZiBu} \mathrm{:}$

\section{Jean NOEL (JNLOG)}

15 place Carnot

69002 Lyon

France

Web site : http://www.jnlog.com

Mel : contact@jnlog.com

The time step used in the calculation is 15 minutes. 


\section{Modeling Assumptions}

For all materials :

$$
\begin{aligned}
& \text { conductivity }=0.00001 \mathrm{~W} / \mathrm{m} . \mathrm{K} \\
& \text { capacity }=0.1 \mathrm{~J} / \mathrm{K} . \mathrm{kg} \\
& \text { density }=0.1 \mathrm{~kg} / \mathrm{m}^{3}
\end{aligned}
$$

\section{Modeling Options}

No options, standard version is used.

\section{Modeling Difficulties}

Data were introduced as described in the document.

\section{Software Errors Discovered and Comparison between Different Versions of the Same Software}

No error was discovered for the moment.

\section{Results}

It seems that the fact that walls with no mass are present conducts to some numerical instabilities. I will do more trials to better understand this possible problem.

7. Other (optional)

\section{Conclusions and Recommendations}

\section{References}




\subsection{Part III: Simulation Field Trial Results}

\subsection{Introduction}

Here we present the simulation results for the field trials of cases MZ320 through MZ360; see Section 3.4 for graphs and tables. These are results after numerous iterations to incorporate clarifications to the test specification, simulation input deck corrections, and simulation software improvements. Where improvements to simulation programs or simulation inputs were made as a result of running the tests, such improvements must have mathematical and physical bases and must be applied consistently across tests. Also, all improvements were required to be documented in modeler reports (see Part II, Section 2.9). Arbitrary modification of a simulation program's input or internal code just for the purpose of more closely matching a given set of results is not allowed. The diagnostic process of trapping bugs discussed in Section 2.4 of Part II also isolated input errors that were corrected, as noted there and in the modeler reports.

Table 3-1 summarizes the following information for the nine programs that were used to generate the simulation results: model-authoring organization, model testing organization ("Implemented by"), and abbreviation labels used in the results graphs and tables. For three of the programs final results were generated only for Case MZ320, as noted in Table 3-1. For cases MZ340 through MZ360 the VA114 modelers provided results for two different modeling approaches for shading and solar radiation transmission through windows: modeling circumsolar diffuse radiation as beam radiation ("VA114-CirBm"), and modeling circumsolar diffuse radiation as diffuse radiation ("VA114-CirDf").

An electronic version of the results is included with the accompanying files MZ-ResultsAnnuals.xls and MZ- RESULTS-Hourlies.XLS, for annual and hourly results respectively. Navigation instructions are included with Sheet A within each of those files.

\subsection{Zone Cooling Load Versus Transmitted Solar Radiation Results for Cases MZ340 through MZ360}

For cases MZ340, MZ350, and MZ355, zone cooling load should be equal to the transmitted total (direct + diffuse) solar radiation because the test cases specify zones that act as calorimeters with: ideal glass (solar transmittance $=1$ for all solar incidence angles, and thermal conductance $=0$ ) and ideal walls (interior solar absorptance $=1$, thermal conductance $=0$ ). Similarly for Case MZ360, total building cooling load should be equal to total solar radiation transmitted through the exterior window (Window AO).

For whole-building simulation programs that do not disaggregate transmitted total solar radiation in their output, zone cooling load results are directly comparable to the transmitted total (direct + diffuse) solar radiation results for cases MZ340, MZ350, and MZ355. Similarly, for Case MZ360, total building cooling load is comparable to total transmitted solar radiation through window AO. Minor differences in zone cooling load versus total transmitted solar radiation may occur if a simulation program: cannot model strictly zero-conductance walls and ceilings, but rather is applying the lowest thermal conductance the simulation allows; does not have perfect iterative tolerance limits; etc. 
Table 3-1. Participating Organizations and Models

\begin{tabular}{|c|c|c|c|}
\hline $\begin{array}{l}\text { Simulation } \\
\text { Program }\end{array}$ & Authoring Organization & Implemented by & Abbreviation \\
\hline $\begin{array}{l}\text { EnergyPlus } \\
2.1 .0 .012\end{array}$ & $\begin{array}{l}\text { LBNL/UIUC/DOE-BT, }{ }^{\mathrm{a}, \mathrm{b}, \mathrm{c}} \text { United } \\
\text { States }\end{array}$ & $\begin{array}{l}\text { GARD Analytics, Inc., United } \\
\text { States }\end{array}$ & EnergyPlus/GARD \\
\hline ESP-r & ESRU, ${ }^{d}$ United Kingdom & ESRU, ${ }^{d}$ United Kingdom & ESP-r/ESRU \\
\hline HTB2 & WSA, ${ }^{e}$ United Kingdom & WSA, ${ }^{e}$ United Kingdom & HTB2/WSA \\
\hline TRNSYS-TUD & $\begin{array}{l}\text { University of Wisconsin/Dresden } \\
\text { University of Technology, United } \\
\text { States/Germany }\end{array}$ & $\begin{array}{l}\text { Dresden University of } \\
\text { Technology, Germany }\end{array}$ & TRNSYS-TUD/TUD \\
\hline TRNSYS-16 & $\begin{array}{l}\text { University of Wisconsin, United } \\
\text { States }\end{array}$ & University of Liège, Belgium & TRNSYS-16/ULg \\
\hline VA114 2.25 & $\begin{array}{l}\text { VABI Software BV, The } \\
\text { Netherlands }\end{array}$ & $\begin{array}{l}\text { VABI Software BV, The } \\
\text { Netherlands }\end{array}$ & $\begin{array}{l}\text { VA114-CirBm/VABI } \\
\text { VA114-CirDf/VABI }\end{array}$ \\
\hline $\begin{array}{l}\text { Simulation } \\
\text { Program } \\
\text { (MZ320 Only) }\end{array}$ & Authoring Organization & Implemented by & Abbreviation \\
\hline CODYRUN & $\begin{array}{l}\text { University of Reunion Island, } \\
\text { France }\end{array}$ & $\begin{array}{l}\text { University of Reunion Island, } \\
\text { France }\end{array}$ & UR \\
\hline COMFIE & EdMP/IZUBA ${ }^{\mathrm{f}, \mathrm{g}}$ France & EdMP, ${ }^{f}$ France & EdMP \\
\hline KoZiBu & INSA-Lyon/JNLOG, & JNLOG, ${ }^{i}$ France & JNLOG \\
\hline
\end{tabular}

aLBNL: Lawrence Berkeley National Laboratory, United States

bUIUC: University of Illinois Urbana/Champaign, United States

'DOE-BT: U.S. Department of Energy, Office of Building Technologies, Energy Efficiency and Renewable Energy, United States

${ }^{d}$ ESRU: Energy Systems Research Unit, University of Strathclyde, United Kingdom

'Welsh School of Architecture, Cardiff University, United Kingdom

fEcole des Mines de Paris, France

${ }^{9}$ IZUBA Energies, France

hINSA-Lyon Thermal Center, France

'Jean Noel, France

\subsection{Further Comments on Results for Multi-Zone Shading Cases MZ340, MZ350, and MZ355}

For the shading cases, the fundamental level of disagreement for transmitted solar radiation when a shading device is present begins with the disagreement for incident solar radiation, which is caused by differences among basic solar processing algorithms. The "delta" shading plots (for sensitivity cases MZ350-MZ340 and MZ355-MZ340) isolate differences among shading models. Absolute differences among programs in incident solar calculations tend to cancel out in this type of comparison. For comparison plots showing absolute transmitted solar radiation with shading present (cases MZ350 and MZ355), disagreements are related to both basic solar processing and shading models. 
Only EnergyPlus and VA114 were able to run Case MZ355 for building self-shading. For those cases the annual results shown in this section for zones A, B, D, and E match the results for Case MZ350 exactly, except for minor differences for VA114 that are noticeable in the tables but not in the graphs. For EnergyPlus the hourly results for Case MZ355 exactly match those for Case MZ350 (see MZ- RESULTS-Hourlies.XLS sheet tab "EnergyPlus"), and were unnecessary to include in the graphs because they would exactly overlay the MZ350 results. For VA114 the only instance where hourly results required for Case MZ355 do not exactly match those for Case MZ350 are for March 15, hour 16, for Zone A only. (Also see Section 2.4.4.7 and MZRESULTS-Hourlies.XLS sheet tabs "VA114-CirBm" and "VA114-CirDf".) These VA114 results are included in the graph with header "BESTEST Multi-Zone: MZ350-MZ340, Delta HighBeam-Day Shading, March 15 (high dn) Hourly Shaded Solar, Zone A (Less Shaded)." All other results for VA114 for Case MZ355 were unnecessary to include in the graphs because they would exactly overlay the VA114 MZ350 results.

\subsection{Results Graphs and Tables}

This section presents graphs of all results followed by results tables. A full set of hourly results graphs is provided; however, summary tables of hourly results are too cumbersome to provide in printed format here, but are available electronically in Sheet A of MZ-RESULTS-Hourlies.XLS. The results tables include dates and hours of occurrences for hourly maxima and minima; times of occurrence are not indicated in the graphs depicting hourly maxima and minima.

See Section 2.7 of Part II for definitions of the abbreviations and acronyms used in the graphs and tables. Case descriptions are summarized in Table 1-1 of Part I. 
IEA BESTEST Multi-Zone: MZ320

Steady-State Zone C Sensible Cooling Load

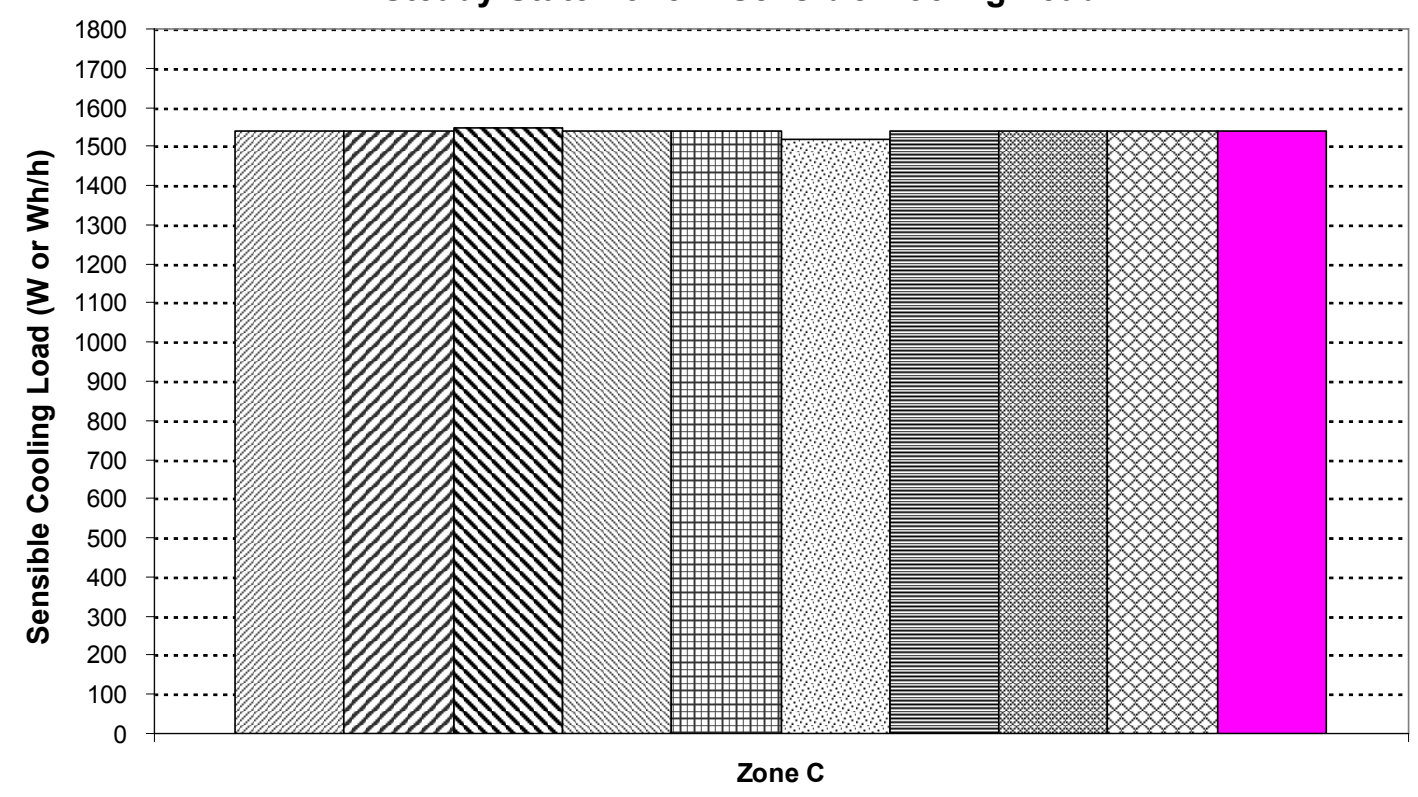

\begin{tabular}{|c|c|c|c|}
\hline 口HTB2/WSA & 口 TRNSYS-TUD/TUD & ه TRNSYS-16/ULg & 图 COMFIE/EdMP \\
\hline$\boxplus$ ESP-r/ESRU & ⿴囗大 CODYRUN/UR & 를 114 NABI & 图 EnergyPlus/GARD \\
\hline 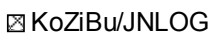 & $\square$ Analytical & & \\
\hline
\end{tabular}

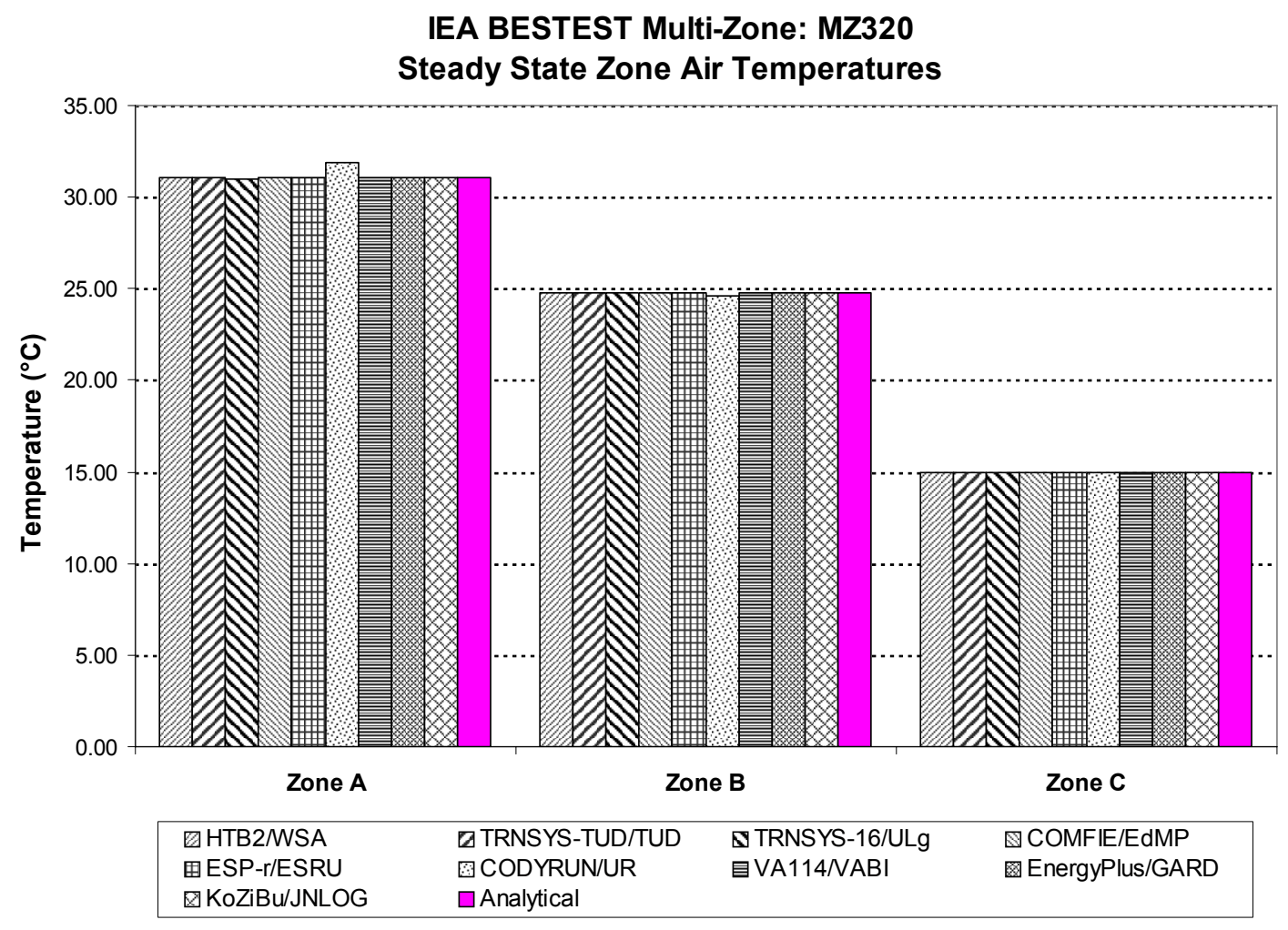


IEA BESTEST Multi-Zone: MZ340

Annual Incident Total Solar Radiation, Facing West

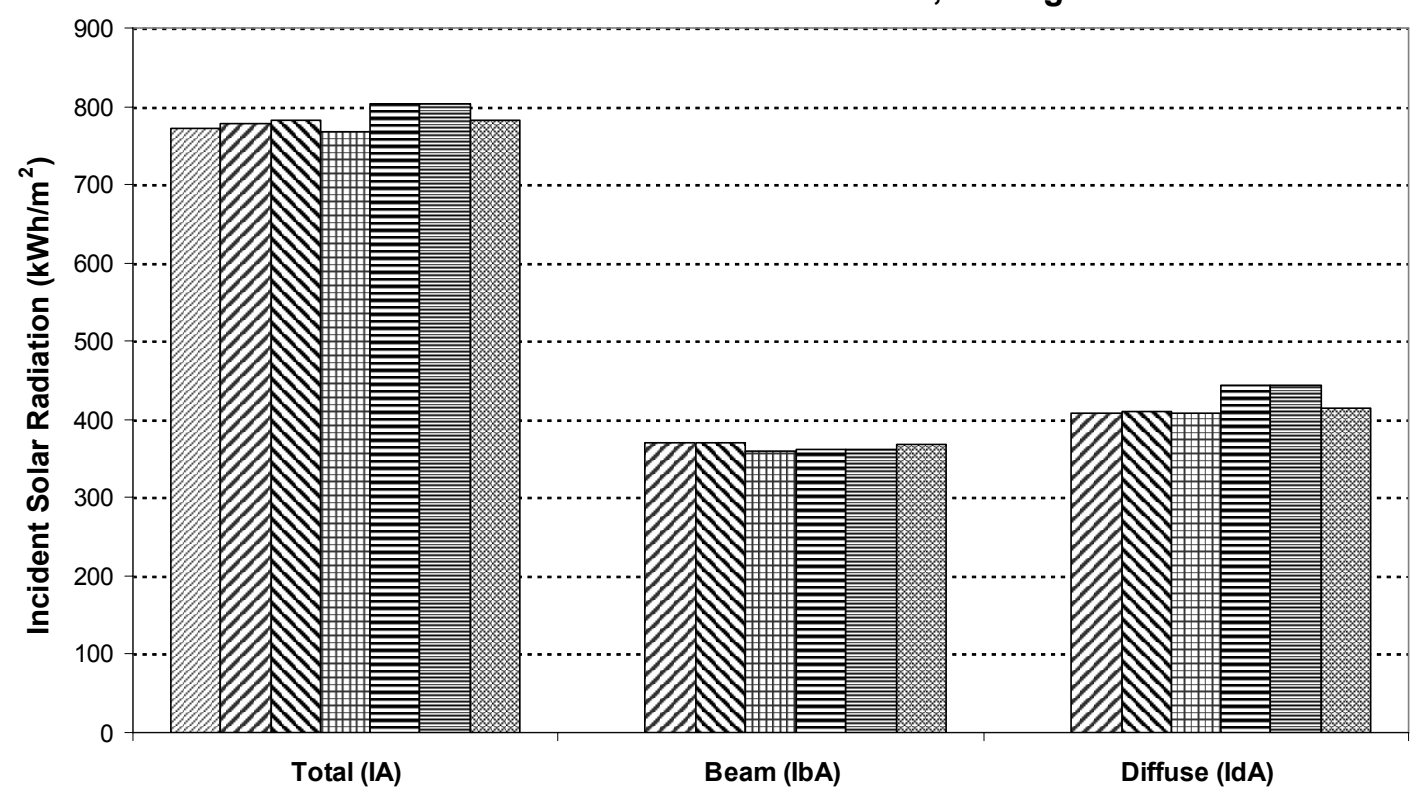

\begin{tabular}{|c|c|c|c|}
\hline 目TB2/WSA & 口TRNSYS-TUD/TUD & N TRNSYS-16/ULg & 田 ESP-r/ESRU \\
\hline$\exists$ VA114-CirBm/NABI & 目VA114-CirDf/VABI & ه EnergyPlus/GARD & \\
\hline
\end{tabular}

IEA BESTEST Multi-Zone: MZ340, MZ350, MZ355

Annual Transmitted TOTAL Solar Radiation, All Zones

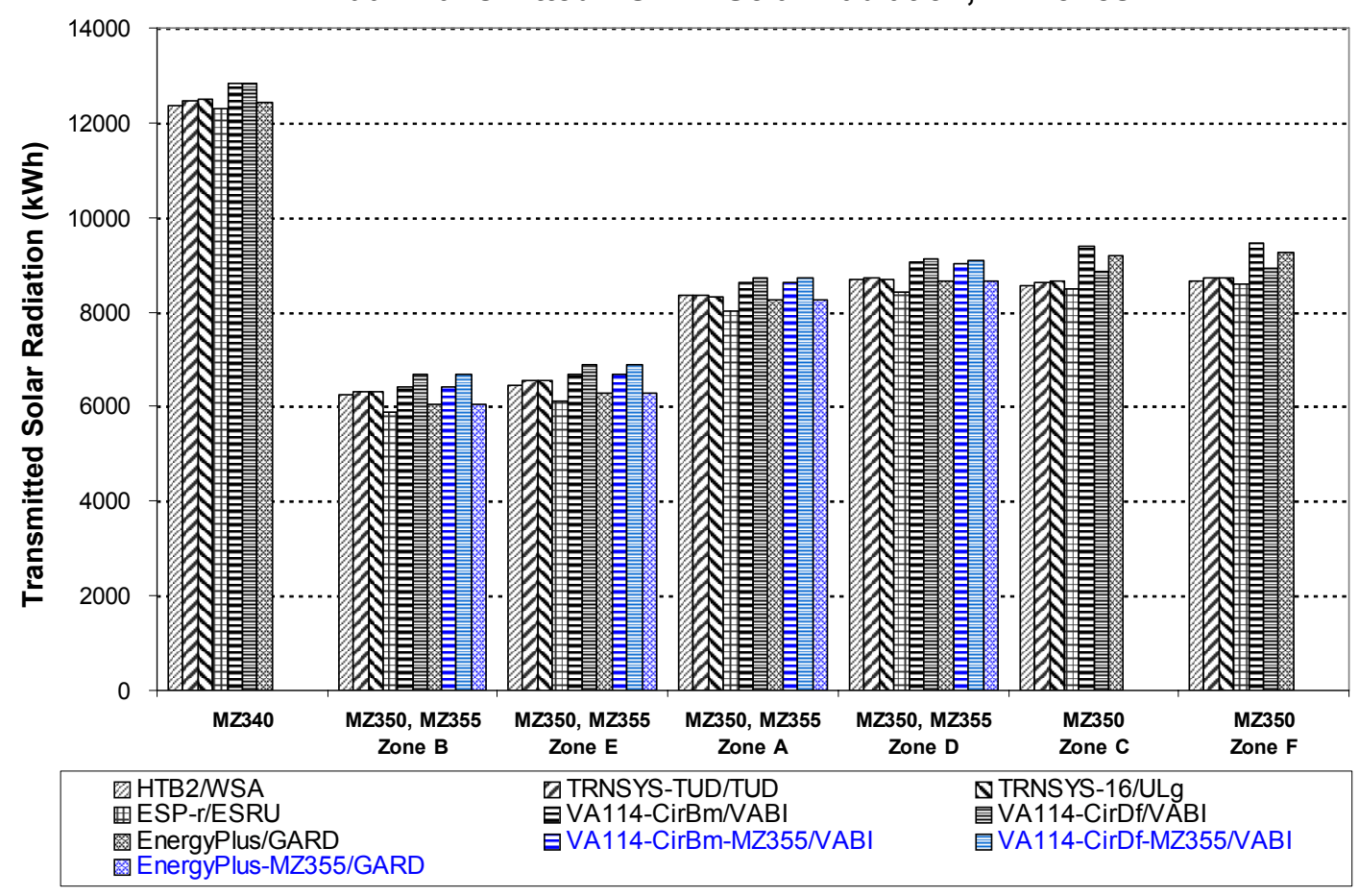


IEA BESTEST Multi-Zone: MZ340, MZ350, MZ355 Annual Transmitted BEAM Solar Radiation, All Zones

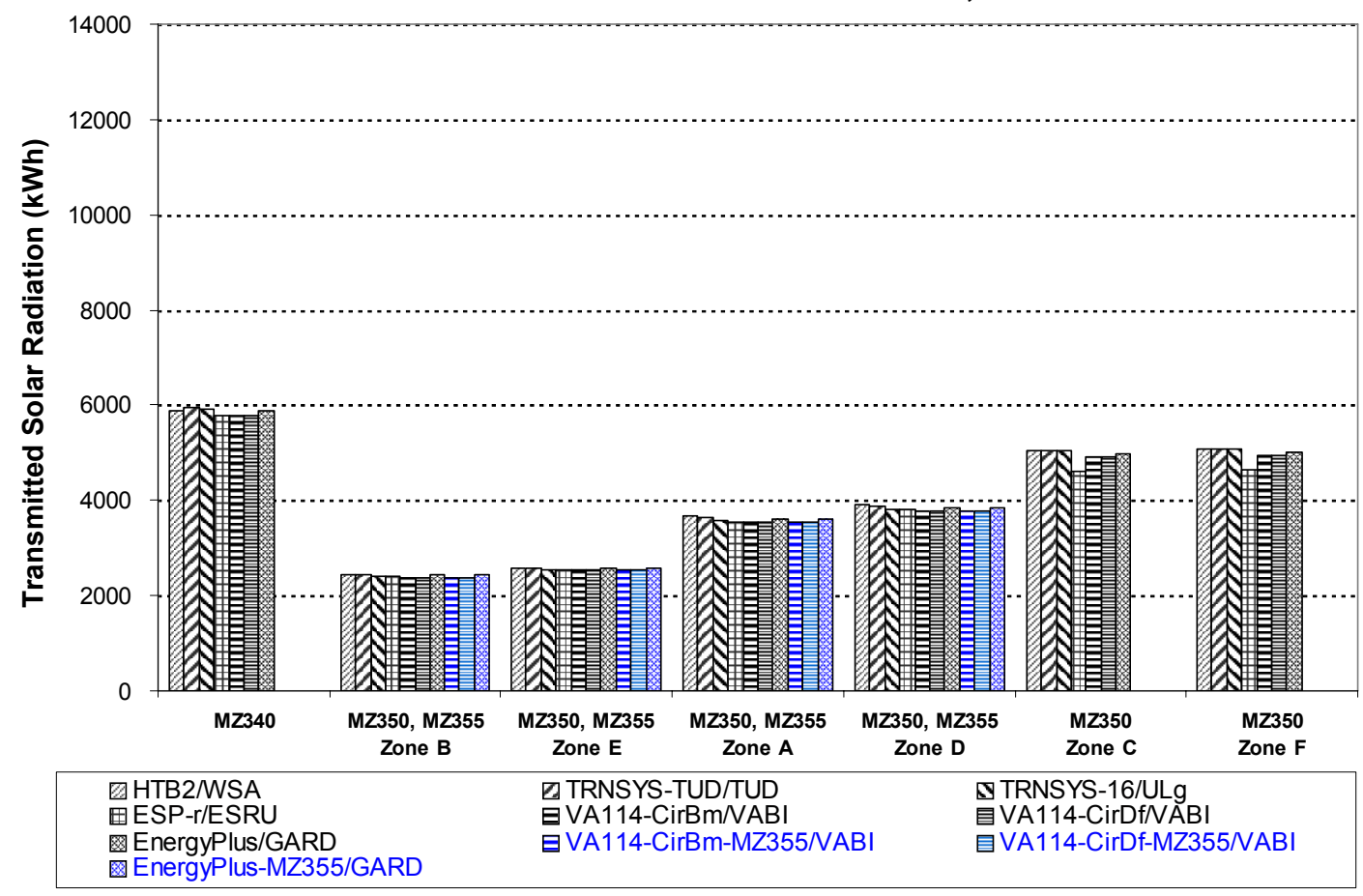

IEA BESTEST Multi-Zone: MZ340, MZ350, MZ355 Annual Transmitted DIFFUSE Solar Radiation, All Zones

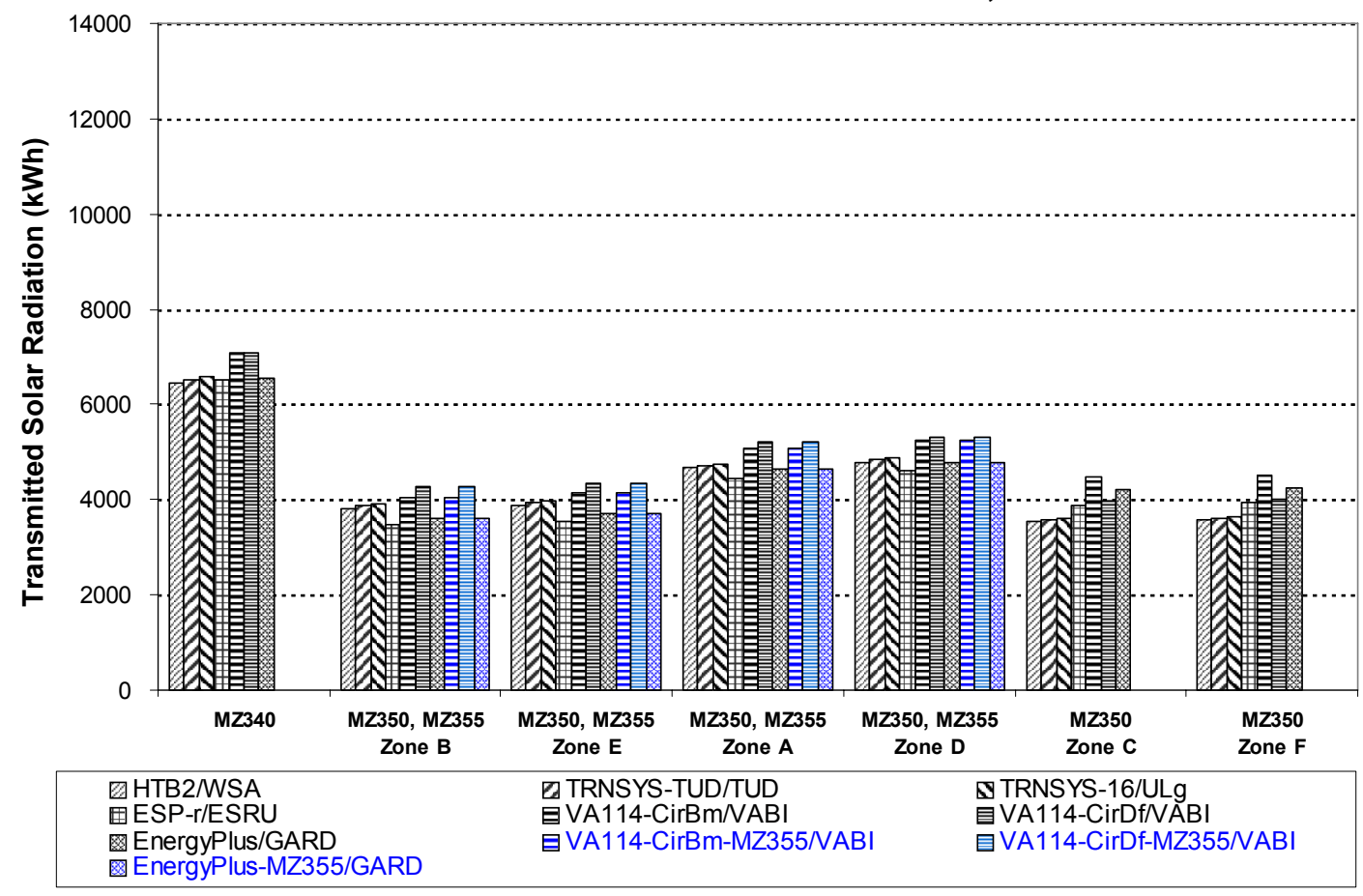


IEA BESTEST Multi-Zone: MZ340, MZ350, MZ355

Annual Sensible Cooling Load, All Zones

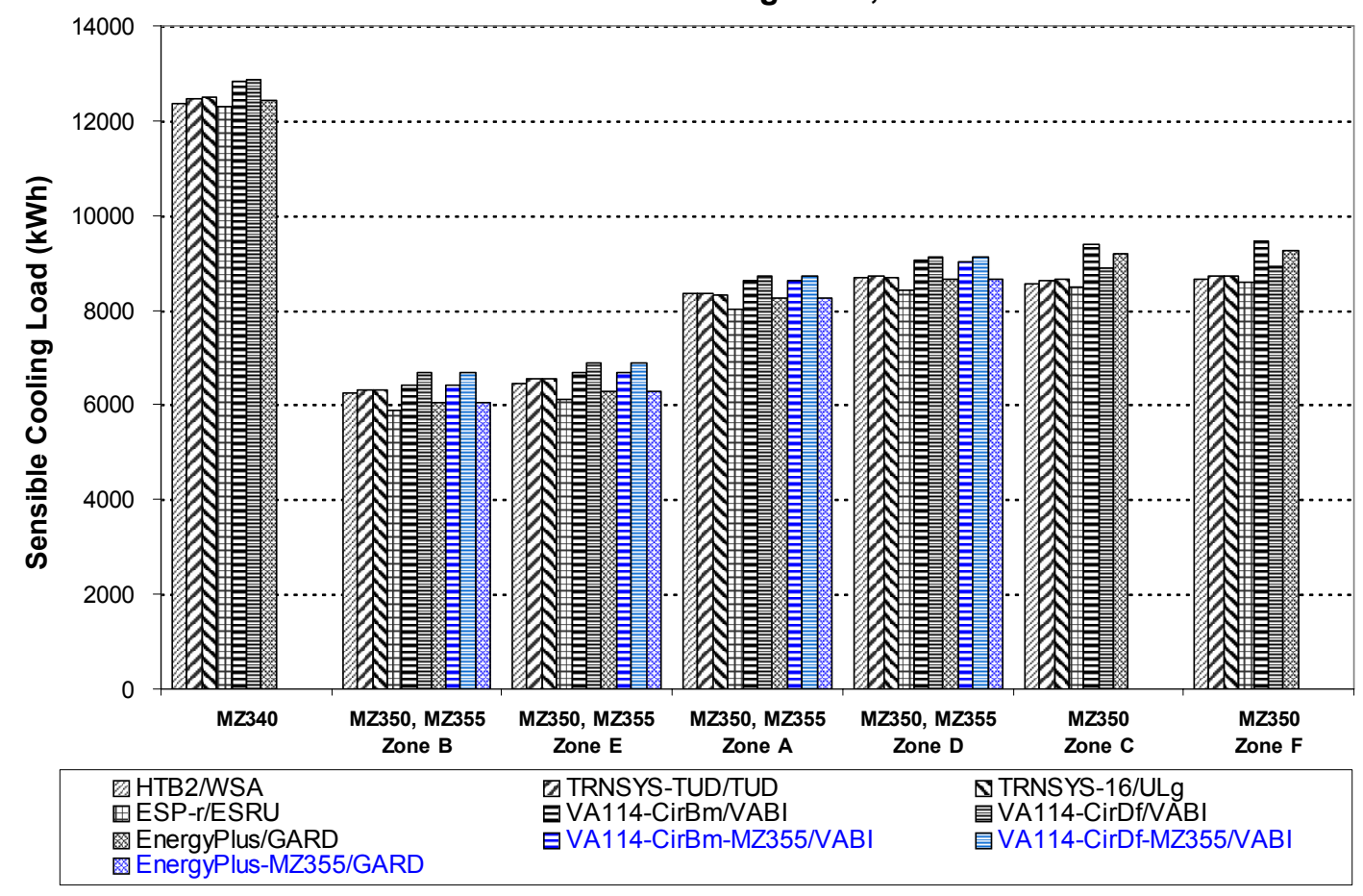

IEA BESTEST Multi-Zone: MZ340, MZ350, MZ355

Annual Sensible Cooling Load, Building

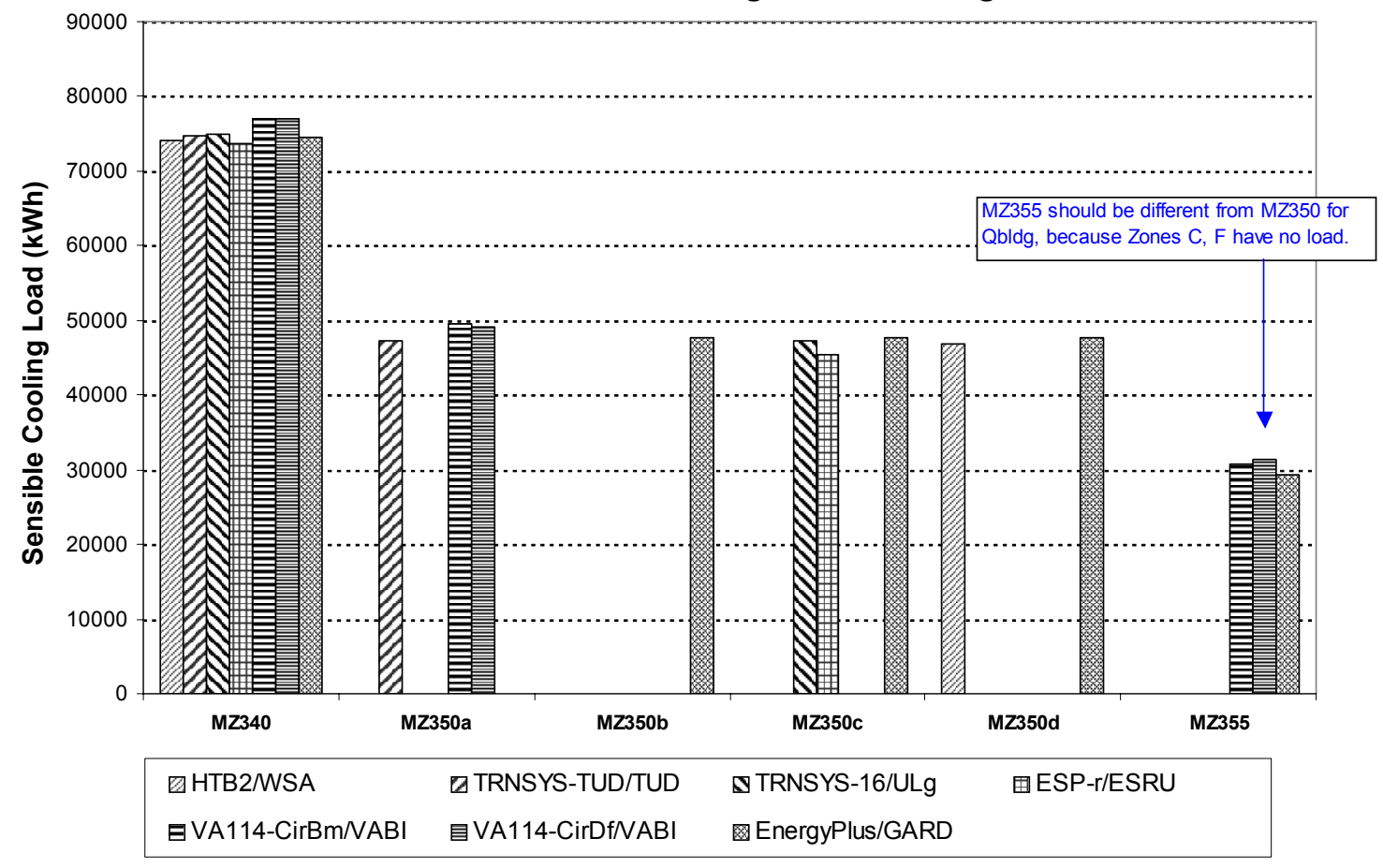




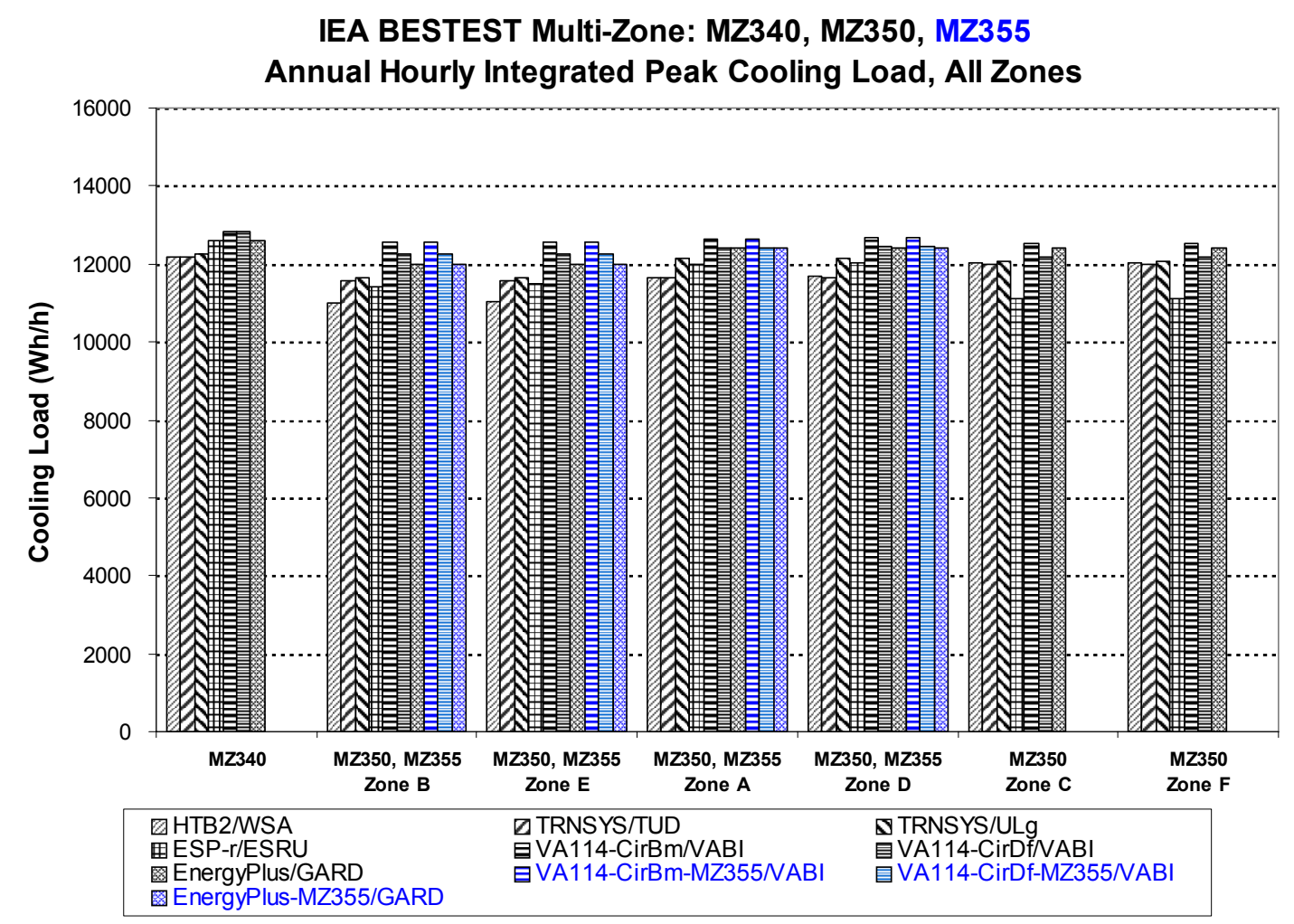

IEA BESTEST Multi-Zone: MZ340, MZ350, MZ355 Annual Hourly-Integrated Peak Sensible Cooling Load, Building

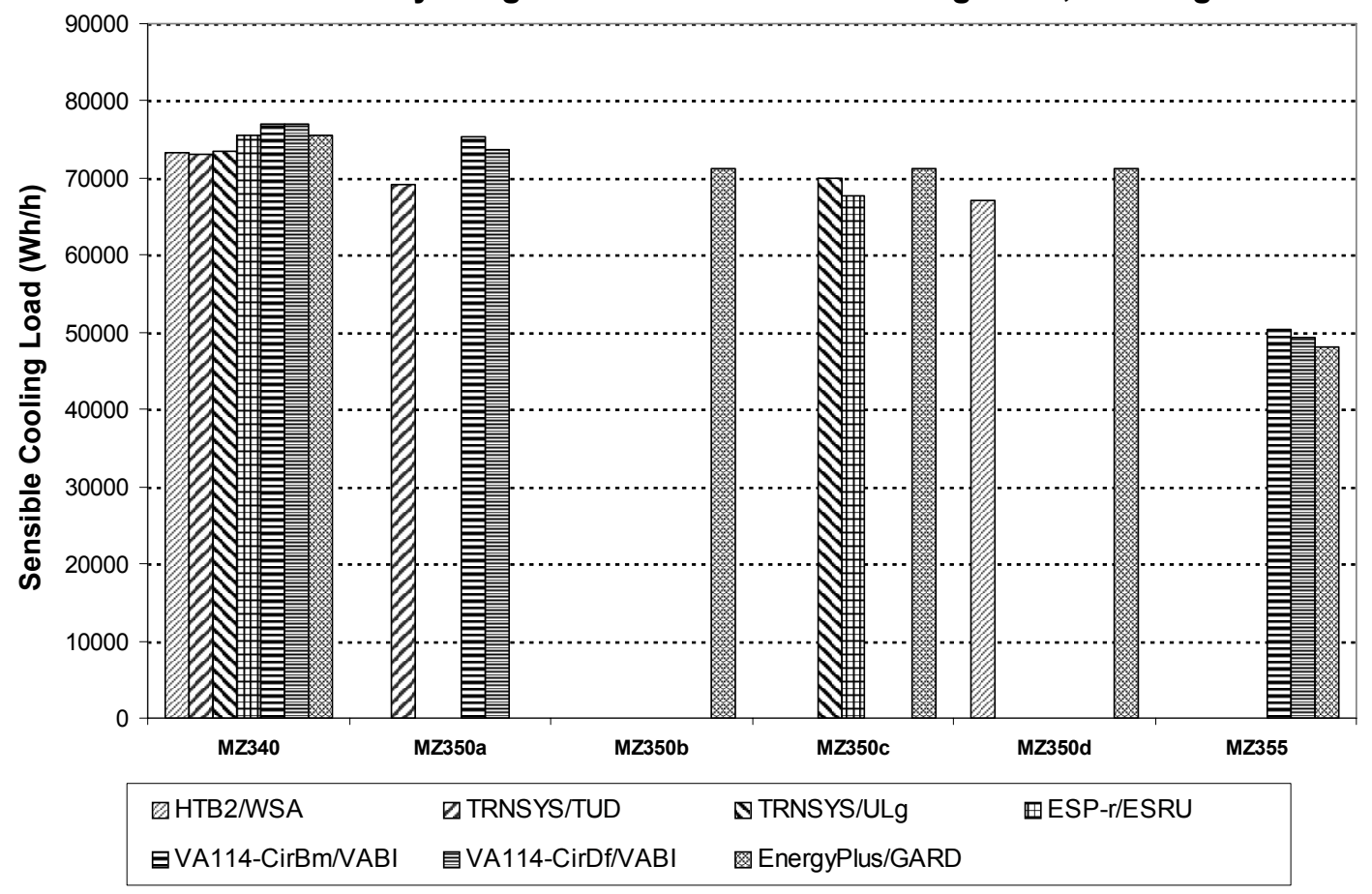


IEA BESTEST Multi-Zone: MZ340, MZ350, MZ355

Annual Mean Air Temperature, All Zones

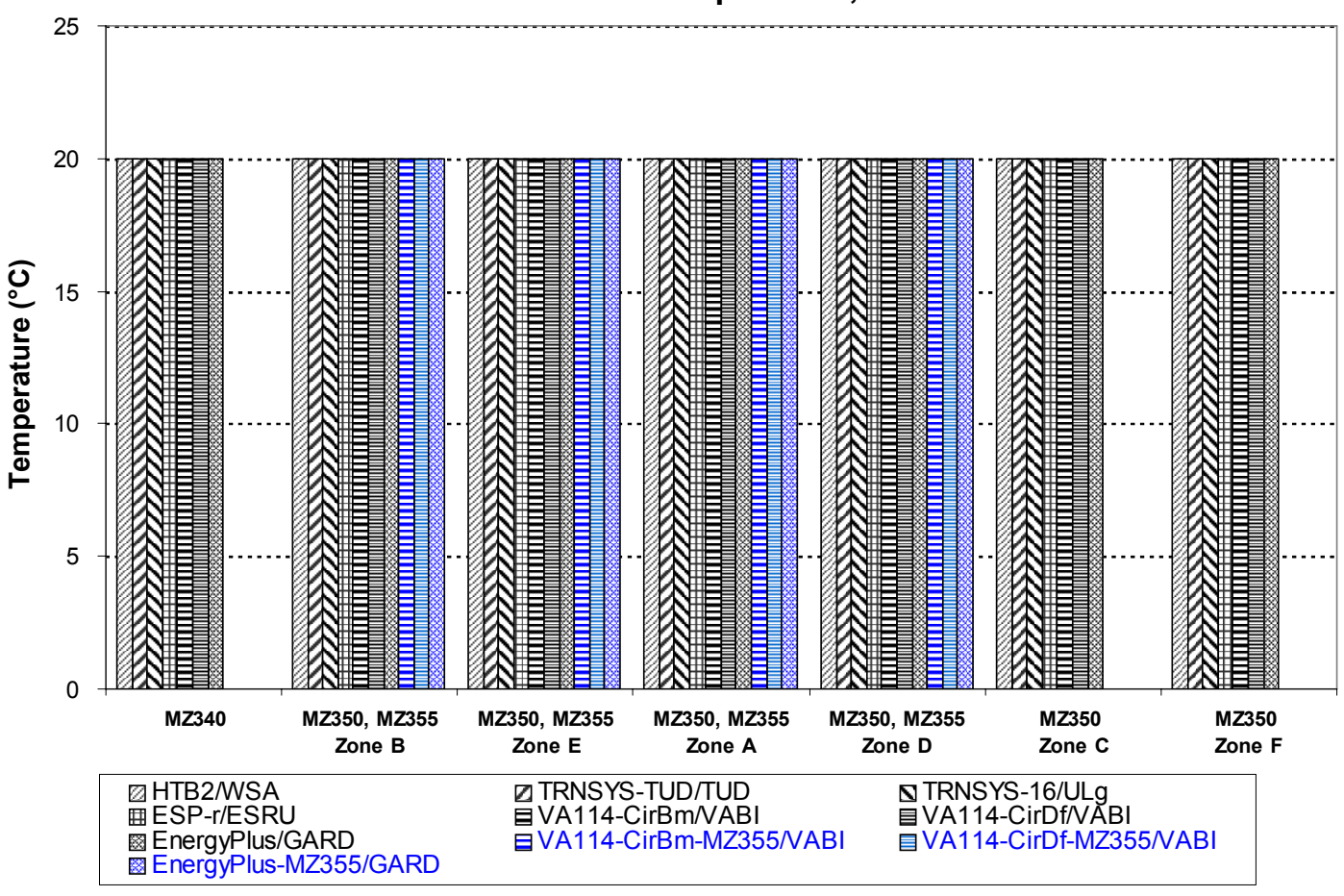

IEA BESTEST Multi-Zone: MZ340, MZ350, MZ355

Annual Maximum Air Temperature, All Zones

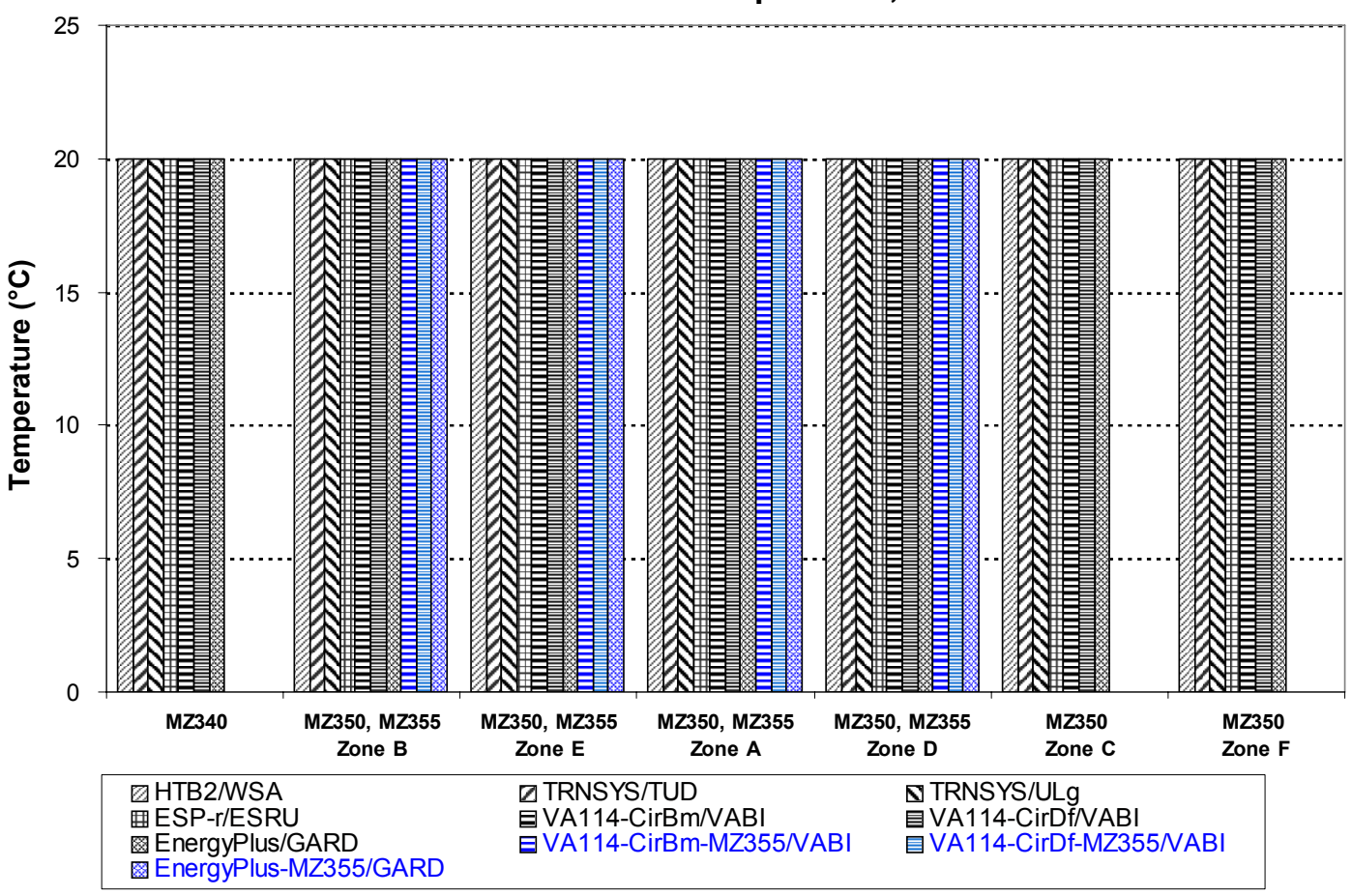



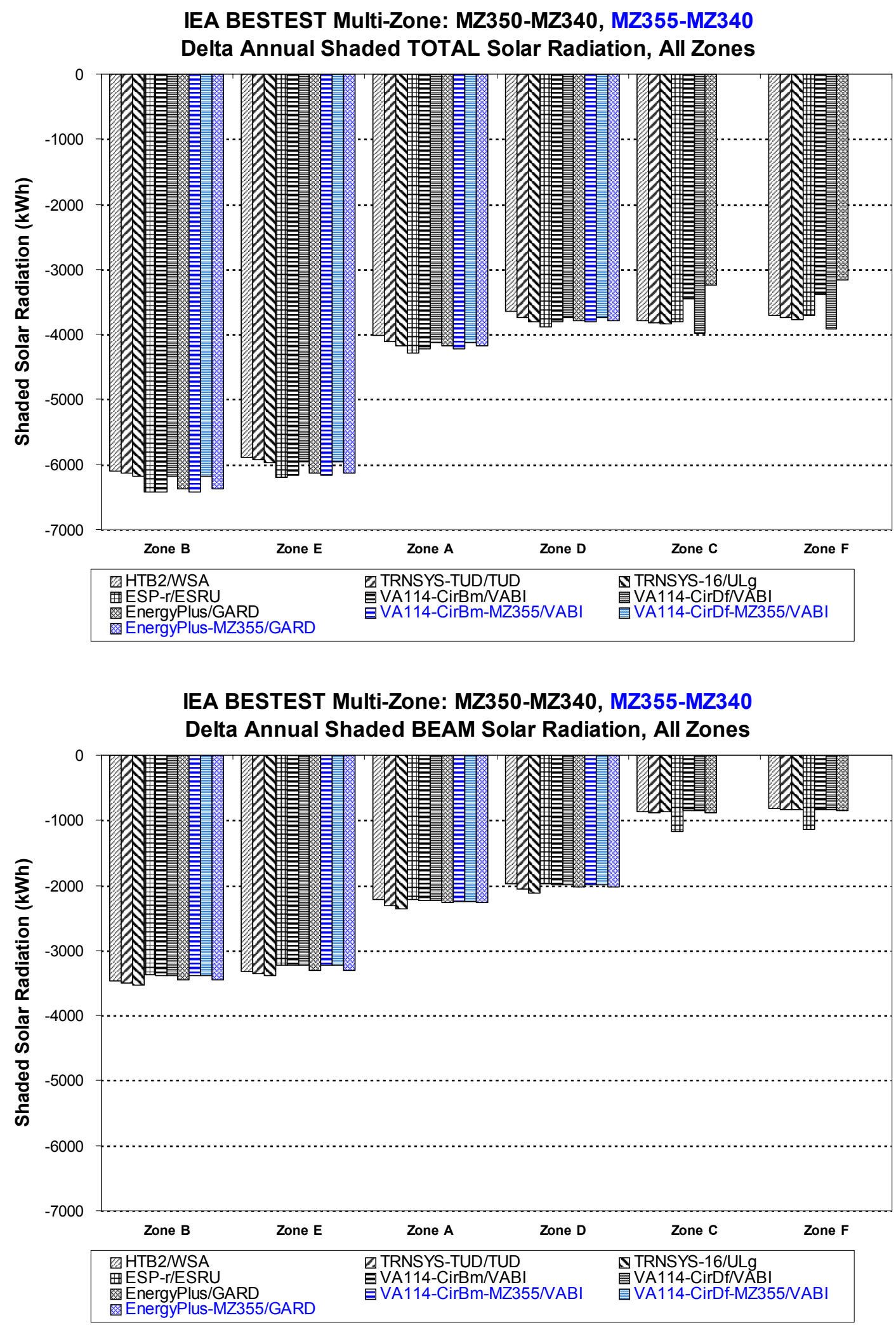


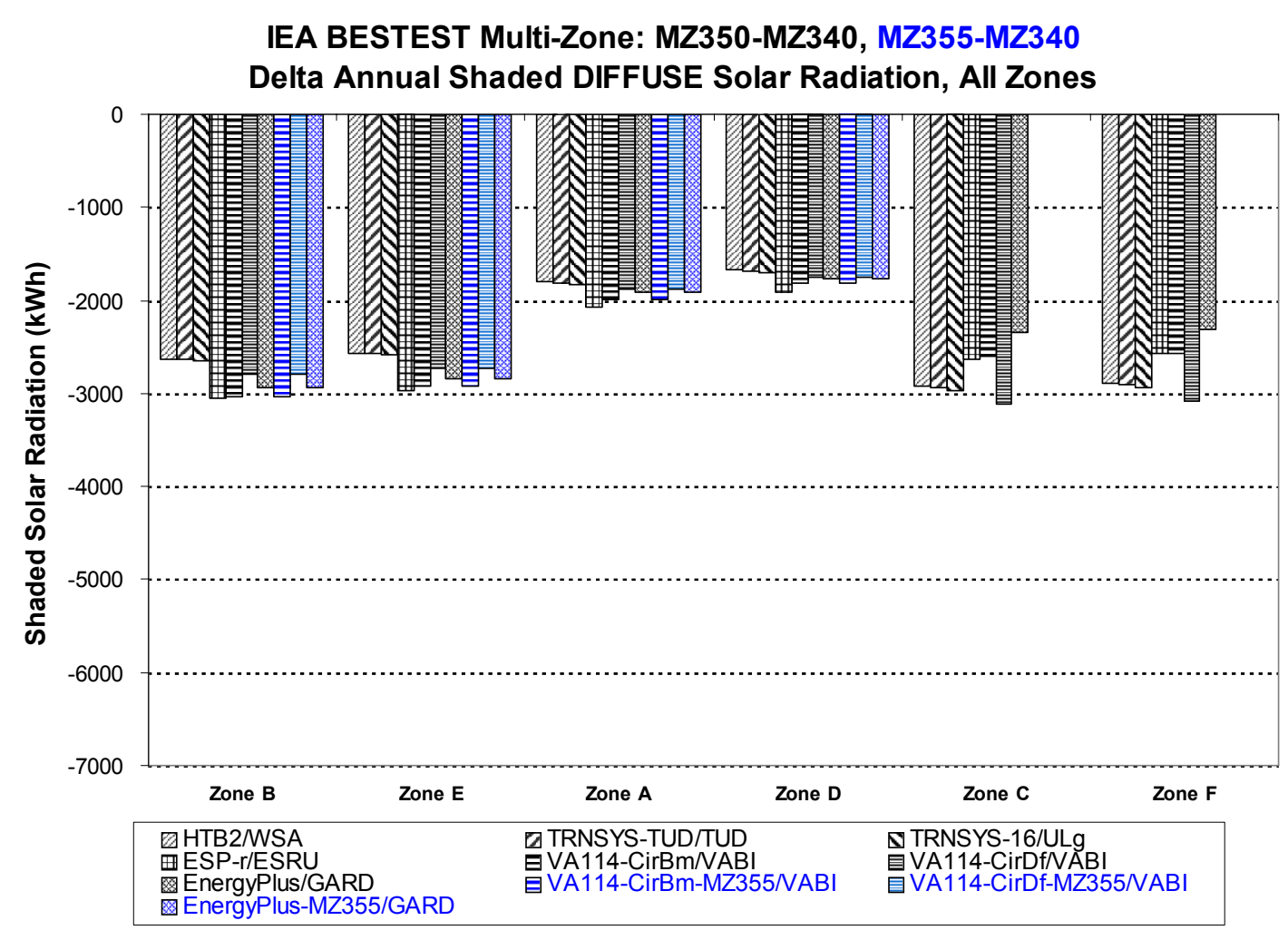

IEA BESTEST Multi-Zone: MZ350/MZ340

Annual Shaded/Unshaded Transmitted Solar Ratios, All Zones

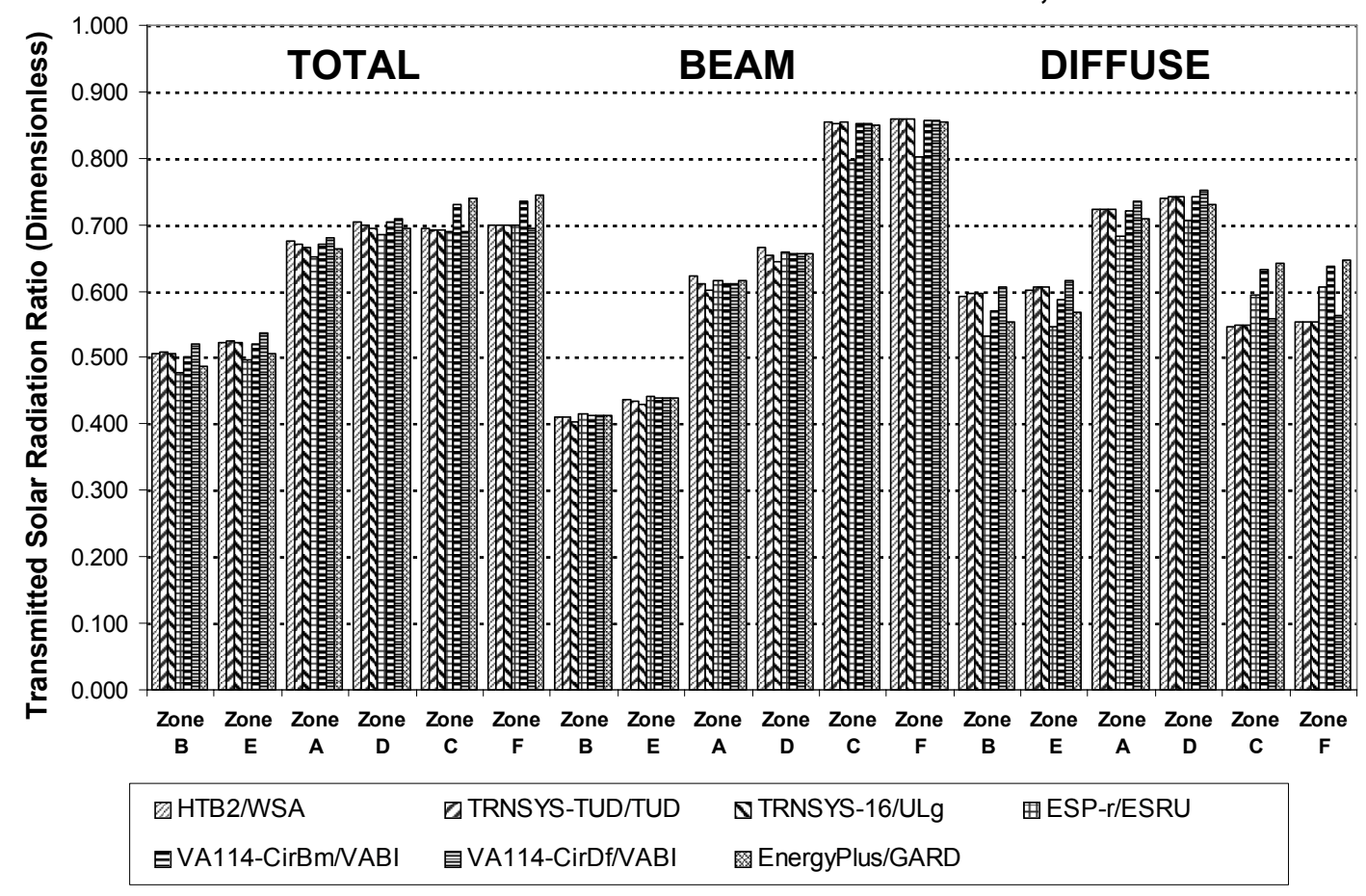


IEA BESTEST Multi-Zone: MZ350-MZ340, MZ355-MZ340

Delta Annual Cooling Load, All Zones

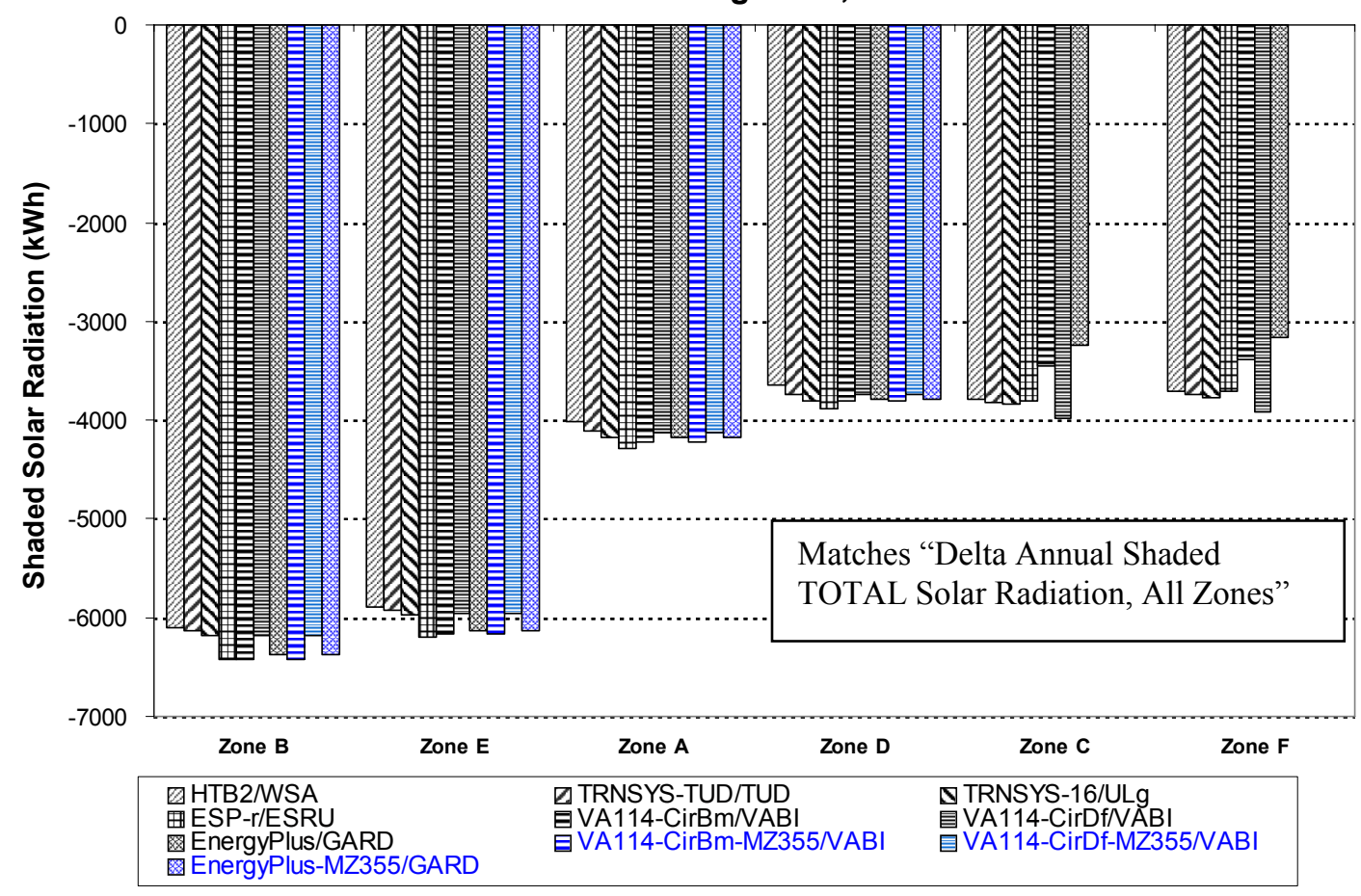

IEA BESTEST Multi-Zone: MZ350-MZ340, MZ355-MZ340

Delta Annual Sensible Cooling Load, Building

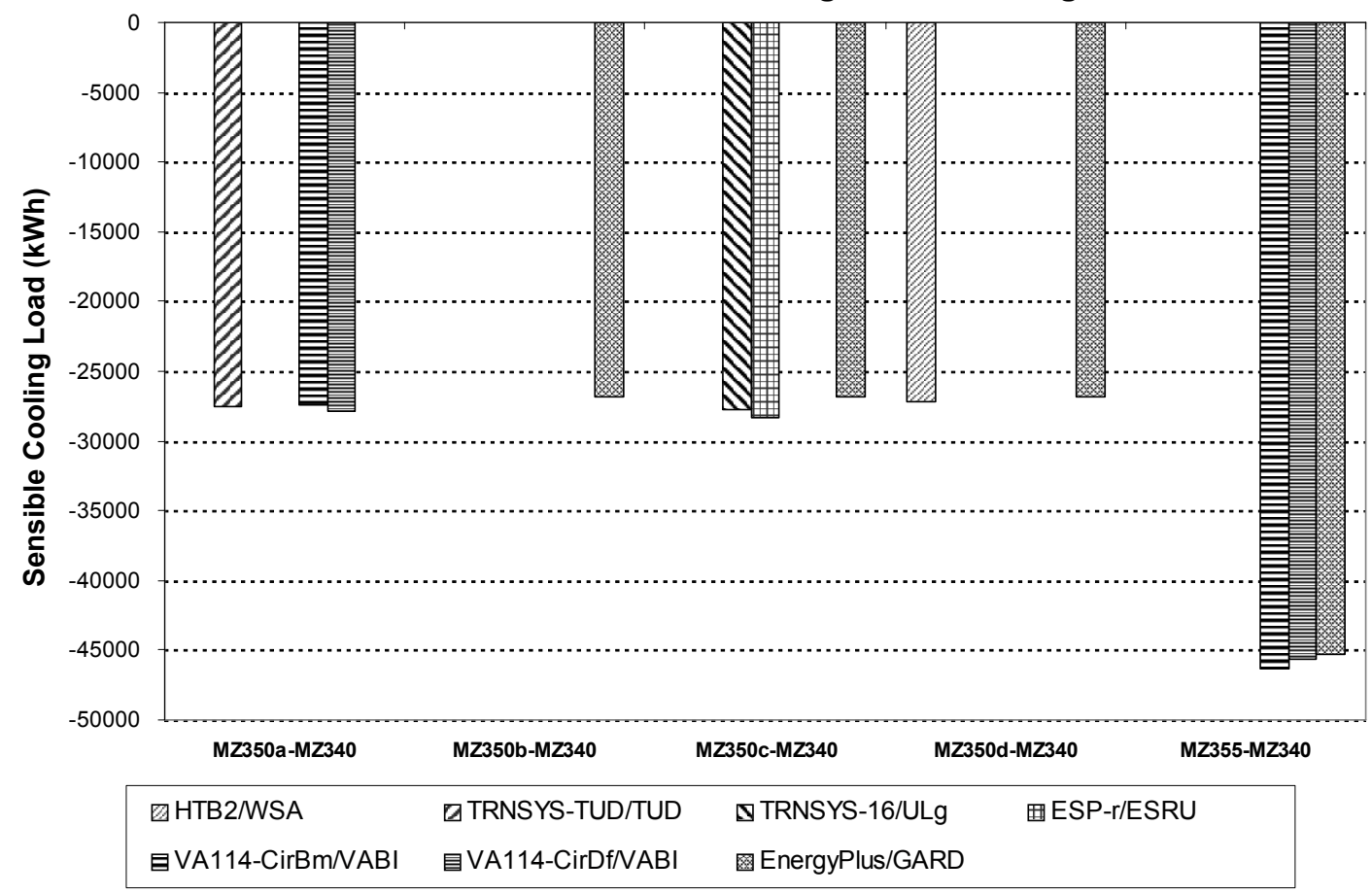




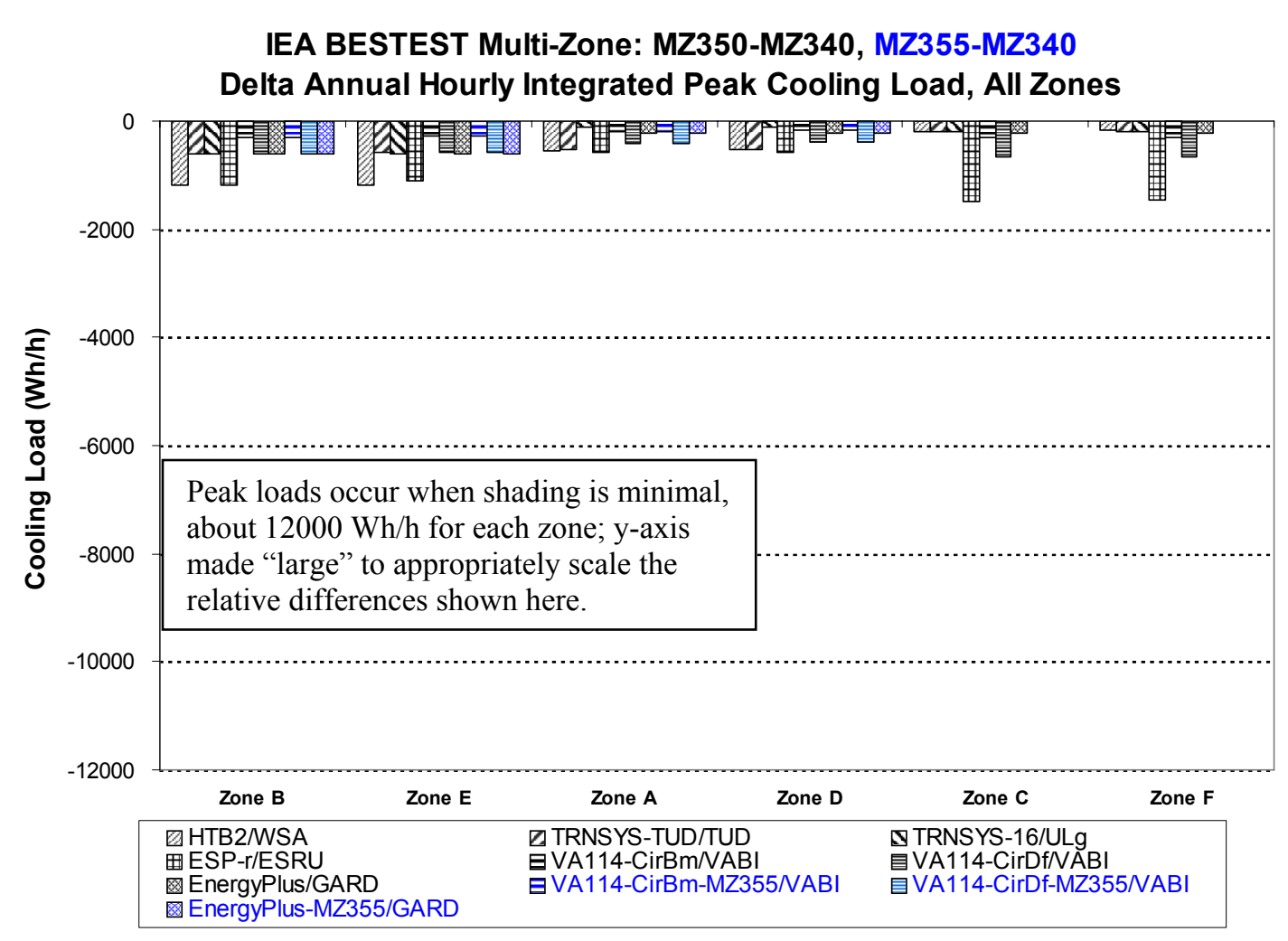

IEA BESTEST Multi-Zone: MZ350-MZ340, MZ355-MZ340

Delta Annual Hourly-Integrated Peak Sensible Cooling Load, Building

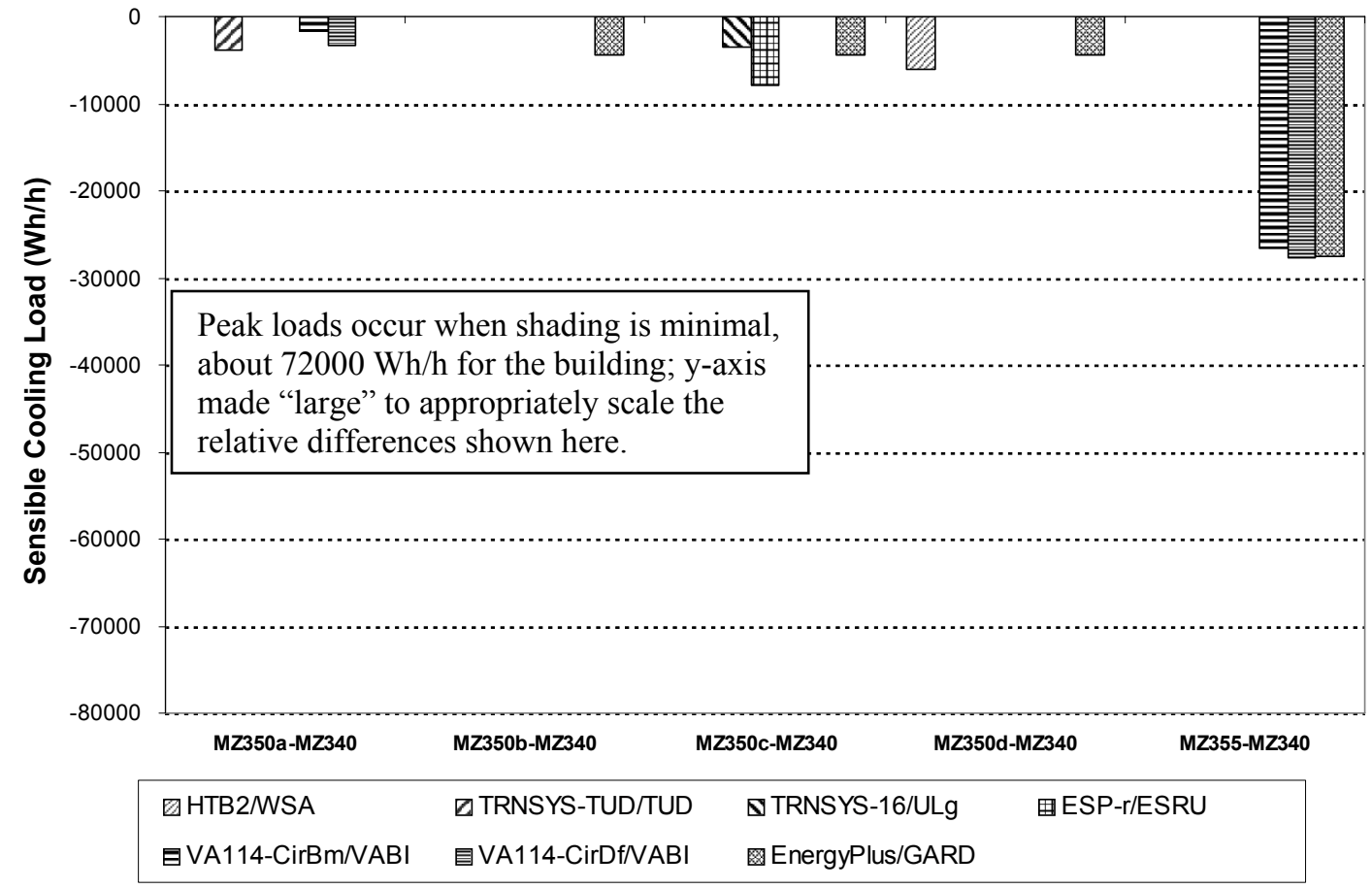


BESTEST Multi-Zone: MZ340 Unshaded March 15 (high dn) Hourly Transmitted Solar, Zone A

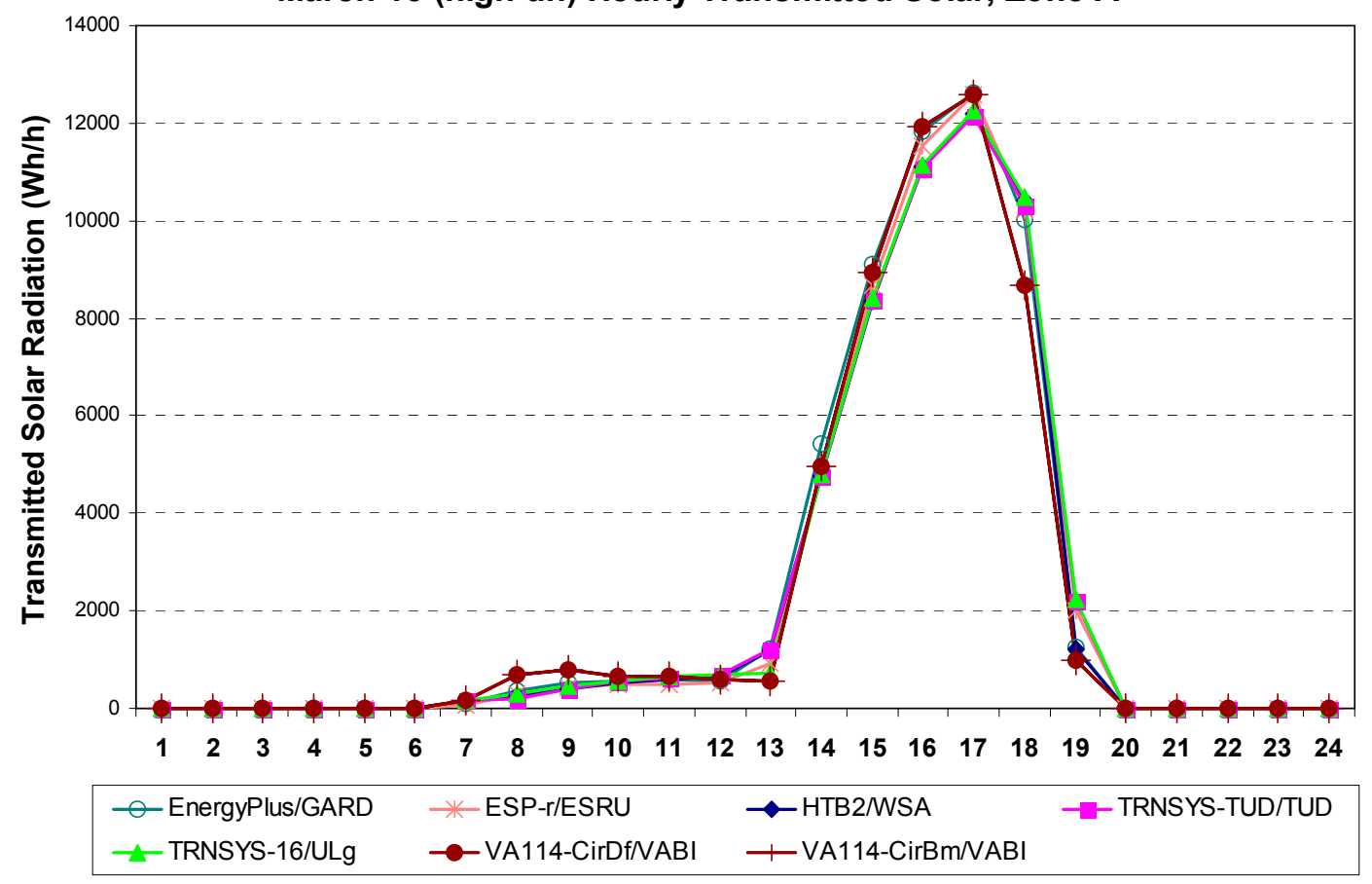

BESTEST Multi-Zone: MZ340 Unshaded March 15 (high dn) Hourly Sensible Cooling Load, Zone A

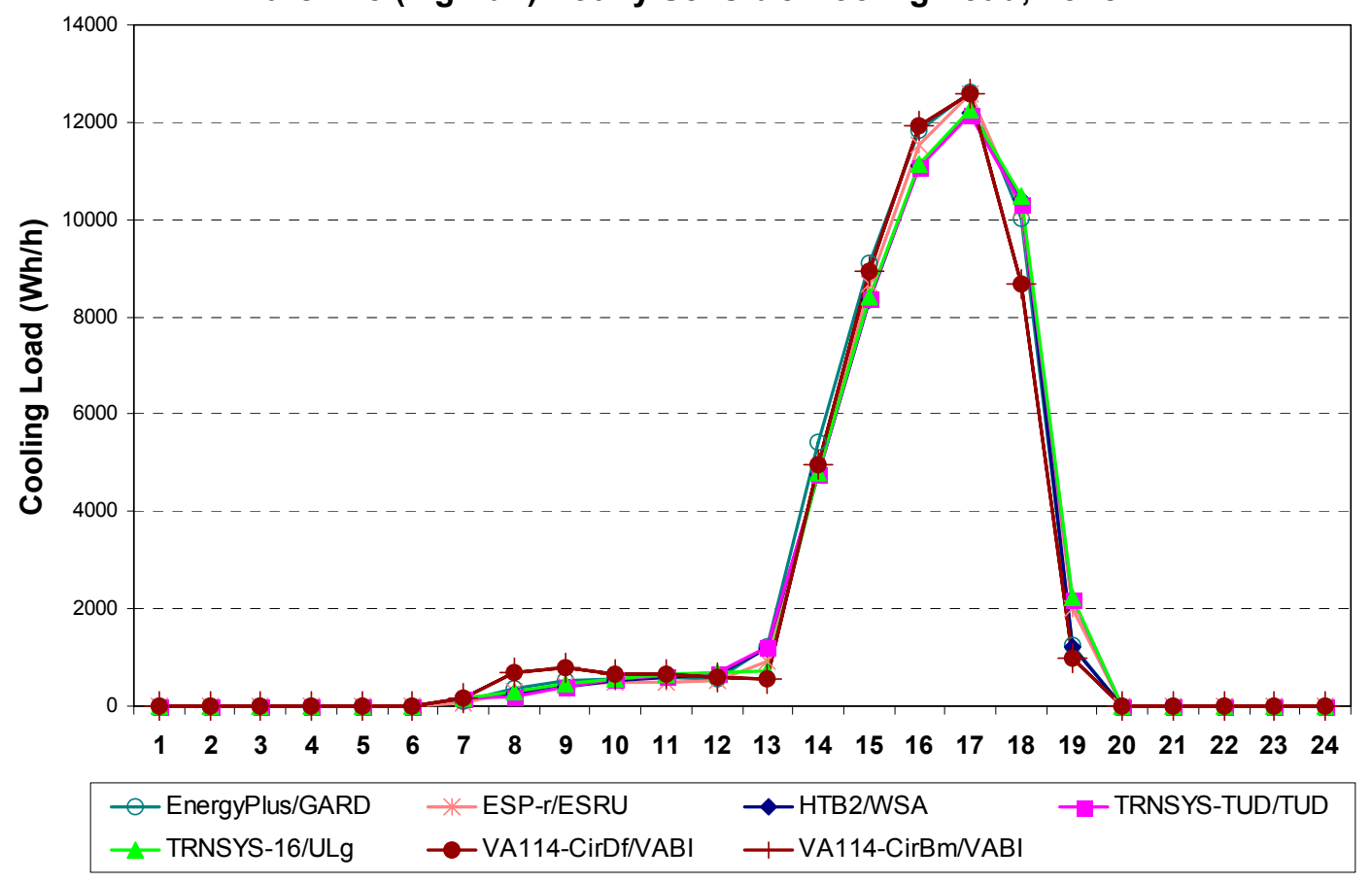


BESTEST Multi-Zone: MZ340 Unshaded

August 4 TOTAL Hourly Transmitted Solar, Zone A

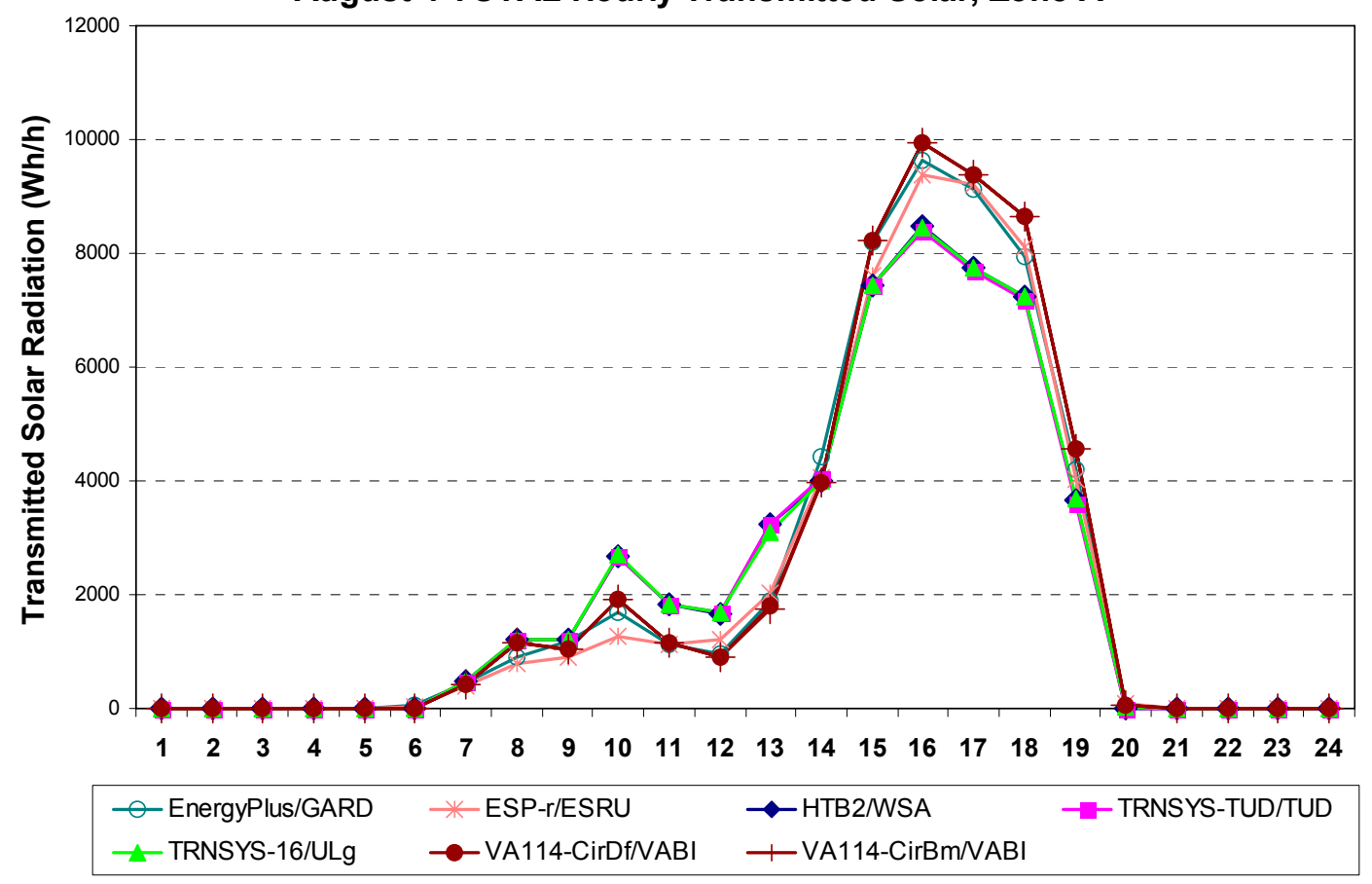

BESTEST Multi-Zone: MZ340 Unshaded August 4 BEAM Hourly Transmitted Solar, Zone A

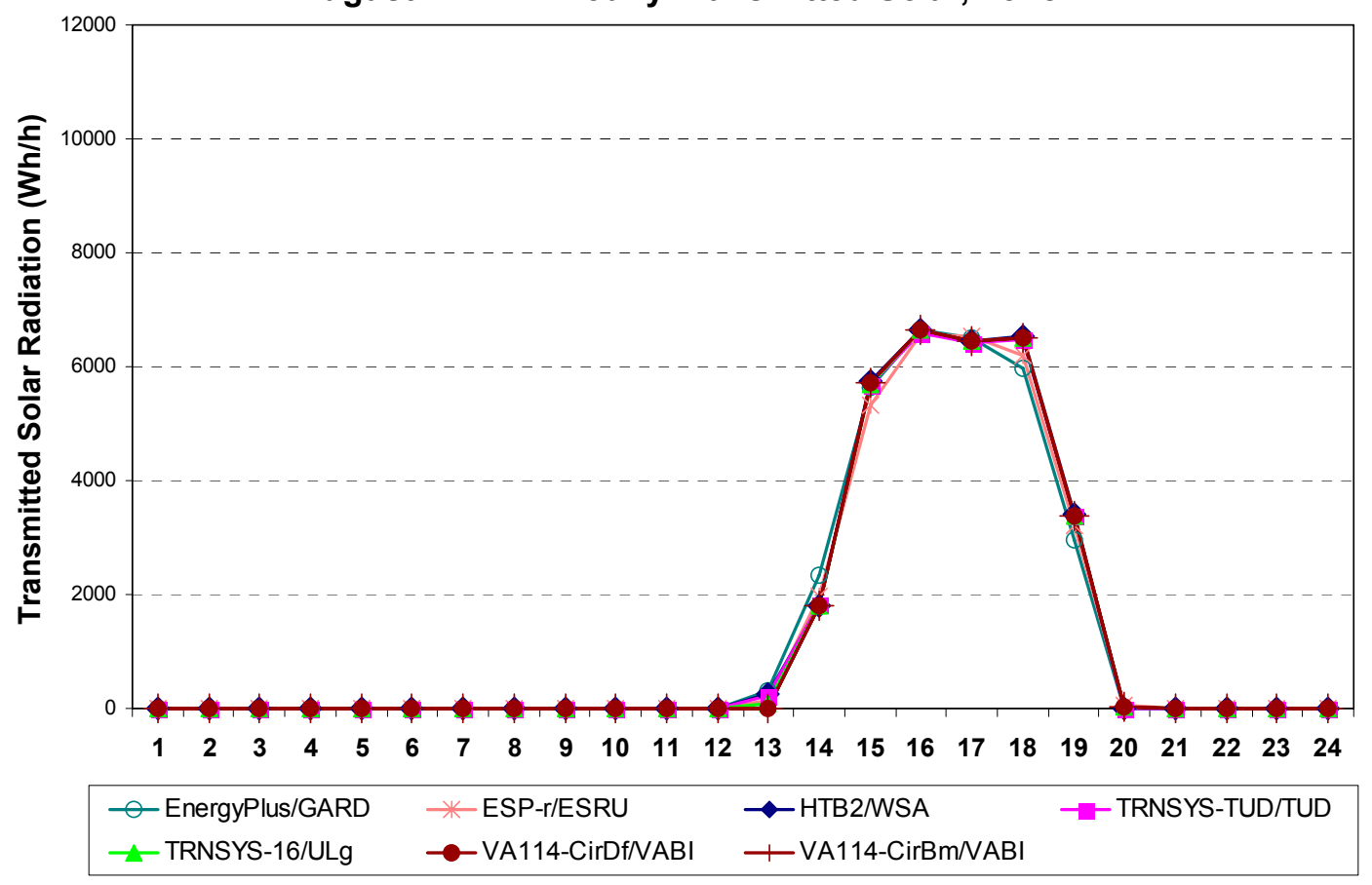



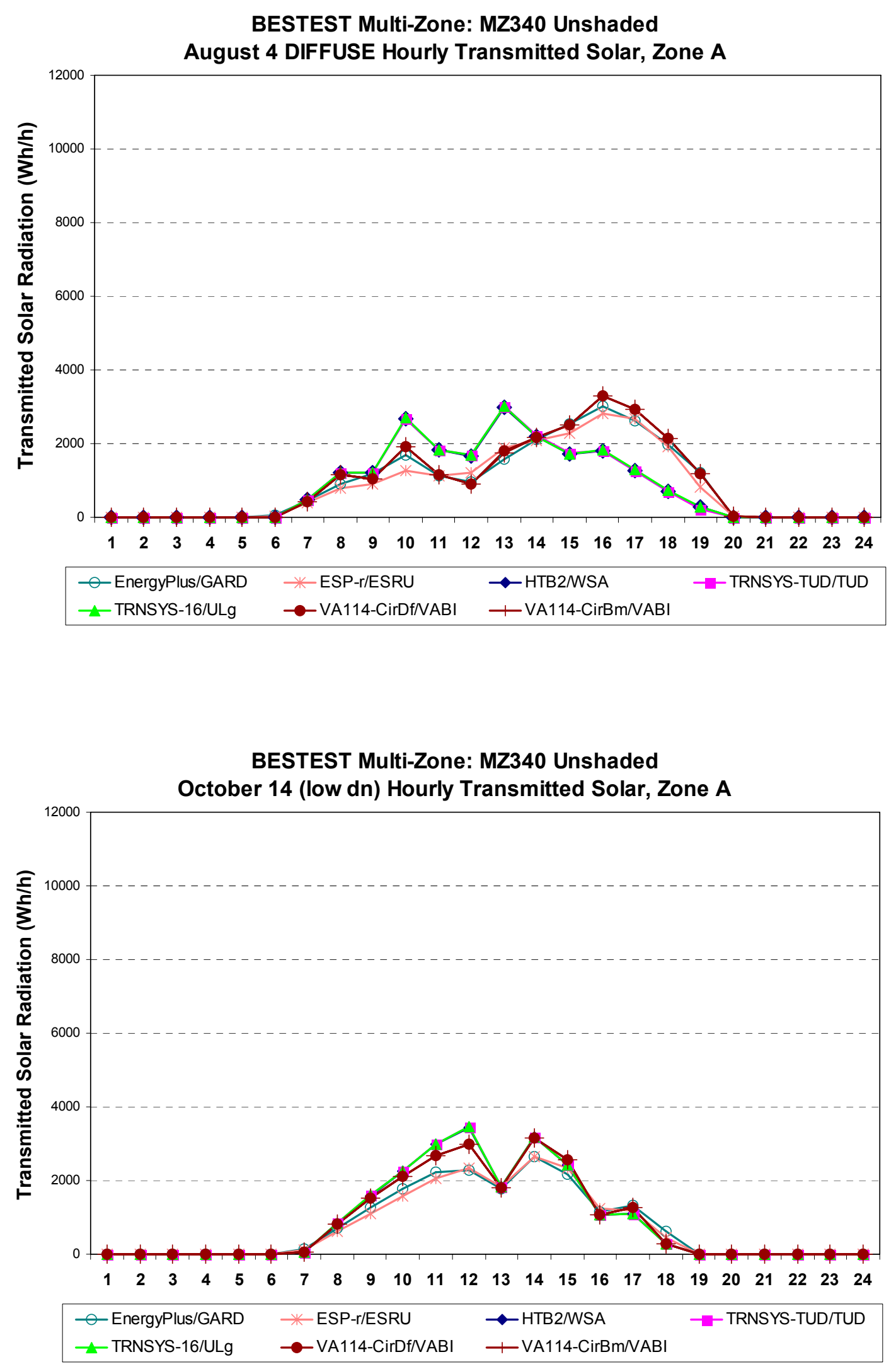

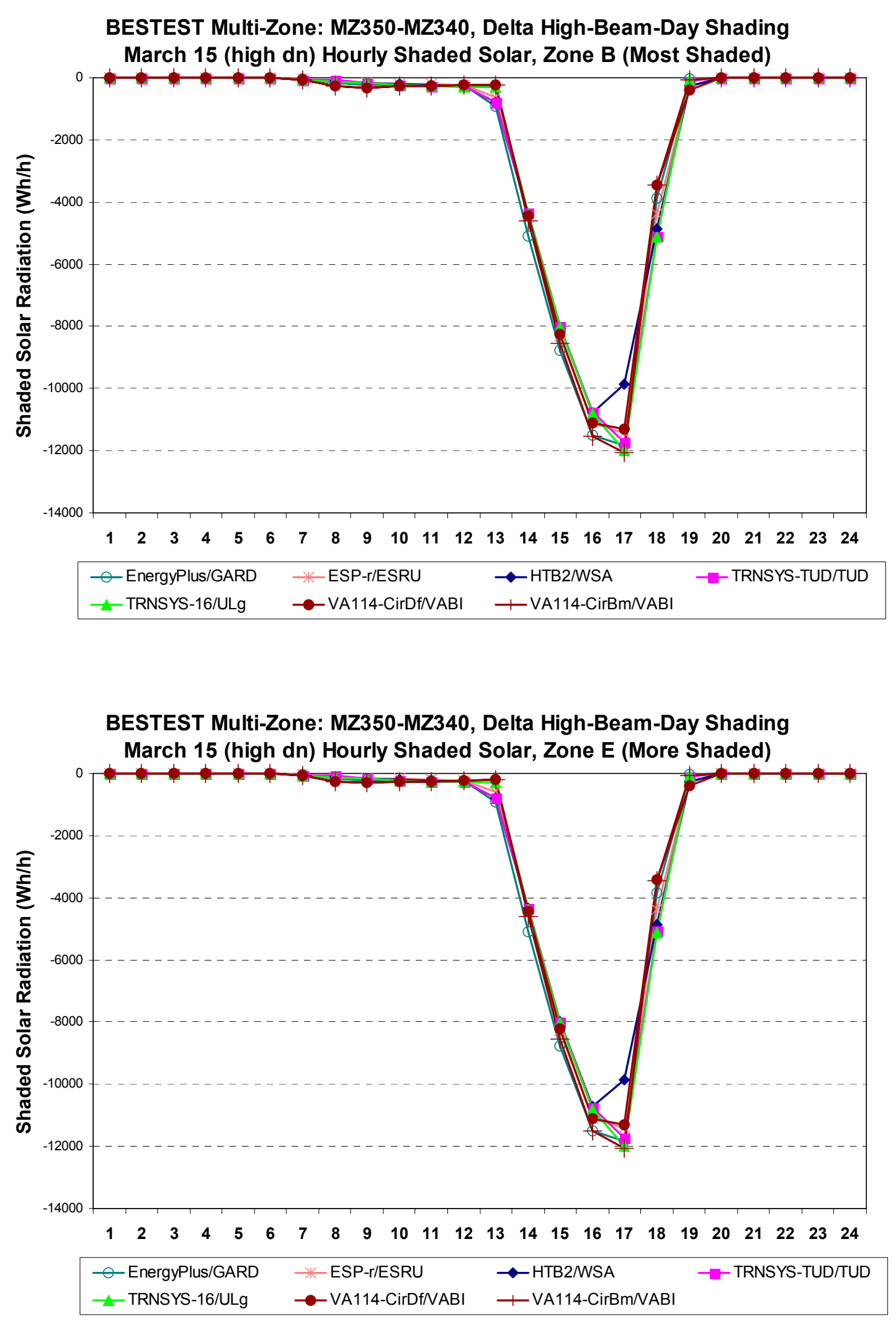


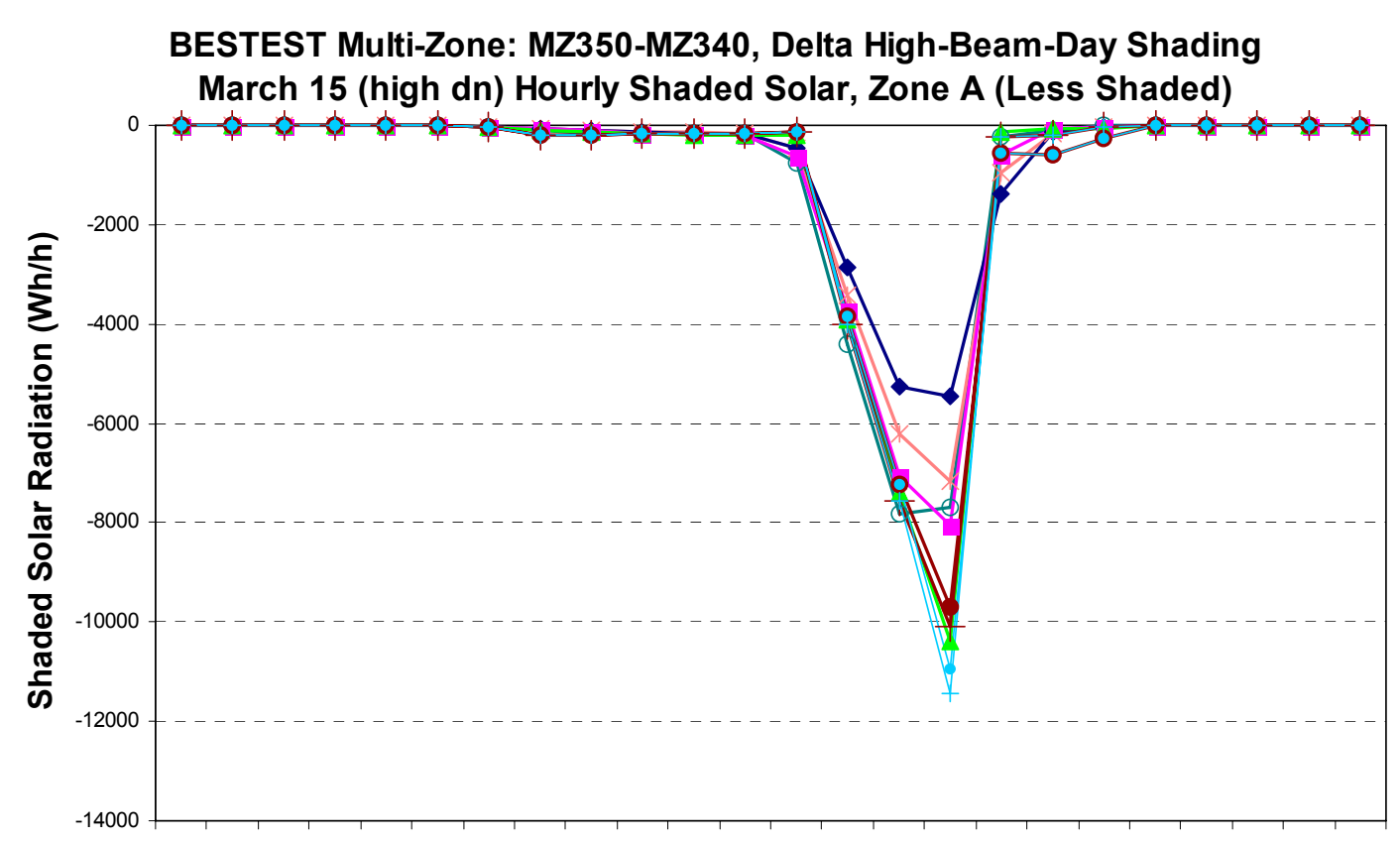

$\begin{array}{llllllllllllllllllllllll}1 & 2 & 3 & 4 & 5 & 6 & 7 & 8 & 9 & 10 & 11 & 12 & 13 & 14 & 15 & 16 & 17 & 18 & 19 & 20 & 21 & 22 & 23 & 24\end{array}$

\begin{tabular}{|c|c|c|}
\hline $\begin{array}{l}\text { - EnergyPlus/GARD } \\
\text { - TRNSYS-TUD/TUD } \\
\text {-VA114-CirBm/NABI }\end{array}$ & $\begin{array}{l}\text { * ESP-r/ESRU } \\
\text { - TRNSYS-16/ULg } \\
\rightarrow-\text { VA114-CirDf-MZ355/NABI }\end{array}$ & $\begin{array}{l}\rightarrow \text { HTB2MSA } \\
\rightarrow-V A 114-C i r D f / N A B I \\
+ \text { VA114-CirBm-MZ355/VABI }\end{array}$ \\
\hline
\end{tabular}

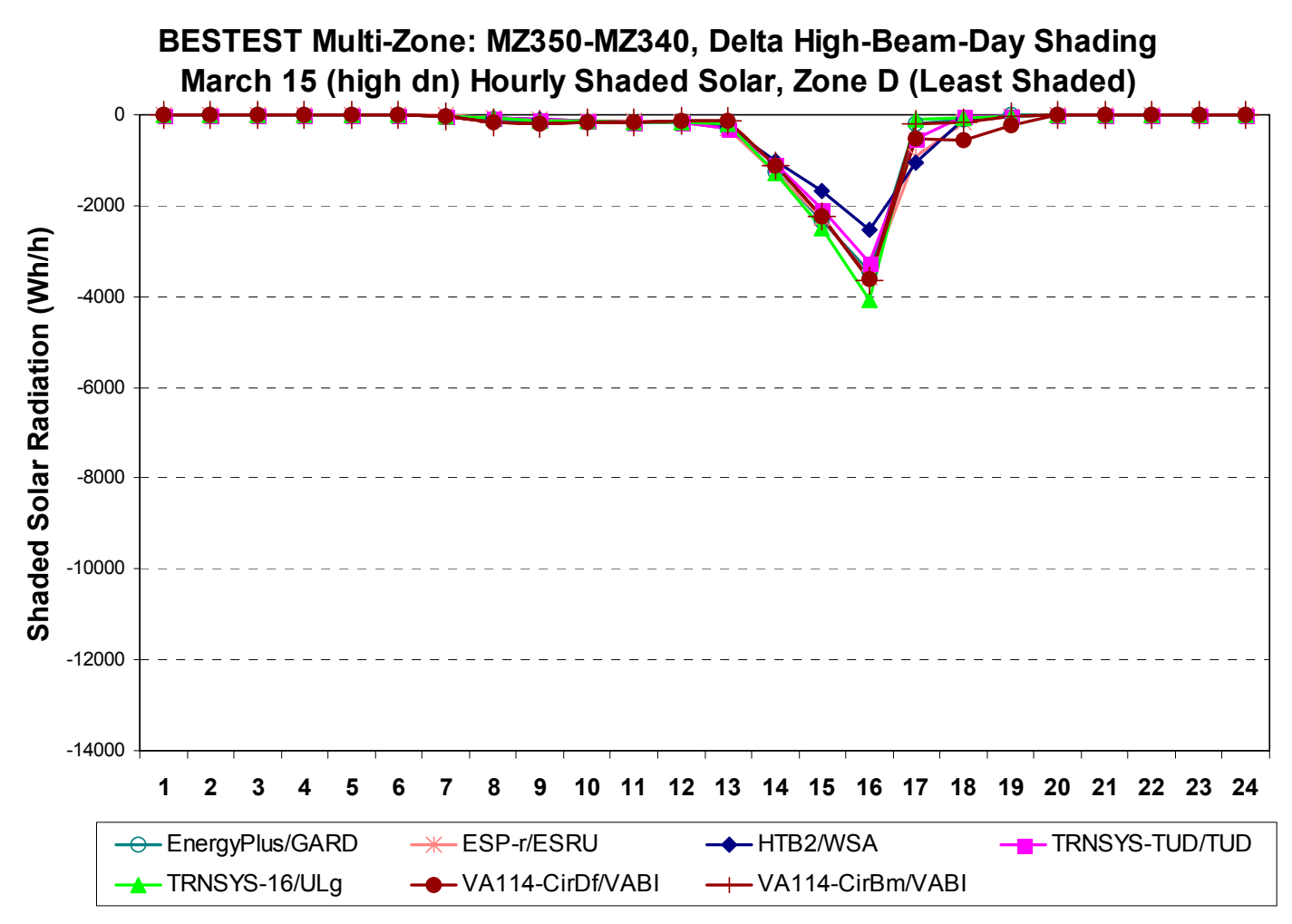



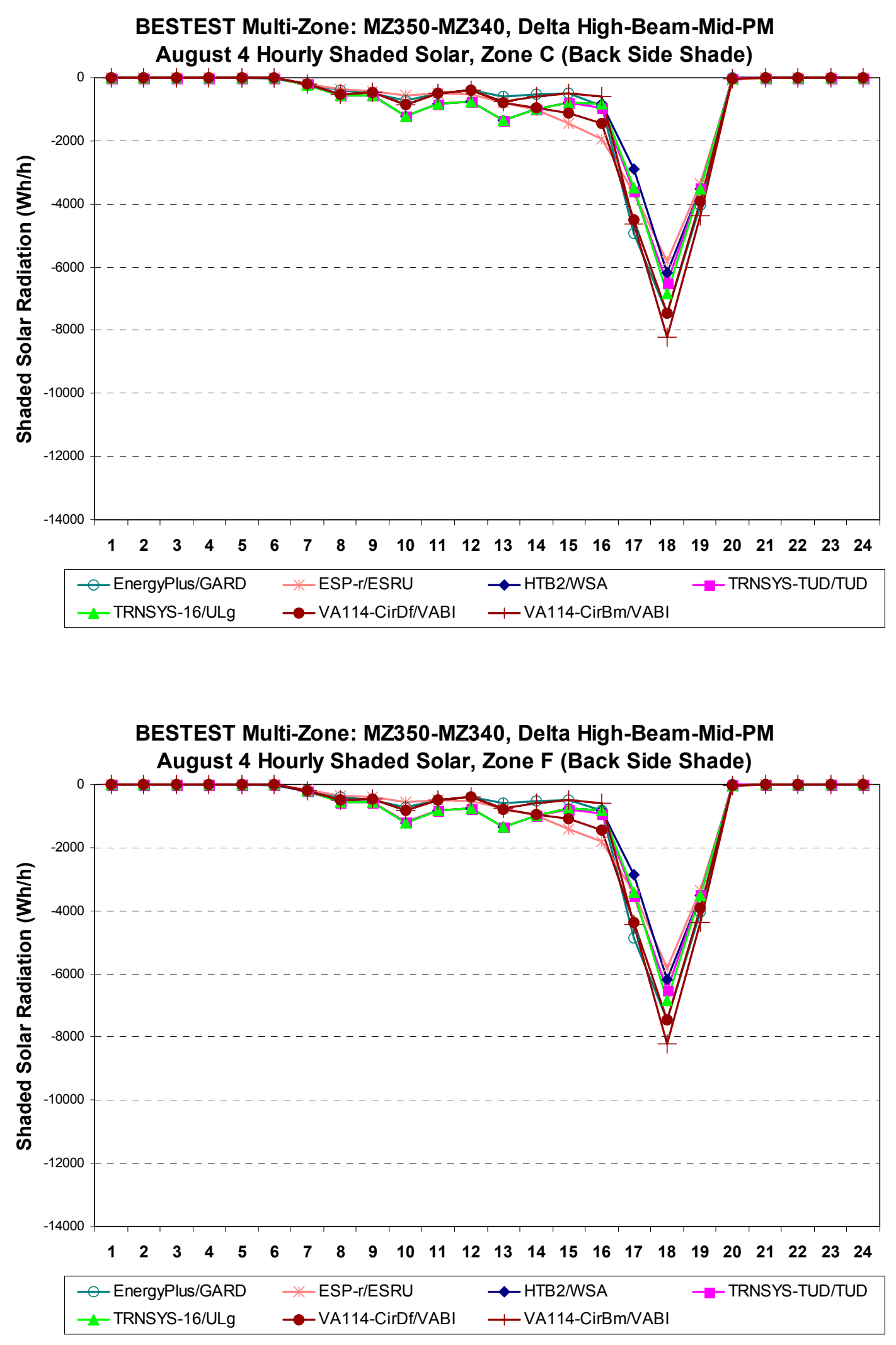


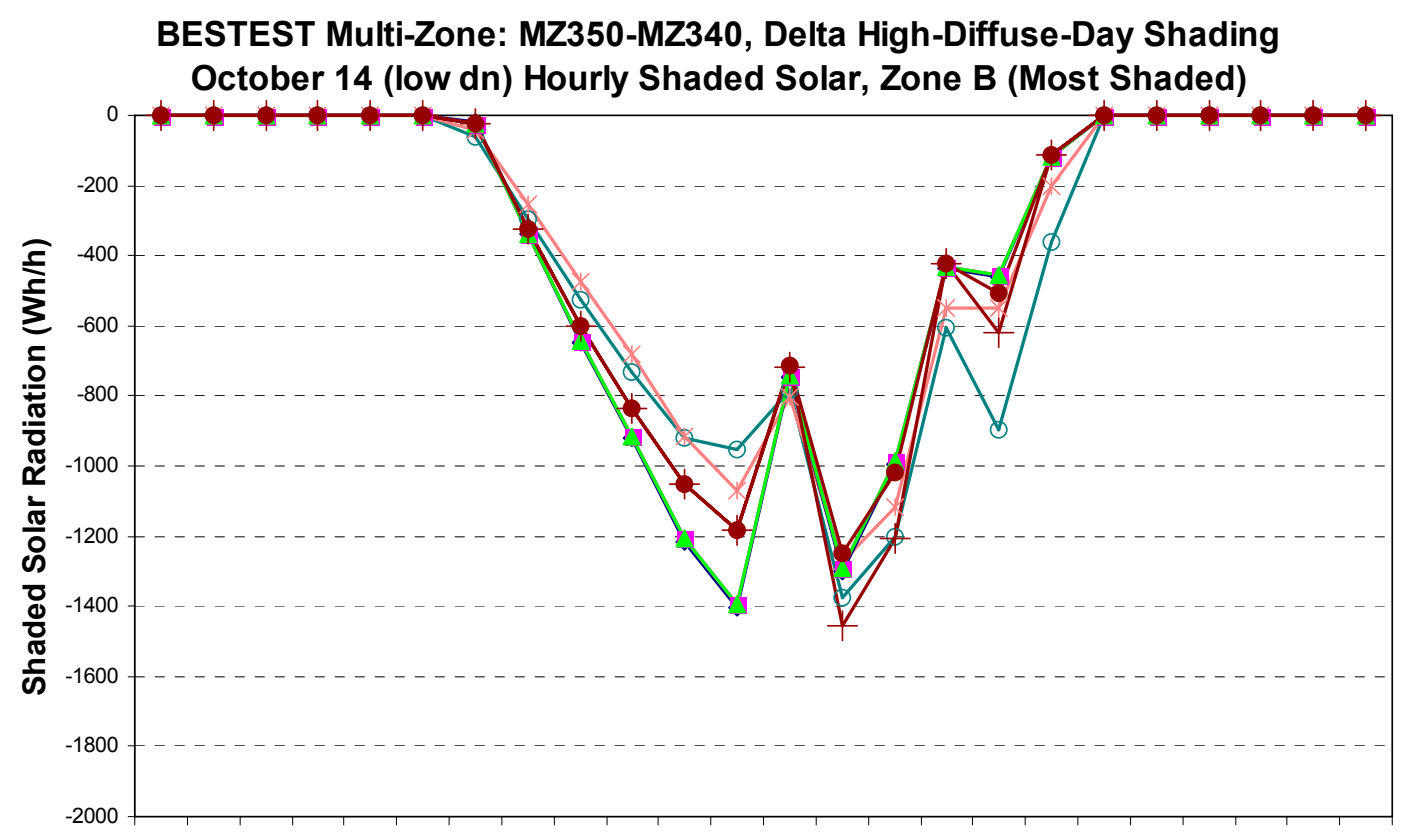

$\begin{array}{llllllllllllllllllllllll}1 & 2 & 3 & 4 & 5 & 6 & 7 & 8 & 9 & 10 & 11 & 12 & 13 & 14 & 15 & 16 & 17 & 18 & 19 & 20 & 21 & 22 & 23 & 24\end{array}$

\begin{tabular}{|c|c|c|c|}
\hline ๑-EnergyPlus/GARD & * ESP-r/ESRU & $\multimap-\mathrm{HTB} 2 / W S A$ & $\rightarrow$ TRNSYS-TUD/TUD \\
\hline$-\leftarrow$ TRNSYS-16/ULg & $\multimap$ VA114-CirDf/NABI & — VA114-CirBm/VABI & \\
\hline
\end{tabular}

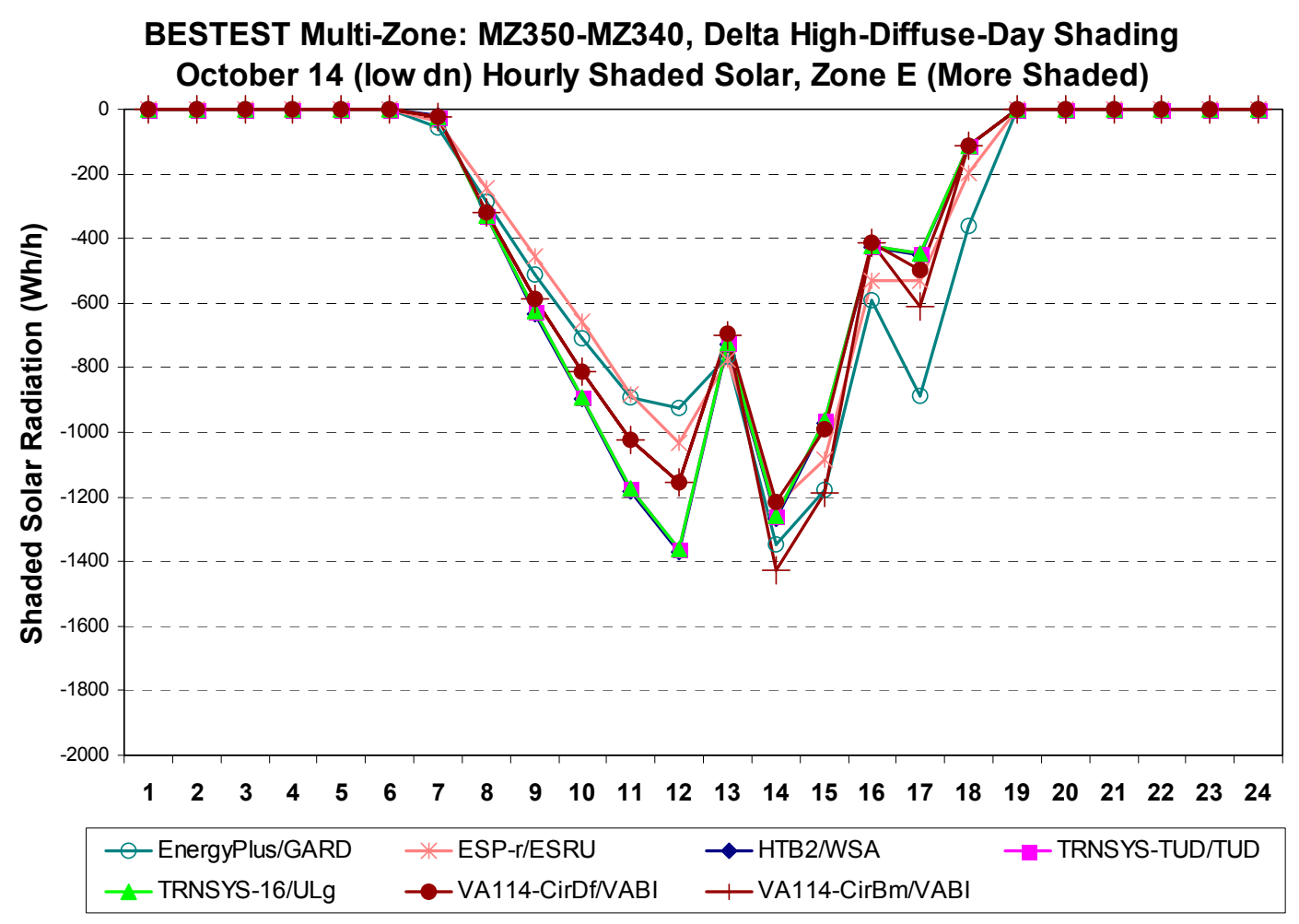



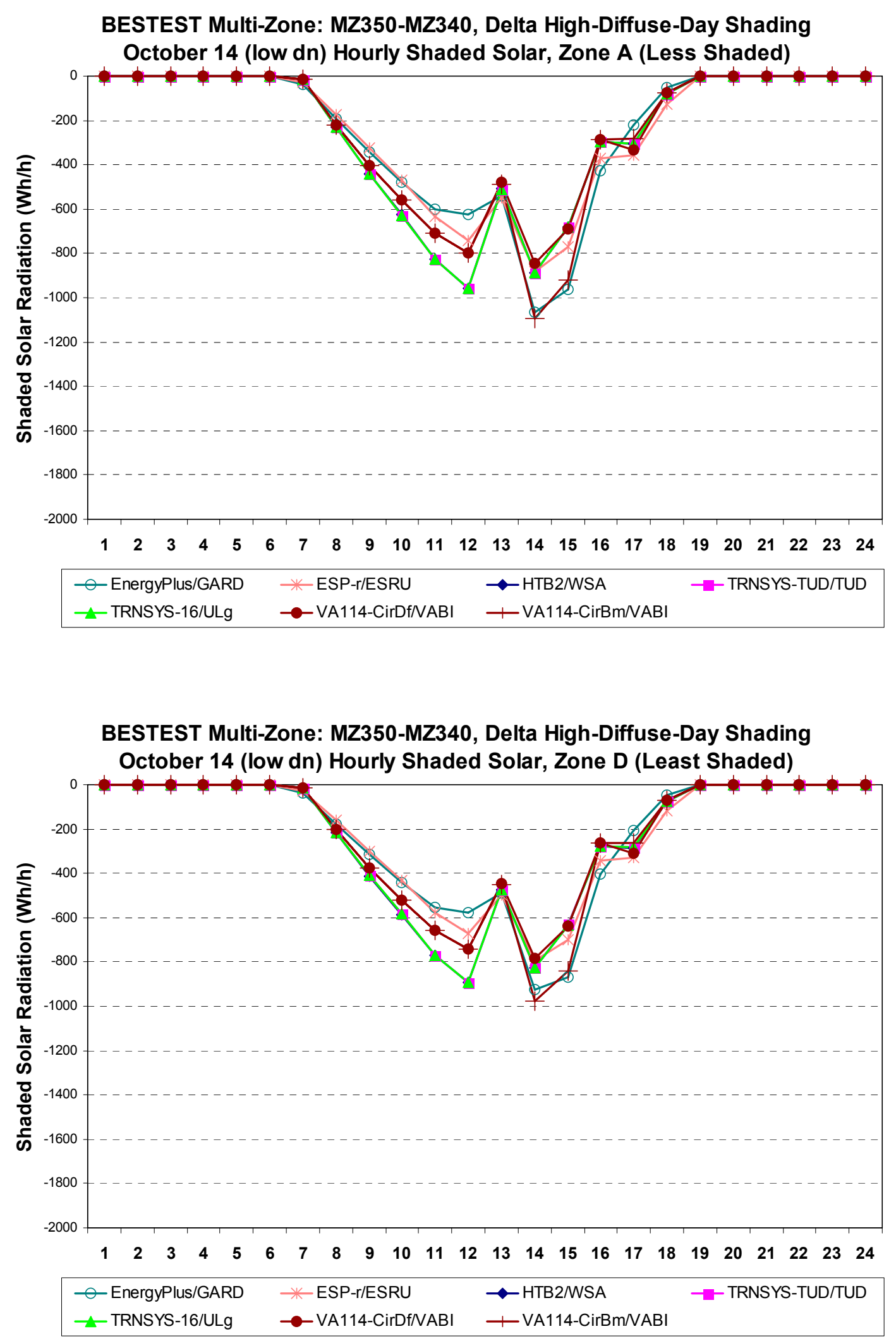


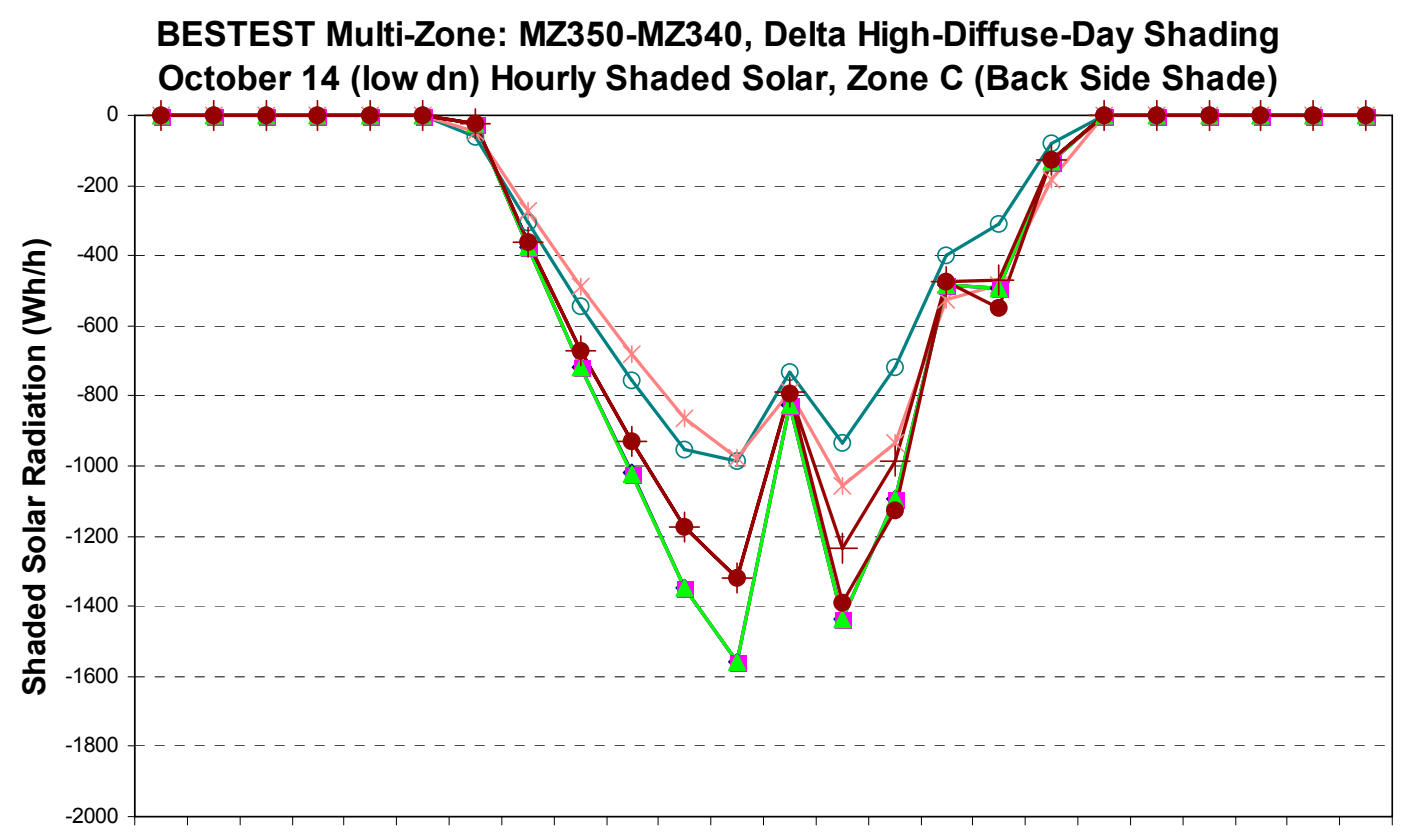

$\begin{array}{llllllllllllllllllllllll}1 & 2 & 3 & 4 & 5 & 6 & 7 & 8 & 9 & 10 & 11 & 12 & 13 & 14 & 15 & 16 & 17 & 18 & 19 & 20 & 21 & 22 & 23 & 24\end{array}$

\begin{tabular}{|c|c|c|c|}
\hline ๑-EnergyPlus/GARD & * ESP-r/ESRU & $\leadsto$ HTB2/WSA & $\rightarrow-T R N S Y S-T U D / T U D$ \\
\hline$\neg$ TRNSYS-16/ULg & - VA114-CirDf/NABI & —VA114-CirBm/VABI & \\
\hline
\end{tabular}

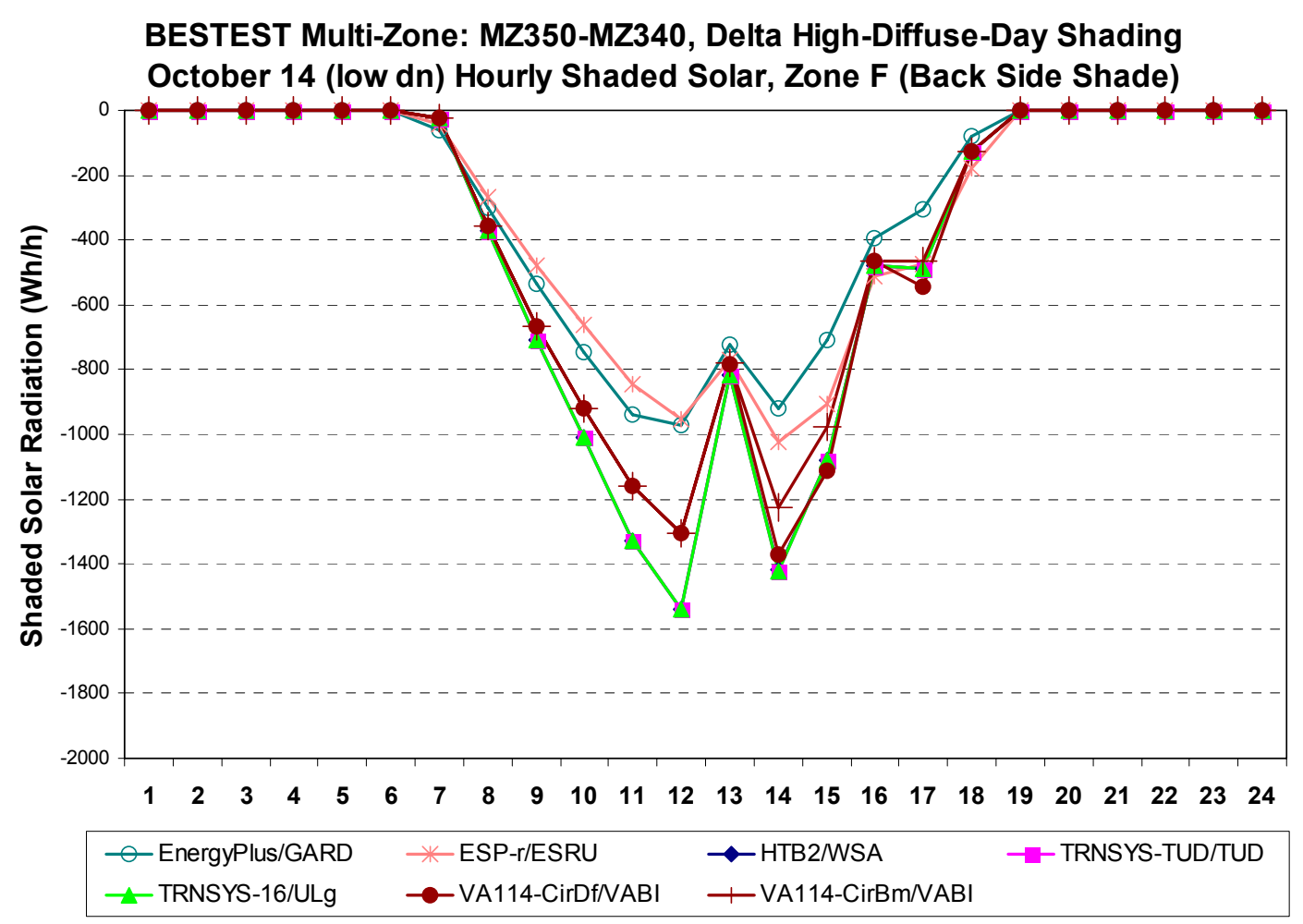



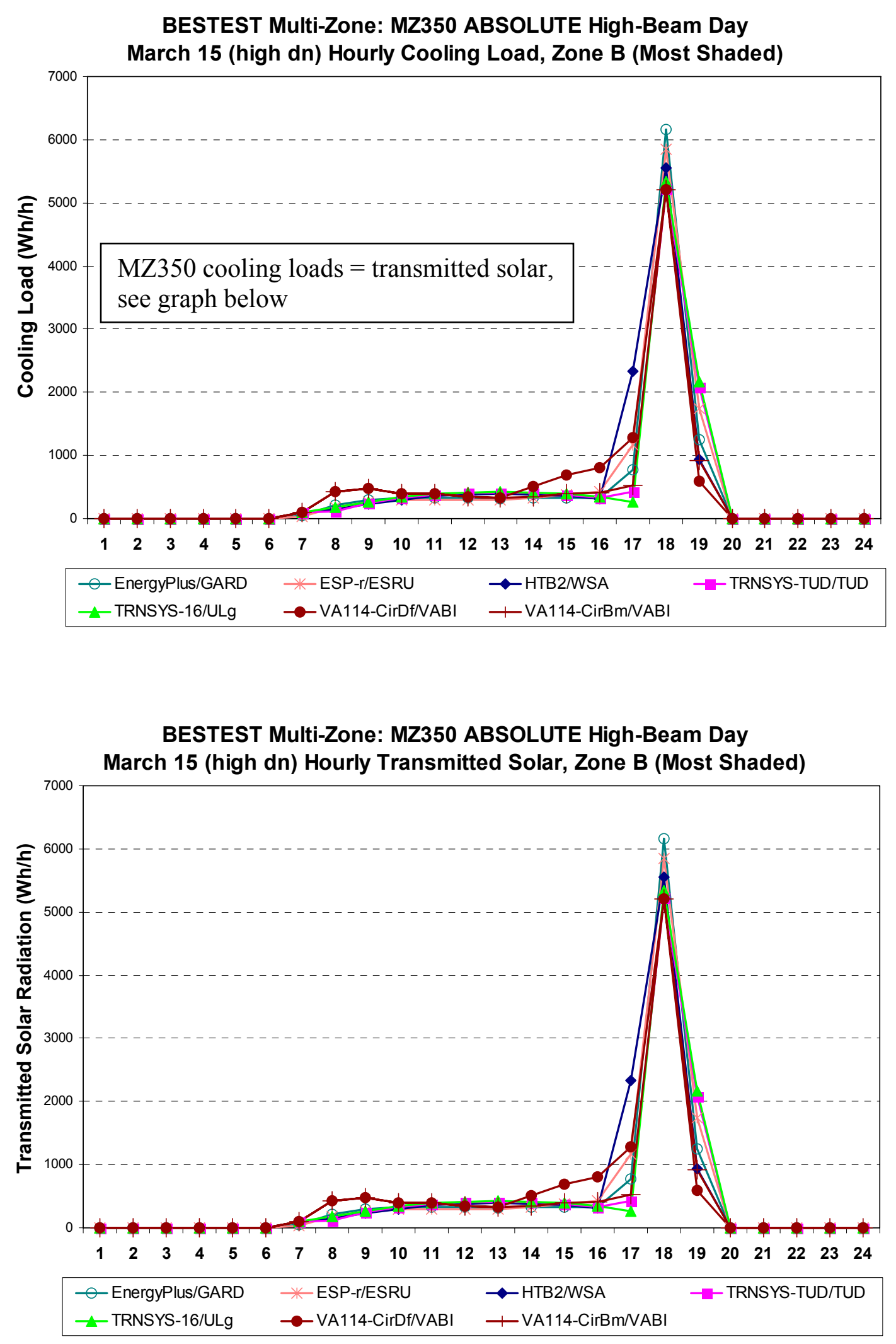

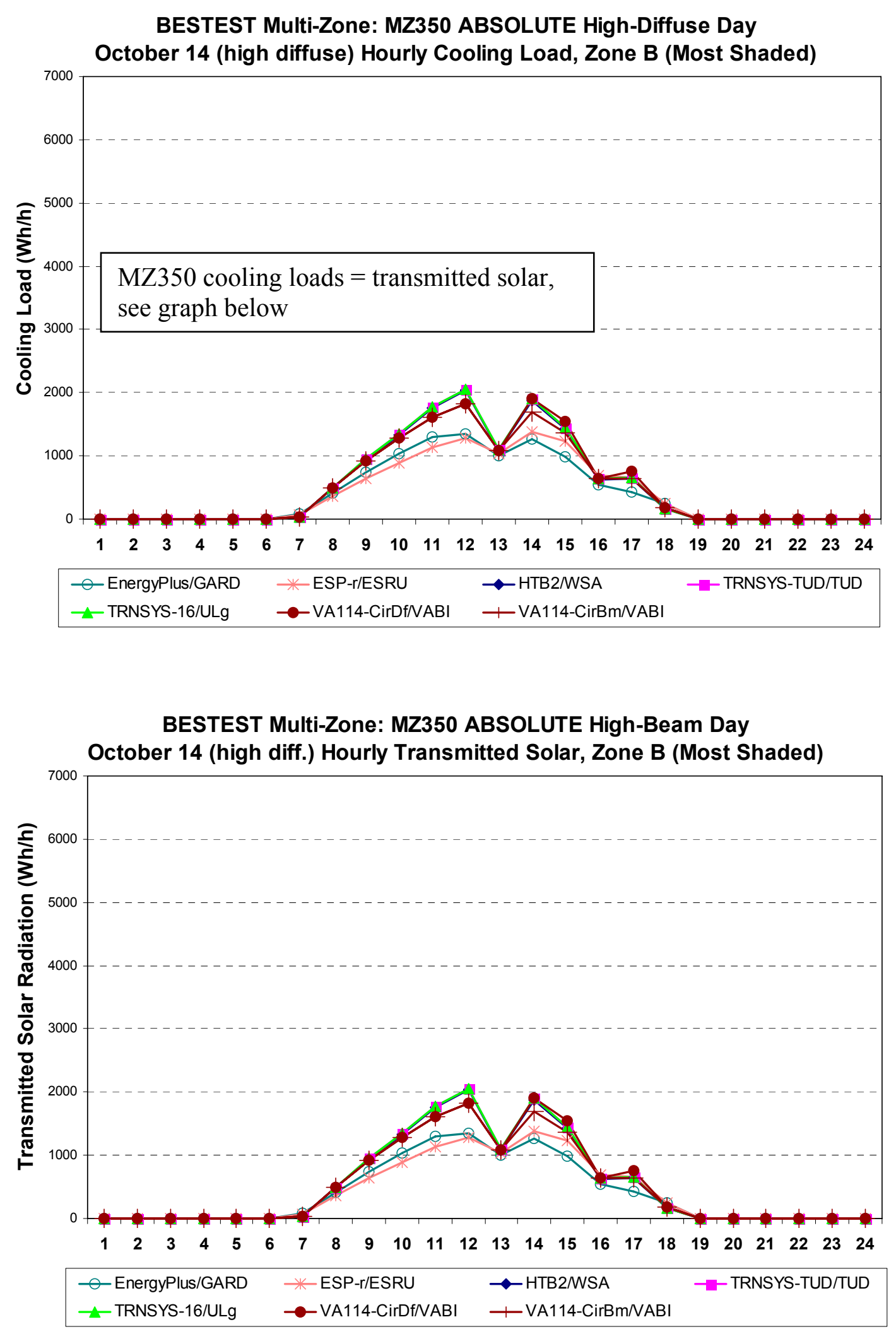


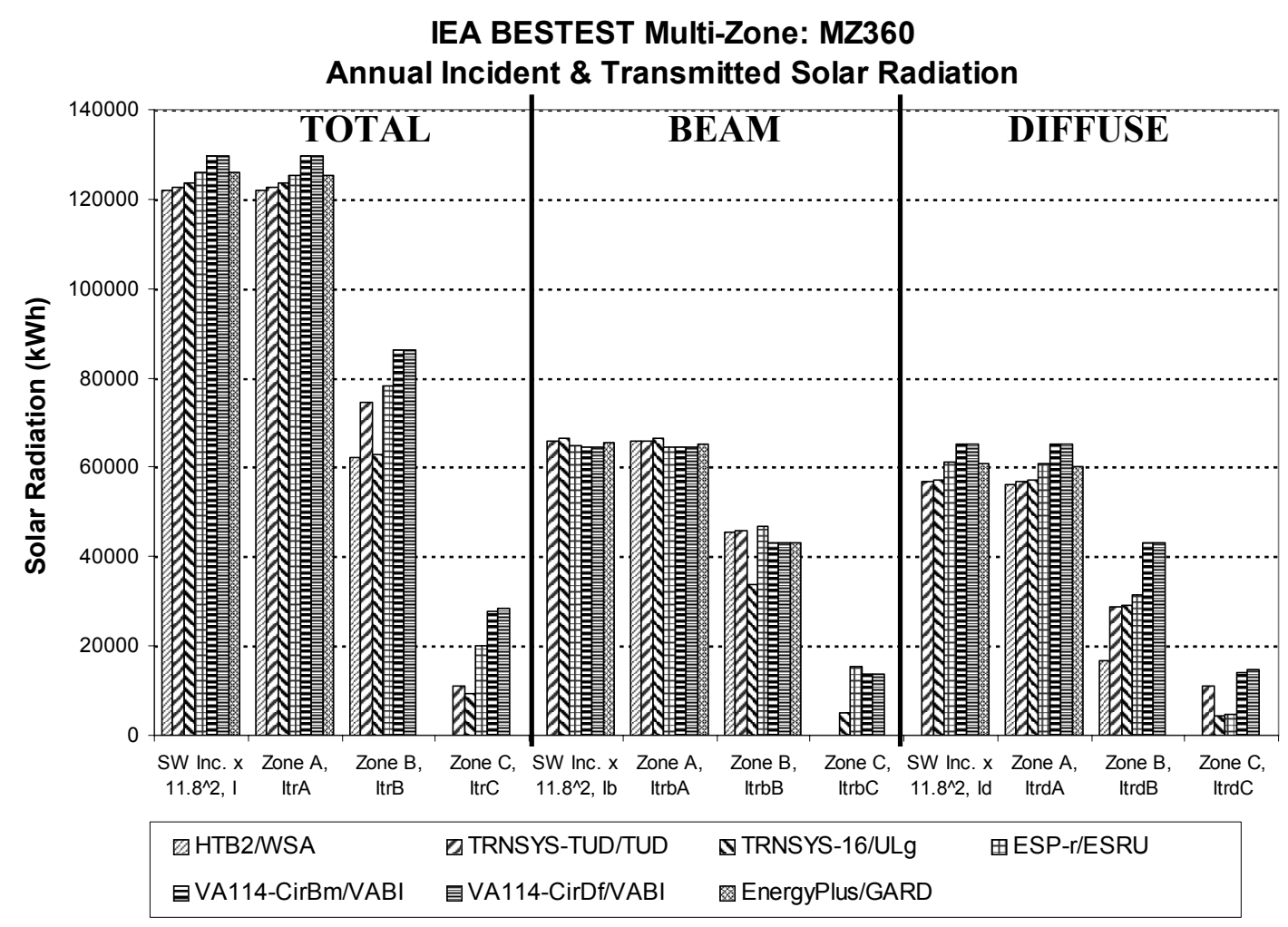

IEA BESTEST Multi-Zone: MZ360

Transmitted Solar Radiation Ratios

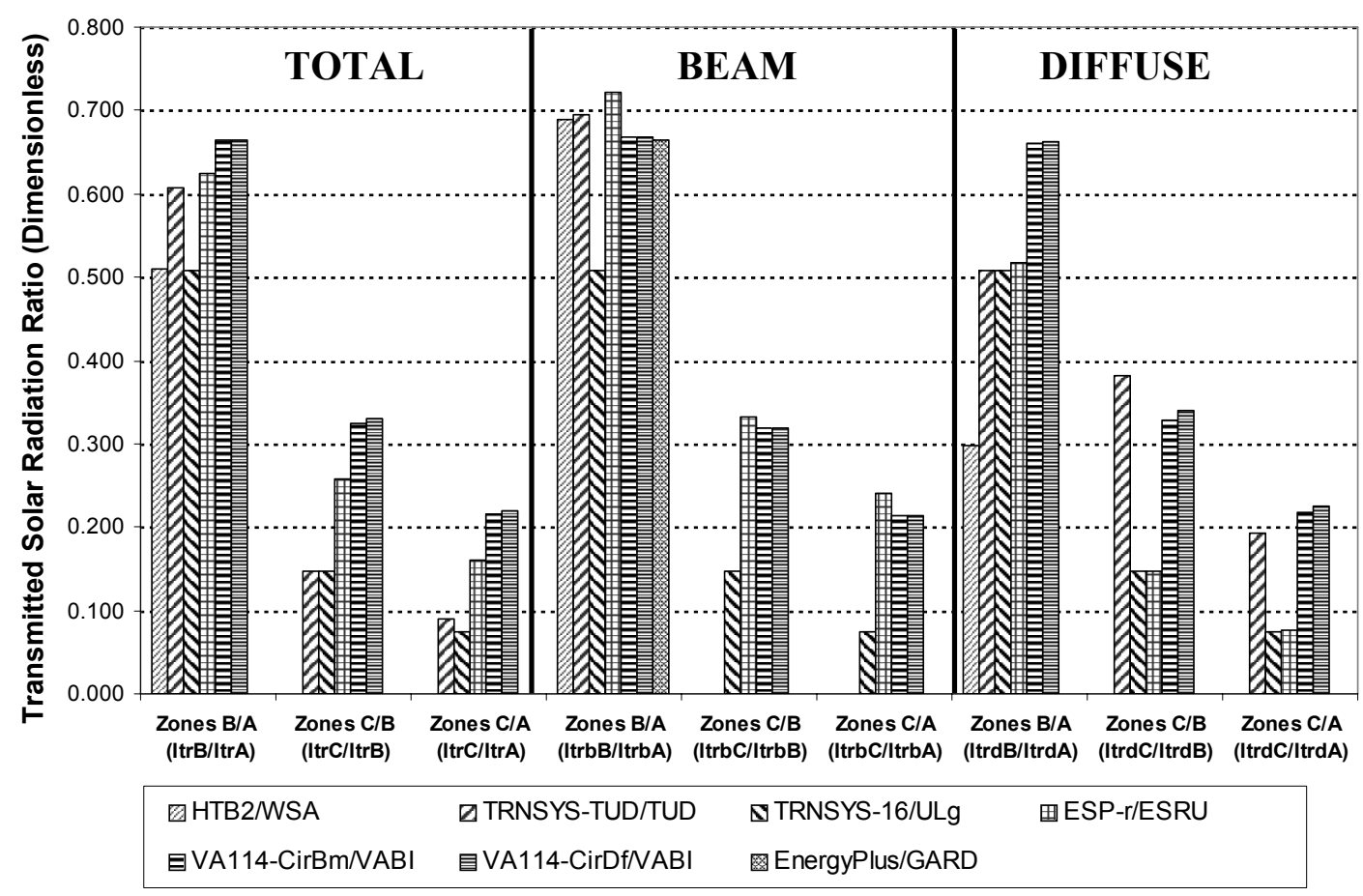



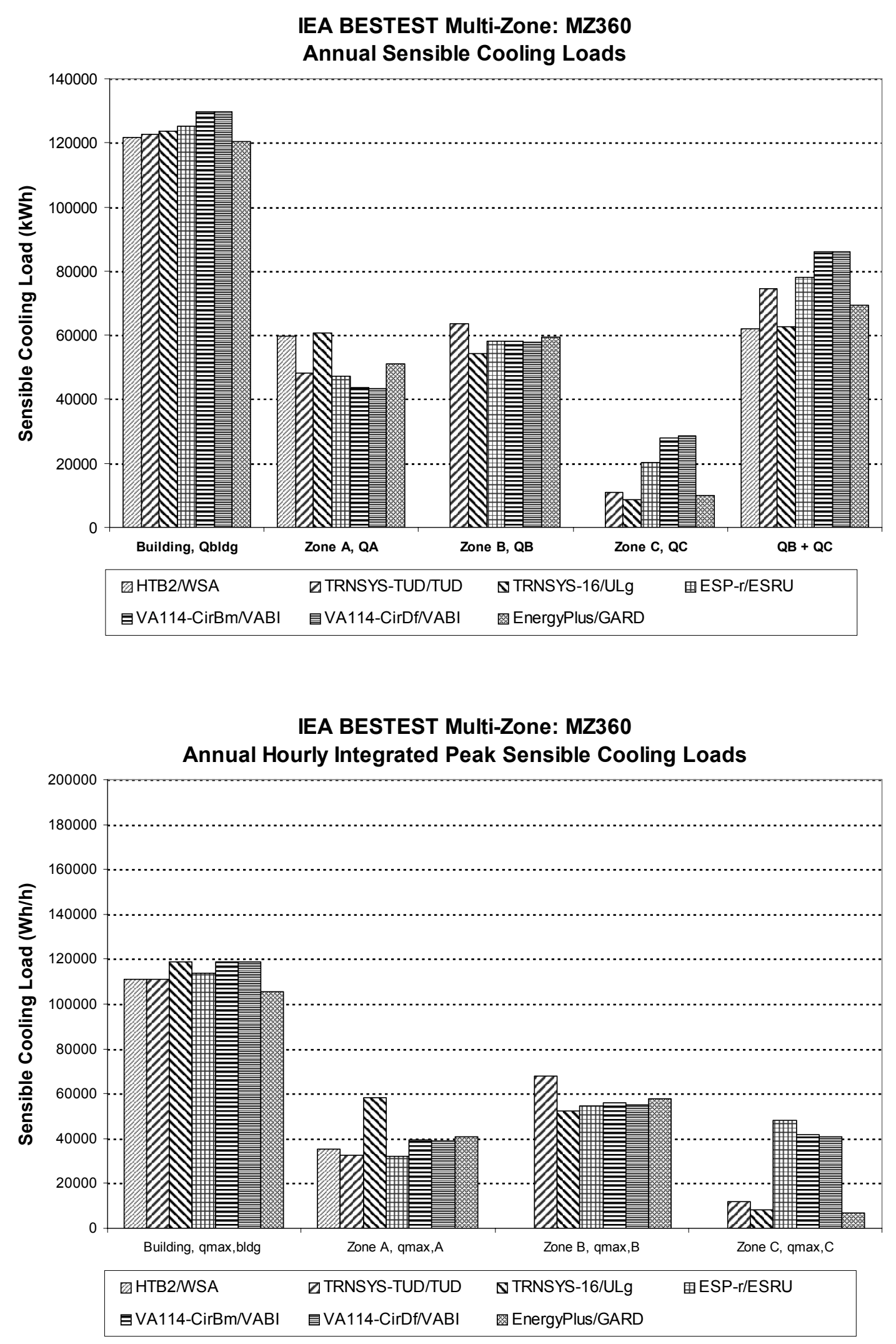

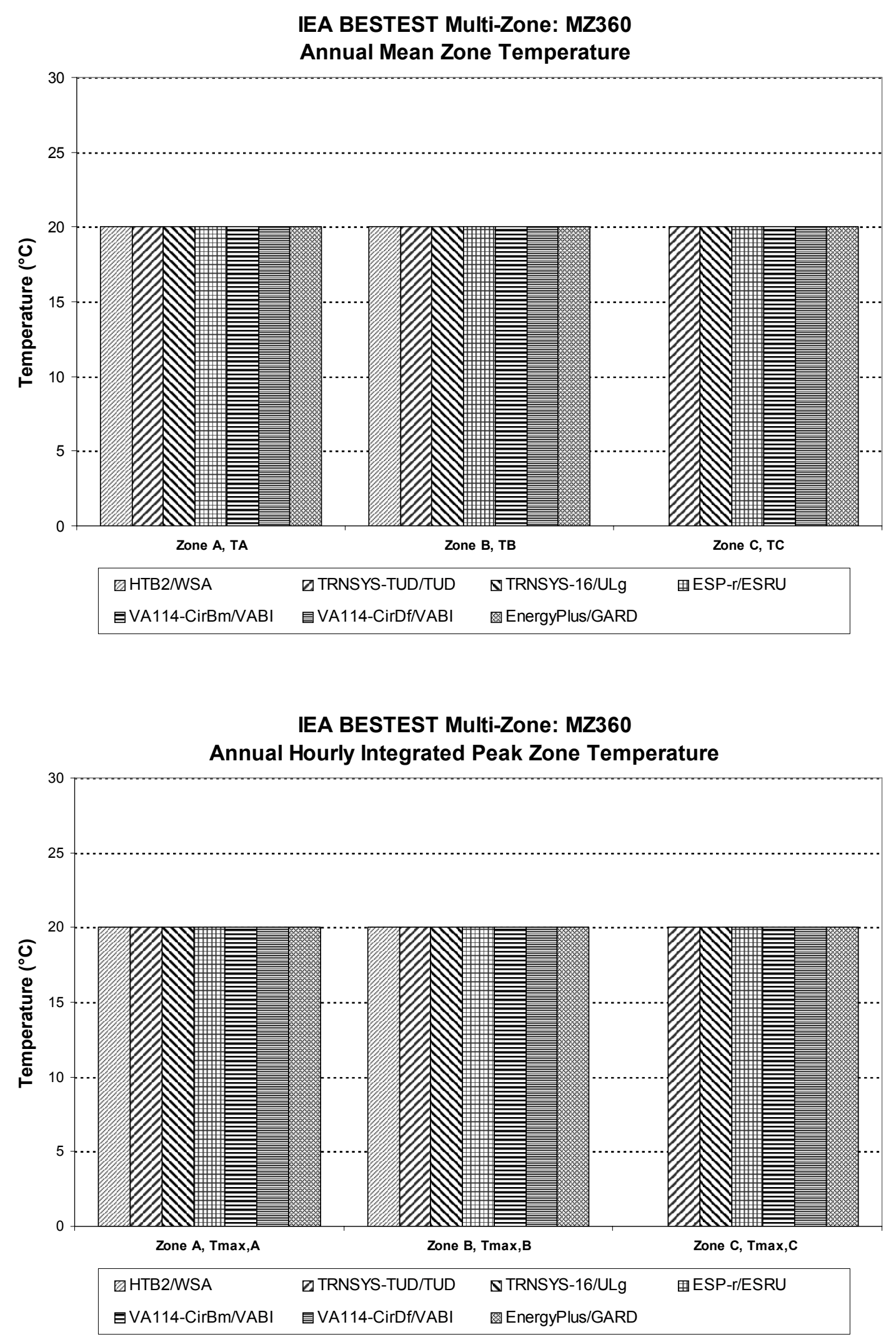

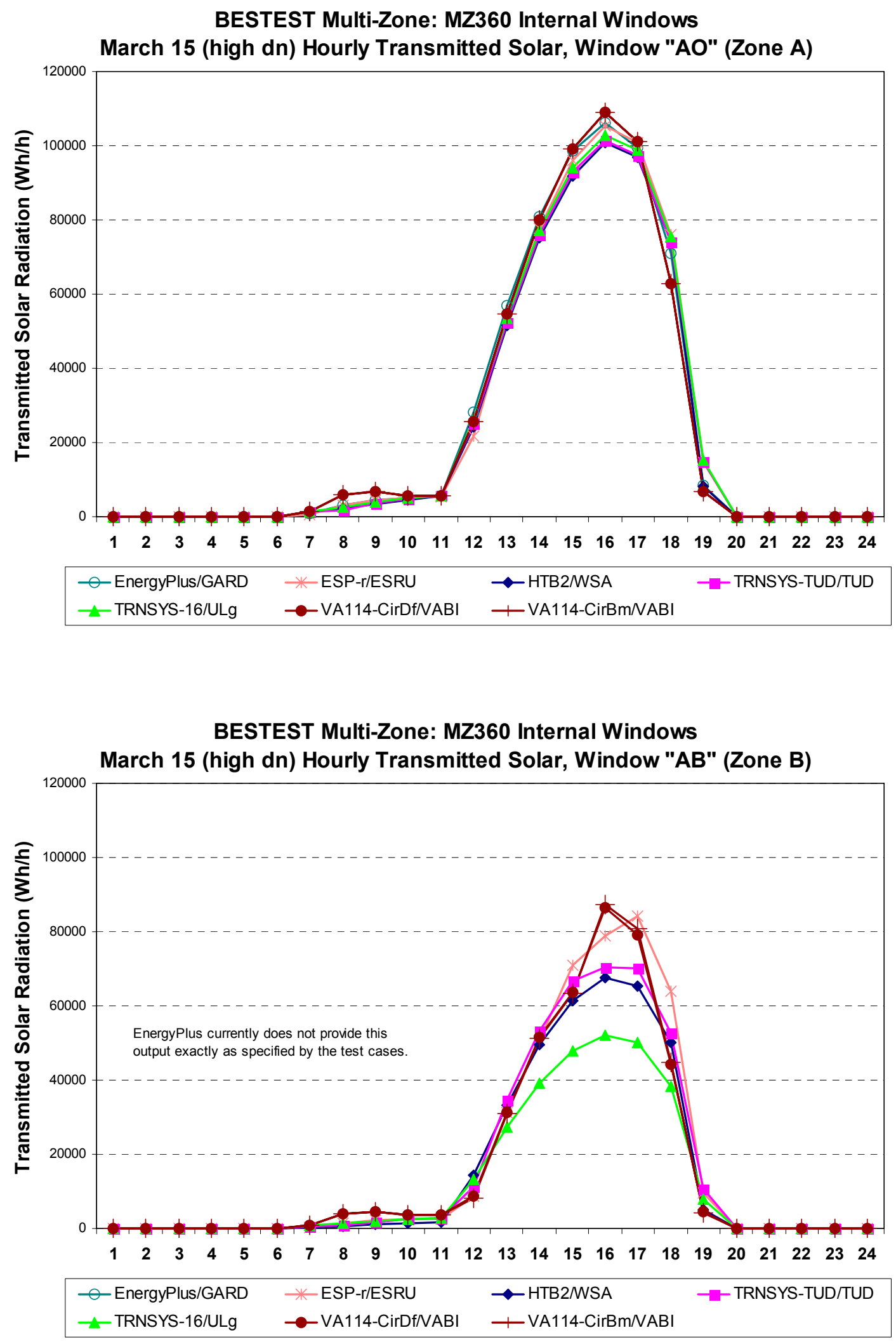

210 

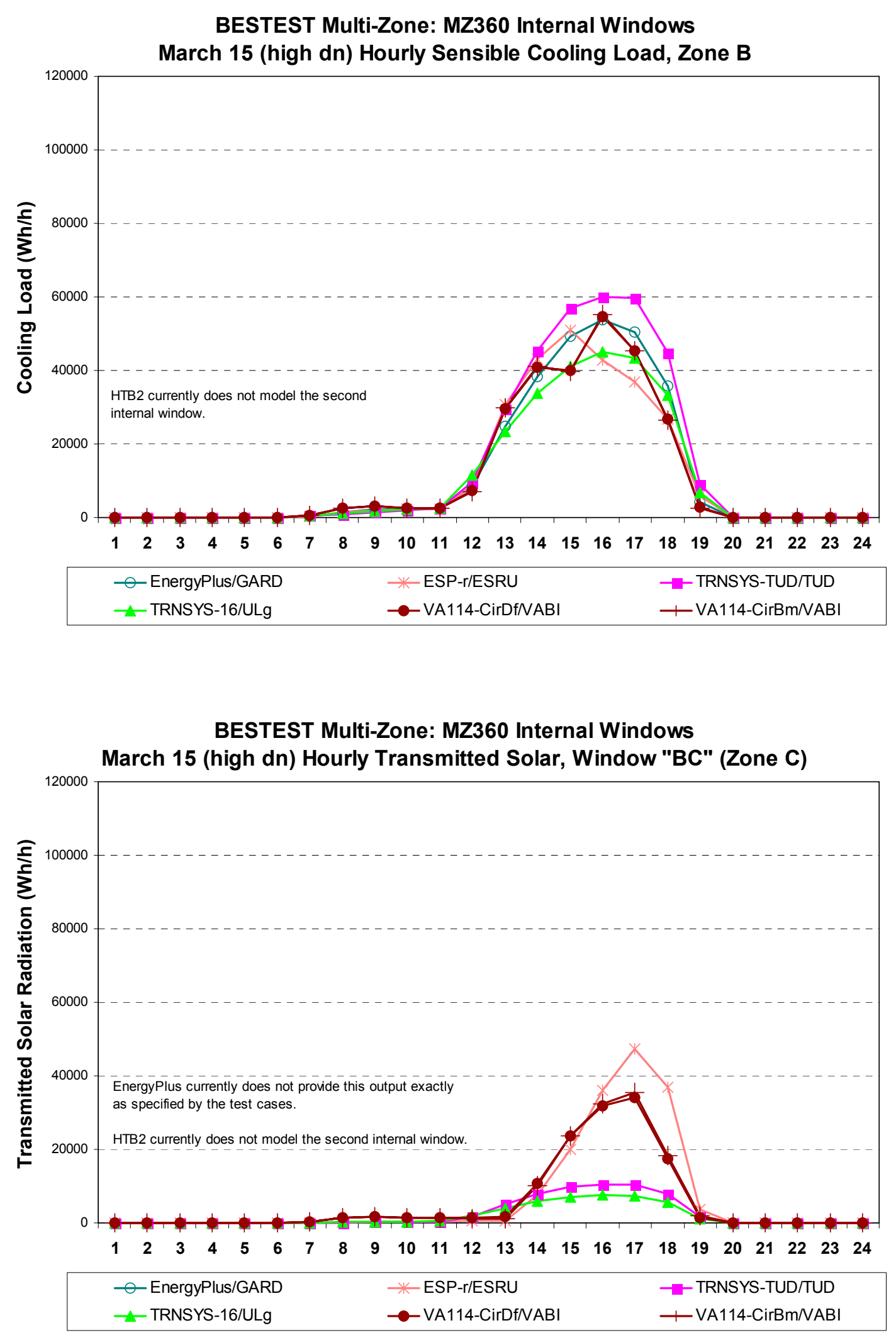

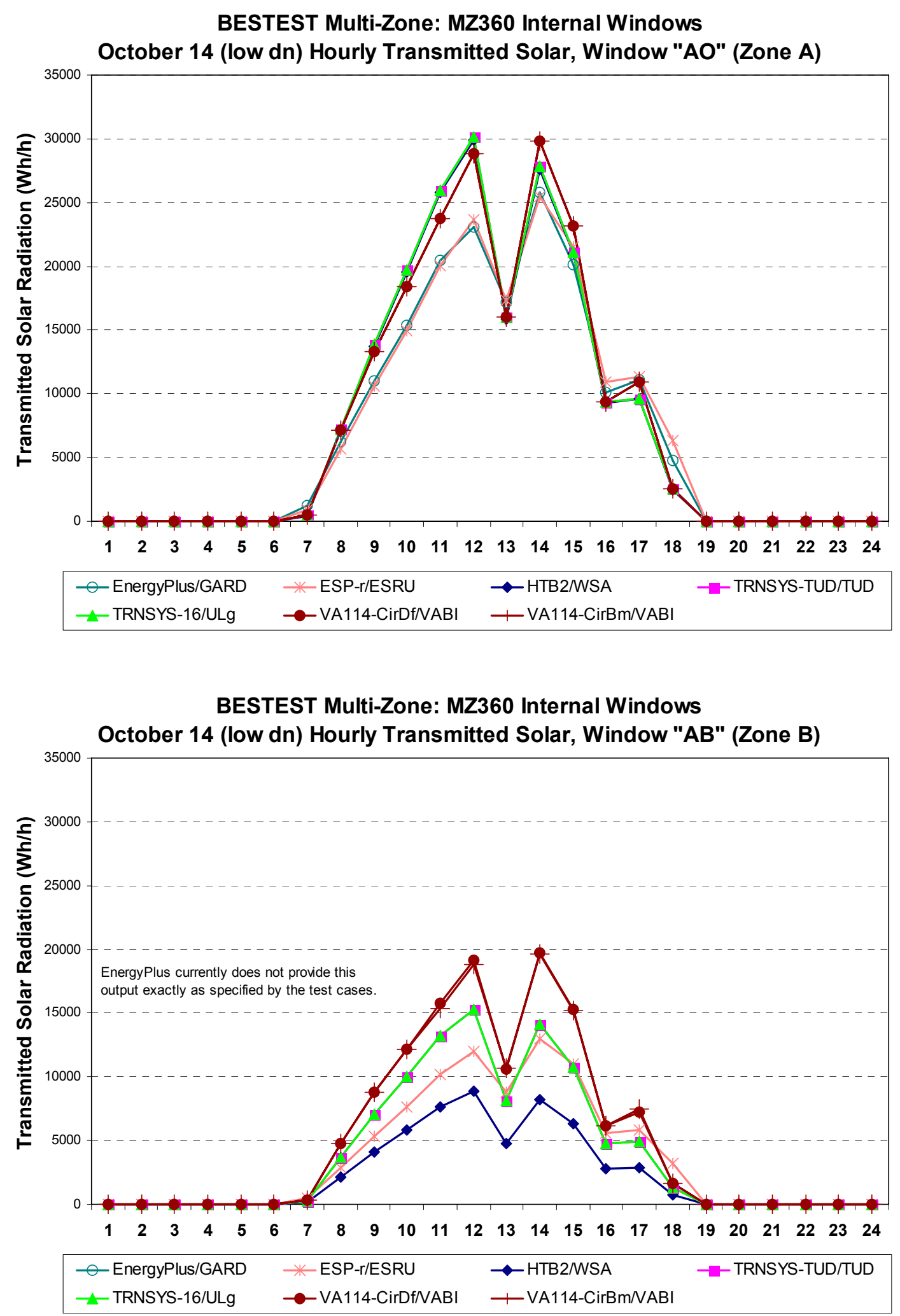

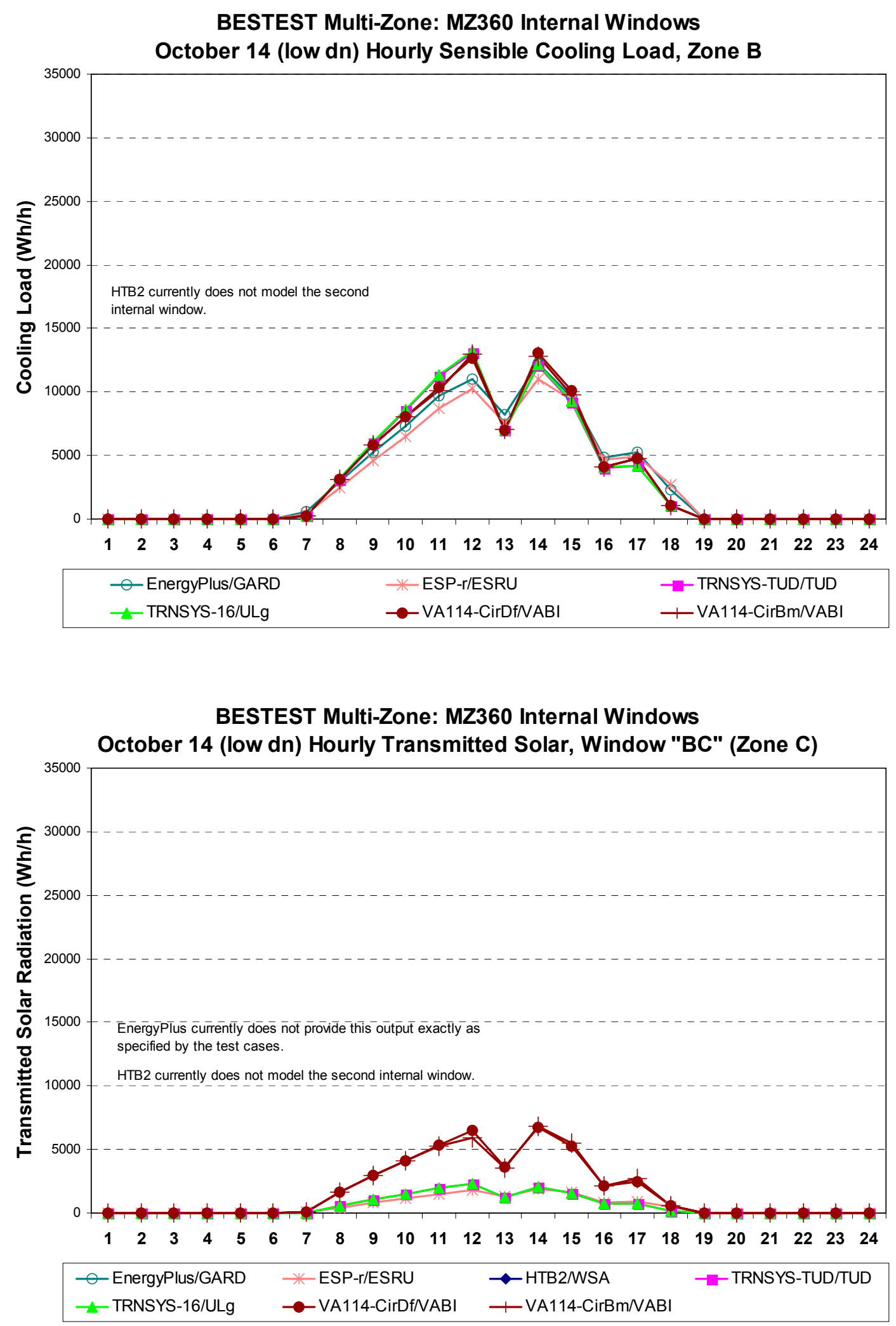


\section{Case MZ320 Steady-State Zone Air Temperatures and Cooling Load}

\begin{tabular}{|c|c|c|c|c|c|c|c|c|c|c|c|c|c|}
\hline & & & & & & & & & & & Statisti & All Resu & \\
\hline & $\begin{array}{l}\text { HTB2 } \\
\text { WSA }\end{array}$ & TRNSYS-TUD & TRNSYS-16 & $\begin{array}{l}\text { COMFIE } \\
\text { FAMP }\end{array}$ & $\begin{array}{l}\text { ESP-r } \\
\text { ESRH }\end{array}$ & CODYRUN & $\begin{array}{r}\text { VA114 } \\
\text { VARI }\end{array}$ & EnergyPlus & KoZiBu & Analytical & in & & (Max-Min) \\
\hline $\mathrm{T}_{\mathrm{A}}\left({ }^{\circ} \mathrm{C}\right)$ & 31.06 & 31.06 & 30.99 & 31.06 & 31.06 & 31.93 & 31.10 & 31.06 & 31.06 & 1.06 & 30.99 & 31.93 & $3.0 \%$ \\
\hline$\| T_{B}\left({ }^{\circ} \mathrm{C}\right)$ & 24.80 & 24.80 & 24.76 & 24.80 & 24.80 & 24.65 & 24.80 & 24.80 & 24.80 & 24.80 & 24.65 & 24.80 & $0.6 \%$ \\
\hline $\mathrm{T}_{\mathrm{C}}\left({ }^{\circ} \mathrm{C}\right)$ & 15.00 & 15.00 & 15.00 & 15.00 & 15.00 & 15.00 & 15.00 & 15.00 & 15.00 & 15.00 & 15.00 & 15.00 & $0.0 \%$ \\
\hline$q_{c}(W h / h)$ & 1541 & 1541 & 1546 & 1541 & 1541 & 1517 & 1541 & 1541 & 1541 & 1541 & 1517 & 1546 & $1.9 \%$ \\
\hline
\end{tabular}




\section{Summary Tables for Multi-Zone Shading Cases MZ340, MZ350, MZ355}

These are compilation summaries of "shading by model" raw results tables, which follow after the summary tables.

MZ340, MZ350, MZ355 Calorimetry, Annual Sensible Cooling Load Summary: Zones, Building

\begin{tabular}{|c|c|c|c|c|c|c|c|c|c|c|}
\hline & \multirow{2}{*}{\multicolumn{3}{|c|}{$\begin{array}{l}\text { Statistics, All Results } \\
\text { (Max-Min) }\end{array}$}} \\
\hline \multicolumn{8}{|c|}{$\begin{array}{c}\text { Annual Sensible Cooling Load, } \mathbf{Q}(\mathbf{k W h} / \mathbf{y}) \\
\text { HTB2 TRNSYS-TUD TRNSYS-16 ESP-r VA114-CirBm VA114-CirDf EnergyPlus }\end{array}$} & & & \\
\hline & WSA & TUD & $U$. Liège & ESRU & VABI & VABI & GARD & Min & Max & /Mean \\
\hline MZ340, Zone A & 12353 & 12454 & 12501 & 12290 & 12846 & 12849 & 12431 & 12290 & 12849 & $4.5 \%$ \\
\hline MZ350, Zone B & 6247 & 6319 & 6317 & 5867 & 6425 & 6671 & 6052 & 5867 & 6671 & $12.8 \%$ \\
\hline MZ350, Zone E & 6460 & 6535 & 6534 & 6098 & 6685 & 6895 & 6291 & 6098 & 6895 & $12.3 \%$ \\
\hline MZ350, Zone A & 8337 & 8338 & 8323 & 8011 & 8625 & 8730 & 8258 & 8011 & 8730 & $8.6 \%$ \\
\hline MZ350, Zone D & 8702 & 8714 & 8696 & 8404 & 9044 & 9113 & 8642 & 8404 & 9113 & $8.1 \%$ \\
\hline MZ350, Zone C & 8567 & 8634 & 8667 & 8485 & 9388 & 8873 & 9193 & 8485 & 9388 & $10.2 \%$ \\
\hline MZ350, Zone F & 8639 & 8708 & 8732 & 8582 & 9452 & 8935 & 9264 & 8582 & 9452 & $9.8 \%$ \\
\hline MZ355, Zone B & & & & & 6420 & 6668 & 6053 & 6053 & 6668 & $9.6 \%$ \\
\hline MZ355, Zone E & & & & & 6685 & 6895 & 6291 & 6291 & 6895 & $9.1 \%$ \\
\hline MZ355, Zone A & & & & & 8620 & 8726 & 8259 & 8259 & 8726 & $5.5 \%$ \\
\hline MZ355, Zone D & & & & & 9034 & 9106 & 8642 & 8642 & 9106 & $5.2 \%$ \\
\hline MZ340, Building & 74117 & 74725 & 75005 & 73741 & 77079 & 77092 & 74585 & 73741 & 77092 & $4.5 \%$ \\
\hline MZ350, Building & 46953 & 47249 & 47268 & 45447 & 49619 & 49217 & 47701 & 45447 & 49619 & $8.8 \%$ \\
\hline MZ355, Building & & & & & 30802 & 31437 & 29245 & 29245 & 31437 & $7.2 \%$ \\
\hline
\end{tabular}

MZ340, MZ350, MZ355 Calorimetry, Annual Peak Cooling Load Summary: Zones, Building

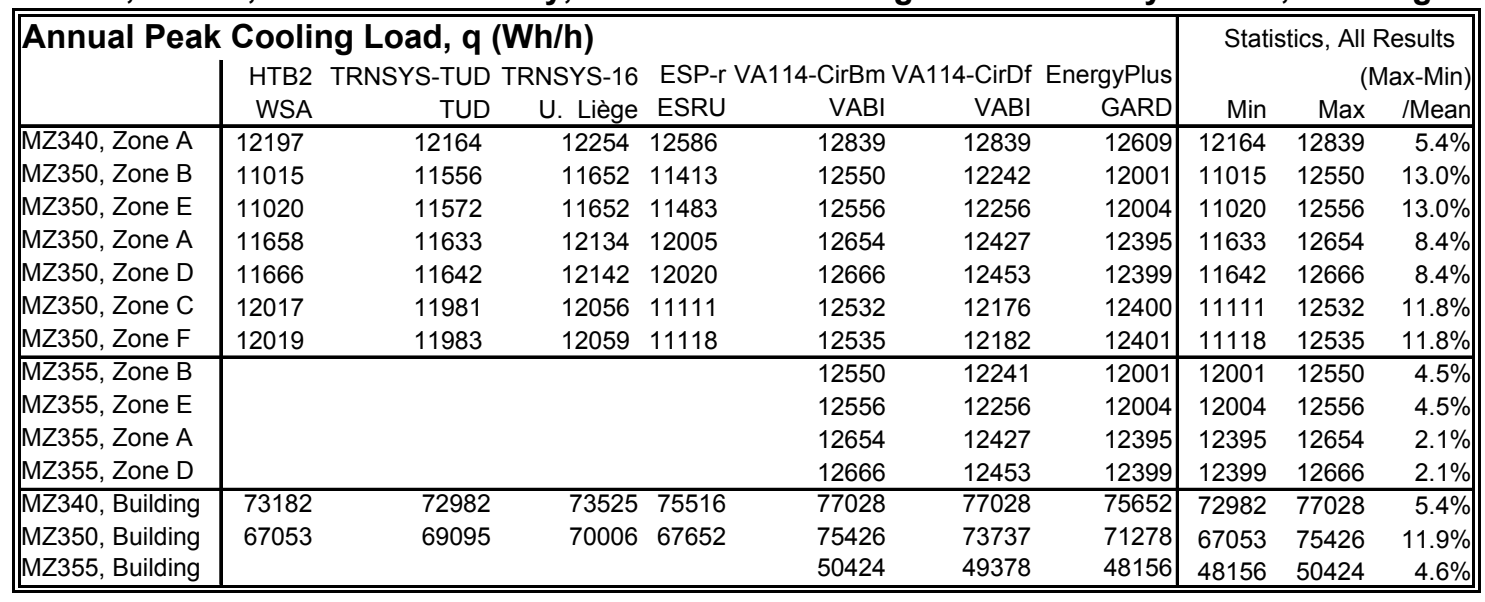

Note: sum of individual zone peak loads is greater than building peak load because individual zone peak loads are non-coincident whereas overall building peak load is based on coincident zone loads. 
MZ350-MZ340, MZ355-MZ340 Delta Annual Cooling Load Summary: Zones, Building

\begin{tabular}{|c|c|c|c|c|c|c|c|c|c|c|}
\hline \multicolumn{8}{|c|}{ Delta Annual Cooling Load, del Q (kWh/y) } & \multicolumn{3}{|c|}{ Statistics, All Results } \\
\hline & HTB2 & TRNSYS-TUD & TRNSYS-16 & ESP-r & VA114-CirBm & VA114-CirDf & EnergyPlus & & & Max-Min) \\
\hline & WSA & TUD & U. Liège & ESRU & VABI & VABI & GARD & Min & Max & /Mean \\
\hline MZ350-MZ340, Zone B & -6106 & -6135 & -6184 & -6423 & -6422 & -6178 & -6378 & -6423 & -6106 & $-5.1 \%$ \\
\hline MZ350-MZ340, Zone E & -5893 & -5919 & -5967 & -6192 & -6161 & -5954 & -6140 & -6192 & -5893 & $-5.0 \%$ \\
\hline MZ350-MZ340, Zone A & -4015 & -4116 & -4178 & -4279 & -4221 & -4119 & -4173 & -4279 & -4015 & $-6.3 \%$ \\
\hline MZ350-MZ340, Zone D & -3650 & -3741 & -3805 & -3886 & -3802 & -3736 & -3789 & -3886 & -3650 & $-6.2 \%$ \\
\hline MZ350-MZ340, Zone C & -3786 & -3820 & -3834 & -3805 & -3458 & -3976 & -3238 & -3976 & -3238 & $-19.9 \%$ \\
\hline MZ350-MZ340, Zone F & -3714 & -3746 & -3769 & -3708 & -3394 & -3914 & -3166 & -3914 & -3166 & $-20.6 \%$ \\
\hline MZ355-MZ340, Zone B & & & & & -6427 & -6181 & -6378 & -6427 & -6181 & $-3.9 \%$ \\
\hline MZ355-MZ340, Zone E & & & & & -6161 & -5954 & -6140 & -6161 & -5954 & $-3.4 \%$ \\
\hline MZ355-MZ340, Zone A & & & & & -4226 & -4123 & -4172 & -4226 & -4123 & $-2.5 \%$ \\
\hline MZ355-MZ340, Zone D & & & & & -3812 & -3743 & -3788 & -3812 & -3743 & $-1.8 \%$ \\
\hline MZ350-MZ340, Building & -27164 & -27476 & -27737 & -28294 & -27460 & -27875 & -26884 & -28294 & -26884 & $-5.1 \%$ \\
\hline MZ355-MZ340, Building & & & & & -46277 & -45655 & -45340 & -46277 & -45340 & $-2.0 \%$ \\
\hline
\end{tabular}

MZ350-MZ340, MZ355-MZ340, Delta Hourly Annual Peak Cooling Load Summary: Zones, Building

\begin{tabular}{|c|c|c|c|c|c|c|c|c|c|c|}
\hline & \multirow{2}{*}{\multicolumn{3}{|c|}{$\begin{array}{l}\text { Statistics, All Results } \\
\text { (Max-Min) }\end{array}$}} \\
\hline \multicolumn{4}{|c|}{$\begin{array}{l}\text { Delta Annual Peak Cooling Load, del q (Wh/h) } \\
\qquad \begin{array}{l}\text { HTB2 TRNSYS-TUD TRNSYS-16 }\end{array}\end{array}$} & \multirow{2}{*}{$\begin{array}{l}\text { ESP-r } \\
\text { ESRU }\end{array}$} & \multirow{2}{*}{$\begin{array}{r}\text { VA114-CirBm } \\
\text { VABI }\end{array}$} & \multirow{2}{*}{$\begin{array}{r}\text { VA114-CirDf } \\
\text { VABI }\end{array}$} & \multirow{2}{*}{$\begin{array}{r}\text { EnergyPlus } \\
\text { GARD }\end{array}$} & & & \\
\hline & WSA & TUD & U. Liège & & & & & Min & Max & /Mean \\
\hline MZ350-MZ340, Zone B & -1183 & -608 & -602 & -1173 & -289 & -597 & -608 & -1183 & -289 & $-123.6 \%$ \\
\hline MZ350-MZ340, Zone E & -1177 & -592 & -602 & -1103 & -282 & -582 & -605 & -1177 & -282 & $-126.8 \%$ \\
\hline MZ350-MZ340, Zone A & -539 & -531 & -121 & -581 & -185 & -412 & -214 & -581 & -121 & $-124.8 \%$ \\
\hline MZ350-MZ340, Zone D & -531 & -522 & -112 & -566 & -172 & -385 & -210 & -566 & -112 & $-127.3 \%$ \\
\hline MZ350-MZ340, Zone C & -180 & -183 & -198 & -1475 & -307 & -662 & -209 & -1475 & -180 & $-281.9 \%$ \\
\hline MZ350-MZ340, Zone F & -178 & -181 & -195 & -1468 & -303 & -656 & -208 & -1468 & -178 & $-283.1 \%$ \\
\hline MZ355-MZ340, Zone B & & & & & -289 & -598 & -608 & -608 & -289 & $-64.0 \%$ \\
\hline MZ355-MZ340, Zone E & & & & & -282 & -582 & -605 & -605 & -282 & $-66.0 \%$ \\
\hline MZ355-MZ340, Zone A & & & & & -185 & -412 & -214 & -412 & -185 & $-84.0 \%$ \\
\hline MZ355-MZ340, Zone D & & & & & -172 & -385 & -210 & -385 & -172 & $-83.4 \%$ \\
\hline MZ350-MZ340, Building & -6129 & -3887 & -3519 & -7864 & -1602 & -3291 & -4374 & -7864 & -1602 & $-142.9 \%$ \\
\hline MZ355-MZ340, Building & & & & & -26604 & -27650 & -27496 & -27650 & -26604 & $-3.8 \%$ \\
\hline
\end{tabular}

Note: absolute value of sum of individual zone peak load differences is less than absolute value of building peak load difference because individual zone peak loads are non-coincident whereas overall building peak load is based on coincident zone loads (as noted on previous page). 
MZ340 West-Facing Annual Incident Solar Radiation: Total, Beam, Diffuse

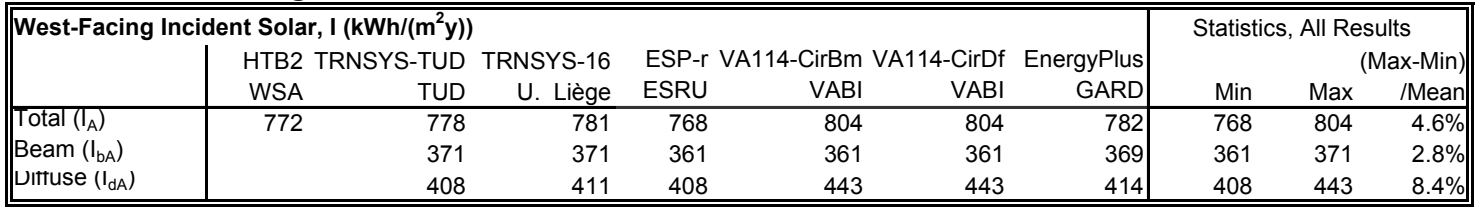

MZ340, MZ350, MZ355 Annual Transmitted Solar Summary: Total, Beam, Diffuse

\begin{tabular}{|c|c|c|c|c|c|c|c|c|c|c|}
\hline \multicolumn{8}{|c|}{ |Annual Transmitted TOTAL Solar, Itr (kWh/y) } & \multirow{2}{*}{\multicolumn{3}{|c|}{$\begin{array}{l}\text { Statistics, All Results } \\
\text { (Max-Min }\end{array}$}} \\
\hline & \multicolumn{2}{|c|}{ HTB2 TRNSYS-TUD } & \multirow{2}{*}{$\begin{array}{r}\text { TRNSYS-16 } \\
\text { U. Liège }\end{array}$} & \multicolumn{3}{|c|}{ ESP-r VA114-CirBm VA114-CirDf } & \multirow{2}{*}{$\begin{array}{r}\text { EnergyPlus } \\
\text { GARD }\end{array}$} & & & \\
\hline & WSA & TUD & & ESRU & VABI & VABI & & Min & Max & /Mean \\
\hline MZ340, Zone A & 12353 & 12454 & 12504 & 12290 & 12844 & 12847 & 12429 & 12290 & 12847 & $4.4 \%$ \\
\hline MZ350, Zone B & 6247 & 6319 & 6317 & 5867 & 6423 & 6669 & 6052 & 5867 & 6669 & $12.8 \%$ \\
\hline MZ350, Zone E & 6460 & 6535 & 6534 & 6098 & 6683 & 6893 & 6290 & 6098 & 6893 & $12.2 \%$ \\
\hline MZ350, Zone A & 8337 & 8338 & 8323 & 8011 & 8623 & 8728 & 8257 & 8011 & 8728 & $8.6 \%$ \\
\hline MZ350, Zone D & 8702 & 8714 & 8696 & 8404 & 9041 & 9111 & 8641 & 8404 & 9111 & $8.1 \%$ \\
\hline MZ350, Zone C & 8567 & 8634 & 8667 & 8485 & 9386 & 8871 & 9192 & 8485 & 9386 & $10.2 \%$ \\
\hline MZ350, Zone F & 8639 & 8708 & 8732 & 8582 & 9450 & 8932 & 9263 & 8582 & 9450 & $9.8 \%$ \\
\hline MZ355, Zone B & & & & & 6418 & 6666 & 6052 & 6052 & 6666 & $9.6 \%$ \\
\hline MZ355, Zone E & & & & & 6683 & 6893 & 6290 & 6290 & 6893 & $9.1 \%$ \\
\hline MZ355, Zone A & & & & & 8618 & 8724 & 8257 & 8257 & 8724 & $5.5 \%$ \\
\hline MZ355, Zone D & & & & & 9032 & 9104 & 8641 & 8641 & 9104 & $5.2 \%$ \\
\hline \multicolumn{8}{|c|}{ |Annual Transmitted BEAM Solar, Itrb (kWh/y) } & \multicolumn{3}{|c|}{ Statistics, All Results } \\
\hline & \multicolumn{2}{|c|}{ HTB2 TRNSYS-TUD } & TRNSYS-16 & \multicolumn{3}{|c|}{ ESP-r VA114-CirBm VA114-CirDf } & EnergyPlus & \multicolumn{3}{|c|}{ (Max-Min) } \\
\hline & WSA & TUD & U. Liège & ESRU & VABI & VABI & GARD & Min & Max & /Mean \\
\hline MZ340, Zone A & 5894 & 5933 & 5930 & 5768 & 5769 & 5769 & 5875 & 5768 & 5933 & $2.8 \%$ \\
\hline MZ350, Zone B & 2426 & 2431 & 2397 & 2397 & 2385 & 2385 & 2428 & 2385 & 2431 & $1.9 \%$ \\
\hline MZ350, Zone E & 2574 & 2579 & 2546 & 2541 & 2537 & 2537 & 2574 & 2537 & 2579 & $1.6 \%$ \\
\hline MZ350, Zone A & 3674 & 3625 & 3572 & 3556 & 3531 & 3531 & 3613 & 3531 & 3674 & $4.0 \%$ \\
\hline MZ350, Zone D & 3919 & 3873 & 3816 & 3796 & 3782 & 3782 & 3857 & 3782 & 3919 & $3.6 \%$ \\
\hline MZ350, Zone C & 5032 & 5056 & 5060 & 4602 & 4911 & 4911 & 4988 & 4602 & 5060 & $9.3 \%$ \\
\hline MZ350, Zone F & 5068 & 5095 & 5089 & 4631 & 4939 & 4939 & 5026 & 4631 & 5095 & $9.3 \%$ \\
\hline MZ355, Zone B & & & & & 2382 & 2382 & 2428 & 2382 & 2428 & $1.9 \%$ \\
\hline ||MZ355, Zone E & & & & & 2537 & 2537 & 2574 & 2537 & 2574 & $1.5 \%$ \\
\hline MZ355, Zone A & & & & & 3527 & 3527 & 3613 & 3527 & 3613 & $2.4 \%$ \\
\hline MZ355, Zone D & & & & & 3774 & 3774 & 3857 & 3774 & 3857 & $2.2 \%$ \\
\hline \multicolumn{8}{|c|}{ ||Annual Transmitted DIFFUSE Solar, Itrd (kWh/y) } & \multicolumn{3}{|c|}{ Statistics, All Results } \\
\hline & \multicolumn{2}{|c|}{ HTB2 TRNSYS-TUD } & TRNSYS-16 & \multicolumn{3}{|c|}{ ESP-r VA114-CirBm VA114-CirDf } & EnergyPlus & \multicolumn{3}{|c|}{ (Max-Min) } \\
\hline & WSA & TUD & U. Liège & ESRU & VABI & VABI & GARD & Min & Max & /Mean \\
\hline MZ340, Zone A & 6459 & 6521 & 6574 & 6522 & 7076 & 7078 & 6554 & 6459 & 7078 & $9.3 \%$ \\
\hline MZ350, Zone B & 3821 & 3888 & 3919 & 3470 & 4038 & 4284 & 3623 & 3470 & 4284 & $21.1 \%$ \\
\hline MZ350, Zone E & 3885 & 3956 & 3988 & 3557 & 4146 & 4355 & 3716 & 3557 & 4355 & $20.2 \%$ \\
\hline MZ350, Zone A & 4664 & 4713 & 4751 & 4455 & 5092 & 5197 & 4645 & 4455 & 5197 & $15.5 \%$ \\
\hline MZ350, Zone D & 4784 & 4841 & 4880 & 4608 & 5259 & 5329 & 4784 & 4608 & 5329 & $14.6 \%$ \\
\hline MZ350, Zone C & 3535 & 3578 & 3607 & 3883 & 4475 & 3960 & 4204 & 3535 & 4475 & $24.1 \%$ \\
\hline MZ350, Zone F & 3570 & 3614 & 3643 & 3951 & 4511 & 3994 & 4238 & 3570 & 4511 & $23.9 \%$ \\
\hline MZ355, Zone B & & & & & 4036 & 4284 & 3623 & 3623 & 4284 & $16.6 \%$ \\
\hline MZ355, Zone E & & & & & 4146 & 4355 & 3716 & 3716 & 4355 & $15.7 \%$ \\
\hline MZ355, Zone A & & & & & 5091 & 5197 & 4645 & 4645 & 5197 & $11.1 \%$ \\
\hline MZ355, Zone D & & & & & 5258 & 5329 & 4784 & 4784 & 5329 & $10.6 \%$ \\
\hline
\end{tabular}


MZ350-MZ340, MZ355-MZ340, Delta Annual Shaded Solar: Total, Beam, Diffuse

\begin{tabular}{|c|c|c|c|c|c|c|c|c|c|c|}
\hline \multicolumn{8}{|c|}{$\mid$\begin{tabular}{|l|l|l|} 
Annual Shaded TOTAL, del & (kWh/y)
\end{tabular}} & \multicolumn{3}{|c|}{ Statistics, All Results } \\
\hline & \multicolumn{2}{|c|}{ HTB2 TRNSYS-TUD } & \multirow{2}{*}{$\begin{array}{r}\text { TRNSYS-16 } \\
\text { U. Liège }\end{array}$} & \multirow{2}{*}{$\begin{array}{l}\text { ESP-r } \\
\text { ESRU }\end{array}$} & \multirow{2}{*}{$\begin{array}{r}\text { VA114-CirBm } \\
\text { VABI }\end{array}$} & \multirow{2}{*}{$\begin{array}{r}\text { VA114-CirDf } \\
\text { VABI }\end{array}$} & \multirow{2}{*}{$\begin{array}{r}\text { EnergyPlus } \\
\text { GARD }\end{array}$} & \multirow[b]{2}{*}{ Min } & \multicolumn{2}{|c|}{ (Max-Min) } \\
\hline & WSA & TUD & & & & & & & Max & /Mean \\
\hline MZ350-MZ340, Zone B & -6106 & -6135 & -6187 & -6423 & -6421 & -6178 & -6377 & -6423 & -6106 & $-5.1 \%$ \\
\hline MZ350-MZ340, Zone E & -5893 & -5919 & -5970 & -6192 & -6161 & -5954 & -6139 & -6192 & -5893 & $-5.0 \%$ \\
\hline MZ350-MZ340, Zone A & -4015 & -4116 & -4181 & -4279 & -4221 & -4119 & -4172 & -4279 & -4015 & $-6.3 \%$ \\
\hline MZ350-MZ340, Zone D & -3650 & -3741 & -3808 & -3886 & -3803 & -3736 & -3788 & -3886 & -3650 & $-6.2 \%$ \\
\hline MZ350-MZ340, Zone C & -3786 & -3820 & -3837 & -3805 & -3458 & -3976 & -3237 & -3976 & -3237 & $-20.0 \%$ \\
\hline MZ350-MZ340, Zone F & -3714 & -3746 & -3772 & -3708 & -3394 & -3915 & -3165 & -3915 & -3165 & $-20.6 \%$ \\
\hline MZ355-MZ340, Zone B & & & & & -6426 & -6181 & -6377 & -6426 & -6181 & $-3.9 \%$ \\
\hline MZ355-MZ340, Zone E & & & & & -6161 & -5954 & -6139 & -6161 & -5954 & $-3.4 \%$ \\
\hline MZ355-MZ340, Zone A & & & & & -4226 & -4123 & -4172 & -4226 & -4123 & $-2.5 \%$ \\
\hline MZ355-MZ340, Zone D & & & & & -3812 & -3743 & -3788 & -3812 & -3743 & $-1.8 \%$ \\
\hline \multicolumn{8}{|c|}{ Annual Shaded BEAM, del trb $_{\text {thWh/y) }}$} & \multicolumn{3}{|c|}{ "Statistics, All Results } \\
\hline & \multicolumn{2}{|c|}{ HTB2 TRNSYS-TUD } & TRNSYS-16 & \multirow{2}{*}{$\begin{array}{l}\text { ESP-r } \\
\text { ESRU }\end{array}$} & \multirow{2}{*}{$\begin{array}{r}\text { VA114-CirBm } \\
\text { VABI }\end{array}$} & \multirow{2}{*}{$\begin{array}{r}\text { VA114-CirDf } \\
\text { VABI }\end{array}$} & \multirow{2}{*}{$\begin{array}{r}\text { EnergyPlus } \\
\text { GARD }\end{array}$} & \multicolumn{3}{|c|}{ (Max-Min) } \\
\hline & WSA & TUD & U. Liège & & & & & Min & Max & /Mean \\
\hline MZ350-MZ340, Zone B & -3468 & -3502 & -3532 & -3371 & -3384 & -3384 & -3447 & -3532 & -3371 & $-4.7 \%$ \\
\hline MZ350-MZ340, Zone E & -3320 & -3354 & -3384 & -3227 & -3232 & -3232 & -3301 & -3384 & -3227 & $-4.8 \%$ \\
\hline MZ350-MZ340, Zone A & -2220 & -2308 & -2358 & -2212 & -2238 & -2238 & -2262 & -2358 & -2212 & $-6.5 \%$ \\
\hline MZ350-MZ340, Zone D & -1975 & -2060 & -2113 & -1972 & -1987 & -1987 & -2018 & -2113 & -1972 & $-7.0 \%$ \\
\hline MZ350-MZ340, Zone C & -862 & -877 & -870 & -1166 & -858 & -858 & -887 & -1166 & -858 & $-33.8 \%$ \\
\hline MZ350-MZ340, Zone F & -826 & -838 & -841 & -1137 & -830 & -830 & -849 & -1137 & -826 & $-35.4 \%$ \\
\hline MZ355-MZ340, Zone B & & & & & -3387 & -3387 & -3447 & -3447 & -3387 & $-1.8 \%$ \\
\hline MZ355-MZ340, Zone E & & & & & -3232 & -3232 & -3301 & -3301 & -3232 & $-2.1 \%$ \\
\hline MZ355-MZ340, Zone A & & & & & -2242 & -2242 & -2262 & -2262 & -2242 & $-0.9 \%$ \\
\hline MZ355-MZ340, Zone D & & & & & -1995 & -1995 & -2018 & -2018 & -1995 & $-1.1 \%$ \\
\hline \multicolumn{8}{|c|}{ Annual Shaded DIFFUSE, del $\left.\right|_{\text {trd }}(\mathrm{kWh} / \mathrm{y})$} & \multirow{2}{*}{\multicolumn{3}{|c|}{$\begin{array}{r}\text { Statistics, All Results } \\
\text { (Max-Min) }\end{array}$}} \\
\hline & HTB2 & S-TUD & TRNSYS-16 & ESP-r & VA114-CirBm & VA114-CirDf & EnergyPlus & & & \\
\hline & WSA & TUD & U. Liège & ESRU & VABI & VABI & GARD & Min & Max & /Mean \\
\hline MZ350-MZ340, Zone B & -2638 & -2633 & -2655 & -3052 & -3038 & -2794 & -2930 & -3052 & -2633 & $-14.8 \%$ \\
\hline MZ350-MZ340, Zone E & -2573 & -2565 & -2586 & -2965 & -2930 & -2723 & -2838 & -2965 & -2565 & $-14.6 \%$ \\
\hline MZ350-MZ340, Zone A & -1795 & -1808 & -1823 & -2067 & -1984 & -1881 & -1909 & -2067 & -1795 & $-14.4 \%$ \\
\hline MZ350-MZ340, Zone D & -1675 & -1681 & -1694 & -1914 & -1817 & -1749 & -1770 & -1914 & -1675 & $-13.6 \%$ \\
\hline MZ350-MZ340, Zone C & -2924 & -2943 & -2967 & -2639 & -2601 & -3118 & -2350 & -3118 & -2350 & $-27.5 \%$ \\
\hline MZ350-MZ340, Zone F & -2889 & -2907 & -2931 & -2571 & -2565 & -3084 & -2316 & -3084 & -2316 & $-27.9 \%$ \\
\hline MZ355-MZ340, Zone B & & & & & -3040 & -2794 & -2930 & -3040 & -2794 & $-8.4 \%$ \\
\hline MZ355-MZ340, Zone E & & & & & -2930 & -2723 & -2838 & -2930 & -2723 & $-7.3 \%$ \\
\hline MZ355-MZ340, Zone A & & & & & -1985 & -1881 & -1909 & -1985 & -1881 & $-5.4 \%$ \\
\hline MZ355-MZ340, Zone D & & & & & -1818 & -1749 & -1770 & -1818 & -1749 & $-3.9 \%$ \\
\hline
\end{tabular}


MZ340, MZ350, MZ355 Calorimetry, Annual Mean Zone Air Temperature Summary

\begin{tabular}{|c|c|c|c|c|c|c|c|c|c|c|}
\hline \multicolumn{8}{|c|}{ Annual Mean Zone Air Temperature, T $\left({ }^{\circ} \mathrm{C}\right)$} & \multirow{2}{*}{\multicolumn{3}{|c|}{$\begin{array}{l}\text { Statistics, All Results } \\
\text { (Max-Min) }\end{array}$}} \\
\hline & \multicolumn{2}{|c|}{ HTB2 TRNSYS-TUD } & \multirow{2}{*}{$\begin{array}{r}\text { TRNSYS-16 } \\
\text { U. Liège }\end{array}$} & \multicolumn{3}{|c|}{ ESP-r VA114-CirBm VA114-CirDf } & \multirow{2}{*}{$\begin{array}{r}\text { EnergyPlus } \\
\text { GARD }\end{array}$} & & & \\
\hline & WSA & TUD & & ESRU & VABI & VABI & & Min & Max & /Mean \\
\hline MZ340 & 20.00 & 20.00 & 20.00 & 20.00 & 20.00 & 20.00 & 20.00 & 20.00 & 20.00 & $0.0 \%$ \\
\hline MZ350, Zone E & 20.00 & 20.00 & 20.00 & 20.00 & 20.00 & 20.00 & 20.00 & 20.00 & 20.00 & $0.0 \%$ \\
\hline MZ350, Zone A & 20.00 & 20.00 & 20.00 & 20.00 & 20.00 & 20.00 & 20.00 & 20.00 & 20.00 & $0.0 \%$ \\
\hline MZ350, Zone F & 20.00 & 20.00 & 20.00 & 20.00 & 20.00 & 20.00 & 20.00 & 20.00 & 20.00 & $0.0 \%$ \\
\hline MZ355, Zone B & & & & & 20.00 & 20.00 & 20.00 & 20.00 & 20.00 & $0.0 \%$ \\
\hline MZ355, Zone E & & & & & 20.00 & 20.00 & 20.00 & 20.00 & 20.00 & $0.0 \%$ \\
\hline MZ355, Zone A & & & & & 20.00 & 20.00 & 20.00 & 20.00 & 20.00 & $0.0 \%$ \\
\hline MZ355, Zone D & & & & & 20.00 & 20.00 & 20.00 & 20.00 & 20.00 & $0.0 \%$ \\
\hline
\end{tabular}

Annual Hourly-Integrated Maximum Zone Air Temperature Summary

\begin{tabular}{|c|c|c|c|c|c|c|c|c|c|c|}
\hline \multicolumn{8}{|c|}{ Annual Maximum Zone Air Temperature, $\mathrm{T}_{\max }\left({ }^{\circ} \mathrm{C}\right)$} & \multirow{2}{*}{\multicolumn{3}{|c|}{$\begin{array}{r}\text { Statistics, All Results } \\
\text { (Max-Min) }\end{array}$}} \\
\hline & HTB2 & TRNSYS-TUD & TRNSYS-16 & ESP-r & VA114-CirBm & VA114-CirDf & EnergyPlus & & & \\
\hline & WSA & TUD & U. Liège & ESRU & VABI & VABI & GARD & Min & Max & /Mean \\
\hline MZ340 & 20.00 & 20.00 & 20.00 & 20.00 & 20.00 & 20.00 & 20.00 & 20.00 & 20.00 & $0.0 \%$ \\
\hline MZ350, Zone B & 20.00 & 20.00 & 20.00 & 20.00 & 20.00 & 20.00 & 20.00 & 20.00 & 20.00 & $0.0 \%$ \\
\hline MZ350, Zone E & 20.00 & 20.00 & 20.00 & 20.00 & 20.00 & 20.00 & 20.00 & 20.00 & 20.00 & $0.0 \%$ \\
\hline MZ350, Zone A & 20.00 & 20.00 & 20.00 & 20.00 & 20.00 & 20.00 & 20.00 & 20.00 & 20.00 & $0.0 \%$ \\
\hline MZ350, Zone D & 20.00 & 20.00 & 20.00 & 20.00 & 20.00 & 20.00 & 20.00 & 20.00 & 20.00 & $0.0 \%$ \\
\hline MZ350, Zone C & 20.00 & 20.00 & 20.00 & 20.00 & 20.00 & 20.00 & 20.00 & 20.00 & 20.00 & $0.0 \%$ \\
\hline MZ350, Zone F & 20.00 & 20.00 & 20.00 & 20.00 & 20.00 & 20.00 & 20.00 & 20.00 & 20.00 & $0.0 \%$ \\
\hline MZ355, Zone B & & & & & 20.00 & 20.00 & 20.00 & 20.00 & 20.00 & $0.0 \%$ \\
\hline MZ355, Zone E & & & & & 20.00 & 20.00 & 20.00 & 20.00 & 20.00 & $0.0 \%$ \\
\hline MZ355, Zone A & & & & & 20.00 & 20.00 & 20.00 & 20.00 & 20.00 & $0.0 \%$ \\
\hline MZ355, Zone D & & & & & 20.00 & 20.00 & 20.00 & 20.00 & 20.00 & $0.0 \%$ \\
\hline
\end{tabular}




\section{Shading-by-Model Raw Data Tables for Cases MZ340, MZ350, MZ355}

MZ340, MZ350, MZ355 Calorimetry, Annual Sensible Cooling Loads

\begin{tabular}{|c|c|c|c|c|c|c|c|}
\hline \multicolumn{8}{|c|}{ Building, $\mathbf{Q}_{\text {bldg }}(\mathrm{kWh})$} \\
\hline & \multicolumn{2}{|c|}{ HTB2 TRNSYS-TUD } & \multirow{2}{*}{$\begin{array}{r}\text { TRNSYS-16 } \\
\text { U. Liège }\end{array}$} & \multicolumn{3}{|c|}{ ESP-r VA114-CirBm VA114-CirDf } & \multirow{2}{*}{$\begin{array}{r}\text { EnergyPlus } \\
\text { GARD }\end{array}$} \\
\hline & WSA & TUD & & ESRU & VABI & VABI & \\
\hline MZ340 & 74117 & 74725 & 75005 & 73741 & 77079 & 77092 & 74585 \\
\hline MZ350a & & 47249 & & & 49619 & 49217 & \\
\hline MZ350b & & & & & & & 47701 \\
\hline MZ350c & & & 47268 & 45447 & & & 47701 \\
\hline MZ350d & 46953 & & & & & & 47701 \\
\hline MZ355 & & & & & 30802 & 31437 & 29245 \\
\hline \multicolumn{8}{|c|}{ Zone $\mathrm{A}, \mathrm{Q}_{\mathrm{A}}(\mathrm{kWh})$} \\
\hline & HTB2 & TRNSYS-TUD & TRNSYS-16 & ESP-r & t-CirBm & 4-CirDf & EnergyPlus \\
\hline & WSA & TUD & U. Liège & ESRU & VABI & VABI & GARD \\
\hline MZ340 & 12353 & 12454 & 12501 & 12290 & 12846 & 12849 & 12431 \\
\hline MZ350a & & 8338 & & & 8625 & 8730 & \\
\hline MZ350b & & & & & & & 8258 \\
\hline MZ350c & & & 8323 & 8011 & & & 8258 \\
\hline MZ350d & 8337 & & & & & & 8258 \\
\hline |MZ355 & & & & & 8620 & 8726 & 8259 \\
\hline \multicolumn{8}{|c|}{ Zone B, $Q_{B}(k W h)$} \\
\hline & HTB2 & TRNSYS-TUD & TRNSYS-16 & ESP-r & 1-CirBm & 4-CirDf & EnergyPlus \\
\hline & WSA & TUD & U. Liège & ESRU & VABI & VABI & GARD \\
\hline MZ340 & 12353 & 12454 & 12501 & 12290 & 12847 & 12849 & 12431 \\
\hline MZ350a & & 6319 & & & 6425 & 6671 & \\
\hline MZ350b & & & & & & & 6052 \\
\hline MZ350c & & & 6317 & 5867 & & & 6052 \\
\hline MZ350d & 6247 & & & & & & 6052 \\
\hline MZ355 & & & & & 6420 & 6668 & 6053 \\
\hline \multicolumn{8}{|c|}{ Zone C, $\mathbf{Q}_{\mathrm{C}}(\mathrm{kWh})$} \\
\hline & HTB2 & TRNSYS-TUD & TRNSYS-16 & ESP-r & t-CirBm & 4-CirDf & EnergyPlus \\
\hline & WSA & TUD & U. Liège & ESRU & VABI & VABI & GARD \\
\hline MZ340 & 12353 & 12454 & 12501 & 12290 & 12846 & 12849 & 12431 \\
\hline MZ350a & & 8634 & & & 9388 & 8873 & \\
\hline MZ350b & & & & & & & 9193 \\
\hline MZ350c & & & 8667 & 8485 & & & 9193 \\
\hline MZ350d & 8567 & & & & & & 9193 \\
\hline MZ355 & $\mathrm{n} / \mathrm{a}$ & $\mathrm{n} / \mathrm{a}$ & $\mathrm{n} / \mathrm{a}$ & $\mathrm{n} / \mathrm{a}$ & $\mathrm{n} / \mathrm{a}$ & $\mathrm{n} / \mathrm{a}$ & $\mathrm{n} / \mathrm{a}$ \\
\hline \multicolumn{8}{|c|}{ Zone D, Q $\mathrm{D}_{\mathrm{D}}(\mathrm{kWh})$} \\
\hline & HTB2 & TRNSYS-TUD & TRNSYS-16 & ESP-r & 1-CirBm & 4-CirDf & EnergyPlus \\
\hline & WSA & TUD & U. Liège & ESRU & VABI & VABI & GARD \\
\hline MZ340 & 12353 & 12454 & 12501 & 12290 & 12846 & 12849 & 12431 \\
\hline MZ350a & & 8714 & & & 9044 & 9113 & \\
\hline MZ350b & & & & & & & 8642 \\
\hline MZ350c & & & 8696 & 8404 & & & 8642 \\
\hline MZ350d & 8702 & & & & & & 8642 \\
\hline MZ355 & & & & & 9034 & 9106 & 8642 \\
\hline \multicolumn{8}{|c|}{ Zone E, $Q_{E}(k W h)$} \\
\hline & HTB2 & TRNSYS-TUD & TRNSYS-16 & ESP-r & 4-CirBm & 4-CirDf & EnergyPlus \\
\hline & WSA & TUD & U. Liège & ESRU & VABI & VABI & GARD \\
\hline MZ340 & 12353 & 12454 & 12501 & 12290 & 12846 & 12849 & 12431 \\
\hline MZ350a & & 6535 & & & 6685 & 6895 & \\
\hline MZ350b & & & & & & & 6291 \\
\hline MZ350c & & & 6534 & 6098 & & & 6291 \\
\hline MZ350d & 6460 & & & & & & 6291 \\
\hline MZ355 & & & & & 6685 & 6895 & 6291 \\
\hline \multicolumn{8}{|c|}{ Zone $F, Q_{F}(k W h)$} \\
\hline & HTB2 & TRNSYS-TUD & TRNSYS-16 & ESP-r & -CirBm & 4-CirDf & EnergyPlus \\
\hline & WSA & TUD & U. Liège & ESRU & VABI & VABI & GARD \\
\hline MZ340 & 12353 & 12454 & 12501 & 12290 & 12846 & 12849 & 12431 \\
\hline MZ350a & & 8708 & & & 9452 & 8935 & \\
\hline$M Z 350 b$ & & & & & & & 9264 \\
\hline MZ350c & & & 8732 & 8582 & & & 9264 \\
\hline MZ350d & 8639 & & & & & & 9264 \\
\hline MZ355 & $\mathrm{n} / \mathrm{a}$ & $\mathrm{n} / \mathrm{a}$ & $\mathrm{n} / \mathrm{a}$ & $\mathrm{n} / \mathrm{a}$ & $\mathrm{n} / \mathrm{a}$ & $\mathrm{n} / \mathrm{a}$ & $\mathrm{n} / \mathrm{a}$ \\
\hline
\end{tabular}


MZ340, MZ350, MZ355, Annual Hourly Integrated Peak Sensible Cooling Loads

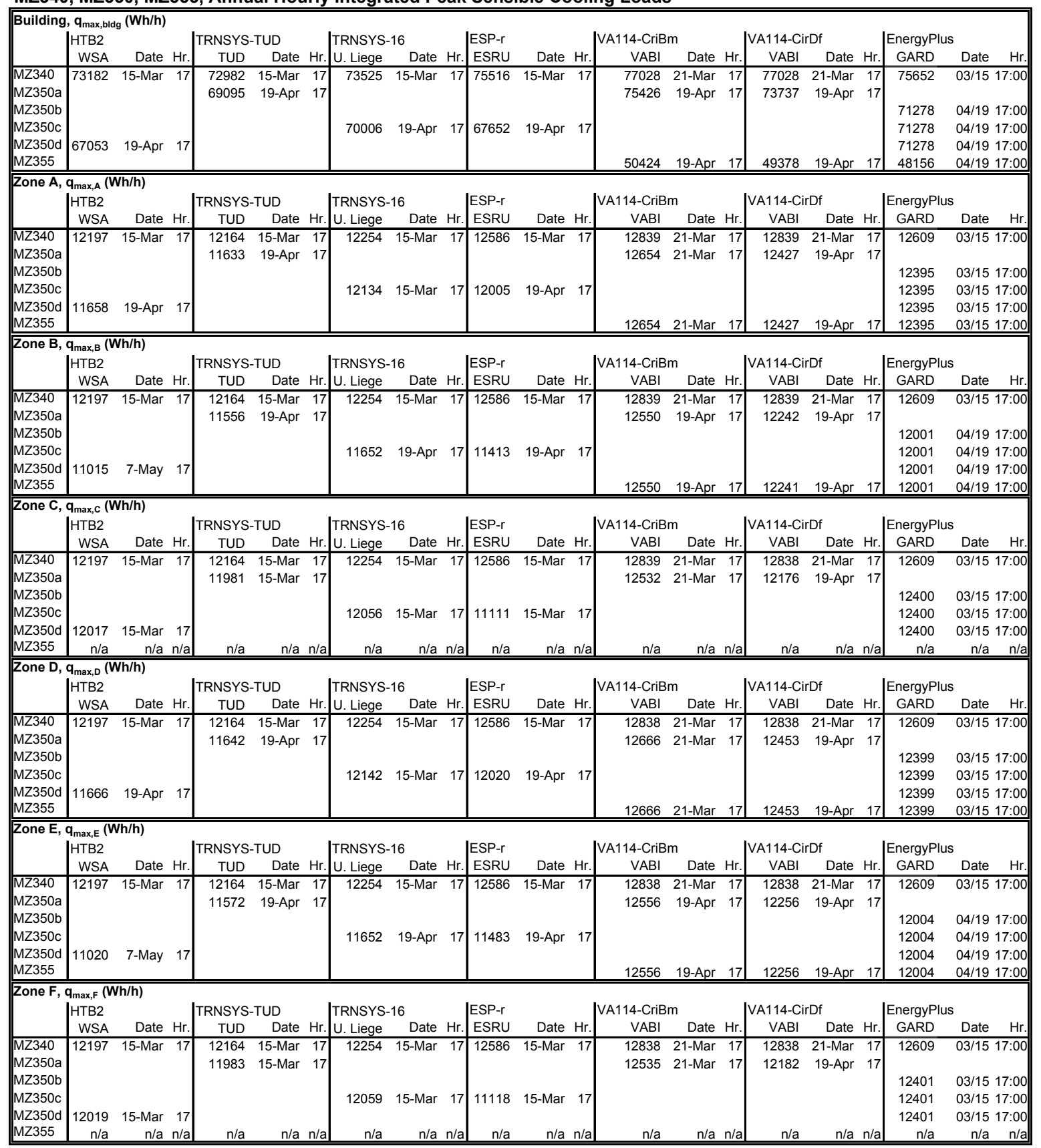


MZ350-MZ340, MZ355-MZ340 Delta Annual Sensible Cooling Loads

\begin{tabular}{|c|c|c|c|c|c|c|}
\hline \multicolumn{7}{|c|}{ Building, del $\mathbf{Q}_{\text {bldg }}(\mathrm{kWh})$} \\
\hline & HTB2 TRNSYS-TUD & TRNSYS-16 & ESP-r & VA114-CirBm & VA114-CirDf & EnergyPlus \\
\hline & WSA & U. Liège & ESRU & VABI & VABI & GARD \\
\hline MZ350a-MZ340 & -27476 & & & -27460 & -27875 & \\
\hline MZ350b-MZ340 & & & & & & -26884 \\
\hline MZ350c-MZ340 & & -27737 & -28294 & & & -26884 \\
\hline MZ350d-MZ340 & -27164 & & & & & -26884 \\
\hline MZ355-MZ340 & & & & -46277 & -45655 & -45340 \\
\hline \multicolumn{7}{|c|}{ Zone A, del $Q_{A}(k W h)$} \\
\hline & HTB2 TRNSYS-TUD & TRNSYS-16 & ESP-r & VA114-CirBm & VA114-CirDf & EnergyPlus \\
\hline & WSA & U. Liège & ESRU & VABI & VABI & GARD \\
\hline MZ350a-MZ340 & -4116 & & & -4221 & -4119 & \\
\hline MZ350b-MZ340 & & & & & & -4173 \\
\hline MZ350c-MZ340 & & -4178 & -4279 & & & -4173 \\
\hline MZ350d-MZ340 & -4015 & & & & & -4173 \\
\hline MZ355-MZ340 & & & & -4226 & -4123 & -4172 \\
\hline \multicolumn{7}{|c|}{ Zone B, del Q $Q_{B}(k W h)$} \\
\hline & HTB2 TRNSYS-TUD & TRNSYS-16 & ESP-r & VA114-CirBm & VA114-CirDf & EnergyPlus \\
\hline & WSA & U. Liège & ESRU & VABI & VABI & GARD \\
\hline MZ350a-MZ340 & -6135 & & & -6422 & -6178 & \\
\hline MZ350b-MZ340 & & & & & & -6378 \\
\hline MZ350c-MZ340 & & -6184 & -6423 & & & -6378 \\
\hline MZ350d-MZ340 & -6106 & & & & & -6378 \\
\hline MZ355-MZ340 & & & & -6427 & -6181 & -6378 \\
\hline \multicolumn{7}{|c|}{ Zone C, del $Q_{C}(k W h)$} \\
\hline & HTB2 TRNSYS-TUD & TRNSYS-16 & ESP-r & VA114-CirBm & VA114-CirDf & EnergyPlus \\
\hline & WSA $\quad$ TUD & U. Liège & ESRU & VABI & VABI & GARD \\
\hline MZ350a-MZ340 & -3820 & & & -3458 & -3976 & \\
\hline MZ350b-MZ340 & & & & & & -3238 \\
\hline MZ350c-MZ340 & & -3834 & -3805 & & & -3238 \\
\hline MZ350d-MZ340 & -3786 & & & & & -3238 \\
\hline MZ355-MZ340 & & & & & & \\
\hline \multicolumn{7}{|c|}{ Zone $\mathrm{D}$, del $\mathrm{Q}_{\mathrm{D}}(\mathrm{kWh})$} \\
\hline & HTB2 TRNSYS-TUD & TRNSYS-16 & ESP-r & VA114-CirBm & VA114-CirDf & EnergyPlus \\
\hline & WSA & U. Liège & ESRU & VABI & VABI & GARD \\
\hline MZ350a-MZ340 & -3741 & & & -3802 & -3736 & \\
\hline MZ350b-MZ340 & & & & & & -3789 \\
\hline MZ350c-MZ340 & & -3805 & -3886 & & & -3789 \\
\hline MZ350d-MZ340 & -3650 & & & & & -3789 \\
\hline MZ355-MZ340 & & & & -3812 & -3743 & -3788 \\
\hline \multicolumn{7}{|c|}{ Zone E, del $Q_{E}(k W h)$} \\
\hline & HTB2 TRNSYS-TUD & TRNSYS-16 & ESP-r & VA114-CirBm & VA114-CirDf & EnergyPlus \\
\hline & WSA $\quad$ TUD & U. Liège & ESRU & VABI & VABI & GARD \\
\hline MZ350a-MZ340 & -5919 & & & -6161 & -5954 & \\
\hline MZ350b-MZ340 & & & & & & -6140 \\
\hline MZ350c-MZ340 & & -5967 & -6192 & & & -6140 \\
\hline MZ350d-MZ340 & -5893 & & & & & -6140 \\
\hline MZ355-MZ340 & & & & -6161 & -5954 & -6140 \\
\hline \multicolumn{7}{|c|}{ Zone $\mathrm{F}$, del $\mathrm{Q}_{\mathrm{F}}(\mathrm{kWh})$} \\
\hline & HTB2 TRNSYS-TUD & TRNSYS-16 & ESP-r & VA114-CirBm & VA114-CirDf & EnergyPlus \\
\hline & WSA & U. Liège & ESRU & VABI & $\mathrm{VABI}$ & GARD \\
\hline MZ350a-MZ340 & -3746 & & & -3394 & -3914 & \\
\hline MZ350b-MZ340 & & & & & & -3166 \\
\hline MZ350c-MZ340 & & -3769 & -3708 & & & -3166 \\
\hline $\begin{array}{l}\text { MZ350d-MZ340 } \\
\text { MZ355-MZ340 }\end{array}$ & -3714 & & & & & -3166 \\
\hline
\end{tabular}


MZ340, MZ350, MZ355 Calorimetry, Delta Hourly Integrated Peak Sensible Cooling Loads

\begin{tabular}{|c|c|c|c|c|c|c|}
\hline \multicolumn{7}{|c|}{ Building, del $q_{\text {max,bldg }}(W h / h)$} \\
\hline & HTB2 TRNSYS-TUD & \multirow{2}{*}{$\begin{array}{r}\text { TRNSYS-16 } \\
\text { U. Liège } \\
\end{array}$} & \multirow{2}{*}{$\begin{array}{l}\text { ESP-r } \\
\text { ESRU }\end{array}$} & \multirow{2}{*}{$\begin{array}{r}\text { VA114-CirBm } \\
\text { VABI }\end{array}$} & \multirow{2}{*}{$\begin{array}{r}\text { VA114-CirDf } \\
\text { VABI }\end{array}$} & \multirow{2}{*}{$\begin{array}{r}\text { EnergyPlus } \\
\text { GARD }\end{array}$} \\
\hline & WSA & & & & & \\
\hline MZ350a-MZ340 & -3887 & & & -1602 & -3291 & \\
\hline MZ350b-MZ340 & & & & & & -4374 \\
\hline MZ350c-MZ340 & & -3519 & -7864 & & & -4374 \\
\hline MZ350d-MZ340 & -6129 & & & & & -4374 \\
\hline MZ355-MZ340 & & & & -26604 & -27650 & -27496 \\
\hline \multicolumn{7}{|c|}{ Zone A, del $q_{\max , A}(W h / h)$} \\
\hline & HTB2 TRNSYS-TUD & TRNSYS-16 & ESP-r & VA114-CirBm & VA114-CirDf & EnergyPlus \\
\hline & WSA $\quad$ TUD & U. Liège & ESRU & VABI & VABI & GARD \\
\hline MZ350a-MZ340 & -531 & & & -185 & -412 & \\
\hline MZ350b-MZ340 & & & & & & -214 \\
\hline MZ350c-MZ340 & & -121 & -581 & & & -214 \\
\hline MZ350d-MZ340 & -539 & & & & & -214 \\
\hline MZ355-MZ340 & & & & -185 & -412 & -214 \\
\hline \multicolumn{7}{|c|}{ Zone B, del $q_{\max , B}(W h / h)$} \\
\hline & HTB2 TRNSYS-TUD & TRNSYS-16 & ESP-r & VA114-CirBm & VA114-CirDf & EnergyPlus \\
\hline & WSA & U. Liège & ESRU & VABI & $\mathrm{VABI}$ & GARD \\
\hline MZ350a-MZ340 & -608 & & & -289 & -597 & \\
\hline MZ350b-MZ340 & & & & & & -608 \\
\hline MZ350c-MZ340 & & -602 & -1173 & & & -608 \\
\hline MZ350d-MZ340 & -1183 & & & & & -608 \\
\hline MZ355-MZ340 & & & & -289 & -598 & -608 \\
\hline \multicolumn{7}{|c|}{ Zone C, del $q_{\max , \mathrm{c}}(\mathrm{Wh} / \mathrm{h})$} \\
\hline & HTB2 TRNSYS-TUD & TRNSYS-16 & ESP-r & VA114-CirBm & VA114-CirDf & EnergyPlus \\
\hline & WSA & U. Liège & ESRU & VABI & VABI & GARD \\
\hline MZ350a-MZ340 & -183 & & & -307 & -662 & \\
\hline MZ350b-MZ340 & & & & & & -209 \\
\hline MZ350c-MZ340 & & -198 & -1475 & & & -209 \\
\hline MZ350d-MZ340 & -180 & & & & & -209 \\
\hline MZ355-MZ340 & & & & & & \\
\hline \multicolumn{7}{|c|}{ Zone $D$, del $q_{\max , \mathrm{D}}(\mathrm{Wh} / \mathrm{h})$} \\
\hline & HTB2 TRNSYS-TUD & TRNSYS-16 & ESP-r & VA114-CirBm & VA114-CirDf & EnergyPlus \\
\hline & WSA $\quad$ TUD & U. Liège & ESRU & VABI & VABI & GARD \\
\hline MZ350a-MZ340 & -522 & & & -172 & -385 & \\
\hline MZ350b-MZ340 & & & & & & -210 \\
\hline MZ350c-MZ340 & & -112 & -566 & & & -210 \\
\hline MZ350d-MZ340 & -531 & & & & & -210 \\
\hline MZ355-MZ340 & & & & -172 & -385 & -210 \\
\hline \multicolumn{7}{|c|}{ Zone $\mathrm{E}$, del $\mathrm{q}_{\max , \mathrm{E}}(\mathrm{Wh} / \mathrm{h})$} \\
\hline & HTB2 TRNSYS-TUD & TRNSYS-16 & ESP-r & VA114-CirBm & VA114-CirDf & EnergyPlus \\
\hline & WSA $\quad$ TUD & U. Liège & ESRU & VABI & VABI & GARD \\
\hline MZ350a-MZ340 & -592 & & & -282 & -582 & \\
\hline MZ350b-MZ340 & & & & & & -605 \\
\hline MZ350c-MZ340 & & -602 & -1103 & & & -605 \\
\hline MZ350d-MZ340 & -1177 & & & & & -605 \\
\hline MZ355-MZ340 & & & & -282 & -582 & -605 \\
\hline \multicolumn{7}{|c|}{ Zone $F$, del $q_{\text {max,F }}(W h / h)$} \\
\hline & HTB2 TRNSYS-TUD & TRNSYS-16 & ESP-r & VA114-CirBm & VA114-CirDf & EnergyPlus \\
\hline & WSA & U. Liège & ESRU & $\mathrm{VABI}$ & VABI & GARD \\
\hline MZ350a-MZ340 & -181 & & & -303 & -656 & \\
\hline MZ350b-MZ340 & & & & & & -208 \\
\hline MZ350c-MZ340 & & -195 & -1468 & & & -208 \\
\hline MZ350d-MZ340 & -178 & & & & & -208 \\
\hline MZ355-MZ340 & & & & & & \\
\hline
\end{tabular}


MZ340, MZ350, MZ355 Annual Transmitted Solar Radiation: Zones A, B

\begin{tabular}{|c|c|c|c|c|c|c|c|}
\hline \multicolumn{8}{|c|}{ Transmitted Total Solar, Zone A, $\mathrm{I}_{\mathrm{tr}, \mathrm{A}}(\mathrm{kWh})$} \\
\hline & \multicolumn{2}{|c|}{ HTB2 TRNSYS-TUD } & \multirow{2}{*}{$\begin{array}{r}\text { TRNSYS-16 } \\
\text { U. Liège }\end{array}$} & \multicolumn{3}{|c|}{ ESP-r VA114-CirBm VA114-CirDf } & \multirow{2}{*}{$\begin{array}{r}\text { EnergyPlus } \\
\text { GARD }\end{array}$} \\
\hline & WSA & TUD & & ESRU & VABI & VABI & \\
\hline MZ340 & 12353 & 12454 & 12504 & 12290 & 12844 & 12847 & 12429 \\
\hline MZ350a & & 8338 & & & 8623 & 8728 & \\
\hline MZ350b & & & & & & & 8257 \\
\hline MZ350c & & & 8323 & 8011 & & & 8257 \\
\hline MZ350d & 8337 & & & & & & 8257 \\
\hline MZ355 & & & & & 8618 & 8724 & 8257 \\
\hline \multicolumn{8}{|c|}{ Transmitted Beam Solar, Zone A, Itrb,A $(k W h)$} \\
\hline & HTB2 & S-TUD & TRNSYS-16 & ESP-r & $-\mathrm{CirBm}$ & 4-CirDf & EnergyPlus \\
\hline & WSA & TUD & U. Liège & ESRU & VABI & VABI & GARD \\
\hline MZ340 & 5894 & 5933 & 5930 & 5768 & 5769 & 5769 & 5875 \\
\hline MZ350a & & 3625 & & & 3531 & 3531 & \\
\hline MZ350b & & & & & & & 3613 \\
\hline MZ350c & & & 3572 & 3556 & & & 3613 \\
\hline MZ350d & 3674 & & & & & & 3613 \\
\hline MZ355 & & & & & 3527 & 3527 & 3613 \\
\hline \multicolumn{8}{|c|}{ Transmitted Diffuse Solar, Zone A, $\mathrm{I}_{\mathrm{trd}, \mathrm{A}}(\mathrm{kWh})$} \\
\hline & HTB2 & S-TUD & TRNSYS-16 & ESP-r & $-\mathrm{CirBm}$ & 4-CirDf & EnergyPlus \\
\hline & WSA & TUD & U. Liège & ESRU & VABI & VABI & GARD \\
\hline MZ340 & 6459 & 6521 & 6574 & 6522 & 7076 & 7078 & 6554 \\
\hline MZ350a & & 4713 & & & 5092 & 5197 & \\
\hline MZ350b & & & & & & & 4645 \\
\hline MZ350c & & & 4751 & 4455 & & & 4645 \\
\hline MZ350d & 4664 & & & & & & 4645 \\
\hline MZ355 & & & & & 5091 & 5197 & 4645 \\
\hline \multicolumn{8}{|c|}{ Transmitted Total Solar, Zone $B, I_{t r, B}$ (kWh) } \\
\hline & HTB2 & S-TUD & TRNSYS-16 & ESP-r & $-\mathrm{CirBm}$ & 4-CirDf & EnergyPlus \\
\hline & WSA & TUD & U. Liège & ESRU & VABI & VABI & GARD \\
\hline MZ340 & 12353 & 12454 & 12504 & 12290 & 12844 & 12847 & 12429 \\
\hline MZ350a & & 6319 & & & 6423 & 6669 & \\
\hline MZ350b & & & & & & & 6052 \\
\hline MZ350c & & & 6317 & 5867 & & & 6052 \\
\hline MZ350d & 6247 & & & & & & 6052 \\
\hline MZ355 & & & & & 6418 & 6666 & 6052 \\
\hline \multicolumn{8}{|c|}{ Transmitted Beam Solar, Zone B, $I_{\text {trb,B }}(k W h)$} \\
\hline & HTB2 & S-TUD & TRNSYS-16 & ESP-r & $-\mathrm{CirBm}$ & 4-CirDf & EnergyPlus \\
\hline & WSA & TUD & U. Liège & ESRU & VABI & VABI & GARD \\
\hline MZ340 & 5894 & 5933 & 5930 & 5768 & 5769 & 5769 & 5875 \\
\hline MZ350a & & 2431 & & & 2385 & 2385 & \\
\hline MZ350b & & & & & & & 2428 \\
\hline MZ350c & & & 2397 & 2397 & & & 2428 \\
\hline MZ350d & 2426 & & & & & & 2428 \\
\hline MZ355 & & & & & 2382 & 2382 & 2428 \\
\hline \multicolumn{8}{|c|}{ Transmitted Diffuse Solar, Zone B, $\mathrm{I}_{\text {trd,B }}(\mathrm{kWh})$} \\
\hline & HTB2 & S-TUD & TRNSYS-16 & ESP-r & $-\mathrm{CirBm}$ & 4-CirDf & EnergyPlus \\
\hline & WSA & TUD & U. Liège & ESRU & VABI & VABI & GARD \\
\hline MZ340 & 6459 & 6521 & 6574 & 6522 & 7076 & 7078 & 6554 \\
\hline MZ350a & & 3888 & & & 4038 & 4284 & \\
\hline MZ350b & & & & & & & 3623 \\
\hline MZ350c & & & 3919 & 3470 & & & 3623 \\
\hline MZ350d & 3821 & & & & & & 3623 \\
\hline MZ355 & & & & & 4036 & 4284 & 3623 \\
\hline
\end{tabular}


MZ340, MZ350, MZ355 Annual Transmitted Solar Radiation: Zones C, D

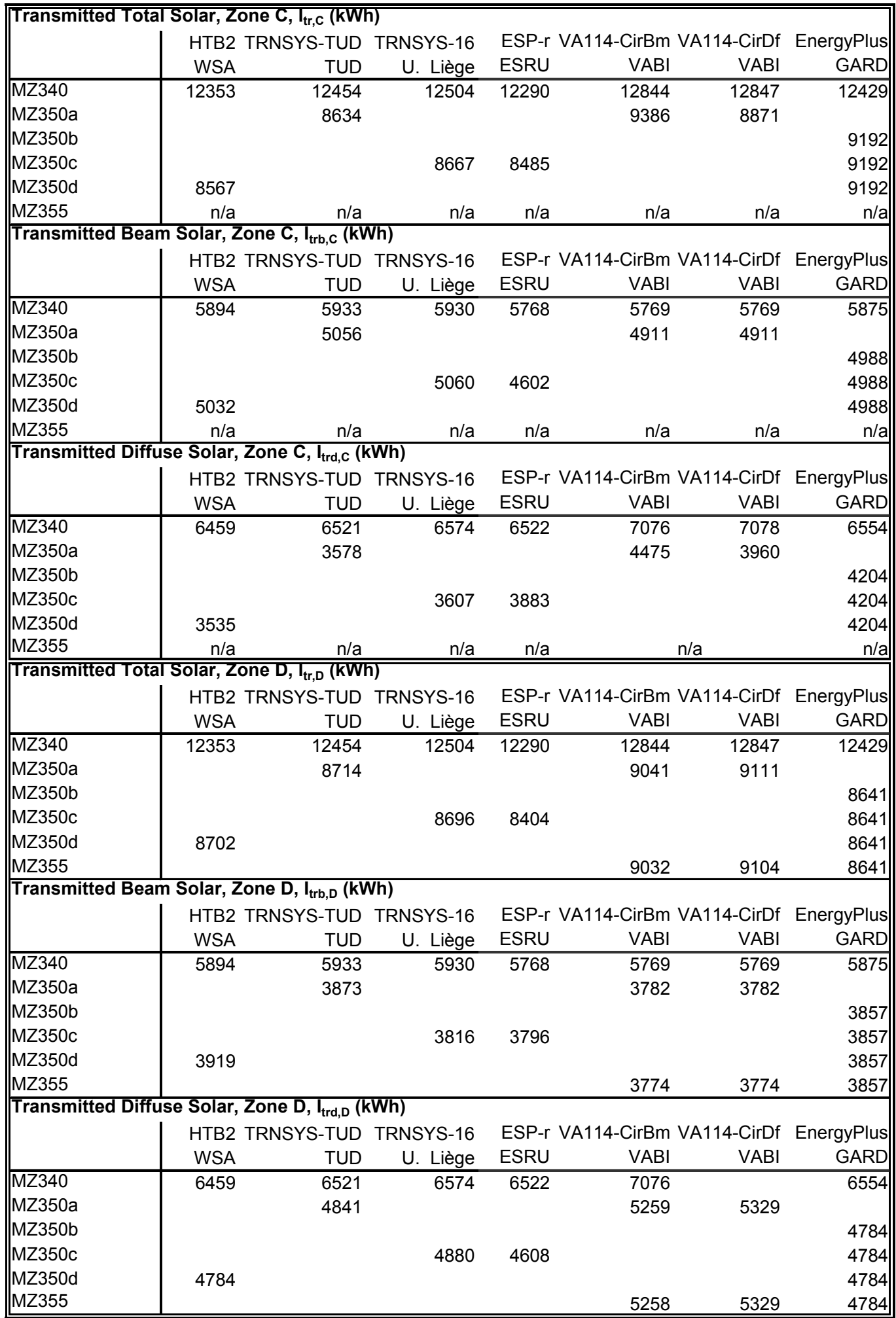


MZ340, MZ350, MZ355 Annual Transmitted Solar Radiation: Zones E, F

\begin{tabular}{|c|c|c|c|c|c|c|}
\hline \\
\hline \multicolumn{2}{|c|}{ Transmitted Total Solar, Zone E, $\mathrm{I}_{\mathrm{tr}, \mathrm{E}}$ (kWh) } & TRNSYS-16 & ESP-r & -CirBm & 4-CirDf & EnergyPlus \\
\hline & WSA & U. Liège & ESRU & VABI & VABI & GARD \\
\hline MZ340 & 12353 & 12504 & 12290 & 12844 & 12847 & 12429 \\
\hline MZ350a & 6535 & & & 6683 & 6893 & 0 \\
\hline MZ350b & & & & & & 6290 \\
\hline MZ350c & & 6534 & 6098 & & & 6290 \\
\hline MZ350d & 6460 & & & & & 6290 \\
\hline MZ355 & & & & 6683 & 6893 & 6290 \\
\hline \multicolumn{7}{|c|}{ Transmitted Beam Solar, Zone E, Itrb,E $(k W h)$} \\
\hline & HTB2 TRNSYS-TUD & TRNSYS-16 & ESP-r & -CirBm & 4-CirDf & EnergyPlus \\
\hline & WSA TUD & U. Liège & ESRU & VABI & VABI & GARD \\
\hline MZ340 & 5894 & 5930 & 5768 & 5769 & 5769 & 5875 \\
\hline MZ350a & 2579 & & & 2537 & 2537 & \\
\hline MZ350b & & & & & & 2574 \\
\hline MZ350c & & 2546 & 2541 & & & 2574 \\
\hline MZ350d & 2574 & & & & & 2574 \\
\hline MZ355 & & & & 2537 & 2537 & 2574 \\
\hline \multicolumn{7}{|c|}{ Transmitted Diffuse Solar, Zone E, $\mathrm{I}_{\text {trd,E }}(\mathrm{kWh})$} \\
\hline & HTB2 TRNSYS-TUD & TRNSYS-16 & ESP-r & -CirBm & 4-CirDf & EnergyPlus \\
\hline & WSA & U. Liège & ESRU & VABI & VABI & GARD \\
\hline MZ340 & 6459 & 6574 & 6522 & 7076 & 7078 & 6554 \\
\hline MZ350a & 3956 & & & 4146 & 4355 & \\
\hline MZ350b & & & & & & 3716 \\
\hline MZ350c & & 3988 & 3557 & & & 3716 \\
\hline MZ350d & 3885 & & & & & 3716 \\
\hline MZ355 & & & & 4146 & 4355 & 3716 \\
\hline \multicolumn{7}{|c|}{ Transmitted Total Solar, Zone $F, \mathrm{I}_{\mathrm{tr}, \mathrm{F}}(\mathrm{kWh})$} \\
\hline & HTB2 TRNSYS-TUD & TRNSYS-16 & ESP-r & -CirBm & 4-CirDf & EnergyPlus \\
\hline & WSA & U. Liège & ESRU & VABI & VABI & GARD \\
\hline MZ340 & 12353 & 12504 & 12290 & 12844 & 12847 & 12429 \\
\hline MZ350a & 8708 & & & 9450 & 8932 & \\
\hline MZ350b & & & & & & 9263 \\
\hline MZ350c & & 8732 & 8582 & & & 9263 \\
\hline MZ350d & 8639 & & & & & 9263 \\
\hline MZ355 & $\mathrm{n} / \mathrm{a}$ & $\mathrm{n} / \mathrm{a}$ & $\mathrm{n} / \mathrm{a}$ & $\mathrm{n} / \mathrm{a}$ & $\mathrm{n} / \mathrm{a}$ & $\mathrm{n} / \mathrm{a}$ \\
\hline \multicolumn{7}{|c|}{ Transmitted Beam Solar, Zone F, $I_{\text {trb,F }}(\mathrm{kWh})$} \\
\hline & HTB2 TRNSYS-TUD & TRNSYS-16 & ESP-r & -CirBm & 4-CirDf & EnergyPlus \\
\hline & WSA & U. Liège & ESRU & VABI & VABI & GARD \\
\hline MZ340 & 5894 & 5930 & 5768 & 5769 & 5769 & 5875 \\
\hline MZ350a & 5095 & & & 4939 & 4939 & \\
\hline MZ350b & & & & & & 5026 \\
\hline MZ350c & & 5089 & 4631 & & & 5026 \\
\hline MZ350d & 5068 & & & & & 5026 \\
\hline MZ355 & $\mathrm{n} / \mathrm{a}$ & $\mathrm{n} / \mathrm{a}$ & $\mathrm{n} / \mathrm{a}$ & $\mathrm{n} / \mathrm{a}$ & $\mathrm{n} / \mathrm{a}$ & $\mathrm{n} / \mathrm{a}$ \\
\hline \multicolumn{7}{|c|}{ Transmitted Diffuse Solar, Zone F, $\mathrm{I}_{\mathrm{trd}, \mathrm{F}}(\mathrm{kWh})$} \\
\hline & HTB2 TRNSYS-TUD & TRNSYS-16 & ESP-r & -CirBm & 4-CirDf & EnergyPlus \\
\hline & WSA & U. Liège & ESRU & VABI & VABI & GARD \\
\hline MZ340 & 6459 & 6574 & 6522 & 7076 & & 6554 \\
\hline MZ350a & 3614 & & & 4511 & 3994 & \\
\hline MZ350b & & & & & & 4238 \\
\hline MZ350c & & 3643 & 3951 & & & 4238 \\
\hline MZ350d & 3570 & & & & & 4238 \\
\hline MZ355 & $\mathrm{n} / \mathrm{a}$ & $\mathrm{n} / \mathrm{a}$ & $\mathrm{n} / \mathrm{a}$ & $n / a$ & $\mathrm{n} / \mathrm{a}$ & $\mathrm{n} / \mathrm{a}$ \\
\hline
\end{tabular}


MZ350-MZ340, MZ355-MZ340, Delta Annual Transmitted TOTAL Solar

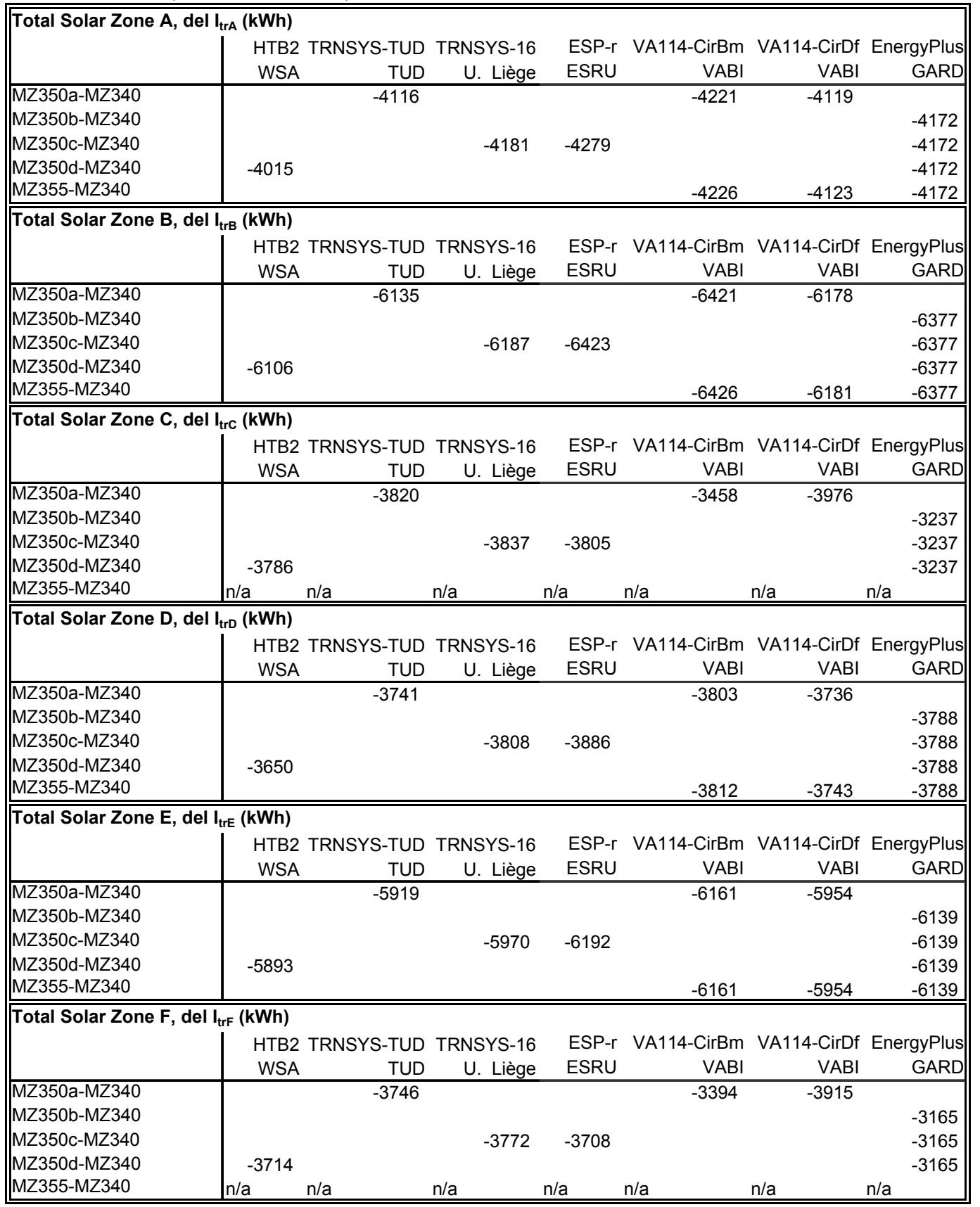


MZ350-MZ340, MZ355-MZ340, Delta Annual Transmitted BEAM Solar

\begin{tabular}{|c|c|c|c|c|c|c|}
\hline \multicolumn{7}{|c|}{ Beam Solar Zone A, del I trbA (kWh) } \\
\hline & HTB2 TRNSYS-TUD & TRNSYS-16 & ESP-r & - VA114-CirBm & VA114-CirDf & EnergyPlus \\
\hline & TUD & U. Liège & ESRU & VABI & VABI & GARD \\
\hline MZ350a-MZ340 & -2308 & & & -2238 & -2238 & \\
\hline MZ350b-MZ340 & & & & & & -2262 \\
\hline MZ350c-MZ340 & & -2358 & -2212 & & & -2262 \\
\hline MZ350d-MZ340 & -2220 & & & & & -2262 \\
\hline MZ355-MZ340 & & & & -2242 & -2242 & -2262 \\
\hline Beam Solar Zon & $\mathrm{I}_{\mathrm{trbB}}(\mathrm{kWh})$ & & & & & \\
\hline & HTB2 TRNSYS-TUD & TRNSYS-16 & ESP-r & VA114-CirBm & VA114-CirDf & EnergyPlus \\
\hline & WSA & U. Liège & ESRU & VABI & VABI & GARD \\
\hline MZ350a-MZ340 & -3502 & & & -3384 & -3384 & \\
\hline MZ350b-MZ340 & & & & & & -3447 \\
\hline MZ350c-MZ340 & & -3532 & -3371 & & & -3447 \\
\hline MZ350d-MZ340 & -3468 & & & & & -3447 \\
\hline MZ355-MZ340 & & & & -3387 & -3387 & -3447 \\
\hline Beam Solar Zon & $\mathrm{I}_{\mathrm{trbc}}(\mathbf{k W h})$ & & & & & \\
\hline & HTB2 TRNSYS-TUD & TRNSYS-16 & ESP-r & VA114-CirBm & VA114-CirDf & EnergyPlus \\
\hline & WSA & U. Liège & ESRU & VABI & VABI & GARD \\
\hline MZ350a-MZ340 & -877 & & & -858 & -858 & \\
\hline MZ350b-MZ340 & & & & & & -887 \\
\hline MZ350c-MZ340 & & -870 & -1166 & & & -887 \\
\hline MZ350d-MZ340 & -862 & & & & & -887 \\
\hline MZ355-MZ340 & $\mathrm{n} / \mathrm{a}$ & $\mathrm{n} / \mathrm{a}$ & $\mathrm{n} / \mathrm{a}$ & $\mathrm{n} / \mathrm{a}$ & $\mathrm{n} / \mathrm{a}$ & $\mathrm{n} / \mathrm{a}$ \\
\hline Beam Solar Zon & $\mathrm{I}_{\mathrm{trbD}}(\mathrm{kWh})$ & & & & & \\
\hline & HTB2 TRNSYS-TUD & TRNSYS-16 & ESP-r & VA114-CirBm & VA114-CirDf & EnergyPlus \\
\hline & WSA $\quad$ TUD & U. Liège & ESRU & VABI & VABI & GARD \\
\hline MZ350a-MZ340 & -2060 & & & -1987 & -1987 & \\
\hline MZ350b-MZ340 & & & & & & -2018 \\
\hline MZ350c-MZ340 & & -2113 & -1972 & & & -2018 \\
\hline MZ350d-MZ340 & -1975 & & & & & -2018 \\
\hline MZ355-MZ340 & & & & -1995 & -1995 & -2018 \\
\hline Beam Solar Zon & $I_{\text {trbE }}(\mathbf{k W h})$ & & & & & \\
\hline & HTB2 TRNSYS-TUD & TRNSYS-16 & ESP-r & VA114-CirBm & VA114-CirDf & EnergyPlus \\
\hline & WSA & U. Liège & ESRU & VABI & VABI & GARD \\
\hline MZ350a-MZ340 & -3354 & & & -3232 & -3232 & \\
\hline MZ350b-MZ340 & & & & & & -3301 \\
\hline MZ350c-MZ340 & & -3384 & -3227 & & & -3301 \\
\hline MZ350d-MZ340 & -3320 & & & & & -3301 \\
\hline MZ355-MZ340 & & & & -3232 & -3232 & -3301 \\
\hline Beam Solar Zon & trbF (kWh) & & & & & \\
\hline & HTB2 TRNSYS-TUD & TRNSYS-16 & ESP-r & VA114-CirBm & VA114-CirDf & EnergyPlus \\
\hline & WSA & U. Liège & ESRU & VABI & VABI & GARD \\
\hline MZ350a-MZ340 & -838 & & & -830 & -830 & \\
\hline MZ350b-MZ340 & & & & & & -849 \\
\hline MZ350c-MZ340 & & -841 & -1137 & & & -849 \\
\hline MZ350d-MZ340 & -826 & & & & & -849 \\
\hline MZ355-MZ340 & $\mathrm{n} / \mathrm{a}$ & $\mathrm{n} / \mathrm{a}$ & $n / a$ & $\mathrm{n} / \mathrm{a}$ & $\mathrm{n} / \mathrm{a}$ & $\mathrm{n} / \mathrm{a}$ \\
\hline
\end{tabular}


MZ350-MZ340, MZ355-MZ340, Delta Annual Transmitted DIFFUSE Solar

\begin{tabular}{|c|c|c|c|c|c|c|}
\hline \multicolumn{7}{|c|}{ Diffuse Solar Zone A, del I trdA $(\mathrm{kWh})$} \\
\hline & HTB2 TRNSYS-TUD & \multirow{2}{*}{$\begin{array}{r}\text { TRNSYS-16 } \\
\text { U. Liège }\end{array}$} & \multirow{2}{*}{$\begin{array}{l}\text { ESP-r } \\
\text { ESRU }\end{array}$} & \multirow{2}{*}{$\begin{array}{r}\text { VA114-CirBm } \\
\text { VABI }\end{array}$} & \multirow{2}{*}{$\begin{array}{r}\text { VA114-CirDf } \\
\text { VABI }\end{array}$} & \multirow{2}{*}{$\begin{array}{r}\text { EnergyPlus } \\
\text { GARD } \\
\end{array}$} \\
\hline & WSA $\quad$ TUD & & & & & \\
\hline MZ350a-MZ340 & -1808 & & & -1984 & -1881 & \\
\hline MZ350b-MZ340 & & & & & & -1909 \\
\hline MZ350c-MZ340 & & -1823 & -2067 & & & -1909 \\
\hline MZ350d-MZ340 & -1795 & & & & & -1909 \\
\hline MZ355-MZ340 & & & & -1985 & -1881 & -1909 \\
\hline \multicolumn{7}{|c|}{ 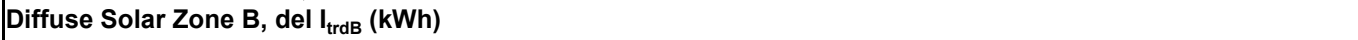 } \\
\hline & HTB2 TRNSYS-TUD & TRNSYS-16 & ESP-r & VA114-CirBm & VA114-CirDf & EnergyPlus \\
\hline & WSA & U. Liège & ESRU & VABI & VABI & GARD \\
\hline MZ350a-MZ340 & -2633 & & & -3038 & -2794 & \\
\hline MZ350b-MZ340 & & & & & & -2930 \\
\hline MZ350c-MZ340 & & -2655 & -3052 & & & -2930 \\
\hline MZ350d-MZ340 & -2638 & & & & & -2930 \\
\hline MZ355-MZ340 & & & & -3040 & -2794 & -2930 \\
\hline \multicolumn{7}{|c|}{ Diffuse Solar Zone C, del I trac $(k W h)$} \\
\hline & HTB2 TRNSYS-TUD & TRNSYS-16 & ESP-r & VA114-CirBm & VA114-CirDf & EnergyPlus \\
\hline & WSA & U. Liège & ESRU & VABI & VABI & GARD \\
\hline MZ350a-MZ340 & -2943 & & & -2601 & -3118 & \\
\hline MZ350b-MZ340 & & & & & & -2350 \\
\hline MZ350c-MZ340 & & -2967 & -2639 & & & -2350 \\
\hline MZ350d-MZ340 & -2924 & & & & & -2350 \\
\hline MZ355-MZ340 & $\mathrm{n} / \mathrm{a}$ & $\mathrm{n} / \mathrm{a}$ & n/a & $\mathrm{n} / \mathrm{a}$ & $\mathrm{n} / \mathrm{a}$ & n/a \\
\hline \multicolumn{7}{|c|}{ Diffuse Solar Zone D, del I trdD $(k W h)$} \\
\hline & HTB2 TRNSYS-TUD & TRNSYS-16 & ESP-r & VA114-CirBm & VA114-CirDf & EnergyPlus \\
\hline & WSA TUD & U. Liège & ESRU & VABI & VABI & GARD \\
\hline MZ350a-MZ340 & -1681 & & & -1817 & -1749 & \\
\hline MZ350b-MZ340 & & & & & & -1770 \\
\hline MZ350c-MZ340 & & -1694 & -1914 & & & -1770 \\
\hline MZ350d-MZ340 & -1675 & & & & & -1770 \\
\hline MZ355-MZ340 & & & & -1818 & -1749 & -1770 \\
\hline \multicolumn{7}{|c|}{ Diffuse Solar Zone E, del $\mathrm{I}_{\text {trdE }}(\mathrm{kWh})$} \\
\hline & HTB2 TRNSYS-TUD & TRNSYS-16 & ESP-r & VA114-CirBm & VA114-CirDf & EnergyPlus \\
\hline & WSA & U. Liège & ESRU & VABI & VABI & GARD \\
\hline MZ350a-MZ340 & -2565 & & & -2930 & -2723 & \\
\hline MZ350b-MZ340 & & & & & & -2838 \\
\hline MZ350c-MZ340 & & -2586 & -2965 & & & -2838 \\
\hline MZ350d-MZ340 & -2573 & & & & & -2838 \\
\hline MZ355-MZ340 & & & & -2930 & -2723 & -2838 \\
\hline \multicolumn{7}{|c|}{ Diffuse Solar Zone F, del I $\mathrm{I}_{\text {traF }}(\mathrm{kWh})$} \\
\hline & HTB2 TRNSYS-TUD & TRNSYS-16 & ESP-r & VA114-CirBm & VA114-CirDf & EnergyPlus \\
\hline & WSA & U. Liège & ESRU & VABI & VABI & GARD \\
\hline MZ350a-MZ340 & -2907 & & & -2565 & -3084 & \\
\hline MZ350b-MZ340 & & & & & & -2316 \\
\hline MZ350c-MZ340 & & -2931 & -2571 & & & -2316 \\
\hline MZ350d-MZ340 & -2889 & & & & & -2316 \\
\hline MZ355-MZ340 & $\mathrm{n} / \mathrm{a}$ & $\mathrm{n} / \mathrm{a}$ & $\mathrm{n} / \mathrm{a}$ & $\mathrm{n} / \mathrm{a}$ & $\mathrm{n} / \mathrm{a}$ & $n / a$ \\
\hline
\end{tabular}


MZ340, MZ350, MZ355 Calorimetry, Annual Mean Zone Air Temperatures

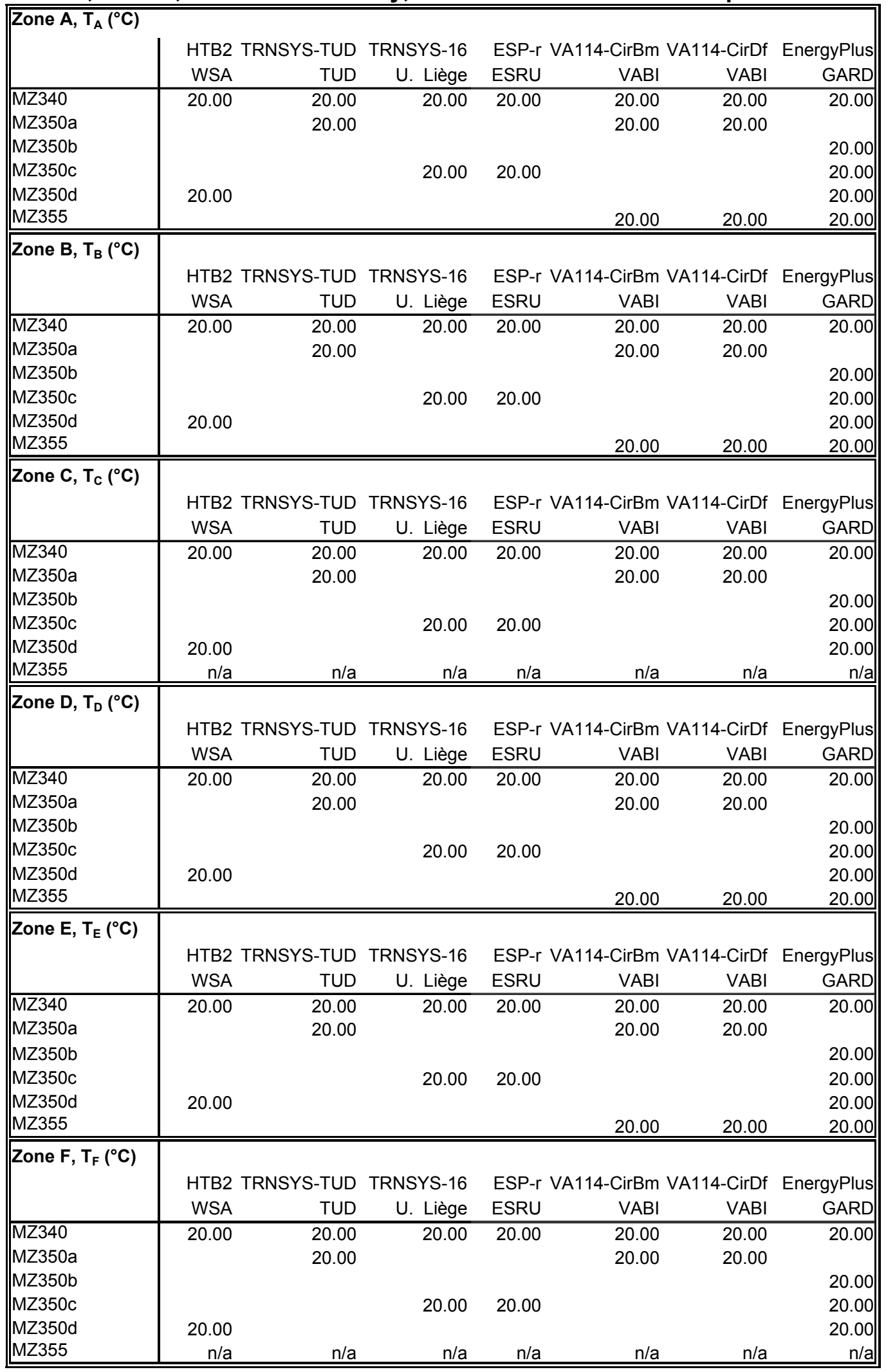


MZ340, MZ350, MZ355, Annual Hourly Integrated Maximum Zone Air Temperatures

\begin{tabular}{|c|c|c|c|c|c|c|c|c|c|c|c|c|c|c|c|c|c|c|c|c|}
\hline \multicolumn{21}{|c|}{ Zone $\mathrm{A}, \mathrm{T}_{\max , \mathrm{A}}\left({ }^{\circ} \mathrm{C}\right)$} \\
\hline & |HTB2 & & & |TRNSYS- & TUD & & |TRNSYS-16 & & & |ESP-r & & & IVA114-CriBm & & & |VA114-CirDf & & & EnergyPlus & \\
\hline & WSA & Date & $\mathrm{Hr}$ & TUD & Date & $\mathrm{Hr}$. & U. Liege & Date & $\mathrm{Hr}$. & ESRU & Date & $\mathrm{Hr}$. & VABI & Date & $\mathrm{Hr}$. & VABI & Date & $\mathrm{Hr}$. & GARD & Date \\
\hline MZ340 & 20.00 & 1-Jan & 1 & 20.00 & 1-Jan & 1 & 20.00 & 1-Jan & 1 & 20.00 & 1-Jan & 1 & 20.00 & 1-Jan & 15 & 20.00 & 1-Jan & 15 & 20.00 & $06 / 1220: 00$ \\
\hline MZ350a & & & & 20.00 & 1-Jan & 1 & & & & & & & 20.00 & 2-Jan & 8 & 20.00 & 2-Jan & 8 & & \\
\hline MZ350b & & & & & & & & & & & & & & & & & & & 20.00 & $05 / 2220: 00$ \\
\hline MZ350c & & & & & & & 20.00 & 1-Jan & 1 & \begin{tabular}{l|l}
1 & 20.00
\end{tabular} & 1-Jan & 1 & & & & & & & 20.00 & $05 / 22 \quad 20: 00$ \\
\hline MZ350d & 20.00 & 1-Jan & 1 & & & & & & & & & & & & & & & & 20.00 & $05 / 2220: 00$ \\
\hline MZ355 & & & & & & & & & & & & & 20.00 & 1-Jan & 8 & 20.00 & 1-Jan & 8 & 20.00 & $05 / 2220: 00$ \\
\hline \multicolumn{21}{|c|}{ Zone B, $\mathrm{T}_{\max , \mathrm{B}}\left({ }^{\circ} \mathrm{C}\right)$} \\
\hline & HTB2 & & & |TRNSYS-7 & TUD & & |TRNSYS-16 & & & ESP-r & & & VA114-CriBm & & & |VA114-CirDf & & & EnergyPlus & \\
\hline & WSA & Date & $\mathrm{Hr}$ & TUD & Date & $\mathrm{Hr}$ & U. Liege & Date & $\mathrm{Hr}$ & ESRU & Date & $\mathrm{Hr}$. & VABI & Date & $\mathrm{Hr}$. & VABI & Date & $\mathrm{Hr}$ & GARD & Date \\
\hline MZ340 & 20.00 & 1-Jan & 1 & 20.00 & 1-Jan & 1 & 120.00 & 1-Jan & 1 & 20.00 & 1-Jan & 1 & 20.00 & 1-Jan & 12 & 20.00 & 1-Jan & 12 & 20.00 & $06 / 1220: 00$ \\
\hline MZ350a & & & & 20.00 & 1-Jan & & & & & & & & 20.00 & 1-Jan & 9 & 20.00 & 1-Jan & 9 & & \\
\hline MZ350b & & & & & & & & & & & & & & & & & & & 20.00 & $06 / 28 \quad 20: 00$ \\
\hline MZ350c & & & & & & & 20.00 & 1-Jan & 1 & 20.00 & 1-Jan & 1 & & & & & & & 20.00 & $06 / 28 \quad 20: 00$ \\
\hline MZ350d & 20.00 & 1-Jan & 1 & & & & & & & & & & & & & & & & 20.00 & $06 / 2820: 00$ \\
\hline MZ355 & & & & & & & & & & & & & 20.00 & 1-Jan & 9 & 20.00 & 1-Jan & 9 & 20.00 & $06 / 28 \quad 20: 00$ \\
\hline \multicolumn{21}{|c|}{ Zone C, $\mathrm{T}_{\text {max }, \mathrm{C}}\left({ }^{\circ} \mathrm{C}\right)$} \\
\hline & |HTB2 & & & |TRNSYS-T & TUD & & |TRNSYS-16 & & & ESP-r & & & |VA114-CriBm & & & |VA114-CirDf & & & EnergyPlus & \\
\hline & WSA & Date & $\mathrm{Hr}$. & TUD & Date & $\mathrm{Hr}$. & U. Liege & Date & $\mathrm{Hr}$ & ESRU & Date & $\mathrm{Hr}$. & VABI & Date & $\mathrm{Hr}$ & VABI & Date & $\mathrm{Hr}$ & GARD & Date \\
\hline MZ340 & 20.00 & 1-Jan & 1 & 20.00 & 1-Jan & & 120.00 & 1-Jan & 1 & 20.00 & 1-Jan & 1 & 20.00 & 1-Jan & & 20.00 & 1-Jan & 11 & 20.00 & $06 / 1220: 00$ \\
\hline MZ350a & & & & 20.00 & 1-Jan & & & & & & & & 20.00 & 1-Jan & 11 & 20.00 & 1-Jan & 11 & & \\
\hline MZ350b & & & & & & & & & & & & & & & & & & & 20.00 & $08 / 1620: 00$ \\
\hline MZ350c & & & & & & & 20.00 & 1-Jan & 1 & 20.00 & 1-Jan & 1 & & & & & & & 20.00 & $08 / 1620: 00$ \\
\hline MZ350d & 20.00 & 1-Jan & 1 & & & & & & & & & & & & & & & & 20.00 & $08 / 1620: 00$ \\
\hline MZ355 & $\mathrm{n} / \mathrm{a}$ & $\mathrm{n} / \mathrm{a}$ & $\mathrm{n} / \mathrm{a}$ & $\mathrm{n} / \mathrm{a}$ & $\mathrm{n} / \mathrm{a}$ & $\mathrm{n} / \mathrm{a}$ & $\mathrm{n} / \mathrm{a}$ & $\mathrm{n} / \mathrm{a}$ & $\mathrm{n} / \mathrm{a}$ & $\mathrm{n} / \mathrm{a}$ & $\mathrm{n} / \mathrm{a}$ & $n / a$ & $\mathrm{n} / \mathrm{a}$ & $\mathrm{n} / \mathrm{a}$ & $\mathrm{n} / \mathrm{a}$ & $\mathrm{n} / \mathrm{a}$ & $\mathrm{n} / \mathrm{a}$ & $\mathrm{n} / \mathrm{a}$ & $\mathrm{n} / \mathrm{a}$ & $\mathrm{n} / \mathrm{a} \quad \mathrm{n} / \mathrm{a}$ \\
\hline \multicolumn{21}{|c|}{ Zone D, $\mathrm{T}_{\text {max }, \mathrm{D}}\left({ }^{\circ} \mathrm{C}\right)$} \\
\hline & HTB2 & & & |TRNSYS-T & TUD & & |TRNSYS-16 & & & ESP-r & & & |VA114-CriBm & & & |VA114-CirDf & & & EnergyPlus & \\
\hline & WSA & Date & $\mathrm{Hr}$ & TUD & Date & $\mathrm{Hr}$ & U. Liege & Date & $\mathrm{Hr}$ & ESRU & Date & $\mathrm{Hr}$. & VABI & Date & $\mathrm{Hr}$. & VABI & Date & $\mathrm{Hr}$ & GARD & Date \\
\hline MZ340 & 20.00 & 1-Jan & 1 & 20.00 & 1-Jan & 1 & 120.00 & 1-Jan & 1 & 20.00 & 1-Jan & 1 & 20.00 & 2-Jan & 10 & 20.00 & 2-Jan & 10 & 20.00 & $06 / 1220: 00$ \\
\hline MZ350a & & & & 20.00 & 1-Jan & 1 & & & & & & & 20.00 & 1-Jan & 13 & 20.00 & 1-Jan & 13 & & \\
\hline MZ350b & & & & & & & & & & & & & & & & & & & 20.00 & $06 / 28 \quad 20: 00$ \\
\hline MZ350c & & & & & & & 20.00 & 1-Jan & 1 & 20.00 & 1-Jan & 1 & & & & & & & 20.00 & $06 / 28 \quad 20: 00$ \\
\hline MZ350d & 20.00 & 1-Jan & 1 & & & & & & & & & & & & & & & & 20.00 & $06 / 2820: 00$ \\
\hline MZ355 & & & & & & & & & & & & & 20.00 & 2-Jan & 13 & 20.00 & 2-Jan & 13 & 20.00 & $06 / 28 \quad 20: 00$ \\
\hline \multicolumn{21}{|c|}{ Zone $\mathrm{E}, \mathrm{T}_{\text {max }, \mathrm{E}}\left({ }^{\circ} \mathrm{C}\right)$} \\
\hline & |HTB2 & & & |TRNSYS-T & TUD & & |TRNSYS-16 & & & ESP-r & & & JVA114-CriBm & & & |VA114-CirDf & & & EnergyPlus & \\
\hline & WSA & Date & $\mathrm{Hr}$ & TUD & Date & $\mathrm{Hr}$. & U. Liege & Date & $\mathrm{Hr}$ & ESRU & Date & $\mathrm{Hr}$. & VABI & Date & $\mathrm{Hr}$ & VABI & Date & $\mathrm{Hr}$ & GARD & Date \\
\hline MZ340 & 20.00 & 1-Jan & $\begin{array}{ll}1 & 1\end{array}$ & 20.00 & 1-Jan & 1 & 20.00 & 1-Jan & 1 & \begin{tabular}{|l|l|}
120.00 \\
\end{tabular} & 1-Jan & 1 & 20.00 & 1-Jan & 12 & 20.00 & 1-Jan & 12 & 20.00 & $06 / 1220: 00$ \\
\hline MZ350a & & & & 20.00 & 1-Jan & 1 & & & & & & & 20.00 & 1-Jan & 16 & 20.00 & 1-Jan & 16 & & \\
\hline MZ350b & & & & & & & & & & & & & & & & & & & 20.00 & $06 / 28 \quad 20: 00$ \\
\hline$M Z 350 c$ & & & & & & & 20.00 & 1-Jan & 1 & 20.00 & 1-Jan & 1 & & & & & & & 20.00 & $06 / 28 \quad 20: 00$ \\
\hline MZ350d & 20.00 & 1-Jan & 1 & & & & & & & & & & & & & & & & 20.00 & $06 / 28 \quad 20: 00$ \\
\hline MZ355 & & & & & & & & & & & & & 20.00 & 1-Jan & 15 & 20.00 & 1-Jan & 15 & 20.00 & $06 / 28 \quad 20: 00$ \\
\hline \multicolumn{21}{|c|}{ Zone $\mathrm{F}, \mathrm{T}_{\text {max }, \mathrm{F}}\left({ }^{\circ} \mathrm{C}\right)$} \\
\hline & |HTB2 & & & |TRNSYS-T & TUD & & |TRNSYS-16 & & & ESP-r & & & |VA114-CriBm & & & |VA114-CirDf & & & |EnergyPlus & \\
\hline & WSA & Date & $\mathrm{Hr}$. & TUD & Date & $\mathrm{Hr}$. & U. Liege & Date & $\mathrm{Hr}$ & ESRU & Date & $\mathrm{Hr}$. & VABI & Date & $\mathrm{Hr}$ & VABI & Date & $\mathrm{Hr}$. & GARD & Date \\
\hline MZ340 & 20.00 & 1-Jan & 1 & 20.00 & 1-Jan & & 120.00 & 1-Jan & 1 & 20.00 & 1-Jan & 1 & 20.00 & 2-Jan & 15 & 20.00 & 2-Jan & 15 & 20.00 & $06 / 1220: 00$ \\
\hline MZ350a & & & & 20.00 & 1-Jan & & & & & & & & 20.00 & 1-Jan & 15 & 20.00 & 1-Jan & 15 & & \\
\hline MZ350b & & & & & & & & & & & & & & & & & & & 20.00 & $01 / 21 \quad 19: 00$ \\
\hline MZ350c & & & & & & & 20.00 & 1-Jan & 1 & \begin{tabular}{l|l}
1 & 20.00
\end{tabular} & 1-Jan & 1 & & & & & & & 20.00 & $01 / 2119: 00$ \\
\hline MZ350d & 20.00 & 1-Jan & 1 & & & & & & & & & & & & & & & & 20.00 & $01 / 2119: 00$ \\
\hline MZ355 & $\mathrm{n} / \mathrm{a}$ & $\mathrm{n} / \mathrm{a}$ & $n / a$ & $\mathrm{n} / \mathrm{a}$ & $\mathrm{n} / \mathrm{a}$ & $\mathrm{n} / \mathrm{a}$ & $\mathrm{n} / \mathrm{a}$ & $\mathrm{n} / \mathrm{a}$ & $\mathrm{n} / \mathrm{a}$ & $\mathrm{n} / \mathrm{a}$ & $\mathrm{n} / \mathrm{a}$ & $\mathrm{n} / \mathrm{a}$ & $\mathrm{n} / \mathrm{a}$ & $\mathrm{n} / \mathrm{a}$ & $\mathrm{n} / \mathrm{a}$ & $\mathrm{n} / \mathrm{a}$ & $\mathrm{n} / \mathrm{a}$ & $\mathrm{n} / \mathrm{a}$ & $\mathrm{n} / \mathrm{a}$ & $\mathrm{n} / \mathrm{a} \quad \mathrm{n} / \mathrm{a}$ \\
\hline
\end{tabular}




\section{Case MZ360 (Internal Windows) Results}

MZ360 Calorimetry, Annual Cooling Loads, Incident and Transmitted Solar, Zone Air Temperatures

\begin{tabular}{|c|c|c|c|c|c|c|c|c|c|c|}
\hline \multicolumn{8}{|c|}{ Annual Sensible Cooling Loads (kWh/y) } & \multicolumn{3}{|c|}{ Statistics, All Results } \\
\hline & HTB2 & TRNSYS-TUD & RNSYS-16 & ESP-r & VA114-CirBm & VA114-CirDf & EnergyPlus & & & Max-Min) \\
\hline & WSA & TUD & U. Liège & ESRU & VABI & VABI & GARD & Min & Max & /Mean \\
\hline Building, $Q_{\text {bldg }}$ & 121816 & 122534 & 123497 & 125312 & 129647 & 129653 & 120538 & 120538 & 129653 & $7.3 \%$ \\
\hline Zone $\mathrm{A}, \mathrm{Q}_{\mathrm{A}}$ & 59734 & 48025 & 60817 & 47177 & 43529 & 43480 & 51113 & 43480 & 60817 & $34.3 \%$ \\
\hline Zone $\mathrm{B}, \mathrm{Q}_{\mathrm{B}}$ & & 63512 & 54130 & 57988 & 58213 & 57751 & 59411 & 54130 & 63512 & $16.0 \%$ \\
\hline Zone C, $Q_{C}$ & & 10997 & 8550 & 20147 & 27905 & 28421 & 10015 & 8550 & 28421 & $112.4 \%$ \\
\hline$Q_{B}+Q_{C}$ & 62082 & 74509 & 62679 & 78135 & 86118 & 86172 & 69425 & 62082 & 86172 & $32.5 \%$ \\
\hline Annual South & "est-Faci & ing Incident Uns & Iaded Solar & $\overline{~(k W h /(m) ~}$ & 2y)) & & & Statistic & cs, All Res & ults \\
\hline & HTB2 & TRNSYS-TUD & RNSYS-16 & ESP-r & VA114-CirBm & VA114-CirDf & EnergyPlus & & & Max-Min) \\
\hline & WSA & TUD & U. Liège & ESRU & VABI & VABI & GARD & Min & $\operatorname{Max}$ & /Mean \\
\hline$\overline{T \text { Total }\left(I_{\mathrm{A}}\right)}$ & 875 & 880 & 887 & 905 & 931 & 931 & 905 & 875 & 931 & $6.2 \%$ \\
\hline Beam $\left(I_{b A}\right)$ & & 472 & 477 & 466 & 464 & 464 & 469 & 464 & 477 & $2.7 \%$ \\
\hline Diffuse $\left(I_{\mathrm{dA}}\right)$ & & 408 & 411 & 438 & 467 & 467 & 436 & 408 & 467 & $13.6 \%$ \\
\hline Annual Trans & itted So & lar, Zone A (kWh & & & & & & Statistic & cs, All Res & ults \\
\hline & HTB2 & TRNSYS-TUD & RNSYS-16 & ESP-r & VA114-CirBm & VA114-CirDf & EnergyPlus & & & Max-Min) \\
\hline & WSA & TUD & U. Liège & ESRU & VABI & VABI & GARD & Min & $\operatorname{Max}$ & /Mean \\
\hline$\overline{T \text { Total }\left(l_{\mathrm{trA}}\right)}$ & 121816 & 122534 & 123569 & 125312 & 129589 & 129595 & 125148 & 121816 & 129595 & $6.2 \%$ \\
\hline Beam & 65822 & 65782 & 66358 & 64605 & 64578 & 64578 & 65065 & 64578 & 66358 & $2.7 \%$ \\
\hline Diffuse (I $\left.I_{\text {trdA }}\right)$ & 55994 & 56752 & 57211 & 60707 & 65011 & 65017 & 60083 & 55994 & 65017 & $15.0 \%$ \\
\hline Annual Trans & itted So & lar, Zone B (kWh & & & & & & Statistic & cs, All Res & \\
\hline & HTB2 & TRNSYS-TUD & RNSYS-16 & ESP-r & VA114-CirBm & VA114-CirDf & EnergyPlus & & & Max-Min) \\
\hline & WSA & TUD & U. Liège & ESRU & VABI & VABI & GARD & Min & $\operatorname{Max}$ & /Mean \\
\hline Total $\left(\mathrm{I}_{\mathrm{trB}}\right)$ & 62082 & 74509 & 62802 & 78135 & 86092 & 86147 & & 62082 & 86147 & $32.1 \%$ \\
\hline Beam ( $\left.I_{\text {trbB }}\right)$ & 45417 & 45665 & 33725 & 46668 & 43095 & 43095 & 43257 & 33725 & 46668 & $30.1 \%$ \\
\hline Diffuse $\left(I_{\text {traB }}\right)$ & 16665 & 28843 & 29076 & 31467 & 42997 & 43052 & & 16665 & 43052 & $82.4 \%$ \\
\hline Annual Trans & itted So & lar, Zone C (kWh & & & & & & Statistic & ss, All Res & ults \\
\hline & HTB2 & TRNSYS-TUD & RNSYS-16 & ESP-r & VA114-CirBm & VA114-CirDf & EnergyPlus & & & Max-Min) \\
\hline & WSA & TUD & U. Liège & ESRU & VABI & VABI & GARD & Min & $\operatorname{Max}$ & /Mean \\
\hline Total $\left(\mathrm{I}_{\mathrm{trC}}\right)$ & & 10997 & 9269 & 20147 & 27898 & 28415 & & 9269 & 28415 & $99.0 \%$ \\
\hline Beam ( $\left(I_{\mathrm{trbc}}\right)$ & & 0 & 4978 & 15505 & 13769 & 13769 & 0 & 0 & 15505 & $193.7 \%$ \\
\hline Diffuse $\left(I_{\text {trac }}\right)$ & & 10997 & 4291 & 4642 & 14130 & 14646 & & 4291 & 14646 & $106.3 \%$ \\
\hline Annual Mean & one Air & 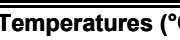 & & & & & & "Statistic & cs, All Res & ults \\
\hline & HTB2 & TRNSYS-TUD & RNSYS-16 & ESP-r & VA114-CirBm & VA114-CirDf & EnergyPlus & & & Max-Min) \\
\hline & WSA & TUD & U. Liège & ESRU & VABI & VABI & GARD & Min & $\operatorname{Max}$ & /Mean \\
\hline Zone $\mathrm{A}, \mathrm{T}_{\mathrm{A}}$ & 20 & 20 & 20 & 20 & 20 & 20 & 20 & 20 & 20 & $0.0 \%$ \\
\hline Zone B, $\mathrm{T}_{\mathrm{B}}$ & 20 & 20 & 20 & 20 & 20 & 20 & 20 & 20 & 20 & $0.0 \%$ \\
\hline Zone $\mathrm{C}, \mathrm{T}_{\mathrm{C}}$ & & 20 & 20 & 20 & 20 & 20 & 20 & 20 & 20 & $0.0 \%$ \\
\hline
\end{tabular}


MZ360, Annual Hourly Integrated Maximum Cooling Loads and Zone Air Temperatures

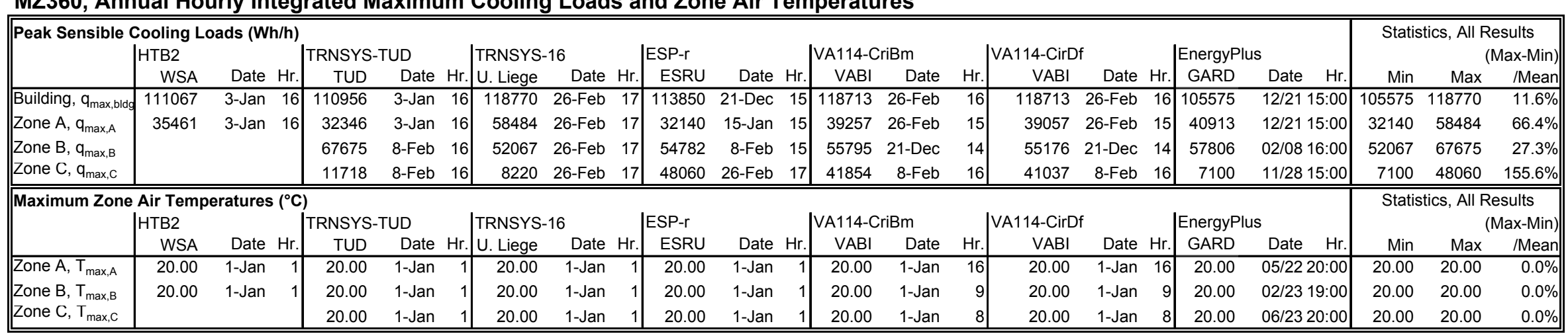




\section{REPORT DOCUMENTATION PAGE}

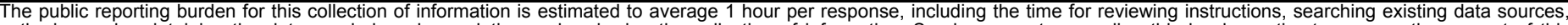

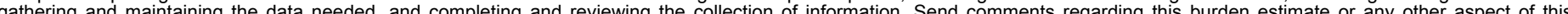

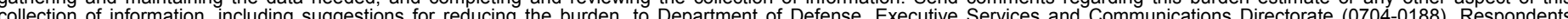

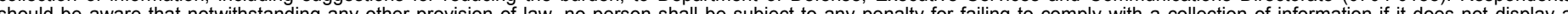

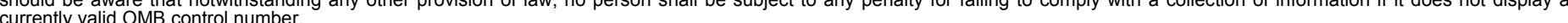

PLEASE DO NOT RETURN YOUR FORM TO THE ABOVE ORGANIZATION.

\begin{tabular}{l|l|l|}
\hline 1. REPORT DATE $(D D-M M-Y Y Y Y)$ & 2. REPORT TYPE & 3. DATES COVERED (FrOm - TO)
\end{tabular}

September 2008

4. TITLE AND SUBTITLE

International Energy Agency Building Energy Simulation Test and

Diagnostic Method (IEA BESTEST) Multi-Zone Non-Airflow In-Depth

Diagnostic Cases: MZ320 - MZ360 5a. CONTRACT NUMBER

DE-AC36-99-G010337

5b. GRANT NUMBER

5c. PROGRAM ELEMENT NUMBER

5d. PROJECT NUMBER

NREL/TP-550-43827

5e. TASK NUMBER

BEC76051

D. Alexander, C. Felsman, P. Strachan, and A. Wijsman 5f. WORK UNIT NUMBER
7. PERFORMING ORGANIZATION NAME(S) AND ADDRESS(ES)

National Renewable Energy Laboratory

1617 Cole Blvd.

Golden, CO 80401-3393
8. PERFORMING ORGANIZATION REPORT NUMBER

NREL/TP-550-43827

9. SPONSORING/MONITORING AGENCY NAME(S) AND ADDRESS(ES)

10. SPONSOR/MONITOR'S ACRONYM(S) NREL

11. SPONSORING/MONITORING AGENCY REPORT NUMBER

12. DISTRIBUTION AVAILABILITY STATEMENT

National Technical Information Service

U.S. Department of Commerce

5285 Port Royal Road

Springfield, VA 22161

13. SUPPLEMENTARY NOTES

14. ABSTRACT (Maximum 200 Words)

This report documents a set of in-depth diagnostic test cases for multi-zone heat transfer models that do not include the heat and mass transfer effects of airflow between zones. These test cases represent an extension to IEA BESTEST, which originally focused on a single-zone configuration except for one test case.

15. SUBJECT TERMS

iea; international energy agency; bestest; building energy simulation test

\begin{tabular}{|c|c|c|}
\hline $\begin{array}{l}\text { a. REPORT } \\
\text { Unclassified }\end{array}$ & $\begin{array}{l}\text { b. ABSTRACT } \\
\text { Unclassified }\end{array}$ & $\begin{array}{l}\text { c. THIS PAGE } \\
\text { Unclassified }\end{array}$ \\
\hline
\end{tabular}

\begin{tabular}{|c|c|}
\hline $\begin{array}{l}\text { 17. LIMITATION } \\
\text { OF ABSTRACT }\end{array}$ & $\begin{array}{l}\text { 18. NUMBER } \\
\text { OF PAGES }\end{array}$ \\
\hline UL & \\
\hline
\end{tabular}

19a. NAME OF RESPONSIBLE PERSON

19b. TELEPHONE NUMBER (Include area code) 